André Luiz Netto Ferreira

\title{
REVISÃO TAXONÔMICA E RELAÇÕES INTERESPECÍFICAS DE LEBIASININAE (OSTARIOPHYSI: CHARACIFORMES: LEBIASINIDAE)
}

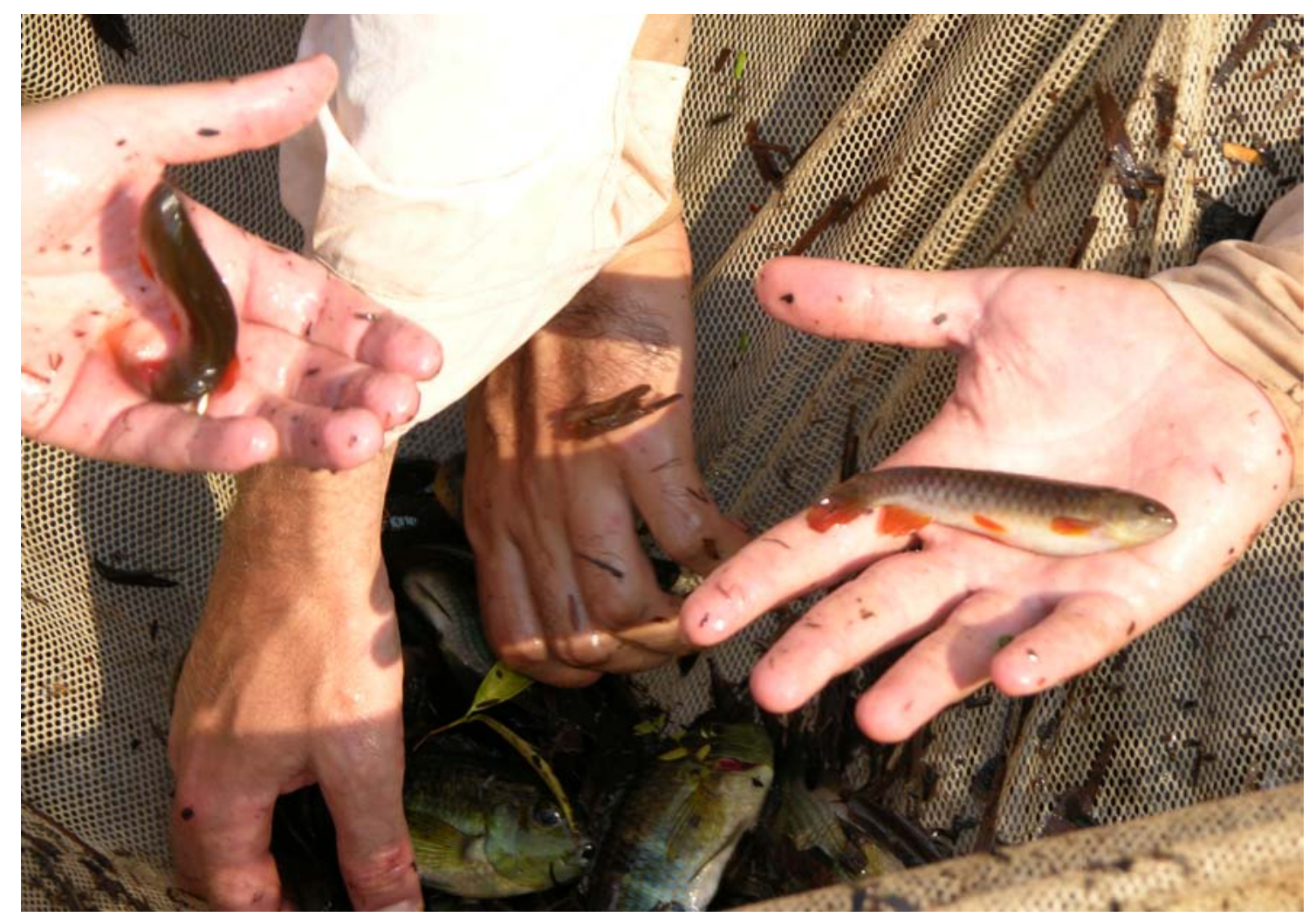

Departamento de Zoologia

Instituto de Biociências

Universidade de São Paulo

Outubro/2010 
André Luiz Netto Ferreira

\section{REVISÃO TAXONÔMICA E RELAÇÕES INTERESPECÍFICAS DE LEBIASININAE (OSTARIOPHYSI: CHARACIFORMES: LEBIASINIDAE)}

Tese apresentada ao Instituto de Biociências da Universidade de São Paulo, para a obtenção de Título de Doutor em Ciências, na Área de Zoologia.

Orientador: Mário C. C. de Pinna

Departamento de Zoologia

Instituto de Biociências

Universidade de São Paulo

Outubro/2010 
Netto-Ferreira, André Luiz

Revisão taxonômica e relações interespecíficas de

Lebiasininae (Ostariophysi: Characiformes: Lebiasinidae) xix+460 pp., 107 fig.

Tese (Doutorado) - Instituto de Biociências da

Universidade de São Paulo. Departamento de Zoologia.

1. Sistemática 2. Neotropical 3. Teleostei 4.

Cladística I. Universidade de São Paulo. Instituto de

Biociências. Departamento de Zoologia.

\section{Banca examinadora}

Prof(a). $\operatorname{Dr}(a)$.

$\operatorname{Prof}(a) . \operatorname{Dr}(a)$.
Prof(a). Dr(a).

Prof(a). Dr(a).

Prof. Dr. Mário C. C. de Pinna Orientador 


\begin{abstract}
AVISO
Esta dissertação é parte dos requerimentos necessários à obtenção do título de doutor, área de Zoologia, e como tal, não deve ser vista como uma publicação no senso do Código Internacional de Nomenclatura Zoológica (apesar de disponível publicamente sem restrições). Desta forma, quaisquer informações inéditas, opiniões e hipóteses, bem como nomes novos, não estão disponíveis na literatura zoológica. Pessoas interessadas devem estar cientes de que referências públicas ao conteúdo deste estudo, na sua presente forma, somente devem ser feitas com aprovação prévia do autor.
\end{abstract}

\title{
NOTICE
}

This dissertation is a partial requirement for the PhD degree in Zoology and, as such, should not be considered as a publication in the sense of the International Code of Zoological Nomenclature (although it is available without restrictions). Therefore, any new information, opinions, and hypotheses, as well as new names, are not available in the zoological literature. Interested people are advised that any public reference to this study, in its current form, should only be done after previous acceptance of the author. 
Àqueles que caminharam comigo, ainda que tenham se juntado tardiamente, nessa longa jornada. Em especial para minhas três pessoinhas queridas. 


\section{Natural Science}

1. Tide Pools

When the ebbing tide retreats

Along the rocky shoreline,

It leaves a trail of tidal pools

In a short-lived galaxy.

Each microcosmic planet

A complete society.

A simple kind mirror

To reflect upon our own.

All the busy little creatures

Chasing out their destinies.

Living in their pools,

They soon forget about the sea...

Wheels within wheels in a spiral array, A pattern so grand and complex,

Time after time we lose sight of the way, Our causes can't see their effects.

\section{Hyperspace}

A quantum leap forward

In time and in space,

The universe learned to expand.

The mess and the magic,

Triumphant and tragic,

A mechanized world out of hand.

Computerized clinic

For superior cynics

Who dance to a synthetic band.

In their own image,
Their world is fashioned.

No wonder they don't understand.

3. Permanent Waves

Science, like nature,

Must also be tamed

With a view towards its preservation.

Given the same

State of integrity,

It will surely serve us well.

Art as expression,

Not as market campaigns

Will still capture our imaginations.

Given the same

State of integrity,

It will surely help us along.

The most endangered species,

The honest man,

Will still survive annihilation.

Forming a world

State of integrity,

Sensitive, open and strong.

Wave after wave will flow with the tide, and bury the world as it does.

Tide after tide will flow and recede, leaving life to go on as it was...

Lee, Lifeson \& Peart 


\section{$\underline{\text { Resumo }}$}

A subfamília Lebiasininae é tradicionalmente dividida em dois gêneros: Lebiasina e Piabucina. Historicamente, tal divisão vem sendo contestada devido à inconsistência dos caracteres que diferenciam os dois gêneros. Com o intuito de investigar as relações entre os Lebiasininae e a validade de Lebiasina e Piabucina, foram analisados 59 representantes de Lebiasinidae e representantes de outras cinco famílias de Characiformes foram examinados como grupo externo adicionais. A análise filogenética incluindo 208 caracteres de diferentes complexos morfológicos, resultou em seis árvores fundamentais com 800 passos. As topologia obtidas recuperam o monofiletismo de Lebiasininae com base em cinco sinapomorfias (4 exclusivas): margem pósterodorsal do infra-orbital 3 com uma projeção que exclui parcial- ou totalmente o infra-orbital 4 do anel orbital; lâmina dorsal do mesetmóide em forma de "T"; margem póstero-ventral do coracóide truncada, sem uma distinta projeção direcionada posteriormente; ramo infra-orbital do canal láterosensorial cefálico se estendendo ao antorbital; mancha na base dos raios médios da nadadeira caudal presente. Por outro lado, estas refutam o monofiletismo de Lebiasina e Piabucina e a sinoníma entre eles é formalmente proposta. O resultado da análise corrobora o monofiletismo de Lebiasinidae (com base em 20 sinapomorfias, 12 exclusivas) e todas as suas demais subunidades. São discutidos eventos graduais de miniaturização em Pyrrhulininae, aparentemente associados a diversos caracteres redutivos, e a evolução dos modos de vida observados em Nannostomus e Pyrrhulinina. Como resultado da revisão taxonômica, 19 das as 22 espécies nominais de Lebiasininae são consideradas válidas e sete são descritas como espécies novas. Entre elas, constam tês novas espécies que até então eram erroneamente classificadas como Lebiasina bimaculata. Todas as espécies são redescritas e novas diagnoses são propostas para cada uma delas. Adicionalmente, uma chave de identificação das espécies (válidas e novas) é apresentada. 


\begin{abstract}
The subfamily Lebiasininae has been traditionally divided into two genera: Lebiasina and Piabucina. Historically, such division has been contested due to the inconsistency of the diagnostic characters differring both genera. To investigate the relationships among the Lebiasininae and the validity of Lebiasina and Piabucina, 59 representatives of the Lebiasinidae were compared, as well as representatives of five other characiform families as additional outgroups. The phylogenetic analysis, including 208 characters, obtained from different morphological complexes, yielded six fundamental trees with 800 steps. The topologies obtained recover the monophyly of the Lebiasininae based in five synapomorphies (four exclusive): postero-dorsal margin of infraorbital 3 with a projection that excludes patrially or completelly the infraorbital 4 from the orbital rim; dorsal surface of the mesethmoid " $\mathrm{T}$ " shaped; postero-ventral margin of coracoid truncate, without a distinct posteriorly projected process; infraorbital ramus of latero-sensory canal extending onto the antorbital; caudal blotch present. On the other hand, the topologies refute the monophyly of Lebiasina and Piabucina, and their synonymy is formally proposed herein. The analysis also recovers the Lebiasinidae as a monophyletic assemblage (based in 20 synapomorhies, 12 exclusive) as well as all other subunities of the family. Gradual miniaturization events apparently associated with several reductive characters and the evolution of life strategies in Nannostomus and Pyrrhulinina are discussed. As a result of the taxonomic review, 19 of the 22 nominal species are considered valid and seven are described as new. Among them, there are three species so far identified as Lebiasina bimaculata. All species are redescribed, their distribution is extended and new diagnoses are proposed to each of them. Additionally, an identification key to the species (valid and new) is presented.
\end{abstract}




\section{$\underline{\text { Agradecimentos }}$}

Primeiramente gostaria de agradecer à minha família por todo o apoio incondicional dado desde sempre e principalmente durante esses quatro anos de São Paulo. Aos meus filhotinhos por todas as vezes que voltei pra casa e fui recebido com sorrisos contendo pura felicidade por me ver. Ao Marcelo e a Miroca, as pessoas que lá atrás me incentivaram bastante a extrapolar os limites de "casa" e vir fazer o doutorado em outra cidade, outro estado. Apesar das diversas vezes em que me senti um estranho numa terra estranha, valeu cada dia. Muito obrigado pelo empurrão!

Durante esses anos de MZUSP tantas pessoas passaram por aqui que acho injusto correr o risco de esquecer alguém na hora listar as pessoas e a importância de cada uma delas no processo, mas tenho certeza de que cada uma delas sabe o papel que teve nessa corrida. Meus agradecimentos especiais vão: para os professores da seção, por toda a ajuda e pelo prazer das histórias contadas na Copa durante o café ou as drinekerias; ao Mario pela orientação, amizade e todas as conversas (sérias, pouco séries ou nada sérias) que tivemos ao longo desses anos; pro Gabiru, pelo companheirismo e amizade ao longo de quase cinco anos lutando contra nossas teses e as forças tentadoras da "deusa da procrastinação"; pra Carinão (mais uma vez) pela amizade, carinho e apoio; pro Pedrinho, pela amizade quase secular e as horas de boteco; pro Flávio, por todas as discussões enriquecedoras (e outras nem tanto, mas de igual valor); pro Cris, também por todas as discussões sobre morfologia de Characiformes; ao Kawada pela ajuda com as automontagens, elas ficaram ótimas. Por último, mas não menos importante, pra Flávia por toda a ajuda, amizade, carinho e companheirismo nessa fase final. Sem você eu não teria tido força pra seguir adiante e terminar o que comecei. Te amo!

Gostaria de agradecer aos curadores e collection managers das instituições que colaboraram imensamente para a condução do projeto (ANSP; BMNH; CAS; CAR; FMNH; IAvH; ICN- MHN; INHS; INPA; MBUCV-V; MCNG; MCP; MCZ; MHNLS; MNRJ; MPEG; NRM; UF; USNM). Desculpem por não citá-los nominalmente, mas o tempo urge. Agradeço especialmente ao Carlos Ardila, Hernán Ortega e Ramiro Barriga por toda hospitalidade em suas coleções; Ao Richard Vari e Marilyn Weitzman por toda a ajuda no tempo que passei no Smithsonian, e a toda a equipe da ictiologia por toda a ajuda oferecida até hoje.

Esse estudo contou com auxílio financeiro da Fundação de Amparo à Pesquisa do Estado de São Paulo (FAPESP). Sem ele, nada disso teria sido possível. 


\section{Sumário}

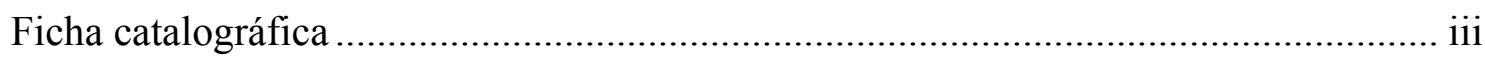

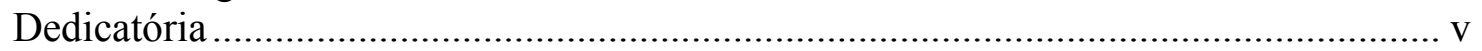

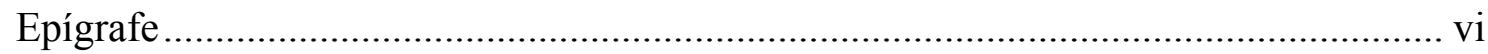

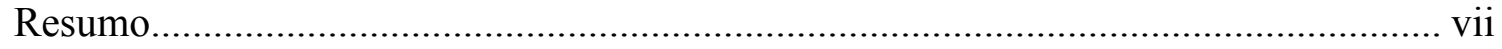

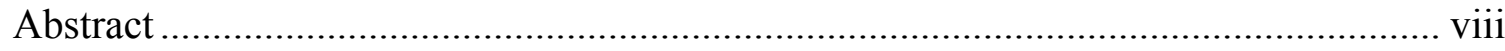

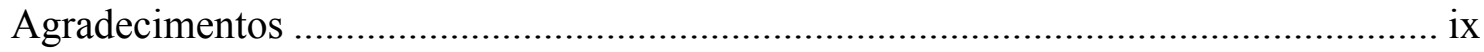

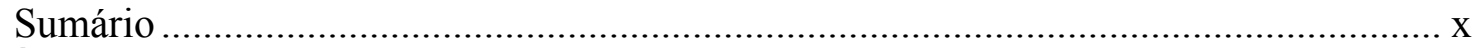

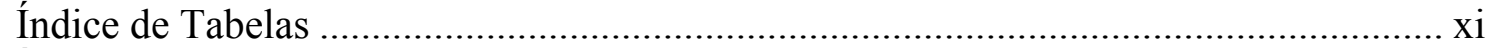

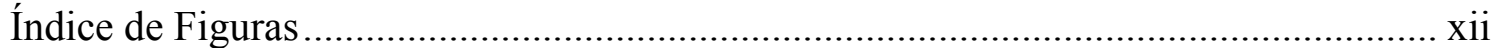

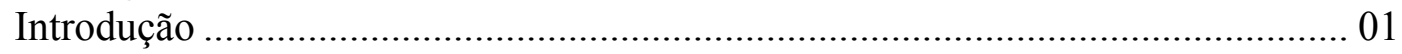

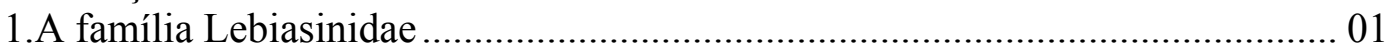

2. A subfamília Lebiasininae ........................................................................ 02

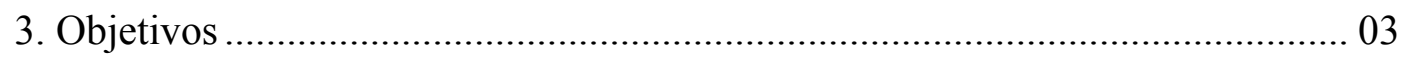

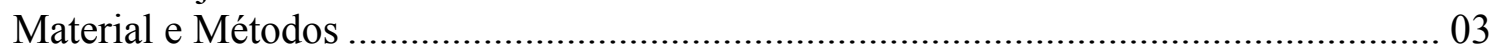

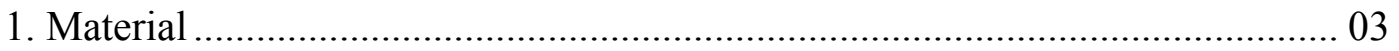

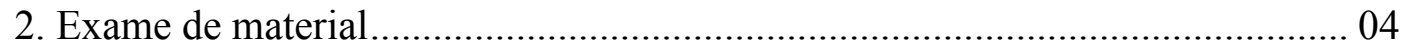

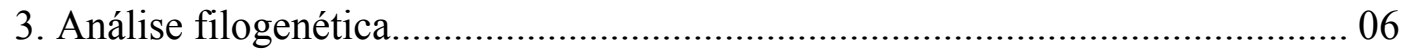

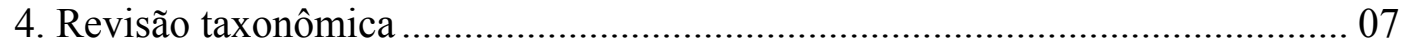

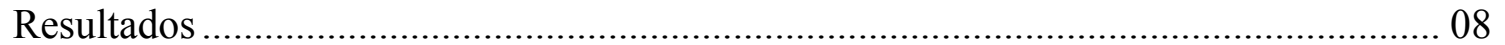

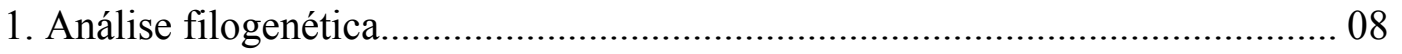

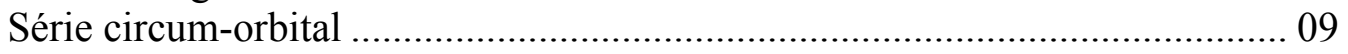

Neurocrânio ......................................................................................... 14

Dentição \& arco mandibular...................................................................... 28

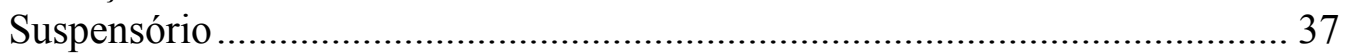

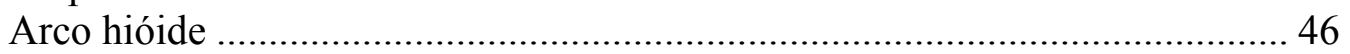

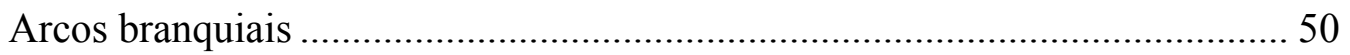

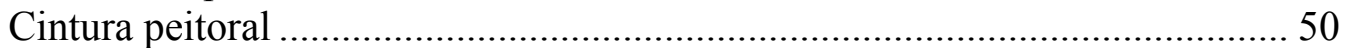

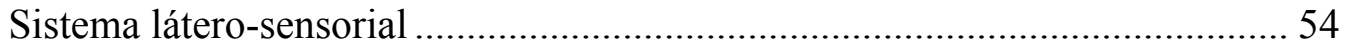

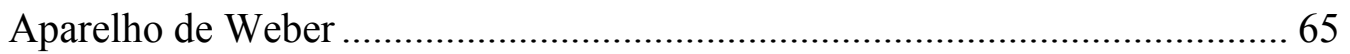

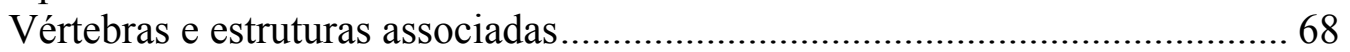

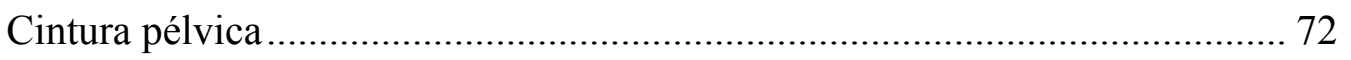

Nadadeira dorsal e estruturas associadas .................................................. 73

Nadadeira anal e estruturas associadas ...................................................... 76

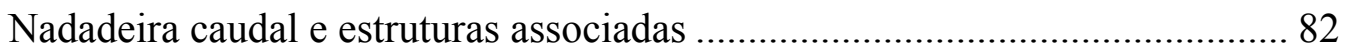

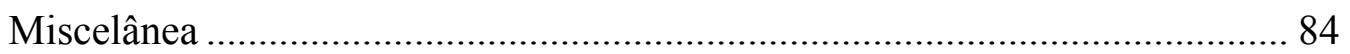

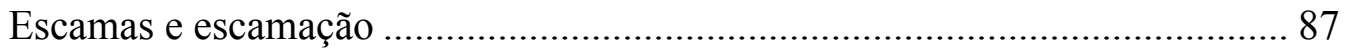

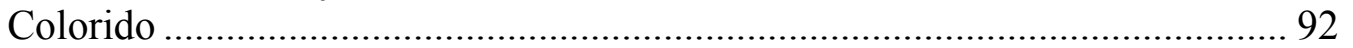

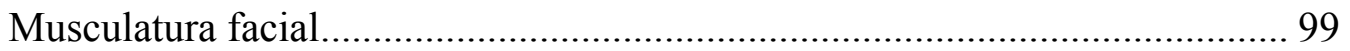

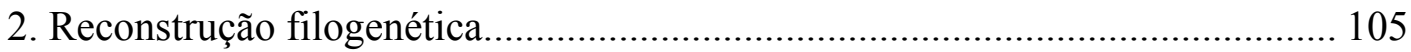

3. Miniaturização em Pyrrhulininae .................................................................... 111

4. Evolução da invertivoria em Lebiasinidae ..................................................... 112

5. Estabilidade morfológica de Lebiasininae, resolução filogenética e diversidade do grupo

6. Revisão taxonômica das espécies de Lebiasininae

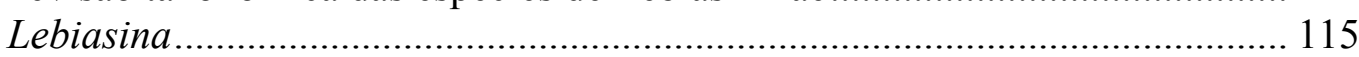

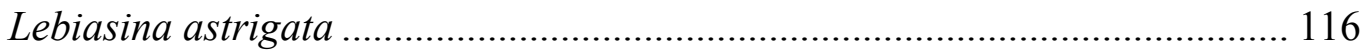

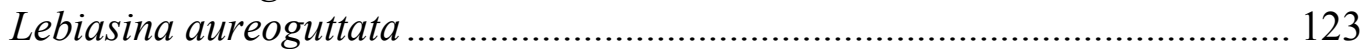

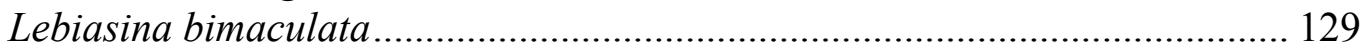

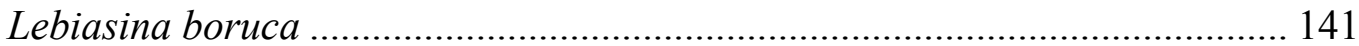




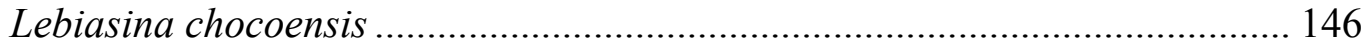

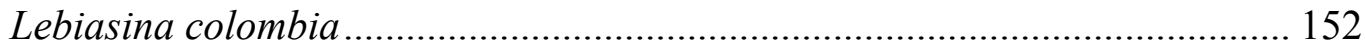

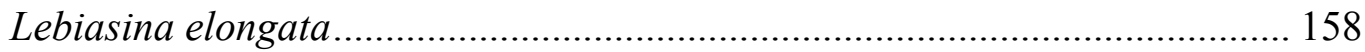

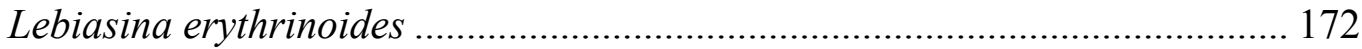

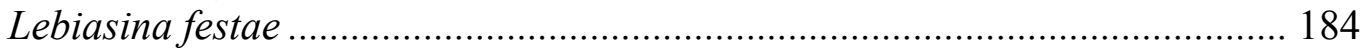

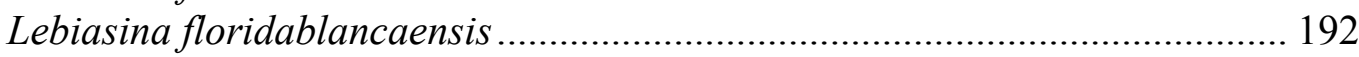

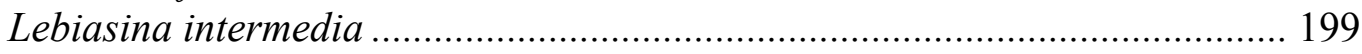

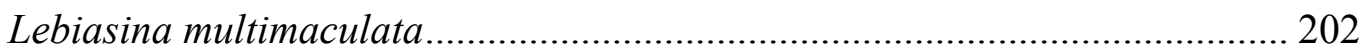

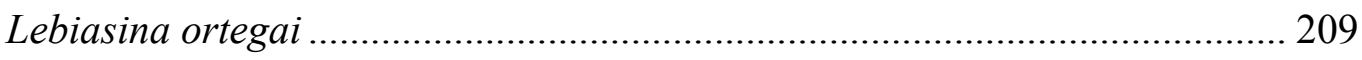

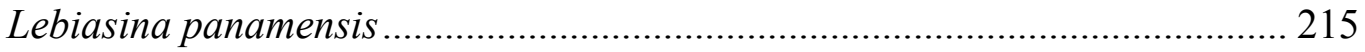

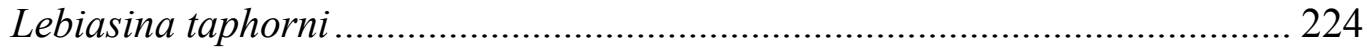

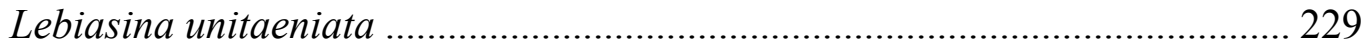

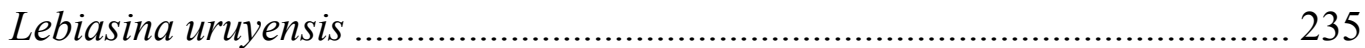

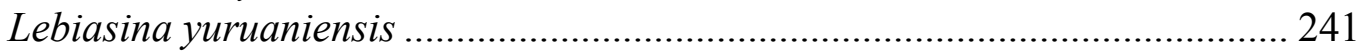

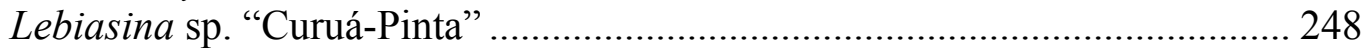

Lebiasina sp. "Curuá-Faixa"........................................................................... 252

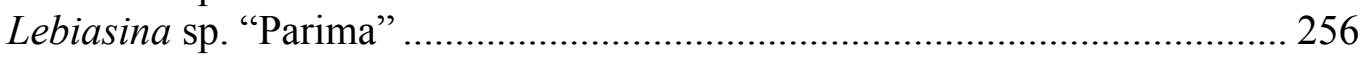

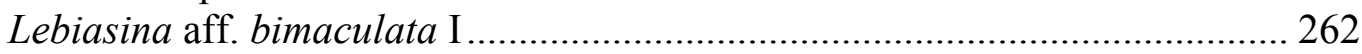

Lebiasina aff. bimaculata II.............................................................. 268

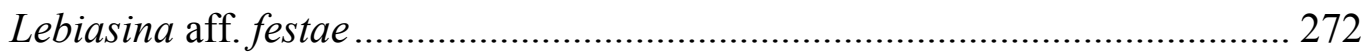

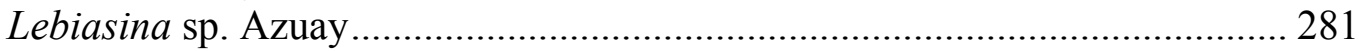

7. Chave artificial de identificação para as espécies de Lebiasininae .................. 287

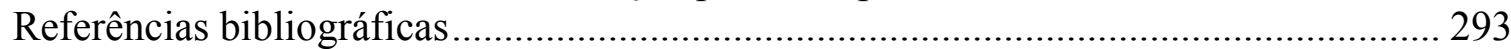

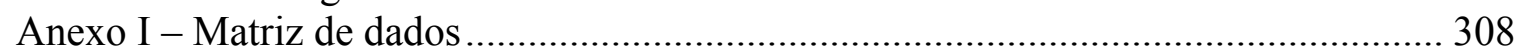

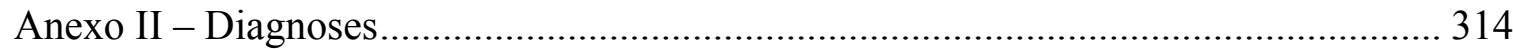

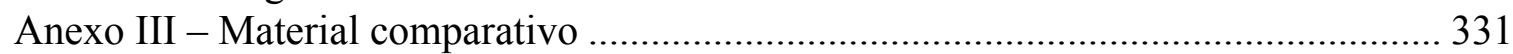

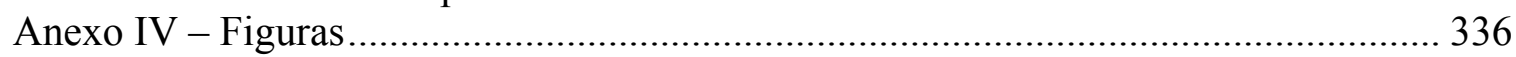




\section{$\underline{\text { Índice de Tabelas }}$}

Tabela 1. Matriz de dados utilizada no estudo filogenético. Caracteres polimórficos foram codificados como: $[01]=\mathrm{A} ;[02]=\mathrm{B} ;[12]=\mathrm{C}$. 307

Tabela 2. Dados morfométricos de Lebiasina astrigata 122

Tabela 3. Dados morfométricos de Lebiasina aureoguttata 128

Tabela 4. Dados morfométricos de Lebiasina bimaculata 141

Tabela 5. Dados morfométricos de Lebiasina boruca ….................................................................146

Tabela 6 Dados morfométricos de Lebiasina chocoensis ...........................................................151

Tabela 7. Dados morfométricos de Lebiasina colombia ..........................................................157

Tabela 8. Dados morfométricos de Lebiasina elongata .......................................................... 171

Tabela 9. Dados morfométricos de Lebiasina erythrinoides .....................................................182

Tabela 10. Dados morfométricos de Lebiasina festae …................................................................192

Tabela 11. Dados morfométricos de Lebiasina floridablancaensis........................................... 198

Tabela 12. Dados e morfométricos de Lebiasina intermedia (retirados de Meinken, 1937).......201

Tabela 13. Dados morfométricos de Lebiasina multimaculata ....................................................208

Tabela 14. Dados morfométricos de Lebiasina ortegai .........................................................214

Tabela 15. Dados morfométricos de Lebiasina panamensis....................................................224

Tabela 16. Dados morfométricos de Lebiasina taphorni ........................................................229

Tabela 17. Dados morfométricos de Lebiasina unitaeniata .........................................................235

Tabela 18. Dados e morfométricos de Lebiasina uruyensis ......................................................241

Tabela 19. Dados morfométricos de Lebiasina yuruaniensis ..................................................247

Tabela 20. Dados morfométricos de Lebiasina sp. "Curuá Pinta" ..........................................251

Tabela 21. Dados morfométricos de Lebiasina sp. "Curuá Faixa"..........................................255

Tabela 22. Dados morfométricos de Lebiasina sp. "Parima" ..................................................262

Tabela 23. Dados morfométricos de Lebiasina aff. bimaculata I............................................268

Tabela 24. Dados morfométricos de Lebiasina aff. bimaculata II ...........................................271

Tabela 25. Dados morfométricos de Lebiasina aff. festae .......................................................281

Tabela 26. Dados morfométricos de Lebiasina sp. Azuay..........................................................286 


\section{$\underline{\text { Índice de Figuras }}$}

Figura 1. Diagrama não enraizado com 800 passos da hipótese de relacionamento das espécies de Lebiasininae 336

Figura 2. Consenso estrito das seis árvores fundamentais. Algarismos em cada ramo indicam os valores do índice de Bremer $(\geq 1)$ e o Bootstrap $(\geq 50)$.

Figura 03. Série circum-orbital de (A) Lebiasina bimaculata MZUSP 80085, 70,1 mm CP e (B) Lebiasina erythrinoides MNRJ 14232, 64,8 mm CP. .338

Figura 04. Série circum-orbital de (A) Derhamia hoffmannorum MTD F 26 492, 28 mm CP e (B) Nannostomus beckfordi MZUSP 22910, 26,9 mm CP. 339

Figura 05. Série circum-orbital de (A) Copeina guttata MZUSP 27088, 65,3mm CP e (B) Copella nigrofasciata DEPRJ 104, 43,4 mm CP. .340

Figura 06. Série circum-orbital de Pyrrhulina australis MZUSP 59567, 31,8 mm CP. 341

Figura 07. Vista dorsal do crânio de (A) Lebiasina bimaculata MZUSP 80085, 70,1 mm CP e (B) Lebiasina erythrinoides MNRJ 14232, 64,8 mm CP. .342

Figura 08. Vista dorsal do crânio de (A) Derhamia hoffmannorum MTD F 26 492, 28 mm CP e (B) Nannostomus beckfordi MZUSP 22910, 26,9 mm CP. .343

Figura 09. Vista dorsal do crânio de (A) Copeina guttata MZUSP 27088, 65,3mm CP e (B) Copella nigrofasciata DEPRJ 104, 43,4 mm CP. .344

Figura 10. Vista dorsal do crânio de Pyrrhulina sp. Capim MZUSP 23816, 37,3 mm CP.........345

Figura 11. Vista ventral do crânio de (A) Lebiasina bimaculata MZUSP 80085, 70,1 mm CP e (B) Lebiasina erythrinoides MNRJ 14232, 64,8 mm CP. .346

Figura 12. Vista dorsal do crânio de (A) Derhamia hoffmannorum MTD F 26 492, 28 mm CP e (B) Nannostomus beckfordi MZUSP 22910, 26,9 mm CP. .347

Figura 13. Vista ventral do crânio de (A) Copeina guttata MZUSP 27088, 65,3mm CP e (B) Copella nigrofasciata DEPRJ 104, 43,4 mm CP. 348

Figura 14. Vista ventral do crânio de Pyrrhulina sp. Capim MZUSP 23816, 37,3 mm CP........349

Figura 15. Vista lateral do crânio de (A) Lebiasina bimaculata MZUSP 80085, 70,1 mm CP e (B) Lebiasina erythrinoides MNRJ 14232, 64,8 mm CP). .350

Figura 16. Vista lateral do crânio de (A) Derhamia hoffmannorum MTD F 26 492, 28 mm CP e (B) Nannostomus beckfordi MZUSP 22910, 26,9 mm CP. 351

Figura 17. Vista lateral do crânio de (A) Copeina guttata MZUSP 27088, 65,3mm CP e (B) Copella nigrofasciata DEPRJ 104, 43,4 mm CP. .352

Figura 18. Vista lateral do crânio de Pyrrhulina australis MZUSP 59567, 31,8 mm CP. .353

Figura 19. Vista medial do suspensório de Lebiasina bimaculata MZUSP 80085, 70,1 mm CP.354 Figura 20. Vista lateral do suspensório de L. bimaculata MZUSP 80085, 70,1 mm CP. .355 
Figura 21. Vista medial do suspensório de Lebiasina erythrinoides MNRJ 14232, 64,8 mm CP. .356

Figura 22. Vista lateral do suspensório de Lebiasina erythrinoides MNRJ 14232, 64,8 mm CP. 357

Figura 23. Vista medial do suspensório de Derhamia hoffmannorum MTD F 26 492, 28 mm CP. .358

Figura 24. Vista lateral do suspensório de Derhamia hoffmannorum MTD F 26 492, 28 mm CP. 359

Figura 25. Vista medial do suspensório de Nannostomus beckfordi MZUSP 22910, 26,9 mm CP. $\rightarrow$ Indica o processo que se articula ventralmente com o mesetmóide. .360

Figura 26. Vista lateral do suspensório de Nannostomus beckfordi MZUSP 22910, 26,9 mm CP. .361

Figura 27. Vista medial do suspensório de Copeina guttata MZUSP 27088, 65,3mm CP.........362

Figura 28. Vista lateral do suspensório de Copeina guttata MZUSP 27088, 65,3mm CP. $\rightarrow$ Indica o processo lateral do dentário. .363

Figura 29. Vista lateral do suspensório de Copella nigrofasciata DEPRJ 104, 43,4 mm CP. $\rightarrow$ Indica o processo lateral do dentário...... .364

Figura 30. Vista medial do suspensório de Pyrrhulina australis MZUSP 59567, 31,8 mm CP. 365 Figura 31. Vista lateral do suspensório de Pyrrhulina australis MZUSP 59567, 31,8 mm CP..366 Figura 32. Vista (à esquerda) e lateral (à direita) do arco hióide (parte) de (A) Lebiasina bimaculata MZUSP 80085, 70,1 mm CP e (B) Lebiasina erythrinoides MNRJ 14232, 64,8 mm CP. .367

Figura 33. Vista (à esquerda) e lateral (à direita) do arco hióide (parte) de (A) Derhamia hoffmannorum MTD F 26 492, 28 mm CP, (B) Nannostomus beckfordi MZUSP 22910, 26,9 mm $\mathrm{CP}$. 368

Figura 34. Vista (à esquerda) e lateral (à direita) do arco hióide (parte) de (A) Copeina guttata MZUSP 27088, 65,3mm CP e (B) Copella nigrofasciata DEPRJ 104, 43,4 mm CP. ..... .369

Figura 35. Vista (à esquerda) e lateral (à direita) do arco hióide (parte) de Pyrrhulina australis MZUSP 59567, 31,8 mm CP. . 370

Figura 36. Uro-hial de (A) Lebiasina bimaculata MZUSP 80085, 70,1 mm CP e (B) Derhamia hoffmannorum MTD F 26 492, 28 mm CP em vista lateral e dorsal. 371

Figura 37. Uro-hial de (A) Nannostomus beckfordi MZUSP 22910, 26,9 mm CP e (B) Copeina guttata MZUSP 27088, 65,3mm CP em vista lateral e dorsal. .372

Figura 38. Uro-hial de (A) Copella nigrofasciata DEPRJ 104, 43,4 mm CP e (B) Pyrrhulina australis MZUSP 59567, 31,8 mm CP em vista lateral e dorsal. .373

Figura 39. Vista medial (A) e lateral (B) da cintura peitoral de Lebiasina bimaculata MZUSP 80085, 70,1 mm CP. 374

Figura 40. Vista medial (A) e lateral (B) da cintura peitoral de Lebiasina erythrinoides MNRJ 14232, 64,8 mm CP. $\rightarrow$ Indica o processo ventral do pós-temporal. 375 
Figura 41. Vista medial (A) e lateral (B) da cintura peitoral de Derhamia hoffmannorum MTD F 26 492, $28 \mathrm{~mm} \mathrm{CP}$

Figura 42. Vista medial (A) e lateral (B) da cintura peitoral de Nannostomus beckfordi MZUSP 22910, 26,9 mm CP......

Figura 43. Vista medial (A) e lateral (B) da cintura peitoral de Copeina guttata MZUSP 27088, $65,3 \mathrm{~mm} \mathrm{CP}$. 378

Figura 44. Vista medial (A) e lateral (B) da cintura peitoral de Copella nigrofasciata DEPRJ 104, 43,4 mm CP. .379

Figura 45. Vista medial (A) e lateral (B) da cintura peitoral de Pyrrhulina australis MZUSP 59567, $31,8 \mathrm{~mm} \mathrm{CP}$. .380

Figura 46. Vista dorsal da cintura peitoral (parte) de (A) Lebiasina bimaculata MZUSP 80085, 70,1 mm CP e (B) Lebiasina erythrinoides MNRJ 14232, 64,8 mm CP, evidenciando os radiais proximais da nadadeira peitoral.

Figura 47. Vista dorsal da cintura peitoral (parte) de (A) Derhamia hoffmannorum MTD F 26492 , $28 \mathrm{~mm}$ CP, (B) Nannostomus beckfordi MZUSP 22910, 26,9 mm CP, evidenciando os radiais proximais da nadadeira peitoral.

Figura 48. Vista dorsal da cintura peitoral (parte) de (A) Copeina guttata MZUSP 27088, 65,3mm CP, (B) Copella nigrofasciata DEPRJ 104, 43,4 mm CP e (C) Pyrrhulina australis MZUSP 59567, $31,8 \mathrm{~mm} \mathrm{CP}$, evidenciando os radiais proximais da nadadeira peitoral. $\rightarrow$ Indicam o radial proximal 4 expandido lateralmente em Copeina, Copella e Pyrrhulina. .383

Figura 49. Vista lateral da nadadeira dorsal de (A) Lebiasina bimaculata MZUSP 80085, 70,1 mm CP e (B) Lebiasina erythrinoides MNRJ 14232, 64,8 mm CP. .384

Figura 50. Vista lateral da nadadeira dorsal de (A) Derhamia hoffmannorum MTD F 26 492, 28 mm CP e (B) Nannostomus beckfordi MZUSP 22910, 26,9 mm CP. .385

Figura 51. Vista lateral da nadadeira dorsal de (A) Copella nigrofasciata DEPRJ 104, 43,4 mm CP e (B) Copeina guttata MZUSP 27088, 65,3mm CP. .386

Figura 52. Vista lateral da nadadeira anal de (A) Lebiasina bimaculata MZUSP 80085, 70,1 mm CP e (B) Lebiasina erythrinoides MNRJ 14232, 64,8 mm CP. .387

Figura 53. Vista lateral da nadadeira anal de (A) Derhamia hoffmannorum MTD F 26 492, 28 mm CP e (B) Nannostomus beckfordi MZUSP 22910, 26,9 mm CP. $\rightarrow$ Indica a articulação do último radial proximal com o espinho hemal. .388

Figura 54. Vista lateral da nadadeira anal de (A) Copeina guttata MZUSP 27088, 65,3mm CP, (B) Copella nigrofasciata DEPRJ 104, 43,4 mm CP e (C) Pyrrhulina australis MZUSP 59567, 31,8 mm CP. .389

Figura 55. Vista lateral do esqueleto caudal de Lebiasina bimaculata MZUSP 80085, 70,1 mm CP. .390

Figura 56. Vista lateral do esqueleto caudal de Lebiasina erythrinoides MNRJ 14232, 64,8 mm CP. 
Figura 57. Vista lateral do esqueleto caudal de Derhamia hoffmannorum MTD F 26 492, 28 mm CP. 392

Figura 58. Vista lateral do esqueleto caudal de Nannostomus beckfordi MZUSP 22910, 26,9 mm CP. $\rightarrow$ Indica o último espinho neural, que encontra-se reduzido nos representantes do gênero Nannostomus. 393

Figura 59. Vista lateral do esqueleto caudal de Copeina guttata MZUSP 27088, 65,3mm CP..369 Figura 60. Vista lateral do esqueleto caudal de Copella nigrofasciata DEPRJ 104, 43,4 mm CP. .394

Figura 61. Vista lateral do esqueleto caudal de Pyrrhulina zigzag MZUSP 61130, 30,7 mm CP. .395

Figura 62. Escamas de (A) Lebiasina bimaculata MZUSP 80085, 70,1 mm CP e (B) Lebiasina erythrinoides MNRJ 14232, 64,8 $\mathrm{mm} \mathrm{CP.} \rightarrow$ Indicam as células formadas pela anastomose dos radii. 396

Figura 63. Escamas de (A) Derhamia hoffmannorum MTD F 26 492, 28 mm CP, (B) Nannostomus beckfordi MZUSP 22910, 26,9 mm CP e (C) Nannostomus eques MZUSP 6423, 33,9 mm CP. 397 Figura 64. Escamas de (A) Copeina guttata MZUSP 27088, 65,3mm CP, (B) Copella nigrofasciata DEPRJ 104, 43,4 mm CP e (C) Pyrrhulina zigzag MZUSP 61130, 30,7 mm CP.398

Figura 65. Vista lateral de Hoplerythrinus unitaeniatus (MZUSP 22310, $80.1 \mathrm{~mm} \mathrm{CP),}$ evidenciando a musculatura facial (A2' e A2', correspondem a seções do adductor mandibulae; $\mathrm{DO}=$ dilatator operculi $; \mathrm{LAP}=$ levator arcus palatini $)$...... 399

Figura 66. Vista lateral de Lebiasina elongata (MUSM 21356, $76.7 \mathrm{~mm} \mathrm{CP}$ ), evidenciando a musculatura facial (A2' e A2"' correspondem a seções do adductor mandibulae; AAP= adductor arcus palatini $; \mathrm{DO}=$ dilatator operculi $\mathrm{LAP}=$ levator arcus palatini $).$ .400

Figura 67. Vista lateral de Nannostomus unifasciatus (MZUSP 29290, 28.4 mm CP), evidenciando a musculatura facial (A2' e A2"' correspondem a seções do adductor mandibulae; AAP= adductor arcus palatini; $\mathrm{DO}=$ dilatator operculi $\mathrm{LAP}=$ levator arcus palatini $).$

Figura 68. Vista lateral de Copeina guttata (MZUSP 27088, $61.2 \mathrm{~mm} \mathrm{CP}$ ), evidenciando a musculatura facial (A2' e A2" correspondem a seções do adductor mandibulae; $\mathrm{AAP}=$ adductor arcus palatini $; \mathrm{DO}=$ dilatator operculi; $\mathrm{LAP}=$ levator arcus palatini)

Figura 69. Vista lateral de Pyrrhulina semifasciata (MZUSP 24154, $45.9 \mathrm{~mm} \mathrm{CP}$ ), evidenciando a musculatura facial (A2' e A2'" correspondem a seções do adductor mandibulae; AAP= adductor arcus palatini; $\mathrm{DO}=$ dilatator operculi; $\mathrm{LAP}=$ levator arcus palatini $).$

Figura 70. Sinapomorfias do grupo externo referentes à topologia da árvore fundamental resultante da análise de parcimônia. Símbolos claros representam transformações com homoplasia, símbolos escuros representam transformações exclusivas. Apenas transformações não ambíguas demonstradas (continua nas figuras 71-75) .404

Figura 71. Sinapomorfias do grupo-externo referentes à topologia da árvore fundamental resultante da análise de parcimônia. Símbolos claros representam transformações com homoplasia, símbolos 
escuros representam transformações exclusivas. Apenas transformações não ambíguas demonstradas (continua nas figuras 72-75) 405

Figura 72. Sinapomorfias do grupo-interno referentes à topologia da árvore fundamental resultante da análise de parcimônia. Símbolos claros representam transformações com homoplasia, símbolos escuros representam transformações exclusivas. Apenas transformações não ambíguas demonstradas (continua nas figuras 73-75) .406

Figura 73. Sinapomorfias do grupo-interno referentes à topologia da árvore fundamental resultante da análise de parcimônia. Símbolos claros representam transformações com homoplasia, símbolos escuros representam transformações exclusivas. Apenas transformações não ambíguas demonstradas (continua nas figuras 74-75).

Figura 74. Sinapomorfias do grupo-externo referentes à topologia da árvore fundamental resultante da análise de parcimônia. Símbolos claros representam transformações com homoplasia, símbolos escuros representam transformações exclusivas. Apenas transformações não ambíguas demonstradas (continua na figura 75). .408

Figura 75. Sinapomorfias do grupo-externo referentes à topologia da árvore fundamental resultante da análise de parcimônia. Símbolos claros representam transformações com homoplasia, símbolos escuros representam transformações exclusivas. Apenas transformações não ambíguas demonstradas. .409

Figura 76. Lebiasina astrigata: .410

Figura 77. Mapa do noroeste da América do Sul com a distribuição de: Lebiasina astrigata (estrelas), L. aureogutatta (losangos); L. elongata (quadrados) e L. sp. Azuay (triângulos). Localidades-tipo representadas por polígonos brancos .412

Figura 78. Lebiasina aureoguttata: .413

Figura 79. Lebiasina bimaculata: .414

Figura 80. Mapa do noroeste da América do Sul com a distribuição de: Lebiasina bimaculata (círculos), Lebiasina aff. bimaculata I (triângulos), Lebiasina aff. bimaculata II (estrela) e Lebiasina aff. festae (quadrados). Localidades-tipo representadas por polígonos brancos. .415

Figura 81. Lebiasina boruca: .416

Figura 82. Mapa do noroeste da América do Sul e sul da América com a distribuição de: Lebiasina boruca (losangos), L. festae (círculos) e L. panamensis (quadrados). Localidades-tipo representada por polígonos brancos. .417

Figura 83. Lebiasina chocoensis: .418

Figura 84. Mapa do noroeste da América do Sul com a distribuição de: Lebiasina chocoensis (círculos), L. colombia (triângulos), L. multimaculata (losangos), L. ortegai (quadrados). Localidades-tipo representada por polígonos brancos.

Figura 85. Lebiasina colombia: .420

Figura 86. Lebiasina elongata: .421 
Figura 87. Lebiasina erythrinoides:

Figura 88. Mapa do norte da América do Sul com a distribuição de: Lebiasina erythrinoides (quadrados) e Lebiasina floridablancaensis (círculos). Localidades-tipo representadas por quadrado branco e círculo escuro. Localidade-tipo de L. pleurotaenia apontada em cinza...... .423

Figura 89. Lebiasina festae .424

Figura 90. Lebiasina floridablancaensis: .425

Figura 91. Ilustração original de Lebiasina intermedia, retirada de Meinken (1937) .426

Figura 92. Mapa do Brasil-Central e parte da bacia do rio Amazonas com a distribuição de: Lebiasina sp. "Curuá-Faixa" (triângulo), L. sp. "Curuá-Pinta” (círculos) e a suposta localidade-tipo de L. intermedia ("próximo a Santarém") .427

Figura 93. Lebiasina multimaculata: .428

Figura 94. Lebiasina ortegai:. .429

Figura 95. Lebiasina panamensis: .430

Figura 96. Lebiasina taphorni: 431

Figura 97. Mapa do norte da América do Sul, na porção oeste do Escudo Guianense, com a distribuição de: Lebiasina taphorni (triângulo), L. unitaeniata (losangos), L. uruyensis (quadrados), L. yuruaniensis (círculos) e L. sp. Parima (estrelas). Localidades-tipo representadas por polígonos brancos. 432

Figura 98. Lebiasina unitaeniata: 433

Figura 99. Lebiasina uruyensis: .435

Figura 100. Lebisina yuruaniensis: A- CAR 290 (73.2 mm SL), Venezuela, Bolívar, Quebrada La Burra, Gran Sabana, El Pauji, antes de chegar ao Tepui el Altar; B- CAR 286 (82.3 mm SL), Venezuela, Bolívar, Gran Sabana, rio El Pauji, antes do salto el Pauji. .436

Figura 101. Lebiasina sp. "Curuá-Pinta”: A- MZUSP 99609 holótipo (85.89 mm SL), Brasil, Pará, Altamira, tributário do rio Curuá, bacia do rio Iriri (drenagem do rio Xingu), próximo à BR-163, 0849’12”S 5458'11”W. B- MZUSP 99610 (65.0 mm SL), mesmos dados do holótipo; C- MZUSP 101423 (54.4 mm SL), Brasil, Pará, Altamira, rio Treze de Maio (sistema do rio Iriri, bacia do rio

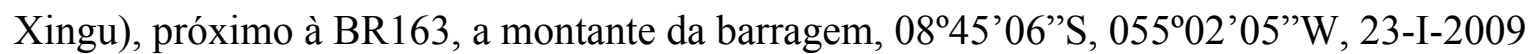
.437

Figura 102. Lebiasina sp. "Curuá-Faixa": A- MZUSP 101375 holótipo (88.8 mm SL), Brasil, Pará, Altamira, tributário do rio Curuá, bacia do rio Iriri (drenagem do rio Xingu), próximo à BR-163, 0849'12" S 05458'11” W; B- MZUSP 99607 (33.7 mm SL) mesmos dados do holótipo. 438

Figura 103. Lebiasina sp. "Parima": A- MNRJ uncat (152.9 mm SL), Brasil, Amazonas, Rio Marari, acampamento entre 700 e 1000m a montante da Missão Marari da aldeia Ianomami, na Serra Tapirapecó, afluente do rio Padauari; B- MNRJ uncat (78.2 mm SL), mesmos dados do holótipo. .439 
Figura 104. Lebiasina aff. bimaculata I: MUSM 7327 (A- 98.4 mm SL; B- 83.2 mm SL), Peru, Piura, Alto Río Piura. 440

Figura 105. Lebiasina aff. bimaculata II: MUSM 13270 (A- 96.7 mm SL; B- 87.4 mm SL), Peru, Piura, Sullana, Quebrada Salado [04³8'24’'S 80¹8'58'W]. .441

Figura 106. Lebiasina aff. festae: MUSM 6530 (A- $121.3 \mathrm{~mm}$ SL; B- $119.3 \mathrm{~mm}$ SL), Peru, Tumbes, BNT, El Gaucho, Quebrada Faical, 550 m elev., 0359’ S 80³1’ W. 442

Figura 107. Lebiasina ap. "Azuay”: MEPN 6001 (A- 120.0 mm SL; B- 109.8 mm SL), Equador, Azuay, quebrada sem nome, afluente do rio Guanache, 200m elev., 0303'38'S 7943'50”W ..443 


\section{Introdução}

\section{A família Lebiasinidae}

Os peixes da família Lebiasinidae constituem um grupo endêmico da região Neotropical, com cerca de 65 espécies válidas distribuídas em sete gêneros. Os gêneros Lebiasina Valenciennes, in Cuvier \& Valenciennes e Piabucina Valenciennes, in Cuvier \& Valenciennes compõem a subfamília Lebiasininae, enquanto Derhamia Géry \& Zarske, Nannostomus Günther, Copeina Fowler, Copella Myers, e Pyrrhulina Valenciennes, in Cuvier \& Valenciennes integram a subfamília Pyrrhulininae (NettoFerreira, 2006). Os representantes da família são peixes de pequeno a médio porte com comprimento padrão em adultos variando desde 1,6 cm em Nannostomus anduzei Fernandez \& Weitzman (Weitzman \& Vari, 1988) e dificilmente ultrapassando $20 \mathrm{~cm}$ em Lebiasininae (Oyakawa, 1998). Devido ao seu pequeno porte, os representantes da família Lebiasinidae não são explorados comercialmente com fins alimentícios, mas são apreciados no ramo da aquariofilia (Hoedeman, 1954; Weitzman \& Weitzman, 2003). As espécies de Lebiasinidae apresentam, de maneira geral, acentuado dimorfismo sexual, relacionado principalmente à coloração e à morfologia da nadadeira anal, sendo que tubérculos nupciais podem estar presentes em machos do gênero Nannostomus (Wiley \& Collete, 1970) e Lebiasina (Netto-Ferreira, 2006).

Um detalhado histórico taxonômico do grupo está disponível em Netto-Ferreira (2006) e Weitzman (1964). Todos os gêneros da família necessitam de revisão taxonômica (Taphorn, 1992; Géry \& Zarske, 2002; Weitzman \& Weitzman, 2003), algo que vem sendo aguardado desde que James Bohlke iniciou seu estudo de revisão dos gêneros Lebiasina e Piabucina na década de 50 (Géry \& Zarske, 2002; Weitzman \& Weitzman, 2003). Desde então, apenas as espécies do gênero Nannostomus foram estudadas, resultando na publicação das revisões de Weitzman (1966) e Weitzman \& Cobb (1975). Além disso, a diagnose da maioria dos gêneros da família tem sido baseada principalmente em combinações de caracteres subjetivos. Netto-Ferreira (2006), em seu estudo das relações filogenéticas dos gêneros de Lebiasinidae, propõe novas diagnoses para todos os gêneros, entretanto, sua análise não abrange as relações entre as espécies da família. 


\section{A subfamília Lebiasininae}

Os Lebiasininae encontram-se distribuídos pelo escudo das Guianas, bacia do Orinoco, bacias andinas do norte da América do Sul, Panamá e Costa Rica. Até recentemente, apenas Lebiasina intermedia Meinken era registrada no baixo Amazonas (localidade tipo "próximo a Santarém"). Este ocorrência é considerada equivocada por Weitzman \& Weitzman (2003), uma vez que nenhum outro representante de Lebiasininae além dos exemplares utilizados na descrição de L. intermedia foi coletado no médio ou baixo Amazonas desde então. Recentemente foram registradas novas espécies oriundas das regiões de cabeceira da bacia do rio Negro (nos estados do Amazonas e Roraima), do rio Braço Norte e afluentes do rio Curuá (Pará), foram registradas.

Tradicionalmente, o gênero Lebiasina é diagnosticado pela ausência de nadadeira adiposa e pela presença de alvéolos (comumente chamados de células) na porção anterior da câmara posterior da bexiga natatória. O gênero Piabucina é diagnosticado pela presença de nadadeira adiposa e bexiga natatória não celular. Devido à ocorrência de espécies consideradas "intermediárias" entre os dois gêneros, a divisão dos Lebiasininae em Lebiasina (atualmente com 13 espécies nominais) e Piabucina (atualmente com nove espécies nominais) tem sido historicamente questionada por diversos autores (Eigenmann \& Allen, 1942; Weitzman, 1964; Machado-Allison, 1974; Dahl, 1971; Géry, 1977; Taphorn, 1992; Géry \& Zarske, 2002) e parece ter sido completamente desconsiderado nas descrições de espécies mais recentes, que foram todas alocadas em Lebiasina (Ardila-Rodríguez 1994, 1999, 2000, 2001, 2002, 2004, 2008a, 2008b, 2010a). De fato, Piabucina festae e Piabucina boruca são espécies com nadadeira adiposa e que apresentam também os alvéolos na câmara posterior da bexiga natatória. Além disso, espécies descritas recentemente apresentam as características diagnósticas de Piabucina, mas foram alocadas em Lebiasina. Böhlke (1958) e Weitzman (1964) mencionam uma revisão das espécies da subfamília Lebiasininae que estaria sendo realizada por James Böhlke, falecido em 1982, onde diversas modificações na classificação do grupo seriam feitas, mas este estudo nunca foi terminado.

Netto-Ferreira (2006) corrobora o monofiletismo da subfamília com base em nove sinapomorfias. Entretanto, o autor refuta o monofiletismo de ambos os gêneros, uma vez que L. bimaculata, a espécie-tipo de Lebiasina, seria mais relacionada a 
Piabucina festae, enquanto P. erythrinoides, a espécie-tipo de Piabucina, estaria incluída em um grupo monofilético incluindo duas espécies de Lebiasina, além de duas outras espécies de Piabucina. Desta maneira, Netto-Ferreira (2006) propõe a sinonimização dos dois gêneros, seguindo a proposta de Eigenmann \& Allen (1942), Géry (1977), Taphorn (1992) e Géry \& Zarske (2002) e reforça a necessidade de uma investigação mais abrangente das relações entre as espécies incluídas nesta subfamília, aspecto não abordado naquela ocasião.

\section{$\underline{\text { 3. Objetivos }}$}

O presente estudo teve como principais objetivos: (1) realizar uma revisão taxonômica das espécies pertencentes à subfamília Lebiasininae; (2) produzir ao final da revisão taxonômica uma chave de identificação das espécies de Lebiasininae, a fim de substituir a única chave, disponível em Géry (1977), que encontra-se desatualizada; (3) apresentar, por meio da metodologia cladística, uma hipótese de relações filogenéticas entre as espécies de Lebiasininae e os demais Lebiasinidae; (4) avaliar a validade e os limites dos gêneros de Lebiasininae.

\section{$\underline{\text { Material e métodos }}$}

\section{Material}

O material examinado no presente estudo encontra-se depositado nas coleções ictiológicas dos museus (abreviações seguem Levinton et al., 1985 e Eschmeyer, 1998): AMNH (American Museum of Natural History, Nova York, Estados Unidos); ANSP (Academy of Natural Sciences of Philadelphia, Philadelphia, Estados Unidos); BMNH (Natural History Museum, Londres, Inglaterra); CAS (California Academy of Sciences, São Francisco, Estados Unidos); CAR (coleção particular de Carlos Ardilla Rodriguez, Barranquilla, Colômbia); FMNH (Field Museum of Natural History, Chicago, Estados Unidos); IAvH (Instituto Alexander von Humboldt, Villa de Leyva, Colômbia); ICNMHN (Instituto de Ciências Naturales - Museo de Historia Natural, Bogotá, Colômbia); INHS (Illinois Natural History Survey, Champaign, Estados Unidos); INPA (Instituto de Pesquisas da Amazônia, Manaus); MBUCV-V (Museo de Biologia da Universidad Central de Venezuela, Caracas, Venezuela); MCNG (Museu de Ciencias Naturales de Guanare, Guanare, Venezuela); MCP (PUC- RS, Museu de Ciência e Tecnologia, Porto Alegre); MCZ (Museum of Comparative Zoology, Harvard, Estados Unidos); MHNLS 
(Museo de Historia Natural La Salle, La Salle, Venezuela); MNHN (Muséum National d'Histoire Naturelle, Genebra, Suíça); MNRJ (Museu Nacional- UFRJ, Rio de Janeiro); MPEG (Museu Paraense Emilio Goeldi, Belém); MZUSP (Museu de Zoologia da Universidade de São Paulo, São Paulo); MZUT (Universita di Torino, Museo Zoológico, Turin, Itália); NRM (Naturhistoriska Riksmuseet, Stockholm, Estocolmo, Suécia), USNM (National Museum of Natural History, Washington D.C., Estados Unidos).

\section{Exame de material}

A obtenção e o exame dos caracteres de morfologia externa foram feitos a partir de exemplares preservados em álcool 70\%. Dados morfométricos foram obtidos com medidas ponto a ponto feitas com um paquímetro digital (com precisão de $0,01 \mathrm{~mm}$ ), seguindo o protocolo proposto por Fink \& Weitzman (1974), incluindo as seguintes medidas e contagens: standard length (comprimento padrão, medido da ponta do focinho até o final do pedúnculo caudal); depth dorsal fin (altura do corpo no ponto de origem da nadadeira dorsal); snout to anal fin origin (distância entre o focinho e a origem da nadadeira anal); snout to pelvic fin origin (distância entre o focinho e a origem da nadadeira pélvica); snout to dorsal fin origin (distância entre o focinho e a origem da nadadeira dorsal); dorsal fin origin to caudal base (distância entre a origem da dorsal e a base da nadadeira dorsal); dorsal fin lenght (comprimento da nadadeira dorsal quando flexionada junto ao corpo); dorsal fin base (distância entre a margem anterior do primeiro e a margem posterior do último raio da dorsal); adipose to caudal peduncle (distância da adiposa ao fim do pedúnculo caudal); caudal peduncle length (comprimento do pedúnculo caudal); caudal peduncle depth (menor altura do pedúnculo caudal); anal fin lenght (comprimento da nadadeira anal flexionada ao corpo); anal fin base (distância entre a margem anterior do primeiro e a margem posterior do último raio da anal); pelvic to anal fin origin (distância entre a origem da pélvica e a origem da anal); pelvic fin length (comprimento da pélvica); pectoral to pelvic fin origin (distância entre a origem da peitoral e a origem da pélvica); pectoral fin length (comprimento da peitoral); snout to pectoral fin origin (distância entre o focinho e a origem da peitoral); bony head length (comprimento da cabeça, medido da ponta do focinho até o ponto mais posterior do opérculo); head width (largura da cabeça); horizontal eye diameter (diâmetro do olho); distance snout tip to eye (distância entre a ponta do focinho e o 
olho); interorbital distance (distância interorbital); lower jaw length (comprimento da mandíbula); upper jaw length (comprimento da maxila, medido desde a face medial do pré-maxilar até a extremidade póstero-ventra do maxilar); scales lateral series (série longitudinal de escamas onde passa a linha lateral); pored lateral line scales (escamas perfuradas da linha lateral); scales horizontal series (número de séries longitudinais de escamas entre a nadadeira dorsal e a nadadeira pélvica, não levando em consideração as escamas das séries médio-dorsal); predorsal scales (escamas da série médio-dorsal entre a cabeça e o início da nadadeira dorsal - não foram levadas em consideração nesta contagem as duas escamas lateralmente posicionadas imediatamente após os parietais, pois as mesmas fazem parte da primeira série longitudinal dorsal do corpo). As medidas relativas ao corpo ou suas sub-unidades são apresentadas em proporção ao comprimento padrão, enquanto que as medidas relativas à cabeça e suas sub-unidades são apresentadas em proporção ao comprimento da cabeça. Cada uma dessas medidas e contagens é acompanhada do número de exemplares examinados (n), intervalo do menor e maior valor da amostra (range), média (mean) e desvio-padrão (SD). A contagem do número de dentes do maxilar, pré-maxilar, série externa do dentário foi feita apenas em exemplares diafanizados. Além disso, foram contados o número de raios das nadadeiras peitoral, pélvica, dorsal, anal e caudal. Na contagem do número de vértebras, aquelas pertencentes ao aparelho de Weber foram incluídas nas contagens referentes às vértebras pré-caudais, bem como as de transição. Foram consideradas vértebras caudais aquelas que apresentam o canal hemal totalmente formado e as parapósifes totalmente fusionadas, formando o espinho hemal. $\mathrm{Na}$ contagem dos raios, o raio adnato da nadadeira anal foi considerado um único raio (a nadadeira dorsal de Lebiasinidae não apresenta raio adnato). Todos os resquícios de raios da nadadeira peitoral foram incluídos na contagem de raios.

Os caracteres osteológicos foram obtidos e examinados a partir de exemplares diafanizados, seguindo a metodologia proposta por Taylor \& van Dyke (1985), ou ainda por meio de radiografias digitais. Os exemplares foram examinados com auxílio de microscópio estereoscópico. A representação das estruturas foi feita por meio de fotografias digitais e ilustrações confeccionadas com auxílio de câmara clara. A nomenclatura osteológica baseou-se nos estudos de Weitzman $(1962,1964)$, seguindo as traduções para o português por Castro \& Castro (1987), exceto pelos termos: ceratobranquial, hipo-hial, ptero-esfenóide e retro-articular ao invés de ceratobranquial, hipial, 
pteroesfenóide e retroarticular; suspensório, ao invés de suspensor, seguindo Britto (2002); endopterigóide ao invés de mesopterigóide seguindo Arratia (1992). A nomenclatura dos ossículos do aparelho de Weber foi mantida em sua forma latinizada. A nomenclatura dos nervos cefálicos seguiu Freihofer (1978) e a miológica seguiu Winterbottom (1974), exceto pela nomenclatura das sub-unidades do adductor mandibulae, que seguiu Datovo e Bockmann (2010). O método de dissecção dos exemplares, para a remoção de complexos ósseos (e.g., suspensório, cesta branquial e cintura escapular), seguiu a técnica proposta por Weitzman (1974), quando possível.

\section{Análise filogenética}

A análise filogenética empregada no estudo das relações interespecíficas de Lebiasininae seguiu os princípios teóricos e metodológicos da Sistemática Filogenética ou Cladística. O método foi proposto originalmente por Hennig $(1950,1966,1968)$ e vem sendo aprimorado por outros autores (e.g., Eldredge \& Cracraft, 1980; Nelson \& Platnick, 1981; Wiley, 1981; Rieppel, 1988; Swofford \& Olsen, 1990; Wiley et al., 1991; Novacek \& Wheeler, 1992; Hall, 1994; Scotland et al., 1994; Harvey et al., 1996; Kitching et al., 1998; Page \& Holmes, 1998; Schuh, 2000; Scotland \& Pennington, 2000; Wiens, 2000). Os 307 caracteres morfológicos examinados por Netto-Ferreira (2006) foram reavaliados, e novos caracteres obtidos por meio da comparação direta do material foi incluído no presente estudo. Foi incluído no estudo filogenético o máximo possível de representantes das espécies de Pyrrhulininae a fim de abranger a maior diversidade possível do grupo.

As análises de parcimônia da matriz de dados foram realizadas com auxílio do programa TNT (Goloboff et al., 2003), por meio do comando MULT com 5000 réplicas e "branch swapping" TBR (tree bissection reconnection). A otimização de caracteres ambíguos não preferiu o algoritmo ACCTRAN (“accelerated transformation") Swofford e Maddison (1987) que prioriza reversões a convergências, preservando as hipóteses de homologias primárias, como proposto por de Pinna (1991). No presente estudo, além do comprimento, as árvores mais parcimoniosas foram avaliadas pelos índices de consistência e retenção (Kluge \& Farris 1969; Farris 1970, 1989, 1991; Goloboff, 1991; Wiley et al., 1991) e os índices de suporte de ramos (Bootstrap Felsenstein, 1985; índice de Bremer - Bremer, 1994, calculado a partir do próprio algoritmo do TNT). 


\section{Revisão taxonômica}

Para a revisão taxonômica das espécies de Lebiasininae, foram analisados dados disponíveis na literatura, bem como material de coleções ictiológicas, incluindo os tipos das espécies, quando disponíveis. Caso contrário, topótipos foram examinados em lugar dos tipos primários. Todas as espécies foram redescritas e suas diagnoses feitas com base em contagens, dados merísticos, morfométricos, colorido e indicando-se as autapomorfias de cada uma delas, seguindo o conceito filogenético de espécie original de Nelson e Platnick (1981) como sumarizado em de Pinna (1999). Estes caracteres foram utilizados também na elaboração da chave de identificação ao final da revisão taxonômica, a fim de facilitar a identificação das espécies, esta baseou-se ao máximo em caracteres de fácil reconhecimento, dispensando caracteres de anatomia interna, quando possível. As listas sinonímicas encontram-se em inglês, que será o idioma para a publicação. 


\section{$\underline{\text { Resultados }}$}

\section{Análise filogenética}

A análise filogenética resultou em seis árvores igualmente parcimoniosas com 800 passos $(\mathrm{CI}=0.37 \mathrm{RI}=0.86)$. A seguir, são listados os caracteres analisados, bem como seus estados, seguindo a numeração da matriz de dados (Tabela 01). Para cada caráter é fornecida uma breve descrição dos estados e dos grupos definidos por suas transformações. Para tais discussões, foi selecionada uma das árvores fundamentais (fig. 01) ao invés do consenso (fig. 02). A título de simplificação da nomenclatura dos subgrupos de Lebiasinidae adotada na discussão, preferiu-se atualizá-la com base nos resultados da análise cladística:

FAMÍLIA LEBIASINIDAE GILL, 1895

SUBFAMÍLIA LEBIASININAE GILL, 1895

GÊNERO LEBIASINA VALENCIENNES, IN CUVIER \& VALENCIENNES (1846)

SubFAmília PyrRhULININAE GiLl, 1895

TRIBO DERHAMIINI

GÊNERO DERHAMIA GÉRY \& ZARSKE, 2002

Tribo PyrRhULININI GiLl, 1895 (e não EIGENMANN, 1910)

SubTribo NANNOSTOMina EIGENMANN, 1909

GÊNERO NANNOSTOMUS GÜNTHER, 1872

SubTribo PyrRhulinina GiLl, 1895 (e não EIGENMANN, 1910)

GÊNERO COPEINA FOWLER, 1906

GÊNERO COPELLA MYERS, 1956

GÊNERo PYRRHULINA VALENCIENNES , IN CUVIER \&VALENCIENNES (1846)

É importante ressaltar que a polarização dos caracteres foi feita a posteriori, com o enraizamento no grupo-externo, de modo que o estado " 0 " não necessariamente indica o estado plesiomórfico dos caracteres, podendo, desta forma, a transformação $(X \rightarrow 0)$ representar uma derivação. Informações entre parênteses acompanhando os títulos dos caracteres referem-se ao: nome do autor que incluiu o caráter em um estudo anterior, ano da publicação/defesa do estudo e número do caráter naquela ocasião. Aqueles caracteres que eventualmente tenham sido modificados para se adequar ao presente 
estudo estão indicados como "- modificado". Foram tratados como ordenados os caracteres: $01-03,06,24,29-32,50,54,63,64,73,77,85,88,94,99,104,106,115$, $119,125,134,135,138,141,146,147,150,151,156,164,166,177,191,195,197$ e 202-205.

\section{Série circum-orbital}

(Figura 03-06)

01. Relação altura /comprimento do antorbital (Campanario, 2000: 24 modificado; Netto-Ferreira, 2006: 02) $-\mathrm{CI}=0.25$; $\mathrm{RI}=0.84$.

(0) mais alto que curto (Weitzman, 1962: fig. 08; Roberts, 1969: fig. 01; Roberts, 1974: fig. 62-dir.; Campanario, 2000: fig. 21 e 22); (1) tão curto quanto alto; (2) mais curto que alto (Weitzman, 1964: fig 06).

Campanario (2000) observou que em Poecilocharax weitzmani, este osso apresenta-se mais baixo e alongado ântero-posteriormente. Nas espécies dos gêneros Derhamia, Pyrrhulina, Copeina, Nannostomus beckfordi, N. limatus, N. marginatus e N. nitidus, o antorbital apresenta-se levemente alongado e baixo. $\mathrm{O}$ alongamento do antorbital é uma sinapomorfia do clado incluindo os Pyrrhulininae (sensu Weitzman \& Cobb, 1975) e Derhamia, adquirido independentemente em Lebiasina sp. Curuá "Faixa" e L. elongata. A ocorrência do estado "2" em representantes do gênero Copella, representa uma sinapomorfia para o gênero, contrariamente ao proposto em NettoFerreira (2006) que sugeriu que os membros do grupo apresentariam o estado "1". de acordo com as árvores fundamentais, a transformação $1 \rightarrow 2$ ocorreu independentemente em $N$. limatus, e representa uma transformação ambígua no clado 123, que, com base em otimização ACCTRAN, ocorreu na base do clado e posteriormente reverteu em $(N$. digrammus $+N$. marilynae) e N. unifasciatus. Devido à ausência do antorbital em Boulengerella e Hoplerythrinus foi atribuído o estado “_” a ambos.

02. Grau de sobreposição do infra-orbital 1 em relação ao maxilar (Lucena, 1993: 29 - modificado; Oyakawa, 1998: 31 - modificado; Zanata, 2000: 04 modificado; Zanata \& Vari, 2005: 07 - modificado; Netto-Ferreira, 2006: 06 modificado) $-\mathrm{CI}=0.6 ; \mathrm{RI}=0.87$.

(0) Sobrepondo-se totalmente à porção látero-posterior do maxilar (Roberts, 1969: fig 01, 02 e 05); (1) sobrepondo-se a grande parte da porção látero-posterior do maxilar; (2) 
sobrepondo-se a uma diminuta porção do maxilar (Weitzman, 1962: fig. 08; Weitzman, 1964: fig 06; Zanata, 2000: fig. 12); (3) não se sobrepondo ao maxilar.

Oyakawa (1998) observou que em Lebiasinidae e Erythrinidae o infra-orbital 1 (IO1) sobrepõe-se lateralmente à porção posterior do maxilar, enquanto que em Acestrorynchus, Hepsetus e Ctenoluciidae este osso sobrepõe-se totalmente ao maxilar. Zanata (2000) e Zanata \& Vari (2005), consideraram como não-homóloga a relação entre o IO1 e o maxilar observada nos Alestidae e Characidae e aquela observada em Erythrinoidea e Acestrorhynchus, devido à forma como o IO1 encobre o maxilar. Aqui, preferiu-se examinar a associação entre infra-orbital e a margem posterior do maxilar. $\mathrm{Na}$ maioria dos táxons examinados, o IO1 sobrepõe-se lateralmente apenas à margem posterior do maxilar. Entre os Lebiasininae, no entanto, o IO1 projeta-se anteriormente, encobrindo grande parte do maxilar nos clados 69 (Lebiasina gr. bimaculata) e 87 (Lebiasina gr. astrigata). A transformação $(2 \rightarrow 1)$ observada nesses clados, corresponde a sinapomorfias adquiridas independentemente nos dois grupos.

03. Grau de sobreposição do infra-orbital $2 \mathrm{em}$ relação ao maxilar $-\mathrm{CI}=0.37$; $\mathrm{RI}=0.88$.

(0) Encobrindo grande parte do maxilar (Roberts, 1969: fig 01, 02 e 05); (1) encobrindo aproximadamente metade da extensão do maxilar; (2) encobrindo apenas a porção posterior do maxilar; (3) maxilar encobrindo a margem anterior do infra-orbital 2 (Weitzman, 1962: fig. 08; Weitzman, 1964: fig 06; Roberts, 1969: fig. 03; Roberts, 1974: fig. 61; Zanata, 2000: fig. 12).

Assim como o infra-orbital 1, o infra-orbital 2 (IO2) encobre lateralmente (ao menos em parte) o maxilar na maioria dos Characiformes. Na maioria dos grupos examinados, o IO2 encobre ao menos a metade posterior do maxilar. Entre os Lebiasininae, o IO2 encobrindo apenas a porção posterior do maxilar representa uma sinapomorfia do clado 77, que posteriormente reverte ao estado "0" no clado 86. Entre os Pyrrhulininae (clado 94) a associação entre os dois ossos parece única entre os Characiformes, uma vez que o maxilar sobrepõe-se ao IO2, que possui sua margem anterior sulcada na porção onde o maxilar se sobrepõe. Em Nannostomus, por sua vez, o diminuto maxilar não alcança o IO2. Por isso, foi atribuído o estado “-” aos representantes do grupo. 
04. Margem ventral do infra-orbital 2 (Netto-Ferreira, 2006: 07) $-\mathrm{CI}=0.20$; $\mathrm{RI}=$ 0.60 .

(0) Contígua à margem antero-ventral do infra-orbital 3 (Weitzman, 1962: fig. 08; Weitzman, 1964: fig 06; Roberts, 1969: fig. 01 a 05; Roberts, 1974: fig. 61; Zanata, 2000: fig. 12; Campanario, 2000: fig.21); (1) não contígua à margem antero-ventral do infra-orbital 3.

Netto-Ferreira (2006) sugeriu que a disjunção entre a margem antero-ventral do infra-orbital 2 e do infra-orbital 3 representaria uma sinapomorfia dos Lebiasininae. Após o exame de espécies adicionais do grupo, constatou-se que tal condição não é amplamente difundida entre os representantes da subfamília, mas corresponde a sinapomorfias homoplásticas dois grupos menos inclusivos (clados 73 e 93) e autapomorfias de Lebiasina aff. bimaculata II e L. floridablancaensis.

05. Área nfra-orbital 3 (Oyakawa, 1998: 32, Netto-Ferreira, 2006: 08) - CI= 1.00; $\mathrm{RI}=1.00$.

(0) Com pequena participação na margem póstero-inferior do anel orbital (Weitzman, 1962: fig. 08; Roberts, 1969: fig. 01 a 05; Roberts, 1974: fig. 61; Zanata, 2000: fig. 12; Campanario, 2000: fig.21); (1) participando amplamente da margem inferior do anel orbital (Weitzman, 1964: fig. 06).

$\mathrm{Na}$ maioria dos Characiformes a porção inferior do anel orbital é formada principalmente pelo primeiro e segundo infra-orbitais. Nos Lebiasinidae, entretanto, o primeiro e o segundo infra-orbitais ocupam uma posição anterior no anel orbital, de maneira que o terceiro infra-orbital (IO3) ocupa grande parte da margem ventral do anel, constituindo uma sinapomorfia para a família. Representantes dos gêneros Derhamia e Nannostomus, por sua vez, apresentam a condição extrema deste caráter, onde IO3 ocupa toda a margem ventral do anel orbital.

06. Margem póstero-dorsal do infra-orbital 3 (Netto-Ferreira, 2006: 11 modificado) $-\mathrm{CI}=0.67 ; \mathrm{RI}=0.96$.

(0) sem uma distinta projeção (Weitzman, 1962: fig. 08; Weitzman, 1964: fig 06; Roberts, 1969: fig. 03 a 05; Roberts, 1974: fig. 61; Zanata, 2000: fig. 12; Campanario, 2000: fig.21); (1) com uma projeção que exclui parcialmente o infra-obital 4 do anel orbital; (2) com uma projeção que exclui o infra-orbital 4 do anel orbital. 
O infra-orbital 3 de exemplares de Lebiasina apresenta-se expandido em sua margem póstero-dorsal, diminuindo a participação do quarto infra-orbital na margem do anel orbital. Entre os demais táxons examinados, apenas Hepsetus apresenta uma discreta projeção similar à encontrada em Lebiasininae, porém, esta não exclui o quarto infra-orbital do anel orbital. Tal condição parece possuir um forte componente ontogenético, onde os exemplares jovens de Lebiasininae apresentam o estado " 0 ” e ao longo do crescimento o infra-orbital 3 se expande dorso-posteriormente, gradualmente excluindo o infra-orbital 4 do anel orbital. Esta condição representa uma sinapomorfia exclusiva da subfamília Lebiasininae.

07. Forma do infra-orbital 4 (Zanata, 2000: 08; Zanata \& Vari, 2005: 13; NettoFerreira, 2006: 10) $-\mathrm{CI}=0.5 ; \mathrm{RI}=0.00$.

(0) Margem anterior tão larga quanto a posterior (Weitzman, 1962, fig. 08; Roberts, 1969, fig. 05; Campanario, 2000: fig.21; Zanata, 2000: fig. 12); (1) margem posterior distintamente mais larga que a anterior (Weitzman, 1964: fig 06; Roberts, 1969: fig. 01, 03 e 04).

08. Infra-orbital 5 (Netto-Ferreira, 2006: 12) - CI=1.00; RI=1.00.

(0). Sem um processo interno; (1) com um processo interno.

Zanata (2000), Zanata \& Vari (2005), e Toledo-Piza (2007) reportam processos digitiformes direcionados medialmente nos infra-orbitais de representantes dos gêneros Brycon (IO2), Chalceus (IO2) e Acestrorhynchus (IO1), respectivamente. Os representantes dos Pyrrhulininae (sensu Weitzman \& Cobb, 1975), por sua vez, apresentam uma projeção curta na face medial do infra-orbital 5 (IO5), que margeia anteriormente o espinho do esfenótico. Em Derhamia e Nannostomus, por sua vez, o infra-orbital 6 (IO6) também apresenta um processo na face interna, o que pode representar uma evidência de que em Copeina, Copella e Pyrrhulina o IO5 estaria fusionado ao IO6. Em ambos os casos, a projeção interna do quinto e sexto ou apenas do sexto infra-orbital se apresenta imediatamente anterior ao espinho do esfenótico.

09. Infra-orbital 6 (Lucena, 1993: 28 - modificado; Campanario, 2000: 22 modificado; Zanata \& Vari, 2005: 15; Netto-Ferreira, 2006: 14) - CI=1.00; RI=1.00. 
(0) Presente (Weitzman, 1962: fig. 08; Weitzman, 1964: fig 06; Roberts, 1969: fig. 01 a 05; Roberts, 1974: fig. 61; Vari, 1995: fig. 01; Zanata, 2000: fig. 12; Campanario, 2000: fig.21); (1) ausente.

Weitzman (1964) afirma que todos os representantes da tribo Pyrhulinini (=Pyrrhulininae sensu Weitzman \& Cobb, 1975) não apresentam o canal do sexto infraorbital totalmente envolto pelo dermosfenótico (= infra-orbital 6 [IO6]) e utiliza esta característica como diagnóstica do grupo. Entretanto, após o exame exemplares de Copeina, Copella e Pyrrhulina, é possível sugerir que o infra-orbital ausente seja o IO6. Lucena (1993), por sua vez, em seu caráter “número de infra-orbitais" observou que Pyrrhulina apresenta apenas cinco infra-orbitais, porém, não especifica qual seria o elemento ausente. A perda do IO6 representa uma sinapomorfia exclusiva do Clado 96.

10. Infra-orbitais (Netto-Ferreira, 2006: 17) $-\mathrm{CI}=0.5 ; \mathrm{RI}=0.00$.

(0) Ossos dérmicos delgados, encobrindo apenas parte da face (Weitzman, 1962, fig. 08; Roberts, 1969, fig. 05); (1) porções lamelares espessas e expandidas, encobrindo toda a face (Weitzman, 1964, fig. 06; Roberts, 1969, fig. 01 a 03).

Os infra-orbitais dos Ctenoluciidae, Erythrinidae, Hepsetidae, Lebiasinidae apresentam as porções lamelares bastante desenvolvidas, encobrindo grande parte da face, sendo que somente uma pequena porção do pré-opérculo e do quadrado permanecem "expostas".

11. Supra-orbital (Lucena, 1993: 26; Vari, 1995: 09; Buckup, 1998: 21; Oyakawa 1998: 07; Zanata \& Vari, 2005: 02; Netto-Ferreira, 2006: 18) - CI=1.00; RI=1.00.

(0) Presente (Weitzman, 1962: fig. 08; Roberts, 1969: fig. 01, 02, 04 e 05; Roberts, 1974: fig. 61 e 62; Vari, 1995: fig. 01); (1) ausente (Weitzman, 1964: fig. 06; Roberts, 1969: fig. 08; Campanario, 2000: fig. 21).

A presença do supra-orbital é uma condição quase universal entre os Characiformes. No entanto, representantes de Lebiasinidae e Erythrinidae não apresentam este osso (condição sinapomórfica do clado 67). Entre os demais representantes da ordem, o supra-orbital está ausente também em diversos Characidae atualmente considerados incertae sedis na família (Malabarba \& Weitzman, 2003), em Crenuchinae (sensu Buckup, 1998) e em Melanocharacidium (Buckup, 1993). 


\section{Neurocrânio}

(Figuras 07-18)

12. Ossificação do nasal (Lucena, 1993: 31; Vari, 1995: 17; Oyakawa, 1998: 03; Zanata \& Vari, 2005: 17; Netto-Ferreira, 2006: 21 e 22) - CI=0.29; RI=0.81.

(0) Ossificação do tubo incompleta ou tubo não ossificado; (1) nasal representado apenas pelo canal ósseo ou com lamelas ósseas pouco desenvolvidas (Weitzman, 1962: fig. 02; Weitzman, 1964: fig. 02; Roberts, 1969: fig. 06 a 10; Roberts, 1974: fig. 62; Oyakawa, 1998: fig 16-20); (2) com amplas lamelas laterais e mediais (Oyakawa, 1998, fig $16-18,19 \mathrm{~B}$ e $20 \mathrm{~A})$

O nasal dos Characiformes é tipicamente tubular (Vari, 1995), podendo apresentar pequenas porções lamelares, como as observadas em Xenocharax spilurus e Acestrorhynchus. Nos Erythrinidae, Ctenoluciidae, Hepsetidae e nos Pyrrhulinini o nasal apresenta porções lamelares bastante desenvolvidas. Lucena (1993), Vari (1995), Oyakawa (1998), codificaram o nasal dos Lebiasininae como sendo um osso lamelar. Entretanto, conforme mencionado em Netto-Ferreira (2006), o nasal apresenta as lamelas muito curtas na maioria das espécies. A ocorrência de ossos nasais com amplas lamelas ósseas é considerada uma sinapomorfia de Erythrinoidea. Entretanto, a topologia obtida no contexto do presente estudo sugere que a expansão das lamelas ósseas do nasal ocorreu independentemente em Hepsetus + Ctenoluciidae, Erythrinidae, Pyrrhulininae e em Lebiasininae nos clados 73, 84 (83, caso L. floridablancaensis também apresente a condição descrita no estado “2”). Zanata \& Vari (2005) reportam a ausência do tubo ósseo no alestídeo Lepidarchus adonis, uma espécie miniaturizada. Em espécies do gênero Nannostomus, o nasal freqüentemente encontra-se pouco ossificado, podendo estar ausente em $N$. eques e nas espécies miniaturizadas $N$. britskii, $N$. digrammus (polimórfico) e N. marilynae (clado 125), além de $N$. anduzei e $N$. minimus, espécies também consideradas miniaturizadas. Dada a ausência do nasal em N. britskii e N. marilynae, o estado "_" foi atribuído a todos os caracteres que tratam de modificações dessa estrutura. o nasal também está ausente em exemplares de $N$. anduzei e N. minimus, espécies consideradas miniaturizadas. Possivelmente, a condição observada em representantes do gênero Copella (em que o osso nasal está representado por uma pequena lamela óssea, não envolvendo o ramo do canal látero-sensorial) também esteja associada a um processo de miniaturização. 
13 Posição do nasal em relação ao pré-maxilar (Zanata, 2000: 09 - modificado; Zanata \& Vari, 2005: 18 - modificado; Netto-Ferreira, 2006: 24) - CI= 0.2; RI=0.67.

(0) Margem anterior não alcançando o ramo lateral do pré-maxilar (Wietzman, 1964, fig 02); (1) margem anterior alcançando ou sobrepondo-se discretamente ao ramo lateral do pré-maxilar (Oyakawa, 1998: fig 18, 19B e 20A); (2) margem anterior distintamente sobreposta ao ramo lateral do pré-maxilar (Oyakawa, 1998: fig 20B).

14. Posição do nasal em relação ao frontal (Netto-Ferreira, 2006: 25$)-\mathrm{CI}=0.5$; $\mathrm{RI}=0.87$.

(0) nasal em contato com o frontal (Weitzman, 1962: fig. 02; Weitzman, 1964: fig. 02; Roberts, 1969: fig. 06 a 10; Campanario, 2000: fig. 18); (1) nasal não alcançando o frontal posteriormente (Oyakawa, 1998: fig. 18B).

A ausência de contato entre o nasal e frontal é uma sinapomorfia de Copella, com ocorrência convergente em $N$. eques. Esta condição está possivelmente associada à redução do osso nasal nestes táxons.

15. Lamelas divergentes ventrais do mesetmóide (Lucena, 1993: 00; Buckup, 1998: 03; Zanata, 2000: 10; Zanata \& Vari, 2005: 22; Netto-Ferreira, 2006: 28).

(0) Desenvolvidas; (1) Curtas ou ausentes.

Weitzman (1964) propôs a redução das lamelas do mesetmóide como uma sinapomorfia dos Lebiasinidae. Tais lamelas também estão ausentes em diversos grupos de Characiformes. Buckup (1998) menciona que as lamelas divergentes ventrais do mesetmóide não foram observadas nos representantes de Erythtrinidae examinados por ele, diferentemente do proposto por Weitzman (1964), que afirma que estas estruturas estão desenvolvidas em Erythrinidae. No presente estudo o único táxon que apresenta as lamelas do mesetmóide é Brycon.

16. Constrição médio-transversal no mesetmóide, anterior à articulação com o etmóide lateral (Netto-Ferreira, 2006: 29) - CI=1.00; $\mathrm{RI}=1.00$.

(0) Ausente; (1) presente.

O mesetmóide dos representantes do gênero Nannostomus apresenta duas abas laterais semelhantes aos processos articulares, porém, as abas do mesetmóide neste 
gênero não sustentam os pré-maxilares ventralmente, como nos Characiformes que apresentam os processos articulares, mas sim, dorsalmente. Em $N$. digrammus e $N$. marilynae, posteriormente a estas abas laterais, o mesetmóide apresenta uma constrição transversal. Tal estado de caráter representa uma sinapomorfia para as duas espécies.

17. Forma da lâmina dorsal do mesetmóide (Oyakawa, 1998: 19; Netto-Ferreira, 2006: 30$)-\mathrm{CI}=0.4 ; \mathrm{RI}=0.88$.

(0) Alongada, com formato aproximadamente cônico em vista dorsal (Roberts, 1969, Fig. 06 a 10); (1) arredondada (Weitzman, 1964, fig. 02; Oyakawa, 1998: fig. 18 e 19); (2) em "T" (Oyakawa, 1998: fig. 20A).

A maioria dos Characiformes apresenta o mesetmóide alongado e aproximadamente cônico. Em Erythrinus, Hoplerythrinus e Lebiasinidae, o mesetmóide apresenta-se arredondado, expandido lateralmente. Em Hoplias, o mesetmóide é alongado, assemelhando-se ao dos Ctenoluciidae e Hepsetidae. Entretanto, a condição observada em Hoplias parece estar relacionada ao relativo alongamento da porção anterior do crânio. Nos Lebiasininae o ramo ascendente não se sobrepõe a toda lâmina dorsal do mesetmóide. Assim, a porção posterior da lâmina óssea é mais larga que a anterior, dando a aparência de um "T". Gregory \& Conrad (1938) ilustraram o mesetmóide de Piabucina, porém, consideraram as porções laterais como ossificações independentes ao mesetmóide. A transformação $0 \rightarrow 1$ representa uma sinapomorfia para o clado 67 (Hoplerythrinus+Lebiasinidae), enquanto que o estádo "2" representa uma sinapomorfia exclusiva de Lebiasininae, independentemente revertida em Lebiasina sp. "Parima" e Lebiasina sp. "Curuá-faixa".

18. Processos articulares do mesetmóide (Buckup, 1998: 02; Zanata, 2000: 11; Zanata \& Vari, 2005: 23; Netto-Ferreira, 2006: 31) - CI=1.00; RI=1.00.

(0) Desenvolvidos (Weitzman, 1962, Fig. 02; Roberts, 1969, Fig. 20); (1) curtos (Weitzman, 1964, Fig. 04; Roberts, 1969, Fig. 08; Oyakawa, 1998: Fig. 22 e 23); (2) ausentes (Roberts, 1969, Fig. 16 e 17).

O mesetmóide dos Characiformes geralmente apresenta um par de processos laminares laterais que apóiam o ramo ascendente do pré-maxilar (Zanata, 2000), além de serem pontos de ligação do maxilar, palatino, endopterigóide e ectopterigóide. Em Lebiasinidae, os processos articulares do mesetmóide são muito curtos. Esta condição 
foi observada também em Apareiodon, Crenuchidae, Cyphocharax e Erythrinidae, não estando evidentes em Ctenoluciidae e Hepsetus. Buckup (1998) e Zanata (2000) consideram o mesetmóide de Hoplias como apresentando os processos desenvolvidos. Após o exame de exemplares dos três gêneros de Erythrinidae, não foi possível observar nenhum exemplar apresentando tais processos desenvolvidos como nos Characidae, por exemplo. Os processos articulares de Erythrinidae e Lebiasinidae parecem estar mais relacionados à ligação da porção anterior do suspensório ao neurocrânio (ver caráter 32). Em Ctenoluciidae e Hepsetidae, os processos articulares parecem não estar presentes, nem mesmo em forma reduzida, como em Lebiasinidae e Erythrinidae. Em ambas as famílias, os pré-maxilares encontram-se fortemente associados aos maxilares. A ausência dos processos articulares do mesetmóide em Ctenoluciidae e Hepsetus pode estar relacionada à ligação da porção anterior do suspensório, firmemente aderida à porção medial do mesetmóide, ao invés de estar ligada aos processos articulares, como na maioria dos demais grupos de Characiformes. Em Hepsetus odoe a ligação é promovida pelos ectopterigóides, que estão inseridos em covas no complexo mesetmóide-vômer. Nos Ctenoluciidae, a ligação ocorre entre o palatino e o mesetmóide, sendo promovida por espessos tendões.

Secioso (1997) descreve dois processos que se prolongam póstero-lateralmente na face ventral do mesetmóide e afirma ainda, que nos Lebiasinidae, tais processos também estariam presentes, entretanto, não seriam tão desenvolvidos quanto os de Erythrinidae. Após exame do material, foi possível identificar os processos indicados por Secioso (1997) como sendo os processos articulares que se encontram curtos em Lebiasinidae e Erythrinidae, além de outros grupos, conforme discutido anteriormente. Além da redução, foi possível observar que os processos articulares encontram-se direcionados ventralmente, ao invés de lateralmente, e também são totalmente cobertos pela lâmina dorsal do mesetmóide. Desta forma, os processos articulares destes dois grupos exercem apenas a ligação da porção anterior do suspensório ao crânio e não o suporte ao pré-maxilar. A ocorrência do estado “1” em Erythrinidae e Lebiasinidae corresponde a uma sinapomorfia para o clado, enquanto que a ausência dos processos articulares do mesetmóide (estado "2") corresponde a uma sinapomorfia do clado Acestrorhynchus, Ctenoluciidae, Hepsetus. 
19. Crista óssea longitudinal da face dorsal do vômer (Lucena, 1993: 04; Oyakawa, 1998: 14; Netto-Ferreira, 2006: 35) - CI=0.20; RI=0.83.

(0) Curta ou ausente; (1) desenvolvida, quase atingindo a porção ventral do mesetmóide.

Oyakawa (1998) observou que a crista na superfície dorsal do vômer de Erythrinidae e Lebiasinidae encontra-se distintamente desenvolvida e quase alcançam a superfície dorsal do mesetmóide. Oyakawa (1998) afirma ainda que em Copella, Copeina e Lebiasina tal crista estaria reduzida. No presente estudo, no entanto, cristas curtas foram observadas apenas em representantes de Lebiasina do clado 76 (posteriormente revertido no clado 85) e no clado 95. Desta maneira, a expansão da crista óssea do vomer representa uma sinapomorfia exclusiva do clado (Erythrinidae +Lebiasinidae), revertida nos grupos supra-citados e presente também em representantes do gênero Nannostomus incluídos no clado 123. Uma vez que o crânio de Ctenoluciidae encontra-se muito deprimido, a superfície dorsal do vômer está em contato diretamente com o mesetmóide. Esta condição não permitiu inferir sobre o estado da crista óssea em Boulengerella lateristriga. Em Hepsetus, por outro lado, o vômer e o mesetmóide encontram-se fusionados, impossibilitando o estabelecimento de homologias entre as porções destes ossos. A ambos os casos, foi atribuída a codificação “?”" para este caráter.

\section{Extensão da crista óssea longitudinal medial da face ventral do} paresfenóide, formando uma quilha (Netto-Ferreira, 2006: 36 ) $-\mathrm{CI}=0.25 ; \mathrm{RI}=0.87$.

(0) Não alcançando a articulação com o vômer ou ausente; (1) estendendo-se anteriormente, até a junção com o vômer (Roberts, 1969, fig. 18).

O paresfenóide dos Lebiasinidae apresenta uma crista ventral se estendendo desde a articulação com o vômer, até próximo à articulação com o pró-ótico. Esta condição está presente também nos Erythrinidae Apareiodon e Cyphocharax. Em Cyphocharax, a crista do paresfenóide está associada a uma crista semelhante presente no vômer. Oyakawa (1998) afirma que a condição observada neste táxon está presente em Ctenoluciidae, Hepsetus e Hoplias, entretanto, em nenhum representante destes grupos foi possível observar a crista ventral do vômer. Além disto, a crista ventral do paresfenóide nos Ctenoluciidae está ausente, bem como em Acestrorhynchus, enquanto em Hepsetus esta crista é representada por uma sutil elevação. A presença da crista 
ventral do paresfenóide é uma sinapomorfia ambígua, em otimização ACCTRAN, do clado (Erythrinidae+Lebiasinidae), que encontra-se revertido em Pyrrhulininae. Este estado de caráter surge independentemente no clado 96 e reverte novamente em Copella.

21. Margem posterior do vômer (Oyakawa, 1998: 18 - modificado; NettoFerreira, 2006: 37) $-\mathrm{CI}=1.00 ; \mathrm{RI}=1.00$.

(0) com uma distinta projeção em forma de cunha direcionada posteriormente (Oyakawa, 1998: fig. 22 e 23); (1) truncada ou arredondada (Weitzman, 1964; fig. 04).

$\mathrm{Na}$ maioria dos Characiformes o vômer possui uma projeção posteriormente direcionada que se articula na face ventral do paresfenóide, promovendo o "encaixe em forma de cunha" descrito por Oyakawa (1998) e Netto-Ferreira (2006). A única exceção observada é a encontrada nos Pyrrhulininae, exceto Derhamia, onde a margem posterior do vômer é truncada ou arredondada, conferindo ao osso um formato um formato aproximadamente quadrangular ou arredondado. Oyakawa (1998) sugere que Erythrinus e Hoplerythrinus também apresentem o estado de caráter "1", entretanto, em tais táxons a condição observada corresponde àquela descrita no estado " 0 ”. A transformação $0 \rightarrow 1$ representa assim uma sinapomorfia exclusiva do clado 95 .

22. Porção anterior do paresfenóide (Oyakawa, 1998: 18 - modificado; NettoFerreira, 2006: 38$)-\mathrm{CI}=0.50 ; \mathrm{RI}=0.93$.

(0) Truncada; (1) com um par de projeções curtas direcionadas anteriormente (Weitzman, 1964, fig. 04); (2) com um par de longas projeções que margeiam a face lateral do vômer.

A porção anterior do paresfenóide da maioria dos táxons examinados apresentase reta, onde a porção posterior do vômer se encaixa. Esta condição é observada também em Lebiasininae e Derhamia. Em Copeina, Copella, Nannostomus e Pyrrhulina, o paresfenóide apresenta em sua porção anterior, um par de processos direcionados anteriormente que margeiam o vômer lateralmente. O desenvolvimento de tais processos representa uma sinapomorfia para o clado 95, estando revertida em $N$. eques e N. britskii. O alongamento destes processos observado em Copeina, Copella e Pyrrhulina, por sua vez, representa uma sinapomorfia para o clado 96. Nestes grupos o ligamento "endopterigóide-vômer" descrito por Arratia (1992) está ligado à margem 
lateral destes processos e não ao vômer, numa associação única do paresfenóide e o suspensório, não observada entre os demais representantes da ordem.

23. Perfil do paresfenóide (Zanata, 2000: 27; Netto-Ferreira, 2006: 39) - CI= 1.00; $\mathrm{RI}=1.00$.

(0) Praticamente reto desde a articulação com o vômer e o proótico; (1) com uma distinta curvatura ventral entre a articulação com o vômer e o proótico (Weitzman, 1962; fig. 03).

O paresfenóide da maioria dos táxons examinados apresenta-se praticamente reto, ao longo em sua porção anterior, desde a articulação com o vômer e o proótico. Zanata (2000) observou que em Alestes baremose e Brycon apresentam uma constrie Nannostomus, no entanto, examinados no presente estudo apresentam o paresfenóide recurvado. A única espécie que apresenta o paresfenóide relativamente reto é Copeina guttata, porém, nesta espécie a curvatura também é evidente. Desta maneira, apenas aos Lebiasininae foi determinado o estado de caráter "praticamente reto em toda sua extensão", característica compartilhada com os Acestrorhynchus, Ctenoluciidae, Erythrinidae e Hepsetidae.

24. Porção posterior do paresfenóide (Zanata, 2000: 28; Netto-Ferreira, 2006: 40) $-\mathrm{CI}=1.00 ; \mathrm{RI}=1.00$.

(0) Bifurcado, dividido em dois longos ramos, posteriormente à articulação com o próótico (Weitzman, 1962, fig. 04; Roberts, 1969: fig. 19 e 20); (1) bifurcação menos acentuada, divisão em dois ramos relativamente curtos, ocorrendo posteriormente, próximo à cápsula lagenar (Roberts, 1969: fig. 16-18); (2) paresfenóide não furcado (Weitzman, 1964, fig. 04).

A porção posterior do paresfenóide de diversos grupos de Characiformes (principalmente Characidae) é bifurcada posteriormente à sua articulação com o próótico (Zanata, 2000). Em Acestrorhynchus, Apareiodon, Brycinus, Crenuchidae, Ctenoluciidae, Erythrinidae, Hepsetidae, Hydrocynus e Xenocharax a porção posterior do paresfenóide bifurca apenas próximo à margem anterior da cápsula lagenar. Nos Alestidae, Crenuchidae e Xenocharax, após a ramificação, as extremidades posteriores mantêm os prolongamentos divergentes livres do basioccipital (Zanata, 2000). Em Acestrorhynchus, Ctenoluciidae, Erythrinidae e Hepsetidae, por sua vez, a bifurcação do 
paresfenóide é muito discreta, sendo que os prolongamentos posteriores estariam fusionados ao basioccipital em Hepsetus e Hoplias (Zanata, 2000). Em Lebiasinidae, por outro lado, o paresfenóide não bifurca. A porção posterior do osso apresenta-se em forma de lança, encaixada nos sulcos presentes no basioccipital. A ausência de bifurcação na porção posterior do paresfenóide representa uma sinapomorfia exclusiva de Lebiasinidae.

25. Forame do nervo nasal (Oyakawa, 1998: 08; Zanata, 2000: 19 - modificado; Netto-Ferreira, 2006: 45) - $\mathrm{CI}=0.33 ; \mathrm{RI}=0.20$.

(0) Delimitado apenas pela cartilagem etmoidal; (1) delimitado pela cartilagem etmoidal e o órbito-esfenóide; (2) delimitado apenas pelo órbito-esfenóide.

26. Porção ântero-ventral do órbito-esfenóide (Netto-Ferreira, 2006: 46) $\mathrm{CI}=0.50 ; \mathrm{RI}=0.00$.

(0) Projetada anteriormente, parte da cartilagem etmoidal ossificada (Weitzman, 1962, fig. 03; Roberts, 1969: fig 11, 12, 14 e 15); (1) curta; parte posterior da cartilagem etmoidal não ossifcada. (Weitzman, 1964, fig. 03; Roberts, 1969: 13).

$\mathrm{Na}$ maioria dos táxons examinados, a porção mais anterior do órbito-esfenóide projeta-se anteriormente à porção principal do osso. Em Erythrinidae e Lebiasinidae, por sua vez, esta projeção não é observada. Desta forma, a porção ventral do órbitoesfenóide é curta e situada posteriormente à porção ântero-dorsal das lamelas deste osso. A ausência da projeção da margem antero-ventral do órbito-esfenóide representa uma sinapomorfia de Erythrinoidea (incluindo Acestrorhynchus).

27. Posição do órbito-esfenóide (Zanata, 2000: 18 - modificado; Netto-Ferreira, 2006: 47) $-\mathrm{CI}=1.00 ; \mathrm{RI}=1.00$.

(0) Situado na porção médio-posterior da órbita (Weitzman, 1962, fig. 03; Roberts, 1969: fig. 11 a 15); (1) situado na porção anterior da órbita (Weitzman, 1964, fig. 03).

De maneira geral, o órbito-esfenóide dos Characiformes situa-se na porção médio-posterior da órbita. Em Erythrinidae e Lebiasinidae, por sua vez, este osso encontra-se posicionado na porção posterior da órbita, próximo ao esfenótico. $O$ deslocamento do órbito-esfenóide para a porção posterior da órbita representa, portanto, uma sinapomorfia para o clado 67. 
28. Processo lamelar na face ventral do órbito-esfenóide (Netto-Ferreira, 2006: 49) $-\mathrm{CI}=0.25 ; \mathrm{RI}=0.86$.

(0) Ausente (Weitzman, 1962, fig. 03; Roberts, 1969: fig. 11 a 15); (1) presente (Weitzman, 1964: fig 03).

O órbito-esfenóide da maioria dos Characiformes, em uma secção transversal, assemelha-se a um "U" ou a um "V". Nos Pyrrhulininae e Acestrorhynchus, o órbitoesfenóide apresenta um processo lamelar em sua face ventral, de modo que um corte transversal do osso assemelha-se a um "Y" (Weitzman, 1964), representando sinapomorfias destes grupos. Um processo lamelar semelhante ao observado nestes táxons também foi observada nos Lebiasininae do clado 92 e secundariamente revertido em L. uruyensis.

29. Margem póstero-ventral do orbitosfenóide $-\mathrm{CI}=1.00 ; \mathrm{RI}=1.00$.

(0) Sem uma projeção lamelar em direção à margem ventral do pterosfenóide; (1) com uma discreta projeção lamelar em direção à margem ventral do pterosfenóide; (2) com uma distinta projeção lamelar em direção à margem ventral do pterosfenóide

$\mathrm{Na}$ maioria dos Characiformes, a margem posterior do orbitosfenóide é aproximadamente reta e encontra-se, em grande parte, em contato com a margem anterior do pterosfenóide. Nos representantes do gênero Copella a margem pósteroventral do osso encontra-se projetada posteriormente em direção ao processo medial do pterosfenóide. Nos representantes do clado 103, o processo é curto, restrito à porção antero-ventral do pterosfenóide, enquanto que o nas Copella gr. arnoldi, este processo encontra-se fortemente direcionado posteriormente alcançando, e por vezes ultrapassando, a vertical que passa pela metade do pterosfenóide. Tais projeções no orbitosfenóide e pterosfenóide possivelmente estão relacionadas a algum tipo de reforço mecânico relacionado ao salto fora da água (especialmente marcante em $C$. gr. arnoldi, que salta para desovar).

30. Margem ventral do pterosfenóide $-\mathrm{CI}=0.43 ; \mathrm{RI}=0.87$.

(0) lisa ou aproximadamente lisa; (1) com uma discreta projeção direcionada medialmente ao neurocrânio; (2) com um distinto processo direcionado medialmente ao 
neurocrânio, não contatando sua contraparte; (3) com um distinto processo direcionado medialmente ao neurocrânio, contatando sua contraparte.

A margem ventral do pterosfenóide na maioria dos Characiformes apresenta-se reta ou discretamente côncava. Nos Pyrrhulininae (exceto Derhamia) o pterosfenóide apresenta-se projetado medialmente em direção ao nervo óptico. Tal condição encontrase revertida em $N$. limatus, $N$. marilynae e nos clados 110 e 121 . Nos representantes do gênero Copella, o pterosfenóide encontra-se distintamente mais pronunciado em direção ao plano coronal sendo que os representantes do clado 98 apresentam a condição extrema do caráter, onde as duas contrapartes podem estar em contato.

31. Margem lateral do frontal (Vari, 1995: 24 - modificado; Secioso, 1997, P4 modificado; Oyakawa, 1998: 10 - modificado; Netto-Ferreira, 2006: 52) - CI= ; RI= .

(0) Sem uma projeção lateral que encapsula parte do dilatator operculi; (1) com uma projeção lateral que encapsula a porção dorsal do dilatator operculi, mas não atinge o espinho do esfenótico; (2) com um processo lateral que alcança o espinho do esfenótico.

Conforme discutido por Vari (1995), Secioso (1997) e Oyakawa (1998), a margem lateral do crânio de Ctenoluciidae e Erythrinidae apresenta-se expandida lateralmente, contatando o espinho do esfenótico, de maneira a formar um tubo por onde passa o dilatator operculi, que alcança a porção média da órbita. Em Lebiasina, os frontais se projetam lateralmente, encobrindo a porção dorsal do dilatator operculi, mas esta esta não forma com o esfenótico um tubo, como o observado em Ctenoluciidae e Erythrinidae. Nos demais Lebiasinidae apresentam o padrão plesiomórfico da ordem Characiformes, onde o frontal não se projeta lateralmente e o dilatator operculi permanece restrito à borda do crânio, posterior ao espinho do esfenótico, condição observada também em Hepsetus. A condição observada na maioria das espécies de Acestrorhynchus, por sua vez, difere da condição presente em Ctenoluciidae e Erythrinidae, uma vez que a porção dorsal do frontal não se projeta lateralmente atingindo o esfenótico. Neste grupo o "tubo" é formado por um forame na lamela interna dos frontais, que se estende até a margem anterior do esfenótico (Vari, 1995). 
32. Espinho do esfenótico (Lucena, 1993: 117 - modificado; Vari, 1995: 23 modificado; Oyakawa, 1998: 11 - modificado; Netto-Ferreira, 2006: 60 - modificado) $\mathrm{CI}=0.29 ; \mathrm{RI}=0.80$.

(0) Aproximadamente vertical, com a porção dorsal próxima à porção principal do osso e contínua à superfície ventral do frontal (Weitzman, 1962: fig. 03; Weitzman, 1964: fig. 03; Roberts, 1969: fig. 11; Vari, 1995: fig. 03); (1) aproximadamente horizontal; porção dorso-lateral do espinho não alcançando a superfície ventral do frontal (Vari, 1995: fig. 03); (2) espinho horizontal, com a porção dorsal não contínua à superfície ventral do frontal (Roberts, 1969: fig. 12, 13 e 15; Vari, 1995: fig. 04).

Vari (1995) observa um processo direcionado posteriormente no espinho do esfenótico de Piabucina panamensis e propõe que este processo seja um indício de reestruturação do espinho semelhante à observada em Acestrorhynchus, Erythrinidae e Ctenoluciidae, que apresentam o espinho orientado horizontalmente. Tal padrão observado por Vari (1995) é compartilhado por todas as espécies de Lebiasininae (exceto L. yuruaniensis). Adicionalmente, o espinho do esfenótico dos Lebiasininae também não alcança a porção ventral dos frontais, permitindo a passagem do dilatator operculi. Nos Pyrrhulininae, somente a porção direcionada verticalmente encontra-se desenvolvida, padrão considerado plesiomórfico entre os Characiformes (Vari, 1995).

De acordo com a hipótese de Vari (1995), a "reestruturação" do espinho em Lebiasininae, teria ocorrido independentemente dos Ctenoluciidae e Erythrinidae, dada a topologia obtida por aquele autor. Com base na presente topologia e na morfologia do espinho do esfenótico, da extensão do dilatator operculi e dos frontais sobrepondo-se a esse músculo, no entanto, prefere-se inferir que a tais estados observados nos Lebiasininae representem um estágio intermediário à condição observada em Pyrrhulininae, onde estes caracteres estão revertidos à condição plesiomórfica da ordem Characiformes.

33. Pterótico (Netto-Ferreira, 2006: 61$)-\mathrm{CI}=1.00 ; \mathrm{RI}=1.00$.

(0) Sem um processo dorsal; (1) com um processo onde se liga um tendão do póstemporal.

A porção antero-dorsal do pterótico de Copeina, Copella e Pyrrhulina apresenta um discreto processo ósseo, onde se liga um dos ligamentos que partem da porção distal do pós-temporal. A presença deste tipo de ligação parece estar relacionada à ausência do 
ramo médio do epoccipital, onde um tendão similar se insere em Lebiasininae e outros táxons que possuem tal ramo. Esta condição representa uma sinapomorfia do clado incluindo os três gêneros.

34. Articulação frontal-pterótico (Lucena, 1993: 15; Buckup, 1998: 12; Campanario, 2000: 09; Zanata \& Vari, 2005: 38; Netto-Ferreira, 2006: 64) - CI=0.50; $\mathrm{RI}=0.96$.

(0) Frontal e pterótico em contato direto dorsalmente (Weitzman, 1962: fig 02; Roberts, 1969: fig. 06 a 10); (1) contato do pterótico com o frontal interrompido pelo esfenótico (Weitzman, 1964: fig. 02; Oykawa, 1998: fig. 18).

A ausência de contato entre o pterótico e o frontal foi proposta como um caráter comum a todos os Pyrrhulininae por Weitzman (1964) e Buckup (1998). Entretanto, esta sinapomorfia do grupo encontra-se revertida em Copeina guttata, onde o frontal e o pterótico encontram-se em contato de modo semelhante ao observado em Lebiasininae e Derhamia. Zanata \& Vari (2005) sugerem que a perda de contato entre o frontal e o pterótico se deve ao encurtamento da porção anterior do pterótico que, por sua vez, expõe o esfenótico. Tal condição foi observada por aqueles autores em Lepidarchus adonis, um alestídeo miniaturizado. A ausência de contato entre o frontal e o pterótico foi observada também por Buckup (1998) em Characidiinae, grupo que também apresenta uma clara tendência à miniaturização (Buckup, 1993). Oyakawa (1998) em sua representação da vista dorsal do crânio de Copella e Pyrrhulina (fig. 18), indica erroneamente o esfenótico como o pterótico.

35. Espinho do pterótico (Lucena, 1993: 17; Netto-Ferreira, 2006: 62) - CI=0.11; $\mathrm{RI}=0.38$.

(0) Longo (Weitzman, 1962: 04; Weitzman, 1964: fig. 04; Roberts, 1969: figs. 16, 17 e 20); (1) curto (Roberts, 1969: fig. 16; Campanario, 2000: fig. 13).

O espinho do pterótico dos Lebiasinidae é tipicamente curto, no entanto, encontra-se desenvolvido em Lebiasina aff. festae, L. taphorni, e nos representantes do clado 81 (revertido em L. ortegai). Entre os demais Lebiasinidae, apenas, Copeina guttata, e os Nannostomus do clado 121 apresentam o espinho alongado. 
36. Ramo médio do epoccipital (Oyakawa, 1998: 25 - modificado; Netto-Ferreira, 2006: 66) $-\mathrm{CI}=1.00 ; \mathrm{RI}=1.00$.

(0) Presente, atingindo o pterótico e o parietal (Weitzman, 1962: fig. 05; Weitzman, 1964: fig. 05; Roberts, 1969: fig. 21 a 25; Campanario, 2000: fig. 16); (1) ausente (Alexander, 1964: fig. 07).

O ramo médio do epoccipital delimita as duas fossas pós-temporais na porção posterior do crânio e está presente na maioria dos Characiformes. Entre os Lebiasinidae percebe-se uma distinta tendência à redução deste ramo, onde em representantes do gênero Nannostomus este ramo é muito estreito representado por uma delgada haste óssea, enquanto que em Copella, Copeina e Pyrrhulina, o mesmo está ausente. Desta maneira os representantes destes três gêneros apresentam uma única fossa bastante desenvolvida na porção posterior do crânio. Weitzman (1964) observou que a fossa póstemporal de Pyrrhulininae é "extremamente desenvolvida anteriormente, com a borda ântero-lateral estendendo-se anteriormente, ou ultrapassando, à junção sincondral entre o esfenótico e o pterótico, anteriormente à margem anterior do forâmen auditivo", entretanto não menciona a ausência do processo medial do epoccipital. Alexander (1964), por sua vez, observa que "os processos dos epióticos [=epoccipital], que geralmente bipartem as aberturas das fossas pós-temporais estão ausentes". Entre os demais Characiformes o único representante a apresentar redução semelhante é o caracídeo Iotabrycon Roberts, conforme ilustrado em Roberts (1973).

37. Projeção posterior do epoccipital (Netto-Ferreira, 2006: 67) $-\mathrm{CI}=0.17$; $\mathrm{RI}=$ 0.61 .

(0) Ausente (Weitzman, 1962: fig. 02; Weitzman, 1964: fig. 02; Roberts, 1969: fig. 06 a 10); (1) presente (Roberts, 1974: fig. 56).

O epoccipital dos Lebiasininae do grupo Lebiasina bimaculata (clado 69) e do clado 92, clado 84 (revertido no clado 86) apresenta um pequeno processo posterior onde se insere parte da musculatura epaxial. Todos os demais Lebiasinidae examinados não possuem este processo posterior. Entre os táxons do grupo-externo, um processo semelhante ocorre apenas em Boulengerella e Hoplerythrinus. Entre os demais Characiformes, tais processos foram observvados apenas nos representantes da família Parodontidae. Roberts (1974) ilustra o longo processo presente em Saccodon wagneri (Kner). 
38. Forames occipitais laterais (Lucena, 1993: 22; Zanata, 2000: 32; Zanata \& Vari, 2005: 45; Netto-Ferreira, 2006: 68) - CI= 0.50; RI=0.87.

(0) Desenvolvidos, ocupando uma grande área da superfície posterior dos exoccipitais (Weitzman, 1964: 05; Roberts, 1974: fig. 59; Campanario, 2000: fig. 16); (1) ocupando uma restrita área ventral da superfície posterior dos exoccipitais, podendo estar ausentes (Weitzman, 1964: fig. 06; Roberts, 1969: fig. 21 a 25).

Os forames occipitais laterais são aberturas na porção posterior dos exoccipitais, próximo aos ossículos do aparelho de Weber. Forames bem desenvolvidos foram observados apenas em Copella e Brycon. Nos demais táxons analisados, os forames encontram-se pequenos ou ausentes em exemplares adultos, no entanto, em exemplares jovens, os mesmos ocupam uma ampla área próximo ao escáfio. A condição observada em Copella representa, possivelmente, um padrão pedomórfico, reforçando a evidência de um processo de miniaturização em Pyrrhulininae também corroborado por outros caracteres discutidos no presente estudo (ver discussão). Padrão oposto foi observado por Zanata \& Vari (2005) em Lepidarchus, espécie miniaturizada onde os forames occipitais estão ausentes, enquanto que nos demais Alestidae, os forames ocupam uma ampla área nos exoccipitais.

39. Sulco formado pelas projeções ventrais do basioccipital (Netto-Ferreira, 2006: 70) $-\mathrm{CI}=1.00 ; \mathrm{RI}=1.00$.

(0) Raso; (1) profundo, expandido lateralmente.

A porção ventral do basioccipital da maioria dos Characiformes apresenta um par de projeções curtas situadas posteriormente às cápsulas lagenares que, quando presentes, estão geralmente associadas ao par de projeções resultantes da bifurcação do paresfenóide. Em Copeina, Copella e Pyrrhulina estas encontram-se muito desenvolvidas, direcionadas látero-ventralmente, formando um sulco profundo na porção posterior do basioccipital que acomoda a aorta dorsal. Em N. marginatus, as projeções estão fundidas, não formando um sulco.

40. Espinho do supra-occipital (Vari, 1995: 31; Netto-Ferreira, 2006: 71) - CI= $0.50 ; \mathrm{RI}=0.00$. 
(0) Completamente exposto; (1) completamente coberto pela musculatura axial, ou com apenas uma diminuta porção exposta.

Na maioria dos Characiformes o espinho do supra-occipital encontra-se exposto, coberto apenas pelo tegumento. Em Ctenoluciidae (exceto Boulengerella lateristriga e B. maculata, que apresentam uma pequena área na base do osso exposta), Erythrinidae, Hepsetidae e Lebiasinidae o espinho do supra-occipital encontra-se totalmente coberto pela musculatura axial. Esta condição é tradicionalmente considerada uma sinapomorfia de Erythrinoidea, no entanto, o presente esquema de relações sugere que em este estado de caráter pode ter surgido independentemente em no clado 66 e 67 (em otimização DELTRAN) ou a ocorrência do estado "0" em Acestrorhynchus pode ser considerada uma perda secundária (em otimização ACCTRAN).

41. Extensão do espinho do supra-occipital $-\mathrm{CI}=0.07$; $\mathrm{RI}=0.48$.

(0) alcançando ou ultrapassando o ponto de contato entre o complexo neural e o supraoccipital; (1) não alcançando o ponto de contato entre o complexo neural e o supraoccipital.

$\mathrm{Na}$ maioria dos Characiformes o espinho do supra-occipital estende-se posteriormente à vertical que passa pela articulação entre o crânio e a área de contato entre o complexo neural e o supraoccipital. Entre os Characiformes tradicionalmente incluídos entre os Erythrinoidea, o espinho do supraoccipital encontra-se reduzido, porém freqüentemente alcança ou ultrapassa o ponto de contato entre estes ossos. Entre os Lebiasinidae, por sua vez, o espinho encontra-se ainda mais reduzido, geralmente não ultrapassando o ponto de contado com o complexo neural (condição compartilhada com Boulengerella). Este caráter

\section{Denticão \& arco mandibular}

\section{(Figuras XX)}

42. Posição da boca (Oyakawa, 1998: 72; Netto-Ferreira, 2006: 73) $-\mathrm{CI}=0.33$; $\mathrm{RI}=$ 0.89 .

(0) Terminal (Weitzman, 1962: fig. 08; Weitzman, 1964: fig. 06; Roberts, 1969: fig. 01 a 05); (1) superior.

A posição superior da boca está relacionada, em diversos grupos, ao hábito alimentar das espécies que se alimentam nos estratos superiores da coluna da água. 
Dentre os táxons examinados, apenas Copeina, Copella, Derhamia e Pyrrhulina apresentam a boca superior. A boca dos Lebiasininae e Erythrininae é discretamente deslocada dorsalmente, podendo ser classificadas como "sub-superior" entretanto, preferiu-se designar apenas aos gêneros mencionados, o estado "1", uma vez que em vista dorsal a boca destes táxons não é observada. A posição superior da boca representa uma sinapomorfia ambígua de Pyrrhulininae que se alimentam tipicamente de insetos alóctones. Esta condição revertida em Nannostomus, que se alimentam de organismos bbentônicos.

43. Morfologia dos dentes (Lucena, 1993: 46 e 53 - modificados; Buckup, 1998: 72 - modificado; Zanata, 2000: 36 - modificado; Zanata \& Vari, 2005: 49 modificado; Netto-Ferreira, 2006:74 - modificado) $-\mathrm{CI}=0.50$; $\mathrm{RI}=0.92$.

(0) Apenas dentes cônicos (Roberts, 1969: fig. 26 a 32); (1) dentes cuspidados com cúspides simétricas; (2) dentes cuspidados com cúspides assimétricas (Weitzman, 1962: fig. 08; Weitzman, 1964: fig. 07; Campanario, 2000: fig. 27).

A presença de dentes cônicos é uma característica típica dos Characiformes predadores, estando amplamente difundida em diversas famílias e subfamílias. Entre os Erythrinoidea apenas os representantes dos gêneros Lebiasina, Derhamia e Nannostomus apresentam dentes cuspidados, geralmente com cúspides assimétricas. A ocorrência de dentes tricúspides relativamente simétricos ocorre apenas entre os Lebiasininae do grupo L. bimaculata pertencentes ao clado 68. Tal condição já havia sido ilustrada por Valenciennes na descrição original de L. bimaculata. Em Lebiasina aff. bimaculata I e L. aff. bimaculata II os dentes do pré-maxilar e o maxilar encontramse alinhados, formando uma única superfície cortante. Entre os representantes de Characidae, a ocorrência de dentes simétricos alinhados com os dentes do maxilar (e.g. representantes dos gêneros Deuterodon, Jupiaba e Monotocheirodon) parece estar associada a uma estratégia alimentar onívora, com forte tendência a herbivoria, contudo, não existem dados acerca dos hábitos alimentares destas espécies de Lebiasina.

44. Ramo ascendente do pré-maxilar (Lucena, 1993: 35; Buckup, 1998: 31; Zanata, 2000: 39; Campanario, 2000: 26; Zanata \& Vari, 2005: 54; Netto-Ferreira, 2006: 78) $-\mathrm{CI}=0.67 ; \mathrm{RI}=0.96$. 
(0) Conspícuo (Weitzman 1962: fig. 02; Roberts, 1969: fig. 06 e 10); (1) curto (Weitzman, 1964: fig. 02; Roberts, 1969: 07); (2) ausente.

A presença de um distinto ramo ascendente no pré-maxilar parece uma condição derivada na ordem Characiformes, presente apenas em Characoidea e Erythrinoidea. os demais grupos, considerados basais na ordem, por sua vez, apresentam apenas uma projeção curta (Zanata \& Vari, 2005), geralmente articulada com a superfície ventral do mestmóide. Dentre os Lebiasinidae, apenas os Lebiasininae e Derhamia apresentam um conspícuo ramo ascendente no pré-maxilar. A redução do ramo ascendente do prémaxilar nos Pyrrhulininae incluídos no clado 95, parece estar associado à flexibilização do movimento destes ossos, enquanto que a redução deste em Acestrorhynchidae e Hepsetidae e sua ausência em Ctenoluciidae parece ausência do ramo em Ctenoluciidae parece estar relacionada à consolidação da forte da associação entre o pré-maxilar, a porção anterior do mesetmóide e o maxilar observada nestes três grupos.

45. Comprimento do ramo ascendente do pré-maxilar (Lucena, 1993: 34 modificado; Secioso, 1997, E1; Netto-Ferreira, 2006: 79) - CI= 0.50; RI=0.96.

(0) Curto, não atingindo as narinas; (1) longo, ultrapassando as narinas anteriores.

Secioso (1997) observou que o ramo ascendente dos Erythrinidae não ultrapassa as narinas, conforme sugerido por Lucena (1993). No material examinado no presente estudo, o ramo ascendente do pré-maxilar só atinge a margem posterior da narina posterior em um exemplar de Erythrinus erythrinus. Ainda assim, foi possível observar que, em todos os exemplares de Erythrinidae e Lebiasininae, o ramo ascendente do prémaxilar estende-se posteriormente à narina anterior, característica compartilhada somente por estes dois grupos. Apesar de Brycon também apresentar o ramo ascendentes bem desenvolvido, em nenhum dos exemplares examinados o ramo ascendente ultrapassa as narinas anteriores.

46. Pré-maxilar (Netto-Ferreira, 2006: 81) - $\mathrm{CI}=1.00 ; \mathrm{RI}=1.00$.

(0) Não apresentando um sulco na sua face interna; (1) apresentando um sulco na face interna.

Os pré-maxilares dos representantes do gênero Nannostomus não apresentam um sulco em sua face interna, onde estes articulam-se com o mesetmóide. Esta condição 
difere da observada nos demais Lebiasinidae e táxons examinados que apresentam em sua área de articulação um sulco que encaixa em um sulco correspondente no mesetmóide. Os sulcos na face interna dos pré-maxilares são muito conspícuos nos Erythrinidae e Lebiasininae, onde os pré-maxilares apresentam-se fortemente relacionados ao mesetmóide. Tal associação com o mesetmóide parece estar relacionada à redução dos processos articulares deste osso. Desta maneira, o ramo ascendente do pré-maxilar articula-se diretamente com a porção laminar do mesetmóide.

47. Articulação do pré-maxilar com o mesetmóide (Netto-Ferreira, 2006: 82) $\mathrm{CI}=1.00 ; \mathrm{RI}=1.00$.

(0) Pré-maxilar articulado com a porção dorsal do mesetmóide (Weitzman, 1962: fig. 02; Roberts, 1969: fig. 06 a 10); (1) pré-maxilar articulado com a porção ventral do mesetmóide, por meio de um processo distinto do ramo ascendente do pré-maxilar e uma projeção da lâmina dorsal do mesetmóide (Weitzman, 1964: fig. 02).

Em representantes do gênero Nannostomus, além do diminuto ramo ascendente, o pré-maxilar apresenta uma outra projeção situada ventralmente ao ramo ascendente que se articula com a face ventral de uma projeção laminar que se projeta da porção antero-lateral do mesetmóide. Tanto esta projeção do pré-maxilar quanto a projeção observada no mesetmóide representam sinapomorfias exclusivas do gênero Nannostomus e parecem ser modificações associadas à mobilidade dos pré-maxilares que os representantes do.

48. Dentição do pré-maxilar (Lucena, 1993: 38; Buckup, 1998: 32; Oyakawa, 1998: 60; Zanata, 2000: 42; Zanata \& Vari, 2005: 57; Netto-Ferreira, 2006: 83) - CI= $1.00 ; \mathrm{RI}=1.00$.

(0) Apenas uma série de dentes do pré-maxilar; (1) duas séries de dentes no pré-maxilar;

(2) três séries de dentes no pré-maxilar.

Todos os gêneros de Lebiasinidae apresentam apenas uma fileira de dentes no pré-maxilar, exceto Pyrrhulina (Eigenmann, 1910; Weitzman, 1964; Géry, 1977; Lucena, 1993; Planquette et al. 1996; Buckup, 1998; Oyakawa, 1998), sendo uma das características utilizadas para diagnosticar este gênero. Entre os demais táxons examinados, apenas Xenocharax possui duas séries de dentes no pré-maxilar, Brycon apresenta três séries e todos os demais táxons examinados possuem apenas uma série. 
49. Margem póstero-ventral do maxilar $-\mathrm{CI}=1.00 ; \mathrm{RI}=1.00$.

(0) sem uma porção de cartilagem fibrosa; (1) com uma distinta porção de cartilaginosa, se estendendo da porção postero-ventral à porção dentígera do osso.

O maxilar da maioria dos Characiformes é composto por uma única peça totalmente ossificada. Nos Lebiasinidae, a porção edêntula da borda anterior apresenta uma porção não ossificada, representada (aparentemente) por uma peça de cartilagem fibrosa. Entre os Lebiasininae a porção cartilaginosa é conspícua, enquanto que nos Pyrrhulininae corresponde apenas a uma pequena peça situada na margem anteroventral do osso. A presença de tal peça cartilaginosa representa uma sinapomordia exclusiva dos Lebiasinidae, no entento, necessita de estudos mais aprofundados para evidenciar sua origem e constituição.

50. Comprimento do maxilar (Lucena, 1993: 42; Buckup, 1998: 33; Zanata, 2000: 45; Netto-Ferreira, 2006: 86 e 87) - CI=0.50; $\mathrm{RI}=0.94$.

(0) Muito curto, não alcançando o infra-orbital 3; (1) geralmente não se estendendo além da borda anterior do infra-orbital 3 (Weitzman, 1964: fig. 06; Roberts, 1974: fig. 61); (2) maxilar relativamente longo, ultrapassando a margem anterior do infra-orbital 3 (Weitzman, 1962: fig. 08; Roberts, 1969: fig. 01 a 05).

O maxilar dos Characiformes é, no geral um osso curto, restrito à porção anterior do focinho nas famílias basais. Entre os Characiformes predadores (e.g. Acestrorhynchidae, Characinae, Cynodontidae e Erythrinidae), o maxilar encontra-se distintamente alongado, geralmente ultrapassando a vertical que passa pelo meio da órbita. Entre os Erythrinoidea, os Lebiasinidae e Ctenoluciidae apresentam o maxilar relativamente curto, apenas atingindo a borda anterior do infra-orbital 3, estando sempre restrito à porção anterior da órbita. No gênero Nannostomus, a redução do maxilar é ainda mais acentuada, uma vez que o osso geralmente não ultrapassa o infra-orbital 1 (exceto em Nannostomus espei). Entre os Lebiasininae a redução dos maxilares parece estar relacionada à redução do tamanho das presas das quais estes animais se alimentam.

51. Extensão do processo ascendente do maxilar (Netto-Ferreira, 2006: 91) - CI= $0.33 ; \mathrm{RI}=0.87$. 
(0) Curto, alcançando o elemento cartilaginoso lateral do palatino (Weitzman, 1964: fig. 06; Oyakawa, 1998: fig. 33A); (1) relativamente longo, alcançando o elemento cartilaginoso lateral do palatino; (2) longo, alcançando o elemento cartilaginoso medial do (Oyakawa, 1998: fig. 33 B e C).

O processo ascendente do maxilar dos Characiformes é tipicamente uma haste óssea relativamente longa que se projeta medialmente atingindo a porção cartilaginosa mesial do palatino. Em Pyrrhulininae (exceto Derhamia), tal ramo encontra-se variavelmente reduzido, estando restrito à porção cartilaginosa lateral do palatino. Entre os representantes do gênero Nannostomus e as Pyrrhulina do clado 111 o processo percorre toda a porção equivalente ao elemento cartilaginoso lateral. Nas demais espécies de Pyrrhulina, Copeina e Copella o curto processo atinge apenas a extremidade lateral da cartilagem. O processo ascendente do maxilar é curto também em Acestrorhynchus, Ctenoluciidae e Hepsetus odoe.

52. Distribuição dos dentes do maxilar (Zanata, 2000: 52; Campanario, 2000: 29; Zanata \& Vari, 2005: 78; Netto-Ferreira, 2006: 93) - CI=0.33; RI=0.89.

(0) Restritos à porção médio-anterior do osso (Weitzman, 1964: fig. 06; Roberts; 1974: fig. 61); (1) dentes distribuídos por toda a margem anterior do osso (Weitzman, 1962: fig. 06; Roberts, 1969: fig. 01 a 05; Oyakawa, 1998: fig. 33).

O maxilar dos Lebiasininae, Derhamia, Nannostomus e as espécies de Pyrrhulina do clado 107 apresenta um pequeno número de dentes, restritos à porção anterior do osso. Em Copeina, Copella, e as demais espécies de Pyrrhulina, por outro lado, os dentes estão distribuídos em praticamente toda a margem anterior do maxilar, condição observada em todos os representantes do grupo externo. A redução do número de dentes no maxilar representa uma sinapomorfia de Lebiasinidae e a reversão dessa condição uma sinapomorfia do clado 96 (posteriormente revertida no clado 107).

53. Sínfise mandibular (Lucena, 1993: 47; Buckup, 1998: 35; Oyakawa, 1998: 68; Campanario, 2000: 30; Zanata \& Vari, 2005: 82; Netto-Ferreira, 2006: 95) - CI= 1.00; $\mathrm{RI}=1.00$.

(0) Dentários unidos por uma simples faceta articular (Roberts, 1974: fog. 69); (1) dentários interdigitados (Zanata \& Vari, 2005: fig. 22). 
Buckup (1998) em seu estudo das relações dos grupos de Characiformes sugere que a sínfise mandibular representada por uma simples faceta articular, constitui o padrão plesiomórfico da ordem. Os representantes do gênero Nannostomus apresentam os dentários unidos apenas por uma faceta articular, uma reversão da condição derivada apresentada pela maioria dos Characoidea e Erythrinoidea (dentários interdigitados).

54. Dentário (Lucena, 1993: 48; Buckup, 1998: 37; Oyakawa, 1998: 64; NettoFerreira, 2006: 96) $-\mathrm{CI}=1.00 ; \mathrm{RI}=1.00$.

(0) Sem depressão conspícua (Roberts, 1969: fig. 16 e 17; Roberts, 1974: fig. 61); (1) com uma discreta depressão localizada posteriormente à sínfise do dentário; (2) com uma depressão conspícua localizada posteriormente à sínfise do dentário (Weitzman, 1964: fig. 07).

A presença de uma conspícua depressão logo após a sínfise dos dentários é uma das características diagnósticas de Pyrrhulininae, propostas por Weitzman (1964). De fato, tal depressão é facilmente observada em exemplares dos gêneros Copeina, Copella, Pyrrhulina e principalmente Nannostomus, bem como em Derhamia hoffmannorum. Exemplares de Lebiasininae e Erythrinidae também apresentam uma depressão na porção anterior do dentário, próxima à sínfise. Apesar de não ser tão conspícua quanto à dos táxons mencionados anteriormente, tal depressão parece homóloga àquela observada nos Pyrrhulininae. Tal depressão parece estar relacionada à expansão da margem mesial dos dentários, que encobrem o istmo parcialmente ou totalmente.

55. Dentário (Netto-Ferreira, 2006: 99) $-\mathrm{CI}=0.50 ; \mathrm{RI}=0.87$.

(0) Sem um distinto sulco onde o maxilar se encaixa quando a boca está fechada ; (1) com um distinto sulco onde o maxilar se acomoda quando a boca está fechada.

$\mathrm{Na}$ maioria dos táxons examinados, os dentários apresentam a superfície lateral relativamente lisa. Em Copeina e Copella, o dentário apresenta, em sua porção lateral, um distinto sulco onde o maxilar se acomoda quando a boca está fechada. Esta projeção não está presente em nenhum outro táxon examinado.

56. Margem mesial dos dentários (Oyakawa, 1998: 63; Netto-Ferreira, 2006: 100) $-\mathrm{CI}=0.33 ; \mathrm{RI}=0.82$. 
(0) Não se projetando medialmente, encobrindo parte do istmo; margens quase paralelas, convergindo pouco em direção à sínfise mandibular (Roberts, 1974: fig. 69); (1) projetando-se medialmente, encobrindo parte ou todo o istmo; convergindo fortemente em direção à sínfise mandibular.

Diferentemente da maioria dos demais Characiformes, a margem mesial dos dentários dos Lebiasinidae apresenta-se variavelmente projetada em direção ao istmo. Em Pyrrhulininae e alguns exemplares de Lebiasina tais projeções encobrem praticamente todo o istmo, enquanto que nas Lebiasina do grupo L. bimaculata e em Lebiasina sp. "Curuá-faixa” esta condição encontra-se revertida.

57. Encaixe da mandíbula em relação à maxila (Oyakawa, 1998: 65; NettoFerreira, 2006: 101) $-\mathrm{CI}=0.50 ; \mathrm{RI}=0.95$.

(0) Não se encaixando internamente aos pré-maxilares quando a boca está fechada; (1) encaixando-se internamente aos pré-maxilares com a boca fechada.

Oyakawa (1998) afirma que apenas em Nannostomus, os dentes do dentário se encaixavam internamente aos dentes dos pré-maxilares. Entretanto, a condição proposta por Oyakawa (1998) como apomórfica para o gênero foi observada em todos os grupos examinados, exceto Copeina, Copella, Derhamia e Pyrrhulina, cujos representantes são prognatos.

58. Fossa dos dentes de reposição da série externa do dentário (Oyakawa, 1998: 70; Netto-Ferreira, 2006: 102) $-\mathrm{CI}=1.00 ; \mathrm{RI}=1.00$.

(0) Rasa e estreita; (1) bastante profunda e larga.

A maioria dos Characiformes apresenta uma única fossa dos dentes de reposição da série externa do dentário, sendo esta, na maioria dos grupos, rasa e estreita. Oyakawa (1998), afirma que a fossa de dentes em Hoplias é profunda e larga, diferentemente dos demais Erythrinoidea. Em representantes do gênero Nannostomus, contudo, a fossa de reposição também apresenta-se bastante alargada e profunda. Todos os demais táxons examinados apresentam a fossa dos dentes de reposição rasa e estreita.

59. Série interna do dentário (Lucena, 1993: 49 - modificado; Buckup, 1998: 36; Zanata, 2000: 55 e 56; Campanario, 2000: 31 - modificado; Netto-Ferreira, 2006: 103) $-\mathrm{CI}=0.20 ; \mathrm{RI}=0.60$. 
(0) Presente, completa (Weitzman, 1964: fig. 07; Roberts, 1969: fig. 26 e 27); (1) presente, incompleta (Weitzman, 1962: fig. 10; Roberts, 1969: fig. 29, 30 e 32; Oyakawa, 1998, 34A); (2) ausente (Roberts, 1974: fig. 65 e 70).

A maioria dos grupos de Lebiasinidae apresenta a série interna do dentário completa. Em Nannostomus, por outro lado, a série interna do dentário pode estar incompleta, representada por apenas uma pequena placa dentígera na porção posterior do dentário, logo após os dentes da série externa. As únicas espécies do gênero Nannostomus que apresentam a série interna do dentário completa são N. britskii, $N$. eques, N. harrisoni, N. marginatus e N. trifasciatus. Entre os demais Characiformes examinados, apenas Hepsetus apresenta a série interna completa. Ardila-Rodríguez (2004) sugere que exemplares de Lebiasina narinensis (=L. astrigata) apresentam três séries de dentes no dentário. No entanto, em nenhum dos exemplares examinados foi observada a ocorrência da terceira série de dentes. É possível que o autor tenha erroneamente considerado como terceira série os dentes de reposição da série interna do dentário no exemplar examinado.

\section{Margem posterior do dentário, onde se encaixa o ângulo-articular.}

(Oyakawa, 1998: 66 - modificado; Netto-Ferreira, 2006: 106) - CI=0.22; RI=0.73.

(0) Com uma acentuada concavidade, onde se encaixa o ramo anterior do ânguloarticular (Weitzman, 1962: fig. ); (1) concavidade pouco acentuada; (2) praticamente reta (Weitzman, 1964: fig. 07; Roberts, 1974: fig. 65 e 70).

O ângulo-articular dos Characiformes apresenta uma porção mediana aproximadamente triangular em vista lateral que se articula com a face medial do dentário. $\mathrm{Na}$ maioria dos táxons examinados, o dentário encobre apenas parte de tal projeção. Em táxons em que o ramo médio do ângulo-articular é relativamente curto, a concavidade na margem posterior do dentário apresenta-se menos acentuada. Em Nannostomus, Copella e Pyrrhulina brevis, a projeção do ângulo-articular anteriormente direcionada é muito reduzida, de maneira que a margem posterior do dentário não apresenta um sulco evidente. Com base em tais observações, é possível sugerir que o sulco da margem posterior do dentário está diretamente associado ao comprimento do ramo médio do ângulo-articular. 
61. Comprimento do osso corono-meckeliano (Netto-Ferreira, 2006: 110) - CI= $0.25 ; \mathrm{RI}=0.80$.

(0) Aproximadamente dez vezes menor que o da cartilagem de Meckel (Roberts, 1969: fig. 26, 27, 29, 30 e 32; Vari, 1995: fig. 06B); (1) Estendendo-se por um quinto, ou mais, na cartilagem de Meckel (Weitzman, 1962: fig. 10 Weitzman, 1964: fig. 07; Roberts, 1974: fig. 65 e 70).

O osso corono-meckeliano geralmente estende-se por um quinto, ou mais da extensão da cartilagem de Meckel. Em Derhamia e Pyrrhulina o osso coronomeckeliano apresenta-se distintamente reduzido, condição apomórfica compartilhada com os Erythrinidae e o clado 65.

62. Forma da cartilagem de Meckel (Netto-Ferreira, 2006: 112) $-\mathrm{CI}=1.00$; RI= 1.00 .

(0) Aproximadamente reta; (1) curva no terço anterior.

A cartilagem de Meckel da maioria dos Characiformes estende-se do ânguloarticular à porção anterior do dentário em trajetória aproximadamente linear. Em Nannostomus, entretanto, a cartilagem de Meckel apresenta uma nítida curvatura, direcionada ventralmente, no terço anterior.

\section{Suspensório}

(Figuras 19-31)

63. Ectopterigóide (Zanata, 2000: 59; Zanata \& Vari, 2005: 98 - modificado; NettoFerreira, 2006: 115$)-\mathrm{CI}=0.33 ; \mathrm{RI}=0.84$.

(0) Longo, geralmente apresentando grande área de articulação com quadrado, atingindo também a porção anterior do palatino (Weitzman, 1962: fig. 10; Roberts, 1969: fig. 26, 29 e 32; Campanario, 2000: fig 27); (1) não tão longo, atingindo apenas a porção posterior do palatino e uma pequena porção do quadrado (Roberts, 1974: fig. 64 e 65); (2) curto; pouco maior que o palatino, atingindo a porção posterior do palatino, mas não articulado com o quadrado; (3) muito curto; menor que o palatino, em contato com a porção posterior do palatino e não articulado com o quadrado (Weitzman, 1964: fig. 07).

Em Acestrorhynchus, Brycon, Ctenoluciidae, Erythrinidae, Hepsetus e Xenocharax, o ectopterigóide é um osso longo, apresentando uma grande área de 
articulação com o quadrado e o palatino. Os Lebiasinidae (exceto Lebiasina elongata e L. panamensis), de maneira geral, apresentam uma tendência à redução deste osso, sendo Copella (do clado 102) e Nannostomus os extremos de tal padrão, onde o ectopterigóide é menor que o palatino.

64. Dentes no ectopterigóide (Lucena, 1993: 56; Buckup, 1998: 22; Oyakawa, 1998: 36 - modificado; Campanario, 2000: 36 - modificado; Netto-Ferreira, 2006: 117) $-\mathrm{CI}=0.20 ; \mathrm{RI}=0.69$.

(0) Ausentes (Roberts, 1969: fig. 28, 29 e 32; Vari, 1995: fig. 08; Oyakawa, 1998: fig. 24A, 25 e 28B; Campanario, 2000: fig. 27); (1) apenas uma série de dentes (Roberts, 1969: fig. 32); (2) duas séries irregulares; (3) múltiplas séries de dentes (Roberts, 1969: fig. 28 e 29; Vari, 1995: fig. 08; Oyakawa, 1998: fig. 24A, 25 e 28B; Campanario, 2000: fig. 27).

A presença de dentes no ectopterogóide é uma característica amplamente difundida nos Characiformes. Entre os grupos tradicionalmente incluídos em Erythrinoidea, apenas Hepsetus e os Pyrrhulininae (exceto Nannostomus beckfordi "Suriname", N. eques e N. marilynae) não apresenta dentes no ectopterigóide. Entre os Lebiasinidae que apresentam dentes no ectopterigóide, estes estão presentes em apenas uma ou duas fileiras irregulares de poucos dentes, diferindo dos demais Erythrinoidea, que apresentam placas com inúmeros dentes viliformes distribuídas por quase toda a margem ventral do osso.

65. Distribuição dos dentes do ectopterigóide (Netto-Ferreira, 2006: 120) - CI= $0.33 ; \mathrm{RI}=0.50$.

(0) Distribuídos ao longo de grande extensão (Roberts, 1969: fig. 28, 29 e 32; Oyakawa, 1998: fig. 28B; Campanario, 2000: fig. 27); (1) restritos à porção anterior (Fig. 29; Oyakawa, 1998: fig. 28B).

Conforme mencionado anteriormente, os dentes do ectopterigóide em Lebiasinidae, quando presentes, encontram-se distribuídos apenas na margem distal da superfície bucal do ectopterigóide. As únicas exceções são L. festae e L. panamensis que apresentam os dentes distribuídos ao longo de grande parte do osso como nos demais Characiformes que apresentam dentes no ectopterigóide. 
66. Dentes do endopterigóide (Lucena, 1993: 56; Vari, 1995: 54; Buckup, 1998: 23; Oyakawa, 1998: 40; Campanario, 2000: 37 - modificado; Netto-Ferreira, 2006: 121) $-\mathrm{CI}=0.80 ; \mathrm{RI}=0.67$.

(0) Ausentes; (1) presentes, restritos à porção posterior do osso; (2) presentes, restritos à porção mediana do osso; (3) restritos à porção anterior do osso; (4) distribuídos por todo o endopterigóide.

A presença de dentes no endopterigóide não é uma característica amplamente distribuída entre os Characiformes (Vari, 1995). Weitzman (1964), Vari (1995) e Buckup (1998) constataram a presença de dentículos no endopterigóide de representantes dos gêneros Hoplerythrinus, Boulengerella e Crenuchus, respectivamente. No presente estudo foi observada a ocorrência de dentes no endopterigóide em Boulengerella lateristriga, Hoplerythrinus, Lebiasina aff. festae, L. boruca, L. festae e L. panamensis. Nas demais espécies de Lebiasinidae os dentes do endopterigóide não estão presentes.

67. Articulação quadrado-ângulo-articular (Zanata, 2000: 68; Zanata \& Vari, 2005: 93; Netto-Ferreira, 2006: 122)- $\mathrm{CI}=0.29 ; \mathrm{RI}=0.84$.

(0) Situada anteriormente ao etmóide lateral (Weitzman, 1964: fig. 07); (1) situada entre o etmóide lateral e o meio da órbita (Weitzman, 1962: fig 08; Roberts, 1974: fig. 61); (2) situada posteriormente ao meio da órbita (Roberts, 1969: fig. 01 a 05).

A articulação quadrado-ângulo-articular da maioria dos Characiformes parece ocorrer entre o etmóide lateral e o meio da órbita. Em Erythrinoidea $(+$ Acestrorhynchus), grupo incluindo espécies essencialmente ictiófagas, no entanto, a articulação da mandíbula com o suspensório encontra-se deslocada posteriormente. A única exceção a esse padrão são os Pyrrhulininae e algumas espécies de Lebiasina dos clados 69 e 75. O encurtamento da mandíbula em Pyrrhulininae pode estar associado à redução do tamanho de corpo e a mudança de nicho alimentar. A codificação "1" atribuída a Lebiasina sp. "Parima" pode estar associada a um componente ontogenético deste caráter, uma vez que o exemplar diafanizado examinado ser um jovem com 40.5 $\mathrm{mm} \mathrm{SL}$. 
68. Quadrado (Zanata, 2000: 59; Netto-Ferreira, 2006: 123) $-\mathrm{CI}=0.14$; $\mathrm{RI}=0.62$. (0) Articulando com o ectopterigóide (Weitzman, 1962: fig 10; Roberts, 1969: fig. 26 a 32; Roberts, 1974: fig. 65 e 70; Oyakawa, 1998: fig. 28; Campanario, 2000: fig. 27); (1) não articulando com o ectopterigóide (Weitzman, 1964: fig. 07).

O ectopterigóide de Copella cf. arnoldi e as espécies incluídas no clado 103, Lebiasina elongata e L. yuruaniensis, e dos representantes do gênero Nannostomus (exceto $N$. eques e $N$. harrisoni) não está diretamente articulado com o quadrado. Tal condição parece estar relacionada à tendencia ao encurtamento do ectopterigóide entre os Lebiasinidae. Condição semelhante à observada nestas espécies ocorre também em Characidium e nos alestídeos Brycinus e Hydrocynus.

69. Fenestra quadrado-metapterigóide (Lucena, 1993: 61; Vari, 1995: 55; Buckup, 1998: 24; Oyakawa, 1998: 44; Netto-Ferreira, 2006: 124) - CI= 1.00; RI= 1.00 .

(0) Presente (Weitzman, 1962: fig 10; Roberts, 1969: fig. 26 a 32; Roberts, 1974: fig. 65 e 70; Oyakawa, 1998: fig. 28A; Campanario, 2000: fig. 27); (1) obliterada (Weitzman, 1964: fig. 07; Oyakawa, 1998: fig. 28B).

A presença da fenestra quadrado-metapterigóide é considerada uma das sinapomorfias da ordem Characiformes. Os Lebiasinidae são os únicos representantes da ordem onde esta fenestra está obliterada (principalmente por expansões ósseas do metapterigóide), sendo esta considerada a principal característica diagnóstica da família (Vari, 1995; Weitzman \& Weitzman, 2003).

70. Metapterigóide (Netto-Ferreira, 2006: 127) $-\mathrm{CI}=1.00 ; \mathrm{RI}=1.00$.

(0) Quase tão alto quanto longo (Weitzman, 1962: fig 10; Roberts, 1969: fig. 26, 28, 29 e 32; Roberts, 1974: fig. 65 e 70; Oyakawa, 1998: fig. 28 a 31; Campanario, 2000: fig. 27); (1) distintamente mais longo que alto (Weitzman, 1964: fig 07).

Na maioria dos Characiformes, o metapterigóide é um osso amplo que delimita as margens dorsal e posterior da fenestra quadrado-metapterigóide sendo quase tão alto quanto longo. Nos Pyrrhulininae o metapterigóide é alongado ântero-posteriormente. Adicionalmente, as projeções lamelares presentes na superfície dorsal do osso onde o adductor arcus palatini se insere, presentes nos demais Characiformes, encontram-se totalmente reduzidas em Copeina, Copella e Pyrrhulina e representadas apenas por 
diminutas projeções em Derhamia e Nannostomus. Desta maneira, em Pyrrhulininae o metapterigóide é distintamente mais longo que alto, sendo quase tão estreito quanto o simplético na maioria das espécies.

71. Porção médio-posterior do metapterigóide (Lucena, 1993: 57 - modificado; Zanata, 2000: 63 - modificado; Campanario, 2000: 35 - modificado; Netto-Ferreira, 2006: 128$)-\mathrm{CI}=0.14 ; \mathrm{RI}=0.75$.

(0) com um forame ou canal delimitado pelo metapterigóide e o hiomandibular (Weitzman, 1962: fig 10; Weitzman, 1964: fig 07; Roberts, 1969: fig. 26, 28, 29 e 32; Roberts, 1974: fig. 65 e 70; Oyakawa, 1998: fig. 28 a 30); (1) com um forame ou canal restrito ao metapterigóide (Campanario, 2000: fig. 27).

O metapterigóide dos Characiformes apresenta um forame por onde passa um vaso sangüíneo que passa da face medial do suspensório para a face lateral. Impropriamente denominado fenestra por Lucena (1993) e Zanata (2000), este forame pode ser delimitado apenas pelo metapterigóide, conforme observado na maioria dos Lebiasinidae e Hoplerythrinus. Diferentemente de Lucena (1993), Zanata (2000) e Campanario (2000), optou-se não considerar a ausência deste forame quando o mesmo não se encontra delimitado totalmente pelo metapterigóide, uma vez que o vaso que o transpassa está presente mesmo nesses casos.

72. Vaso que transpassa a porção médio-posterior do metapterigóide (NettoFerreira, 2006: 129) $-\mathrm{CI}=0.25 ; \mathrm{RI}=0.83$.

(0) Passando por um forame; (1) passando por um canal curto.

Em Copeina, Copella e Pyrrhulina, a passagem do vaso pelo metaptergióide ocorre por meio de um pequeno canal, diferindo da condição geral observada nos demais Characiformes, onde o vaso atravessa diretamente o metapterigóide, não percorrendo o osso. Condição similar, adquirida independentemente, foi observada em L. ortegai.

73. Comprimento do simplético (Oyakawa, 1998: 46 - modificado; Netto-Ferreira, 2006: 130$)-\mathrm{CI}=0.5 ; \mathrm{RI}=0.67$.

(0) Curto (Weitzman, 1962: fig 10; Roberts, 1969: fig. 26 e 32; Roberts, 1974: fig. 65 e 70; Oyakawa, 1998: fig. 28A; Campanario, 2000: fig. 27); (1) longo (Roberts, 1969: fig. 
28; Roberts, 1974: fig. 65 e 70; Oyakawa, 1998: fig. 28B); (2) bastante longo, apresentando quase o mesmo comprimento que o metapterigóide (Weitzman, 1964: fig. 07).

O simplético dos Lebiasinidae encontra-se conspicuamente alongado ânteroposteriormente, de maneira a apresentar comprimento semelhante ao do metapterigóide. Esta condição é mais conspícua no gênero Nannostomus. Em Copeina guttata, o simplético é mais curto que nos demais Lebiasinidae e é expandido dorso-ventralmente. $\mathrm{Na}$ maioria dos demais grupos, o simplético encontra-se alongado, porém, em menor nível que o dos Lebiasinidae.

74. Extensão do pré-opérculo (Oyakawa, 1998: 41; Netto-Ferreira, 2006: 132).

(0) Estendendo-se anteriormente até próximo ao ângulo-articular (Weitzman, 1962: fig 10; Roberts, 1969: fig. 26, 28, 29 e 32; Roberts, 1974: fig. 65 e 70; Campanario, 2000: fig. 27); (1) distante do ângulo-articular, alcançando somente o processo pósteroinferior do quadrado (Weitzman, 1964: fig. 07).

O pré-opérculo é o osso por onde se estende o ramo do canal látero-sensorial facial, comunicando o sistêma látero-sensorial do crânio ao sistema na mandíbula . Oyakawa (1998) observou que o pré-opérculo dos representantes do gênero Nannostomus não se estende anteriormente, até próximo ao ângulo-articular. Tal observação foi confirmada em todos os representantes deste gênero, examinados no presente estudo, onde o pré-opérculo não alcança a região anterior do suspensório. Em alguns indivíduos, a porção laminar anterior do pré-opérculo encontrava-se reduzida, permanecendo apenas o canal ósseo, que alcança apenas a cartilagem situada entre o metapterigóide e o ramo posterior do quadrado.

75. Forma do hiomandibular (Campanario, 2000: 34 - modificado; Netto-Ferreira, 2006: 133).

(0) Tão alto quanto longo; (1) mais alto que longo (Fig. 29 a 41).

O hiomandibular da maioria dos Characiformes é um osso distintamente mais alto que longo, com curtas porções lamelares, situadas ventralmente à área de articulação com o esfenótico e o pterótico. Em Acestrorhynchidae, Ctenoluciidae e Hepsetidae o hiomandibular é relativamente deprimido, quase tão alto quanto longo, apresentando grandes porções lamelares, projetadas anteriormente e em forte associação 
com a projeção lamelar do metapterigóide. Toledo-Piza (2007) discute a presença de uma associação entre as porções lamelares do hiomandibular e do metapterigóide descrita por Roberts (1969) para Acestrorhynchus e Salminus. Toledo-Piza (2007) sugere que a condição observada por Roberts em Salminus não seja homóloga à observada em Acestrorhynchidae, no entanto, esta condição não difere da observada também em Ctenoluciidae e Hepsetus. Adicionalmente, entre todos os táxons examinados, exceto Acestrorhynchus, Hepsetus e Ctenoluciidae, o nervo facial passa da face medial da hiomandíbula para a face lateral deste osso por meio de um canal por onde o osso percorre. Nestes três táxons a hiomandíbula apresenta apenas um forame por onde o nervo transpassa o osso. Uma série de caracteres provenientes de outros complexos morfológicos corrobora a próxima relação entre estas três famílias (ver discussão).

76. Área de articulação do hiomandibular com o crânio (Netto-Ferreira, 2006: 135) $\mathrm{CI}=1.00 ; \mathrm{RI}=1.00$.

(0) Única (Weitzman, 1962: fig 10; Weitzman, 1964: fig 07; Roberts, 1969: fig. 29; Roberts, 1974: fig. 65 e 70; Oyakawa, 1998: fig. 28B, 29-31; Campanario, 2000: fig. 27); (1) dividida em duas áreas bem distintas.

Conforme dito anteriormente, o hiomandibular dos Characiformes apresenta, tipicamente, uma área de articulação com o crânio, se estendendo desde o esfenótico até o pterótico. Em sua porção anterior, situada próxima ao espinho do esfenótico, a área de articulação do hiomandibular se expande lateralmente formando um côndilo. Os representantes dos gêneros Copeina, Copella e Pyrrhulina, apesar de apresentam uma estreita área de articulação no hiomandibular, este apresenta dois côndilos distintos, um articulando com o esfenótico e o outro articulando em parte com o esfenótico e com o pterótico. As implicações da formação de um segundo côndilo na movimentação da hiomandíbula nestes táxons não é clara, necessitando estudos aprofundados de anatomia funcional.

\section{Processo lamelar na porção dorso-posterior do hiomandibular (Netto-} Ferreira, 2006: 136) $-\mathrm{CI}=0.20 ; \mathrm{RI}=0.75$.

(0) Longo, ultrapassando a área de articulação do hiomandibular com o pterótico e o esfenótico ; (1) curto, contíguo à articulação do hiomandibular, mas sim próximo à área 
de articulação do hiomandibular com o pterótico; (2) curto, próximo da articulação como o opérculo; (3) ausente.

O hiomandibular da maioria dos Characiformes apresenta um distinto processo laminar originado entre a articulação com o crânio e o côndilo de articulação com o opérculo. Tipicamente, esta projeção encontra-se contígua à área de articulação com o crânio, podendo ultrapassá-la em alguns casos. A maioria dos Lebiasininae apresentam o padrão plesiomórfico (estado “1”), no entanto, o espinho encontra-se mais alongado em L. festae, L. erythrinoides e nas espécies do clado 88. Nos Pyrrhulininae (exceto Copeina), o processo encontra-se tipicamente curto ou ausente na maioria das espécies.

78. Forma do opérculo (Netto-Ferreira, 2006: 132) - $\mathrm{CI}=0.50 ; \mathrm{RI}=0.00$.

(0) Opérculo com formato elíptico (Weitzman, 1962: fig 10; Roberts, 1969: fig. 31 e 32); (1) com formato aproximadamente trapezoidal, porção ventral alongada posteriormente (Weitzman, 1964: fig 07; Roberts, 1969: fig. 29; Roberts, 1974: fig. 65 e 70; Oyakawa, 1998: fig. 28B, 29-31; Campanario, 2000: fig. 27).

De maneira geral, o opérculo dos Characiformes apresenta o formato trapezoidal. Tal condição é observada em Crenuchidae, Ctenoluciidae, Erythrinidae, Hepsetidae, Lebiasinidae, Parodontidae e Xenocharax. Todos os demais táxons examinados apresentam o opérculo com formato aproximadamente elíptico.

79. Margem anterior do opérculo (Zanata, 2000: 69 - modificado; Campanario, 2000: 38 - modificado; Netto-Ferreira, 2006: 138) - $\mathrm{CI}=0.09$; $\mathrm{RI}=0.65$.

(0) Superfície anterior, dorsalmente à articulação com o hiomandibular, lisa (Roberts, 1969: fig. 28); (1) apresentando um distinto processo, (Roberts, 1974: fig. 64).

A margem anterior do opérculo da maioria dos Characiformes apresenta um processo ósseo onde se insere parte do dilatator operculi. Tal processo está presente na maioria dos Pyrrhulininae examinados, e a perda secundária do processo representa uma sinapomorfia do clados 117, 124, Nannostomus eques, Copella carsevenensis e Pyrrhulina sp. “Tapajós". O surgimento independente do processo ocorre no clado 65, Lebiasina aff. festae, L. taphorni e Lebiasina sp. "Curuá-faixa”. A 
80. Margem posterior do opérculo $-\mathrm{CI}=0.09 ; \mathrm{RI}=0.44$.

(0) Convexa ; (1) aproximadamente reta (Ardila-Rodríguez, 2008b: 23, fig. 10 A, C, D);

(2) côncava (Ardila-Rodríguez, 2008b: 23, fig. 10 B).

A margem posterior do opérculo dos Characiformes é tipicamente convexa. Nos Lebiasinidae, no entanto, a margem do opérculo é distintamente côncava na maioria dos representantes examinados, revertendo à condição plesiomórfica nos clados 107 (revertido para o estado "2" novamente no clado 112), 116, 120. Em algumas espécies, a margem posterior do opérculo é aproximadamente reta. Esta condição não foi tratada como sendo necessariamente um estado intermediário na transição entre a condição côncava e a conexa, ou vice versa.

\section{$\underline{\text { Arco Hióide }}$}

\section{(Figuras 32-38)}

81. Comprimento do basi-hial (Oyakawa, 1998: 50; Netto-Ferreira, 2006: 140) $\mathrm{CI}=0.12 ; \mathrm{RI}=0.65$.

(0) Longo (Weitzman, 1964: fig 08; Roberts, 1969: fig. 33, 34 e 37; Roberts, 1974: fig. 74; Campanario, 2000: fig. 33); (1) curto (Weitzman, 1962: fig 11; Roberts, 1969: fig. 35 e 36$)$.

O basi-hial apresenta o comprimento bastante variável entre os Characiformes, no entanto, a ocorrência do estado " 0 " parece a condição mais difundida entre os grupos (oyakawa, 1998). Entre os representantes de Lebiasinidae, no entanto, o basi-hail é tipicamente curto, condição compartilhada com Brycon e Erythrinidae. Esta condição encontra-se revertida em Copella (exceto C. nattereri e espécies do clado 97), Derhamia, Lebiasina sp. "Parima" e Nannostomus (exceto N. marginatus).

82. Extremidade anterior do basi-hial (Oyakawa, 1998: 51 - modificado; NettoFerreira, 2006: 141) $-\mathrm{CI}=0.50 ; \mathrm{RI}=0.75$.

(0) Estreita (Weitzman, 1964: fig 08; Roberts, 1969: fig. 33, 34 e 37; Roberts, 1974: fig. 74); (1) larga (Weitzman, 1962: fig 11; Roberts, 1969: fig. 35; Campanario, 2000: fig. $33)$.

Oyakawa (1998) observa que a porção anterior do basi-hial de Erythrinidae e Piabucina (=Lebiasina) é bastante alargada lateralmente. A condição considerada "larga" por Oyakawa (1998) refere-se apenas à condição observada em Erythrinidae, 
onde o basi-hial é distintamente mais largo que em todos os demais Characiformes examinados. Foram consideradas largas a extremidade anterior do basi-hial da maioria dos táxons examinados, exceto em $N$. unifasciatus e $N$. harrisoni, representando uma sinapomorfia do clado 120. Condição similar foi observada em Acestrorhynchus, Ctenoluciidae, Hepsetus (clado 65).

83. Parte óssea do basi-hial (Oyakawa, 1998: 52; Netto-Ferreira, 2006: 142) - CI= $1.00 ; \mathrm{RI}=1.00$;

(0) Formada por dois elementos ósseos justapostos longitudinalmente (Roberts, 1969: fig. 33, 34 e 37; Secioso, 1997: fig. 14); (1) formado por um único elemento ósseo (Weitzman, 1964: fig 08).

Em Lebiasinidae a parte óssea do basi-hial é composta por um único elemento ósseo. Na maioria dos os demais grupos examinados no presente estudo, a parte óssea do basi-hial é composta de duas porções: um elemento autógeno que se articula com o basi-branquial 1 posteriormente e um elemento dérmico situado dorsalmente à porção cartilaginosa do elemento autógeno.

84. Cerato-hial anterior e hipo-hial dorsal (Netto-Ferreira, 2006: 143).

(0) Não conectados ao basi-hial por meio de um tecido conectivo frouxo; (1) conectados à extremidade do basi-hial por meio de um ligamento denso.

Os cerato-hiais e hipo-hiais dorsais de Acestrorhynchus, Ctenoluciidae, Erythrinidae, Hepsetidae e Lebiasinidae apresentam um tecido ligamentoso denso que se liga à porção látero-ventral do basi-hial. Nos demais táxons examinados no presente estudo, o ligamento apresenta-se distintamente mais frouxo que nestes grupos, contituindo uma sinapomorfia de Erythrinoidea (incluindo Acestrorhynchus).

85. Superfície lateral dos cerato-hiais anterior e posterior (Vari, 1995: 58; Oyakawa, 1998: 49; Zanata, 2000: 72; Netto-Ferreira, 2006: 144) - CI=0.40; RI=0.88. (0) Sem interdigitações (Weitzman, 1962: fig. 11B; Weitzman, 1964: fig 08A); (1) com interdigitações; (2) com fortes interdigitações.

A presença de interdigitações na superfície lateral do contato entre os ceratohiais anterior e posterior parece ser uma condição mais amplamente distribuída entre os Characiformes que as interdigitações na superfície medial destes ossos. Vari (1995) 
sugeriu que a origem destas interdigitações em Acestrorhynchus, (Ctenoluciidae +Erythrinidae) e Lebiasininae teria ocorrido independentemente. Com base no presente esquema de relações, no entanto, é possível sugerir a origem comum desta estrutura em tais famílias, tendo sido revertida em Hepsetus e Pyrrhulininae.

86. Borda ventral do cerato-hial anterior (Lucena, 1993: 68; Zanata, 2000: 70; Netto-Ferreira, 2006: 146) $-\mathrm{CI}=0.14 ; \mathrm{RI}=0.79$.

(0) Relativamente lisa (Weitzman. 1964: fig. 08); (1) apresentando distintas reentrâncias (Roberts, 1969: fig. 36).

Zanata (2000) observou grande variação no grau de desenvolvimento das reentrancias e projeções da margem ventral do cerato-hial anterior, considerando presentes apenas aquelas fortemente marcadas. Entre os Lebiasinidae, Lebiasina unitaeniata e maioria dos Pyrrhulininae (exceto Copeina, Copella carsevennensis e as espécies de Nannostomus do clado 125 e $N$. unifasciatus) apresentam reentrâncias onde se inserem os processos proximais dos primeiros raios branquiostégios.

87. Raios branquiostégios (Lucena, 1993: 70; Vari, 1995: 61; Secioso, 1997, 11; Buckup, 1998: 30; Oyakawa, 1998: 48; Toledo-Piza, 2000: 35; Zanata, 2000: 73; Campanario, 2000: 40; Zanata \& Vari, 2005: 112; Netto-Ferreira, 2006: 147) - CI= $1.00 ; \mathrm{RI}=1.00$.

(0) Três (Weitzman, 1964: fig. 08B); (1) quatro (Weitzman, 1962: fig 11C; Roberts, 1969: fig. 33, 34, 36 e 37; Roberts, 1974: fig. 73); (2) cinco (Roberts, 1969: fig; 35; Campanario, 2000: fig. 30).

O número de raios branquiostégios varia de três a cinco elementos entre os grupos de Characiformes (Buckup, 1998). Entre os Lebiasinidae, o número de raios varia de três (Pyrrhulininae - sensu Weitzman \& Cobb, 1975) a quatro (Lebiasininae e Derhamia). O primeiro e o segundo branquiostégio dos Lebiasininae e Derhamia apresentam um processo proximal, que se articula com a margem látero-ventral da face medial do cerato-hial anterior. O terceiro e quarto raios não apresentam tal processo e estão articulados com a face lateral do cerato-hial anterior e o cerato-hial posterior, respectivamente. O branquiostégio ausente nos Pyrrhulininae (sensu Weitzman \& Cobb, 1975) parece corresponder ao primeiro branquiostégio dos Lebiasininae, uma vez que os representantes deste grupo apresentam apenas um raio com processo dorsal 
articulando com a margem mesial da face interna do cerato-hial anterior e os demais raios encontram-se deslocados posteriormente. A ocorrência de três branquiostégios só foi observada em Apareiodon affinis, enquanto que a maioria dos demais táxons examinados apresenta quatro raios. Os Erythrinidae, por sua vez, apresentam cinco raios branquiostégios.

88. Margem anterior do(s) raio(s) branquiostégio(s) articulado(s) com a face medial do cerato-hial anterior (Mattox, 2010: 101) - $\mathrm{CI}=0.25 ; \mathrm{RI}=0.84$.

(0) Com uma longa projeção, direcionada anteriormente; (1) com uma projeção curta; (2) reta.

Mattox (2010) observou que na maioria dos Characiformes a margem anterior dos dois branquiostégios mais anteriores apresenta uma distinta aba direcionada anteriormente, sendo que diversos gêneros de Characinae apresentam raios branquiostégios bastante delgados, sem tais projeções. Com base nos grupos amostrados, pôde-se estabelecer um estado intermediário aos dois discutidos por Mattox (2010), onde a aba do raio é distintamente mais curta que no estado “0”. Esta condição representa uma sinapomorfia ambígua de Pyrrhulinini, revertida em N. harrisoni e Copeina. A ausência da projeção anterior dos branquiostégios representa uma sinapomorfia de Copella (revertida em Copella gr. eigenmanni) e adquirida independentemente no clado 116. Nannostomus britskii, N. digrammus e N. marilynae apresentaram polimorfismo neste caráter, onde os estados " 1 " e " 2 " foram observados.

89. Comprimento do inter-hial (Netto-Ferreira, 2006: 150$)-\mathrm{CI}=0.50 ; \mathrm{RI}=0.67$.

(0) Longo, maior que a metade da altura dos cerato-branquiais (Roberts, 1969: fig. 33 a 37; Vari, 1995: fig. 09A); (1) curto, menor que a metade da altura dos cerato-branquiais (Weitzman, 1962: fig. 11C; Weitzman, 1964: fig. 08B; Roberts, 1974: fig. 73).

O inter-hial da maioria dos Characiformes é um osso relativamente longo, em forma de bastão. Nos Lebiasinidae este osso encontra-se comprimido e distintamente mais curto, onde a altura do inter-hial não ultrapassa, ou ultrapassa discretamente, a altura do sulco no cerato-hial posterior onde o osso está ligado. Tal condição é compartilhada com Brycon, no entanto, este caráter parece ter surgido independentemente nos dois grupos. 
90. Lamelas laterais do uro-hial (Zanata, 2000: 74; Campanario, 2000: 43; Zanata \& Vari, 2005: 113; Netto-Ferreira, 2006: 152) $-\mathrm{CI}=0.50 ; \mathrm{RI}=0.90$.

(0) Ausentes (Campanario, 2000: fig. 32); (1) presentes (Weitzman, 1962: 11B; Weitzman, 1964: fig. 08A; Roberts, 1974: fig. 73).

$\mathrm{O}$ uro-hial situa-se anteriormente à cintura peitoral podendo apresentar duas projeções lamelares direcionadas látero-ventralmente que são variavelmente desenvolvidas entre os Characiformes. Na maioria dos Lebiasinidae (exceto Copella) as abas laterais estão presentes, porém restritas à porção anterior do uro-hial, sendo muito curtas quando comparadas às dos demais Characiformes. Os representantes do gênero Copella são os únicos lebiasinídeos que não apresentam estas projeções, condição compartilhada com Acestrorhynchus, Ctenoluciidae e Hepsetus.

\section{$\underline{\text { Arcos Branquiais }}$}

91. Dentículos viliformes no faringo-branquial 2 (Lucena, 1993: 72; NettoFerreira, 2006: 155) $-\mathrm{CI}=0.10 ; \mathrm{RI}=0.61$.

(0) Presentes (Roberts, 1969: fig. 33 a 37); (1) ausentes.

O faringo-branquial 2 da maioria dos Characiformes apresenta um número variável de dentículos viliformes (dois ou três, como em Copeina guttata e na maioria das espécies de Nannostomus, ou diversos em Acestrorhynchus, Ctenoluciidae e Hepsetus). A ausência destes dentículos constitui uma sinapomorfia do clado 78 (secundariamente revertido em Lebiasina sp. "Parima", L. taphorni, e L. sp. "Azuay”). A perda ocorre também, de modo independente, em Derhamia e nos clados 115, 121 (revertido em N. unifasciatus) e 100 (Copella e Pyrrhulina).

92. Margem lateral do cerato-branquial $-\mathrm{CI}=0.08 ; \mathrm{RI}=0.54$.

(0) Sem um processo espiniforme lateral; (1) com um processo espiniforme lateral.

A margem lateral do quinto cerato-branquial apresenta uma discreta projeção lateral, aparentemente homóloga ao processo digitiforme presente na face látero-ventral dos cerato-branquiais. A perda de tal projeção parece ter ocorrido diversas vezes entre os grupos examinados, no entanto, a perda destes processos é considerada uma sinapomorfia homoplástica entre dos clados 74, 76 (revertida no clado 86) e 123. 


\section{Cintura peitoral}

\section{(Figuras 39-48)}

93. Extra-escapular (Lucena, 1993: 93; Buckup, 1998: 52; Campanario, 2000: 63; Zanata \& Vari, 2005: 127; Netto-Ferreira, 2006: 163) - CI=0.33; RI=0.92.

(0) Presente, não sobreposto lateralmente ao opérculo (Weitzman, 1962: fig. 19; Roberts, 1969: fig. 48 e 51; Oyakawa, 1998: fig. 37; Campanario, 2000: fig. 43); (1) presente, sobrepondo-se ao opérculo lateralmente; (2) ausente.

O extra-escapular é uma ossificação dérmica que conecta o canal láterosensorial cefálico ao sistema da cintura peitoral e do corpo. Entre os Lebiasininae o osso pode apresentar-se expandido dorso-ventralmente, com sua margem ventral sobrepondo-se ao opérculo. Tal condição representa uma sinapomorfia homoplástica dos clados 69 (revertida no clado74) e 75 .

Weitzman (1964), na definição da tribo Pyrrhulinini (= Pyrrhulininae sensu Weitzman \& Cobb, 1975), afirma que o canal extra-escapular e o osso propriamente dito estão ausentes nos representantes do grupo. Lucena (1993) e Buckup (1998) indicam a ausência desta ossificação em Nannostomus e Pyrrhulina. Entretanto, o extraescapular está ausente apenas em Copella, Pyrrhulina, Nannostomus britskii, $N$. limatus, N. marilynae e N. nitidus. Em Copeina e nas demais espécies de Nannostomus, inclusive $N$. harrisoni (examinado por Weitzman, 1964 e Lucena, 1993) e $N$. unifasciatus (examinado por Buckup, 1998). Na figura 02 do estudo de Weitzman (1964), este indica o extra-escapular de N. harrisoni, entretanto, o osso ilustrado é, na verdade, o pós-temporal. De acordo com a topologia obtida, a perda do extra-escapular em Nannostomus ocorreu ao menos duas vezes de modo independente da ocorrida no clado 100. A proposta da ausência do extra-escapular como uma característica diagnóstica do grupo constituído pelos gêneros Copeina, Copella, Pyrrhulina e Nannostomus, os Pyrrhulinini, torna-se inválida.

94. Face ventral do pós-temporal (Lucena, 1993: 92; Buckup, 1998: 53; Zanata \& Vari, 2005: 130; Netto-Ferreira, 2006: 164) - CI=0.50; RI=0.92.

(0) Com um distinto processo derivado da ossificação do ligamento que conecta este osso ao pterótico (Weitzman, 1962: fig. 19; Roberts, 1969: fig. 48, 51 e 52; Oyakawa, 1998: fig. 37; Campanario, 2000: fig. 43); (1) com um diminuto processo derivado da 
ossificação do ligamento que conecta este osso ao pterótico; (2) sem tal processo, ligamento não ossificado (Weitzman, 1964: fig. 10; Roberts, 1974: fig. 76).

Weitzman (1964) observou que na tribo Pyrrhulinini (=Pyrrhulininae sensu Weitzman \& Cobb, 1975) o processo médio-ventral do pós-temporal está ausente. Na maioria dos demais Characiformes examinados no presente estudo, este processo está presente. Entretanto, no clado 69 o processo médio-ventral do pós-temporal também está ausente.

95. Margem póstero-ventral do cleitro (Lucena, 1993: 88; Oyakawa, 1998: 81; Buckup, 1998: 57; Netto-Ferreira, 2006: 165) - CI=0.50; RI=0.93.

(0) Margem do cleitro entalhada próximo à nadadeira peitoral; margem ventral do entalhe formando um distinto processo (Buckup, 1998: fig. 04); (1) margem do cleitro convexa (Weitzman, 1962: fig. 18; Buckup, 1998: fig. 04).

Buckup (1998) observou que a margem posterior do cleitro de Charax, Cynopotamus e Phenacogaster apresenta um entalhe e que a margem ventral deste entalhe forma um distinto processo. Oyakawa (1998), por sua vez, observou que Acestrorhynchus, Ctenoluciidae, Hepsetus e Nannostomus apresentam uma "depressão na região póstero-inferior do cleitro". A “depressão" citada por Oyakawa (1998) representa uma condição semelhante à de Phenacogaster, ilustrada por Buckup (1998). A ausência deste entalhe representa uma sinapomorfia do clado 67, revertida em Nannostomus.

96. Pós-cleitro 2 (Lucena, 1993: 89; Vari, 1995: 65; Secioso, 1997, A5; Buckup, 1998: 58; Zanata, 2000: 60; Zanata \& Vari, 2005: 133; Netto-Ferreira, 2006: 168).

(0) Presente (Weitzman, 1962: fig. 19; Weitzman, 1964: fig. 10; Roberts, 1969: fig. 51 e 52; Roberts, 1974: fig. 76; Oyakawa, 1998: fig. 37); (1) ausente (Roberts, 1969: fig. 51 e 53).

O pós-cleitro 2 está ausente em Hepsetus, Ctenolucius e Boulengerella lateristriga e B. maculata. Entre os Lebiasinidae este osso está ausente também nos representantes do gênero Copella e em Pyrrhulina sp. "Tapajós" e P. vitatta. 
97. Pós-cleitro 3 (Lucena, 1993: 90; Vari, 1995: 64; Secioso, 1997, A5; Buckup, 1998: 59; Zanata, 2000: 60; Zanata \& Vari, 2005: 134; Netto-Ferreira, 2006: 169) - CI= $0.25 ; \mathrm{RI}=0.85$.

(0) Presente (Weitzman, 1962: fig. 19; Weitzman, 1964: fig. 10; Roberts, 1969: fig. 51 e 52; Roberts, 1974: fig. 76; Oyakawa, 1998: fig. 37) (1) ausente (Roberts, 1969: fig. 51 e 53).

Assim como o pós-cleitro 2, o pós-cleitro 3 está ausente em Hepsetus e todos os Ctenoluciidae. Buckup (1998) observou que os representantes do gênero Pyrrhulina apresentam apenas dois elementos pós-cleitrais, sendo que o mais inferior deles não apresenta um elemento em forma de espinho. Desta maneira, Buckup (1998) concluiu que o elemento faltante seria o pós-cleitro 3. Esta condição foi observada em todos os representantes de Pyrrhulina examinados. Além de Pyrrhulina, o pós-cleitro 3 está ausente também nos Lebiasininae do clado 74 e Lebiasina festae.

98. Moldura do forame escapular (Secioso, 1997, S13; Netto-Ferreira, 2006: 172) $-\mathrm{CI}=0.20 ; \mathrm{RI}=0.78$.

(0) Totalmente ossificada (Secioso, 1997: fig. 17); (1) com uma porção cartilaginosa entre a escápula e o cleitro (Secioso, 1997: fig. 15).

Secioso (1997) observou que a porção anterior da escápula que forma a moldura do forame escapular está ausente em Erythrinidae, assim, o forame é delimitado pela escápula e o cleitro. Secioso (1997) sugere que esta condição seria exclusiva dos Erythrinidae, entretanto, a ausência da porção anterior da moldura escapular foi observada também Pyrrhulininae. Esta condição representa uma sinapomorfia de Erythrinidae + Lebiasinidae, secundariamente revertida em L. bimaculata e no clado 78.

99. Margem póstero-ventral do coracóide (Netto-Ferreira, 2006: 174) - $\mathrm{CI}=0.33$; $\mathrm{RI}=0.90$.

(0) Truncada (Roberts, 1969: fig. 51); (1) com uma discreta projeção; (2) apresentando um distinto processo direcionado posteriormente.

$\mathrm{Na}$ maioria dos grupos examinados, a porção póstero-ventral do coracóide apresenta um distinto processo direcionado posteriormente, que se encontra variavelmente desenvolvido. Na maioria dos Lebiasininae, porém, o coracóide não apresenta tal processo, sendo sua porção posterior arredondada. Em Lebiasina uruyensis 
e no clado 74, esta condição encontra-se revertid, no entanto, o processo posterior é distintamente mais curto que nos demais Characiformes que o apresentam, condição similar à observada em Derhamia. Devido à redução do coracóide em Erythrinidae, não foi possível codificar a condição em Hoplerythrinus, atribuindo assim a codificação “?”.

100. Forame na região média do coracóide, próximo ao mesocoracóide (Lucena, 1993: 85; Oyakawa, 1998: 82; Netto-Ferreira, 2006: 175) - CI=0.17; RI=0.82.

(0) Presente (Weitzman, 1962: fig. 20; Lucena, 1993: fig. 10; Buckup, 1998: fig. 03; Campanario, 2000: fig. 43); (1) ausente (Roberts, 1969: fig. 51).

$\mathrm{Na}$ maioria dos grupos examinados, o coracóide apresenta um forame, quase adjacente à área de articulação com o mesocoracóide. Oyakawa (1998) codificou como "ausente" o forame da região média do coracóide de Hepsetus odoe. Roberts (1969, fig. 48), por sua vez, ilustra a cintura peitoral de Hepsetus, onde o forame médio do coracóide é representado. No presente estudo, a presença do forame foi observada neste táxon. A ausência do forame representa uma sinapomorfia ambígua de Pyrrhulininae

101. Espaço delimitado pelo coracóide e o cleitro (Lucena, 1993: 82; Secioso, 1997, N3; Buckup, 1998: 56; Oyakawa, 1998: 83; Campanario, 2000: 66; NettoFerreira, 2006: 176) $-\mathrm{CI}=0.25 ; \mathrm{RI}=0.40$.

(0) Presente (Weitzman, 1962: fig. 19; Weitzman, 1964: fig. 10; Roberts, 1969: fig. 48,50 e 52; Roberts, 1974: fig. 74; Buckup, 1998: fig. 03A); (1) estreito ou ausente (Roberts, 1969: fig. 51; Buckup, 1998: fig. 03B; Campanario, 2000: fig. 43).

$\mathrm{Na}$ cintura peitoral da maioria dos Characiformes ocorre um hiato na articulação entre o cleitro e o coracóide. Em Erythrinidae e Crenuchidae, este espaço está ausente. Secioso (1997) afirma que o espaço inter-ósseo pode estar presente ou ausente em indivíduos de uma mesma população, entretanto, o material examinado no presente estudo, em todos os indivíduos o espaço está ausente. Campanario (2000) codifica o estado "presente" para Hoplias sp., possivelmente um erro de codificação. Assim como nos demais Characiformes, o espaço inter-ósseo entre o cleitro e o coracóide é amplo na maioria das espécies de Lebiasinidae. Porém, conforme observado por Weitzman (1964), o espaço inter-ósseo está ausente ou muito reduzido em Nannostomus harrisoni, condição também observada no presente estudo. Tal espaço também encontra-se muito reduzido ou ausente nos clados 115 e 124 . 
102. Radial proximal 4 (Netto-Ferreira, 2006: 177 ) $-\mathrm{CI}=1.00 ; \mathrm{RI}=1.00$.

(0) Tão largo quanto os radiais 2 e 3 (Weitzman, 1962: fig. 19; Weitzman, 1964: fig. 10; Roberts, 1969: fig. 48,50 a 52; Roberts, 1974: fig. 74; Buckup, 1998: fig. 03A); (1) mais largo que os radiais 2 e 3; quase tão largo quanto o radial 1.

$\mathrm{Na}$ maioria dos grupos examinados no presente estudo, o radial proximal 4 apresenta-se tão largo quanto os radiais proximais 2 e 3 , sendo muito estreito e curto em Acestrorhynchus, Ctenoluciidae e Hepsetus, freqüentemente não contatando diretamente o cleitro ou o coracóide. Em Copeina, Copella e Pyrrhulina, o radial proximal 4 é expandido lateralmente, apresentando largura semelhante à do radial proximal 1, uma sinapomorfia exclusiva do grupo.

103. Número de raios ramificados da nadadeira peitoral (Campanario, 2000: 69 modificado; Netto-Ferreira, 2006: 179) $-\mathrm{CI}=0.20 ; \mathrm{RI}=0.50$.

(0) 15 ou mais (Weitzman, 1962: fig. 20; Roberts, 1969: fig. 48, 50 a 52); (1) menos de 15 raios ramificados (Weitzman, 1964: fig. 10; Roberts, 1974: fig. 76; Campanario, 2000: fig. 43).

A nadadeira peitoral de Acestrorhynchus, Chalceus, Ctenoluciidae, Erythrinidae, Hepsetus e Xenocharax a nadadeira peitoral apresenta mais de 15 raios ramificados. Na maioria dos Lebiasinidae, por sua vez, a nadadeira peitoral apresenta menos de 15 raios ramificados, condição revertida em Lebiasina sp. "Parima", L. yuruaniensis, L. aureogutatta e L. sp. “Azuay”.

\section{Sistema látero-sensorial}

(Figuras 03-18; 39-45)

104. Canal sensorial do maxilar (Zanata, 2000: 50; Zanata \& Vari, 2005: 75; NettoFerreira, 2006: 182) $-\mathrm{CI}=0.17 ; 0.61$.

(0) Restrito à metade anterior do osso (Campanario, 2000: fig 24); (1) estendendo-se por grande parte do osso (Roberts, 1969: fig 02).

Diferentemente dos demais ramos do sistema látero-sensorial, o canal presente no maxilar dos Characiformes não forma um distinto tubo ósseo com duas distintas extremidades abertas não apresentando tampouco poros ao longo do tubo. Menezes (1976) sugere que o canal do maxilar não apresenta função sensorial como os demais 
canais, mas serve de passagem para nervos e vasos. Na maioria dos táxons examinados, o canal do maxilar é representado principalmente por sulcos na superfície látero-anterior do osso, com a porção mais basal podendo apresentar um aspecto tubular, ainda que na maioria dos casos, o "tubo" não se encontre fechado. Na porção médio-posterior, no entanto, o canal é representado apenas por diminutos sulcos ou poros onde os neuromastos isolados afloram. Em Lebiasinidae, o canal do maxilar encontra-se restrito à porção anterior do osso na maioria dos táxons examinados. Esta condição aparentemente representa o padrão plesiomórfico da ordem e é compartilhadao com Crenuchidae, Anostomoidea e Xenocharax. O canal está ausente nos exemplares de Hemiodus e Apareiodon examinados. A condição observada em Nannostomus é bastante similar à destes dois táxons, porém, o maxilar de todos os representantes do gênero apresentam sempre um pequeno poro ou sulco, por onde passa um neuromasto ou canal. Em todos os demais táxons examinados, o canal do maxilar estende-se por grande parte do osso.

105. Ramo nasal do sistema látero-sensorial (Oyakawa, 1998: 04; Netto-Ferreira, 2006: 183$)-\mathrm{CI}=1.00 ; \mathrm{RI}=1.00$.

(0) Incluído no osso nasal (Weitzman, 1962: fig. 02; Weitzman, 1964: fig. 02; Roberts, 1969: fig. 06 a 08 e 10; Oyakawa, 1998: fig 16, 17, 18A, 19 e 20); (1) não incluído no osso nasal (Oyakawa, 1998: fig. 19B).

Conforme mencionado anteriormente, o nasal porta a porção mais anterior do canal látero-sensorial cefálico (Vari, 1995) da maioria dos Characiformes, uma vez que em Acestrorhynchus o canal se estende ainda mais anteriormente, alcançando os prémaxilares. Nos representantes do gênero Copella, o ramo nasal do canal látero-sensorial não está envolto pelos nasais (Oyakawa, 1998) e é representado por uma linha de neuromastos que percorre a margem medial do nasal. Desta forma, o nasal de Copella corresponde apenas à porção lamelar do osso. A redução do nasal em C. compta, C. nigrofasciata e C. nattereri parece estar relacionada à perda deste ramo do canal sensorial.

106. Ramo parietal do canal látero-sensorial supra-orbital no frontal e no parietal (Vari, 1995: 27; Secioso, 1997: S2; Buckup, 1998: 16; Zanata \& Vari, 2005: 156; Netto-Ferreira, 2006: 185) $-\mathrm{CI}=0.67 ; \mathrm{RI}=0.95$. 
(0) Presente, um ramo do canal supra-orbital se estende da área pós-orbital, atravessando os parietais (Weitzman, 1962: fig. 09; Roberts, 1969: fig 08 e 10; Roberts, 1974: fig. 56; Oyakawa, 1998: fig 16, 17 e 20B; Campanario, 2000: fig. 13); (1) não alcançando os parietais (Roberts, 1969: fig. 06 e 07; Oyakawa, 1998: fig 20A); (2) ausente (Weitzman, 1964: fig. 02; Oyakawa, 1998: fig 18 e 19).

O ramo supra-orbital do canal látero-sensorial cefálico origina-se na região posterior dos frontais a partir do canal pterótico e apresenta quatro porções. $\mathrm{O}$ ramo nasal, situado mais anteriormente, o ramo epifiseano, situado dorsalmente à barra epifiseana, um ramo que se comunica com o ramo anterior do canal do infra-orbital 6 e por último, o ramo parietal, que se estende posteriormente, em direção ao parietal. Na maioria dos Characiformes, o ramo parietal do canal supra-orbital estende-se posteriormente sobre os parietais e se liga ao canal supra-temporal. Em Lebiasininae e Derhamia, o ramo parietal é curto e nunca se estende posteriormente, alcançando os parietais. Condição semelhante está presente em Ctenoluciidae e Hepsetidae, apesar de nesses grupos o ramo parietal do canal supra-orbital, ser distintamente mais desenvolvido do que em Lebiasininae e Derhamia, e terminando próximo ao limite entre o frontal e o parietal. Além disto, nestes grupos, o canal direciona-se ao pterótico. Vari (1995) já havia observado tal modificação em Hepsetus odoe, entretanto, considerou-a não homóloga à condição observada em Ctenoluciidae, uma vez que o ramo em Hepsetus seria mais desenvolvido. Nos demais gêneros de Lebiasinidae o ramo parietal do canal supra-orbital está ausente. Em alguns exemplares observa-se um poro em posição semelhante àquela por onde o ramo parietal se origina, porém, nestes casos, o ramo foi considerado ausente, por não haver ramificação do canal. Nos demais táxons examinados, o ramo parietal se estende sobre os parietais e, exceto em Erythrinidae, este ramo se liga ao canal supra-temporal.

107. Canal látero-sensorial no antorbital (Zanata, 2000: 01; Netto-Ferreira, 2006: 186) $-\mathrm{CI}=0.50 ; \mathrm{RI}=0.98$.

(0) Ausente (Weitzman, 1962: fig. 02; Weitzman, 1964: fig 02; Roberts, 1969: fig 01, 04 e 05; Campanario, 2000: fig. 21 a 23); (1) presente, contínuo ao canal látero-sensorial do primeiro infra-orbital.

Tipicamente, o canal látero-sensorial da série circum-orbital dos Characiformes encontra-se envolto por um tubo ósseo dos óssos da série circum-orbital, não se 
estendendo ao antorbital. Zanata (2000), entretanto, constatou a presença de estrias ou resquícios do canal no antorbital de Salminus e algumas espécies de Brycon, e sugeriu que em Bryconops e Crenuchus spilurus, o canal látero-sensorial do infra-orbital 1 se estenderia até o antorbital. No material de C. spilurus examinado, o antorbital apresenta um rugosidades e pequenos poros na face externa. Entretanto, o canal sensorial do infraorbital 1 termina em um poro situado anteriormente ao antorbital, diferente, portanto, da condição observada por Zanata (2000). No presente estudo, o único grupo que apresenta condição semelhante à descrita por Zanata (2000) são os Lebiasininae (exceto $L$. ortegai). Entretanto, a porção do canal sensorial no antorbital dos Lebiasininae é representada por uma depressão sobre a qual o canal se estende e termina em um poro. Ao contrário do afirmado por Weitzman (1962 e 1964), não foi observada a ocorrência de canal látero-sensorial em representantes do gênero Nannostomus, mas apenas pequenos poros em poucos exemplares (Fig. 10).

108. Canal sensorial do infra-orbital 1 (Netto-Ferreira, 2006: 187) $\mathrm{CI}=0.50 ; \mathrm{RI}=$ 0.87 .

(0) Totalmente envolto pelo osso (Weitzman, 1962: fig. 09; Weitzman, 1964: fig. 06; Roberts, 1969: fig 01 a 05; Roberts, 1974: fig. 61 e 62; Vari, 1995: fig 01) (1) parcialmente envolto, ou totalmente excluído da lamela óssea.

Entre os representantes de Lebiasinidae examinados no presente estudo, a maioria dos táxons apresenta o canal totalmente envolto pela lamela óssea do infraorbital 1. Apenas nos representantes do gênero Copella o tubo ósseo não envolve o sistema sensorial da série circumorbital, que formam pit lines assim como os observados sobre o nasal. Entre os demais Characiformes examinados, todos apresentam o canal sensorial totalmente envolto pelo infra-orbital 1.

109. Canal látero-sensorial do infra-orbital 2 (Netto-Ferreira, 2006: 188) - CI= $0.20 ; \mathrm{RI}=0.78$.

(0) Totalmente incluído no osso (Weitzman, 1962: fig. 09; Weitzman, 1964: fig. 06; Roberts, 1969: fig 01 a 05; Vari, 1995: fig 01); (1) parcialmente envolto, ou totalmente excluído da lamela óssea.

O canal látero-sensorial da maioria das espécies de Nannostomus encontra-se excluído da porção lamelar do infra-orbital 2, que pode apresentar uma pequena 
depressão próximo à área de contato com o infra-orbital 1. Em representantes de $N$. eques, N. harrisoni e N. unifasciatus, no entanto, o canal encontra-se totalmente incluído na lamela óssea. A inclusão do canal sensorial do infra-orbital 2 na lamela óssea era considerada diagnóstica do gênero Poecilobrycon (=Nannostomus), juntamente com o comprimento do focinho, correspondendo entre 0,8 e 1,2 vezes ao diâmetro da órbita (Weitzman, 1966). Apesar de Weitzman (1966) sugerir que o canal estaria inserido na lamela óssea do infra-orbital 2 nos representantes da subtribo Pyrrhulinina (=Pyrrhulinini sensu Weitzman \& Cobb, 1975), o canal sensorial do infraorbital 2 está ausente também nos representantes dos gêneros Copella, bem como nos demais elementos circumorbitais.

110. Canal sensorial do infra-orbital 3 (Netto-Ferreira, 2006: 189) $-\mathrm{CI}=1.00$; $\mathrm{RI}=$ 1.00 .

(0) Totalmente incluído no osso (Weitzman, 1962: fig. 09; Roberts, 1969: fig 01 a 05; Roberts, 1974: fig. 61 e 62; Vari, 1995: fig 01); (1) parcialmente envolto, ou totalmente excluído da lamela óssea (Weitzman, 1964: fig. 06).

O tubo ósseo por onde passa o canal sensorial no infra-orbital 3 está ausente em todos os Pyrrhulininae. Em todos os exemplares examinados ocorrem projeções ósseas que estão em contato com a borda dorsal do sistema sensorial, entretanto, em nenhum dos casos estas projeções o envolvem, nem ao menos parcialmente. Nestes táxons o sistema sensorial é representado por pelo menos uma série de neuromastos expostos, situados muito proximamente entre si. Em Copeina, ocorrem múltiplas séries de neuromastos no sulco formado no IO3 para passagem do "canal".

111. Canal sensorial do Infra-orbital 4 (Netto-Ferreira, 2006: 190) $-\mathrm{CI}=0.50$; $\mathrm{RI}=$ 0.97 .

(0) Totalmente incluído no osso (Weitzman, 1962: fig. 09; Roberts, 1969: fig 01 a 05; Roberts, 1974: fig. 61 e 62); (1) parcialmente envolto, ou totalmente excluído da lamela óssea (Weitzman, 1964: fig. 08).

Assim como o IO3, o infra-orbital 4 da maioria dos Pyrrhulininae (exceto Copeina) não envolve completamente o sistema sensorial. Esta condição representa uma sinapomorfia da subfamília, revertida em Copeina. 
112. Canal sensorial do infra-orbital 5 (Netto-Ferreira, 2006: 191$)-C I=0.50 ; R I=$ 0.97 .

(0) Totalmente incluído no osso (Weitzman, 1962: fig. 09; Roberts, 1969: fig 01 a 05; Roberts, 1974: fig. 61 e 62; Vari, 1995: fig 01); (1) parcialmente envolto, ou totalmente excluído da lamela óssea (Weitzman, 1964: fig. 06).

A formação do tubo ósseo por onde passa o canal sensorial no infra-orbital 5 se comporta de maneira muito semelhante à formação do mesmo no IO4. Ver discussão acima.

113. Canal sensorial do infra-orbital 6 (Netto-Ferreira, 2006: 192) $-\mathrm{CI}=1.00 ; \mathrm{RI}=$ 1.00 .

(0) Totalmente incluído no osso (Weitzman, 1962: fig. 09; Roberts, 1969: fig 01 a 05; Roberts, 1974: fig. 61 e 62; Vari, 1995: fig 01); (1) parcialmente incluído, ou totalmente excluído.

Conforme mencionado anteriormente, Weitzman (1964) propõe a ausência do canal sensorial do dermosfenótico (= infra-orbital 6) como uma característica diagnóstica da tribo Pyrhulinini (= Pyrrhulininae sensu Weitzman \& Cobb, 1975). Entretanto, os representantes de Copeina, Copella e Pyrrhulina não apresentam o infraorbital 6 (Fig. 05 a 07). Desta forma, foi atribuída a codificação incomparável aos representantes dos gêneros Copeina, Copella e Pyrrhulina. O canal do infra-orbital 6 está envolto pela tubo ósseo nos Lebiasininae e todos os demais Characiformes examinados, exceto em Derhamia e Nannostomus.

114. Ramo póstero-dorsal do canal látero-sensorial do infra-orbital 6 (Vari, 1995: 15; Netto-Ferreira, 2006: 193) $-\mathrm{CI}=1.00 ; \mathrm{RI}=1.00$.

(0) Presente (Weitzman, 1962: fig. 09; Roberts, 1969: fig 01 a 05; Roberts, 1974: fig. 61 e 62; Vari, 1995: fig 01 A e B); (1) ausente (Vari, 1995: fig. 01C).

O canal látero-sensorial do infra-orbital 6 encontra-se tripartido na maioria dos Characiformes, onde o ramo direcionado anteriormente se conecta com o canal supraorbital, um ramo orientado posteriormente, que se conecta ao pterótico e o ventral que se conecta com o canal do infra-orbital 5 (Vari, 1995). Vari (1995) observou também que em Boulengerella lateristriga e B. maculata o canal do infra-orbital 6 apresenta-se bipartido, com apenas um ramo orientado dorsalmente e sugere que este seria homólogo 
ao ramo anterior, uma vez que este se conecta ao ramo supra-orbital do canal láterosensorial. No entanto, o canal observado nestas duas espécies de Boulengerella é um tanto incomum, uma vez que o mesmo é orientado posteriormente, enquanto que o ramo anterior do canal de todos os demais Characiformes é direcionado anteriormente. Desta maneira, considerou-se aqui que o ramo observado em B. lateristriga e B. maculata representa o ramo posterior do canal sensorial e não o anterior. É interessante ressaltar que o canal do pterótico é curto em ambas espécies, permanece restrito àquele osso, o que poderia ter levado a um rearranjo da conexão do canal do IO6 com o ramo supraorbital. A perda do ramo posterior do IO6 foi observada observada apenas em Lebiasininae, Derhamia e Nannostomus. No caso de Copeina, Copella e Pyrrhulina, foi atribuída a condição incomparável, devido à ausência do IO6.

115. Ramo supra-orbital do canal látero-sensorial cefálico $-\mathrm{CI}=0.31 ; \mathrm{RI}=0.75$.

(0) Tubo ósseo estendendo-se desde os nasais, alcançando o ramo que percorre os infraorbitais e o ramo pterótico; (1) tubo ósseo ultrapassando a barra epfiseana, mas não alcançando os infra-orbitais posteriormente; (2) tubo ósseo estendendo-se desde os nasais até o "ramo epifisiano"; (3) tubo ósseo não alcançando a barra epifisiana; (4) tubo ósseo ausente.

Conforme mencionado anteriormente, o canal supra-orbital origina-se na porção posterior do frontal, próximo à articulação com o pterótico, e se estende até a margem anterior do osso, próximo ao contato com o nasal. Tal condição está presente na maioria dos Characiformes examinados. Em Nannostomus e Copella, no entanto, o ramo supraorbital encontra-se variavelmente encurtado, geralmente restrito à região da barra epifiseana em ambos os grupos, porém podendo estar ainda mais curtos, podendo o tubo ósseo estar ausente (e. g. Copella nattereri). Em ambos os gêneros, as áreas expostas do canal supra-orbital apresentam linhas de neuromastos expostos. Tal característica parece estar associada com o processo de miniaturização que parecer ocorrer em ambos os grupos. 
116. Anastomose dos canais supra-orbital e pterótico (Lucena, 1993: 14; Vari, 1995: 28; Secioso, 1997: P3; Buckup, 1998: 11; Campanario, 2000: 11; Netto-Ferreira, 2006: 194$)-\mathrm{CI}=0.33 ; \mathrm{RI}=0.50$.

(0) Canal supra-orbital conectado ao canal pterótico; (1) porções do canal supra-orbital e do canal pterótico não conectadas entre si.

Lucena (1993), Vari (1995), Secioso (1997), Buckup (1998) e Campanario (2000) observaram que apesar de diversos grupos de Characiformes apresentarem o canal supra-orbital conectado ao canal pterótico, esta conexão poderia não ocorrer em alguns grupos. Entre os táxons examinados, o canal supra-orbital e canal pterótico não estão conectados em Ctenoluciidae, Erythrinidae e Hepsetus. Foi atribuída a codificação incomparável aos representantes de Nannostomus (exceto $N$. trifasciatus e $N$. unifasciatus que apresentam o canal do pterótico), Copella e Pyrrhulina, devido à ausência do canal pterótico neste grupo.

117. Canal pterótico (Vari, 1995: 28; Buckup, 1998: 14 - modificado; Zanata \& Vari, 2005: 159 - modificado; Netto-Ferreira, 2006: 195) - CI=0.43; RI=0.87.

(0) Ausente (Weitzman, 1964: fig 02); (1) restrito ao pterótico (Vari, 1995: fig. 05); (2) atingindo o canal supra-orbital (Weitzman, 1962: fig. 09); (3) atingindo o ramo posterior do canal do infra-orbital 6 (Roberts, 1969: fig. 03).

A ausência de um ramo do canal látero-sensorial passando pelo pterótico foi proposta por Weitzman (1964) como uma característica compartilhada pelos Pyrrhulininae (sensu Weitzman \& Cobb, 1975). Entretanto, representantes do gênero Copeina examinados no presente estudo apresentam um ramo do canal látero-sensorial no pterótico conectado ao canal supra-orbital, condição que ocorre também em Lebiasininae e Derhamia. Conforme mencionado anteriormente, este estado de caráter parece estar relacionada à perda do ramo posterior do infra-orbital 6, onde o ramo do pterótico se liga na maioria dos demais Characiformes.

118. Canal pterótico-pré-operculo-mandibular (Netto-Ferreira, 2006: 196) - CI= $0.50 ; \mathrm{RI}=0.50$.

(0) Presente; (1) ausente.

A maioria dos táxons examinados apresenta um ramo do canal sensorial que conecta o canal pterótico ao canal pré-opérculo-mandibular, o canal pterótico-pré- 
opérculo-mandibular. Quando presente, este canal encontra-se geralmente envolto pelo tubo ósseo denominado supra-pré-opérculo. Em Alestidae, Hemiodontidae e Parodontidae, no entanto, este tubo ósseo está ausente. Os Lebiasinidae, bem como os Crenuchidae, Ctenoluciidae e Erythrinidae, além de não apresentarem o supra-préopérculo*, também não apresentam o canal pterótico-pré-opérculo-mandibular. Esta condição representa uma sinapomorfia adquirida independentemente no clado 67 e em Ctenoluciidae.

* - Ainda que os Erythrinidae e Hepsetidae apresentem um osso dérmico de homologia incerta localizado dorsalmente ao pré-opérculo, considerou-se aqui que tal ossificação em Erythrinidae seja o supra-opérculo descrito por Vari (1995) e Oyakawa (1998), já que o grupo não apresenta o canal pterótico-pré-opérculo-mandibular.

119. Canal supratemporal (Lucena, 1993: 19; Vari, 1995: 29; Oyakawa, 1998: 26; Zanata \& Vari, 2005: 158; Netto-Ferreira, 2006: 198) - CI=0.50; RI=0.97.

(0) As duas contrapartes se contatando na porção sagital do crânio, onde se abre um poro (Weitzman, 1962: fig. 09; Roberts, 1969: fig 06 a 10; Roberts, 1974: fig. 56; Oyakawa, 1998: fig. 16, 17 e 20); (1) curto, contrapartes não se contatando; (2) ausente (Weitzman, 1964: fig. 02; Oyakawa, 1998: fig. 18 e 19).

O ramo parietal do canal supratemporal nos Pyrrhulininae (sensu Weitzman \& Cobb, 1975) encontra-se ausente na maioria das espécies, exceto em Copeina guttata. Nos representantes deste táxon, apesar de presente, o ramo parietal do canal supratemporal é curto, restrito a um par de pequenos canais que terminam em um poro antes de encontrar suas contrapartes. Condição semelhante à observada em C. guttata ocorre em Boulengerella lateristriga. Em todos os demais táxons examinados o ramo parietal do canal supra-temporal atravessa os parietais e as duas contrapartes estão conectadas, ou pelo menos, quase alcançando o limite entre os parietais. A perda do canal supratemporal em Pyrrhulinini é dependente de otimização, podendo ter ocorrido independentemente em Nannostomus e em (Copella + Pyrrhulina) uma vez que em Copeina o canal está presente, ainda que reduzido. Ou a perda do canal é homóloga se o canal presente em Copeina ser considerado análogo ao observado nos demais Characiformes. 
120. Posição do canal supratemporal (Oyakawa, 1998: 23; Netto-Ferreira, 2006: 199) $-\mathrm{CI}=1.00 ; \mathrm{RI}=1.00$.

(0) Transversalmente na margem posterior dos parietais (Weitzman, 1962: fig. 09; Roberts, 1969: fig 06 a 10; Roberts, 1974: fig. 56; Oyakawa, 1998: fig. 16, 17 e 20B); (1) transversalmente na região média dos parietais (Oyakawa, 1998: fig. 19B e 20A).

O ramo do canal látero-sensorial supratemporal, que se origina no extraescapular, atravessa transversalmente a porção média dos parietais em Lebiasininae, Copeina e Derhamia, diferentemente dos demais Characiformes, onde o canal atravessa a porção posterior do parietal, próximo à articulação com o supra-occipital. Tal condição parece estar associada ao padrão de escamação da cabeça dos Lebiasinidae, onde as escamas da região dorsal da cabeça se estendem anteriormente até o meio dos parietais, bem como a grande porção do osso coberta pela musculatura axial. Devido à ausência do canal nos demais Lebiasinidae, foi atribuída a estes a codificação “-”.

121. Canal látero-sensorial no extra-escapular (Lucena, 1993: 19 - modificado; Buckup, 1998: 17 - modificado; Netto-Ferreira, 2006: 200) - CI= 0.50; RI=0.86.

(0) Presente (Weitzman, 1962: fig. 19; Roberts, 1969: fig. 48 e 51; Oyakawa, 1998: fig. 37; Campanario, 2000: fig. 43); (1) ausente.

O canal sensorial no extra-escapular da maioria dos táxons examinados conectase ao canal pterótico, supratemporal e também ao canal do pós-temporal. Entre os Lebiasinidae o canal do extra-escapular está presente apenas nos Lebiasininae e Derhamia. Em Copeina, apesar de estarem presentes os ramos parietal e pterótico, o canal látero-sensorial do extra-escapular está ausente. Em todos os representantes do gênero Nannostomus que apresentam o extra-escapular, o canal também está ausente. Nos demais gêneros, o extra-escapular está ausente, por isso, a estes táxons, foi atribuída a codificação incomparável.

122. Ramo do canal látero-sensorial no pós-temporal (Oyakawa, 1998: 79 modificado; Zanata \& Vari, 2005: 160; Netto-Ferreira, 2006: 201 - modificado) - CI= $0.50 ; \mathrm{RI}=0.97$.

(0) presente, conectando o canal do extra-escapular ao do supra-cleitro (Roberts, 1969: fig. 48 e 51; Roberts, 1974: fig. 76; Oyakawa, 1998: fig. 37; Campanario, 2000: fig. 43). (1) ausente (Weitzman, 1964: fig 10). 
O pós-temporal da maioria dos Characiformes apresenta um ramo do canal sensorial que se conecta ao extra-escapular anteriormente e ao supra-cleitro ventralmente. Em Pyrrhulinini, por sua vez, o ramo do canal sensorial no pós-temporal está ausente. Em Hoplerythrinus, diferentemente do proposto por Oyakawa (1998), o pós-temporal não apresenta um poro por onde o canal do extra-escapular se conecta com o do supra-cleitro a conexão entre os dois ramos ocorre diretamente, sem participação do pós-cleitro. Por isso, foi atribuído o estado “2” para este táxon.

123. Ramo do canal látero-sensorial no supra-cleitro (Lucena, 1993: 91; Buckup, 1998: 54; Zanata \& Vari, 2005: 161; Netto-Ferreira, 2006: 202)- CI= 0.50; RI=0.97.

(0) Presente (Roberts, 1969: fig.51; Oyakawa, 1998: fig. 37; Campanario, 2000: fig. 43); (1) ausente (Weitzman, 1974: fig. 10).

O ramo do canal sensorial do supra-cleitro está ausente em Copella, Nannostomus e Pyrrhulina. Em Copeina o canal sensorial do supra-cleitro é representado por um ramo muito curto com um poro. Na porção superior do supracleitro de Nannostomus, é possível observar, por meio de luz transmitida, uma área oca em posição semelhante à do canal do supra-cleitro de Derhamia e dos Lebiasininae. Assim como a perda do canal supra-temporal, a perda do canal do supra-cleitro em Pyrrhulinini é dependente de otimização, onde a perda pode ter ocorrido independentemente em Nannostomus e (Copella + Pyrrhulina), ou a perda do canal teria ocorrido uma única vez e a condição observada em Copeina não seria homóloga à dos demais Characiformes.

124. Canal sensorial do supra-cleitro (Oyakawa, 1998: 80; Netto-Ferreira, 2006: 203) $-\mathrm{CI}=0.50 ; \mathrm{RI}=0.75$.

(0) Simples, com um canal conectando o sistéma látero-sensorial cefálico à linha lateral (Campanario, 2000: fig. 43); (1) bifurcado, com um pequeno ramo maior percorrendo a porção anterior, em direção à extremidade inferior e um ramo menor situado posteriormente (Oyakawa, 1998: fig. 37).

Oyakawa (1998) observou que os Erythtrinidae e os Lebiasininae apresentam o ramo do canal sensorial do supra-cleitro bifurcado, com um ramo curto situado posteriormente, percorrendo a porção anterior do osso e terminando em um poro, enquanto que o outro ramo estende-se ventralmente e está conectado à linha lateral. Tal 
condição também está presente em Derhamia enquanto que Copeina apresenta a condição generalizada dos Characiformes (canal simples), confirmando a observação de Oyakawa (1998), que sugere também que a condição observada nos Pyrrhulininae (= Pyrrhulinini do presente estudo) seria semelhante à observada em Acestrorhynchus, Ctenoluciidae e Hepsetus odoe.

125. Linha lateral (Vari, 1995: 72; Oyakawa, 1998: 95; Zanata, 2000: 125 modificado; Campanario, 2000: 80 - modificado; Zanata \& Vari, 2005: 162; NettoFerreira, 2006: 204) $-\mathrm{CI}=0.67$; $\mathrm{R}=0.95$.

(0) Completa; (1) curta, restrita à porção anterior do corpo; (2) sem escamas perfuradas.

Em todas as espécies de Lebiasinidae a linha lateral encontra-se reduzida se comparada à da maioria dos Characiformes, que apresentam a linha lateral se estendendo desde a cintura peitoral até a nadadeira caudal. Em Lebiasininae, Copeina, Derhamia e Nannostomus a linha lateral é representada por três a sete escamas perfuradas (Weitzman \& Weitzman, 2003), sendo que as espécies de Pyrrhulina e Copella examinadas não apresentam escamas com poros se abrindo para o meio externo, apesar de apresentar um tubo curto nas duas ou três mais anteriores. Géry \& Zarske (2002), citam espécies não descritas de Lebiasininae (entre elas Lebiasina sp. "Parima") com linha lateral completa, porém, em nenhum dos exemplares examinados foram observadas mais de sete escamas perfuradas na linha lateral.

\section{Aparelho de Weber}

126. Porção médio-distal da parapófise da segunda vértebra $-\mathrm{CI}=0.33$; $\mathrm{RI}=$ 0.60 .

(0) Orientada em direção ao crânio, geralmente ultrapassando a margem anterior da primeira vértebra; (1) transversal ao eixo longitudinal do corpo.

$\mathrm{Na}$ maioria dos táxons examinados, a parapófise da segunda vértebra apresenta um formato retilíneo e encontra-se direcionada anteriormente, geralmente ultrapassando a margem anterior da primeira vértebra. Em Copella compta e as espécies do clado 97, bem como em Hepsetus e Boulengerella lateristriga, a porção médio-distal da parapófise encontra-se flexionada lateralmente, de maneira que esta assume uma orientação transversal em relação ao eixo longitudinal do corpo. 
127. Processo laminar na margem anterior do tripus $-\mathrm{CI}=0.14 ; \mathrm{RI}=0.45$.

(0) Reduzido ou ausente; (1) presente, direcionado transversalmente ao eixo do corpo, estendendo-se da base do tripus ao ponto onde se insere o ligamento que conecta o este osso ao intercalarium.

$\mathrm{Na}$ maioria dos táxons examinados, o tripus apresenta uma projeção lamelar anterior que se estende do ponto onde se insere o ligamento que conecta o tripus ao intercalarium, até a porção proximal do osso. Este processo encontra-se reduzido ou ausente nas espécies de Copeina, Copella do clado 97, nos Nannostomus do clado 123 (revertido em $N$. trifasciatus e $N$. harrisoni) e Pyrrhulina semifasciata e poderia ser considerado uma evidência dos processos de miniaturização no grupo, no entanto, esta condição é observada também em Hepsetus e Boulengerella, espécies de maior porte.

\section{Processo ventral na face mesial da base do processo transformador do tripus} $-\mathrm{CI}=0.50 ; \mathrm{RI}=0.96$.

(0) Ausente; (1) presente.

O tripus apresenta, na maioria dos grupos examinados, um pequeno processo direcionado ventralmente situado na base do processo transformador do osso. Os Pyrrhulininae (exceto Copeina), no entanto, não apresentam tal processo. A perda dessa estrutura representa uma sinapomorfia do grupo revertida secundariamente em Copeina e é proposta aqui como mais um caráter redutivo que evidencia a tendência de miniaturização que ocorre no grupo.

129. Porção lamelar do complexo neural (Lucena, 1993: 77; Buckup, 1998: 48; Netto-Ferreira, 2006: 210) $-\mathrm{CI}=0.33 ; \mathrm{RI}=0.75$.

(0) Estendendo-se posteriormente, dorsalmente ao espinho neural da quarta vértebra (Weitzman, 1962: fig. 12; Weitzman, 1964: fig. 09; Roberts, 1969: fig. 38, 40, 44 e 46; Roberts, 1974: fig. 75; Campanario, 2000: fig. 35); (1) estendendo-se apenas até o arco neural da quarta vértebra (Roberts, 1969: fig. 42).

$\mathrm{Na}$ maioria dos grupos examinados no presente estudo, o complexo neural apresenta uma porção lamelar que se estende posteriormente, em direção ao espinho neural do quarto centro vertebral. $\mathrm{Na}$ maioria dos Lebiasinidae a porção lamelar do complexo neural é muito curta, ou ausente. Esta condição é compartilhada com os Erythrinidae e representa uma sinapomorfia do clado 67. Nas espécies do gênero 
Nannostomus incluídas no clado 122, revertem a condição apomórfica do clado 67 e apresentam a porção lamelar relativamente desenvolvida, estendendo-se posteriormente, conforme ilustrado por Weitzman (1964).

130. Altura do complexo neural do aparelho de Weber (Netto-Ferreira, 2006: 211) $-\mathrm{CI}=1.00 ; \mathrm{RI}=1.00$.

(0) Alongada (Weitzman, 1962: fig. 12; Roberts, 1969: fig. 38, 40, 42, 44 e 46; Roberts, 1974: fig. 75; Campanario, 2000: fig. 35); (1) curta (Weitzman, 1964: fig. 09).

$\mathrm{Na}$ maioria dos grupos examinado, o complexo neural é uma ossificação articulada com o terceiro e quarto arcos neurais e encontra-se alongada anteriormente, em direção ao supra-occipital, com a porção dorsal distintamente mais afilada que a ventral. Em Derhamia hoffmannorum e os demais Pyrrhulininae, por outro lado, o complexo neural é curto, quase tão alto quanto longo, condição não observada em nenhum outro táxon examinado no presente estudo.

131. Forma das costelas da quarta vértebra (Lucena, 1993: 78 - modificado; Buckup, 1998: 50 - modificado; Netto-Ferreira, 2006: 212) - $\mathrm{CI}=1.00 ; \mathrm{RI}=1.00$.

(0) Extremidade cônica ou subcilíndrica (Weitzman, 1962: fig. 12; Roberts, 1969: fig. 38 a 47; Roberts, 1974: fig. 76; Campanario, 2000: fig. 35); (1) Lamelares, direcionadas posteriormente (Weitzman, 1964: fig 09).

Lucena (1993) e Buckup (1998) afirmam que em Lebiasina, Pyrrhulina e Nannostomus, a costela da quarta vértebra apresenta aspecto lamelar, e está direcionada posteriormente, situada ventralmente ao quinto centro-vertebral. Entre os táxons examinados, foi possível observar que a costela da quarta vértebra dos Lebiasinidae encontra-se mais desenvolvida que nos demais grupos, onde as mesmas ultrapassam discretamente a margem lateral do tripus. Com a expansão no sentido longitudinal, as costelas da quarta vértebra situam-se ventralmente ao quinto centro e suas porções médio-dorsais estão associadas à porção médio-lateral das costelas da quinta vértebra, por meio de tecido conectivo. Apesar desta reorientação, o ossa suspensoria permanece restrito à porção ventral da quarta vértebra. Vari (1995), por sua vez, afirma que a costela da quarta vértebra em Ctenoluciidae é reorientada posteriormente, de maneira que o ossa suspensoria está situado abaixo do quinto centro vertebral, porém, diferentemente de Lebiasinidae, a porção lateral da costela da quarta vértebra não se 
situa abaixo do quinto centro e é cônica. Devido às condições distintas relativas à costela da quarta vértebra de Lebiasinidae e Ctenoluciidae, os estados descritos em Lucena (1993) e Buckup (1998), tratam apenas da forma das costelas da quarta vértebra, e não da sua posição em relação ao quinto centro, uma vez que os padrões observados entre as duas famílias não parecem homólogos.

132. Pós-zigapófise da quarta vértebra (Zanata, 2000: 85; Netto-Ferreira, 2006: 215) $-\mathrm{CI}=0.12 ; \mathrm{RI}=0.36$.

(0) Ausente (Weitzman, 1964: fig 09; Campanario, 2000: fig. 35); (1) presente (Roberts, 1969: fig. 38, 40, 42 e 44).

A maioria dos Characiformes apresenta a pós-zigapófise do quarto centro vertebral. Na maioria dos Lebiasinidae e em Brycon, porém, esta estrutura está ausente, representando perdas independentes no dois grupos. Entre os Lebiasinidae, no entanto, esta condição encontra-se revertida em Lebiasina aff. bimaculata II, L. aureogutatta e corresponde a sinapomorfia do clados 111 e 113 (perdida em Pyrrhulina sp. “Tapajós”).

\section{Vértebras e estruturas associadas}

133. Pré-zigapófise da quinta vértebra (Netto-Ferreira, 2006: 216) $-\mathrm{CI}=0.07$; $\mathrm{RI}=$ 0.41 .

(0) Ausente (Roberts, 1974: fig. 76); (1) presente.

Em Lebiasinidae, a presença da pré-zigapófise do quinto centro vertebral parece uma característica mais amplamente distribuída que a presença da pós-zigapófise da quarta vértebra. A presença desta estrutura representa o padrão plesiomórfico da família, no entanto, em vários clados ocorre a perda da mesma. Entre eles o único em que a perda representa uma sinapomorfia não-ambígua é o clado 77 (revertido em Lebiasina sp. "Curuá-faixa”, L. erythrinoides e no clado 88).

134. Costela da quinta vértebra (Lucena, 1993: 81 - modificado; Buckup, 1998: 51 - modificado; Oyakawa, 1998: 76 - modificado; Zanata, 2000: 88 - modificado; Zanata \& Vari, 2005: 115 - modificado; Netto-Ferreira, 2006: 217) - CI=0.67; RI=0.50.

(0) Costela do quinto centro com um processo próximo à base (Roberts, 1969: fig. 47);

(1) base da costela da quinta vértebra expandida, mas sem um processo próximo à base;

(2) costela do quinto centro sem tal processo e não expandida (Roberts, 1969: fig. 41). 
A ocorrência de um processo próximo à base das costelas da quinta vértebra conectado aos ossa suspensoria por meio de um tecido ligamentoso parece uma condição plesiomórfica em Characiformes (Roberts, 1969). Roberts (1969) também observou que, em Ctenolucius, Hepsetus, Hoplias e Salminus, este processo está ausente. Lucena (1993) e Oyakawa (1998) observaram que este processo está ausente também em Lebiasinidae e nos demais Erythrinidae. Este processo encontra-se, de fato, ausente em todos os representantes examinados destas famílias, entretanto, nos dois grupos, a costela da quinta vértebra apresenta-se expandida próximo à base, sem formar um processo distinto. Em Ctenoluciidae e Hepsetus odoe, a base da costela da quinta vértebra não apresenta o processo ou a dilatação. Por isso, foi criado mais um estado, a fim de discernir a condição observada em Erythrinidae e Lebiasinidae da observada em Ctenoluciidae e Hepsetus.

135. Supraneurais (Zanata, 2000: 95 - modificado; Netto-Ferreira, 2006: 219) - CI= $0.50 ; \mathrm{RI}=0.86$.

(0) Com um aspecto cilíndrico; (1) alargadas na região próxima à extremidade superior;

(2) Expandidas ântero-posteriormente, com aspecto lamelar.

Os supraneurais da maioria dos táxons examinados são representados por elementos ósseos com aspecto cilíndrico. Em Nannostomus (exceto $N$. harrisoni e $N$. unifasciatus), a extremidade dorsal dos supraneurais é alargada, sendo a condição deste caráter observada em Nannostomus harrisoni e N. unifasciatus, onde os supraneurais apresentam amplas lamelas ósseas. Tal condição ocorre também em Boulengerella lateristriga.

136. Supraneural da quinta vértebra (Netto-Ferreira, 2006: 220$)-\mathrm{CI}=0.33$; RI= 0.90 .

(0) Presente; (1) ausente.

Em Copeina, Copella e Pyrrhulina o supraneural da quinta vértebra está ausente. A mesma condição é observada em Erythrinidae. Em todos os demais Lebiasinidae e demais táxons examinados no presente estudo, a supraneural da quinta vértebra está presente. Em alguns exemplares de Lebiasininae e Nannostomus os primeiros supraneurais não apresentavam-se ossificados. No entanto, nestes casos considerou-se os elementos supraneurais como presentes. O quinto supraneural está 
ausente também em Boulengerella lateristriga e Erythrinidae. A perda do elemento representa uma sinapomorfia adquirida independentemente nos três clados.

137. Supraneural da sexta vértebra (Netto-Ferreira, 2006: 221$)-\mathrm{CI}=0.14 ; \mathrm{RI}=$ 0.60 .

(0) Presente; (1) ausente.

Assim como o elemento da quinta vértebra, o supraneural da sexta vértebra está ausente na maioria das espécies de Copella (revertida em C. carsevennensis e no clado 101) e Pyrrhulina (revertida em $P$. sp. "Trombetas" e $P$. vittata), condição compartilhada também com Eythrinidae e Boulengerella lateristriga. Em todos os demais táxons examinados, o elemento supraneural da sexta vértebra está presente.

138. Vértebras pré-caudais (Lucena, 1993: 79 - modificado; Campanario, 2000: 49 - modificado; Netto-Ferreira, 2006: 222) $-\mathrm{CI}=0.33$; $\mathrm{RI}=0.57$.

(0) Menos de 18 vértebras pré-caudais; (1) 18 a 30 vértebras pré-caudais; (2) Mais de 30 vértebras pré-caudais.

A maiora dos táxons examinados no presente estudo apresenta entre 18 e 25 vértebras pré-caudais, enquanto Copella nattereri, Nannostomus britskii, N. marginatus, e as Pyrrhulina do clado 114, apresentam entre 16 e 17 vértebras pré-caudal. Representantes deste clado apresentam também um raio principal a menos no lóbulo dorsal da nadadeira caudal. Em Acestrorhynchus, Ctenoluciidae e Hepsetus odoe, por sua vez, ocorre um incremento do número de vértevras pré-caudais, e os representantes destes grupos apresentam entre 31 e 32 vértebras pré-caudais.

139. Vértebras (Lucena, 1998: 80; Campanario, 2000: 49 - modificado; NettoFerreira, 2006: 223) $-\mathrm{CI}=0.50 ; \mathrm{RI}=0.00$.

(0) Número de vértebras pré-caudais maior que o de caudais; (1) número de vértebras pré-caudais menor ou igual ao de vértebras caudais.

Dentre os táxons examinados no presente estudo, apenas Copella compta e $C$. carsevennensis apresentam o número de vértebras caudais maior ou igual ao de vértebras pré-caudais. Em C. compta, tal modificação não parece estar relacionada à redução de vértebras pré-caudais, mas sim no aumento do número total de vértebras, o 
que confere um aspecto discretamente mais alongado para os representantes desta espécie.

140. Pré-zigapófises das vértebras pré-caudais (Netto-Ferreira, 2006: 224), CI= $0.50 ; \mathrm{RI}=0.96$.

(0) Tamanho e forma semelhantes às pós-zigapófises; (1) pré-zigapófises espiniformes, bastante alongadas.

Em Lebiasininae, Derhamia e Nannostomus as pré-zigapófises dos centros vertebrais pré-caudais são distintamente mais longas que as pós-zigapófises e praticamente retilíneas, estando discretamente deslocadas distalmente no espinho neural. Nos demais Lebiasinidae e na maioria dos demais táxons examinados as prézigapófises são, geralmente, praticamente tão desenvolvidas quanto as pós-zigapófises e são recurvadas anteriormente, estando sempre associadas à base do espinho neural. A forma das pré-zigapófises representa uma sinapomorfia de Lebiasinidae, posteriormente revertida em Copeina, Copella e Pyrrhulina, onde zigapófises encontram-se mais curtas que em todos os demais Characiformes examinados.

141. Espinhos neurais das vértebras pré-caudais (Netto-Ferreira, 2006: 225) - CI= $1.00 ; \mathrm{RI}=1.00$.

(0) Não associados às pós-zigapófises; (1) associados à porção proximal das pószigapófises; (2) associados à médio-distal das pós-zigapófises.

$\mathrm{Na}$ maioria dos Characiformes examinados, o espinho neural encontra-se conectado à porção basal da pós-zigapófise por meio de uma discreta lamela óssea. Em Copeina, Copella e Pyrrhulina, esta lamela óssea encontra-se distintamente mais desenvolvidas, alcançando a porção médio-distal das pós-zigapófises, de maneira que estas aparentam ser diminutas quando comparadas às dos demais grupos. Tais modificações parecem estar relacionadas a reforço mecânico dado o modo de vida dos representantes deste gênero, que habitam estratos superficiais da coluna d'água e freqüentemente saltam da água.

Em Nannostomus observa-se o padrão inverso, onde a lamela óssea conectando o espinho neural e a pós-zigapófise estão ausentes. Tal condição parece estar relacionada à diminuição do tamanho do corpo observada neste grupo. 
142. Espinho neural da última vértebra (Netto-Ferreira, 2006: 253$)-\mathrm{CI}=0.33$; $\mathrm{RI}=$ 0.71 .

(0) Tão ou mais desenvolvido que o espinho neural da vértebra anterior (Weitzman, 1962: fig. 15; Roberts, 1969: fig. 57 a 60; Oyakawa, 1998: fig. 38B e 39B; Campanario, 2000: fig. 38); (1) distintamente mais curto que o espinho neural da vértebra anterior (Roberts, 1969: fig.56).

Roberts (1969, fig. 56) ilustra o esqueleto caudal de Hepsetus odoe, com o espinho neural da última vértebra curto. No presente estudo esta condição foi observada também em Apareiodon, Cyphocharax, Pyrrhulina australis e pelo menos um exemplar de todas as espécies examinadas do gênero Nannostomus, de maneira que, em $N$. digrammus, N. limatus, N. marginatus, N. marilynae e $N$. nitidus, este caráter apresentou polimorfismo, onde o espinho neural da última vértebra pode apresentar-se nas condições descritas nos dois estados deste caráter.

\section{Cintura pélvica}

(Figura XX)

143. Raios das nadadeiras pélvicas (Netto-Ferreira, 2006: 231) $\mathrm{CI}=1.00 ; \mathrm{RI}=1.00$.

(0) Raios laterais mais longos que os mediais; (1) raios mediais tão longos quanto os raios laterais (nadadeiras pélvicas arredondadas); (2) raios mediais mais longos que os laterais (pélvicas lanceoladas).

A nadadeira pélvica da maioria dos Characiformes examinados apresenta o formato aproximadamente elíptico, onde o raio indiviso e os raios ramificados situados mais lateralmente apresentam-se mais longos que os demais. Em Lebiasininae, Derhamia e Erythrinidae, por sua vez, o segundo, terceiro e quarto raios ramificados encontram-se discretamente mais longos que os demais, conferindo à nadadeira um aspecto distintamente arredondado. Em Copeina, Copella e Pyrrhulina, por sua vez, estes raios são distintamente mais longos que os demais, de maneira que, quando a nadadeira está estendida, conferindo uma forma única entre os representantes da ordem, onde a mesma possui o formato aproximadamente quadrangular. 


\section{Nadadeira Dorsal e Estruturas Associadas}

\section{(Figura 49-51)}

144. Radiais mediais da nadadeira dorsal (Fink \& Fink, 1981: 106; Netto-Ferreira, 2006: 234) $-\mathrm{CI}=0.20 ; \mathrm{RI}=0.87$.

(0) Presentes (Weitzman, 1962: fig. 16); (1) ausentes (Campanario, 2000: fig. 41).

Os pterigióforos das nadadeiras dorsal e anal são constituídos de três elementos básicos, os radiais proximais, mediais e distais. Fink \& Fink (1981), observaram que os radiais mediais dos pterigióforos das nadadeiras dorsal e anal estavam ausentes em Hoplias, Ctenolucius, Parodon, Saccodon, diversos Citharinidae e Distichodontidae, além dos Siluriformes e alguns Gonorhynchiformes. Entre os táxons examinados, os radiais mediais da nadadeira dorsal estão ausentes em Boulengerella, Copeina, Copella, Pyrrhulina e algumas espécies de Nannostomus (clados 115 e 124). Nos exemplares examinados de Erythrinidae e Ctenolucius, os radiais mediais encontram-se fortemente associados aos radiais proximais, entretanto, pode-se perceber uma discreta cartilagem que delimita os dois elementos. Em um exemplar de Erythrinus Erythrinus com 66,6 mm CP, os elementos radiais medial e proximal estão evidenciáveis, enquanto que em um exemplar com $111 \mathrm{~mm} \mathrm{CP}$ os dois elementos estão fusionados. Desta maneira, é possível sugerir que em Erythrinidae os elementos radias proximal e medial se fundem ao longo da ontogenia. Em Lebiasinidae ou nos demais grupos onde o elemento medial não está individualizado, não foi possível observar se o elemento se individualiza do radial proximal e posteriormente se funde ao mesmo, ou se este sequer se diferencia ao longo da ontogenia.

145. Peça terminal ou suporte da nadadeira dorsal (Netto-Ferreira, 2006: 237) $\mathrm{CI}=0.17 ; \mathrm{RI}=0.78$.

(0) Presente (Weitzman, 1962: fig. 16; Campanario, 2000: fig. 41); (1) Fusionada ao último pterigióforo.

A peça terminal é o elemento mais posterior da nadadeira dorsal e é onde se insere o músculo supracarinalis posterioris. Na maioria dos táxons examinados, este elemento apresenta-se como uma ossificação independente do pterigióforo mais posterior, estando articulada com este por meio de uma peça variavelmente desenvolvida. Em Copeina, Copella e Pyrrhulina, a peça terminal e o pterigióforo posterior representam uma única ossificação. Esta condição ocorre também em 
Nannostomus marginatus, N. marilynae, N. trifasciatus, Hoplerythrinus e Boulengerella lateristriga, e representam fusões independentes entre si e da condição observada em Pyrrhulinina.

146. Posição da nadadeira dorsal (Vari, 1995: 80; Zanata, 2000: 97; Netto-Ferreira, 2006: 238$)-\mathrm{CI}=0.40 ; \mathrm{RI}=0.87$.

(0) Situada no meio do corpo; (1) situada no terço posterior do corpo; (2) situada no quarto posterior do corpo.

A posição da nadadeira dorsal apresenta-se variável entre os Lebiasinidae. Em Lebiasininae, Copeina e Nannostomus a nadadeira dorsal está situada na porção média do corpo, enquanto que em Copella e Pyrrhulina a mesma está deslocada posteriormente, atingindo o terço posterior do corpo. A nadadeira dorsal de Derhamia hoffmannorum situa-se posteriormente à de todos os demais Lebiasinidae, conforme mencionado por Géry \& Zarske (2002). Entre os demais táxons examinados, a maioria apresenta a nadadeira dorsal situada na porção média do corpo, exceto Acestrorhynchus e Hepsetus, onde a nadadeira também atinge o terço posterior do corpo e Ctenoluciidae, onde a nadadeira dorsal alcança o quarto posterior do corpo.

147. Posição da nadadeira dorsal em relação à nadadeira anal (Zanata, 2000: 98; Campanario, 2000: 77 - modificado; Netto-Ferreira, 2006: 239) $\mathrm{CI}=0.40 ; \mathrm{RI}=0.75$.

(0) Base do último raio da nadadeira dorsal alcançando a vertical que passa pela origem do quinto raio ramificado da nadadeira anal; (1) base do último raio da nadadeira dorsal atingindo ou ultrapassando discretamente a vertical que passa pela origem da nadadeira anal; (2) base do último raio da dorsal situado anteriormente à vertical que passa pela origem da nadadeira anal.

O deslocamento posterior da nadadeira dorsal não parece estar diretamente relacionado à sua posição em relação à nadadeira anal. Mesmo as espécies que apresentam este deslocamento, podem apresentar a porção distal do último raio da dorsal situado anteriormente aos primeiros raios da anal, como é o caso de Acestrorhynchus, Hepsetus e Pyrrhulina. Na maioria dos táxons que apresenta a nadadeira dorsal na região média do corpo, a mesma encontra-se anteriormente aos primeiros raios da nadadeira anal, com exceção de Crenuchus, que apresenta a dorsal extensa, alcançando os raios indivisos da anal. Nas espécies do gênero Copella e em 
Derhamia hoffmannorum, a porção proximal do último raio da nadadeira dorsal também alcança os raios indivisos da nadadeira anal. Em Ctenoluciidae, que apresentam a nadadeira dorsal muito deslocada posteriormente, a condição observada é aquela descrita no estado “ 0 ”.

148. Nadadeira adiposa (Vari, 1995: 81; Secioso, 1997: S14; Campanario, 2000: 78; Netto-Ferreira, 2006: 240$)-\mathrm{CI}=0.11 ; \mathrm{RI}=0.69$.

(0) Presente; (1) ausente.

A presença ou ausência da nadadeira adiposa é um caráter altamente variável entre os Characiformes (Buckup, 1998). O autor menciona ainda que esta nadadeira está freqüentemente ausente em Lebiasina bimaculata, L. multimaculata e Nannostomus eques. Weitzman (1964) e Weitzman e Weitzman (2003) discutem a variabilidade deste caráter em ambas as espécies de Lebiasina, entretanto, afirmam que a mesma está ausente em todos os representantes examinados. De fato, a adiposa está ausente em todos os exemplares de L. bimaculata e L. multimaculata examinados, bem como em $N$. eques. As únicas espécies onde foi observado polimorfismo com relação à presença/ ausência de nadadeira adiposa foram Lebiasina aff. festae, onde uma nadadeira adiposa rudimentar está presente em apenas oito dos 382 exemplares examinados, e Nannostomus trifasciatus, que possivelmente constitui um complexo de espécies com ampla distribuição, onde os exemplares provenientes do rio Madre de Dios (Peru) não apresentam a nadadeira adiposa.

Buckup (1998) afirma ainda que as espécies de Pyrrhulina apresentam nadadeira adiposa. Tal observação é errônea, na medida em que a perda da adiposa representa uma sinapomorfia do clado 100 (Copeina, Copella e Pyrrhulina). A perda da adiposa ocorre independentemente nos clados 68, 90, 75 e 117 (revertido em Nannostomus nitidus) bem como em L. multimaculata e N. britskii e Erythrinidae.

Por fim, apesar de Buckup (1998) ter optado por não incluir este caráter devido à sua variabilidade inter e intra-específica, principalmente entre os Lebiasinidae, este caráter parece ser bastante consistente no grupo e carrega um sinal filogenético bastante forte para resolver as relações entre seus representantes. 


\section{Nadadeira anal e estruturas associadas}

\section{(Figuras 52-54)}

149. Forma da nadadeira anal (Netto-Ferreira, 2006: 241) $\mathrm{CI}=1.00 ; \mathrm{RI}=1.00$.

(0) Raios anteriores mais desenvolvidos que os "medianos" (Zanata \& Vari, 2005: fig 39A); (1) raios "medianos" mais desenvolvidos que os raios anteriores (nadadeira anal arredondada).

A nadadeira anal de Erythrinidae e Lebiasinidae apresenta os raios médios mais longos que os raios indivisos anteriores, de maneira que a nadadeira apresenta formato arredondado, representando uma sinapomorfia do clado 67. Esta condição difere da observada nos demais representantes de Characiformes examinados no presente estudo, onde os raios indivisos posteriores e os primeiros raios ramificados são os mais longos que os demais raios ramificados, de maneira que o perfil da margem distal da nadadeira é côncava.

150. Radiais proximais da nadadeira anal dos machos adultos (Netto-Ferreira, 2006: 242$)-\mathrm{CI}=0.40 ; \mathrm{RI}=0.88$.

(0) Forma e tamanho semelhantes aos das fêmeas, praticamente paralelos entre si; (1) distintamente mais robustos, praticamente paralelos entre si; (2) distintamente mais robustos, porção proximal dos radiais convergentes entre si em relação ao esqueleto axial, discretamente rotacionados anteriormente.

Weitzman (1966) e Weitzman \& Cobb (1975) observaram as modificações existentes na nadadeira anal dos representantes do gênero Nannostomus, entretanto, estas observações limitaram-se à morfologia dos raios. Além das diferentes modificações presentes em cada espécie deste e os demais gêneros de Lebiasinidae, foi possível observar também que os pterigióforos dos machos, na maioria das espécies examinadas, apresentam-se mais robustos nos machoa que nas fêmeas. Além disso, em Pyrrhulinina e Nannostomus digrammus, a porção proximal dos radiais proximais estão discretamente rotacionados anteriormente e apresentam-se convergentes entre si em relação ao esqueleto axial. Esta condição difere da observada na maioria dos demais grupos examinados, onde os radiais proximais da nadadeira anal de machos e fêmeas apresentam-se em série orientada ântero-posteriormente, estando quase paralelos. A intensidade da mudança na disposição é variável entre as espécies do gênero. Em Nannostomus trifasciatus, por exemplo, os pterigióforos de machos e fêmeas quase não 
apresentam diferenças, enquanto que em $N$. beckfordi e $N$. digrammus, o padrão observado em machos e fêmeas difere intensamente. Em Lebiasina sp. "Curuá-pinta", L. sp. "XIII de maio" e N. britskii, espécies onde o dimorfismo sexual é muito discreto, os pterigióforos de machos e fêmeas não apresentam diferenças significativas entre si, como na maioria dos demais Characiformes.

151. Associação dos pterigióforos da nadadeira anal dos machos (Netto-Ferreira, 2006: 243$)-\mathrm{CI}=0.50 ; \mathrm{RI}=0.96$.

(0) Radiais proximais não associados entre si; (1) em contato por uma junção sincondral; (2) radiais proximais adjacentes em contato direto, fortemente anquilosados.

Na maioria dos Characiformes, os elementos radiais da nadadeira anal não estão diretamente em contato, estando ligados entre si por meio de ligamentos que conectam a porção anterior de um pterigióforo à margem anterior do pterigióforo adjacente (Weitzman et al., 2005). Em Pyrrhulinini (não foram observados machos adultos de Derhamia) os radiais mediais (ou a região correspondente a estes quando os elementos proximais e mediais estão fusionados) da nadadeira anal, em sua porção distal, encontram-se fortemente conectados. Em Copeina na maioria das espécies de Nannostomus (exceto N. britskii, que apresenta o estado " 0 ", e N. digrammus, que apresenta o estado "2") o contato entre os pterigióforos ocorre por meio de uma sinartrose com um discreto elemento cartilaginoso. Em Nannostomus, no entanto, apenas os quatro ou cinco pterigióforos mais anteriores estão unidos, enquanto que em Copeina todos os pterigióforos encontram-se conectados. Em Copella e Pyrrhulina, por sua vez, os pterigióforos encontram-se fortemente anquilosados, de maneira que não é possível separar os elementos. Weitzman et al. (2005, fig. 5) descrevem condição similar à de Copella e Pyrrhulina para Bryconadenos Weitzman et al. e Attonitus Ortega \& Vari, onde seis e três pterigióforos anteriores encontram-se anquilosados, respectivamente. Tais modificações parecem estar associadas a reforço mecânico uma vez que nestes grupos a nadadeira anal apresenta grande importância na reprodução.

152. Lamelas laterais dos radiais proximais da nadadeira anal (Netto-Ferreira, 2006: 244) $-\mathrm{CI}=1.00 ; \mathrm{RI}=1.00$.

(0) Curtas, restritas à superfície lateral dos radiais proximais; (1) alongadas, estendendose ventralmente e sobrepondo-se lateralmente à primeira lepidotríquea. 
Os pterigióforos dos Characiformes apresentam um par de lamelas laterais curtas que se estendem lateralmente entre a base do radial proximal e a área de articulação os mediais (ou na área equivalente a estes quando ausentes). Em Copeina, Copella e Pyrrhulina, as lamelas laterais do quarto ao nono radiais proximais estendemse ventralmente, sobrepondo-se lateralmente a parte da primeira lepidotríquea.

153. Radiais mediais da nadadeira anal (Fink \& Fink, 1981: 106; Zanata \& Vari, 2005: 191; Netto-Ferreira, 2006: 245); $\mathrm{CI}=0.50 ; \mathrm{RI}=0.95$.

(0) Presentes (Weitzman, 1962: fig. 17); (1) ausentes (Fink \& Fink, 1981: fig. 22B; Campanario, 2000: fig. 47 e 49; Zanata \& Vari, 2005: fig 39 a 42).

Conforme mencionado anteriormente, os raios das nadadeiras anal e dorsal são sustentados pelos pterigióforos, que são compostos de três elementos: o radial proximal, o medial e o distal. Weitzman (1962) afirma que do primeiro ao quinto pterigióforo da nadadeira anal de Brycon meeki estão presentes apenas os radiais proximais e os distais. Nos Lebiasininae, Derhamia e Nannostomus, apenas os três ou quatro primeiros pterigióforos da nadadeira anal não possuem os radiais mediais diferenciados. Em Copeina, Copella e Pyrrhulina, os radiais mediais dos nove pterigióforos estão ausentes. Tal condição foi observada também em Apareiodon, Boulengerella e Crenuchidae. Fink \& Fink (1981) observaram que os radiais mediais de Hoplias e Ctenolucius estão ausentes, porém, conforme mencionado anteriormente, nos exemplares examinados no presente estudo, os dois elementos encontram-se fortemente unidos, mas é possível vislumbrar os limites entre eles. Vari (1995) observou que, em ambas as famílias, o único elemento, aparentemente resultante da fusão do radial proximal e o radial medial, apresenta um processo cartilaginoso orientado pósteroventralmente que se ossifica ao longo da ontogenia. Zanata \& Vari (2005), em seu estudo das relações de Alestidae, observam que, em grande parte dos representantes deste clado os radiais proximais e mediais também estão fusionados, entretanto, consideraram esta condição como não homóloga à dos demais Characiformes.

154. Peça terminal ou suporte da nadadeira anal (Netto-Ferreira, 2006: 246) - CI= $0.33 ; \mathrm{RI}=0.91$.

(0) Presente (Weitzman, 1962: fig 17; Zanata \& Vari, 2005: fig. 39); (1) Fusionada ao último pterigióforo ou ausente (Zanata \& Vari, 2005: fig. 40 e 41). 
De maneira similar à peça terminal da nadadeira dorsal, a peça terminal da nadadeira anal está presente na maioria dos Characiformes. Este é o elemento mais posterior da estrutura e onde se inserem os infracarinalis posterioris. Os representantes de Copeina, Copella e Pyrrhulina não apresentam a peça terminal semelhante à descrita por Weitzman (1962). Tal condição foi observada também no clado 115 (Nannostomus limatus e L. nitidus) e em Boulengerella lateristriga, condições adquiridas independentemente.

155. Número de raios da nadadeira anal (Lucena, 1993: 103; Buckup, 1998: 65 modificado; Zanata, 2000: 112 - modificado; Campanario, 2000: 74 - modificado; Netto-Ferreira, 2006: 247) $-\mathrm{CI}=0.50 ; \mathrm{RI}=0.00$.

(0) Nadadeira anal relativamente longa, com mais de 13 raios (totais); (1) nadadeira anal com 13 raios (totais) ou menos.

Buckup (1998) em seu estudo das relações filogenéticas dos grupos de Characiformes sugere que a presença de menos de 13 raios totais na nadadeira anal seja o padrão plesiomórfico de Characiformes. A maioria dos Lebiasinidae examinados apresenta três raios indivisos e nove raios $( \pm 1)$, sendo o último adnato. A única exceção é Derhamia hoffmannorum, que apresenta três raios indivisos e nove ou 10 raios ramificados na anal. Condição semelhante à observada nos Lebiasinidae ocorre também na maioria dos demais táxons examinados, exceto em Acestrorhynchus e Brycon. Com base na presente hipótese de relações, o aumento de raios da nadadeira anal ocorreu de maneira independente nestes dois táxons.

156. Área de inserção dos músculos inclinadores na primeira lepidotríquea dos raios da nadadeira anal em machos adultos (Zanata \&Vari, 2005: 189; NettoFerreira, 2006: 248) $\mathrm{CI}=0.25 ; \mathrm{RI}=0.65$.

(0) Curta e arredondada (Weitzman, 1962: fig. 17; Fink \& Fink, 1981: fig. 22; Campanario, 2000: fig. 47 e 49) (1) alongada e arredondada; (2) alongada e espiniforme (Zanata \& Vari, 2005: fig. 42).

Conforme mencionado anteriormente, Weitzman (1966) e Weitzman e Cobb (1975) observaram que a nadadeira anal dos representantes do gênero Nannostomus apresenta modificações que estão relacionadas à corte. Além do espessamento dos raios, das membranas inter-radiais e da alteração da disposição dos radiais proximais da 
nadadeira anal, os exemplares machos da maioria dos representantes deste gênero possuem a porção proximal da primeira lepidotríquea distintamente alongada, espiniforme, direcionada ântero-dorsalmente. Nannostomus digrammus é a única exceção observada, apesar de apresentar diversas autapomorfias que envolvem modificações na nadadeira anal. A condição observada neste táxon é a mesma observada nos demais Lebiasinidae (ainda que nenhum exemplar macho de Derhamia tenha sido examinado), onde a área de inserção dos músculos encontra-se alongada dorsalmente, mas possui a extremidade arredondada. Tais modificações diferem de todos os demais Characiformes examinados, onde a margem da primeira lepidotríqueaquea é arredondada ou com um discreto processo. Zanata \& Vari (2005) observaram condição semelhante à observada em Lebiasinidae em diversos Alestidae que apresentam dimorfismo sexual associado à nadadeira anal, no entanto, sugerem que os músculos eretores estejam ligados a estas projeções e não os inclinadores. No presente estudo a musculatura de exemplares de Alestidae não foi examinada com intuito de clarificar esta questão, o que se faz necessário, dada esta incongruência. Ainda que este caráter tenha sido codificado como “?” em Hoplerythrinus, é possível que este táxon compartilhe a condição "1" com os demais Lebiasinidae, dada a ocorrência de diversos caracteres relacionados a modificações da nadadeira anal

157. Último pterigióforo da nadadeira anal (Netto-Ferreira, 2006: 249) - CI=0.50; $\mathrm{RI}=0.50$.

(0) Não articulando com o espinho hemal situado dorsalmente a este; (1) articulando com o espinho hemal situado dorsalmente a este.

Em Nannostomus beckfordi ("Pará" e "Suriname") e N. marginatus, o radial proximal do pterigióforo mais posterior da nadadeira anal apresenta a sua porção basal alargada (discretamente em N. marginatus) antero-posteriormente. Assim como o radial proximal, o espinho hemal adjacente a este também encontra-se expandido e os dois elementos apresentam-se articulados. Esta condição não foi observada em nenhum outro representante do gênero Nannostomus, ou qualquer caraciforme examinado no presente estudo. 
158. Raios da nadadeira anal (Vari, 1995: 76; Netto-Ferreira, 2006: 250) - CI= $0.50 ; \mathrm{RI}=0.75$.

(0) Não expandidos nos machos; (1) expandidos nos machos.

Weitzman (1966), Vari (1995) e Oyakawa (1998) observaram que os raios da nadadeira anal dos Lebiasinidae apresentam-se alargados ântero-posteriormente. Condição observada também em Ctenolucius (Vari, 1995) e Hoplerythrinus (Oyakawa, 1998). A maioria dos Characiformes, porém, não apresenta modificações envolvendo o espessamento dos raios da nadadeira anal, exceto em poucos grupos atualmente incluídos em Characidae.

\section{Ponto de inserção dos músculos inclinadores do último raio da nadadeira} anal (Oyakawa, 1998: 106; Netto-Ferreira, 2006: 251) $\mathrm{CI}=0.50 ; \mathrm{RI}=0.93$.

(0) Ligando-se à porção proximal da primeira lepidotríquea; (1) ligando-se à porção distal do raio.

Oyakawa (1998) descreve uma "espessa membrana" que ocorre em machos de Pyrrhulina, Copella, Lebiasininae e Hoplerythrinus e afirma que esta estrutura está relacionada ao dimorfismo sexual presente nestes grupos. A presença desta "membrana" foi confirmada nos representantes destes táxons, e também em Copeina guttata, que Oyakawa (1998) considerou como não possuindo a estrutura. Entretanto, foi possível constatar que a estrutura descrita por Oyakawa (1998) trata-se de fato do feixe de músculos inclinadores do último raio da nadadeira anal que está inserida na porção distal da primeira lepidotríquea. Em Derhamia hoffmannorum este estado foi codificado como incerteza, uma vez que exemplares machos adultos deste grupo não foram examinados. A condição observada em Nannostomus é semelhante à dos demais Characiformes examinados, aparentemente uma condição pedomórfica do grupo.

160. Membranas inter-radiais da nadadeira anal em machos adultos (Oyakawa, 1998: 107; Netto-Ferreira, 2006: 252) $\mathrm{CI}=0.33 ; \mathrm{RI}=0.84$.

(0) Não espessadas; (1) Espessadas.

Outro caráter relacionado ao dimorfismo sexual observado em Lebiasinidae e Hoplerythrinus é o espessamento das membranas inter-radiais da nadadeira anal. Oyakawa (1998) afirma que este espessamento ocorre em Hoplerythrinus, Lebiasininae, Copella e Pyrrhulina. Esta condição está presente também em Copeina guttata e todos 
os representantes do gênero Nannostomus (exceto $N$. britskii que não apresenta um padrão de dimorfismo sexual tão conspícuo quanto os demais congêneres). Este caráter foi codificado como incerteza em Derhamia hoffmannorum, uma vez que o material disponível deste táxon é constituído apenas de indivíduos jovens.

\section{Nadadeira caudal e estruturas associadas}

(Figura 55-61)

161. Número de epurais (Lucena, 1993: 106 e 107; Buckup, 1998: 68 e 69; Oyakawa, 1998: 88; Zanata, 2000: 115; Campanario, 2000: 53; Zanata \& Vari, 2005: 148; Netto-Ferreira, 2006: 256) $-\mathrm{CI}=0.33 ; \mathrm{RI}=0.84$.

(0) Três (Weitzman, 1962: fig. 15; Roberts, 1969: fig. 56, 57 e 60; Campanario, 2000: fig. 38); (1) dois (Roberts, 1974: fig. 78; Oyakawa, 1998: fig. 38B); (2) um (Roberts, 1969: fig. 58; Oyakawa, 1998: fig. 39B; Géry, \& Zarske, 2002: fig. 07).

O número de epurais é variável entre os Lebiasinidae. Na maioria dos Lebiasininae e em Nannostomus, dois epurais estão presentes. Em Lebiasina astrigata, L. panamensis e L. sp. "Azuay” apenas um epural está presente, condição compartilhada com os demais gêneros de Lebiasinidae e com Erythrinidae. Dois epurais foram observados também em Acestrorhynchus e Brycon. Enquanto que em Ctenoluciidae e Hepsetidae foram observados três epurais.

162. Hipural 5 (Netto-Ferreira, 2006: 261) $-\mathrm{CI}=0.50 ; \mathrm{RI}=0.94$.

(0) Porção distal não voltada em direção ao hipural 4 (Weitzman, 1962: fig. 15; Roberts, 1969: fig. 56, 57, 59 e 60; Roberts, 1974: fig. 78; Oyakawa, 1998: fig. 38B e 39B; Campanario, 2000: fig. 38); (1) porção distal expandida e direcionada ventralmente, em direção ao hipural 4.

Em Copeina, Copella e Pyrrhulina (exceto P. vittata), a porção distal do hipural 5 apresenta-se projetada ventralmente, em direção ao hipural 4. Esta condição não foi observada em nenhum outro gênero de Lebiasinidae ou representante da ordem Characiformes examinado. Esta condição está possivelmente relacionada à perda do hipural 6 em Pyrrhulinina. 
163. Hipural 6 (Campanario, 2000: 51; Netto-Ferreira, 2006: 262) - CI=1.00; RI= 1.00 .

(0) Presente Weitzman, 1962: fig. 15; Roberts, 1969: fig. 56, 57, 59 e 60; Roberts, 1974: fig. 78; Oyakawa, 1998: fig. 38B e 39B; Campanario, 2000: fig. 38); (1) ausente .

Conforme mencionado no caráter anterior, o hipural 6 de Copeina, Copella e Pyrrhulina está ausente, uma condição compartilhada apenas pelos representantes destes três gêneros de Lebiasinidae. Todos os demais táxons examinados apresentam o hipural 6.

164. Raios pró-correntes do lóbulo superior da nadadeira caudal (Campanario, 2000:54; Netto-Ferreira, 2006: 263); $\mathrm{CI}=0.67$; RI=0.98.

(0) Sete ou mais (Weitzman, 1962: fig. 15; Roberts, 1969: fig. 56, 58, 59 e 60); (1) seis ou cinco (Campanario, 2000: fig. 38); (2) quatro ou três.

Os raios pró-correntes da nadadeira caudal são pequenos raios indivisos que não estão associados aos hipurais. Nos Lebiasinidae, ocorre uma tendência de redução do número de raios pró-correntes. Em Lebiasininae e Derhamia estão presentes sete ou mais raios pró-correntes, enquanto Copeina e as espécies de Nannostomus apresentam seis ou cinco raios. No caso de Copella e Pyrrhulina, estão presentes apenas três ou quatro raios, condição revertida em C. compta. Entre demais Characiformes examinados, todos apresentam mais de sete raios.

165. Raios principais do lóbulo superior da nadadeira caudal (Netto-Ferreira, 2006: 264$)-\mathrm{CI}=0.33 ; \mathrm{RI}=0.33$.

(0) Dez (Weitzman, 1962: fig. 15; Roberts, 1969: fig. 56, 57, 59 e 60; Campanario, 2000: fig. 38); (1) nove (Roberts, 1969: fig. 58).

Os raios principais da nadadeira caudal são os que constituem efetivamente a porção funcional dos lóbulos da nadadeira. Os raios do lóbulo superior são sustentados pelos hipurais 3 a 6. Weitzman (1962) afirma que a maioria dos Characiformes apresenta dez raios principais (um indiviso e nove ramificados) no lóbulo superior e nove (um indiviso e oito ramificados) no lóbulo inferior. A maioria dos táxons examinados no presente estudo apresenta a condição proposta por Weitzman (1962). Entretanto, os Erythrinidae, Pyrrhulina australis, P. sp. “Tapajós 1" e P. sp. "Tapajós 2", apresentam apenas nove raios no lóbulo superior da nadadeira caudal. Em sua 
representação do esqueleto caudal de Hoplias, Roberts (1969, fig. 58) parece ter considerado o raio pró-corrente mais desenvolvido do lóbulo superior como um raio principal, de maneira que o exemplar ilustrado por Roberts apresenta dez raios no lóbulo superior. Esta condição representa uma sinapomorfia homoplástica de Erythrinidae e do clado 114 (revertida em P. vittata).

166. Raios pró-correntes do lóbulo inferior da nadadeira caudal (Campanario, 2000:54; Netto-Ferreira, 2006: 265) - CI=0.40; RI=0.93.

(0) Sete ou mais (Weitzman, 1962: fig. 15; Roberts, 1969: fig. 56, 58, 59 e 60); (1) seis ou cinco (Campanario, 2000: fig. 38); (2) quatro ou três.

Assim como os raios pró-correntes do lóbulo superior da nadadeira caudal, os raios pró-correntes do lóbulo inferior dos Lebiasinidae apresentam uma tendência à redução. Os Lebiasininae e Derhamia apresentam sete ou mais raios pró-correntes. Copeina e todas as espécies de Nannostomus apresentam seis ou cinco raios, e em Copella (exceto C. metae e C. nigrofasciata) e Pyrrhulina, estão presentes apenas três ou quatro raios. Entre demais Characiformes examinados, todos apresentam mais de sete raios.

\section{Miscelânia}

(Figura XX)

167. Narina anterior e posterior (Oyakawa, 1998: 5; Campanario, 2000: 79; NettoFerreira, 2006: 271) $-\mathrm{CI}=0.33 ; \mathrm{RI}=0.90$.

(0) Justapostas, separadas por uma estreita membrana; (1) Distantes entre si, separadas por uma larga membrana.

A narina anterior da maioria dos Characiformes apresenta-se justaposta à narina posterior. Diferentemente dos demais Lebiasinidae, em Copella e Nannostomus, bem como em Erythrinidae, as narinas anterior e a posterior estão separadas por uma ampla membrana. Com base na presente hipótese, tal condição surgiu independentemente em cada um destes grupos. 
168. Narina anterior (Oyakawa, 1998: 06 - modificado; Netto-Ferreira, 2006: 273) $-\mathrm{CI}=0.50 ; \mathrm{RI}=0.93$.

(0) Não tubular; (1) tubular.

$\mathrm{Na}$ maioria dos Lebiasinidae e nos Erythrinidae, a narina anterior é tubular (sinapomorfia do clado 67). Em Nannostomus esta condição encontra-se revertida, sendo semelhante à observada nos demais Characiformes examinados, onde a narina anterior apresenta apenas uma projeção de pele na margem posterior, mas não é tubular. Oyakawa (1998) afirma que a narina anterior de Copella e Pyrrhulina não seria tubular, entretanto, em todos os representantes de ambos os gêneros examinados no presente estudo, a narina anterior é semelhante à dos demais.

169. Forma da pupila (Netto-Ferreira, 2006: 275) $-\mathrm{CI}=1.00 ; \mathrm{RI}=1.00$.

(0) Pupila circular; (1) porção anterior da pupila alongada em direção ao infra-orbital 1, apresentando uma forma aproximadamente triangular.

A pupila da maioria dos Characiformes examinados é circular, entretanto, nas espécies de Nannostomus do clado 123 a margem anterior da pupila apresenta-se projetada anteriormente, apresentando o formato aproximadamente triangular.

170. Órgãos de contato na porção ventral da cabeça (Netto-Ferreira, 2006: 276) $\mathrm{CI}=1.00 ; \mathrm{RI}=1.00$.

(0) Ausentes; (1) Pequenos órgãos circulares de tamanhos variados presentes na porção ventral da cabeça, próximo à sínfise mandibular.

Wiley \& Collete (1970) observaram que exemplares machos que Nannostomus bifasciatus apresentam tubérculos nupciais na região ventral da cabeça, próximo à sínfise do dentário. Além de $N$. bifasciatus, no presente estudo, foi possível observar tubérculos nupciais em $N$. beckfordi, $N$. limatus, $N$. marginatus e $N$. nitidus, além de uma espécie não descrita da bacia do Solimões, semelhante a Nannostomus digrammus. Em Lebiasininae, órgãos de contatou ou "breeding tubercles" estão presentes na face, nadadeiras pares, nadadeira anal e em algumas escamas, no entanto, em nenhum exemplar foram observados estruturas similares (em estrutura e topologia) às observadas no clado 117. 
171. Bexiga natatória (Netto-Ferreira, 2006: 280$)-\mathrm{CI}=0.50 ; \mathrm{RI}=0.83$.

(0) Parede da câmara posterior homogênea em toda sua extensão, não formando alvéolos; (1) parede da porção anterior da câmara posterior apresentando um complexo sistema de alvéolos.

Graham et al. (1977) e Graham et al. (1978) discutem a capacidade de respiração aérea, comparando o modo de respiração em em Lebiasina festae, L. panamensis e os Erythrinidae. Os autores ressaltam que em L. festae e Erythrinidae (Erythrinus e Hoplerythrinus) a parede do terço anterior da câmara posterior apresenta uma série decrescente de bandas interligadas transversalmente, subdividindo a parede da bexiga em 3-4 camadas de compartimentos progressivamente menores em direção à periferia, dando origem ao termo "celular". Valenciennes (in Cuvier \& Vallenciennes, 1846) considera esta uma característica diagnóstica do gênero Lebiasina (Eigenmann \& Allen, 1942; Weitzman, 1964; Weitzman \& Weitzman, 2003), ilustrando esta condição na descrição de Lebiasina bimaculata. Entre os demais Lebiasininae, esta condição é observada apenas nas espécies do clado 69 e representa uma sinapomorfia para o clado, com origem independente em Erythrinidae. É interessante ressaltar que as espécies do clado 69 são, predominantemente, espécies de áreas baixas distribuídas na costa pacífica do sul do Peru ao norte da Costa Rica (exceto L. festae, que está presente também na bacia do rio Atrato).

172. Raios das nadadeiras (Netto-Ferreira, 2006: 281$)-\mathrm{CI}=0.50 ; \mathrm{RI}=0.92$.

(0) Ramificações em duas ou mais partes, a partir da porção média; (1) com ramificações apenas na porção distal.

Os raios das nadadeiras da maioria dos táxons examinados no presente estudo ramificam-se a partir da porção média. Nos representantes do gênero Nannostomus e Derhamia, os raios (principalmente das nadadeiras peitorais) apresentam-se em geral bifurcados apenas na porção distal do raio, uma condição aparentemente pedomórfica de Pyrrhulininae, revertida em Pyrrhulinina.

173. Raios filamentosos (Netto-Ferreira, 2006: 282$)-\mathrm{CI}=0.33 ; \mathrm{RI}=0.85$.

(0) Ausentes; (1) presentes.

Géry (1977) utiliza a presença de raios filamentosos nas nadadeiras para diferenciar Copella e Pyrrhulina de Copeina. De fato, a presença de raios filamentoso s 
nas nadadeiras representa uma sinapomorfia do clado 100 (Copella+Pyrrhulina), estando revertida em Pyrrhulina sp. "Capim", e no clado 114. Raios filamentosos são observados também em exemplares machos de Erythrinus erythrinus e alguns representantes de Characidae.

\section{Escamas e escamação}

(Figuras 62-64)

174. Radii (Zanata, 2000: 133 e 134 - modificados; Zanata \& Vari, 2005: 172 modificado; Netto-Ferreira, 2006: 283 - modificado) $\mathrm{CI}=0.50$; $\mathrm{RI}=0.00$.

(0) Restritos à porção posterior da escama; (1) origem no centro das escamas, orientados anterior e posteriormente, podendo estar verticalmente direcionados .

Os radii são sulcos presentes nas escamas que podendo variar em número e extensão. Cockerel (1914) observa que os radii dos Lebiasininae, Nannostomus e Pyrrhulina originam-se proximamente ao meio da escama, ligeiramente acima, sendo fortes e amplos. Além disto, Cockerel (1914) menciona que os radii estão orientados ântero-pesteriormente, principalmente, mas também ocorrem radii orientados verticalmente. Inclusive, apenas com base em caracteres relativos às escamas, Cockerel (1914) propõe, a relação mais estreita de Nannostomus e Poecilobrycon (atualmente sinônimo júnior de Nannostomus) com Pyrrhulina, sendo que até então, Nannostomus e Poecilobrycon formavam, juntamente com os Characidiinae, a subfamília Nannostomatinae. As diferenças entre a morfologia das escamas dos representantes dos gêneros Nannostomus e Poecilobrycon e Characidium foram observadas também por Hoedeman (1956) e Weitzman (1966). O padrão de todos os Lebiasinidae examinados é semelhante ao descrito por Cockerel (1914), que compara a escama dos Lebiasinidae à dos Erythrinidae, exceto pela diferente intensidade de anastomose dos radii em cada gênero. De fato, as escamas dos Erythrinidae são bastante semelhantes às dos Lebiasinidae. Os Ctenoluciidae e Hepsetus apresentam padrão, semelhante ao dos Lebiasinidae. E apenas Xenocharax e Cyphocharax não apresentam radii, enquanto que em Acestrorhynchus e Brycon estão restritos à porção posterior da escama. 
175. Anastomose dos radii (Zanata, 2000: 135; Netto-Ferreira, 2006: 284) - CI= $0.50 ; \mathrm{RI}=0.96$.

(0) Ausente; (1) presente, formando células.

Em seu estudo das relações filogenéticas das espécies do gênero Brycon, Zanata (2000) discorda das características utilizadas na chave dicotômica de Géry (1977) para diferenciar Alestes e Bryconaethiops de Brycinus, com base na anastomose dos radii, além de utilizar esta característica como sinapomorfia de Brycon e do clado incluindo Triportheus e Lignobrycon. Entretanto, Zanata (2000) não menciona quais foram seus critérios para considerar a anastomose dos radii. Examinando suas pranchas, foi possível observar que as escamas consideradas anastomosadas são aquelas onde dois ou mais radii se encontram e se fundem antes de atingir o centro de origem dos mesmos, mas ainda assim, existe incongruência com relação ao padrão dos radii que Zanata (2000) considerou anastomosadas, ou não. Seguindo este critério, os radii de todos os Lebiasinidae e a maioria das espécies que apresentam os radii conforme descrito no estado " 2 " do caráter anterior (origem no centro das escamas, orientados anterior e posteriormente, podendo estar verticalmente direcionados) apresentariam-se anastomosados, sendo que os radii que se encontram fundidos são freqüentemente os orientados verticalmente. Desta forma, haveria certa redundância entre este caráter e o anterior. Assim, no presente estudo preferiu-se considerar escamas com radii anastomosados aquelas a que Zanata (2000) refere-se como apresentando "radii fortemente anastomosados", onde estes formam células, lembrando uma espécie de mosaico. Esta condição está presente em todos os representantes de Lebiasininae, Erythrinus e Hoplerythrinus. A presença de radii formando células já havia sido notada por Valenciennes (1849) e Fowler (1911), na descrição de Lebiasina erythrinoides e L. aureoguttata, aos quais os autores chamaram de "rede" formada pelos raios da escama, e estrias radiais reticuladas, respectivamente.

176. Borda anterior das escamas (Lucena, 1993: 121; Netto-Ferreira, 2006: 285) $\mathrm{CI}=0.50 ; \mathrm{RI}=0.91$.

(0) Apresentando conspícuas ondulações; (1) lisa ou com ondulações não conspícuas.

A borda anterior das escamas da maioria Characiformes parece ser praticamente lisa. Em Lebiasinidae (exceto Copella) e Erythrinidae, estas apresentam ondulações bastante conspícuas. Nos representantes do gênero Copella, no entanto, tais ondulações 
estão ausentes, ou representadas apenas por discretas ondulações, condição observada também em Brycon e no clado 65. A presença destas ondulações representa, portanto, uma sinapomorfia do clado 67 que é revertida em Copella.

177. Escamação da região dorsal da cabeça (Lucena, 1993: 24; Vari, 1995: 74; Buckup, 1998:18; Oyakawa, 1998:01; Zanata, 2000: 128; Zanata \& Vari, 2005: 168 modificado; Netto-Ferreira, 2006: 286) $-\mathrm{CI}=0.75$; $\mathrm{RI}=0.93$.

(0) Não se estendendo sobre o espinho do supra-occipital até a região média dos parietais; (1) estendendo-se sobre o espinho do supra-occipital até a região posterior dos parietais; (2) escamas cobrindo a região média dos parietais; (3) encobrindo grande parte dos parietais.

Roberts (1969) observa dois padrões básicos de escamação da região dorsal da cabeça entre os Characiformes. No primeiro, as escamas estão dispostas ao longo da margem posterior do espinho do supra-occipital condição observada em Acestrorhynchus e Brycon. No segundo padrão, que Roberts (1969) considera primitivo entre os caracóides, as escamas cobrem o espinho do supra-occipital e se estendem até a região posterior dos parietais, como observado em Ctenoluciidae e Hepsetidae. Oyakawa (1998), por sua vez, observou que na maioria dos Lebiasinidae e também em Erythrinidae as escamas da região dorsal da cabeça não só cobrem o supra-occipital, como também se estendem à região média dos parietais (sinapomorfia do clado 67). Oyakawa (1998) observou ainda que em Nannostomus, as escamas recobrem grande parte dos parietais, quase alcançando os frontais na maioria das espécies, condição sinapomórfica do gênero, sendo que, em $N$. anduzei, a escama mais anterior alcança o limite entre os parietais e os frontais.

178. Escamas sobre os parietais (Vari, 1995: 75; Netto-Ferreira, 2006: 287) - CI= $0.33 ; \mathrm{RI}=0.91$.

(0) Não inseridas em uma concavidade na porção posterior dos parietais; (1) inseridas em uma concavidade na porção posterior dos parietais.

Roberts (1969), além de observar o padrão de escamação da região dorsal dos Ctenoluciidae, Erythrinidae e Hepsetidae, observa também que nestes grupos as escamas estão inseridas em concavidades nos parietais. Vari (1995) confirma a observação de Roberts (1969) e afirma que tal condição está presente também nos 
Lebiasinidae. Vari (1995) considera ainda que em Ctenoluciidae existe uma concavidade anterior a esta crista, onde as escamas estão inseridas. A inserção das escamas em concavidades nos parietais foi observada em representantes das famílias Ctenoluciidae, Erythrinidae, Hepsetidae nos Pyrrhulinina. Nos Lebiasininae, Derhamia e Nannostomus, as escamas não estão inseridas em concavidades, apenas recobrem os parietais. Em Acestrorhynchus, ocorre uma concavidade semelhante à presente nestes grupos, entretanto, não foi possível determinar se as escamas estão inseridas nesta concavidade, ou não, uma vez que as escamas dos Acestrorhynchidae são pequenas.

\section{Primeira série longitudinal de escamas.}

(0) Estendendo-se desde o crânio até a nadadeira caudal; (1) alcançando pelo menos a vertical que passa pela origem da nadadeira anal, mas não ultrapassando a vertical que passa pela adiposa; (2) desde o crânio até o término da nadadeira dorsal; (3) alcançando a origem da nadadeira dorsal; (4) não alcançando a origem da nadadeira dorsal, mas ultrapassando a origem da nadadeira pélvica; (5) alcançando a origem da pélvica.

A maioria dos Characiformes apresenta escamas diminutas dispostas em séries longitudinais aproximadamente regulares. Em Lebiasinidae e Erythrinidae as escamas são grandes e espessas, dispostas em séries bastante regulares. A primeira série longitudinal de Erythrinidae se estende por todo o corpo, desde os parietais até a margem distal do pedúnculo caudal. Em Lebiasinidae, por sua vez, a primeira série longitudinal apresenta uma tendência à redução, se estendendo por todo o corpo apenas em Lebiasina erythrinoides, L. floridablancaensis, Derhamia e Nannostomus. Entre os demais Lebiasininae, a série de escamas alcançando a origem da nadadeira anal representa uma sinapomorfia do clado 69, enquanto que no clado (78) esta alcança apenas o término da nadadeira dorsal, estando revertida para o estado " 0 " no clado $81 \mathrm{e}$ transformando-se novamente 0-1 no clado 84. Em Pyrrhulinina, a redução da primeira série longitudinal ocorre de maneira independente, alcançando o término da nadadeira dorsal em Copeina e apenas alcançando a origem da nadadeira dorsal na maioria das espécies de Copella (exceto C. nigrofasciata). Em Pyrrhulina, por sua vez, a primeira série longitudinal de escamas não atinge a origem da nadadeira dorsal, ou sequer ultrapasa podendo estar restrita a apenas três escamas em P. eleanorae. Em Acestrorhynchus, Boulengerella e Hepsetus, as escamas encontram-se dispostas em séries irregulares, portanto, não foi possível estabelecer a homologia entre a primeira 
série longitudinal neste grupo e os demais, por isso, foi atribuído o estado “?” para estes táxons.

180. Escamas da quinta série longitudinal dos machos adultos (Oyakawa, 1998: 108; Netto-Ferreira, 2006: 294) $-\mathrm{CI}=0.50 ; \mathrm{RI}=0.95$.

(0) Com mesma forma e tamanho que as demais escamas do corpo ao longo de toda série, tecido epitelial não entumecido; (1) escamas da quinta série longitudinal apresentando-se alongadas posteriormente, com tecido epitelial entumecido, desde a vertical que passa pela origem da nadadeira anal, podendo estender-se posteriormente por quase todo o pedúnculo caudal.

Oyakawa (1998) observou que a "segunda série longitudinal de escamas acima da nadadeira anal dos machos" de Hoplerythrinus e Lebiasininae é modificada. A condição descrita por Oyakawa (1998) foi confirmada em Hoplerythrinus, porém, está presente apenas nos Lebiasininae do clado 78. Nestas espécies, as escamas da quinta série longitudinal encontram-se alongadas posteriormente, assumindo um formato aproximadamente triangular, estendendo-se desde a origem da nadadeira anal e geralmente alcançando a vertical que passa pela extremidade distal da nadadeira quando adpressa ao corpo, podendo estender-se por quase todo o pedúnculo caudal. O epitélio na superfície destas escamas apresenta-se distintamente hipertrofiado, assumindo um aspecto esponjoso (sendo possivelmente rico de tecido glandular). Apesar da grande similaridade entre os padrões envolvendo caracteres sexuais secundários observados entre os dois grupos, a hipótese mais parcimoniosa indica que todas estas condições surgiram independentemente no clado 78 e Hoplerythrinus e parecem ser condições únicas entre os Characiformes.

181. Escamas da sexta série longitudinal dos machos adultos (Netto-Ferreira, 2006: 295) $\mathrm{CI}=1.00 ; \mathrm{RI}=1.00$.

(0) Com mesma forma e tamanho que as demais escamas do corpo ao longo de toda a série, tecido epitelial não entumecido; (1) escama da sexta série longitudinal situada na vertical que passa pela origem da anal distintamente hipertrofiada, oblonga, demais escamas da série com epitélio entumecido ao longo da base da nadadeira anal.

Diferentemente das espécies do clado 78, os Lebiasininae do clado 69 apresentam modificações na sexta série longitudinal, de maneira que a escama situada 
na vertical que passa pela origem da nadadeira anal é distintamente maior que as demais escamas desta série. Esta condição já havia sido observada por Bussing, na descrição de L. boruca, no entanto, este considerou-a como exclusiva daquela espécie, graças ao pequeno universo comparativo utilizado por aquele autor na descrição da espécie. Esta condição é exclusiva do referido clado e não foi observada em nenhum outro grupo de Characiformes.

182. Escamas sobre a nadadeira caudal (Oyakawa, 1998: 104; Netto-Ferreira, 2006: 296) $-\mathrm{CI}=0.33 ; \mathrm{RI}=0.93$.

(0) Presentes somente na base dos lóbulos da nadadeira; (1) estendendo-se pelo menos até a metade do comprimento dos lóbulos.

Oyakawa (1998) observou que em Copeina, Lebiasina e Pyrrhulina as escamas da nadadeira caudal se estendem posteriormente, cobrindo mais da metade dos lóbulos da nadadeira. No presente estudo, escamas estendendo-se à metade dos lóbulos da nadadeira caudal foram observadas na maioria dos lebiasinídeos examinados, exceto nos representantes do gênero Copella, Nannostomus britskii, Pyrrhulina australis, $P$. brevis, P. semifasciata, Pyrrhulina sp. "Solimões" e Pyrrhulina sp. "Trombetas". Entre os táxons do grupo externo, escamas estendendo-se até a metade dos lóbulos da nadadeira caudal foram observadas apenas em Apareiodon affinis.

\section{Colorido}

183. Mancha umeral $-\mathrm{CI}=0.25 ; \mathrm{RI}=0.88$.

(0) Ausente; (1) presente.

A maioria dos Lebiasininae (exceto Lebiasina sp. "Parima") apresenta uma mancha escura arredondada na região umeral. A homologia desta mancha com a presentes em outros grupos de Characiformes (e.g. Acestrorhynchidae, Characidae, Characidiinae e Cynodontidae) é incerta, no entanto, a presença desta, bem como sua forma e posição representam caracteres informativos à taxonomia de sistemática da maioria destes grupos, especialmente os Characidae. Entre os Lebiasininae, este caráter não possui tal importância, uma vez que em todas as espécies examinadas, a mancha umeral apresenta-se bastante uniforme. 
184. Faixa primaria (Netto-Ferreira, 2006: 297) $-\mathrm{CI}=0.67 ; \mathrm{RI}=0.83$.

(0) Ausente; (1) presente ao longo de toda a ontogenia; (2) distinta em exemplares jovens, porém difusa (ou ausente) em exemplares adultos.

Weitzman (1966), em sua primeira revisão do gênero Nannostomus, convenciona a nomenclatura das faixas longitudinais presentes em representantes daquele gênero. Tal convenção é aplicável a todos os representantes da família. De maneira similar aos Nannostomus, os Lebiasininae e Derhamia apresentam, em sua grande maioria, duas faixas longitudinais: a faixa primária estende-se ao longo da quarta série longitudinal de escamas, desde o focinho até a porção distal do pedúnculo caudal, (Weitzman, 1966). A presença desta faixa parece uma característica compartilhada entre os Erythrinidae e Lebiasinidae, ainda que espécies de Anostomidae, Curimatidae e Parodontidae apresentem faixas longitudinais similares à observada nestas famílias, bem como às demais faixas de Lebiasinidae. Porém, devido à distância filogenética entre estes grupos é possível sugerir que estas tenham surgido independentemente. Em Boulengerella lateristriga, por sua vez, está presente uma faixa similar à observada no clado 67, mas esta encontra-se associada a outras duas faixas longitudinais tornando a homologia entre estas incerta.

Em Lebiasina taphorni e L. uruyensis a faixa primária encontra-se relativamente conspícua em exemplares jovens. No entanto, ao longo da ontogenia, a faixa primária torna-se gradativamente menos conspícua, estando representada apenas por manchas irregulares ao longo do corpo dos exemplares. Tal processo ontogenético de redução da faixa primária corresponde a uma sinapomorfia do clado formado por estas duas espécies.

185. Composição da faixa primária $-\mathrm{CI}=0.50 ; \mathrm{RI}=0.83$.

(0) Composta apenas de pigmento dérmico, subjacente à pele; (1) composta de pigmento subjacente (dérmico) e superficial (epidérmico).

Entre os Lebiasinidae, a faixa primária é plesiomorficamente composta deduas camadas de pigmento: uma camada de pigmento dérmico, subjacente à pele e outra de pigmento epidérmico. Nas espécies do clado 69 , no entanto, a faixa primária é composta essencialmente da camada dérmica de pigmento, constituindo uma sinapomorfia para o grupo. 
186. Extensão da faixa primária $-\mathrm{CI}=0.50 ; \mathrm{RI}=0.86$.

(0) Estendendo-se desde o focinho até os raios mediais da nadadeira caudal; (1) estendendo-se desde o focinho até a porção distal do pedúnculo caudal, mas não alcançando os raios mediais; (2) estendendo-se desde o focinho, ultrapassando a origem da nadadeira dorsal, mas não alcançando o pedúnculo caudal; (3) estendendo-se desde o focinho, ultrapassando a cintura peitoral, mas não alcançando a origem da nadadeira dorsal; (4) estendendo-se desde o focinho, alcançando a margem posterior do opérculo.

A faixa primária de Erythrinidae e Lebiasinidae tipicamente se estende por todo o corpo. Em Pyrrhulinina, porém, a faixa primária apresenta-se curta na maioria das espécies, estendendo-se desde o focinho até a margem posterior do opérculo. Esta condição, no entanto, encontra-se revertida nas espécies de Copella do clado 103 e nas Pyrrhulina do clado 107 (revertida ao estado "4" em P. australis e P. vittata).

187. Série longitudinal de manchas arredondadas $-\mathrm{CI}=0.67 ; \mathrm{RI}=0.86$.

(0) ausente; (1) formando uma série de pequenas manchas, geralmente ocupando a área de uma única escama; (2) formando uma série de manchas grandes, distintamente encobrindo parte ou em sua totalidade, as escamas da terceira, quarta e quinta séries longitudinais.

De maneira geral, a faixa primária dos Lebiasininae apresenta-se contínua desde a região anterior do corpo até a porção distal do pedúnculo caudal. Nas espécies do clado 83 , no entanto, a faixa primária encontra-se fragmentada em um número variável de manchas arredondadas. Na maioria das espécies, estas manchas são grandes como descritas no estado “2”. Em Lebiasina astrigata, L. multimaculata, L. panamensis e L. sp. "Azuay", no entanto, estas manchas apresentam-se pequenas, restritas, geralmente, a uma escama da quarta série longitudinal.

188. Faixa secundária (Netto-Ferreira, 2006: 298) $-\mathrm{CI}=0.29 ; \mathrm{RI}=0.85$.

(0) Ausente; (1) estendendo-se ao longo das escamas da primeira e segunda séries longitudinais; (2) estendendo-se ao longo das escamas da segunda e terceira séries longitudinais.

A faixa secundária estende-se dorsalmente à faixa primária, desde a porção látero-dorsal da cabeça, percorrendo principalmente pela segunda série longitudinal de escamas, até a porção distal do pedúnculo caudal (Weitzman, 1966), sendo que, em 
Nannostomus marginatus e Lebiasina sp. "Parima" esta se estende até os raios da nadadeira caudal. Entre os Lebiasininae, a faixa secundária percorre plesiomorficamente a primeira e segunda séries longitudinais, no entanto, em L. floridablancaensis e nos clados 88 e 93, esta encontra-se deslocada ventralmente, passando pela segunda e terceira séries de escamas. A perda da faixa secundária representa sinapomorfias independentes dos Lebiasininae do clado 80, Nannostomus unifasciatus e os Pyrrhulinina. Desta maneira, foi atribuída a codificação “-” para estes grupos nos caracteres 189 e 190.

189. Composição da faixa secundária $-\mathrm{CI}=0.25 ; \mathrm{RI}=0.81$.

(0) inconspícua, representada apenas por pigmento dérmico, subjacente às escamas; (1) conspícua, representada tanto por pigmento dérmico quanto epidérmico.

Entre as espécies de Lebiasininae a faixa secundária é composta basicamente por pigmento dérmico, resultando em uma faixa inconspícua na maioria das espécies. Nos representantes dos clados 88 e 90, em que a faixa secundária passa ao longo da segunda e terceira séries longitudinais de escamas, a faixa apresenta uma camada epidérmica de cromatóforos, tornando-a bastante conspícua. Tal condição é observada também em Pyrrhulininae (exceto Pyrrhulinina, onde a faixa está ausente), e representa aquisições independentes nestes três grupos.

190. Continuidade da faixa secundária $-\mathrm{CI}=0.50 ; \mathrm{RI}=0.50$.

(0) faixa contínua; (1) faixa fragmentada, representada por uma série de pequenas manchas escuras.

Assim como a faixa primária, a faixa secundária encontra-se tipicamente contínua na maioria das espécies de Lebiasinidae. Em Derhamia e no clado 119 (Nannostomus limatus e $N$. nitidus) esta encontra-se fragmentada, formando uma série de pequenas manchas escuras, na base de cada escama da segunda série longitudinal. Esta condição representa uma sinapomorfia homoplástica destes dois grupos.

191. Faixa "intermediária" $-\mathrm{CI}=1.00 ; \mathrm{RI}=1.00$.

(0) Ausente; (1) presente, restrita ao IO 3; (2) se estendendo do IO 3 à vertical que passa pela origem da nadadeira anal, ao longo da quinta série longitudinal de escamas. 
As espécies de Lebiasininae do clado 93 apresentam uma faixa situada entre a faixa primária e a faixa terciária. Geralmente restrita à margem ventral do infra-orbital 3, esta faixa não figura entre aquelas descritas por Weitzman (1966) e em Lebiasina sp. "Parima" esta se estende até a vertical que passa pela origem da nadadeira anal.

192. Faixa terciária (Netto-Ferreira, 2006: 299) $-\mathrm{CI}=0.17$; $\mathrm{RI}=0.17$.

(0) Ausente; (1) presente.

A faixa terciária é a mais ventral, geralmente se estendendo desde a mandíbula até a nadadeira anal, passando ventralmente à origem da nadadeira peitoral (Weitzman, 1966), ao longo da das escamas da sexta série longitudinal, podendo alcançar a porção ventral da quinta. Entre os táxons examinados, a faixa terciária está presente em Nannostomus britskii, $N$. eques, $N$. limatus, $N$. marginatus, $N$. marilynae, $N$. trifasciatus e Lebiasina sp. "Parima". Apesar de ser um caráter de grande importância para a taxonomia de Nannostomus, este caráter não parece apresentar um sinal filogenético muito forte, aparentemente causando mais ruídos à análise do que resolvendo relações entre as espécies do gênero.

193. Faixa quaternária (Netto-Ferreira, 2006: 300$)-\mathrm{CI}=0.50 ; \mathrm{RI}=0.00$.

(0) Ausente; (1) Presente.

Presente apenas em Nannostomus britskii e N. eques, a faixa quaternária estende-se dorsalmente à faixa secundária, ao longo da primeira série longitudinal de escamas (Weitzman, 1978). O presente esquema de relações sugere o surgimento independente desta faixa nestas duas espécies.

194. Bandas oblíquas (Netto-Ferreira, 2006: 301$)-\mathrm{CI}=1.00 ; \mathrm{RI}=1.00$.

(0) Ausente; (1) presente.

A maioria das espécies do gênero Nannostomus apresenta dois tipos de coloração (Weitzman, 1966). A coloração diurna, que consiste principalmente das faixas longitudinais. E a coloração noturna, que consiste em duas bandas oblíquas, estando a primeira situada anteriormente à nadadeira dorsal e a segunda anterior à nadadeira anal, com sua porção posterior situada dorsalmente aos primeiros raios da anal. Ainda que seu colorido constitua-se basicamente de bandas oblíquas, Weitzman (1966) sugere que as bandas observadas Nannostomus espei não sejam homólogas às observadas nas 
demais espécies. Não existe registro de padrão semelhante ao observado em Nannostomus para os demais Lebiasinidae ou Characiformes, que no período da noite apenas contraem os cromatóforos, assumindo uma coloração mais pálida.

195. Deposição de guanina nas escamas $-\mathrm{CI}=0.67 ; \mathrm{RI}=0.87$.

(0) deposição de guanina homogênea, inconspícua; (1) quarta escama da linha lateral com uma distinta mancha prateada (quando fixado); (2) base das escamas da terceira, quarta e quinta (ou mesmo sexta) séries longitudinais com manchas prateadas, formando séries longitudinais.

A maioria das espécies de Lebiasinidae apresenta três a quatro séries longitudinais de manchas que variam do amarelo claro ao vermelho intenso. Na maioria destas, no entanto, existe pouca deposição de guanina nas escamas. Nos Lebiasininae do clado 69, ocorre intensa deposição de guanina ao menos na quarta escama da linha lateral. Em Lebiasina boruca e nas espécies do clado 68, por sua vez, ocorre intensa deposição de guanina nas escamas da terceira, quarta e quinta (ou mesmo sexta) séries longitudinais com manchas prateadas, formando distintas séries longitudinais de manchas prateadas, onde, em vida, as manchas resultantes de deposição de pigmentos carotenóides se dispõem.

196. Mancha ovalada na nadadeira dorsal (Netto-Ferreira, 2006: 303 ) $-\mathrm{CI}=0.14$; $\mathrm{RI}=0.74$.

(0) Ausente; (1) presente.

Em exemplares adultos de Lebiasininae, a mancha ovalada da dorsal está ausente, entretanto, na porção média da nadadeira, observa-se pequenas manchas nas membranas interradiais. Em exemplares jovens estas "manchas" são representadas por uma única mancha ovalada relativamente conspícua, que aparentemente se fragmenta e se tornan menos conspícua ao longo da ontogenia. O presente esquema de relações refuta a homologia entre esta mancha e a observada na porção médio-distal da nadadeira dorsal das espécies de Copeina, Copella e Pyrrhulina. Uma conspícua mancha está presente nos raios indivisos da nadadeira dorsal de N. marginatus. Zarske (2009), utiliza essa característica para diferenciar $N$. rubrocaudatus Zarske (que apresenta uma mancha inconspícua na base dos raios indivisos) de $N$. marginatus e $N$. mortenthaleri (que apresentam a mancha na porção médio-distal). 
197. Mancha na base dos raios médios da nadadeira caudal (Netto-Ferreira, 2006: 304) $-\mathrm{CI}=0.40 ; \mathrm{RI}=0.88$.

(0) Ausente; (1) presente, geralmente conspícua, situada no pedúnculo caudal e raios mediais da nadadeira caudal; (2) presente, geralmente pouco conspícua, situada somente sobre os raios da nadadeira caudal.

A maioria das espécies de Lebiasininae apresenta uma mancha ovalada na porção distal do pedúnculo caudal, que alcança a base dos raios médios da nadadeira caudal. Mancha similar está presente também em Acestrorhynchus, bem como representantes de Characidae, Cynodontidae e outras famílias de Characiformes. Esta mancha, no entanto, está secundariamente ausente nas espécies dos clados 72 e 80, representando perdas independentes da mancha. Nas espécies do clado 93, por sua vez, a mancha encontra-se deslocada posteriormente não se sobrepondo ao pedúnculo caudal, estando assim, restrita aos raios médios da caudal, uma condição sinapomórfica deste clado.

\section{Raios pró-correntes do lóbulo superior e inferior da nadadeira caudal} (Netto-Ferreira, 2006: 305) $-\mathrm{CI}=1.00 ; \mathrm{RI}=1.00$.

(0) Despigmentados, ou apresentando pigmentação semelhante à dos demais raios; (1) Fortemente pigmentados em machos adultos.

Representantes adultos dos gêneros Copella e Pyrrhulina freqüentemente apresentam uma estreita e sutil pigmentação negra nas margens ventrais das nadadeiras pélvicas, anal e caudal. Em Copella compta, C. metae, C. nattereri, C. nigrofasciata e C. vilmae, não apenas as margens das nadadeiras são pigmentadas, mas também os raios pró-correntes dos lóbulos superior e inferior da nadadeira caudal, em toda sua extensão. Esta condição não foi observada em nenhum exemplar das espécies do grupo $C$. arnoldi ou qualquer outro caraciforme, onde os raios pró-correntes apresentam colorido semelhante ao dos demais raios. Zarske e Géry (2006) utilizam a ausência deste padrão de pigmentação como um dos caracteres diagnósticos de C. meinkeni Zarske \& Géry e que diferenciam aquela espécie de $C$. nattereri. De fato, exemplares que se assemelham à forma descrita por aqueles autores não apresentam esta mancha, no entanto, somente um estudo com contexto de revisão pode determinar se $C$. meinkeni é de fato uma espécie válida, dada sua semelhança com C. nattereri. 
199. Colorido da nadadeira caudal (Zanata, 2000: 143 - modificado; NettoFerreira, 2006: 306) $-\mathrm{CI}=0.33 ; \mathrm{RI}=0.50$.

(0) Nadadeira caudal pouco pigmentada, ou com pigmentação homogênea; (1) Lóbulo inferior da nadadeira caudal pigmentado.

A nadadeira caudal da maioria dos representantes de Lebiasinidae examinados apresenta a nadadeira caudal hialina (Copeina, Copella, Derhamia e Pyrrhulina) ou possuem pigmentação homogênea (Lebiasininae). A maioria dos representantes do gênero Nannostomus, por sua vez, apresenta os raios médios da nadadeira caudal são pigmentados, devido ao prolongamento da faixa primária sobre os raios. Já em Nannostomus britskii, N. eques, N. harrisoni e N. unifasciatus, o lóbulo inferior da nadadeira caudal apresenta-se fortemente pigmentado, podendo formar ocelos que variam de tonalidade do amarelo ao vermelho em $N$. eques, $N$. harrisoni e $N$. unifasciatus (Weitzman, 1966; Weitzman \& Cobb, 1975). Weitzman e Cobb (1975) relatam uma população de $N$. trifasciatus que apresentam um ocelo rudimentar no lóbulo inferior da nadadeira caudal, no entanto, os exemplares examinados aqui não apresentam tal condição.

\section{Musculatura facial}

(Figuras 65-69)

\section{Nota sobre a homologia dos ramos do adductor mandibulae:}

Plesiomorficamente, o adductor mandibulae de Teleostei encontra-se representado por quatro subdivisões: a seção Aw, que ocupa a fossa meckeliana na mandíbula; uma seção mais lateral, denominada A1, que está associada ao ligamentum primordiale e ao maxilar; a seção A2, que ocupa grande parte da face; e a seção A3, que está inserida na porção mais medial da face, estando geralmente associada ao hiomandibular e o metapterigóide (Winterbottom, 1974).

Gosline (1989) sugere que em Ostariophysi, a porção mais lateral do músculo não seria homóloga ao A1 dos Acanthopterygii. Enquanto que nos Teleostei superiores o A1 parece se originar a partir da porção ântero-dorsal do A2 que se associa ao ligamentum primordiale (Winterbottom, 1974), nos Ostariophysi o ramo mais lateral do músculo diferencia-se a partir da porção antero-ventral do A2, e se associa à porção látero-posterior do ângulo-articular (Gosline, 1989). Diogo e Chardon (2000) sugerem o 
emprego da terminologia "A1-OST" para distinguir estes músculos dado a origem independente destes. Datovo e Bockmann (2010), por sua vez, discutem as homologias e subdivisões do músculo em Nematogenyidae e Trichomycteridae e propõem que a seção “A1-OST" seria, naqueles grupos, resultante da associação entre dois ramos distintos do adductor mandibulae: o A2' e o A3' propostos por aqueles autores. Entre os exemplares examinados, observou-se que em Characiformes, o adductor mandibulae, além do Aw (quando este está presente), apresenta apenas uma seção direcionada posteriormente, com origem nos ossos da face. Esta seção do músculo parece homóloga à seção A2 descrita por Winterbottom (1974) e Datovo e Bockmann (2010), e encontrase tripartida na maioria dos táxons examinados. Seguindo a nomenclatura adotada pelos últimos, a classificação das três seções seriam: A2' - correspondendo à seção mais lateral, geralmente inserida na porção posterior do ângulo-articular; A2" - seção mediana e mais desenvolvida, inserida por meio de tecido aponeurótico no osso coronomeckeliano, esta seção é separada da A2' pelo ramo mandibular do nervo trigêmeo; A2" - seção mais medial, separada da A2" pelo levator arcus palatini, geralmente apresentando uma porção aponeurótica que converge para a porção aponeurótica da seção A2" (Alexander, 1964), inserindo-se na face lateral do metapterigóide, simplético, pré-opérculo e hiomandibular (= A2b de Howes, 1976 e à A3 de Howes - observada em Serrasalmus -, Alexander, 1964 e Mattox, 2010).

200. Forma do perfil do Adductor mandibulae $-\mathrm{CI}=0.25 ; \mathrm{RI}=0.70$.

(0) Aproximadamente triangular; (1) aproximadamente quadrangular; (2) aproximadamente elíptico.

$\mathrm{Na}$ maioria dos táxons examinados, o adductor mandibulae apresenta um formato aproximadamente triangular. Em grupos ictiófagos e algumas espécies de Lebiasininae, o adductor mandibulae apresenta-se expandido ântero-posteriormente de maneira que o músculo assuma uma forma aproximadamente quadrangular. Em Nannostomus, por outro lado, a seção A2" do adductor mandibulae encontra-se fortemente reduzida, de modo que o perfil do músculo assume um formato aproximadamente elíptico. Tal redução parece estar associada à expansão da região orbital no gênero, de maneira que a área de inserção dos músculos também encontra-se diminuída. 
201. Seção A2' do Adductor mandibulae $-\mathrm{CI}=1.00 ; \mathrm{RI}=1.00$.

(0) Ligado principalmente ao ângulo-articular e ao tecido aponeurótico do A2"; (1) ligado principalmente ao ligamentum primordiale e ao maxilar.

Conforme mencionado anteriormente, a seção A2' do adductor mandibulae está associada principalmente à porção posterior do ângulo-articular dos Characiformes. Alexander (1964) constatou que este ramo estaria associado ao ligamentum primordiale em Pyrrhulina. A condição descrita por Alexander está presente em todos os Pyrrhulininae examinados e constitui uma sinapomorfia deste grupo. Esta condição é compartilhada com representantes de Anostomidae, Curimatidae e Hemiodontidae (Gosline, 1989), bem como Citharinidae e Distichodontidae (Vari, 1979).

202. Extensão da seção A2' do Adductor mandibulae $-\mathrm{CI}=0.50 ; \mathrm{RI}=0.95$.

(0) Músculo restrito à porção anterior da face, inserido apenas na porção horizontal do pré-opérculo e encobrindo apenas uma pequena fração do ramo A2"; (1) ramo A2' se estendendo posteriormente, inserido na porção horizontal do pré-opérculo, encobrindo o A2" em grande parte; (2) A2' inserido-se tanto na porção horizontal do pré-opérculo quanto na vertical, encobrindo quase todo ramo A2".

A seção A2' do adductor mandibulae de Boulengerella e Ctenolucius encontrase expandida, encobrindo grande parte da seção A2" lateralmente (Gosline, 1989). Tal condição está presente também em Lebiasininae, Hoplerythrinus. Na maioria dos Characiformes, no entanto, esta seção encontra-se restrita à porção anterior da face (Alexander, 1964; Howes, 1976). A condição derivada observada nos Lebiasininae, encontra-se revertida em Pyrrhulininae, com uma redução subseqüente em Nannostomus, onde a seção A2' encobre principalmente o tecido aponeurótico do A2" e uma pequena porção das fibras musculares propriamente ditas.

203. Origem dorsal da seção A2" do Adductor mandibulae $-\mathrm{CI}=0.75 ; \mathrm{RI}=0.99$.

(0) Não encobrindo ou encobrindo apenas a porção ventral do Levator arcus palatini (LAP); (1) encobrindo grande parte do LAP, mas não atingindo o espinho do esfenótico (EE); (2) encobrindo grande parte do LAP e alcançando o EE; (3) encobrindo praticamente todo o LAP e inserindo-se medialmente ao Dilatator operculi.

A seção A2" do adductor mandibulae dos Lebiasininae e demais grupos examinados (exceto Pyrrhulininae) examinados por todo ramo vertical do pré-opérculo 
e o hiomandibular, inserindo-se medialmente ao dilatator operculi, alcançando ao menos a articulação do hiomandibular com o crânio. Entre os Pyrrhulininae, por sua vez, a seção A2" do adductor mandibulae encontra-se variavelmente reduzida: apenas alcançando o espinho do esfenótico em Copeina e Derhamia; encobrindo grande parte do levator arcus palatini, mas não alcançando o espinho do esfenótico em Copella e Pyrrhulina; restrito à porção ventral do levator arcus palatini em Nannostomus. Conforme mencionado anteriormente, a redução do A2 em Pyrrhulininae parece estar relacionada à expansão da área da órbita, e possivelmente também à mudança de nicho dos representantes deste grupo em relação aos demais Erythrinoidea.

\section{Seção A2" do Adductor mandibulae $-\mathrm{CI}=0.60 ; \mathrm{RI}=0.95$.}

(0) Um feixe muscular denso, inserido ventralmente ao LAP na face lateral e medial da porção lamelar do hiomandibular; (1) pequenos feixes espaçados, inseridos no metapterigóide e face lateral da porção lamelar do hiomandibular; (2) representado por um diminuto feixe muscular, ligado apenas ao metapterigóide; (3) ausente.

Gosline (1989) sugere que em alguns grupos de Characiformes a seção "interna" (=A2"+A2"”) encontra-se subdivida em duas porções, separadas principalmente pelo levator arcus palatini. $\mathrm{O}$ autor ressalta que este ramo encontra-se insipiente em Acestrorhynchus e conspícuo em Charax e Hydrolycus. De fato, este ramo encontra-se ausente em Acestrorhynchus pantaneiro, mas é representada por um feixe denso de fibras musculares inseridas na porção lamelar ventral do hiomandibular e na porção lamelar dorsal do metapterigóide em Lebiasininae, Erythrinidae e Boulengerella. Em Pyrrhulininae, esta seção é representada apenas por pequenos feixes espaçados inseridos em uma restrita área do metapterigóide e do hiomandibular. Em Nannostomus, por sua vez, este ramo é representado apenas por um diminuto feixe muscular associado à porção ventral do metapterigóide. Gosline (1989) afirma ainda que em Piabucina (=Lebiasina) e Hoplias, este ramo apresenta a porção aponeurótica separada da seção A2", diferentemente dos demais grupos examinados por aquele autor. No entanto, em todos os grupos examinados, a seção A2"” apresenta uma porção aponeurótica porém, variavelmente desenvolvida. Este caráter representa evidências adicionais à tendências redutivas em Pyrrhulininae. 
205. Adductor arcus palatini (Lucena, 1993: 114) $-\mathrm{CI}=0.40 ; \mathrm{RI}=0.93$

(0) Estendendo-se por todo o palato, desde o hiomandibular até o palatino, inserindo-se lateralmente ao longo da borda medial do meta- e endopterigóide, e medialmente ao longo da crista ventral do parasfenóide, desde a articulação deste com o esfenótico até os etmóides laterais; (1) estendendo-se por todo o palato, desde o hiomandibular até o palatino, inserindo-se lateralmente ao longo da borda medial do metapterigóide e toda a superfície dorsal do endopterigóide (que apresenta uma discreta crista onde o músculo se insere), e medialmente ao longo da crista ventral do parasfenóide; (2) restrito à porção posterior do palato.

Howes (1976) em seu estudo da musculatura craniana de Cynodontidae e Characinae observou que o adductor arcus palatini nestes grupos apresenta-se, geralmente, restrito à porção médio-posterior do metapterigóide e do endopterigóide. Mattox (2010), por sua vez, observou que em Boulengerella, Brycon, Hepsetus, Hoplias, Salminus e Serrasalmus este músculo se estende anteriormente, alcançando a face ventral do vômer. Apesar de não ter sido observado nenhum exemplar onde o adductor arcus palatini alcançasse a margem ventral do vômer (ao menos da porção principal do osso, situada anteriormente aos etmóides laterais) foi possível confirmar as demais observações de Mattox (2010) em Brycon, Boulengerella, Hepsetus e Hoplerythrinus, bem como a maioria dos Lebiasinidae. Em Copella e Pyrrhulina, além da extensão anterior do músculo, o adductor arcus palatini encobre praticamente todo o endopterigóide, diferentemente de todos os demais táxons examinados, onde ao menos uma pequena área do osso permanece "exposta". Em ambos os gêneros, a margem lateral do endopterigóide apresenta uma discreta crista, possivelmente relacionada à expansão da área de inserção do músculo no osso. Em Nannostomus, por outro lado, o músculo permanece restrito à porção posterior do "palato", onde apenas poucas fibras alcançam a porção médio-dorsal do endopterigóide.

206. Inserção da margem posterior do adductor arcus palatini $-\mathrm{CI}=1.00$; $\mathrm{RI}=$ 1.00 .

(0) margem dorsal do metapterigóide sem uma quilha onde se insere o músculo; (1) margem dorsal do metapterigóide com uma distinta quilha onde a margem ventro-lateral do músculo se insere. 
A inserção do adductor arcus palatini ocorra principalmente no metapterigóide e no hiomandibular (Winterbottom,1974). Em ambos os ossos estão presentes expansões lamelares, no sentido anterior e ventral no hiomandibular, e um par de projeções do metapterigóide: uma anterior, orientada mais lateralmente, contínua com o endopterigóide e outra posterior, orientada medialmente e contínua com a expansão do hiomandibular. Tais projeções proporcionam uma expansão da área de inserção do músculo na porção posterior da fissura infraorbitalis e estão presentes na maioria dos grupos examinados. Em Pyrrhulininae, no entanto, as projeções do metapterigóide encontram-se gradualmente reduzidas. Ambas estão presentes em Derhamia, ainda que rudimentares, em Nannostomus apenas a anterior está presente (podendo estar ausente nas espécies do clado 125), e nos Pyrrhulinina ambas estão ausentes.

207. Origem do dilatator operculi (Vari, 1995: 83; Secioso, 1997, S16; Buckup, 1998: 78; Netto-Ferreira, 2006: 307) $-\mathrm{CI}=0.33$; $\mathrm{RI}=0.93$.

(0) Origem limitada à superfície lateral do frontal e superfície do espinho do esfenótico;

(1) Origem além do espinho do esfenótico, passando pelo menos ao longo de parte da órbita.

Plesiomorficamente, o dilatator operculi dos Characiformes encontra-se restrito à fossa do músculo, delimitada principalmente pelo esfenótico e o pterótico. Vari (1995) observou que o dilatator operculi dos Lebiasininae se estende anteriormente ao espinho do esfenótico, alcançando a região média da órbita, condição compartilhada com com Acestrorhynchus, Ctenoluciidae e Erythrinidae. Os Pyrrhulininae, por sua vez, apresentam morfologia semelhante à dos demais Characiformes, condição também observada em Hepsetidae. A reversão dos caracteres relacionados à musculatura facial em Pyrrhulininae parecem estar associados à tendência à miniaturização do grupo, que ocorre de maneira gradual, estando as condições extremas em representantes de Nannostomus, Copella e Pyrrhulina do clado 107.

\section{Inserção do dilatator operculi no hiomandibular $-\mathrm{CI}=1.00 ; \mathrm{RI}=1.00$.}

(0) Ligando-se diretamente à superfície do osso; (1) inserção por meio de um processo na superfície lateral do osso.

$\mathrm{Na}$ maioria dos táxons examinados, a superfície lateral do hiomandibular apresenta-se aproximadamente lisa. Nas Lebiasina do clado 88, por sua vez, uma 
pequena porção do dilatator operculi está inserida em um pequeno processo presente na superfície lateral do osso e direcionado posteriormente, condição não observada em nenhum outro táxon examinado no presente estudo.

\section{Reconstrução filogenética}

A seguir são discutidos o monofiletismo de Lebiasinidae e seus subgrupos, (enumerados na fig. 01). As sinapomorfias de cada nó (Fig. 70) são referentes à árvore fundamental selecionada (fig. 01), onde somente as transformações livres de ambigüidade são citadas. As relações do grupo externo serão brevemente discutidas, uma vez que estas não representam o objetivo do presente estudo. Tal ressalva se aplica também às relações inter-específicas de Copella, Nannostomus e Pyrrhulina.

O monofiletismo de Lebiasinidae foi corroborado com base em 20 sinapomorfias não ambíguas, sendo 12 exclusivas, a maioria envolvendo a redução de ossos, do número de dentes e perda de partes do canal látero-sensorial, caracteres geralmente associados a processos de miniaturização (Weitzman \& Vari, 1988; Zanata \& Vari, 2005). Este resultado contraria as hipóteses de Oyakawa (1998) e Moreira (2007) que sugeriram o parafiletismo de Lebiasinidae. Tais resultados aparentemente se deram por: 1- o conjunto de caracteres examinados não inclui os caracteres considerados sinapomórficos da família; 2- inclusão de caracteres plesiomórficos de Erythrinoidea, ou que tenham surgindo independentemente em Erythrinidae, Lebiasininae e Pyrrhulininae. Moreira (2007) menciona que, entre os caracteres examinados em seu estudo não foram incluídos 10 dos caracteres considerados apomórficos da família (e.g. ausência da fenestra quadrado-metapterigóide - caráter 69), e que a inclusão destes poderia alterar a topologia obtida. O monofiletismo de Lebiasinidae já havia sido corroborado por Vari (1995) e Buckup (1998), no entanto, aqueles estudos não tinham o intuito de testar a condição monofilética do grupo. $\mathrm{O}$ resultado obtido aqui constitui a hipótese mais robusta $($ Bremer $=18$; Bootstrap $=100)$ das relações do grupo, e não deixa margens a dúvidas quanto ao monofiletismo da família.

A subfamília Pyrrhulininae (clado 94), representa o subgrupo mais diverso de Lebiasinidae, tanto em número de espécies quanto em formas. O grupo é definido por 25 sinapomorfias, (15 exclusivas), das quais a maioria envolve modificações associadas a hábitos alimentares (na região oral - caráter 50 e 54; e musculatura facial - caracteres 
201-204, 206 e 207), e redução de canais látero-sensoriais cefálicos (principalmente da série circum-orbital - caracteres 110-113). O gênero monotípico Derhamia é o mais basal do grupo sendo externamente semelhante aos Lebiasininae, o que aparentemente induziu Géry e Zarske (2002) a incluírem o gênero naquela família. O táxon é definido com base em cinco autapomorfias. A hipertrofia do canal látero-sensorial supra-orbital e dos neuromastos associados a este constitui uma condição exclusiva do gênero.

O monofiletismo da tribo Pyrrhulinini (clado 95) é corroborado por 15 sinapomorfias (sete exclusivas) e ratifica a tendência à redução de canais sensoriais observada na subfamília, aparentemente associada a minaturização. Nos representantes da tribo o ramo parietal do canal supra-orbital (caráter 106) e os canais associados à região pós-temporal e à cintura peitoral são perdidos (caracteres 119, 121 e 122). Outros caracteres relacionados a eventos de miniaturização observados no grupo envolvem a redução do processo posterior do vômer (caráter 21), do número de raios branquiostégios (caráter 87) e de raios pró-correntes da nadadeira caudal (caracteres 164 e 166). A tribo Pyrrhulinini encontra-se dividida em duas sub-unidades, as quais exploram vertentes opostas do consumo de macro-invertebrados. Os Nannostomina especializaram-se na apreensão de larvas de insetos autóctones (principalmente larvas de Chironomidae), enquanto os Pyrrhulinina alimentam-se essencialmente de insetos alóctones (principalmente formigas e cupins).

A sub-tribo monotípica Nannostomina (clado 118) é corroborada por 25 sinapomorfias (15 exclusivas), apresentando-se radicalmente modificada em relação aos demais Lebiasinidae e mais ainda em relação aos Erythrinoidea (de maneira geral, predadores de médio a grande porte). Tamanho é o nível de modificação que historicamente diversas propostas de relações Nannostomus foram relacionados a diferentes grupos de Characiformes: 'Anostomatina' (sensu Günther, 1864 Steindachner, 1876; Eigenmann e Eigenmann, 1891; Boulenger, 1904); Characidiinae (Boulenger, 1895; Eigenmann, 1909); Hemiodontinae (sensu Eigenmann, 1909 Regan, 1911); Leporininae e Parodontinae (sensu Fowler, 1950). É interessante ressaltar que Nannostomus apresenta a junção sincondral dos dentários e a articulação do prémaxilar com a superfície ventral do mesetmóide, características plesiomórficas em Characiformes. Estes caracteres podem ter induzido aqueles autores a propor relações próximas entre os Nannostomina e os grupos mencionados acima, que atualmente são considerados Characiformes basais (Buckup, 1998; Moreira, 2007). A reversão da 
articulação entre os dentários (caráter 53) e do pré-maxilar com o mesetmóide (caráter 47) e as sinapomorfias envolvendo a musculatura facial (caracteres 200, 202-205) são relacionadas aos hábitos alimentares do grupo. A relação de grupo-irmão de Nannostomina com os Pyrrhulinina contraria Oyakawa (1998), que sugeriu que este grupo estaria mais proximamente relacionado a Copella e Pyrrhulina.

A sub-tribo Pyrrhulinina é definida com base em 27 sinapomorfias (11 exclusivas). A maioria destas envolve restruturações de complexos morfológicos, aparentemente devidas à perda de ossos ou parte destes. Entre elas, é interessante ressaltar a associação única entre o paresfenóide e o suspensório, onde o paresfenóide apresenta um par de projeções direcionadas anteriormente (caráter 22) que margeiam a face lateral do vômer (que se encontra bastante reduzido em Pyrrhulininae), onde se insere o ligamento "endopterigóide-vômer" descrito por Arratia (1992). A inserção do ligamento lateral da porção distal do pós-temporal no crânio, que nos demais Characiformes ocorre no ramo médio do epoccipital, neste grupo ocorre no pterótico (caráter 32), aparentemente devido à perda do ramo médio do epoccipital (caráter 36), que apresenta um processo em sua face dorsal para a inserção do ligamento. Adicionalmente, a expansão da porção distal do hipural 5 em direção ao hipural 4 (caráter 162), parece ser outra restruturação relacionada à perda de um elemento ósseo, o hipural 6 (caráter 163). Por fim, os caracteres (144 e 153) que envolvem a perda dos radiais mediais das nadadeiras anal e dorsal, juntamente com a projeção da lamela transversal dos pterigióforos da nadadeira anal (caráter 152) e a junção sincondral entre estes pterigióforos (caráter150) - sinapomorfia de Pyrrhulinini posteriormente modificada no clado 100) parecem ser modificações subseqüentes associadas a um reforço estrutural destas nadadeiras, de grande importância na corte e na reprodução em Lebiasinidae.

Com três espécies nominais e possivelmente apenas uma válida, o gênero Copeina pode ser diagnosticado com base em 12 autapomorfias, nenhuma delas exclusiva. O gênero constitui o grupo-irmão do clado 100, incluindo as espécies de Copella e Pyrrhulina, sendo este definido por 10 sinapomorfias, quatro exclusivas. A maioria das sinapomorfias deste clado envolve caracteres redutivos: perda dos dentes do faringo-branquial 2 (caráter 91), sistema látero-sensorial do corpo sem escamas perfuradas (caráter 125), ausência do extra-escapular (caráter 93), do supraneural da vértebra 6 (caráter 137) e da peça terminal da nadadeira dorsal (caráter 145), redução do 
número de raios pró-correntes (caráter 164) e do número de escamas na primeira série longitudinal (caráter 179). As demais sinapomorfias envolvem caracteres sexuais secundários de machos (e. g. anquilose dos pterigióforos da nadadeira anal, presença de raios filamentosos nas nadadeiras dorsal e anal - caracteres 151 e 173) e alimentares (deslocamento da nadadeira dorsal para o terço posterior do corpo - caráter 146). Todos os gêneros deste clado necessitam de revisão e concentram os maiores problemas taxonômicos de Lebiasinidae, conforme descritos em Weitzman e Weitzman (2003). Zarske e Géry (2006) sugerem que o gênero Holotaxis poderia ser um sinônimo de Copeina, com base na sugestão de Eigenmann \& Eigenmann (1889). No entanto, após o exame do tipo de Holotaxis laetus Cope (= Pyrrhulina laeta)foi possível constatar que o exemplar não apresenta nenhuma das sinapomorfias de Copeina, mas sim do clado Copella + Pyrrhulina. Ainda que o tipo de H. laetus encontre-se praticamente destruído, é possível constatar a ausência do extra-escapular, da anquilose dos pterigióforos da nadadeira anal e do deslocamento da nadadeira dorsal para a região posterior do exemplar, além da ausência do pós-cleitro 3, condição diagnóstica de Pyrrhulina. Portanto, é possível concluir que Holotaxis seja, de fato, um sinônimo júnior de Pyrrhulina, conforme sugerido por Eigenmann e Eigenmann (1889), Taphorn (1992) e Weitzman e Weitzman (2003).

O monofiletismo de Copella é sustentado por 15 sinapomorfias, três exclusivas. Dentre elas, quatro (caracteres 105, 108, 109 e 115) envolvem redução dos tubos ósseos por onde passam o canal látero-sensorial nos demais Characiformes, que em Copella são representados por linhas de neuromastos expostos. A presença de forames occipitais laterais desenvolvidos (caráter 38) aparentemente representa um caso de pedomorfose, uma vez que exemplares jovens de Lebiasininae e Pyrrhulina apresentam os forames similarmente desenvolvidos. Porém, nestes grupos os forames são gradativamente obliterados ao longo da ontogenia, podendo estar ausentes em exemplares adultos. Os representantes do gênero Copella agruparam-se em dois clados consistentes. O primeiro (clado 98), inclui as espécies do grupo C. arnoldi, com a faixa primária reduzida, alcançando apenas a margem posterior do opérculo. O grupo é sustentado por três sinapomorfias, duas exclusivas. Ambas representam estágios posteriores de modificações aparentemente relacionadas a reforço mecânico do crânio no orbitosfenóide (caráter 29) e pterosfenóide (caráter 35), possivelmente associado ao hábito reprodutivo destas espécies que saltam para desovar fora da água (Planquette et 
al., 1996; Weitzman \& Weitzman, 2003). O segundo (clado 103), inclui as espécies do grupo $C$. compta, que apresentam a faixa primária bem desenvolvida, com exceção de Copella meinkeni Zarske e Géry e algumas populações de Copella nattereri, e também é suportado por três sinapomorfias, uma exclusiva. A característica mais marcante do grupo envolve a intensa pigmentação dos raios pró-correntes da nadadeira caudal em machos adultos (caráter 198), condição não observada em C. meinkeni e proposta como diagnóstica da espécie em relação às demais por Zarske e Géry (2006).

Se por um lado a maioria dos gêneros de Pyrrhulininae apresenta diversas sinapomorfias que corroboram o seu monofiletismo, o gênero Pyrrhulina conta com apenas quatro sinapomorfias, nenhuma delas exclusiva. As características que permitem o reconhecimento do gênero envolvem principalmente a presença de duas séries de dentes no pré-maxilar, a ausência do pós-cleitro 3, proporções de altura do corpo, posição da nadadeira dorsal em relação a anal e outros caracteres plésiomórficos de Lebiasinidae ausentes em Copella (e.g. narina anterior e posterior sobrepostas, maxilar aproximadamente reto vs. narinas separadas por uma membrana e maxilar curvo, em forma de "S" em Copella). Apesar do baixo suporte dos clados dentro do gênero, é interessante observar que o clado 107 (Pyrrhulina australis, P. vittata, P. zigzag, P. sp. Tapajós I e $P$. sp. Tapajós II) inclui as Pyrrhulina de menor tamanho (não ultrapassando $35.0 \mathrm{~mm} \mathrm{SL}$, enquanto que as demais espécies geralmente ultrapassam os $50 \mathrm{~mm} \mathrm{SL}$ ). A principal característica deste grupo é a redução do número de dentes no maxilar (caráter 52 - restritos à porção médio-anterior do osso vs. distribuídos por toda a margem anterior nos demais Pyrrhulinina). Distalmente neste clado, ocorrem outros eventos redutivos, como a diminuição do número de vértebras pré-caudais (caráter 138), presença de nove raios principais no lóbulo superior da nadadeira caudal (caráter 165), perda dos raios filamentosos nas nadadeiras dorsal e anal (caráter 173) (clado 113), forame do nervo nasal delimitado apenas pela cartilagem etmoidal (caráter 25) e ausência do pós-cleitro 2 (caráter 96) (clado 112).

De maneira semelhante a Pyrrhulina, o monofiletismo da subfamília Lebiasininae é suportado por poucas sinapomorfias (cinco, quatro exclusivas): exclusão parcial ou total do infra-orbital 4 do anel orbital; lâmina dorsal do mesetmóide em forma de "T" (revertida em Lebiasina sp. "Parima" e L. sp. "Curuá"); margem posterior do coracóide truncada (revertida em $L$. aff. bimaculata I e $L$. aff. bimaculata II); ramo infra-orbital do canal látero-sensorial cefálico se estendendo ao antorbital (revertida em 
L. ortegai); mancha caudal (revertida independentemente nos clados 72 e 80). Lebiasina e Piabucina por sua vez, são grupos polifiléticos em suas atuais composições. De acordo com a presente hipótese filogenética a subfamília encontra-se dividida em duas principais linhagens que, feitas as devidas adequações taxonômicas, poderiam tornar os dois gêneros monofiléticos. No entanto, dado o baixo suporte do clado correspondente a 'Piabucina' preferiu-se considerá-lo um sinônimo júnior de Lebiasina, seguindo a nomenclatura proposta anteriormente por outros autores (Eigenmann \& Allen, 1942; Weitzman, 1964; Machado-Allison, 1974; Dahl, 1971; Géry, 1977; Taphorn, 1992; Ardila-Rodríguez 1994, 1999, 2000, 2001, Géry \& Zarske, 2002; Ardila-Rodríguez 2002, 2004, 2008a, 2008b, 2010).

O primeiro clado é o das Lebiasinas "verdadeiras", que apresentam a parede da câmara posterior da bexiga natatória com um sistema de alvéolos (caráter 171). O monofiletismo do grupo é sustentado também por outras sete sinapomorfias (duas exclusivas). A principal sinapomorfia, além das modificações da bexiga, está relacionada ao padrão de dimorfismo sexual envolvendo as modificações das escamas da sexta série longitudinal (caráter 181), uma condição exclusiva deste clado. O grupo encontra-se subdividido em dois clados principais, o primeiro (clado 68) é definido por três sinapomorfias, a principal delas sendo a presença de dentes tricúspides com cúspides simétricas (caráter 43). Esta característica possivelmente está associada a mudanças nos hábitos alimentares dos representantes do grupo. $\mathrm{O}$ outro grupo (clado 73) é definido por quatro sinapomorfias, as principais envolvendo o aumento do número de dentes no ectopterigóide e a presença de dentes na porção posterior do endopterigóide (caracteres 64 e 66, respectivamente), condição única entre os Lebiasinidae.

O segundo clado inclui as espécies que se enquadrariam ao gênero Piabucina, considerado aqui um sinônimo de Lebiasina, conforme mencionado anteriormente. $\mathrm{O}$ monofiletismo do grupo é sustentado por quatro sinapomorfias, a principal delas também relacionada ao padrão de dimorfismo sexual envolvendo modificações nas escamas da quinta série longitudinal (caráter 180), condição muito similar à observada em Hoplerythrinus. Lebiasina elongata representa o táxon mais basal deste clado que apresenta três principais grupos de espécies: os clados 75, 83 e 93. O clado 93 é definido por três sinapomorfias: margem póstero-ventral do infra-orbital 2 não contígua à margem antero-ventral do infra-orbital 3 (caráter 04); posição da faixa secundária, 
passando pelas escamas da segunda e terceira séries longitudinais de escamas (caráter 188); a presença da faixa "intermediária" geralmente restrita ao infra-orbital 3, mas se estendendo por todo o corpo em Lebiasina sp. Parima (caráter 191); e o deslocamento posterior da mancha caudal, que não alcança o pedúnculo caudal anteriormente (caráter 197). O clado 75 é diagnosticado pelo extra-escapular hipertrofiado e a ausência da nadadeira adiposa (caracteres 93 e 148). Neste grupo, o ramo palatino do nervo facial transpassa o vômer em dois pontos (um anterior e outro posterior), enquanto que nas demais espécies de Lebiasinidae, e nos demais Characiformes examinados, o ramo palatino passa lateralmente ao vômer. Por fim, o clado 83 corresponde ao grupo das Lebiasina que apresentam uma série longitudinal de manchas arredondadas situada ao longo da faixa primária (caráter 187).

\section{Miniaturização em Pyrrhulininae}

Weitzman e Vari (1988) em seu estudo da miniaturização em peixes sulamericanos listam como verdadeiras miniaturas 85 espécies que não ultrapassam os 26 $\mathrm{mm}$ SL ou que atingem a maturidade sexual com menos de $20 \mathrm{~mm}$ SL. Estes limites, reconhecidamente arbitrários, visavam propiciar uma primeira aproximação nos estudos em miniaturização em peixes de água doce. Naquela ocasião, os autores listaram três espécies miniaturizadas de Lebiasinidae, todas elas representantes do gênero Nannostomus (N. anduzei, N. marginatus e N. minimus). Interessantemente os autores não consideraram $N$. britskii, $N$. digrammus e $N$. marilynae como espécies miniaturizadas. No caso de $N$. digrammus e $N$. marilynae, isso aparentemente se deu, devido a Weitzman e Cobb (1975) listarem exemplares examinados com $28 \mathrm{~mm}$ e 32 mm de $N$. digrammus e $N$. marilynae respectivamente. Tais exemplares eram espécimes de aquário, onde comumente os indivíduos ultrapassam o tamanho máximo da espécie na natureza. Além disso, exemplares destas espécies certamente atingem a maturidade sexual com menos de $20 \mathrm{~mm}$ SL, o segundo critério estabelecido por Weitzman e Vari (1988) para caracterização de eventos de miniaturização. No caso de N. britskii, por sua vez, não se conhecem exemplares maiores que $26 \mathrm{~mm}$ SL e portanto a espécie deveria figurar entre aquelas consideradas miniaturizadas.

Entre as espécies de Copella, por sua vez, é possível sugerir um forte "componente pedomórfico" dado o número de caracteres redutivos observados no grupo, ainda que todas as espécies ultrapassem $35 \mathrm{~mm}$ SL. Padrão similar é observado 
nas espécies de Pyrrhulina do clado 107, grupo onde os maiores exemplares geralmente não ultrapassam $32 \mathrm{~mm} \mathrm{SL}$, diagnosticado principalmente por apresentar nove raios principais na nadadeira caudal. Ainda que os representantes destes três gêneros ultrapassem, na grande maioria dos casos, o comprimento padrão sugerido por Weitzman \& Vari (1988) para a identificação de espécies miniaturizadas, o contexto filogenético dos Pyrrhulininae e o acúmulo de caracteres redutivos nestes grupos, permite sugerir uma tendência redutiva na subfamília como um todo, que culminou em três eventos independentes de miniaturização em um senso menos restrito do termo, conforme observado por de Pinna (1996) para a tribo Hoplomizontini (Aspredinidae, Siluriformes). É interessante observar que a subfamília Pyrrhulininae está incluída em Erythrinoidea, grupo onde estão alocadas algumas das maiores espécies de Characiformes: Boulengerella cuvieri (675 mm SL - Vari, 1995; Zanata \& Vari, 2005), Hoplias aimara (Valenciennes) (aprox. $850 \mathrm{~mm}$ SL - MZUSP) e H. lacerdae MirandaRibeiro (aprox. 900 mm SL - MZUSP 106200). Este padrão é similar ao observado em Alestidae (Zanata \& Vari, 2005) e Sisoroidea (de Pinna, 1996), onde casos de miniaturização e gigantismo ocorrem de maneira gradual, mas bastante próximos filogeneticamente, evidenciando a especialização em estratégias praticamente opostas em um curto intervalo filogenético. Também de modo similar ao descrito por de Pinna (1996), o entruncamento ontogenético nos Pyrrhulininae miniaturizados parece ter ocorrido de modo gradual, ao invés de transformações abruptas.

\section{Evolução da invertivoria em Lebiasinidae}

Os Lebiasinidae parecem representar uma radiação adaptativa de Eythrinoidea que deixou de ser essencialmente piscivora e passou a explorar insetos como fonte de alimento. Tal mudança parece ter ocorrido de maneira súbita no grupo, uma vez que os Lebiasininae, linhagem mais basal da família, alimentam-se essencialmente de insetos (Ardila-Rodríguez, 1978) alóctones (principalmente) e autóctones. Além de artrópodes as Lebiasina também consomem pequenos peixes, bem como flores, frutos e outros itens de origem vegetal ainda que em pequenas proporções (Breder, 1927; Zaret \& Rand, 1971; Taphorn \& Lilyestrom, 1980; Taphorn, 1992; Román-Valencia, 2004), configurando uma dieta praticamente onívora e generalista. Em Pyrrhulininae, por sua vez, parece haver uma especificidade maior na dieta. Ainda que não existam estudos sobre os hábitos alimentares do grupo, Géry e Zarske (2002) afirmam que exemplares 
de Derhamia em aquário aceitam apenas alimentos recém caídos na água, desprezandoos quando afundam. Em Pyrrhulinina, todos os exemplares preparados para diafanização apresentavam apenas formigas e cupins em seus conteúdos estomacais, enquanto que os Nannostomus examinados apresentavam praticamente apenas larvas de Chironomidae. A topologia obtida aqui sugere que a aparente especificidade alimentar observada em Pyrrhulininae representa uma condição derivada em Erythrinoidea. Além disso, a mudança de estratégia observada em Nannostomus parece ter permitido a diminuição da competição inter-específica direta com os demais Pyrrhulininae, o que talvez possibilite a ocorrência em simpatria de espécies de ambos os grupos.

\section{Estabilidade morfológica de Lebiasininae, resolução filogenética e diversidade do grupo.}

Machado-Allison (1974) ressalta uma grande similaridade dos dados merísticos e morfométricos de L. erythrinoides e L. unitaeniata. De fato, praticamente todas as espécies de Lebiasina apresentam sobreposições em contagens e proporções do corpo, que dificultam a utilização destes caracteres na taxonomia alfa das espécies. Tal "estabilidade" está refletida também nos caracteres anatômicos utilizados no estudo filogenético das espécies do gênero, exceto quando compara-se táxons filogeneticamente distantes. Nos demais casos, os caracteres que distinguem as espécies ou grupos de espécies dentro desses clados na maioria dos casos envolvem modificações em ossos dérmicos, no padrão de escamação e principalmente no padrão de colorido. Tal padrão parece se repetir nos demais gêneros de Lebiasinidae, até mesmo no gênero Nannostomus, grupo submetido a duas revisões taxonômicas (Weitzman, 1966; Weitzman \& Cobb, 1975), onde a diagnose da maioria das espécies envolve principalmente caracteres colorido.

Apesar de representar uma importante fonte de caracteres, principalmente em casos onde a morfologia é pouco variável, caracteres de colorido podem ser muito plásticos. Em Lebiasininae, por exemplo, fenótipos envolvendo a distribuição ou intensidade da faixa secundária surgiram independentemente diversas vezes no grupo, enquanto que em Nannostomus, a faixa terciária foi perdida pelo menos quatro vezes. Weitzman e Weitzman (1982) sugeriram pares de espécies do gênero Nannostomus, baseando-se principalmente em padrões de colorido. Dentre os grupos propostos por aqueles autores, somente o par $N$. digrammus e $N$. marilynae é corroborado como 
grupos-irmãos Tal contraste entre os resultados obtidos aqui e por aqueles autores, evidencia o problema em utilizar caracteres de colorido em análises filogenéticas, pelo menos aqueles que se revelam muito plásticos. Isso possivelmente resultou na "resistência de Nannostomus à metologia cladista" mencionada por Weitzman e Weitzman (1982) e Weitzman e Vari (1989). Talvez, o melhor uso de caracteres de colorido nestes casos seja sua otimização diretamente nas árvores fundamentais, conforme descrito por de Pinna (1996) e Daugeron (1997) para caracteres comportamentais.

O resultado do exame de exemplares contrariou a hipótese de relacionamento dos terminais do clado 80 (Lebiasina sp. "Curuá-Pinta" (L. sp. Cachimbo + L. sp. "XIII de maio")) e 92 (Lebiasina sp. Parima (L. unitaeniata (L. yuruaniensis (L. taphorni + L. uruyensis)))). No primeiro caso (clado 80), apesar dos três terminais formarem um grupo monofilético totalmente resolvido, não foram observados caracteres que os separassem consistentemente em diferentes unidades biológicas. Já L. unitaeniata e L. yuruaniensis, que, apesar de serem quase idênticas externamente, não possuem uma relação de grupo-irmão. Ao invés disso, L. yuruaniensis representa o grupo irmão do clado incluíndo L. taphorni e L. uruyensis. O único caráter que suporta o monofiletismo do clado incluindo estas três espécies é o forame na porção posterior do metapterigóide que é delimitado posteriormente pelo hiomandibular (caráter 71). Uma hipótese ad hoc que explicaria tal fenômeno envolve uma separação insipiente entre L. unitaeniata e $L$. yuruaniensis, devido a uma zona híbrida que permitiria a continuidade do fluxo gênico entre as duas espécies.

\section{Revisão taxonômica das espécies de Lebiasininae}

\section{Lebiasininae}

\section{Lebiasininae Gill, 1895}

\section{Lebiasininae Eigenmann, 1910 \\ Piabucininae Eigenmann, 1910}

Diagnose. Estão incluídos nesta subfamília os lebiasinídeos que apresentam as seguintes características: ramo do canal látero-sensorial infra-orbital estendendo-se ao antorbital; margem póstero-dorsal do infra-orbital 3 com uma projeção que exclui parcial- ou totalmente o infra-orbital 4 do anel orbital; frontal com um processo lateral 
que encapsula a porção superior do dilatator operculi, mas não atinge o espinho do esfenótico; lâmina dorsal do mesetmóide em forma de "T"; margem póstero-ventral do coracóide truncada, sem uma projeção direcionada posteriormente; radii anastomosados, formando células; escamas da quinta ou sexta séries longitudinais modificadas em machos adultos, cobertas por tecido epitelial hipertrofiado; mancha na base dos raios médios da nadadeira caudal presente.

Táxons incluídos. Os gêneros Lebiasina e Piabucina são os grupos tradicionalmente incluídos na subfamília. Recentemente, Géry \& Zarske sugeriram a inclusão de Derhamia no grupo, no entanto, a hipótese filogenética apresentada aqui contradiz a proposta daqueles autores, uma vez que Derhamia estaria mais proximamente relacionado aos Pyrrhulinina. Além disso, a presente hipótese de relações aponta o polifiletismo de Lebiasina e Piabucina. Conforme discutido anteriormente, apesar da possibilidade de propor mudanças taxonômicas que tornariam os dois gêneros grupos naturais, preferiu-se sinonimizar os dois grupos, seguindo os questionamentos de diversos autores (Eigenmann \& Allen, 1942; Weitzman, 1964; Machado-Allison, 1974; Dahl, 1971; Géry, 1977; Taphorn, 1992; Ardila-Rodríguez 1994, 1999, 2000, 2001, 2002; Géry \& Zarske, 2002; Ardila-Rodríguez 2004, 2008a, 2008b, 2010a). Desta maneira, apenas um gênero com 22 espécies nominais está incluído no grupo.

\section{Lebiasina Valenciennes, in Cuvier \& Valenciennes}

Lebiasina Valenciennes, in Cuvier \& Valenciennes, 1847: 531.

Piabucina Valenciennes, in Cuvier \& Valenciennes, 1849: 161.

Espécie-tipo. Lebiasina bimaculata Valenciennes, in Cuvier \& Valenciennes, tipo por monotipia. Gênero feminino.

Espécies incluídas. Lebiasina astrigata, L. aureoguttata, L. bimaculata, L. boruca, L. chocoensis, L. colombia, L. elongata, L. erythrinoides, L. festae, L. floridablancaensis, L. intermedia, L. multimaculata, L. ortegai, L. panamensis, L. taphorni, L. unitaeniata, L. uruyensis, L. yuruaniensis, L. sp. "Curuá-Faixa”, L. sp. “Curuá-Pinta”, L. sp. Parima, L. aff. bimaculata I, L. aff. bimaculata II, L. aff. festae, L. sp. Azuay 
Diagnose. Ver diagnose para Lebiasininae.

\section{Lebiasina astrigata (Regan)}

(Figura 76)

Piabucina astrigata Regan 1903: 622.- Eigenmann, 1910: 439 [catalog; distribution imprecise].- Eigenmann, 1920a: 16 [although not entirely correct].- Eigenmann, 1923a: 126 [key to the species, type-locality, habitat and distribution (distribution not entirely correct, since the species do not occur in the Esmeraldas river basin)].- MachadoAllison, 1974: 582 [diversity of Lebiasina and 'Piabucina'].- Eschmeyer, 1998: 151 [catalog].- Weitzman \& Weitzman, 2003:246 [checklist].

Lebiasina astrigata.- Géry, 1977: 126 [Key to the species of Lebiasina - Géry was among the first authors to synonymize Piabucina with Lebiasina, even though the validity of the genus had already been questioned by Eigenmann and Allen, 1942].Ardila-Rodríguez, 2000: 4 [L. yuruaniensis description].

Lebiasina nariñensis, Ardila-Rodriguez 2002 [mispelled, later corrected to L. narinensis in Maldonado et al., 2005].

Lebiasina narinensis.- Maldonado-Ocampo et al., 2005: 95 [field guide; description, biology, ecology, comments and list of specimens in museums].

Série-tipo. Síntipos: BMNH 1898.4.28.164-166 (3), 1901.3.29.71 (1), 1902.7.29.59 (1).

Localidade-tipo. Rios San Javier, Paramba e Sapayo, nordeste do Equador.

\section{Material examinado.}

BMNH 1898.4.28:164-6 síntipos (3, 70-67.9 mm SL), Equador, Carchi/Imbabura. Paramba, Rosenberg.

BMNH 1902.7.29:59 lectótipo (1, 160 mm SL), Esmeraldas, Río Sapayo, Rosenberg.

CAR 187 (11, 70.6-138.4 mm SL), Colômbia, Nariño, quebradas afluentes da Quebrada Indó [Quebrada Indún: $01^{\circ} 42^{\prime} 00^{\prime} \mathrm{N} 78^{\circ} 19^{\prime} 00^{\prime \prime} \mathrm{W}$ ], que desembocam no rio Telembí (Km 82, 83, 86 [da via] Tumaco-Pasto), 06-X-2002, C. Ardila-Rodriguez; 
CAR 480 (2, 116.2-132.5 mm SL), Cauca, Colombia, Rio Guapi [, 5-XI-2002, S. Usma; CAS (SU uncat), (4, 122.4-130.2 mm SL) Equador, Esmeraldas. baixo rio Santiago próximo a Borbón, $01^{\circ} 05^{\prime} 30^{`} \mathrm{~N} 78^{\circ} 59^{\prime} \mathrm{W}$. M. Olalla;

ICNMHN 2340 (1, 101.8 mm SL) Colômbia, Nariño, II-1995, G. Galvis;

ICNMHN 2340-1 (1, 92.3 mm SL) Colômbia, Nariño, II-1995, G. Galvis;

ICNMHN 3187 (2, 23,44-54,78 mm SL), Colômbia, Nariño, 20-VIII-1971, A. Alvarez;

MCZ 54125 (3, 112.5-141.9 mm SL), Equador, Esmeraldas, rios Cayapas, Hoja Blanca e San Miguel [bacia do rio Santiago], nas imediações de San Miguel [de Cayapas], $78^{\circ} 55^{\prime} \mathrm{W} 00^{\circ} 46^{\prime} \mathrm{N}$, unknown date, Myata \& Rankis;

MEPN 3645 (1, $78.3 \mathrm{~mm} \mathrm{SL})$, Equador, Esmeraldas, Carondelet [0107'29’'N $\left.78^{\circ} 45^{\prime} 42^{\prime} \mathrm{W}\right]$ ou La Boca na confluência do rio Tululbí com el río Bogotá. Afluente del río Santiago, X-1953, M. Olalla;

MEPN 3777 (4, 107.6-121.8 mm SL), Equador, Esmeraldas, estero Finca Kolynos a 2 $\mathrm{km}$ da desembocadura do rio Cachaví no rio Bogotá, 0104'N 7848’W, 03-X-1984, R. Barriga;

MEPN 3778 (4, 115.5-134.1 mm SL), Equador, Esmeraldas, estero Finca Kolynos a 2 $\mathrm{km}$ da desembocadura do rio Cachaví no rio Bogotá, $01^{\circ} 04^{\prime} \mathrm{N} 78^{\circ} 48^{\prime} \mathrm{W}, 03-\mathrm{X}-1984$, R. Barriga;

MEPN 3779 (1, 35.3 mm SL), Equador, Esmeraldas, San Miguel de Cayapas, Estero MAG (Ministerio de Agricultura y Ganaderia) próximo à guarita [sistema do rio Santiago], 0046’N 7855'W, 12-VIII-1985, R. Barriga et al.;

MEPN 3780 (6, 122.2-169.8 mm SL), Equador, Esmeraldas, estero Finca Kolynos a 2 $\mathrm{km}$ da desembocadura do rio Cachaví no rio Bogotá, $01^{\circ} 04^{\prime} \mathrm{N} 78^{\circ} 48^{\prime} \mathrm{W}, 03-\mathrm{X}-1984$, R. Barriga;

MEPN 3781 (2, 156.6-167.5 mm SL), Equador, Esmeraldas, estero Limoncito, afluente do rio María a $5 \mathrm{~km}$ de Borbón, 0103'33”N 7856’03”W, 05-X-1984, R. Barriga et al.; MEPN 3842 (1, 131.5 mm SL), Equador, Esmeraldas, rio Balsalito afluente do rio Cachaví [bacia do rio Santiago], 0106’09”N, 7842’16”W, VII-1962, M. Olalla; MEPN 4109 (4, 93.2-101.2 mm SL), Equador, Carchi, quebrada Pailón [00²8’59’N $77^{\circ} 55^{\prime} 01^{\prime}$ W] entre a escola e a casa comunal de Pailón, 09-XII-1987, R. Barriga \& J. Pasuy; 
MEPN 4130 (1, 56.9 mm SL), Equador, Carchi, baía pequena da Quebrada Negra [Colômbia, Nariño, afluente do Río San Juan, drenagem do rio Mira], sítio San Marcos, 0103'25’'N 78¹8'14’W, 08-XI-1987, R. Barriga et al.;

MEPN 4415 (1, 103.1 mm SL), Equador, Esmeraldas, rio Mataje, sitio El Pan, 02II-1988, R. Barriga et al.;

MEPN 4416 (1, 104.5 mm SL), Equador, Esmeraldas, estero Quebrada Yarumal, margem esquerda do río Mataje, a meia hora do Centro Comunal Mataje [01¹2’04”N, 78³3'42”W Fritts et al., 2002], 01³0’N 7843’W [Colômbia, Nariño, rio Mira], 03II-1988, R. Barriga et al.;

MEPN 4417 (1, 111.3 mm SL), Equador, Esmeraldas, Quebrada Cangare, próximo a Mataje, $01^{\circ} 13^{\prime} \mathrm{N} 78^{\circ} 44^{\prime} \mathrm{W}, 05-\mathrm{II}-1988$, R. Barriga et al.;

MEPN 4418 (23, 29.2-105.4 mm SL), Equador, Esmeraldas, estero do río Mira, $80 \mathrm{~m}$ a jusante da Casa Manuel Puy, $01^{\circ} 13^{\prime}$ N 78³6’W, 9-II-1988, R. Barriga et al.;

MEPN uncat (4, 92.1-101.7 mm SL), Equador, Carchi, quebrada entre a escola e a casa Comunal de San Marcos, $01^{\circ} 03^{\prime} 38^{\prime} \mathrm{N}$ 78 $18^{\prime} 00^{\prime \prime} \mathrm{W}$ [coordenadas correspondem a Colômbia, Nariño, na bacia do rio Mira], 09-IX-1987, R. Barriga, J. Pasuy;

MEPN uncat (4, 118.5-138.3 mm SL), Equador, Esmeraldas, pequeno tributário do rio Huembi [01 $\left.011^{\prime} 08^{\prime} \mathrm{N} 78^{\circ} 49^{\prime} 17^{\prime \prime} \mathrm{W}\right]$ afluente do rio Santiago, 15-IX-1993, Barriga et al.;

NRM 27294 (1, 124.08 mm SL), Colômbia, Nariño, La Guayacana, vale do rio Güiza, bacia do rio Mira, 400 m elev., 1.4333 -78.45 [01²0’24’N 78³3’26”W], V-1947, K. von Sneidern et al.;

USNM 288016 (2, 38.8-85.9 mm SL), Equador, Esmeraldas, San Miguel, Estero MAG (Ministerio de Agricultura y Ganaderia) próximo à guarita, $00^{\circ} 46^{\prime} \mathrm{N} 78^{\circ} 55^{\prime} \mathrm{W}$ San Miguel de Cayapas, 12-VIII-1985, R. Barriga et al.;

USNM uncat (1, $109.5 \mathrm{~mm}$ SL), Equador, Esmeraldas, Carondelet [01 07'29’'N 78 45'42”W], estero Lava Pata, tributário do rio Bogotá, 16-IX-1993, R. Barriga et al.; USNM 398311. (6, 42.2-116.5 mm SL), Equador, Esmeraldas, córrego sem nome, afluente da margem direita do Rio Cayapas [0105'00”N 7903'00”W] em Playa Ancha, 0,5 Km a jusante de San Miguel, 14-IX-1993, R. Barriga; 
USNM 398314 (13, 13.5-88.9 mm SL), Equador, Esmeraldas, córrego sem nome, afluente da margem direita do rio Cayapas $\left[01^{\circ} 05^{\prime} 00^{\prime} \mathrm{N} 79^{\circ} 03^{\prime} 00^{\prime \prime} \mathrm{W}\right]$ em Playa Ancha, 0,5 Km a jusante de San Miguel, 14-IX-1993, R. Barriga.

Diagnose. Lebiasina astrigata difere de Lebiasina bimaculata, L. aff. bimaculata I, L. aff. bimaculata II, L, boruca, L. festae e L. aff. festae por não apresentar a parede da câmara posterior da bexiga natatória "celular", por apresentar as escamas da quinta série longitudinal com tecido epitelial hipertrofiado nos machos adultos e por não apresentar escamas com intensa deposição de guanina (vs. parede da bexiga natatória "celular", escamas da sexta série longitudinal modificadas em machos adultos, ao menos a quarta escama da linha lateral com intensa deposição de guanina). A espécie difere de Lebiasina sp. "Curuá-Pinta" por apresentar faixas longitudinais e mancha caudal, e não apresentar manchas escuras na base das escamas da segunda à quinta séries longitudinais (vs. faixas longitudinais e mancha caudal ausentes; manchas escuras presentes na base das escamas da segunda à quinta séries longitudinais). Difere de Lebiasina elongata, L. erythrinoides, L. intermedia, L. taphorni, L.unitaeniata, L. uruyensis, L. yuruaniensis, L. sp. “Curuá-Faixa” e L. sp. "Parima” por apresentar uma série longitudinal de pequenas manchas arredondadas (vs. série longitudinal de manchas escuras ausente). Lebiasina astrigata difere ainda de L. taphorni, L. unitaeniata, L. uruyensis, L. yuruaniensis e L. sp. "Parima", pela ausência da faixa "intermediária" e pela mancha caudal alcançar o pedúnculo caudal anteriormente (vs. faixa "intermediária" presente; mancha caudal não alcançando o pedúnculo caudal anteriormente). Entre as espécies do clado 83, Lebiasina astrigata se diferencia de $L$. colombia, L. floridablancaensis, L. ortegai e L. panamensis por apresentar faixa primária inconspícua (vs. faixa primária conspícua ao longo de todo o corpo em $L$. ortegai e exemplares adultos de L. panamensis; porção anterior da faixa primária conspícua em L. colombia e exemplares jovens de L. panamensis; porção posterior da faixa primária conspícua em L. floridablancaensis). A espécie se distingue de $L$. multimaculata e L. chocoensis por apresentar a faixa secundária conspícua, passando pelas escamas da segunda e terceira séries longitudinais (vs. faixa secundária inconspícua estendendo-se ao longo das escamas da primeira e segunda séries longitudinais). A espécie se diferencia de L. aureoguttata por apresentar numerosas manchas pequenas distribuídas ao longo da quarta série longitudinal de escamas e a 
faixa secundária alcançando o término da nadadeira dorsal (vs. poucas manchas grandes distribuídas ao longo da quarta série longitudinal, faixa secundária alcançando a vertical que passa pela origem da nadadeira adiposa). Lebiasina astrigata se diferencia de Lebiasina sp. Azuay pelos seguintes caracteres: faringo-branquial 2 edêntulo; nasal estendendo-se anteriormente, alcançando o ramo lateral do pré-maxilar; espinho do supra-occipital curto, não alcançando o ponto de contato entre o complexo neural e o supra-occipital; faixa primária alcançando a vertical que passa pelo término da nadadeira dorsal (vs. faringo-branquial 2 apresentando dentes; nasal não alcançando o ramo lateral do pré-maxilar; espinho do supra-occipital ultrapassando o ponto de contato entre o complexo neural e o supra-occipital; faixa primária alcançando a nadadeira caudal).

Descrição. Dados morfométricos apresentados na tabela 2. Vista lateral do Lectótipo e exemplares coletados recentemente representados na Figura 76. Corpo comprimido e alongado. Perfil dorsal da cabeça e do corpo convexo do lábio superior até até a origem da nadadeira dorsal, tornando-se praticamente reto entre os parietais e a origem da dorsal. Perfil reto na base da dorsal e levemente côncavo posteriormente até a origem dos raios pró-correntes da nadadeira caudal. Perfil ventral da cabeça e tronco convexo desde o lábio inferior até a origem da pélvica, reto deste ponto até a origem da nadadeira anal, convexo na base da anal e côncavo do término da anal até a origem dos pró-correntes ventrais da nadadeira caudal.

Espécie discretamente prognata, boca subsuperior. Maxilar alcançando o meio da órbita. Apenas uma série de 9 (1), 10 (3), 11 (13) ou 12 (1) dentes tricúspides decrescendo posteriormente no pré-maxilar. Maxilar com 4 (6), 5 (3), 6 (6)ou 7 (3) dentes tricuspidados. Dentário com duas séries de dentes; 12 (1), 13 (4), 14 (2) ou 15 (1) dentes tricúspides pedunculados com a cúspide central distintamente mais longa que as cúspides laterais na série externa, série interna com dentes diminutos, na maioria, cônicos (podendo ser tricúspides posteriormente) estendendo-se desde a sínfise até próximo ao processo coronóide. Raios-branquiostégios 4, três articulando com o ceratobranquial anterior e um com o ceratobranquial posterior.

Escamas ciclóides, circuli restritos à borda da escama, diversos radii (aproximadamente 20) convergindo para o centro da escama, estando intensamente anastomosados no centro, formando diversas células. Série longitudinal da linha lateral 
com 28 (2), 29* (19), 30 (16), 31 (1) a 32 (1) escamas, 4* (1), 5 (6) ou 6 (32) perfuradas. Séries longitudinais entre a nadadeira dorsal e a pélvica 7. Escamas prédorsais 13 (1) 14 (21) a 15* (17). Escamas da primeira série longitudinal 18 (3), 19 (6), 20 (16), 21* (13) a 22 (1) alcançando a vertical que passa pelo ânus. Escamas circumpedunculares 12 .

Nadadeira peitoral i, 12 (1), 13* (15), 14 (21) ou 15 (1). Ponta da peitoral não alcançando a vertical que passa pela origem da pélvica. Raios da nadadeira pélvica i, 7. Supraneurais 11 ou 12, anteriores aos espinhos neurais dos centros 5 ao $15^{*}$ (7) ou 16 (10). Nadadeira dorsal iii, 7 (5) ou ii, 8* (33). Primeiro pterigióforo da nadadeira dorsal inserido posteriormente ao espinho neural do centro $15^{*}(7)$ ou $16(10)$. Margem distal da nadadeira dorsal arredondada quando expandida. Origem da nadadeira dorsal distintamente mais próxima à base da nadadeira caudal que da ponta do focinho. Base do último raio da dorsal distintamente anterior à vertical que passa pela origem da nadadeira anal. Nadadeira anal iii, 8, último raio adnato. Margem distal da nadadeira anal arredondada. Primeiro pterigióforo da nadadeira anal inserido posteriormente ao arco hemal do centro $24 *(7), 25$ (8) ou 26 (2). Nadadeira adiposa presente. Um ou dois epurais presentes. Nadadeira caudal furcada, lóbulo superior distintamente mais longo que o inferior, ambos arredondados. Raios principais da nadadeira caudal i, 9/i, 8. Prócorrentes dorsais 9 (5); pró-correntes ventrais 8 (2), 9 (2) ou 10 (1). Vértebras précaudais 24 (4) ou 25 (1); vértebras caudais 16 (2) ou 17 (3).

Colorido. Cor de fundo predominantemente amarela. Coloração escura estendendo-se desde o lábio superior até a porção exposta dos parietais e ao longo da série medial e primeira série de escamas até a origem da nadadeira caudal. Maxilar, ossos circumorbitais e série opercular densamente pigmentados próximo à porção dorsal da cabeça, tornando-se gradualmente amarelada ventralmente; opérculo com uma distinta mancha escura na região médio-inferior. Estreita faixa negra estendendo-se da porção dorsal da órbita, passando pelos infra-orbitais 5 e 6 , alcançando a face dorsal do opérculo. Lábio inferior moderadamente pigmentado; restante da mandíbula e toda porção ventral da cabeça com pigmentação escassa.

Tronco tornando-se gradualmente amarelado ventralmente. Região abdominal amarela, com diminutos cromatóforos entre o istmo e a origem da nadadeira anal. Mancha umeral arredondada, conspícua em indivíduos jovens, porém difusa em adultos. 
Faixa primária representada por seis a nove manchas pequenas e arredondadas, geralmente ocupando amplitude de uma escama da quarta série longitudinal, estando distribuídas entre a mancha umeral e a mancha caudal. Ao longo da ontogenia, as manchas mais anteriores, localizadas entre a peitoral e a pélvica, tornam-se inconspícuas e as posteriores podem coalescer. Última mancha deslocada dorsalmente, estando situada principalmente na terceira série longitudinal de escamas, podendo estar ausente. Faixa secundária estendendo-se principalmente ao longo da terceira séries longitudinais de escamas, desde os epoccipitais à vertical que passa pela metade da nadadeira anal, sendo geralmente mais conspícua em sua porção anterior até a vertical que passa pelo término da nadadeira dorsal. Terceira, quarta e quinta séries longitudinais de escamas com pequenas manchas escuras próximo à base. Base da dorsal distintamente mais escura que o dorso. Mancha caudal alongada verticalmente, situada na extremidade do pedúnculo caudal e estendendo-se à base de 9 raios medianos da nadadeira caudal. Nadadeiras peitoral, pélvica, anal, adiposa e caudal hialinas; raios da nadadeira dorsal com cromatóforos nos primeiro ponto de ramificação na porção média dos raios; base do segundo ao oitavo raios ramificados com uma mancha conspícua.

Dimorfismo sexual. Exemplares machos de Lebiasina astrigata apresentam o padrão mais difundido de dimorfismo sexual entre as Lebiasina, que consiste em: raios da nadadeira anal alongados e espessados, aumento da base da nadadeira anal; hipertrofia dos músculos inclinadores dos raios da anal e dos processos espiniformes na face dorsal da primeira lepidotríquea onde estes músculos se ligam; escamas da quinta série longitudinal com o epitélio hipertrofiado desde a vertical que passa pela origem da nadadeira anal até a vertical que passa pela ponta dos raios da anal quando adpressos ao corpo. Órgãos de contato e diferenças merísticas ou morfométricas além daquelas relacionadas à nadadeira anal não foram observadas.

Distribuição. Norte do Equador e sul da Colômbia, a oeste dos Andes, nas bacias dos rios Mataje, Mira, Santiago e Telembí (Figura 77).

Tabela 2. Dados morfométricos de Lebiasina astrigata.

$\begin{array}{cccc}\mathrm{n} & \text { Range } & \text { Mean } & \text { SD } \\ 59 & 16,5-169,8 & 107,0 & 160,0\end{array}$


Depth dorsal fin origin

Snout to anal fin origin

Snout to pelvic fin origin

Snout to dorsal fin origin

Dorsal fin origin to caudal base

Dorsal fin length

Dorsal fin base

Adipose fin to caudal peduncle

Length caudal peduncle

Depth caudal peduncle

Anal fin length

Anal fin base

Pelvic- to anal fin origin

Pelvic fin length

Pectoral to pelvic fin origin

Pectoral fin length

Snout to pectoral fin origin

Bony head length

Head width

Morphometrics \% of HL

Horizontal eye diameter

Distance snout tip to eye

Interorbital distance

Length lower jaw

Length upper jaw

\begin{tabular}{rccc}
$18,2-23,7$ & 21,3 & 1,4 & 20,2 \\
$72,0-78,1$ & 75,6 & 1,6 & 72,5 \\
$48,6-55,5$ & 52,2 & 1,3 & 50,6 \\
$54,4-59,4$ & 57,3 & 1,1 & 54,7 \\
$41,4-47,1$ & 44,0 & 1,2 & 47,1 \\
$16,6-19,9$ & 18,3 & 0,8 & 17,4 \\
$7,1-9,2$ & 8,4 & 0,5 & 9,1 \\
$11,0-14,1$ & 12,1 & 0,7 & 13,3 \\
$13,4-17,7$ & 15,7 & 1,1 & 17,3 \\
$10,3-12,6$ & 11,5 & 0,5 & 11,4 \\
$17,8-24,9$ & 20,3 & 2,0 & 17,8 \\
$10,0-15,5$ & 12,2 & 1,5 & 11,1 \\
$22,2-26,5$ & 24,3 & 1,0 & 24,7 \\
$12,2-16,7$ & 14,0 & 0,8 & 13,5 \\
$26,9-34,1$ & 31,7 & 1,4 & 31,4 \\
$14,5-17,5$ & 16,3 & 0,8 & 14,7 \\
$20,5-22,7$ & 21,6 & 0,6 & 21,3 \\
$22,1-24,6$ & 23,2 & 0,6 & 23,4 \\
& & & \\
$56,5-67,0$ & 60,6 & 2,7 & 57,3 \\
$17,7-24,3$ & 20,6 & 1,6 & 18,7 \\
$25,9-31,0$ & 28,3 & 1,3 & 26,7 \\
$36,5-41,0$ & 38,6 & 1,2 & 37,3 \\
$40,8-47,2$ & 43,9 & 1,7 & 45,3 \\
$33,5-40,3$ & 37,2 & 1,6 & 40,3 \\
\hline & & &
\end{tabular}

\section{Lebiasina aureoguttata (Fowler)}

(Figura 78)

Piabucina aureoguttata Fowler, 1911: 493.- Eigenmann, 1923a: 126 [key to the species of 'Piabucina', type-locality, habitat, description].- Machado-Allison, 1974: 582 [diversity of Lebiasina and 'Piabucina'].- Eschemeyer, 1998: 168 [catalog]. Weitzman, \& Weitzman, 2003: 246 [checklist].

Piabucina sp.- Eigenmann, 1914:28-29 ["Among a large number of specimens of Lebiasina, recently collected by Mr. Henn, in Ecuador, a few are found which have the adipose" - specimens collected in 1913 during the Landon Expedition, represented herein by IU 13534];

Piabucina aureoguttatus.- Eigenmann, 1920a: 16 [mispelling; distribution]

Piabucina astrigata (non Regan).- Eigenmann, 1923a: 126 [specimens from rio Mindo, Esmeraldas river basin; IU 13534 depicted in fig. 6].- Glodek, 1978: 5, table 1 [inferred from distribution]

Lebiasina (Piabucina) astrigata.- Géry, 1972: 91-92 [inferred from distribution]. 
Lebiasina aureoguttata.- Géry, 1977: 126 [Key to the species of Lebiasina].

Série-tipo. Holótipo: ANSP 39103

Localidade-tipo. Afluente do rio Chimbo, próximo a Bucay, Província de Guayas, oeste do Equador.

\section{Material examinado.}

ANSP 39103 Holótipo (1, 127.6 mm SL), Equador, Guayas, Afluente do rio Chimbo, próximo a Bucay [02¹0’00”S 7906’00”W], VII-1911, S. N. Rhoads;

ANSP 45474 (1, 80.5 mm SL), Mina [Equador, Guayas, Río Minas, bacia do rio Guayas, coordenada aproximada $\left.02^{\circ} 41^{\prime} 26^{\prime \prime} \mathrm{S} 79^{\circ} 38^{\prime} 16^{\prime \prime} \mathrm{W}\right]$, unknown date and collector;

CAS uncat (ex-IU 13534) (32, 43.3-90.7 mm SL), Equador, Pichincha, rio Mindo [afluente do rio Guayllabamba, bacia do rio Esmeraldas], fazenda a oeste de Quito, [000’ㅇ $\left.78^{\circ} 35^{\prime} \mathrm{W}\right]$, VIII a IX-1913, A. Henn;

CAS uncat (3, 112.7-128.9 $\mathrm{mm}$ SL) Pichincha, rio Blanco, afluente do rio Guayllabamba, bacia do rio Esmeraldas, $\left[00^{\circ} 02^{\prime} \mathrm{S} 79^{\circ} 05^{\prime} \mathrm{W}\right]$, unknown date, M. Olalla et al.;

FMNH 93122 (19/80, 38.1-141.6 mm SL), Equador, Los Rios, pequena poça no Centro Científico Rio Palenque [00³5’00”S 79²2’00”W], 8-XI-1978, G. L. Goldek, D. Taphorn, J. Gourley \& J. Carter;

MCNG 19378 (1, $104.0 \mathrm{~mm}$ SL), Equador, Bolívar, rio Chimbo [205’56”S 7941'47’W], 13-V-1991, D. C. Taphorn;

MCZ 48728 (1, 57.1 mm SL), Equador, Pichincha, arroio Guanecilla (afl. rio Blanco), 10 km SE Santo Domingo de los Colorados, 00¹3'S 7909’W, 23-X-1971, T. Roberts; $15-25-41$

MEPN 4015 (1, $74.1 \mathrm{~mm} \mathrm{SL})$, Equador, Esmeraldas, rio Milpe entre o rio Saloya e Yambi, afluente do rio Blanco, bacía do rio Esmeraldas, $00^{\circ} 05^{\prime} 12^{\prime} \mathrm{S}$ 7859’15”W, 15XII-1959, M. Olalla et al.;

MEPN 6232 (5, 79.4-112.9 mm SL), Equador, Bolivar, Rio Chanquil, a montante de San José del Tambo, 29-VIII-2005, R. Barriga; 
MEPN 9469 (4, 73.6-142.9 mm SL), Equador, Pichincha, rio Pachijal, afluente do rio Guayllabamba [bacia do rio Esmeraldas], 0¹2’10”N 7843’16” W, 10-X-1962, M. Olalla;

MEPN 9490 (9, 84.7-107.0 mm SL), Equador, Cotopaxi, estero sem nome próximo à Granja Integral Salesiana a $1 \mathrm{Km}$ de Guasaganda, 0047'46”N 7909'18’W, 06IV-2004, R. Barriga \& R. Chango.

Diagnose. Lebiasina aureoguttata difere de Lebiasina bimaculata, L. aff. bimaculata I, L. aff. bimaculata II, L, boruca, L. festae e L. aff. festae por não apresentar a parede da câmara posterior da bexiga natatória “celular", por apresentar as escamas da quinta série longitudinal com tecido epitelial hipertrofiado nos machos adultos e por não apresentar escamas com intensa deposição de guanina (vs. parede da bexiga natatória "celular", escamas da sexta série longitudinal modificadas em machos adultos, ao menos a quarta escama da linha lateral com intensa deposição de guanina). A espécie difere de Lebiasina sp. "Curuá-Pinta” por apresentar faixas longitudinais e mancha caudal, e não apresentar manchas escuras na base das escamas da segunda à quinta séries longitudinais (vs. faixas longitudinais e mancha caudal ausentes; manchas escuras presentes na base das escamas da segunda à quinta séries longitudinais). Difere de Lebiasina elongata, L. erythrinoides, L. intermedia, L. taphorni, L. unitaeniata, L. uruyensis, L. yuruaniensis, L. sp. "Curuá-Faixa" e L. sp. "Parima” por apresentar uma série longitudinal de pequenas manchas arredondadas (vs. série longitudinal de manchas escuras ausente). Lebiasina aureoguttata difere ainda de L. taphorni, L. unitaeniata, L. uruyensis, L. yuruaniensis e L. sp. "Parima", pela ausência da faixa "intermediária" e pela mancha caudal alcançar o pedúnculo caudal anteriormente (vs. faixa "intermediária" presente; mancha caudal não alcançando o pedúnculo caudal anteriormente). Entre as espécies do clado 83, Lebiasina aureoguttata se diferencia de L. colombia, L. floridablancaensis, L. ortegai e L. panamensis por apresentar faixa primária inconspícua (vs. faixa primária conspícua ao longo de todo o corpo em $L$. ortegai e exemplares adultos de L. panamensis; porção anterior da faixa primária conspícua em L. colombia e exemplares jovens de L. panamensis; porção posterior da faixa primária conspícua em L. floridablancaensis). A espécie se distingue de $L$. multimaculata e L. chocoensis por apresentar a faixa secundária conspícua, passando pelas escamas da segunda e terceira séries longitudinais (vs. faixa secundária 
inconspícua estendendo-se ao longo das escamas da primeira e segunda séries longitudinais). A espécie se diferencia de L. astrigata e L. sp. Azuay por apresentar poucas manchas grandes distribuídas ao longo da quarta série longitudinal, faixa secundária alcançando a vertical que passa pela origem da nadadeira adiposa ( $v s$. numerosas manchas pequenas distribuídas ao longo da quarta série longitudinal de escamas; faixa secundária alcançando o término da nadadeira dorsal em Lebiasina astrigata; faixa primária alcançando a nadadeira caudal em L. sp. Azuay).

Descrição. Dados morfométricos apresentados na tabela 3. Vista lateral do holótipo e exemplares coletados recentemente representados na figura 77. Corpo comprimido e alongado. Perfil dorsal da cabeça e do corpo convexo do lábio superior até até a origem da nadadeira dorsal, tornando-se praticamente reto entre os parietais e a origem da dorsal. Perfil reto na base da dorsal e levemente côncavo posteriormente até a origem dos raios pró-correntes da nadadeira caudal. Perfil ventral da cabeça e tronco convexo desde o lábio inferior até a origem da pélvica, reto deste ponto até a origem da nadadeira anal, convexo na base da anal e côncavo do término da anal até a origem dos pró-correntes ventrais da nadadeira caudal.

Espécie discretamente prognata, boca subsuperior. Maxilar não alcançando a vertical que passa pela metade da órbita. Apenas uma série de 10* (13), 11 (8) ou 12 (1) dentes tricúspides decrescendo posteriormente no pré-maxilar. Maxilar com 5 (10), 6 (7), 7 (5) dentes tricuspidados. Dentário com duas séries de dentes: 10 (2), 11 (7), 12 (6) ou 14 (5) dentes tricúspides pedunculados com a cúspide central distintamente mais longa que as cúspides laterais na série externa, série interna com dentes diminutos, na maioria, cônicos (podendo ser tricúspides posteriormente) estendendo-se desde a sínfise até próximo ao processo coronóide. Raios-branquiostégios 4, três articulando com o ceratobranquial anterior e um com o ceratobranquial posterior.

Escamas ciclóides, circuli restritos à borda da escama, diversos radii (aproximadamente 22) convergindo para o centro da escama, estando intensamente anastomosados no centro, formando diversas células. Série longitudinal da linha lateral com 28* (3), 29 (8), 30 (7) ou 31 (7), das quais 4 (1), 5 (9) 6* (13)ou 7 (2) são perfuradas. Séries longitudinais entre a nadadeira dorsal e a pélvica 7. Escamas prédorsais 13 (1), 14* (16), 15 (6) ou 16 (1). Escamas da primeira série longitudinal 18* 
(4), 19 (9), 20 (3) a 21 (2), alcançando a vertical que passa pela origem da nadadeira anal. Escamas circumpedunculares 12 .

Nadadeira peitoral i, 13 (8) 14* (9), 15 (7), 16 (1). Ponta da peitoral não alcançando a vertical que passa pela origem da pélvica. Raios da nadadeira pélvica i, 7. Supraneurais 11,12 ou 13, anteriores aos espinhos neurais dos centros 5 a 15* (15), 16 (27) ou 17 (6). Nadadeira dorsal ii, 7 (3) ou ii, 8* (21). Primeiro pterigióforo da nadadeira dorsal inserido posteriormente ao espinho neural do centro $15^{*}(15), 16$ (27) ou 17 (6). Margem distal da nadadeira dorsal arredondada quando expandida. Origem da nadadeira dorsal distintamente mais próxima à base da nadadeira caudal que da ponta do focinho. Base do último raio da dorsal distintamente anterior à vertical que passa pela origem da nadadeira anal. Nadadeira anal iii, 8, último raio adnato. Margem distal da nadadeira anal arredondada. Primeiro pterigióforo da nadadeira anal inserido posteriormente ao arco hemal do centro 24* (4), 25 (26), 26 (17) ou 27 (1). Nadadeira adiposa presente. Um ou dois epurais. Nadadeira caudal furcada, lóbulo superior distintamente mais longo que o inferior, ambos arredondados. Raios principais da nadadeira caudal ii,8+i,8 (5) ou i,9+i,8 (19). Pró-correntes dorsais 8 (1); pró-correntes ventrais 7 (1). Vértebras pré-caudais 23 (1), 24 (4), 25 (1); vértebras caudais 16 (3), 17 (3).

Colorido. Cor de fundo predominantemente amarela. Coloração escura estendendo-se desde o lábio superior até a porção exposta dos parietais e ao longo da série medial e primeira série de escamas até a origem da nadadeira caudal. Maxilar, ossos circumorbitais e série opercular densamente pigmentados próximo à porção dorsal da cabeça, tornando-se gradualmente amarelada ventralmente; opérculo com uma distinta mancha escura na região médio-inferior. Estreita faixa negra estendendo-se da porção dorsal da órbita, passando pelos infra-orbitais 5 e 6 , alcançando a face dorsal do opérculo. Lábio inferior intensamente pigmentado; restante da mandíbula e toda porção ventral da cabeça com pigmentação escassa.

Tronco tornando-se gradualmente amarelado ventralmente. Região abdominal amarela, com diminutos cromatóforos entre o istmo e a origem da nadadeira anal. Mancha umeral arredondada, conspícua em indivíduos jovens e, geralmente, indivíduos adultos. Faixa primária representada por seis a oito manchas largas e alongadas distribuídas entre a mancha umeral e a mancha caudal. Manchas distintamente maiores 
que as observadas em L. astrigata, ocupando toda a escama da quarta série longitudinal e também a porção dorsal e a porção ventral de escamas da terceira e quinta séries longitudinais, respectivamente. Ao longo da ontogenia, ao contrário de L. astrigata, as manchas mais anteriores não se tornam inconspícuas e as posteriores raramente coalescem. Faixa secundária estendendo-se ao longo da segunda e terceira séries longitudinais de escamas, desde os epoccipitais à vertical que passa pela origem da nadadeira adiposa. Terceira, quarta e quinta séries longitudinais de escamas com sutis manchas escuras na base. Base da dorsal distintamente mais escura que o dorso. Mancha caudal alongada verticalmente, situada na extremidade do pedúnculo caudal e estendendo-se à base de 8 a 9 raios medianos da nadadeira caudal. Nadadeiras peitoral, pélvica, anal, adiposa e caudal hialinas; raios da nadadeira dorsal com cromatóforos nos primeiro ponto de ramificação na porção média dos raios.

Dimorfismo sexual. Exemplares machos de Lebiasina aureoguttata apresentam o padrão mais difundido de dimorfismo sexual entre as Lebiasina, descrito acima para Lebiasina astrigata.

Distribuição. Equador a oeste dos Andes, nas bacias dos rios Guayas e Esmeraldas (Figura 77).

Tabela 3. Dados morfométricos de Lebiasina aureoguttata.

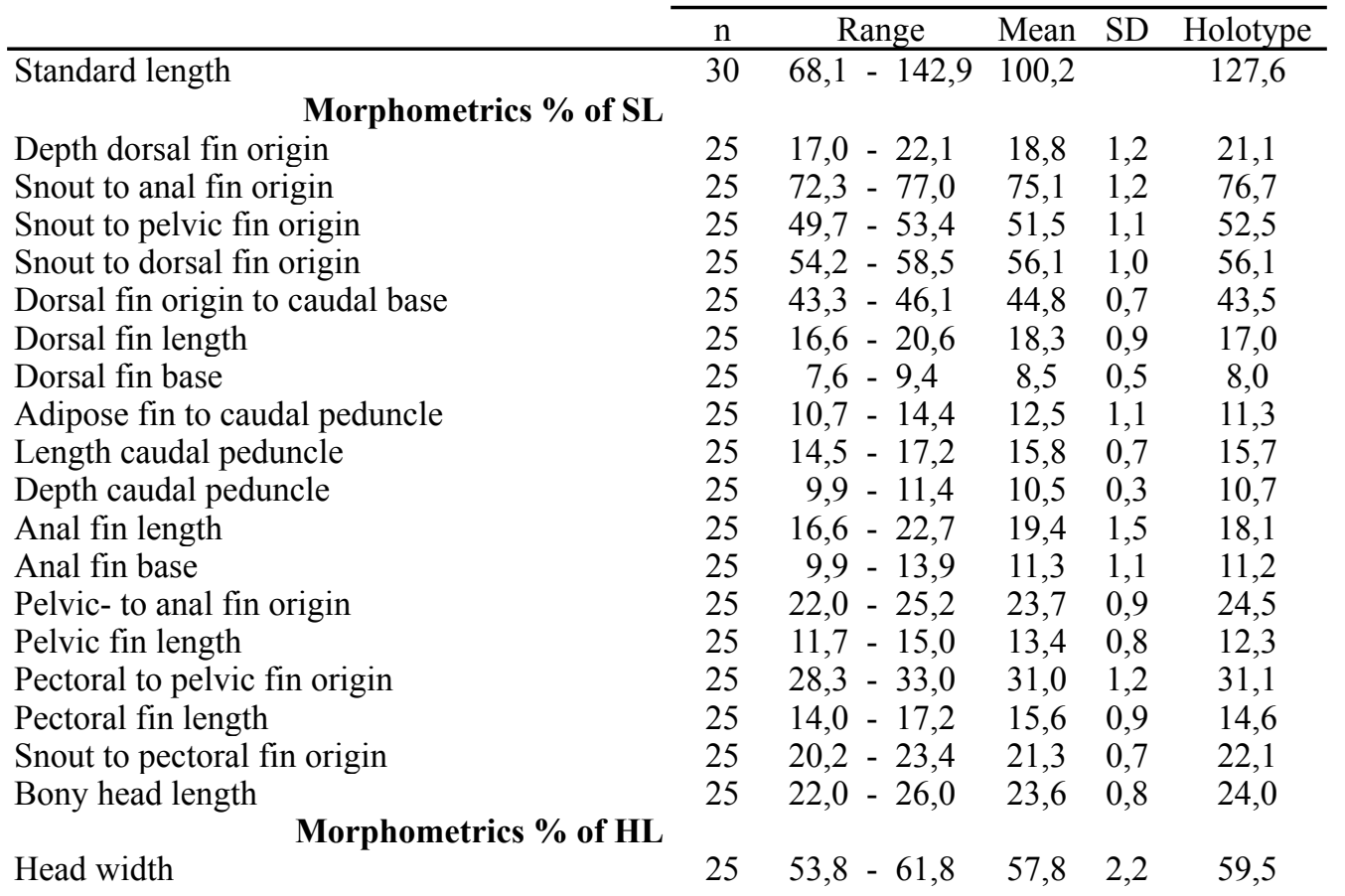


Horizontal eye diameter Distance snout tip to eye

Interorbital distance

Length lower jaw

Length upper jaw
$25 \quad 17,8-22,9 \quad 20,2 \quad 1,4 \quad 18,8$

$\begin{array}{lllll}25 & 26,0-32,3 & 28,6 & 1,7 & 29,8\end{array}$

$25 \quad 34,5-39,4 \quad 37,0 \quad 1,4 \quad 38,3$

$25 \quad 42,7-47,0 \quad 44,8 \quad 1,1 \quad 45,1$

$\begin{array}{lllll}25 & 36,5-41,4 & 38,7 & 1,3 & 38,0\end{array}$ 
Lebiasina bimaculata Valenciennes, in Cuvier \& Valenciennes

(Figura 79)

Lebiasina bimaculata Valenciennes, in Cuvier \& Valenciennes, 1846: 531; fig 587.Günther, 1864: xviii [summary]; 285 [inferred from known distribution "Fine specimen. Bay of Callao. Presented by Professor Nation" the bay of Callao is located in Lima, close to the delta of the Rimac river].- Steindachner, 1879: 22-23 [inferred from known distribution; localities and brief description].- Eigenmann \& Eigenmann, 1889: 113 [inferred from known distribution; synonymy; distribution (partly incorrect, including specimens from all Peru and also Ecuador); brief description].- Eigenmann \& Eigenmann, 1891: 45 [inferred from known distribution; distribution partly incorrect].Gill, 1895: 207.- Starks, 1906 [distribution, specimens from Callao and Eten only].Eigenmann, 1910: 439 [catalog; distribution partly incorrect].- Regan, 1913b: 279 [checklist].- Cockerell, 1914: 107 [scale morphology].- Evermann \& Radcliffe, 1917: 29 [synonymy, distribution (specimens from Callao and Pacasmayo only).- Eigenmann, 1920a: 16 - [distribution; specimens from Pacasmayo only].- Eigenmann, 1920b: 9-10 [IU 15299?].- Eigenmann, 1923a: 123 [key to the species and synonymy]; 124 [material examined, of which, only lots IU 15167, IU 15168, IU 15169, IU 15170, IU 15202 and IU 15299 are L. bimaculata].- Eigenmann, 1923b: 446 ["Liza de agua dulce and Huaija of Guayaquil are different names for the same fish - Lebiasina bimaculata." (actually, the specimens from Guayaquill pertain to a different species recognized here)].Meinken, 1937: 49-50 [comparisons with L. intermedia].- Pearson, 1937, 87-90 [distribution in Cajamarca, Peru, IU 17587, 17589, 17590; introcuction in Marañon river by pre-Conquest indians].- Arnold \& Ahl, 1936: 89 [specimens in aquarium].Eigenmann \& Allen, 1942: 279 [distribution (incorrect; comments on Pearson's hypothesis of introduction in the upper Marañon; natural predator of yellow-fever mosquito; aquarium trade species in Lima].- Fowler, 1945: 132 [common names and synonymy].- Fowler, 1950: 366 [common names for Lebiasina bimaculata; synonymy; distribution (partially incorrect)]; Böhlke, 1958: 94 [type specimen only, all other are Lebiasina aff. festae].- Weitzman, 1964 [morphology].- Weitzman, 1966.- MachadoAllison, 1974: 582 [diversity of Lebiasina and 'Piabucina'].- Weitzman, \& Cobb, 1975.- Ortega \& Vari, 1986: 10 [checklist; distribution incorrect; specimens from the Chira basin to the Southern pacific coast of Peru are L. bimaculata. To the North of the 
large desert between the departments of Lambayeque and Piura, occur three other species of the complex].- Castro et al., 1998: 79 .- Eschemeyer, 1998: 229 [catalog].Ardila-Rodríguez, 2000: 4 [L. yuruaniensis description]; 2002: 17 [taxonomic history of Lebiasininae; rather incomplete].- Weitzman \& Weitzman, 2003: 243 [checklist].

Lebiasina (Lebiasina) bimaculata.- Géry, 1972: 126 [key to the species of Lebiasininae].

Série-tipo. Holótipo: MNHN 0141.

Localidade-tipo. Río Rimac, próximo a Lima, Peru.

\section{Material examinado.}

All from Peru:

ANSP 71628 (1, $66.0 \mathrm{~mm}$ SL), Lima, Lima, 1203'S, 7703'W, 01-I-1939, W. Weyrauch;

CAS 70422 (15/54, 46.3-80.1 mm SL), La Libertad, Cultambo, estação no rio Jequetepeque próximo a Pacasmayo [07¹9’40’'S 79²5’47’W], 12-I-1919, C. H. Eigenmann;

CAS 70425 (23, 20.7-85.8 mm SL), Cajamarca, a montante de Chilete [07¹3’12’'S 78 50'16”W], bacia do rio Jequetepeque, unknown date, N.E. Pearson;

CAS uncat (ex-IU 15167) (14, 37.8-121.5 mm SL), Lima, Puente Piedra [1152’38’S 7704'57’W margem direita do rio Chillón], margem direita, 26-I-1919, C. H. Eigenmann (Irwin Expedition);

CAS uncat (ex-IU15202) (10, 29.2-91.9 mm SL), Lima, Chosica [1156’30”S 76²1'54”W], rio Rimac a montante de Lima, [800 m elev.], 10-X-1918, C. H. Eigenmann (Irwin Expedition);

CAS uncat (ex-IU 15299) (1, 21.3 mm SL), Lima, Matucana [1150’39”S 76²3’04”W, Río Rimac, aprox. 2000 m elev.], VIII-1918, C. H. Eigenmann;

CAS 70420 (ex-IU 17587) (12, 34.4-162.0 mm SL), La Libertad, Pacasmayo, Laguna Hornito [07¹9'41”S 79³5'26”W], desembocadura do rio Jequetepeque, IX-1923, N. E. Pearson; 
CAS uncat (ex-IU 17589) (5, 73.1-35.6 mm SL), Cajamarca, rio Cajamarca [07¹4'00’'S 78²3'00’'W]; VII-1923, N. E. Pearson.

CAS uncat (ex-IU 17590) (66, 24.3-104.1 mm SL), Cajamarca, Paipay, na desembocadura do rio Paipay no rio Crisnejas [07²1'06”S $77^{\circ} 57^{\prime} 02^{\prime \prime} \mathrm{W}$ ], afluente do rio Marañon, VIII-1923, N. E. Pearson.

LIRP 4379 (4, 43.0-49.1 mm SL), Cajamarca, Magdalena, rio Jequetepeque (ponto 2), 07¹3’35’S 7850’00”W, 26-XI-2002, C. Oliveira, M.C.C. de Pinna, A.L. Alves \& M. Velásquez;

MCZ 54123 (1, 121.3 mm SL), Lima, Chosica [1156’30”S 7641'54”W], rio Rimac, $40 \mathrm{Km}$ a sudeste de Lima, 27-II-1939, J. A. Griswold Jr.

MUSM 30419 (3, 51.2-82.3 mm SL), Ancash, Santa, el Castillo, Rio Santa [0856’13”S 78³5'19’'W], 10-XI-2000, H. Ortega et al.;

MUSM 5188 (4, 35.2-46.1), Cajamarca, San Ignacio a $2 \mathrm{Km}$ do Rio Tabaconas, Tributário do Rio Tabaconas [0507’22”S 7857’10”W], 13-VIII-1986, E. Holm \& J. Patalas;

MUSM 347 (1, 116.5 mm SL), Lima, Rimac, Rio Rimac, Urb. Zarate [1202’23”S $77^{\circ} 05^{\prime} 50^{\prime}$ 'W], 16-VI-1983, H. Ortega;

MUSM 349 (3, 89.3-90.5 mm SL), La Libertad, Rio Chicama [0747’35”S 7909’22”W], 04-X-1968, IMARPE;

MUSM 350 (4, 62.0-35.5 mm SL), La Libertad, Ascope, Río Chicama [0744’28’S 7905'23”W], 03-X-1968, IMARPE;

MUSM 1242 (2, 44.7-87.0 mm SL), Lambayeque, Chiclayo, La Florida, Río Saña [0655'49’'S 79³4'55’W], kp 908, 19-VII-1953, F. Ancieta \& H. W. Koepke;

MUSM 1727 (1, 69.0 mm SL), Lima, Pativilca, Barranca, Albufera de Médio Mundo [1055'42”S 77³9'56”W], 13-I-1974, F. Ancieta;

MUSM 1762 (1, 115.3 mm SL), Cajamarca?, Jequetepeque, Rio Jequetepeque, 15XII-1987, M. Fukushima;

MUSM 2877 (1, $63.3 \mathrm{~mm}$ SL), Lima, Chancay, Huaura, Vilcahuaura [1105'09’S 77²9’28’W], 12-I-1991, F. Chang;

MUSM 2880 (13, 43.1-97.0 mm SL), Lima, Chancay, Huaura, río Huaura [1104’30’S 77³5'56”W], 09-II-1992, F. Chang;

MUSM 2893 (6, 52.0-78.4 mm SL), Lima, Chancay, Huaura, ramal del rio Huaura Km 12 [1104’30”S 77³5’56”W], 17-IV-1990, F. Chang; 
MUSM 2894 (11, 36.8-90.1 mm SL), Lima, Carabayllo, Trapiche, Río Chillón [1143'57’'S 7658'18’'W], 08-X-1990, H. Ortega et al.;

MUSM 2895 (4, 32.3-86.8 mm SL), Lima, Cieneguilla, Río Cieneguilla, 1208’00”S 7649’00”W, 10-VII-1987, H. Ortega et al.;

MUSM 2896 (25, 22.9-99.8 mm SL), Lima, Chillón, Carabayllo, Río Chillón [11'51'46”S 7701'42”W], 02-VIII-1991, P. Baltazar;

MUSM 2898 (4, 66.6-94.1 mm SL), Lima, Lurin, Rio Lurin [12¹5'13”S 7653’42”W] 18-XII-1988, H. Ortega \& P. Baltazar;

MUSM 2992 (1, 91.7 mm SL), Ancash, Santa (Chimbote) [0859’45’S 78³7’27’W], Bocatona-Tablones Km 52, 10-II-1990, P. B., S. V., A. S.;

MUSM 3000 (3, 28.7-34.6 mm SL), Ancash, Santa, Rio Santa [0858’14”S 78॰37'56”W], 09-II-1990, P. B., S.V., A.S.;

MUSM 3124 (9, 59.11-40.41 mm SL), Lima, Lurín, Rio Lurin [12¹5’13”S 7653’42”W], 18-VII-1991, H. Ortega;

MUSM 3244 (3, 34.8-78.8 mm SL), Cajamarca? Jequetepeque, Rio Jequetepeque, 02VIII-1986, CEDEPIS;

MUSM 3418 (58, 113.31-33.59 mm SL), Lima, Huaral, Río Chancay [11³1'03”S 77¹0'59'W], 17-V-1992, H. Ortega et al.;

MUSM 3426 (3, 38.25-75.81 mm SL), Lima, Huaral, Río Chancay [11³1'03”S 77¹0'59’W], 17-V-1992, H. Ortega \& F. Chang;

MUSM 3432 (10, 3.2-89.1 mm SL), Lima, Chancay, Huaura, Río Huaura [1104’30”S 77³5'56”W], 16-VIII-1992, H. Ortega, L. Coll \& D. Elguera;

MUSM 14183 (3, 62.0-94.6 mm SL), Lima [Huanuco?], Laguna de Ventanilla, 13V-1998, E. Castro \& N. Carrasco;

MUSM 5173 (2, 53.9-54.3 mm SL), Lima, Chancay, Pativilca, Rio Pativilca [1043'19”'S 7746’26”W], 22-X-1992, F. Rodriguez \& C. Palma;

MUSM 5174 (3, 72.9-91.5 mm SL), Lima, Chancay, Paramonga, Río Fortaleza [10³9’21’S 7750’25’W], 21-X-1992, F. Rodriguez \& C. Palma;

MUSM 5175 (2, 49.9-81.3 mm SL), Lima, Chancay, Pativilca, Rio Pativilca a jusante [da cidade: $10^{\circ} 43^{\prime} 41^{\prime \prime S} 77^{\circ} 46^{\prime} 47^{\prime \prime} \mathrm{W}$ ], 22-X-1992, H. Ortega \& D. Elguera;

MUSM 5179 (2, 104.6-116.9 mm SL), La Libertad, Chiclayo, Chongoyape, La Puntilla, Rio Reque [0645’33”S 79³0'42”W], 01-V-1988, unknown collector; 
MUSM 6863 (1, 122.9 mm SL), Lima, Chorrillos, Pantanos de Villa (sistema do rio Rimac), Canal aberto, Estação hidrométrica no. 3 [12¹2'54”S 7659’23”W], 28I-1995, O. Huamán \& E. Castro;

MUSM 7105 (1, 121.0 mm SL), Lima, Chorrillos, Pantanos de Villa (Río Rimac system), canal abierto, Estação hidrométrica no. 3 [12 $12^{\prime} 54^{\prime}$ 'S 7659'23”W], 13II-1994, E. Castro \& O. Huamán;

MUSM 7126 (1, 149.5 mm SL), Lima, Chorrillos, Pantanos de Villa (Rio Rimac system), canal dentro do campo de Golf [12¹2’53.7’S 7659’22.8”'W], 23-IX-1990, P. Baltazar \& V. Vera;

MUSM 7313 (7, 106.3-152.2 mm SL), Lima, Chorrillos, Pantanos de Villa (Rio Rimac system), Estação “Canal Abiertos” [12¹2’53.7”S 7659’22.8”W], 17-XII_1994, E. Castro \& O. Huamán;

MUSM 7632 (1, 75.8 mm SL), Lima, Huacho, Río Huaura [1104’57.7’S 77³7’30.5’W], 03-XII-1990, L. Araujo;

MUSM 7683 (6, 53.8-76.8 mm SL), La Libertad, Trujillo, Laredo, Menocucho, Río Moche [0801'49.3’'S 7850’33”W], 10-XII-1991, H. Ortega et al.;

MUSM 10732 (4, 32.7-76.5 mm SL), Lima, Chancay, Huaura, Km 12 carretera. Huaura-Sayán. Afluente do río Huaura [1105’09.2”S 77²9’27.8”W], 17-IV-1990, F. Chang;

MUSM 12540 (20), Cajamarca, Rio Jequetepeque 300 m elev., 18-IV-1954, H.W. Koepke;

MUSM 12769 (12, 38.6-102.3 mm SL), Lambayeque, Chiclayo, río Chongoyape [06³7’58’'S 79²4'20’W], 17-VII-1953, H. W. Koepke;

MUSM 12770 (1, 124.8 mm SL), Lima, Pachamac, Lagunas cerca ruínas (Rio Lurin system) [12¹2’43.8’S 7652’22.3”W], 04-XI-1951, H. W. Koepke;

MUSM 12772 (4, 41.5-104.9 mm SL), Lima, Chillón, Trapiche, Río Chillón

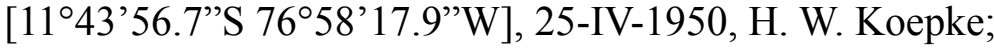

MUSM 12773 (1, 100.8 mm SL), Lima, Rio Rimác, Mercado de Lima [12²’23.0”S 7705'50.3”W], unknown date, R. C. Cooker;

MUSM 12774 (1, 87.0 mm SL), Cajamarca, entre Cutervo y Tambillo, unknown date and collector;

MUSM 12776 (1, 105.5 mm SL), La Libertad, Río Chicama, 00-X-1958, Fernandéz; 
MUSM 14182 (64, 11.7-86.0 mm SL), Lima, Canta, Santa Rosa de Quives, Río Chillón [11'40’3.8”S 7647'26.2”W], 17-VII-1998, H. Ortega;

MUSM 15016 (8, 35.7-64.6 mm SL), Cajamarca, Contumaza, Río Jequetepeque, Tembladera, frente a Ventanillas [07¹6’42.4”S 79¹6'13.4”W], 30-III-1999, E. Castro; MUSM 15022 (4, 68.64-72.42 mm SL), Cajamarca, Contumaza, Río Jequetepeque, Tembladera [07¹5’24.5’S 79 7’59.4”W], 29-III-1999, E. Castro;

MUSM 15101 (3, 43.1-70.6 mm SL), Lima, Huaura, Calderas, rio Huaura entre Huaura

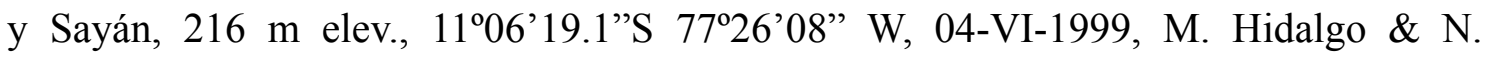
Salcedo;

MUSM 15102 (2, 18.8-64.5 mm SL), Lima, Huaura, Sayán, rio Huanangue 1102’44”S 7707’12.4’W, 731 m elev., 03-VI-1999 M. Hidalgo \& N. Salcedo;

MUSM 15931 (40, 50.0-106.3 mm SL), Lima, Pachacamác, Rio Lurín, Puente Jamboinga 208m aprox. [12¹2’45.6”S 7652’23.8”W], 07-II-2000, M. Hidalgo;

MUSM 15933 (23, 34.29-72.59 mm SL), Lima, Pachacamác, Rio Lurín, Puente Jamboinga 250m aprox. [12¹2’45.6”S 7652’23.8”W], 07-II-2000, M. Hidalgo;

MUSM 17957 (3, 67.3-74.9 mm SL), Lima, Canta, Santa Rosa de Quives, Río Chillon [1140’03.8”'S 7647’26.2”W], 11-VI-1999, H. Ortega;

MUSM 17963 (6, 24.-91.5 mm SL), Lima, Carabayllo, Trapiche, Río Chillón [1143'56.7’S 7658'17.9”W], 11-VII-1994, H. Ortega;

MUSM 18013 (2, 37.4-47.3 mm SL), Cajamarca, Contumaza, Rio Jequetepeque, a jusante de Magdalena, 1074 m elev., 07²13'47.4”S 7842'55.1”W, 04-III-2001, M. Hidalgo;

MUSM 18027 (8, 73.2-88.9 mm SL), Cajamarca, Cajamarca, Granada, Río Jequetepeque $1336 \mathrm{~m}$ elev., 07¹5'27.7’'S 078³8'48.6”W, 12-III-2001, M. Hidalgo \& C. Palma;

MUSM 18031 (6, 36.4-63.0 mm SL), Cajamarca, Contumaza, Rio Jequetepeque, a jusante de Magdalena, 1074 m elev., 07²13'47.4”S 7842'55.1”W, 19-III-2001, M. Hidalgo \& C. Palma;

MUSM 18035 (3, 40.9-59.4 mm SL), Cajamarca, Contumaza, Rio Jequetepeque, Bajada de la Paloma, 1050 m elev., 07¹3'25.4”S 7843'45.6”W, 19-III-2001, M. Hidalgo \& C. Palma; 
MUSM 18039 (5, 35.4-65.2 mm SL), Cajamarca, Contumaza, Río Jequetepeque, Trasval, próximo a Chilete $07^{\circ} 13$ '27.5’S 7848’31.4”W, 19-III-2001, M. Hidalgo \& C. Palma;

MUSM 18049 (17, 28.8-70.9 mm SL), La Libertad, Pacasmayo, Río Jequetepeque, Puente carretera Panamericana Norte, 96 m elev., 07¹9’31.4”S 78²8’49.6”W, 21III-2001, M. Hidalgo \& C. Palma;

MUSM 18641 (7, 35.5-50.4 mm SL), Cajamarca, Contumaza, Río Jequetepeque, Granada, $1336 \mathrm{~m}$ elev., 07¹5'27.7”S 78³8'48.6”W, 28-III-2001, M. Hidalgo \& C. Palma;

MUSM 18644 (8, 33.9-60.8 mm SL), Cajamarca, Contumaza, Rio Jequetepeque, Bajada de la Paloma, 1050 m elev., 07²13'25.4”S 7843'45.6”W, 28-IV-2001, M. Hidalgo \& C. Palma.

MUSM 18654 (10, 42.7-73.3 mm SL), La Libertad, Pacasmayo, Río Jequetepeque, Puente carretera Panamericana Norte, 96 m elev., 07¹9'31.4”S 78²8'49.6”W, 30IV-2001 M. Hidalgo \& C. Palma;

MUSM 18867 (7, 41.2-70.0 mm SL), Cajamarca, Contumaza, Chilete, Río Jequetepeque, Trasval, $900 \mathrm{~m}$ elev., 07²13’36.8”S 7848'57.8”W, 29-IV-2001, M. Hidalgo \& C. Palma;

MUSM 19644 (1, 32.55 mm SL), Lima, Carabayllo, Río Chillón [1151'46.0”S 7701'42.33”W], 01-X-2001, L. Chocano \& B. Rengifo;

MUSM 19648 (2, 51.8-56.1 mm SL), Lima, Ventanilla, R. Chillón [1156'13.8”S 7707'51.3’W], 01-X-2001, L. Chocano \& B. Rengifo;

MUSM 19856 (59, 32.2-60.0 mm SL), Cajamarca, Choropampa, Río Magdalena, bacia do Jequetepeque, 1608 m elev., 07²1'24”S 78³4'29.9”W, 22-III-2002, M. Hidalgo \& C. Palma;

MUSM 19860 (5, 37.5-83.4 mm SL), Cajamarca, Contumaza, Chilete, Río Jequetepeque, Trasval $900 \mathrm{~m}$ elev., 07¹3'36.8”S 7848'57.8”W, 21-III-2002, M. Hidalgo \& C. Palma;

MUSM 19864 (9, 37.4-60.7 mm SL), La Libertad, Pacasmayo, Río Jequetepeque, Puente carretera Panamericana Norte, 96 m elev., 07¹9'31.4”'S 78²8'49.6”W, 21III-2002, M. Hidalgo \& C. Palma; 
MUSM 19872 (3, 45.7-53.7 mm SL), Cajamarca, Jequetepeque, Contumaza, Rio Jequetepeque, Bajada de la Paloma 07²13'25.4”S 7843'45.6”W 1050 m elev. 3 21III-2002 M. Hidalgo \& C. Palma;

MUSM 20730 (5, 53.3-86.5 mm SL), La Libertad, Ascope [0742’41.3”S 7906’29.5”W], Río Grande [0740’00”S 78³6’60”W], alto Chicama, 09-X-2002, Golder Team;

MUSM 30492 (2, 55.4-72.5 mm SL), Lima, Canta, Yangos, Rio Chillón, Puente Trapiche, 07-XI-2000, H. Ortega \& B. Reginfo;

MUSM uncat (2, 86.1-89.4 mm SL), Cajamarca, Cañariaco [0556’43.3”S 79¹5’23.7’W], bacia do Cañariaco, 30-I-2008, B. Reginfo \& V. Correa;

MUSM uncat (3, 49.1-89.7 mm SL), Lima, alto rio Lurin, 21-IX-2008, H. Ortega, G. I.

T. Núñez \& J. Espino;

MUSM uncat (14, 41.2-79.9 mm SL), Lima, Canta, Santa Rosa de Quives, Río Chillon km 66 [1140’3.8’S 7647’26.2’W], 25-VI-1995, H. Ortega et al.;

MZUSP 24355 (2, 81.7-98.9 mm SL), Lima, Albufera Del Médio Mundo [1055’42.3”S 77³9’56”W], 09-I-1971, IMARPE;

MUSM 31586 (8, 69.0-104.2 mm SL), Lambayeque, Ferreñafe, Kañaris, Rio Huancabamba, Quebrada Yerma[0644'32.5”S 7945'19.4”W], 19-IX-2007 B. Rengifo \& V. Meza;

MZUSP 80083 (13, 34.0-47.9 mm SL), Cajamarca, Magdalena, rio Jequetepeque (ponto 1), 7¹5’30”S 78³8’47’W, 26-XI-2002, C. Oliveira, M.C.C. de Pinna, A.L. Alves \& M. Velásquez;

MZUSP 80085 (80, 20.3-86.7 mm SL), Cajamarca, Magdalena, rio Jequetepeque (ponto 2), 7¹3’35’S 7850’0”W, 26-XI-2002, C. Oliveira, M.C.C. de Pinna, A.L. Alves \& M. Velásquez;

ROM 50765 (13, 45.2-113.8 mm SL), Cajamarca, Baños del Inca, afluente do rio Chonta [0707’60’S 7842’00’W], XI-1984, B. Reyes;

ROM 50770 (1, 115.0 mm SL), Lima, tributário do rio Rimac, VIII-1985, M. Urbina; ROM 52206 (8, 28.6-77.7 mm SL), Cajamarca, afluente do rio Tabaconas, cerca de 2 $\mathrm{km}$ a montante da desembocadura do rio Tabaconas no rio Chinchipe, afluente do rio Marañon [05²4’30”S 7846’30”W, 33 km N de Jaen], 07-VII-1986, E. Holm \& J. Patalas; 
ROM 52203 (2, 100.6-107.3 mm SL), Cajamarca, rio Mashcon [Río Mashoon: 07009'00”S 78³2’00”'W], $8 \mathrm{~km}$ a leste de Cajamarca, na Estação Agricultora Experimental La Victoria, VII-1986, E. Holm \& J. Patalas;

ROM 52207 (12, 39.1-89.5 mm SL), Cajamarca, tributário do rio Huancabamba [05 $\left.52^{\prime} 50.0^{\prime \prime} \mathrm{S} 78^{\circ} 47^{\prime} 19.9^{\prime \prime} \mathrm{W}\right]$, cerca de $74 \mathrm{~km}$ a oeste da rodovia em direção a Jaen, entre Pucara e Guabel, VII-1986, E. Holm \& J. Patalas;

ROM 52208 (24, 13.2-65.5 mm SL), Cajamarca, rio Jequetepeque a oeste de Chilete [07¹3’21’S 7850’39’W], VII-1986, E. Holm \& J. Patalas;

ROM 52209 (26, 23.00-61.4 mm SL) Ancash, rio Sechin, cerca de $4 \mathrm{~km}$ a leste de Buena Vista e a $14 \mathrm{~km}$ a leste da rodovía Pan-America, em Casma [9²9’03”S 78¹8’15’W], VII-1986, E. Holm \& J. Patalas;

SU 39290 (1, 70.7 mm SL), Brasil, rio Bellavista [Bellavista: 5³9'29”S 7841'16”W Peru, Amazonas, a aprox. 17 km de Bágua, bacia do rio Marañon], unknown date, G.K. Noble;

USNM 53515 (1, 82.8 mm SL), Peru, Lima, Callao na boca do rio Rimac [1201'53"S 7708'40”W], 1900?, P. O. Simons;

USNM $53520(3,67.1-113.4 \mathrm{~mm}$ SL), Lambayeque, Eten [rio Eten, em Eten: 0653'53.8’S 7952'3.7’'W], unknown date, P. O. Simons;

USNM 77523 (7, 61.6-112.8 mm SL), Lima, rio Rimac, 06-XI-1907, R. E. Coker;

USNM 77575 (2, 45.4-53.4 mm SL), Peru, La Libertad, Pacasmayo [07²4’02"S 79³3'45"W], 12-III-1907, R. E. Coker?.

USNM 83022 (2, 96.1-102.0 mm SL), Peru, unknown date, Wilkes Expedition;

USNM 83630 (18, 42.4-69.6 mm SL), La Libertad, Cultambo [07¹9’40.3”S 79²5'47.0”W], I-1919, C. H. Eigenmann;

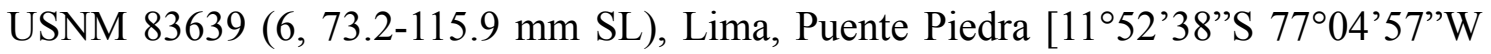
margem direita do rio Chillón], 26-I-1919, C. H. Eigenmann (Irwin Expedition);

USNM 88692 (1, 116.2 mm SL), La Libertad, Salaverry, rio Moche [809’33.3”S 7901'55.8’W], 23-X-1926, W. L. Schmitt;

USNM 88693 (6, 27.9-90.2 mm SL), La Libertad, Salaverry, rio Moche [809’33.3”S 7901'55.8”W], 20-X-1926, W. L. Schmitt;

USNM 119951 (1, 142.6 mm SL), Peru, 11-VIII-1942, Thayer Expedition;

USNM 122593 (7, 72.6-119.5 mm SL), Lima, rio Rímac, unknown collector [Wilkes Expedition?]. 
Diagnose. Lebiasina bimaculata diferencia-se de Lebiasina astrigata, L. aureoguttata, L. chocoensis, L. colombia, L. elongata, L. erythrinoides, L. floridablancaensis, L. intermedia, L. multimaculata, L. ortegai, L. panamensis, L. taphorni, L. unitaeniata, L. uruyensis, L. yuruaniensis, L. sp. Azuay, L. sp. "Curuá-Faixa”, L. sp. "Curuá-Pinta” e L. sp. "Parima" pelas seguintes características: parede da câmara posterior da bexiga natatória "celular"; escamas da sexta série longitudinal modificadas em machos adultos; três ou quatro séries longitudinais de escamas com intensa deposição de guanina ( $v s$. parede da bexiga natatória não "celular"; modificações nas escamas da quinta série longitudinal nos machos adultos; escamas sem intensa deposição de guanina). $L$. bimaculata diferencia-se de L. boruca, L. festae e L. aff. festae por apresentar dentes com as cúspides laterais quase tão desenvolvidas quanto a cúspide central e por não apresentar dentes no endopterigóide (vs. dentes com cúspide central distintamente mais longa que as laterais; endopterigóide apresentando dentes). A espécie diferencia-se de $L$. aff. bimaculata I e L. aff. bimaculata II por apresentar a moldura do forame escapular totalmente ossificada e apresentar o pós-cleitro 3 (vs. moldura do forame escapular com uma porção cartilaginosa entre a escápula e o cleitro; pós-cleitro 3 ausente). A espécie diferencia-se ainda de $L$. aff. bimaculata I por não apresentar uma inflexão no maxilar (vs. porção dentígera do maxilar flexionada anteriormente, dentes do pré-maxilar e maxilar formando uma única superfície cortante).

Descrição. Dados morfométricos apresentados na tabela 4. Corpo comprimido e alongado. Perfil dorsal da cabeça distintamente convexo do lábio superior até até a origem da nadadeira dorsal. Perfil reto na base da dorsal e levemente côncavo posteriormente até a origem dos raios pró-correntes da nadadeira caudal. Perfil ventral da cabeça e tronco convexo desde o lábio inferior até a origem da pélvica, reto deste ponto até a origem da nadadeira anal, convexo na base da anal e côncavo do término da anal até a origem dos pró-correntes ventrais da nadadeira caudal.

Espécie discretamente prognata, boca terminal. Maxilar quase alcançando a margem anterior da órbita. Apenas uma série de 10 (9) ou 11 (4) dentes tricúspides decrescendo posteriormente no pré-maxilar. Maxilar com 3 (3), 4 (4) ou 5 (6) dentes tricuspidados. Dentário com duas séries de dentes: 12 (6), 13 (1), 14 (1) ou 15 (1) dentes tricúspides pedunculados com a cúspide central distintamente mais longa que as 
cúspides laterais na série externa, série interna com dentes diminutos, na maioria, cônicos (podendo ser tricúspides posteriormente) estendendo-se desde a sínfise até próximo ao processo coronóide. Raios-branquiostégios 4, três articulando com o ceratobranquial anterior e 1 com o ceratobranquial posterior.

Escamas ciclóides, circuli restritos à borda da escama, diversos radii (aproximadamente 29) convergindo para o centro da escama, fortemente anastomosados no centro, formando numerosas células. Série longitudinal da linha lateral com 26 (2), 27 (34), 28 (97), 29 (62) ou 30 (2) escamas, das quais apenas 4 (17), 5 (70), 6 (126) ou 7 (2) são perfuradas. Séries longitudinais entre a nadadeira dorsal e a pélvica 7. Escamas pré-dorsais 11 (4), 12 (78), 13 (128) ou 14 (2). Escamas da primeira série longitudinal 16 (1), 17 (1), 18 (4), geralmente ultrapassando a vertical que passa pela origem da nadadeira anal. Escamas circumpedunculares 12.

Nadadeira peitoral i, 12 (4), 13 (71), 14 (91), 15 (28) ou 16 (6). Ponta da peitoral não alcançando a vertical que passa pela origem da pélvica. Raios da nadadeira pélvica i, 6 (2), i, 7 (193) ou i, 8 (5). Supraneurais 9 ou 10 anteriores aos espinhos neurais dos centros 5 a 13 (4) ou 14 (23). Nadadeira dorsal ii, 7 (90) ii, 8 (95) em apenas um exemplar examinado. Primeiro pterigióforo da nadadeira dorsal inserido posteriormente ao espinho neural do centro 13 (4) ou 14 (23). Margem distal da nadadeira dorsal arredondada quando expandida. Origem da nadadeira dorsal distintamente mais próxima à base da nadadeira caudal que da ponta do focinho. Base do último raio da dorsal distintamente anterior à vertical que passa pela origem da nadadeira anal. Nadadeira anal iii, 7 (5), iv, 7 (2) ou iii, 8 (192), último raio adnato. Margem distal da nadadeira anal arredondada. Primeiro pterigióforo da nadadeira anal inserido posteriormente ao arco hemal do centro 22 (6), 23 (18) ou 24 (2). Nadadeira adiposa ausente. Um ou dois epurais. Nadadeira caudal furcada, lóbulo superior com forma e tamanho similar ao inferior, ambos arredondados. Raios principais da nadadeira caudal geralmente i, 9/i, 8 (194) (casos aberrantes: i, 8/ i, 8 - 7; ii, 8/i, 7 - 2; ii, 8/i, 8 - 9; i, 9/i, 7 - 2; i, 9/ii, 7 - 2; i, 10/i,8 - 2;i, 8/i, 8). Pró-correntes dorsais 8; pró-correntes ventrais 9. Vértebras pré-caudais 22 (6); vértebras caudais 15 (1) ou 16 (5).

Colorido. Cor de fundo predominantemente amarela. Coloração escura estendendo-se desde o lábio superior até a porção exposta dos parietais e ao longo da série medial e primeira série de escamas até a origem da nadadeira caudal. Maxilar, ossos 
circumorbitais e série opercular densamente pigmentados próximo à porção dorsal da cabeça, tornando-se gradualmente amarelada ventralmente e com sutil deposição de guanina. Lábio inferior pouco pigmentado; restante da mandíbula e toda porção ventral da cabeça com pigmentação escassa.

Tronco tornando-se gradualmente amarelado ventralmente. Região abdominal amarela, com diminutos cromatóforos entre o istmo e a origem da nadadeira anal. Mancha umeral arredondada, conspícua em indivíduos jovens, porém inconspícua ou ausente em indivíduos adultos. Faixa primária ampla, percorrendo as escamas da terceira, quarta e quinta séries longitudinais, estendendo-se da região umeral até a vertical que passa pela origem dos raios pró-correntes da nadadeira caudal, não alcançando a mancha caudal. Faixa secundária estendendo-se ao longo da primeira e segunda séries longitudinais de escamas, desde os epoccipitais à vertical que passa pela origem da nadadeira anal. Base das escamas da segunda, terceira, quarta, quinta e sexta séries longitudinais de escamas com deposição de guanina, que em exemplares vivos é coberta por pigmentos que variam do rosa ao vermelho intenso; deposição de guanina na quinta escama da linha lateral mais intensa. Mancha caudal arredondada, situada na extremidade do pedúnculo caudal e estendendo-se à base de seis raios medianos da nadadeira caudal. Nadadeiras peitoral, pélvica, dorsal, anal e caudal hialinas.

Dimorfismo sexual. Exemplares machos de Lebiasina bimaculata apresentam acentuado dimorfismo sexual, consistindo no padrão geral dos demais congêneres: raios da nadadeira anal alongados e espessados, aumento da base da nadadeira anal; hipertrofia dos músculos inclinadores dos raios da anal; órgãos de contato distribuídos na porção lateral da cabeça, face medial dos raios da nadadeira peitoral e face ventral dos raios da nadadeira pélvica. Esta espécie, no entanto, apresenta as escamas da sexta série longitudinal modificadas ao longo da base da anal, estando a escama que se encontra na vertical que passa pela origem da nadadeira anal hipertrofiada. Tal escama é distintamente maior que as demais escamas do corpo e com maior acúmulo de epitélio. Bussing menciona que tal cará ter seria exclusivo de L. boruca, mas é compartilhado com todas as espécies do grupo L. bimaculata, L. boruca e L. festae. Diferenças merísticas ou morfométricas além daquelas relacionadas ao comprimento dos raios e da base da nadadeira anal não foram observadas. 
Distribuição. Peru a oeste dos Andes, desde a bacia do rio Lurin, ao sul de Lima, até o rio Chira, próximo a Chiclayo (depto Lambayeque) e alto rio Marañón (Figura 80).

Tabela 4. Dados morfométricos de Lebiasina bimaculata.

\begin{tabular}{|c|c|c|c|c|}
\hline & & & & \\
\hline Standard length & & $\frac{108}{1520}$ & $\frac{\text { Mrean }}{700}$ & \\
\hline \multicolumn{5}{|c|}{ Morphometrics \% of SL } \\
\hline Depth dorsal fin origin & 174 & $21,7-29,2$ & 25,4 & 1,5 \\
\hline Snout to anal fin origin & 174 & $70,5-81,0$ & 75,4 & 2,0 \\
\hline Snout to pelvic fin origin & 174 & $48,7-57,0$ & 52,6 & 1,6 \\
\hline Snout to dorsal fin origin & 174 & $52,4-59,6$ & 55,9 & 1,4 \\
\hline Dorsal fin origin to caudal base & 174 & $42,7-49,6$ & 46,2 & 1,4 \\
\hline Dorsal fin length & 174 & $16,9-21,5$ & 19,3 & 1,0 \\
\hline Dorsal fin base & 173 & $7,6-10,2$ & 8,7 & 0,5 \\
\hline Length caudal peduncle & 173 & $11,6-17,0$ & 14,6 & 0,9 \\
\hline Depth caudal peduncle & 174 & $11,2-13,7$ & 12,6 & 0,5 \\
\hline Anal fin length & 174 & $16,9-26,8$ & 20,9 & 2,8 \\
\hline Anal fin base & 172 & $8,3-15,6$ & 12,0 & 2,1 \\
\hline Pelvic- to anal fin origin & 174 & $19,7-30,3$ & 23,7 & 1,5 \\
\hline Pelvic fin length & 174 & $12,6-17,7$ & 14,9 & 0,9 \\
\hline Pectoral to pelvic fin origin & 173 & $27,2-35,2$ & 30,8 & 1,5 \\
\hline Pectoral fin length & 174 & $15,7-19,9$ & 17,8 & 0,8 \\
\hline Snout to pectoral fin origin & 174 & $20,6-26,1$ & 22,7 & 1,0 \\
\hline Bony head length & 174 & $22,3-28,4$ & 25,2 & 1,0 \\
\hline \multicolumn{5}{|c|}{ Morphometrics \% of HL } \\
\hline Head width & 173 & $50,5-66,8$ & 57,9 & 3,2 \\
\hline Horizontal eye $\mathrm{d}$ & 174 & $15,4-26,5$ & 21,0 & 2,1 \\
\hline Distance snout tip to eye & 173 & $22,5-30,4$ & 26,3 & 1,6 \\
\hline Interorbital distance & 173 & $31,4-38,6$ & 34,5 & 1,2 \\
\hline Length lower jaw & 174 & $33,7-46,6$ & 39,8 & 2,3 \\
\hline Length upper jaw & 137 & $28,2-37,6$ & 32,6 & 1,7 \\
\hline
\end{tabular}

\section{Lebiasina boruca (Bussing)}

(Figura 81)

Piabucina boruca, Bussing, 1967.- Fromm, 1977: 262 [general comments on the color pattern, behavior and habitat].- Alpírez, 1985: 303 [distribution and material in collections].- Bussing, 1987: 94, map 10 [distribuition]; 95, figure 4 [adult female depicted]; 96 [description, ecology, distribution]; 1998: 125-126 [checklist; diagnosis (poor); ecology; distribution; pictures in vivo].- Eschmeyer, 1998: 229 [catalog].Hoyer, 2008: 5-9 [collection trip description; habitat description; general comments; photos in vivo].

Piabucina sp.- Loftin, 1966: 116 ["However, there is an unreported Piabucina present on the Pacific slope of Costa Rica. I have examined specimens of this and believe it to be an undescribed species."]. 
Lebiasina boruca.- Géry, 1977: 127 [key to the species of Lebiasininae].

Série-tipo. Holótipo: LACM 9239-1. Parátipos: LACM 2714 (2), 2926 (1), 2957 (2), 4743 (6), 4871 (1); UCR 42-2 (4).

Localidade-tipo. Córrego 7,5 $\mathrm{km}$ ao sul da rodovia Interamericana, na estrada para Golfito, Puntarenas, sudoeste da Costa Rica, elevação de 20 m.

\section{Material examinado.}

ANSP 140656 (3, 68.2-78.7 mm SL), Costa Rica, Puntarenas, córrego grande na rodovia Palmar Norte-Puerto Cortes, saindo de Palmar Norte, $9^{\circ} 00^{\prime} \mathrm{N} 83^{\circ} 30^{\prime} \mathrm{W}, 28-$ II-1979, D. Fromm \& P. Fromm;

ANSP 140657 (11, 45.6-100.5 mm SL), Costa Rica, $19.4 \mathrm{~km}$ ao sul da ponte do rio Terraba [08 52'14.7’N 83²0’35.8’W], 26-II-1979, D. Fromm e P. Fromm;

ANSP 151023 (4, 77.9-92.7 mm SL), Panamá, Chiriqui, riacho $29 \mathrm{~km}$ ao sul da rodovia Interamericana na rodovia Canoas-Puerto Armuelles [08 $19^{\prime} 9.6^{\prime \prime} \mathrm{N} 82^{\circ} 49^{\prime} 34.0^{\prime \prime} \mathrm{W}$ ], 28I-1983, D. Fromm \& D. Weber;

ANSP 164237 (1, $87.6 \mathrm{~mm} \mathrm{SL})$, Costa Rica, San José, canal lateral na rodovia a $500 \mathrm{~m}$ do rio Peje [09¹0’37.0”N 83²5’20.1’W], 09-III-1989, D. Fromm;

ANSP 164252 (4, 57.0-79.7 mm SL), Costa Rica, Puntarenas, canal de drenagem na rodovia Interamericana cerca de $20 \mathrm{Km}$ de Palmar Norte [0852'8.6” $3^{\circ} 3^{\circ} 20^{\prime} 27.2^{\prime \prime} \mathrm{W}$, 10-III-1989, D. Fromm;

LACM 9239 Holótipo (1, 117.4 mm SL), Costa Rica, Puntarenas, córrego a 7.5 Km ao Sul de “1H” na estrada para Golfito [08 $37^{\circ} 11.23^{\prime} \mathrm{N} 83^{\circ} 03^{\prime} 36.7$ ” ], rodovia Panamericana, 5-I-1964, W. Bussing, et al.;

LACM 4871 Parátipo (1, 137.4 mm SL), mesmos dados do holótipo;

LACM 4743 Parátipos (5/6, 17.6-24.4 mm SL), Costa Rica, Puntarenas, rio Convento,

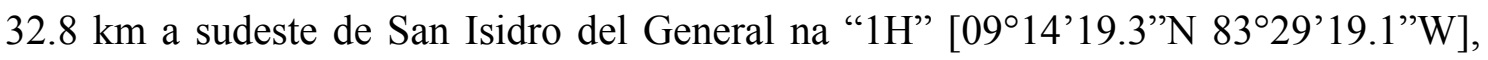
25-VII-1964, N. Scott \& T. Clarke;

LACM 2926 Parátipo (1, 117.4 mm SL), Costa Rica, Puntarenas, rio Sonador?, a 6.5 km ao noroeste de Volcán na “1H”, $570 \mathrm{~m}$ elev. [09¹4’47.72” $\mathrm{N}$ 8329’37.45”W], 27XII-1961, W. Bussing \& S. Jiménez; 
LACM 2714 Parátipos (2, 49.2-117.7 mm SL), Costa Rica, San José, rio Peje, afluente do rio General, $11 \mathrm{~km}$ ao sul de San Isidro del General na "1H” [09¹6’36.4”N 83³9'11.7’W], 560 m elev., 27-XII-1961, W. Bussing \& S. Jiménez C.;

LACM 2957 (2, 46.6-48.2 mm SL), Costa Rica, San José, rio Peje, afluente do rio General, 11 km ao sul de San Isidro del General na "1H”, 560 m elev., 27-XII-1961, W. Bussing \& S. Jiménez C.;

UCR 42-2 Parátipos (4, 114.2-121.4 mm SL), Costa Rica, Alajuela, áreas pantanosas entre La Marina e Águas Zarcas, 10¹8’N 8418’W, 18-VIII-1961, W. Bussing \& S. Jiménez C.;

UF 19537 (1, 97.0 mm SL), Costa Rica, San Jose, rio San Isidro (=rio Chirripo) e pequeno tributário em San Isidro del General, na via 2 (rodovia Panamericana), 6VII-1973, C.R. Gilbert \& Equipe da ASIH;

USNM 194229 (2, 55.5-107.6 mm SL), Costa Rica, San Jose, rio Unión próximo a San Isidro [09²2’00”N 8341'17.2”W] na rodovia Pan-Americana , 20-I-1963, A. Greenberg.

Diagnose. Lebiasina boruca diferencia-se de Lebiasina astrigata, L. aureoguttata, L. chocoensis, L. colombia, L. elongata, L. erythrinoides, L. floridablancaensis, L. intermedia, L. multimaculata, L. ortegai, L. panamensis, L. taphorni, L. unitaeniata, L. uruyensis, L. yuruaniensis, L. sp. Azuay, L. sp. “Curuá-Faixa”, L. sp. “Curuá-Pinta” e L. sp. "Parima" pelas seguintes características: parede da câmara posterior da bexiga natatória "celular"; escamas da sexta série longitudinal modificadas em machos adultos; duas a três séries longitudinais de escamas com intensa deposição de guanina (vs. parede da bexiga natatória não "celular"; modificações nas escamas da quinta série longitudinal nos machos adultos; escamas sem intensa deposição de guanina). A espécie distingue-se de Lebiasina bimaculata, L. aff. bimaculata I, L. aff. bimaculata II por apresentar dentes com a cúspide central distintamente mais longa que as laterais e dentes no endopterigóide ( $v s$. dentes com as cúspides laterais quase tão desenvolvidas quanto a cúspide central e por não apresentar dentes no endopterigóide). Lebiasina boruca difere de L. festae e L. aff. festae pela presença de duas a três séries longitudinais de escamas apresentando depósito de guanina e pela presença de uma conspícua mancha escura na porção proximal dos raios posteriores da nadadeira dorsal (vs. apenas a quarta escama da linha lateral com intensa deposição de guanina; porção 
proximal dos raios anteriores da nadadeira dorsal com uma discreta mancha escura). A espécie difere ainda de L. festae pela pela presença do pós-cleitro 3 (vs. pós-cleitro 3 ausente) e de Lebiasina aff. festae pela ausência de uma mancha arredondada na base da nadadeira caudal (vs. mancha caudal presente).

Descrição. Dados morfométricos apresentados na tabela 5. Corpo comprimido e alongado. Perfil dorsal da cabeça distintamente convexo do lábio superior até até a origem da nadadeira dorsal. Perfil reto na base da dorsal e levemente côncavo posteriormente até a origem dos raios pró-correntes da nadadeira caudal. Perfil ventral da cabeça e tronco convexo desde o lábio inferior até a origem da pélvica, reto deste ponto até a origem da nadadeira anal, convexo na base da anal e côncavo do término da anal até a origem dos pró-correntes ventrais da nadadeira caudal.

Espécie discretamente prognata, boca terminal. Maxilar quase alcançando a margem anterior da órbita. Apenas uma série de 9 (4), 10 (9), 11 (11) ou 12 (5) dentes tricúspides decrescendo posteriormente no pré-maxilar. Maxilar com 4 (4), 5 (5), 6 (2), 7 (12), 8 (2), 9 (2) ou 10 (1) dentes tricuspidados. Dentário com duas séries de dentes: 11 (5), 12 (6), 14 (3), 15 (1) ou 16 (2) dentes tricúspides pedunculados com a cúspide central distintamente mais longa que as cúspides laterais na série externa, série interna com dentes diminutos, na maioria, cônicos (podendo ser tricúspides posteriormente) estendendo-se desde a sínfise até próximo ao processo coronóide. Raiosbranquiostégios 4, três articulando com o ceratobranquial anterior e 1 com o ceratobranquial posterior.

Escamas ciclóides, circuli restritos à borda da escama, poucos radii (aproximadamente 12) convergindo para o centro da escama, fortemente anastomosados no centro, formando numerosas células. Série longitudinal da linha lateral com 28 (4), 29 (4), 30* (14) ou 31 (3) escamas, das quais apenas 5 (2), 6* (24) ou 7 (1) são perfuradas. Séries longitudinais entre a nadadeira dorsal e a pélvica 7. Escamas prédorsais 13 (15) ou 14* (10). Escamas da primeira série longitudinal 20 (4), 21 (7), 22* (7) ou 23 (1), geralmente ultrapassando a vertical que passa pela metade da nadadeira anal. Escamas circumpedunculares 12 .

Nadadeira peitoral i, $12(2), 13 *(16)$ ou 14 (9). Ponta da peitoral não alcançando a vertical que passa pela origem da pélvica. Raios da nadadeira pélvica i, 7. Supraneurais 9 ou 10*, anteriores aos espinhos neurais dos centros 5 a 14 (11) ou 15* (4). Nadadeira 
dorsal ii, 8. Primeiro pterigióforo da nadadeira dorsal inserido posteriormente ao espinho neural do centro 14 (11) ou 15* (4). Margem distal da nadadeira dorsal arredondada quando expandida. Origem da nadadeira dorsal distintamente mais próxima à base da nadadeira caudal que da ponta do focinho. Base do último raio da dorsal distintamente anterior à vertical que passa pela origem da nadadeira anal. Nadadeira anal iii, 8, último raio adnato. Margem distal da nadadeira anal arredondada. Primeiro pterigióforo da nadadeira anal inserido posteriormente ao arco hemal do centro 23 (1), 24 (11), 25 (3). Nadadeira adiposa presente. Dois epurais. Nadadeira caudal furcada, lóbulo superior similar em forma e tamanho o inferior, ambos arredondados. Raios principais da nadadeira caudal geralmente i, 9/i, 8 (26) ou ii, 8/i, 8 (1). Prócorrentes dorsais 9 (2); pró-correntes ventrais 8 (2). Vértebras pré-caudais 23 (8); vértebras caudais $16(8)$.

Colorido. Cor de fundo predominantemente amarela. Coloração escura estendendo-se desde o lábio superior até a porção exposta dos parietais e ao longo da série medial e primeira série de escamas até a origem da nadadeira caudal. Maxilar, ossos circumorbitais e série opercular pouco pigmentados próximo à porção dorsal da cabeça, tornando-se gradualmente amarelada ventralmente e com discreta deposição de guanina. Lábio inferior pouco pigmentado; restante da mandíbula e toda porção ventral da cabeça com pigmentação escassa.

Tronco tornando-se gradualmente amarelado ventralmente. Região abdominal amarela, com diminutos cromatóforos entre o istmo e a origem da nadadeira anal. Mancha umeral arredondada, conspícua em indivíduos jovens, porém inconspícua ou ausente em indivíduos adultos. Faixa primária ampla, percorrendo as escamas da terceira, quarta e quinta séries longitudinais, estendendo-se da região umeral até a vertical que passa pela origem dos raios pró-correntes da nadadeira caudal. Faixa secundária estendendo-se ao longo da primeira e segunda séries longitudinais de escamas, desde os epoccipitais à vertical que passa pela origem da nadadeira anal. Base das escamas da terceira, quarta e quinta séries longitudinais de escamas com deposição de guanina, que em exemplares vivos é coberta por pigmentos que variam do rosa ao vermelho intenso. Quinta escama da linha lateral com um deposição de guanina mais intensa. Base da dorsal distintamente mais escura que o dorso. Mancha caudal ausente. Nadadeiras peitoral, pélvica, anal, adiposa e caudal hialinas. Porção proximal do 
segundo raio não ramificado e dos raios ramificados da nadadeira dorsal densamente pigmentados.

Dimorfismo sexual. Exemplares machos de Lebiasina boruca apresentam o padrão de dimorfismo sexual semelhante ao descrito para L. bimaculata. Diferenças merísticas ou morfométricas além daquelas relacionadas ao comprimento dos raios e da base da nadadeira anal não foram observadas.

Distribuição. Oeste da Costa Rica e noroeste do Panamá, bacias dos rios Grande de Térraba e Cato e próximo às cidades de Águas Zarcas (Costa Rica) e Puerto Armuelles (Panamá) (fig. 82).

Tabela 5. Dados morfométricos de Lebiasina boruca.

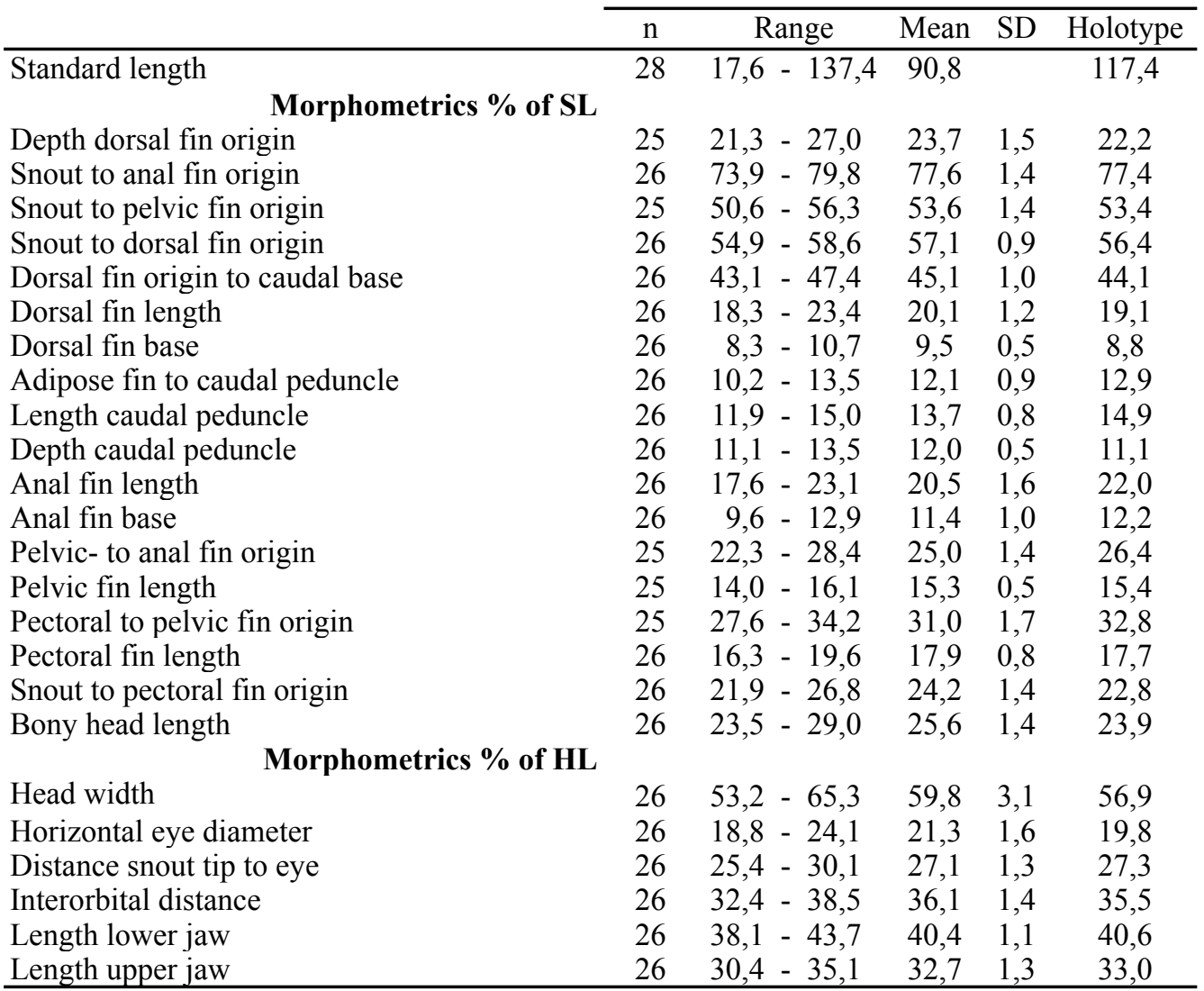

\section{Lebiasina chocoensis}

(Figura 83)

Lebiasina multimaculata (non Boulenger).- Eigenmann, 1920a: 16 [distribution; specimens from Atrato river basin] . 
Lebiasina astrigata (non Regan).- Géry, 1977: 112 [figure on top of page; inferred from color pattern].

Piabucina panamensis (non Gill).- Eigenmann, 1920a: 16 [distribution; specimens from Atrato river basin].- Fowler, 1944: 227-228 [specimens from Nuquí: ANSP 84172].

\section{Material examinado.}

ANSP 84172 (3, 64.0-112.0 mm SL), Colômbia, Chocó, Nuquí [0543'N 77²16’W], alto Río Jurubidá [Río Jurudidá $05^{\circ} 50^{`} \mathrm{~N} 77^{\circ} 17^{\prime} \mathrm{W}$, ao norte de Baudó e oeste de Quibdó], 03-VI-1940, Colombia Zoological Survey.

CAR 148 (4, 48.3-120.4 mm SL), Colômbia, Chocó, Yuto [05³2’52.5”N 76³8'7.5’W], Quebrada la Josefa, 18-IX-2005, C. Ardila-Rodriguez;

CAR 15-04-12 (2, 59.8-98.6 mm SL), Colômbia, Valle del Cauca, Reserva Florestal Escalarete, Rio Escalarete, 11a 18-[?]-1975, J. S. Usma;

CAR 15-04-20 (2, 72.0-94.0 mm SL), Antioquia, Colômbia, Rio Calles, Valle de Perdidas, Urrao [06 $\left.{ }^{\circ} 19^{\prime} 11^{\prime}{ }^{\prime} \mathrm{N} 7^{\circ} 08^{\prime} 18^{\prime \prime} \mathrm{W}\right], 500$ m elev., 10-VII-1997, L. E.Velásquez; CAR 15-04-35 (6, 132.3-88.7 mm SL), Colômbia, Chocó, Quibdó [0541’31"N 76³9’20"W], Rio Pacurita, 11-I-2003, C. Ardila-Rodriguez;

CAR 15-04-37 (8, 69.7-144.1 mm SL), Colômbia, Chocó, quebrada afluente do rio Tutunendo [0546’56"N 76³4’18’W], Quibdó, 15-I-2003, C. Ardila-Rodriguez;

CAR 15-04-39 (12/18, 18.9-136.8 mm SL), Colômbia, Chocó, quebrada afluente do rio Tutunendo [0546’56"N 76³4’18’W], Quibdó, 18, 15-I-2003, C. Ardila-Rodriguez;

CAR 183 (11, 39.7-102.1 mm SL), Colômbia, Chocó, Quibdó [0541’31"N 76³9’20"W], Rio Pacurita, 11-I-2003, C. Ardila-Rodriguez;

CAR 185 (6/7, 108.0-148.6 mm SL), Colômbia, Chocó, Quebrada afluente del Rio Tutunendo [0546’56"N 76³4'18’W], Quibdó, 07-I-2003, C. Ardila-Rodriguez; IAvH-P 573 (1, 76.8 mm SL), Colômbia, Chocó, Río del Valle [0606’37"N 77²4’45"W, drenagem costeira], 20-VIII-1975, P. Silverstone;

IAvH-P 6322 (1, 52.3 mm SL), Colômbia, Atrato, Chocó, Yuto [05³2'52.5”N 76³8'7.5'W], Quebrada [sem nome] na bacia do rio Atrato, 1, 25-VI-2008, Chaverra \& Cuesta; 
IAvH-P 6323 (1, 68.6 mm SL), Colômbia, Atrato, Chocó, Yuto [05³2’52”N 76³8'07’W], rio Yuto, 24-VIII-2008, Chaverra \& Cuesta;

IAvH-P 6325 (3, 43.4-45.2 mm SL), Colômbia, Atrato, Chocó, Yuto [05³2’52.5”N $76^{\circ} 38^{\prime} 7.5^{\prime \prime} \mathrm{W}$, Quebrada que conecta com a quebrada Doña Josefa, 3, 22-jun-08, Chaverra \& Cuesta;

IAvH-P 6326 (1, 36.3 mm SL), Colômbia, Atrato, Chocó, Yuto, Río Yuto, 24-VIII-2008, Chaverra \& Cuesta;

IAvH-P 6327 (2, 56.9-65.4 mm SL), Colômbia, Atrato, Chocó, Yuto [05³2’52.5”N 76³8'7.5'W], poça de água na quebrada Doña Josefa, 26-IX-08, Chaverra \& Cuesta;

IAvH-P 6328 (1, 114.3 mm SL), Colômbia, Atrato, Chocó, Yuto [05³2’52.5”N 76³8'7.5”W], Río Yuto, 26-VI-2008, Chaverra \& Cuesta;

IAvH-P 6329 (1, 95.6 mm SL), Colômbia, Atrato, Chocó, Yuto [05³2’52.5”N 76³8'7.5”W], Quebrada que conecta com a quebrada Doña Josefa, 22-VI-2008, Chaverra \& Cuesta;

ICNMHN 1602 (5, 95.9-132.2 mm SL), Colômbia, Chocó, San Francisco de Inchó, pequeno afluente do rio Inchó, X-1987, César Román-Valencia;

ICNMHN 1877 (1, $92.1 \mathrm{~mm}$ SL), Colômbia, Chocó, rio Cabi [0541'00"N 76²0'00"W], afluente do Atrato, 23-X-1990, Tulia Rivas;

ICNMHN 6872 (4, 65.6-107.1 mm SL), Colômbia, Chocó, Quibdó, quebrada afluente do rio Tutunendo [0546'56"N 76³4'18’W], unknown date and collector.

Diagnose. Lebiasina chocoensis diferencia-se de Lebiasina bimaculata, L. aff. bimaculata I, L. aff. bimaculata II, L, boruca, L. festae e L. aff. festae por não apresentar a parede da câmara posterior da bexiga natatória "celular", por apresentar as escamas da quinta série longitudinal com tecido epitelial hipertrofiado nos machos adultos e por não apresentar escamas com intensa deposição de guanina ( vs. parede da bexiga natatória “celular", escamas da sexta série longitudinal modificadas em machos adultos, ao menos a quarta escama da linha lateral com intensa deposição de guanina). A espécie difere de Lebiasina sp. "Curuá-Pinta" por apresentar faixas longitudinais e mancha caudal, e não apresentar manchas escuras na base das escamas da segunda à quinta séries longitudinais (vs. faixas longitudinais e mancha caudal ausentes; manchas escuras presentes na base das escamas da segunda à quinta séries longitudinais). Difere de Lebiasina elongata, L. erythrinoides, L. intermedia, L. taphorni, L. unitaeniata, L. 
uruyensis, L. yuruaniensis, L.sp. "Curuá-Faixa" e L. sp. "Parima" por apresentar uma série longitudinal de pequenas manchas arredondadas (vs. série longitudinal de manchas escuras ausente). Lebiasina chocoensis difere ainda de L. taphorni, L. unitaeniata, L. uruyensis, L. yuruaniensis e L. sp. "Parima" pela faixa secundária passando ao longo das escamas da primeira e segunda séries longitudinais, ausência da faixa "intermediária" e pela mancha caudal alcançar o pedúnculo caudal anteriormente (vs. faixa secundária passando ao longo das escamas da segunda e terceira séries longitudinais, faixa "intermediária" presente; mancha caudal não alcançando o pedúnculo caudal anteriormente). Entre as espécies do clado 83, Lebiasina chocoensis se diferencia de L. colombia, L. floridablancaensis, L. ortegai e L. panamensis por apresentar faixa primária inconspícua (vs. faixa primária conspícua ao longo de todo o corpo em L. ortegai e exemplares adultos de L. panamensis; porção anterior da faixa primária conspícua em L. colombia e exemplares jovens de L. panamensis; porção posterior da faixa primária conspícua em L. floridablancaensis). A espécie se distingue de Lebiasina astrigata, L. aureoguttata e L. sp. Azuay por apresentar a faixa secundária inconspícua estendendo-se ao longo das escamas da primeira e segunda séries longitudinais (vs. faixa secundária conspícua, passando pelas escamas da segunda e terceira séries longitudinais). A espécie diferencia-se de L. multimaculata por apresentar poucas manchas grandes distribuídas ao longo da quarta série longitudinal e nadadeira adiposa (vs. numerosas manchas pequenas distribuídas ao longo da quarta série longitudinal de escamas, nadadeira adiposa ausente).

Descrição. Dados morfométricos apresentados na tabela 5. Corpo comprimido e alongado. Perfil dorsal da cabeça e do corpo convexo do lábio superior até até a origem da nadadeira dorsal, tornando-se praticamente reto entre os parietais e a origem da dorsal. Perfil reto na base da dorsal e levemente côncavo posteriormente até a origem dos raios pró-correntes da nadadeira caudal. Perfil ventral da cabeça e tronco convexo desde o lábio inferior até a origem da pélvica, reto deste ponto até a origem da nadadeira anal, convexo na base da anal e côncavo do término da anal até a origem dos pró-correntes ventrais da nadadeira caudal.

Espécie discretamente prognata, boca subsuperior. Maxilar alcançando o meio da órbita. Apenas uma série de 9 (1), 10 (3), 11 (13) ou 12 (1) dentes tricúspides decrescendo posteriormente no pré-maxilar. Maxilar com 4 (6), 5 (3), 6 (6)ou 7 (3) 
dentes tricuspidados. Dentário com duas séries de dentes; 12 (1), 13 (4), 14 (2) ou 15 (1) dentes tricúspides pedunculados com a cúspide central distintamente mais longa que as cúspides laterais na série externa, série interna com dentes diminutos, na maioria, cônicos (podendo ser tricúspides posteriormente) estendendo-se desde a sínfise até próximo ao processo coronóide. Raios-branquiostégios 4, três articulando com o ceratobranquial anterior e um com o ceratobranquial posterior.

Escamas ciclóides, circuli restritos à borda da escama, diversos radii convergindo para o centro da escama, estando intensamente anastomosados no centro, formando diversas células. Série longitudinal da linha lateral com 28 (2), 29* (19), 30 (16), escamas, 5 (1), 6 (18) ou 7 (1) perfuradas. Séries longitudinais entre a nadadeira dorsal e a pélvica 7. Escamas pré-dorsais 12 (1), 13 (14) ou14 (5). Escamas da primeira série longitudinal ultrapassando a vertical que passa pela origem da nadadeira anal. Escamas circumpedunculares 12 .

Nadadeira peitoral i, 12 (5), 13 (12) ou 14 (3). Ponta da peitoral não alcançando a vertical que passa pela origem da pélvica. Raios da nadadeira pélvica i, 7. Supraneurais 11 (3), anteriores aos espinhos neurais dos centros 5 ao 15 (3). Nadadeira dorsal iii, 7 (3) ou ii, $8^{*}$ (27). Primeiro pterigióforo da nadadeira dorsal inserido posteriormente ao espinho neural do centro 15 (3). Margem distal da nadadeira dorsal arredondada quando expandida. Origem da nadadeira dorsal distintamente mais próxima à base da nadadeira caudal que da ponta do focinho. Base do último raio da dorsal distintamente anterior à vertical que passa pela origem da nadadeira anal. Nadadeira anal iii, 8, último raio adnato. Margem distal da nadadeira anal arredondada. Primeiro pterigióforo da nadadeira anal inserido posteriormente ao arco hemal do centro 24 (2) ou 25 (1). Nadadeira adiposa presente. Epurais 1 (1) ou 2 (2). Nadadeira caudal furcada, lóbulo superior distintamente mais longo que o inferior, ambos arredondados. Raios principais da nadadeira caudal i, 9/i, 8. Pró-correntes dorsais 8 (1) ou 9 (1); pró-correntes ventrais 8 (1) ou 9 (1). Vértebras pré-caudais 23 (1) ou 24 (2); vértebras caudais 16 (1) ou 17 (2).

Colorido. Cor de fundo predominantemente amarela. Coloração escura estendendo-se desde o lábio superior até a porção exposta dos parietais e ao longo da série medial e primeira série de escamas até a origem da nadadeira caudal. Maxilar, ossos circumorbitais e série opercular densamente pigmentados próximo à porção dorsal da 
cabeça, tornando-se gradualmente amarelada ventralmente; opérculo com uma distinta mancha escura na região médio-inferior. Faixa negra estendendo-se da porção dorsal da órbita, passando pelos infra-orbitais 5 e 6 e face dorsal do opérculo, inconspícua. Lábio inferior intensamente pigmentado; restante da mandíbula e toda porção ventral da cabeça com pigmentação escassa.

Tronco tornando-se gradualmente amarelado ventralmente. Região abdominal amarelada, com diminutos cromatóforos entre o istmo e a origem da nadadeira anal. Mancha umeral arredondada, conspícua em indivíduos jovens, porém difusa em adultos. Faixa primária representada por cinco a oito manchas arredondadas, sucessivamente maiores no sentido antero-posterior, distribuídas entre a mancha umeral e a mancha caudal. Diferentemente de L. astrigata, as manchas mais anteriores, localizadas entre a peitoral e a pélvica, apresentam intensidade similar à das mais posteriores; manchas posteriores não coalescem. Última mancha deslocada dorsalmente, estando situada principalmente na terceira série longitudinal de escamas, podendo estar ausente. Faixa secundária inconspícua, estendendo-se ao longo da primeira e segunda séries longitudinais de escamas, desde os epoccipitais à vertical que passa pelo término da nadadeira dorsal. Terceira, quarta e quinta séries longitudinais de escamas com pequenas manchas escuras próximo à base e na porção mais distal destas. Base da dorsal discretamente mais escura que o dorso. Mancha caudal alongada verticalmente, situada na extremidade do pedúnculo caudal e estendendo-se à base de 9 raios medianos da nadadeira caudal. Nadadeiras peitoral, pélvica, anal e caudal hialinas; raios da nadadeira dorsal com diminutos cromatóforos na base.

Dimorfismo sexual. Exemplares machos de Lebiasina chocoensis apresentam o padrão mais difundido de dimorfismo sexual entre as Lebiasina, descrito acima para $L$. astrigata.

Distribuição. Noroeste da Colômbia, nas bacias dos rios del Valle (Pacífico) e Atrato (Atlântico) (Figura 84). 
Tabela 6 Dados morfométricos de Lebiasina chocoensis.

\begin{tabular}{lccccc} 
& $\mathrm{n}$ & Range & Mean & SD & Holotype \\
\cline { 2 - 6 } & 36 & $18,9-148,7$ & 94,9 & & 111,4 \\
Standard length & Morphometrics \% of SL & & & & \\
& 20 & $19,3-23,5$ & 21,3 & 0,9 & 23,5 \\
Depth dorsal fin origin & 20 & $71,2-77,5$ & 74,7 & 1,4 & 74,6 \\
Snout to anal fin origin & 20 & $48,8-55,0$ & 50,9 & 1,4 & 50,6 \\
Snout to pelvic fin origin & 20 & $54,2-57,7$ & 56,1 & 1,1 & 57,5 \\
Snout to dorsal fin origin & 20 & $43,6-48,0$ & 45,3 & 1,0 & 45,2 \\
Dorsal fin origin to caudal base & 20 & $14,5-19,6$ & 18,3 & 1,3 & 18,9 \\
Dorsal fin length & 20 & $7,6-9,1$ & 8,4 & 0,4 & 8,5 \\
Dorsal fin base & 20 & $12,0-14,1$ & 13,0 & 0,6 & 13,5 \\
Adipose fin to caudal peduncle & 20 & $14,6-18,4$ & 16,4 & 1,0 & 16,5 \\
Length caudal peduncle & 20 & $11,3-13,1$ & 12,3 & 0,5 & 13,1 \\
Depth caudal peduncle & 20 & $18,0-23,8$ & 20,2 & 1,7 & 21,3 \\
Anal fin length & 20 & $10,5-15,1$ & 12,7 & 1,2 & 13,1 \\
Anal fin base & 20 & $22,7-26,7$ & 24,4 & 1,1 & 24,1 \\
Pelvic- to anal fin origin & 20 & $12,6-15,5$ & 13,7 & 0,8 & 13,0 \\
Pelvic fin length & 20 & $28,3-34,6$ & 31,0 & 1,7 & 30,0 \\
Pectoral to pelvic fin origin & 20 & $14,9-17,3$ & 15,9 & 0,7 & 15,6 \\
Pectoral fin length & 20 & $19,0-22,3$ & 21,1 & 0,8 & 21,2 \\
Snout to pectoral fin origin & 20 & $21,6-23,9$ & 22,9 & 0,8 & 23,3 \\
Bony head length & & & & & \\
& \multicolumn{1}{c}{ Morphometrics \% of HL } & & & & \\
Head width & 20 & $55,7-62,9$ & 59,9 & 1,8 & 62,9 \\
Horizontal eye diameter & 20 & $17,5-22,2$ & 20,5 & 1,3 & 18,8 \\
Distance snout tip to eye & 20 & $26,2-32,8$ & 28,6 & 1,7 & 32,0 \\
Interorbital distance & 20 & $35,9-39,5$ & 37,8 & 1,0 & 37,9 \\
Length lower jaw & 20 & $41,9-47,4$ & 44,4 & 1,5 & 42,9 \\
Length upper jaw & 20 & $36,2-39,7$ & 38,0 & 0,9 & 37,1 \\
\hline
\end{tabular}

\section{Lebiasina colombia Ardila-Rodriguez}

(Figura 85)

Lebiasina colombia Ardila Rodríguez, 2008a.

Lebiasina multimaculata (non Boulenger).- Dahl \& Medem, 1964: 58 [specimens from rio Sinu; the author remarks the presence of the adipose fin in specimens from that locality, highlighting the condition as an unusual feature in L. multimaculata; the authors propose a distribution pattern to the species (“desde Río Verde hasta Esmeraldas") but the information as it is does not allow to objectively precise these localities in Colombia. It is most likely that the authors refer to L. colombia as well as Lebiasina chocoensis, L. multimaculata itself, L. astrigata and even L. aureoguttata].Dahl, 1971: 120 [see comments for Dahl \& Medem, 1964].

Série-tipo. Holótipo: CAR190. Parátipos: ICNMHN5314, CAR191, CAR192. 
Localidade-tipo. Quebrada El Higuerón, afluente do rio Sinú, Tierralta, Departamento de Córdoba, Colômbia.

\section{Material examinado.}

CAR 15-04-43 Parátipos (4/8, 100.5-166.2 mm SL), Colômbia, Córdoba, Tierralta [08¹1'38.6”N 7604'44.0”W], Quebrada el Higuerón, afluente do rio Sinú, 23III-2003, C. Ardila-Rodriguez;

CAR 15-04-44 Parátipos (10, 59.7-138.0 mm SL), Colômbia, Córdoba, Tierralta [08¹1'38.6”N 7604'44.0”W], Quebrada el Higuerón, afluente do rio Sinú, 23III-2003, C. Ardila-Rodriguez;

CAR 190 Holótipo (1, 131.6 mm SL), Colômbia, Córdoba, Tierralta [08¹1'38.6”N 7604'44.0”W], Quebrada el Higuerón, afluente do rio Sinú, 23-III-2003, C. ArdilaRodriguez;

CAR 408 (5/7, 94,4-125.6 mm SL), Colômbia, Córdoba, quebrada la Corobá, afluente da Quebrada Tuis Tuis [08 $\left.03^{\prime} 38.83^{\prime \prime} \mathrm{N} 76^{\circ} 07^{\prime} 53.7^{\prime \prime} \mathrm{W}\right], 22-\mathrm{X}-2008$, C. ArdilaRodriguez;

CAR 447 (1, 94,4-125.6 mm SL), Colômbia, Córdoba, Vereda Zacón, Rio Manso [07³9'60”N 76¹0’00”W], PNN [Parque Nacional Natural] Paramillo, 11-VI-2009, C. Ardila-Rodriguez;

CAS uncat (ex-SU 49514) (1, 59.8 mm SL), Colômbia, Córdoba, Crucito [09²4’N 7549’W], alto rio Sinú, 22-I-1957, G. Dahl;

CAS uncat (ex-SU 50889), Panamá, San Blas [Comarca Kuna Yola], Pito, estação 3, Río Pito, próximo a Cabo Tiburón [próximo à fronteira com a Colômbia.], $08^{\circ} 42^{`} \mathrm{~N}$ 77³1’W, 05-I-1957, J. B. Coman;

ICNMHN 5314 Parátipo (1, 71.44 mm SL), Colômbia, Córdoba, Tierralta, rio Sinú, próximo à desembocadura do rio Urrá [0756’21.4”N $76^{\circ} 11^{\prime} 58.1^{\prime}$ 'W], 01-I-99, J. Lundberg;

ICNMHN 10692 (3, 79.4-115.4 mm SL), Colômbia, Córdoba, Tierralta [08¹1'38.6”N 7604’44.0”W], Quebrada el Higuerón, afluente do rio Sinú, VII-2001, C. A. Cipamocha.

Diagnose. Lebiasina colombia diferencia-se de Lebiasina bimaculata, L. aff. bimaculata I, L. aff. bimaculata II, L, boruca, L. festae e L. aff. festae por não 
apresentar a parede da câmara posterior da bexiga natatória "celular", por apresentar as escamas da quinta série longitudinal com tecido epitelial hipertrofiado nos machos adultos e por não apresentar escamas com intensa deposição de guanina (vs. parede da bexiga natatória “celular", escamas da sexta série longitudinal modificadas em machos adultos, ao menos a quarta escama da linha lateral com intensa deposição de guanina). A espécie difere de Lebiasina sp. "Curuá-Pinta" por apresentar faixas longitudinais e mancha caudal, e não apresentar manchas escuras na base das escamas da segunda à quinta séries longitudinais (vs. faixas longitudinais e mancha caudal ausentes; manchas escuras presentes na base das escamas da segunda à quinta séries longitudinais). Difere de Lebiasina elongata, L. erythrinoides, L. intermedia, L. taphorni, L. unitaeniata, L. uruyensis, L. yuruaniensis, L. sp. "Curuá-Faixa" e L. sp. "Parima” por apresentar uma série longitudinal de pequenas manchas arredondadas (vs. série longitudinal de manchas escuras ausente). Lebiasina colombia difere ainda de L. taphorni, L. unitaeniata, L. uruyensis, L. yuruaniensis e L. sp. "Parima" pela faixa secundária passando ao longo das escamas da primeira e segunda séries longitudinais, ausência da faixa "intermediária" e pela mancha caudal alcançar o pedúnculo caudal anteriormente (vs. faixa secundária passando ao longo das escamas da segunda e terceira séries longitudinais, faixa "intermediária" presente; mancha caudal não alcançando o pedúnculo caudal anteriormente). Entre as espécies do clado 83, Lebiasina colombia difere de L. astrigata, L. aureoguttata, L. chocoensis, L. floridablancaensis, L. multimaculata, L. ortegai e L. sp. Azuay por apresentar a faixa primária conspícua apenas na porção anterior do corpo (vs. faixa primária inconspícua em L. astrigata, $L$. aureoguttata, L. chocoensis, L. multimaculata e L. sp. Azuay; conspícua ao longo de todo o corpo em L. ortegai; com apenas a porção posterior conspícua em L. floridablancaensis). A espécie diferencia-se ainda de Lebiasina astrigata, L. aureoguttata, L. floridablancaensis e L. sp. Azuay por apresentar a faixa secundária inconspícua, estendendo-se ao longo das escamas da primeira e segunda séries longitudinais (vs. faixa secundária conspícua, passando pelas escamas da segunda e terceira séries longitudinais) e de L. multimaculata por apresentar a porção anterior da faixa primária conspícua e nadadeira adiposa ( $v s$. faixa primária inconspícua, nadadeira adiposa ausente). Lebiasina colombia distingue-se de L. panamensis por apresentar apenas a porção anterior da faixa primária conspícua ao longo de toda a ontogenia; mancha umeral similar em tamanho à espessura da faixa primária e às manchas do 
corpo; mancha caudal distintamente arredondada (vs. faixa primária com a porção anterior conspícua em jovens, mas, geralmente, completa em exemplares adultos, estendendo-se posteriormente, alcançando a mancha caudal; mancha umeral distintamente mais espessa que as manchas do corpo e a faixa primária; mancha caudal distintamente triangular).

Descrição. Dados morfométricos apresentados na tabela 7. Corpo comprimido e alongado. Perfil dorsal da cabeça e do corpo convexo do lábio superior até até a origem da nadadeira dorsal, tornando-se praticamente reto entre os parietais e a origem da dorsal. Perfil reto na base da dorsal e levemente côncavo posteriormente até a origem dos raios pró-correntes da nadadeira caudal. Perfil ventral da cabeça e tronco convexo desde o lábio inferior até a origem da pélvica, reto deste ponto até a origem da nadadeira anal, convexo na base da anal e côncavo do término da anal até a origem dos pró-correntes ventrais da nadadeira caudal.

Espécie discretamente prognata, boca subsuperior. Maxilar ultrapassando a margem anterior da órbita. Apenas uma série de 10 (2) dentes tricúspides decrescendo posteriormente no pré-maxilar. Maxilar com 5 (2) dentes tricuspidados. Dentário com duas séries de dentes: 12 (2) dentes tricúspides pedunculados com a cúspide central distintamente mais longa que as cúspides laterais na série externa, série interna com dentes diminutos, na maioria, cônicos (podendo ser tricúspides posteriormente) estendendo-se desde a sínfise até próximo ao processo coronóide. Raiosbranquiostégios 4, três articulando com o ceratobranquial anterior e 1 com o ceratobranquial posterior.

Escamas ciclóides, circuli restritos à borda da escama, diversos radii (aproximadamente 19) convergindo para o centro da escama, fortemente anastomosados no centro, formando numerosas células. Série longitudinal da linha lateral com 28* (5), 29 (8) ou 30 (2) escamas, das quais apenas $5^{*}(11)$ ou 6 (4) são perfuradas. Séries longitudinais entre a nadadeira dorsal e a pélvica 7. Escamas da primeira série longitudinal 18 (3), 19*(8), 20 (2) ou 21 (2), geralmente ultrapassando a vertical que passa pela metade da nadadeira anal. Escamas pré-dorsais 12 (3), 13* (7) ou 14 (5). Escamas circumpedunculares 12.

Nadadeira peitoral i, 11 (1), 12* (6), 13 (7) ou 14 (1). Ponta da peitoral não alcançando a vertical que passa pela origem da pélvica. Nadadeira pélvica i, 7. 
Supraneurais 10 (2) ou 11 (1) anteriores aos espinhos neurais dos centros 5 a 14 (2) ou 15 (1). Nadadeira dorsal ii,7 (1) ou ii, $8^{*}$ (14). Primeiro pterigióforo da nadadeira dorsal inserido posteriormente ao espinho neural do centro 14 (1) ou 15 (1). Margem distal da nadadeira dorsal arredondada quando expandida. Origem da nadadeira dorsal distintamente mais próxima à base da nadadeira caudal que da ponta do focinho. Base do último raio da dorsal distintamente anterior à vertical que passa pela origem da nadadeira anal. Nadadeira anal iii, 8, último raio adnato. Margem distal da nadadeira anal arredondada. Primeiro pterigióforo da nadadeira anal inserido posteriormente ao arco hemal do centro 24 (2). Nadadeira adiposa presente. Epurais 2. Nadadeira caudal furcada, lóbulo superior distintamente mais longo que o inferior, ambos arredondados. Raios principais da nadadeira caudal i, 8/i, 7 (1), ii, 8/i,8 (1), i, 9/i, 8* (12), i, 10/1, 8(1). Pró-correntes dorsais 7 (1) 8 (2) ou 9 (2); pró-correntes ventrais 8 (1) 9 (3) ou 10 (1). Vértebras pré-caudais 23 (4) 24 (1); vértebras caudais 16 (1) ou 17 (4).

Colorido. Cor de fundo predominantemente amarela. Coloração escura estendendo-se desde o lábio superior até a porção exposta dos parietais e ao longo da série medial e primeira série de escamas até a origem da nadadeira caudal. Maxilar, ossos circumorbitais e série opercular pouco pigmentados, porção lateral da cabeça tornandose gradualmente amarelada ventralmente; opérculo com uma distinta mancha escura na região médio-inferior. faixa negra passando pelos infra-orbitais 5 e 6 e margem dorsal do opérculo fragmentada em três porções. Lábio inferior pouco pigmentado; restante da mandíbula e toda porção ventral da cabeça com pigmentação escassa.

Tronco tornando-se gradualmente amarelado ventralmente. Região abdominal amarela, com diminutos cromatóforos entre o istmo e a origem da nadadeira anal. Mancha umeral arredondada, conspícua em indivíduos jovens e indivíduos adultos. Faixa primária representada por seis a oito manchas largas e alongadas distribuídas entre a mancha umeral e a mancha caudal; mancha umeral e manchas mais anteriores conectadas por uma estreita faixa passando pelas escamas da terceira e quarta séries longitudinais, se estendendo atá a vertical que passa pela origem do último raio da nadadeira dorsal. Manchas distintamente maiores que as observadas em L. astrigata, ocupando toda a escama da quarta série longitudinal e também a porção dorsal e a porção ventral de escamas da terceira e quinta séries longitudinais, respectivamente. Ao longo da ontogenia, ao contrário de L. astrigata, as manchas mais anteriores não se 
tornam inconspícuas e as posteriores não coalescem. Última mancha levemente deslocada dorsalmente, estando situada na terceira e quarta séries longitudinais, podendo estar ausente. Faixa secundária estendendo-se ao longo da primeira e segunda séries longitudinais de escamas, desde os epoccipitais à vertical que passa pelo meio da nadadeira anal. Porção mediana da terceira, quarta e quinta séries longitudinais de escamas com áreas claras, formando três séries longitudinais (em vida, tais áreas apresentam pigmentos carotenóides, variando do amarelo ao vermelho). Base da nadadeira dorsal distintamente mais escura que o dorso. Mancha caudal distintamente redonda, situada na extremidade do pedúnculo caudal, estendendo-se à base de 8 a 9 raios medianos da nadadeira caudal. Nadadeiras peitoral, pélvica, anal, adiposa e caudal hialinas; mancha escura na base dos raios ramificados da nadadeira dorsal.

Dimorfismo sexual. Exemplares machos de Lebiasina colombia apresentam o padrão mais difundido de dimorfismo sexual entre as Lebiasina, descrito acima para Lebiasina astrigata.

Distribuição. Espécie endêmica da bacia do rio Sinú, drenagem atlântica ao norte da Colômbia (fig. 84).

Tabela 7. Dados morfométricos de Lebiasina colombia.

\begin{tabular}{|c|c|c|c|c|c|}
\hline & & & & & \\
\hline & $\mathrm{n}$ & Range & Mean & SD & Holotype \\
\hline Standard length & 19 & $59,9-166,2$ & 110,3 & & 131,6 \\
\hline \multicolumn{6}{|c|}{ Morphometrics \% of SL } \\
\hline Depth dorsal fin origin & 15 & $17,3-22,6$ & 20,7 & 1,2 & 20,8 \\
\hline Snout to anal fin origin & 15 & $72,6-76,6$ & 74,2 & 1,1 & 74,3 \\
\hline Snout to pelvic fin origin & 15 & $51,0-54,8$ & 52,2 & 1,0 & 52,2 \\
\hline Snout to dorsal fin origin & 15 & $53,1-56,4$ & 54,6 & 1,0 & 54,5 \\
\hline Dorsal fin origin to caudal base & 15 & $44,5-47,8$ & 46,4 & 1,0 & 47,4 \\
\hline Dorsal fin length & 15 & $16,2-20,5$ & 19,2 & 1,0 & 19,0 \\
\hline Dorsal fin base & 15 & $7,8-9,3$ & 8,7 & 0,4 & 9,3 \\
\hline Adipose fin to caudal peduncle & 15 & $11,1-14,5$ & 13,5 & 0,9 & 13,9 \\
\hline Length caudal peduncle & 15 & $14,9-18,4$ & 16,9 & 1,0 & 15,8 \\
\hline Depth caudal peduncle & 15 & $9,9-12,4$ & 11,2 & 0,6 & 10,9 \\
\hline Anal fin length & 15 & $18,3-23,8$ & 20,3 & 1,8 & 18,6 \\
\hline Anal fin base & 15 & $11,5-14,6$ & 12,7 & 1,0 & 11,7 \\
\hline Pelvic- to anal fin origin & 15 & $21,7-24,8$ & 23,0 & 0,9 & 22,2 \\
\hline Pelvic fin length & 15 & $12,7-15,2$ & 14,1 & 0,7 & 13,4 \\
\hline Pectoral to pelvic fin origin & 15 & $29,5-34,6$ & 31,7 & 1,3 & 32,0 \\
\hline Pectoral fin length & 15 & $15,8-17,7$ & 16,7 & 0,6 & 17,5 \\
\hline Snout to pectoral fin origin & 15 & $20,3-23,2$ & 21,7 & 0,8 & 21,5 \\
\hline Bony head length & 15 & $22,9-25,3$ & 24,1 & 0,6 & 23,9 \\
\hline \multicolumn{6}{|c|}{ Morphometrics \% of HL } \\
\hline Head width & 15 & $53,5-62,7$ & 57,0 & 2,5 & 62,7 \\
\hline Horizontal eye diameter & 15 & $17,1-23,0$ & 20,5 & 1,8 & 19,9 \\
\hline Distance snout tip to eye & 15 & $25,4-28,8$ & 26,9 & 1,0 & 28,1 \\
\hline
\end{tabular}




\section{Lebiasina elongata (Boulenger)}

(Figura 86)

Piabucina elongata Boulenger, 1887: 280, plate 23.- Eigenmann \& Eigenmann, 1891:

52 [catalog].- Eigenmann, 1910: 439 [catalog].- Eigenmann \& Allen, 1942: 278.-

Machado-Allison, 1974: 582 [diversity of Lebiasina and 'Piabucina'].- Fowler, 1950:

365.- Saul, 1975: 93 [habitat, feeding and life habits - specimens examined ANSP

130567].- Ortega \& Vari, 1986: 10 [checklist].- Eschmeyer, 1998: 522 [catalog].

Piabucina unitaeniata (non Günther).- Steindachner, 1883.- Eigenmann \& Eigenmann, 1891: 52 [catalog].- Eigenmann, 1910: 439.- Fowler, 1950: 365 [specimens from upper Amazonas, Ecuador].

Lebiasina (Piabucina) elongata.- Géry, 1972: 90 [synonymy; description; comments on differences observed in Boulenger's original description and the two juvenile specimens Géry observed at that occasion].

Lebiasina elongata.- Géry, 1977: 127 [key to the species of Lebiasina].- MaldonadoOcampo et al., 2005: 92 [field guide; brief description, feeding habits, distribution in Colombia; comments on the validity of Piabucina].

Lebiasina aureoguttata (non Fowler), Ardila-Rodríguez 2002 [specimens used in the description of L. narinensis to distinguish both species].

Série-tipo. Síntipos: BMNH 1880.12.8.123-124 (2), 1880.12.5.255-257 (3).

Localidade-tipo. Canelos e Sarayacu, leste do Equador. 


\section{Material examinado.}

All from Colombia:

CAR 136 (9/10, 22.7-66.2 mm SL), Caquetá, quebrada Pabarpaco [¿01 ${ }^{\circ} 04^{\prime} 54^{\prime \prime} \mathrm{N}$ 7546'19'W?], alto rio Caquetá, unknown date and collector;

CAR 149 (2, 72.6-117.7 mm SL), Putumayo, Orito, vereda el Líbano, alto rio Putumayo, prédio UMIYAC, $00^{\circ} 40^{\prime} 53.8^{\prime} \mathrm{N}, 7^{\circ} 02^{\prime} 07.2^{\prime} \mathrm{W}, 775-850 \mathrm{~m}$ elev., I. Giraldo et al., 4 a 16-III-2003;

CAR 15-04-19 (3, 71.8-128.6 mm SL), Putumayo, rio Liquimo, afluente do rio Cararay, 1959, M. Olalla;

IAvH-P 1734 (5, 46.7-56.1 mm SL), Cauca, Santa Rosa [0140’58.0”N 76³4’37.3”W], rio Tambor, afluente do rio Caquetá, C. Santamaria, 18-X-1998;

IAvH-P 4364 (1, 75.3 mm SL), quebrada alto Caquetá, unknown date, C. ArdilaRodriguez;

IAvH-P 6200 (1, 102.1 mm SL), Putumayo, Mocoa [01¹0’25.8”N 76³8’46.4”W], rio Pepino [01 $14^{\prime} 48.2^{\prime} \mathrm{N}$ 76³3'49.0”W], afluente do rio Caquetá, 09-III-2009, J. Maldonado \& A. Ortega;

IAvH-P 6221 (7, 70.0-129.1 mm SL), Putumayo, quebrada paralela a um rio sem nome, tributário do rio Rumiyaco [00²7’03.9”N 7709’32.2”W], afluente do rio Caquetá [o rio Rumiyaco é afluente do Rio Putumayo], 06-III-2009, J. Maldonado \& A. Ortega; ICNMHN 11136 (1, 145.8 mm SL), Putumayo, Orito [0041'52.2”N 7653'43.2”W], rio Blanco, sistema do rio Putumayo, XI-1959, unknown collector;

ICNMHN 14056 (4, 36.1-87.2 mm SL), Putumayo, Mocoa, rio Mocoa [=Rio Pepino 01¹4'49.0”N 76³3'49.0”W], 4-8-XI-1959, G. Dahl;

All from Ecuador:

ANSP 130567 (6, 34.77-106.16 mm SL), Napo, Santa Cecília, córrego tributário do rio Conejo, 006’00” N, 7651’00” W, 7-VI-1967, W. G. Saul et al.;

ANSP $141507(11,54.1-122.6 \mathrm{~mm}$ SL), Napo [Orellana], rio Yasuni [0052’S $\left.75^{\circ} 24^{\prime} \mathrm{W}\right], 192 \mathrm{~m}$ elev., afluente do rio Napo, próximo à fronteira Equador-Peru, IX-1966, O.Ollala;

BMNH 1880.12.8.123 Paralectótipo (1, 102.5 mm SL), Pastaza, Canelos [01³5'22.0’S 7744'47.7'W, alto rio Bobonaza, afl. margem esquerda do rio Pastaza, afl. margem esquerda do rio Marañon], 1870, Buckley; 
BMNH 1880.12.8.124 Lectótipo (1, 109.5 mm SL), Pastaza, Canelos [01³5'22.0”S 7744'47.7'W, alto rio Bobonaza, afl. margem esquerda do rio Pastaza, afl. margem esquerda do rio Marañon], 1870, Buckley;

CAS 39641 (2, 48.0-75.4 mm SL), Napo, cavernas em El Jumandi, Archidona, $450 \mathrm{~m}$ elev. [Archidona 054’26.2”S 7748’34.6”W, sistema do rio Misahuallí, aprox. $9 \mathrm{~km}$ a norte de Tena], III-1977, H. G. Real,

CAS uncat (10, 49.0-88.4 mm SL), Napo, rio Coca, a montante das cachoeiras, próximo ao vulcão Reventador, 1300 m elev., [0008’S 7740’W], VII-1946?, K. T. Goldschmid; CAS uncat $(2,100.0-104.3 \mathrm{~mm} \mathrm{SL})$, Napo. cavernas em Latas, $4 \mathrm{Km}$ ao norte de Archidona, quebrada afluente do rio Misahuallí [0052’34.9”S 7748'15.5”W?], tributário do rio Napo, unknown date, Pe. P. I. Porras;

CAS uncat (1, $64.0 \mathrm{~mm} \mathrm{SL})$, Napo. cavernas em Latas, $4 \mathrm{Km}$ ao norte de Archidona, quebrada afluente do rio Misahuallí [0052’34.9”S 7748'15.5”W?], tributário do rio Napo, unknown date, Pe. P. I. Porras;

CAS uncat (2, 75.6-93.9 mm SL), Zamora-Chinchipe, canal nas imediações de Zamora. [Zamora $04^{\circ} 04^{\prime} \mathrm{S} 78^{\circ} 58^{\prime} \mathrm{W}$, alto rio Zamora, tributário do rio Santiago, afluente Marañon, 1000 m elev], 17-I-1958, G. Frymire \& C. Dodson;

MCNG 19375 (5, 40.0-101.5 mm SL), Napo, rio Chuniaruco, 1978, D. C. Taphorn; MCNG 19377 (5, 102.1-151.7 mm SL), Sucumbios, Puerto Libre [002’58’N 76²7’27’W], 1978, D. C. Taphorn;

MCNG 19379 (4, 101.5-129.1 mm SL), Orellana, rio Cotorpino [rio Cotapino, 0043'S 77²3'W afl. rio Aguarico?], 1978, D. C. Taphorn;

MCNG 19380 (2, 91.0-97.6 mm SL), Pastaza, rio Chicherata [assentamento Chichirota (Chichirata) $02^{\circ} 23^{\prime}$ 'S $\left.76^{\circ} 39^{\prime} \mathrm{W}\right], 1978$, D. C. Taphorn;

MEPN 1255 (1, 104.4 mm SL), Napo, quebrada junto a Sarayacu, km 28 na rodovia Tena-Baeza [00³8'55.7’S 7748'5.5’W], 1981, D. J. Stewart et al.;

MEPN 1262 (2, 98.9-169.9 mm SL), Orellana, rio Payamino, 00²5’18’'S 7705’51” W [00²6’34.2”S 7706’04.5”W, entre Estrella Yacu e Puerto Francisco Orellana:], unknown date, D. J. Stewart et al.;

MEPN 1728 (1, $138.6 \mathrm{~mm}$ SL), Orellana, rio Pacayacu 2 próximo ao centro da comunidade Santa Rosa de Arapino [coordenada mais próxima de Santa Rosa de Arapino: 00³9'00'S 77³1'00”W - obtida em Persson, 2003], 1997, R. Crawford; 
MEPN 1946 (1, 98.7 mm SL), Zamora Chinchipe, San Antonio de Guadalupe, Zamora, 1250 m elev., 0350’48” S 7853’45” W, 21-III-1979, R. Barriga;

MEPN 2052 (9, 78.0-128.7 mm SL), Zamora Chinchipe, quebrada Tunantza, $1150 \mathrm{~m}$ elev., 0400'30”S 7853'05'W, 25-III-1979, R. Barriga et al.;

MEPN 2105 (5, 63.9-135.7 mm SL), Zamora Chinchipe, rio Paquintza, na finca El Tributario, a 100m de Santa Cruz, 750 m elev., 08-III-2005, R. Barriga et al.;

MEPN 2156 (10, 63.6-111.5 mm SL), Napo, poça do rio Salado, $700 \mathrm{~m}$ antes da

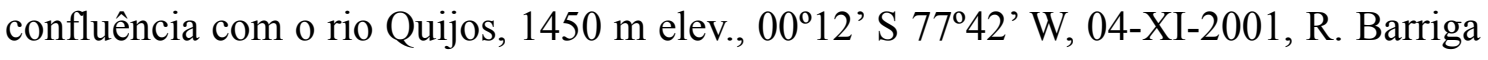
\& E. Salcedo;

MEPN 2289 (25, 18.0-99.2 mm SL), Sucumbíos, rio Azuelo, na rodovia Quito-Lago, Agro-Proyecto OCP, 850 m elev., 0001'10”S 77²8'12”W, 23-VI-2004, R. Barriga \& D. J. Stewart;

MEPN 2352 (9, 47.6-115.6 mm SL), Zamora-Chinchipe, quebrada Rancho Alegre, 0400’30’S 7853’05’W, 15-III-1979, R. Barriga et al.;

MEPN 2508 (3, 41.5-87.0 mm SL), Orellana, estero sem nome, afluente do rio Tiputini, 215 m elev., 00³6’21' S 76²9’18’ W, 03-III-2004, R. Barriga \& D. J. Stewart;

MEPN 2746 (5, 95.0-107.2 mm SL), Napo, rio Granadilla, 20m a jusante do

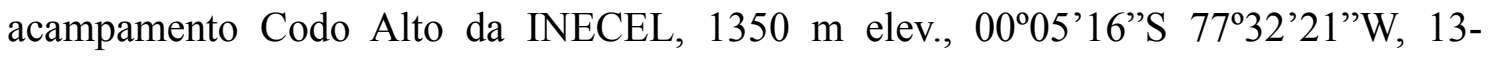
IX-1990, R.Barriga;

MEPN 2761 (9, 91.9-112.6 mm SL), Napo, rio Cotapino [0043'00.0”S 77²3'00.0’W], 465 m elev., 01-VIII-1966, M. Olalla;

MEPN 2765 (8, 54.8-67.0 mm SL), Napo, rio Campamento Rodeo, $256 \mathrm{~m}$ elev., 00³8'16”S 7653'18”W, 03-IX-1990, R. Barriga;

MEPN 2858 (18, 21.3-135.9 mm SL), Napo, rio Tutakamo, 700m. da casa de Agustin Narvaez, a 7km. da estrada para a antena da EMETEL, $980 \mathrm{~m}$ elev., 0042’16”S 7742’25’'W, 22-VI-1995, R. Barriga;

MEPN 2949 (2, 89.4-129.8 mm SL), Pastaza, rio Landayacu, a montante e a jusante da plataforma do poço Moretecocha, 410 m elev., 09-XII-1990, R. Barriga;

MEPN 2952 (2, 106.2-125.6 mm SL), Napo, rio Coca, na desembocadura do rio Reventador a uma distância de 300 m, [0008'S 7740'W], 27-IX-1990, R. Barriga; MEPN $4623(6,112.7-138.8 \mathrm{~mm}$ SL), Napo, estero Sunka a $20 \mathrm{~min}, 0.5 \mathrm{~km}$ do poço de petróleo Sunka, 02-XII-1988, R. Barriga et al.; 
MEPN 4624 (9, 87.32-113.8 mm SL), Napo, rio Granadilla, 200m a jusante do acampamento de CODO ALTO da INECEL, 13-IX-1990, R. Barriga;

MEPN 4625 (19, 20.0-98.6 mm SL), Napo, rio Salado, braço e margem direita do braço principal, 1990, R. Barriga;

MEPN 4665 (12, 31.7-69.4 mm SL), Zamora-Chinchipe, estanque Ijisán, canal que deságua na laguna de Ijisán, 0405’19”S 78³9’15”W, 23-VII-1993, R.Barriga;

MEPN 4762 (4, 63.6-90.3 mm SL), Zamora-Chinchipe, quebrada Mayaycu, a $2 \mathrm{Km}$ da desembocadura no rio Nangaritza a 200m. do destacamento militar Mayaycu, $1000 \mathrm{~m}$ elev., 0353'10” S 7840’05” W [0353'03.9”S 7840'51.4”W], 18-VII-1993, R. Barriga;

MEPN 4998 (1, 77.7 mm SL), Orellana, estero sem nome na rodovia Auca-Perenco, afluente do rio Tiputini, $215 \mathrm{~m}$ elev., 0059'31.9'S 76¹8'54.9'W, 29-X-2005, R. Barriga;

MEPN 5018 (4, 42.3-113.0 mm SL), Napo, rio Jondachi, próximo à ponte a jusante da população de Jondachi, 800 m elev., 0047’48”S 7746’31”W, 06-IX-2004, R. Barriga \& L. Grefa;

MEPN 5202 (20, 25.4-75.7 mm SL), Napo, rio Piedras, Finca Chico, próximo à estrada Quito-Lago Agrio, 00²2'16”S 7543’18”W, 03-X-1990, R. Barriga;

MEPN 5211 (6, 75.0-104.8 mm SL), Napo, rio Coca, estero Venado, $3 \mathrm{Km}$ a jusante do acampamento Codo Bajo da INECEL, 17-IX-1990, R. Barriga;

MEPN 5216 (7, 98.9-126-8 mm SL), Napo, rio Granadilla, 200m a jusante do acampamento Codo Alto da INECEL, 1350 m elev., 0005’16” s 77³2’21’W, 13IX-1990, R. Barriga;

MEPN 5217 (1, $165.1 \mathrm{~mm}$ SL), Napo, rio Alvarado, $2 \mathrm{Km}$ a jusante do heliporto Codo Bajo da INECEL, $00^{\circ} 03$ '55’'S 77²8'45”W, 18-IX-1990, R. Barriga;

MEPN 5262 (11, 31.0-116.7 mm SL), Zamora-Chinchipe, quebrada Rancho Alegre, 1150 m elev., 0400’30”S 7853'05’W, 15-III-1979, R. Barriga et al.;

MEPN 5448 (4, 92.5-136.3 mm SL), Zamora Chinchipe, quebrada Rancho Alegre, 1150 m elev., 0400'30'S 7853'05”W, 15-III-1979, R. Barriga;

MEPN 5518 (1, 82.4 mm SL), Napo, Centro Comunal Guagua Sumaco [0043’45.5”S 77³4'09'W], 0042'18’'S 77³6'18’W, 03-V-1989, P. Mena;

MEPN 5608 (12, 40.7-131.4 mm SL), Pastaza, rio Arajuno, sitio la Independencia, [mun. rio Arajuno $01^{\circ} 05^{\prime} 48.5^{\prime}$ 'S 77³5'22.2”W], 03-IX-1997, R. Barriga \& B. Andy; 
MEPN 5667 (6, 49.5-66.6 mm SL), Morona-Santiago, arroio Pirulí, a 200m da quebrada Palenque Nº 1, 05-VII-1991, R. Barriga;

MEPN 5669 (9, 53.9-137.9 mm SL), Napo, rio Alvarado, a $2 \mathrm{Km}$ do acampamento Codo Bajo da INECEL, 0003'55’S 77²8’45’W, 18-IX-1990, R. Barriga;

MEPN 5875 (2, 114.3-142.0 mm SL), Zamora-Chinchipe, porto El Dorado no rio Nangaritza, $1000 \mathrm{~m}$ elev., 0353’10” S 7840’05” W [0353'03.9”S 7840’51.4”W], 19-III-1979, R. Barriga et al.;

MEPN 5975 (1, 126.8 mm SL), Napo, caverna de Jumandi, rio Misahuallí, 820 m elev., 0054'18’'S 7748’24’W, 11-III-1979, Albuja et al.;

MEPN 6075 (2, 54.6-67.9), Pastaza, cabeceira do rio Capahuari, $450 \mathrm{~m}$ elev., 0204’18”S 77¹0’21’W, VI-1957, Pablo Mena;

MEPN 6076 (1, 118.7 mm SL), Puyo, rio Pindo Grade, 01³8’25’S 7757’15’W, 03VIII-1985, N. Pantusi;

MEPN 6169 (4, 93.9-113.4 mm SL), Napo, rio Cotapino, VIII-1966, M. Olalla; MEPN 6217 (3, 63.4-97.6 mm SL), Pastaza, rio Pastaza, II-1967, M. Olalla; MEPN 6220 (1, $149.3 \mathrm{~mm}$ SL), rio Villano, afluente do rio Ciuraray, 01³0’15”S 77²9’40’W, V-1948, M. Olalla;

MEPN 6904 (3/10, 62.1-120.1 mm SL), Morona-Santiago, quebrada próxima a Chuchumbletza, a sudoeste de Gualaquiza [0332’23.3”S 78³2’33.6”W], 950 m elev., 03³2’S 78³0'W, tributário do rio Zamora, afluente do rio Santiago, 25-III-1979, R. Barriga et al.

MEPN 7007 (4, 111.6-134.1 mm SL), Zamora-Chinchipe, rio Nangaritza, margem direita do rio Zamora, a montante de Los Encuentros, a oeste de Paquisha[0356'03.5”S 7840’40.4’W], 0354’S 78³9’W, 19-III-1979, R. Barriga et al.;

MEPN 7412 (5, 88.3-126.6 mm SL), unknown collection site, XI-1950, unknown collector;

MEPN 7625 (2, 73.6-75.5 mm SL), Orellana, quebrada sem nome, $2 \mathrm{Km}$ ao sul do rio Tiputini, Km 35 da rodovia Pampeya-Iro, 19-III-2000, R. Barriga;

MEPN 7784 (1, 56.0 mm SL), Zamora-Chinchipe, pântano lateral junto à via Los Encuentros-Paquisha, 900 m elev., 27-III-2008, R. Barriga et al.;

MEPN 7789 (9, 67.9-108.2 mm SL), Zamora-Chinchipe, nascente do rio Salado, afluente do rio Zamora, a sudeste de Pindol na direção de los Encuentros, $900 \mathrm{~m}$ elev., 27-III-2008,R. Barriga et al.; 
MEPN 7791 (1, $26.8 \mathrm{~mm}$ SL), Zamora-Chinchipe, rio La Delicia, a $3 \mathrm{Km}$ de "La Centza”, 868 m elev., 24-III-2008, R. Barriga;

MEPN 7794 (1, 120.5 mm SL), Zamora-Chinchipe, rio La Delicia, a $3 \mathrm{Km}$ de "La Centza”, 868 m elev., 0346’09”S 78³6’06” W, 24-III-2008, R. Barriga;

MEPN 8640 (7, 95.1-113.4 mm SL), Pastaza, rio Bobonaza, 400 m elev., 1955, M. Olalla;

MEPN 9131 (5, 83.2-137.1 mm SL), Napo, Rio Pucuno, $300 \mathrm{~m}$ elev., 0103'56”S 77³8’16”W, XII-1965, M. Olalla;

MEPN 9230 (1, $158.1 \mathrm{~mm}$ SL), Orellana, rio Payamino, próximo à desembocadura no rio Napo, 350 m elev., $00^{\circ} 25^{\prime} 18^{\prime}$ 'S $77^{\circ} 05^{\prime} 51^{\prime \prime} \mathrm{W}$, unknown date, H. Mena;

MEPN 9310 (3, 59.2-110.7 mm SL), Pastaza, rio Yandia, a montante da ponte a $2.5 \mathrm{Km}$ ao sul de Santa Clara, 800 m elev., 01¹5'59’S 7754'08’W, 28-IX-2005, S. Brandi; MEPN 9316 (5, 46.5-125.1 mm SL), Pastaza, rio Cedroyaru, 5km a sudeste do 'sítio' La Independencia, afluente do rio Arajuno, $950 \mathrm{~m}$ elev., $01^{\circ} 15^{\prime} 28^{\prime} \mathrm{S} 77^{\circ} 52^{\prime} 18^{\prime \prime} \mathrm{W}, 04-$ IX-1997, R. Barriga;

MEPN 9320 (5, 106.5-129.5 mm SL), Morona-Santiago, rio Llushin, ao norte de Arapicos, 1000 m elev., 0153’20”S 7757’15’W, II-1955, R. Olalla;

MEPN 9321 (1, $114.0 \mathrm{~mm}$ SL), Morona-Santiago, rio Macuma, $600 \mathrm{~m}$ elev., $02^{\circ} 08^{\prime} 45^{\prime}$ S 7740’05’W, V-1953, B. Pazmiño;

MEPN 9465 (1, 30.5 mm SL), Sucumbíos, rio Diamante 1, Bloco Santa Fe, 265 m elev., $00^{\circ} 05^{\prime} 55^{\prime} \mathrm{N} 77^{\circ} 11^{\prime 2} 22^{\prime} \mathrm{W}, 02-\mathrm{II}-1999$, R. Barriga \& K. Galacatos;

MEPN 9477 (8, 46.4-60.4 mm SL), Napo, rio Quijos antes da confluência com o rio Salado, 1430 m elev., 00¹1'16”S 7742’25”W, 28-IX-2003, R. Barriga;

MEPN 9484 (3, 79.9-121.4 mm SL), Napo, Challuayacu, 1200 m elev., 0045’26”S 7748’26’W, 23-X-1989, R. Moreno;

MEPN 9485 (3, 33.2-53.9 mm SL), Sucumbios, rio Cristal, afluente do rio Bermejo, rio San Miguel, sistema do rio Putumayo, $00^{\circ} 16^{\prime} 35^{\prime \prime} \mathrm{N} 77^{\circ} 11^{\prime} 48^{\prime \prime} \mathrm{W}, 26-\mathrm{V}-2003$, R. Barriga;

MEPN 9486 (5, 33.7-77.6 mm SL), Sucumbios, quebrada sem nome, 100m antes do ‘Sítio’ La Libertad, 0002’28’S 77³0’26”W, 08-VII-2005, R. Barriga \& V. Chillagano; MEPN 9488 (5, 106.8-129.8 mm SL), Morona-Santiago, Macas, Parque Nacional Sangay, Laguna de Sardinayacu, 1800 m elev., 01³5'16”S 78¹1’24”W, unknown date and collector; 
MEPN 9489 (15, 48.3-107.6 mm SL), Pastaza, cabeceira do rio Capahuari, 450 m elev., 0204’18’S 77¹0’21’W, XI-1957, P. Mena;

MEPN uncat (3, 79.9-121.4 mm SL), Orellana, rio Challuayacu [01¹9'48.9'S 7701'22.3’'W], 23-X-1989, R. Barriga;

MEPN uncat. (15, 19.1-25.6 mm SL), Napo, rio Quijos [0009'17.66”S 77²3’48.3”W], remanso a jusante da catarata San Rafael, 21-IX-1983, R. Barriga et al;

MEPN uncat. (2, 78.1-97.1 mm SL), Zamora-Chinchipe, Finca Torres, na margem do rio Zamora [0346'4.6”S 7841'48.4”W], afluente do rio Santiago, a nordeste da paróquia Yantzaza, 650 m elev., 0345'S 7842’W, 26-IX-1978, R. Barriga;

MZUSP 38687 (2, 54.1-66.2 mm SL), Napo, cerca de $6 \mathrm{~km}$ NE do rio Quijos, na ponte sobre o Rio Salado, Bacia do Rio Napo, $0^{\circ} 9.3^{\prime}$ S, $77^{\circ} 38.8^{\prime}$ W, D. Stwart \& M. Ibarra;

NRM 28656 (1, 128.8 mm SL), Zamora-Chinchipe, rio Zamora, 00-00-1937, R. B. Blomberg;

SU 58363 (1, 53.1 mm SL), Alpayaca, Rio Pastaza, 900 m elev., comprados por F. H. Rosemberg;

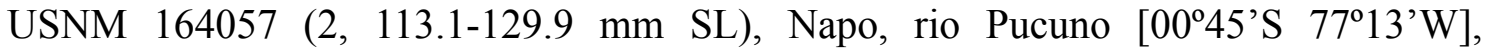
tributário do rio Suno, afluente do rio Napo, 300-350 m elev., XI-1950, M. Olalla;

USNM 164062 (7, 67.8-108.7 mm SL), Napo, rio Misahuallí [Misahuallí 0102’00.3”S 77³9’52.0”W], V-1952, M. Olalla;

USNM 164065 (4, 77.2-122.5 mm SL), Pastaza, Rio Arajuno [mun. rio Arajuno $01^{\circ} 05^{\prime} 48.5^{\prime}$ 'S $77^{\circ} 35^{\prime} 22.2^{\prime}$ W], afluente do rio Napo, a nordeste de El Puyo, 1000-1500 m elev. , III-1953, C. Estrella;

USNM 258065 (3, 44.1-74.7 mm SL), Napo, quebrada em Sarayacu [00³9’18.9’S $\left.77^{\circ} 46^{\prime} 55.2^{\prime \prime} \mathrm{W}\right]$ a $28 \mathrm{~km}$ do rio Jondachi, afluente do rio Misahuallí, sistema do rio Napo, na rodovia Baeza-Archidona, 1500 m elev., 14-XI-1981, D. J. Stewart et al.; USNM 258066 (10, 22.7-92.5 mm SL), Napo, rio Quijos, cerca de $7.8 \mathrm{~km}$ a nordeste do

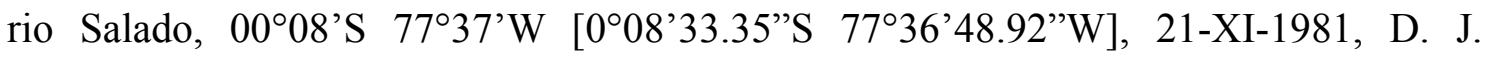
Stewart et al.;

USNM 258067 (3, 55.4-71.6 mm SL), Napo, quebrada afluente do rio Misahuallí,em

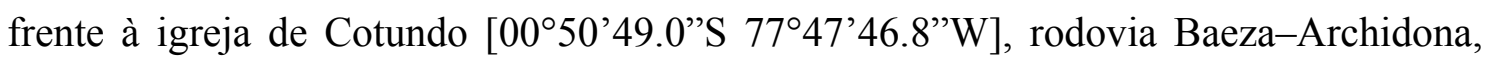
$00^{\circ} 52^{\prime}$ S $77^{\circ} 50^{\prime} \mathrm{W}, 13-\mathrm{XI}-1981$, D. J. Stewart et al.; 
USNM uncat (ex-FMNH 94420) (12, 21.1-75.2 mm SL), Napo [Sucumbíos], quebrada aflente do rio Dué, tributário do rio Aguarico, sistema do rio Napo, $8.8 \mathrm{Km}$ ao sudoeste de Lumbaquí, $00^{\circ} 01^{\prime} \mathrm{N} 77^{\circ} 24^{\prime} \mathrm{W}, 22-X I-1981$, D. Stewart et al.

all from Peru:

LAC 36357-27 (1, 143.5 mm SL), Amazonas. Río Cenepa, vicinity of Huampami [Huampam: 04²8’3’S 7809’22.9’W], VII a VIII-1978, J. E. Cadle;

LAC 36357-28 (1, $35.6 \mathrm{~mm} \mathrm{SL),} \mathrm{Amazonas,} \mathrm{rio} \mathrm{Cenepa,} \mathrm{vicinity} \mathrm{of} \mathrm{Huampami}$ [Huampam: 04²8’3’S 7809’22.9’W], VII a VIII-1978, J. E. Cadle;

LAC 39663-6 (1, 79.0 mm SL), Amazonas, córrego Berlin, 0.5 milhas a oeste de Huampami, rio Cenepa, [Huampam 04²8’3”S 7809’22.9”W, Huampani, margem esquerda do rio Cenepa], 31-VII-1977, R. McDiarmid;

LAC 39686-10 (16, 43.8-102.7), Amazonas, rio Cenepa, imediações de Shaim [río Shaíme? 03³0'S 7744’W], 18-VII a 18-VIII-1977, R. McDiarmid;

LAC 39687-1 (1, 119.3 mm SL), Peru, Amazonas, rio Cenepa, nas proximidades de Sua, 22-VIII-1977, R. McDiarmid;

MUSM 5662 (1, 38.4 mm SL), Amazonas, Condorcanqui, PV22 [0401'00.4”S 78²4'7.9’W], Río Comainas, afluente do rio Marañon, 18-VII-1994, H. Ortega;

MUSM 5664 (1, 104.7 mm SL), Amazonas, Condorcanqui, PV22 [0401'00.4’'S 78²4'7.9’W], Río Comainas, afl. R. Marañon, 20-VII-1994, H. Ortega;

MUSM 5666 (1, $118.2 \mathrm{~mm}$ SL), Amazonas, arroio Condorcangui, rio Comainas, a jusante do acampamento PV22 [0401'00.4”S 78²4'7.9”W], 16-VI-1994, H. Ortega;

MUSM 5672 (4, 22.9-88.3 mm SL), Amazonas, Condorcanqui, PV22 [0401'00.4”S 78²4’7.9”W], Río Comainas, bacia Río Marañon, Quebrada 3, 22-VII-1994, H. Ortega;

MUSM 6138 (1, 123.2 mm SL), Amazonas, Condorcanqui, PV22, [0401'00.4”S 78²4'7.9’W] C. Rio Marañón, Río Comainas, 24-VII-1994, H. Ortega;

MUSM 6155 (1, 106.39 mm SL), Amazonas, Condorcanqui, PV22 [0401'00.4”S 78²4'7.9’W], Río Comainas, bacia do rio Marañon, Quebrada 3, 25-VII-1994, H. Ortega;

MUSM 6160 (4, 60.1-104.1 mm SL), Amazonas, Condorcanqui, PV22 [0401'00.4’S 78²4'7.9'W], Río Comainas, bacia do rio Marañon, Quebrada 2, 19-VII-1994, H. Ortega; 
MUSM 6175 (2, 21.0-27.4 mm SL), Amazonas, Condorcanqui, PV22 [0401'00.4”S 78²4’7.9’W], Río Comainas, bacia do rio Marañón, 16-VII-1994, H. Ortega;

MUSM 21296 (3, 23.5-83.7 mm SL), Amazonas, Condorcanqui, Cenepa, próximo ao rio Alto Cenepa, $750 \mathrm{~m}$ elev., 17m 0794678/9581235 [0347’04.24’'S 78²0’32.6”W], 19-XI-2003, B. Rengifo \& M. Velásquez;

MUSM 21366 (1, 22.7 mm SL), Amazonas, Condorcanqui, Cenepa, próximo ao rio Alto Cenepa, 792 m elev., 17m 0796083/9599325 [03³7’15.2”S 78²0’00.5”W], 20XI-2003, B. Rengifo \& M. Velásquez;

MUSM 21356 (35, 25.1-88.7 mm SL), Amazonas, Condorcanqui, Cenepa, próximo ao rio Alto Cenepa, $898 \mathrm{~m}$ elev., 17m 0797546/9605132 [03³4’6.6”S 78¹9’16.0”W], 19XI-2003, B. Rengifo \& M. Velásquez;

MUSM 21358 (3, 55.0-99.3 mm SL), Amazonas, Condorcanqui, Cenepa, próximo ao rio Alto Cenepa, 874m elev., 17m 0797082/960319X, 19-XI-2003, B. Rengifo \& M. Velásquez;

MUSM 21359 (1, 41.3 mm SL), Amazonas, Condorcanqui, Cenepa, próximo ao rio Alto Cenepa, 949 m elev., 17m 0795605/9602498 [03³5’32.6”S 78²0’21.1’W], 19XI-2003, B. Rengifo \& M. Velásquez;

MUSM 21361 (3, 44.6-73.1 mm SL), Amazonas, Condorcanqui, Cenepa, próximo ao rio Alto Cenepa, 787 m elev., 17m 0796093/9600456 [03³6’38.9’'S 78²0’3.8”W], 19XI-2003, B. Rengifo \& M. Velásquez;

MUSM 21355 (1, 16.7 mm SL), Amazonas, Condorcanqui, Cenepa, próximo ao rio Alto Cenepa, 877 m elev., 17m 0797890/9606115, 19-XI-2003, B. Rengifo \& M. Velásquez;

MUSM uncat (1, $108.1 \mathrm{~mm}$ SL), Peru, Amazonas, arroio Condorcangui, rio Comainas, no acampamento PV22 [0401'00.4”S 78²4’7.9’W], 22-VII-1994, H. Ortega.

Diagnose. Lebiasina elongata difere de Lebiasina bimaculata, L. aff. bimaculata I, L. aff. bimaculata II, L, boruca, L. festae e L. aff. festae por não apresentar a parede da câmara posterior da bexiga natatória “celular", por apresentar as escamas da quinta série longitudinal com tecido epitelial hipertrofiado nos machos adultos e por não apresentar escamas com intensa deposição de guanina (vs. parede da bexiga natatória "celular", escamas da sexta série longitudinal modificadas em machos adultos, ao menos a quarta escama da linha lateral com intensa deposição de guanina). A espécie difere de 
Lebiasina sp. "Curuá-Pinta” por apresentar faixas longitudinais e mancha caudal, e não apresentar manchas escuras na base das escamas da segunda à quinta séries longitudinais (vs. faixas longitudinais e mancha caudal ausentes; manchas escuras presentes na base das escamas da segunda à quinta séries longitudinais). Lebiasina elongata difere de L. taphorni, L. unitaeniata, L. uruyensis, L. yuruaniensis e L. sp. "Parima" pela faixa secundária passando ao longo das escamas da primeira e segunda séries longitudinais, ausência da faixa "intermediária" e pela mancha caudal alcançar o pedúnculo caudal anteriormente ( $v s$. faixa secundária passando ao longo das escamas da segunda e terceira séries longitudinais, faixa "intermediária" presente; mancha caudal não alcançando o pedúnculo caudal anteriormente). A espécie difere de Lebisina astrigata, L. aureoguttata, L. chocoensis, L. colombia, L. floridablancaensis, L. multimaculata, L. ortegai e L. panamensis por não apresentar uma série longitudinal de manchas arredondadas distribuídas ao longo das escamas da quarta série longitudinal (vs. série longitudinal de manchas arredondadas distribuídas ao longo das escamas da quarta série longitudinal). Distingue-se ainda de Lebisina astrigata, L. aureoguttata, L. chocoensis, L. colombia, L. floridablancaensis e L. multimaculata por apresentar a faixa primária conspícua, estendendo-se ao longo de praticamente todo o corpo (vs. faixa primária inconspícua em Lebisina astrigata, L. aureoguttata, L. chocoensis e L. multimaculata; apenas a porção anterior da faixa primária conspícua em L. colombia; apenas a porção posterior da faixa primária conspícua em L. floridablancaensis). Difere de L. erythrinoides, L. intermedia e L. sp. "Curuá-Faixa" pelo infra-orbital 2 sobrepondo-se lateralmente a grande parte do maxilar e apresentar a primeira série longitudinal de escamas alcançando apenas a vertical que passa pela metade da nadadeira anal (vs. infra-orbital 2 sobrepondo-se apenas à porção posterior do maxilar; primeira série longitudinal de escamas alcançando a origem da nadadeira caudal em $L$. erythrinoides; primeira série longitudinal de escamas alcançando o término da nadadeira dorsal em L. intermedia e L. sp. "Curuá-Faixa"). Lebiasina elongata difere ainda de L. erythrinoides por apresentar 12 escamas circumpedunculares (vs. 14 escamas circumpedunculares) e de L. intermedia e L. sp. "Curuá-Faixa” pela ausência de uma ou mais séries longitudinais de manchas escuras situadas ventralmente à faixa primária; faixa primária não alcançando a mancha caudal posteriormente (vs. uma a três séries longitudinais de manchas escuras situadas ventralmente à faixa primária; faixa primária alcançando a mancha caudal posteriormente). Adicionalmente, L. elongata 
pode ser diferenciada de L. sp. "Curuá-Faixa" por apresentar a lâmina dorsal do mesetmóide em forma de " $\mathrm{T}$ " e o ramo palatino do nervo facial percorrendo a margem lateral do vômer (vs. lâmina dorsal do mesetmóide arredondada; ramo palatino do nervo facial transpassando a superfície ventral do vômer).

Descrição. Dados morfométricos apresentados na tabela 8. Corpo comprimido e alongado. Perfil dorsal da cabeça e do corpo convexo do lábio superior até até a origem da nadadeira dorsal, tornando-se praticamente reto entre os parietais e a origem da dorsal. Perfil reto na base da dorsal e levemente côncavo posteriormente até a origem dos raios pró-correntes da nadadeira caudal. Perfil ventral da cabeça e tronco convexo desde o lábio inferior até a origem da pélvica, reto deste ponto até a origem da nadadeira anal, convexo na base da anal e côncavo do término da anal até a origem dos pró-correntes ventrais da nadadeira caudal.

Espécie discretamente prognata, boca terminal. Maxilar alcançando a margem anterior da órbita. Apenas uma série de 9 (44), 10* (28), 11 (12) ou (12) ou 12 (2) dentes tricúspides decrescendo posteriormente no pré-maxilar. Maxilar com 4 (1), 5 (7), 6* (19), 7 (31), 8 (24) ou 9 (9) dentes tricuspidados. Dentário com duas séries de dentes: 10 (4), 11 (11), 12 (21), 13* (22), 14* (8), 15 (1), 16 (1) ou 17 (2) dentes tricúspides pedunculados com a cúspide central distintamente mais longa que as cúspides laterais na série externa, série interna com dentes diminutos, na maioria, cônicos (podendo ser tricúspides posteriormente) estendendo-se desde a sínfise até próximo ao processo coronóide. Raios-branquiostégios 4, três articulando com o ceratobranquial anterior e 1 com o ceratobranquial posterior.

Escamas ciclóides, circuli restritos à borda da escama, diversos radii (aproximadamente 24) convergindo para o centro da escama, fortemente anastomosados no centro, formando numerosas células. Série longitudinal da linha lateral com 30 (5), 31 (17), 32 (16) ou 33 (18) escamas, das quais apenas 4 (1), 5 (12), 6 (29) ou 7 (4) são perfuradas. Séries longitudinais entre a nadadeira dorsal e a pélvica 7. Escamas prédorsais 12 (1), 13 (5), 14* (30) ou 15 (12). Escamas da primeira série longitudinal 19 (5), 20 (15), 21 (12), 22 (6), 23 (3) ou 24 (1), geralmente ultrapassando a vertical que passa pela metade da nadadeira anal. Escamas circumpedunculares 12.

Nadadeira peitoral i, 11 (1), 12 (12), 13* (20), 14 (20), 15 (2). Ponta da peitoral não alcançando a vertical que passa pela origem da pélvica. Raios da nadadeira pélvica 
i, 7* (53) ou 1,8 (4). Supraneurais 10, 11 ou 12 anteriores aos espinhos neurais dos centros 5 a 14 (11), 15 (50)ou 16* (29). Nadadeira dorsal ii, 7 (2), iii, 7 (2) ii, 8* (46). Primeiro pterigióforo da nadadeira dorsal inserido posteriormente ao espinho neural do centro 14 (11), 15 (50) ou 16* (29). Margem distal da nadadeira dorsal arredondada quando expandida. Origem da nadadeira dorsal distintamente mais próxima à base da nadadeira caudal que da ponta do focinho. Base do último raio da dorsal distintamente anterior à vertical que passa pela origem da nadadeira anal. Nadadeira anal iii, $8^{*}(60)$, iii, 9 (2), último raio adnato. Margem distal da nadadeira anal arredondada. Primeiro pterigióforo da nadadeira anal inserido posteriormente ao arco hemal do centro 24 (12), 25 (39), 26* (39). Nadadeira adiposa presente. Um ou dois epurais. Nadadeira caudal furcada, lóbulo superior distintamente mais longo que o inferior, ambos arredondados. Raios principais da nadadeira caudal i, 8/i, 8 (1), ii, 8/i, 8 (3), i, 9/i, 7 (1), i, 9/i, 8* (48) ou i, 10/i, 8 (1). Pró-correntes dorsais 7 (1), 8 (1), 9 (2), 10 (2) ou 11 (1); pró-correntes ventrais 8 (2) 9 (3), 9 (2). Vértebras pré-caudais 24 (1) 25 (5) 26 (3); vértebras caudais 17 (1) $18(5) 19$ (3).

Colorido. Cor de fundo predominantemente amarela. Coloração escura estendendo-se desde o lábio superior até a porção exposta dos parietais e ao longo da série medial e primeira série de escamas até a origem da nadadeira caudal. Maxilar, ossos circumorbitais e série opercular densamente pigmentados próximo à porção dorsal da cabeça, tornando-se gradualmente amarelada ventralmente; opérculo com uma distinta mancha escura na região médio-inferior. Estreita faixa negra estendendo-se da porção dorsal da órbita, por toda margem dorsal dos infra-orbitais 5 e 6 , do opérculo e da membrana opercular. Lábio inferior intensamente pigmentado; restante da mandíbula e toda porção ventral da cabeça com pigmentação escassa.

Tronco tornando-se gradualmente amarelado ventralmente. Região abdominal amarela, com diminutos cromatóforos entre o istmo e a origem da nadadeira anal. Mancha umeral arredondada, conspícua em indivíduos jovens e, geralmente, indivíduos adultos. Faixa primária estreita, contínua àquela passando pelos infra-orbitais e margem dorsal do opérculo, alcançando a vertical que passa pela origem dos raios pró-correntes da nadadeira caudal. Faixa secundária estendendo-se ao longo da primeira e segunda séries longitudinais de escamas, desde os epoccipitais à extremidade do pedúnculo caudal. Terceira, quarta e quinta séries longitudinais de escamas com sutis manchas 
escuras na base. Base da dorsal distintamente mais escura que o dorso. Mancha caudal verticalmente alongada na extremidade do pedúnculo caudal, estendendo-se à base de 5 a 6 raios medianos da nadadeira caudal. Nadadeiras peitoral, pélvica, anal, adiposa e caudal hialinas. Base dos raios ramificados 2-8 da nadadeira dorsal escura; primeiro ponto de ramificação na porção média dos raios com discretas manchas.

Dimorfismo sexual. Exemplares machos de Lebiasina elongata apresentam o padrão mais difundido de dimorfismo sexual entre as Lebiasina, descrito acima para Lebiasina astrigata.

Distribuição. Porção cis-andina do Equador e Peru, Sul da Colômbia nos Rios Marañon, Napo, Caquetá e Putumayo (Fig. 77).

Tabela 8. Dados morfométricos de Lebiasina elongata.

\begin{tabular}{|c|c|c|c|c|c|}
\hline & & & & & \\
\hline & $\mathrm{n}$ & Range & Mean & SD & Lectotype \\
\hline Standard length & 110 & $16,7-151,6$ & 90,8 & & 109,5 \\
\hline \multicolumn{6}{|c|}{ Morphometrics \% of SL } \\
\hline Depth dorsal fin origin & 59 & $16,9-23,8$ & 19,5 & 1,3 & 19,9 \\
\hline Snout to anal fin origin & 59 & $71,2-78,6$ & 74,1 & 1,4 & 75,8 \\
\hline Snout to pelvic fin origin & 59 & $46,0-52,5$ & 49,1 & 1,1 & 49,3 \\
\hline Snout to dorsal fin origin & 59 & $50,7-56,1$ & 53,5 & 1,1 & 53,9 \\
\hline Dorsal fin origin to caudal base & 59 & $21,0-49,7$ & 46,8 & 3,6 & 48,8 \\
\hline Dorsal fin length & 59 & $16,4-20,9$ & 19,2 & 0,9 & 20,7 \\
\hline Dorsal fin base & 59 & $7,8-10,9$ & 9,3 & 0,7 & 10,9 \\
\hline Adipose fin to caudal peduncle & 59 & $10,2-14,7$ & 12,9 & 0,9 & 12,6 \\
\hline Length caudal peduncle & 59 & $13,6-18,0$ & 16,2 & 0,9 & 18,0 \\
\hline Depth caudal peduncle & 59 & $9,9-11,7$ & 10,9 & 0,4 & 11,7 \\
\hline Anal fin length & 59 & $17,2-23,2$ & 19,8 & 1,6 & 21,3 \\
\hline Anal fin base & 59 & $9,6-14,4$ & 12,0 & 1,3 & 12,8 \\
\hline Pelvic- to anal fin origin & 59 & $22,6-28,5$ & 25,5 & 1,3 & 28,3 \\
\hline Pelvic fin length & 59 & $11,6-15,0$ & 13,5 & 0,8 & 13,7 \\
\hline Pectoral to pelvic fin origin & 57 & $26,0-32,0$ & 28,8 & 1,2 & 29,7 \\
\hline Pectoral fin length & 58 & $13,8-17,6$ & 15,8 & 0,9 & 15,5 \\
\hline Snout to pectoral fin origin & 59 & $18,2-22,8$ & 21,0 & 0,9 & 21,0 \\
\hline Bony head length & 59 & $20,5-26,2$ & 23,4 & 1,0 & 22,8 \\
\hline \multicolumn{6}{|c|}{ Morphometrics \% of HL } \\
\hline Head width & 59 & $47,2-60,4$ & 53,8 & 2,6 & 53,2 \\
\hline Horizontal eye diameter & 59 & $17,4-25,5$ & 20,4 & 2,0 & 18,8 \\
\hline Distance snout tip to eye & 59 & $24,7-31,5$ & 27,8 & 1,5 & 25,6 \\
\hline Interorbital distance & 59 & $31,1-36,4$ & 33,5 & 1,3 & 36,4 \\
\hline Length lower jaw & 59 & $40,5-48,9$ & 45,7 & 1,7 & 47,2 \\
\hline Length upper jaw & 59 & $35,3-42,3$ & 38,7 & 1,6 & 40,4 \\
\hline
\end{tabular}




\section{Lebiasina erythrinoides (Valenciennes, in Cuvier \& Valenciennes)}

(Figura 87)

Piabucina erythrinoides Valenciennes, in Cuvier \& Valenciennes, 1849: 161; pl. 160-161.- Günther, 1864: xix [summary]; 311 [brief description; distribution].Eigenmann \& Eigenmann, 1891: 52.- Eigenmann, 1910: 439 [catalog].- Eigenmann, 1923a: 125.- Eigenmann \& Allen, 1942: 278 [P. erythrinoides as type species of the genus Piabucina;reported as bearing two rows of teeth in the maxilla].- Schultz, 1944: 291 [key to the species of Piabucina]; 292 [synonymy].- Fernández-Yépez \& Martin, 1953: 227-229 [checklist].- Mago-Leccia, 1970: 74 [checklist].- Machado-Allison, 1974: 582 [diversity of Lebiasina and 'Piabucina'].- Taphorn \& Lilyestrom, 1980: 14 [key to freshwater species of Venezuela].- Taphorn, 1992: 464 [key to Lebiasinidae in Río Apure]; 468-470 [diagnosis (adipose fin mistakenly reported as absent) general comments on color pattern, distribution, habitats, abundance in Río Apure, feeding habits, reproductive behavior, and role food resource].- Galvis et al., 1997: 32 [synonymy; description; habits; incorrect distribution].- Taphorn et al., 1997: 78 [checklist].- Eschmeyer, 1998: 541 [catalog].- Weitzman \& Weitzman, 2003: 246 [checklist].- Maldonado-Ocampo et al., 2005: 93 [field guide; description, biology, ecology, comments and list of specimens in museums].

Piabucina pleurotaenia Regan, 1903: 623 [specimens from Merida; P. pleurotaenia as distinct from $P$. erythrinoides by number of scales on lateral line series].- Eigenmann, 1910: 439 [catalog].- Schultz, 1944: 291 [key to species of Piabucina]; 292-293 [color pattern; examined material: USNM 121403, USNM 121402, USNM 121404, USNM 121401, USNM 121400, USNM 86265, FMNH 41997]; fig. 36.- Fernández-Yépez \& Martin, 1953: 229.- Mago-Leccia, 1970: 74 [checklist].- Fernández-Yépez, 1972: 13.Machado-Allison, 1974: 579-583 [general comments on habits; commercial importance; diversity of Piabucina and validity].- Géry, 1977: 127 [key to the species of Lebiasininae].- Ardila-Rodríguez, 1978 [common names; meristic and morphometric data; feeding habits; reproductive biology; distribution].- Taphorn \& Lilyestrom, 1980 $[P$. pleurotaenia as junior synonym of $P$. erythrinoides; sexual dimorphism, growth, lateral line system, habitats and feeding habits].- Eschmeyer, 1998: 1355 [catalog].Weitzman \& Weitzman, 2003: 246 [checklist]. 
Lebiasina erythrinoides.- Géry, 1977: 126 [key to the species of Lebiasininae].- ArdilaRodríguez, 1999: 5 [description of L. provenzanoi]; 2000: 5 [species of Lebiasininae in Venezuela].

Lebiasina uruyensis (non Fernandez-Yepez).- Benigno, 1985: 129 [photo of young specimen].

Série-tipo. Holótipo: MNHN 4014.

Localidade-tipo. Lago Maracaibo, no lado próximo a Parija, Venezuela.

\section{Material examinado.}

CAR 15-04-06 (8, 43.9-139.8 mm SL), Colômbia, Norte de Santander, Bochalema [07³6’48.21'N 72³9'8.2”W], quebrada Chiracoca, 16-X-1997, C. Ardila-Rodriguez; CAR 15-04-08 (2, 111.1-129.7 mm SL), Colômbia, Norte de Santander, Bochalema [07³6'48.21'N 72³9'8.2”W], quebrada Chiracoca, 16-X-1997, C. Ardila-Rodriguez;

CAR 15-04-09 (1, 88.1 mm SL), Colômbia, Norte de Santander, Chinácota, vereda Teneria a Puente Vargas, a $3.3 \mathrm{Km}$ ao sudoeste de Chinácota [07³4’36.3”N 72³5’25.0’W], 1400-1420 m elev., 3-X-1992, J. D. Linch;

CAR 15-04-16 (1, 94.2 mm SL), Venezuela, Lara, quebrada Los Manguitos [quebrada El Manguito: 0956'12”N 6954’12’W], afluente do rio Claro, VII-1994, C. ArdilaRodriguez \& E. Y. Ardila;

CAR 15-04-17 (7, 69.2-141.3 mm SL), Venezuela, Carabobo, rio San Diego (afluente Lago Valencia) [10¹3’40”N 6757’10’W], 25-VII-1974, J. Baskin;

CAR 15-04-18 (4, 74.4-150.8 mm SL), Venezuela, Carabobo, rio San Diego (afluente Lago Valencia) [10¹3’40’N 6757’10’W], 25-VII-1974, J. Baskin;

CAR 15-04-22 (1, 86.3 mm SL), Colômbia, Norte de Santander, Ocaña, rio El Algodonal [86’10” N 7314’34” W], 08-IV-2001, A. San Juan;

CAR 15-04-26 (1, 133.2 mm SL), Colômbia, Norte de Santander, Ocaña [08¹4’00.3”N 73²1'24.1’W], rio Tejo, 04-VI-2001, C. Ardila-Rodriguez; 
CAR 15-04-27 (21, 48.9-125.9 mm SL), Colômbia, Norte de Santander, rio El

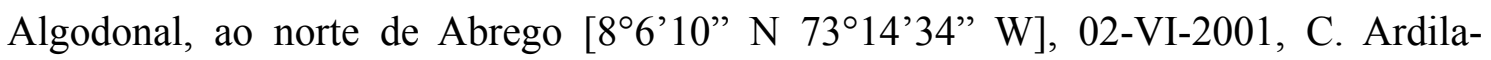
Rodriguez;

CAR 15-04-28 (12, 47.4-122.4 mm SL), Colômbia, Norte de Santander, rio Algodonál, ao norte de Abrego [86’10” N 73¹4’34” W], 03-VI-2001, C. Ardila Rodriguez;

CAR 15-04-29 (53, 50.9-135.5 mm SL), Colômbia, Norte de Santander, Abrego, quebrada Guayabal [0808’39.8”N 73¹7’16.2”W], 05-VI-2001, C. Ardila-Rodriguez;

CAR 15-04-30 (2, 150.7-151.7 mm SL), Colômbia, Norte de Santander, rio Algodonál, ao norte de Abrego [86'10” N 73¹4’34” W], 09-VII-2001, C. Ardila-Rodriguez;

CAR 154 (5, 75.8-162.5 mm SL), Colômbia, Norte de Santander, Bochalema [07³6'48.21'N 72³9'8.2”W], quebrada Chiracoca, 16-X-1997, C. Ardila-Rodriguez;

CAR 205 (3, 33.9-69.5 mm SL), Colômbia, Norte de Colombia, Santander, Pamplonita, quebrada Mutiscua [Mutiscua pop.: 7¹7'59.4”N 7244'58.6”W], 06-VI-2004, C. Ardila-Rodriguez;

CAR 292 (9, 28.0-108.6 mm SL), Venezuela, Lara, Rio Claro [10²’56”N 69¹5’56”W], 21-VII-2006, C. Ardila-Rodriguez, R. Ardila-Rodriguez;

CAR 409 (11, 41.1-165.1 mm SL), Colômbia, Casanare, Yopal, quebrada la Calabosa, afluente do rio Cravo Sur [rio Cravo Sur em Yopal: 5²1’20.4”N 72²3’53.3”W], 11-10-2008, C. Ardila-Rodriguez;

CAR 450 (ex-MHNLS 4336) (2, 130.0-153.4 mm SL), Venezuela, Yaracuy, quebrada el Charcal [Quebrada el Charal: 10³1'22.8’’N 6857’45.9”W], Finca Jaguar, 06-II-1987, Colonnello et al.;

CAR 479 (ex-MHNLS 31.6-67.8 mm SL), Venezuela, Yaracuy, quebrada el Charcal [Quebrada el Charal: 10³1'22.8’N 6857'45.9’W], Finca Jaguar, serra de Aroa, 24VII-1985, C. Lasso, J. Medina;

CAS uncat (7, 25.6-73.6 mm SL), Venezuela, Carabobo, rio Mariara, $12 \mathrm{Km}$ a oeste de Maracay [10¹6’02.5’N 6743'03.8’'W], 14 Jan 1938, F. E. Bond;

CAS uncat (4, 85.9-103.6 mm SL), Venezuela, Carabobo, quebrada afluente da quebrada Barreras, afluente do rio Paito, $20 \mathrm{Km}$ a oeste de Valencia [Barreras (Barrera) $10^{\circ} 08^{\prime} \mathrm{N} 68^{\circ} 10^{\prime} \mathrm{W}$, rio Paito $\left.09^{\circ} 54^{\prime} \mathrm{N} 68^{\circ} 09^{\prime} \mathrm{W}\right], 14-\mathrm{I}-1938$, F. E. Bond;

CAS uncat $(1,139.3 \mathrm{~mm} \mathrm{SL})$, Venezuela, Cojedes, tributário do rio Tamanaco, afluente do rio Paye, $20 \mathrm{~km}$ a nordeste de San Carlos [rio Tamanaco $09^{\circ} 45^{\prime} \mathrm{N} 68^{\circ} 24^{\prime} \mathrm{W}$ ], 09III-1938, F. E. Bond; 
CAS uncat $(6,59.6-101.0$ mm SL), Venezuela, Lara, quebrada Guajira em Guarico, 3 $\mathrm{Km}$ ao sul de Tocuyo, 1000 m elev. [quebrada Guajira 09²5'N 6949’W], 11-III-1938, F. E. Bond;

CAS uncat $(1,16.5 \mathrm{~mm} \mathrm{SL})$, Venezuela, Lara, rio Bucares, afluente do rio Tocuyo, 40 $\mathrm{Km}$ ao sul de Carora [949'25.7’N 70¹3'13.2”W], encosta nordeste dos Andes, 16III-1938, F. E. Bond;

CAS uncat (4, 53.6-83.2 mm SL)Venezuela, Mérida, rio Chama [rio Chama em Merida: $\left.08^{\circ} 35^{\prime} 51.3^{\prime} \mathrm{N} 71^{\circ} 08^{\prime} 55.8^{\prime \prime W}\right], 11-\mathrm{VI}-1938$, F. E. Bond;

CAS uncat (9, 45.8-135.6 mm SL), Venezuela, Mérida, afluente do rio Chama, noroeste de Estánques, $70 \mathrm{Km}$ ao sudoeste de Mérida [Estanques 08²8’07.5”N 71³2’03.9”W], 13-VI-1938, F. E. Bond;

CAS uncat (ex-IU 4098) (1, 142,52 mm SL), Venezuela, Mérida, rio Chama [rio Chama em Merida: $08^{\circ} 35^{\prime} 51.3^{\prime} ’ \mathrm{~N} 71^{\circ} 08^{\prime} 55.8^{\prime}$ W], 11-VI-1938, F. E. Bond;

CAS uncat (3, 40.7-60.6 mm SL), Venezuela, Trujillo, quebrada Tebor, $30 \mathrm{Km}$ ao norte de Trujillo [09³9’28.4’N 70²6’17.5’W], sistema do rio Motatán, 14-III-1938, F. E. Bond;

CAS uncat (2, 45.3-89.4 mm SL), Venezuela, Trujillo, tributário do rio Monay, $40 \mathrm{Km}$ ao norte de Trujillo [rio Monay $09^{\circ} 34^{\prime} \mathrm{N} 70^{\circ} 36^{\prime} \mathrm{W}$, tributário da margem esquerda do rio Carache, próximo à desembocadura no rio Motatán], 14-III-1938, F. E. Bond;

CAS uncat (1, $84.4 \mathrm{~mm} \mathrm{SL})$, Venezuela, Trujillo, tributário do rio Carache, afluente do rio Motatán, $50 \mathrm{Km}$ ao norte de Trujillo [09³9'15.44”N 70³3’42.8’W], 13-III-1938, F. E. Bond;

CAS uncat (2, 40.1-70.0 mm SL), Venezuela, Yaracuy, rio Yaracuy, $8 \mathrm{Km}$ ao sudeste de San Felipe, 24-I-1938, F. E. Bond;

IAvH-P 53 (4, 94.4-135.1 mm SL), Colômbia, Guajira, arroio Tabaco [Arroyo Tabaco próximo à mina de carvão $11^{\circ} 6^{\prime} 18^{\prime}$ 'N 72³2'54”W], 08-IX-1985, M. B.?;

IAvH-P 3227 (2, 83.5-102.9 mm SL), Colômbia, Casanare, quebrada El Tigre [Caño el Tigre: 0455’00’N 72¹9’00”W], setor Floreña A, 06-II-1997, M. Camargo;

IAvH-P 3228 (10, 19.2-156.2 mm SL), Colômbia, Casanare, quebrada El Tigre [Caño el Tigre: 0455’00’'N 72¹9’00’W], setor Floreña A, 06-II-1997, M. Camargo;

IAvH-P 3297 (19, 56.4- 127.1 mm SL), Colômbia, Casanare, quebrada La Chula, bacia do rio Cravo Sur, 06-II-2000, HIDROESTUDIOS S.A. 
IAvH-P 3481 (1, 123.8 mm SL), Colômbia, Casanare, Yopal, rio Charte [444'41'”N $\left.72^{\circ} 10^{\prime} 35^{\prime \prime} \mathrm{W}\right]$, piemonte Llanero, 03-II-1998, equipe auditoria ambiental;

IAvH-P 3482 (3, 93.0-137.9 mm SL), Colômbia, Casanare, Yopal, quebrada Bocachico, afluente do rio Charte, 21-II-2000, V. Ortiz

IAvH-P 3484 (1, 86.6 mm SL), Colômbia, Casanare, quebrada Cañuela, 02-VIII-2000, S. Rincon;

IAvH-P 3486(2, 158.7-177.7 mm SL), Colômbia, Casanare, Yopal, quebrada Bocachico, afluente do rio Charte, 18-VIII-1999, V. Ortiz;

IAvH-P 3487 (3, 115.4-134.3 mm SL), Colômbia, Casanare, quebrada Aguatoca $\left[05^{\circ} 22^{\prime} 32.5^{\prime} \mathrm{N} 72^{\circ} 24^{\prime} 53.8^{\prime} \mathrm{W}\right]$, caño La Veranera del sistema do rio Cravo Sur, unknown date, L. Narvaez;

IAvH-P 3488 (2, 99.6-156.3 mm SL), Colômbia, Casanare, Yopal, quebrada Bocachico, afluente do rio Charte, 23-XI-1999, V. Ortiz;

IAvH-P 4735 (2, 101.7-101.9 mm SL), Colômbia, Norte de Santander, Pamplonita, quebrada Mutiscua, 07-V-2008, C. Ardila-Rodríguez;

IAvH-P 9209 (1, 27.5 mm SL), Colômbia, Casanare, Pore, rio Pore, 100 m a jusante da

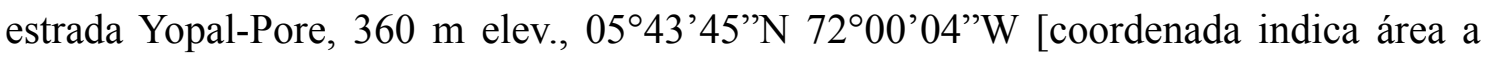
montante da cidade], unknown date, J. Maldonado et al.;

IAvH-P 9210 (3, 60.5-94.8 mm SL), Colômbia, Casanare, Yopal, quebrada Agua Blanca, afluente do rio Cravo Sur, $760 \mathrm{~m}$ elev., 05²8'17.6’ $\mathrm{N} 72^{\circ} 27^{\prime} 04.5^{\prime \prime} \mathrm{W}$, unknown date, J. Maldonado et al.;

IAvH-P 9211 (11, 50.5-167.2 mm SL), Colômbia, Casanare, Yopal, quebrada La Morreña afluente do rio Cravo Sur, $720 \mathrm{~m}$ elev., $05^{\circ} 27^{\prime} 49.5^{\prime \prime} \mathrm{N} 72^{\circ} 27^{\prime} 17.2^{\prime \prime} \mathrm{W}$, unknown date, J. Maldonado et al.;

IAvH-P 9550 (1, 158.4 mm SL), Colômbia, Casanare, Yopal, quebrada La Aguatoca na ponte da estrada para El Morro, 357 m elev., 05²6’21.2”N 72²7’09.7’W, unknown date, J. Bogotá et al.;

IAvH-P 9551 (2, 73.1-123.9 mm SL), Colômbia, Casanare, Yopal, quebrada La Tablona afluente do rio Cravo Sur, 515 m elev., 05²6’25.2”N 72²7’37.7’'W, unknown date, J. Bogotá et al.;

IAvH-P 9552 (4/6, 26.9-102.58 mm SL), Colômbia, Casanare, Yopal, quebrada Agua Blanca, afluente do rio Cravo Sur, $760 \mathrm{~m}$ elev., 05²6’17.6”N 72²7’4.5”'W, unknown date, J. Bogotá et al.; 
IAvH-P 9791 (1, 97.9 mm SL), Colômbia, Norte de Santander, quebrada La Llana bacia do rio Catatumbo, trecho médio, unknown date, J. Maldonado et al.;

IAvH-P 9792 (1, 140.8 mm SL), Colômbia, Norte de Santander, quebrada Vijagual, bacia do rio Catatumbo, unknown date, J. Maldonado et al.;

IAvH-P 9793 (7, 53.0-147.4 mm SL), Colômbia, Norte de Santander, Caño Seco, bacia do rio Catatumbo, trecho médio, unknown date, J. Maldonado et al.;

IAvH-P 9794 (4, 48.0-96.4 mm SL), Colômbia, Norte de Santander, quebrada Burbura, bacia do rio Catatumbo, unknown date, J. Maldonado et al.;

IAvH-P 9795 (1, 82.9 mm SL), Colômbia, Norte de Santander, rio antes do "aserrio" El Divizo, bacia do rio Catatumbo, trecho médio, unknown date, J. Maldonado et al.;

ICNMHN 913 (3, 99.2-143.5 mm SL), Colômbia, Norte de Santander, Ocaña, rio Algodonal [86'10" N 73¹4’34” W], Sistema do rio Catatumbo, unknown date and collector;

ICNMHN 1049 (7, 48.6-100.2 mm SL), Colômbia, Casanare, Paz de Ariporo, riacho Gras, afluente do rio Tate, sistema do rio Ariporo [sistema do rio Meta: 5 $55^{\prime} 0^{\prime \prime} \mathrm{N}$ 7153'0’'W], 14-II-1974, P. Cala

ICNMHN 2210 (4, 29.4-79.1 mm SL), Colômbia, Casanare, Yopal, quebrada M, bacia do rio Cravo Sur [rio Cravo Sur in Yopal: 5²1'20.4”N 72²3'53.3”W], piemonte llanero, 700 m elev., 08-X-1959, G. Dahl;

ICNMHN 2364 (1, 57.0 mm SL), Colômbia, Norte de Santander, quebrada el Tigre, afluente do rio Catatumbo, Km 1 da via Gamarra-Cúcuta [Cúcuta: 754'8.92”N 72²9'52.42”W], 31-I-1980, G. Arango;

ICNMHN 2635 (3, 69.4-127.1 mm SL), Colômbia, Norte de Santander, aprox. 5 Km desde Pamplonita-Cúcuta [07²9’29.1’N 72³7’57.2”W], X-1960, unknown colector;

ICNMHN 5317 (1, $135.3 \mathrm{~mm}$ SL) Colômbia [Norte de Santander], Ocaña [08 $14^{\prime} 00.3^{\prime \prime} \mathrm{N} 73^{\circ} 21^{\prime} 24.1$ 'W], quebrada La Vaca, Aguas Claras, unknown date and collector;

INHS 28887 (3, 56.2-79.8 mm SL), Venezuela, Yaracuy, rio Crucito, bacia do rio Aroa (drenagem do mar do Caribe) [10²9’08’N 68³9’40”W], 1993, unknown colector ;

INHS 28919 (3, 64.5-127.3 mm SL), Venezuela, Carabobo, rio Capa, bacia do rio Urama (drenagem do mar do Caribe) $\left[10^{\circ} 18^{\prime} 44.1^{\prime} \mathrm{N} 68^{\circ} 17^{\prime} 00^{\prime \prime} \mathrm{W}\right]$, 1993, unknown coletor; 
INHS 31812 (5, 37.8-81.1 mm SL), Venezuela, Barinas, córrego Arenosa, sistema dos rio La Yuca e Masparro [0846’14’N 70¹5’30’W], 1993, unknown coletor;

INHS 34955 (2, 163.2-192.9 mm SL), Venezuela, Trujillo, córrego afluente do Montatán [09¹2’46”N 7040’08’W], 1995, coletor?;

INHS 59850 (1, 88.8 mm SL), Venezuela, Mérida, rio Escalante, drenagem do lago Maracaibo [08³8'00.6”N 7154'54.4’W], 1991, coletor?;

INHS 60031 (1, 120.8 mm SL), Venezuela, Trujillo, rio Buena Vista, drenagem do lago Maracaibo [9॰18'16.5”N 7052’38.0”W], 1991, coletor?;

ICNMHN 820 (2, 114.7-149.5 mm SL), Colômbia, Guajira, arroio Tabaco, unknown collector and date;

MBUCV-V uncat (19, 48.2-122.8 mm SL), Venezuela, Yaracuy, quebrada Grande $\left[10^{\circ} 09^{\prime} 22.00^{\prime} \mathrm{N} 68^{\circ} 38^{\prime} 56.0^{\prime \prime} \mathrm{W}\right]$, próximo à ponte do rio Yaracuy, na estrada NirguaChivacoa, sistema do rio Cojedes, 19-III-1978, F. Mago-Leccia;

MBUCV-V uncat (1, $46.9 \mathrm{~mm}$ SL), Venezuela, Barinas, rio Masparro, entre Boconoito e Barrancas, em frente a Masparro [0847'40.7’N 7004'46.8’W], 21-X-1977, F, MagoLeccia;

MBUCV-V uncat (2, 97.0-108.2 mm SL), Venezuela [Yaracuy], quebrada Grande [1009’22.00”N 68³8'56.0”W], sistema do rio Cojedes, estrada Nirgua-Chiracoa, próximo à ponte Yaracay, 19-V-1978, F, Mago-Leccia;

MNRJ 14230 (7, 53.4-82.6 mm SL), Venezuela, Barinas, Quebrada afluente do rio Qui, $2 \mathrm{Km}$ ao norte da rodovia, a montante da fazenda Qui, 804’30”N, 7056’55”W, 30V-1982, D.C. Taphorn \& C. G. Lilyestrom;

MNRJ 14231 (10, 51.4-128.9 mm SL), Venezuela, Barinas, Guanare, riacho desembocando na represa de Boconó, 903’10”N, 7005’40”W, 06-II-1983, D.C. Taphorn;

MNRJ 14232 (7, 88.2-37.6 mm SL; 2 c\&s, mm SL), Venezuela, Tachira, Junin, córrego Rio Grande, 740’30’N, 72²2’0’W, 28-V-1982, D.C. Taphorn \& C. G. Lilyestrom; MZUSP 72091 (5, 51.5-139.3 mm SL), Venezuela, Carabobo, rio San Diego (afluente Lago Valencia) [10¹3’40”N 6757'10’W], 25-VII-1974, Y. Aguano \& J. Baskin; UF 25457 (3, 71.7-129.2 mm SL), Venezuela, Zulia, Heras, ponte sobre o rio Frio na rodovia Panamericana [08 58'08.0”N 71²4'58.4”W], 24-IX-1974, D. C. Taphorn \& C.G. Lilyestrom; 
UF 26048 (1, $52.2 \mathrm{~mm} \mathrm{SL})$, Venezuela, Portuguesa, Araure, Los Tagues [09³1’04’N 6916'05’W], 1973, S.R. Telford;

UF 26049 (1, $128.8 \mathrm{~mm}$ SL), Venezuela, Portuguesa, Araure, Los Tagues [09³1’04’N 69¹6’05’W], 1973, S.R. Telford;

UF 33903 (3, mm SL), Venezuela, Portuguesa, rio Tucupido em Las Canoas, a montante da represa [0854’31.8’’ 6943'41.6”W], 18-III-1982, D. C. Taphorn et al.

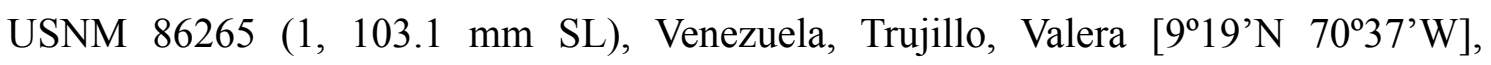
unknown date, H. Pittier;

USNM 101611 (1, 115.0 mm SL), Colômbia, Norte de Santander, rio Pamplonita, próximo a Cucuta [rio Pamplonita $08^{\circ} 20^{\prime} \mathrm{N} 72^{\circ} 27^{\prime} \mathrm{W}$, tributário rio Zulia, sistema do Lago Maracaibo], 1935, M. Nicéforo;

USNM 121401 (1, 39.8 mm SL), Venezuela, Zulia, rio Cobre, afluente do rio Quinta, afluente do rio La Grita, a jusante de La Grita, sistema do rio Zulia [sistema do rio Catatumbo], 31-III-1942, L. P. Schultz;

USNM 121402 (1, 77.9 mm SL), Venezuela, Trujillo, rio San Pedro na ponte, sistema do rio Motatán, 20-III-1942, L. P. Schultz;

USNM 121403 (2, 107.9-127.9 mm SL), Venezuela, Trujillo, Río San Juan na ponte, sistema do rio Motatán, bacia do lago Maracaibo, 20-III-1942, L. P. Schultz;

USNM 121404 (2, 85.7-96.2 mm SL), Venezuela, Mérida, rio Barregas a jusante de Ejido, afluente do rio Chama. [Ejido $08^{\circ} 33^{\prime}$ N $71^{\circ} 14^{\prime}$ W], 29-III-1942, L. P. Schultz;

USNM 123758 (1, 148.0 mm SL), Colômbia, Note de Santander, Salazar, 60 Km a oeste de cúcuta $\left[07^{\circ} 46^{\prime} 16^{\prime \prime} \mathrm{N} 72^{\circ} 48^{\prime} 39^{\prime \prime W}\right], 12-\mathrm{X}-1936$, M. Niceforo;

USNM 346902 (3/5, 14.2-15.6 mm SL), Venezuela, Falcon, rio Mitarem, Serra de San Luis, antiga estrada entre Cabare e San Luis, 440 m elev., $11^{\circ} 06^{\prime} \mathrm{N} 69^{\circ} 38^{\prime} \mathrm{W}$, unknown date, R. Suarez \& M. Campo.

Diagnose. Lebiasina erythrinoides difere de Lebiasina bimaculata, L. aff. bimaculata I, L. aff. bimaculata II, L, boruca, L. festae e $L$. aff. festae por não apresentar a parede da câmara posterior da bexiga natatória “celular", por apresentar as escamas da quinta série longitudinal com tecido epitelial hipertrofiado nos machos adultos e por não apresentar escamas com intensa deposição de guanina (vs. parede da bexiga natatória “celular", escamas da sexta série longitudinal modificadas em machos adultos, ao menos a quarta escama da linha lateral com intensa deposição de guanina). A espécie difere das demais 
congêneres (exceto L. floridablancaensis) por apresentar a primeira série longitudinal de escamas estendendo-se até a base da nadadeira caudal e 14 escamas circumpedunculares. Adicionalmente, a espécie difere de Lebiasina sp. "Curuá-Pinta" por apresentar faixas longitudinais e mancha caudal, e não apresentar manchas escuras na base das escamas da segunda à quinta séries longitudinais (vs. faixas longitudinais e mancha caudal ausentes; manchas escuras presentes na base das escamas da segunda à quinta séries longitudinais). Lebiasina erythrinoides difere de L. taphorni, L. unitaeniata, L. uruyensis, L. yuruaniensis e L. sp. "Parima" pela faixa secundária passando ao longo das escamas da primeira e segunda séries longitudinais, ausência da faixa "intermediária" e pela mancha caudal alcançar o pedúnculo caudal anteriormente (vs. faixa secundária passando ao longo das escamas da segunda e terceira séries longitudinais, faixa "intermediária" presente; mancha caudal não alcançando o pedúnculo caudal anteriormente). A espécie difere de Lebisina astrigata, L. aureoguttata, L. chocoensis, L. colombia, L. floridablancaensis, L. multimaculata, L. ortegai e L. panamensis por não apresentar uma série longitudinal de manchas arredondadas distribuídas ao longo das escamas da quarta série longitudinal (vs. série longitudinal de manchas arredondadas distribuídas ao longo das escamas da quarta série longitudinal). Distingue-se ainda de Lebisina astrigata, L. aureoguttata, L. chocoensis, L. colombia, L. floridablancaensis e L. multimaculata por apresentar a faixa primária conspícua, estendendo-se ao longo de praticamente todo o corpo (vs. faixa primária inconspícua em Lebisina astrigata, L. aureoguttata, L. chocoensis e L. multimaculata; apenas a porção anterior da faixa primária conspícua em L. colombia; apenas a porção posterior da faixa primária conspícua em L. floridablancaensis). Lebiasina erythrinoides difere de L. elongata e L. sp. "Curuá-Faixa" por apresentar o antorbital distintamente mais alto que largo ( $v s$. antorbital tão longo quanto alto). A espécie difere ainda de $L$. sp. "Curuá-Faixa" e também de L. intermedia pela ausência de uma ou mais séries longitudinais de manchas escuras situadas ventralmente à faixa primária; faixa primária não alcançando a mancha caudal posteriormente (vs. uma a três séries longitudinais de manchas escuras situadas ventralmente à faixa primária; faixa primária alcançando a mancha caudal posteriormente). Adicionalmente, L. erythrinoides pode ser diferenciada de L. sp. "Curuá-Faixa” por apresentar a lâmina dorsal do mesetmóide em forma de " $\mathrm{T}$ " e o ramo palatino do nervo facial percorrendo a margem lateral do vômer 
(vs. lâmina dorsal do mesetmóide arredondada; ramo palatino do nervo facial transpassando a superfície ventral do vômer).

Descrição. Dados morfométricos apresentados na tabela 9. Corpo comprimido e alongado. Perfil dorsal da cabeça e do corpo convexo do lábio superior até até a origem da nadadeira dorsal, tornando-se praticamente reto entre os parietais e a origem da dorsal. Perfil reto na base da dorsal e levemente côncavo posteriormente até a origem dos raios pró-correntes da nadadeira caudal. Perfil ventral da cabeça e tronco convexo desde o lábio inferior até a origem da nadadeira pélvica, reto deste ponto até a origem da nadadeira anal, convexo ao longo da base da a base da anal e côncavo dali até a origem dos raios pró-correntes ventrais da nadadeira caudal.

Espécie discretamente prognata, boca subsuperior. Maxilar alcançando a margem anterior da órbita. Apenas uma série de 9 (1), 10 (10), 11 (13) ou 12 (1) dentes tricúspides decrescendo posteriormente no pré-maxilar. Maxilar com 5 (2), 6 (6), 7 (9), 8 (3), 9 (4), 10 (3) ou 11 (1) dentes tricuspidados. Dentário com duas séries de dentes: 11 (1), 12 (2, 13 (4), 14 (4), 15 (5) ou 16 (4) dentes tricúspides pedunculados com a cúspide central distintamente mais longa que as cúspides laterais na série externa, dentes decrescendo gradualmente posteriormente; série interna com dentes diminutos, na maioria, cônicos (podendo ser tricúspides posteriormente) estendendo-se desde a sínfise até próximo ao processo coronóide. Raios-branquiostégios 4, três articulando com o ceratobranquial anterior e 1 com o ceratobranquial posterior.

Escamas ciclóides, circuli restritos à borda da escama, diversos radii (aproximadamente 26) convergindo para o centro da escama, fortemente anastomosados no centro, formando numerosas células. Série longitudinal da linha lateral com 31 (2), 32 (16), 33 (15), 34 (7) ou 35 (2) escamas, das quais apenas 4 (1), 5 (6), 6 (36) ou 7 (3) perfuradas. Séries longitudinais entre nadadeiras dorsal e pélvica 7. Escamas pré-dorsais 13 (12), 14 (29) ou 15 (3). Escamas da primeira série longitudinal estendendo-se ao longo de todo o corpo (exceto em raros exemplares onde esta termina anteriormente à nadadeira adiposa). Escamas circumpedunculares 14, exceto em exemplares onde a primeira série de escama não se estende por todo o corpo, que apresentam 12.

Nadadeira peitoral i, 11 (1), 12 (9), 13 (22), 14 (16) ou 15 (1). Ponta da peitoral não alcançando a vertical que passa pela origem da pélvica. Raios da nadadeira pélvica i, 7. Supraneurais 10 (15), 11 (84) ou 12 (23), anteriores aos espinhos neurais dos 
centros vertebrais 5 a 14 (15), 15 (84) ou 16 (23). Nadadeira dorsal ii, 7 (2), iii, 7 (1), ii, 8 (43) ou ii, 9 (1). Primeiro pterigióforo da nadadeira dorsal inserido posteriormente ao espinho neural do centro vertebral 14 (15), 15 (84) ou 16 (23). Margem distal da nadadeira dorsal arredondada quando expandida. Origem da nadadeira dorsal distintamente mais próxima à base da nadadeira caudal que da ponta do focinho. Base do último raio da dorsal distintamente anterior à vertical que passa pela origem da nadadeira anal. Nadadeira anal iii, 8, último raio adnato. Margem distal da nadadeira anal arredondada. Primeiro pterigióforo da nadadeira anal inserido posteriormente ao arco hemal do centro 24 (2), 25 (44), 26 (50) ou 27 (8). Nadadeira adiposa presente. Epurais 2. Nadadeira caudal furcada, lóbulo superior distintamente mais longo que o inferior, ambos arredondados. Raios principais da nadadeira caudal i, 8/i, 8 (1), ii,8 / ii, 6 (1), i, 9/i, 7 (3), i, 9/i, 8 (40). Pró-correntes dorsais 8 (1), 9 (2), 10 (1) ou 11 (1); prócorrentes ventrais 10 (9) ou 11 (1). Vértebras pré-caudais 24 (8) ou 25 (5); vértebras caudais 17 (1) ou $18(12)$.

Colorido. Cor de fundo predominantemente amarela. Coloração escura estendendo-se desde o lábio superior até a porção exposta dos parietais e ao longo da série medial e primeira série de escamas até a origem da nadadeira caudal. Maxilar, ossos circumorbitais e série opercular pouco pigmentados próximo à porção dorsal da cabeça, tornando-se gradualmente amarelada ventralmente; opérculo com uma distinta mancha escura na região médio-inferior. Estreita faixa negra estendendo-se da porção dorsal da órbita, por toda margem dorsal dos infra-orbitais 5 e 6 , do opérculo e da membrana opercular. Lábio inferior intensamente pigmentado; restante da mandíbula e toda porção ventral da cabeça com pigmentação escassa.

Tronco tornando-se gradualmente amarelado ventralmente. Região abdominal amarela, com diminutos cromatóforos entre o istmo e a origem da nadadeira anal. Mancha umeral arredondada, conspícua em indivíduos jovens e, geralmente, indivíduos adultos. Faixa primária estreita, contínua àquela passando pelos infra-orbitais e margem dorsal do opérculo, alcançando a vertical que passa pela origem dos raios pró-correntes da nadadeira caudal. Faixa secundária estendendo-se ao longo da primeira e segunda séries longitudinais de escamas, desde os epoccipitais à extremidade do pedúnculo caudal. Terceira, quarta e quinta séries longitudinais de escamas com sutis manchas escuras na base. Mancha caudal verticalmente alongada na extremidade do pedúnculo 
caudal, estendendo-se à base de 5 a 6 raios medianos da nadadeira caudal. Nadadeiras peitoral, pélvica, anal, adiposa e caudal hialinas. Base dos raios ramificados 2-4 da nadadeira dorsal com uma discreta mancha escura; primeiro ponto de ramificação na porção média dos raios com discretas manchas.

Dimorfismo sexual. Exemplares machos de Lebiasina erythrinoides apresentam o padrão mais difundido de dimorfismo sexual entre as Lebiasina, descrito acima para Lebiasina astrigata.

Distribuição. Sistema do lago Maracaibo, rios Apure e Meta na bacia do rio Orinoco e drenagens costeiras a leste do lago Maracaibo até o sistema do lago Valencia, Venezuela e Colômbia (Fig. 88).

Tabela 9. Dados morfométricos de Lebiasina erythrinoides.

\begin{tabular}{|c|c|c|c|c|c|}
\hline & & & & & \\
\hline & $\mathrm{n}$ & Range & Mean & SD & Holotype \\
\hline Standard length & 112 & $14,2-213,0$ & 89,9 & & \\
\hline \multicolumn{6}{|c|}{ Morphometrics \% of SL } \\
\hline Depth dorsal fin origin & 49 & $17,9-23,9$ & 20,7 & 1,5 & \\
\hline Snout to anal fin origin & 50 & $71,9-78,0$ & 74,6 & 1,4 & \\
\hline Snout to pelvic fin origin & 50 & $47,4-53,8$ & 50,4 & 1,3 & \\
\hline Snout to dorsal fin origin & 50 & $52,0-58,5$ & 54,9 & 1,4 & \\
\hline Dorsal fin origin to caudal base & 50 & $43,4-49,6$ & 46,2 & 1,4 & \\
\hline Dorsal fin length & 50 & $11,0-19,6$ & 13,1 & 1,4 & \\
\hline Dorsal fin base & 50 & $9,3-22,1$ & 19,1 & 2,1 & \\
\hline Adipose fin to caudal peduncle & 50 & $7,4-10,1$ & 8,8 & 0,6 & \\
\hline Length caudal peduncle & 50 & $13,5-18,5$ & 15,4 & 1,0 & \\
\hline Depth caudal peduncle & 50 & $9,7-12,1$ & 10,7 & 0,6 & \\
\hline Anal fin length & 50 & $17,2-22,7$ & 19,2 & 1,5 & \\
\hline Anal fin base & 50 & $8,7-13,9$ & 10,6 & 1,2 & \\
\hline Pelvic- to anal fin origin & 50 & $21,3-30,2$ & 25,0 & 1,6 & \\
\hline Pelvic fin length & 50 & $11,9-15,6$ & 13,8 & 0,9 & \\
\hline Pectoral to pelvic fin origin & 50 & $25,8-31,7$ & 28,4 & 1,5 & \\
\hline Pectoral fin length & 50 & $14,1-19,5$ & 16,5 & 1,1 & \\
\hline Snout to pectoral fin origin & 50 & $19,0-26,1$ & 22,7 & 1,5 & \\
\hline Bony head length & 50 & $20,4-27,4$ & 23,9 & 1,5 & \\
\hline \multicolumn{6}{|c|}{ Morphometrics \% of HL } \\
\hline Head width & 50 & $50,9-72,0$ & 56,7 & 4,3 & \\
\hline Horizontal eye diameter & 50 & $16,2-31,8$ & 25,1 & 3,8 & \\
\hline Distance snout tip to eye & 50 & $25,1-32,3$ & 27,9 & 1,7 & \\
\hline Interorbital distance & 50 & $31,9-38,7$ & 35,2 & 1,7 & \\
\hline Length lower jaw & 50 & $37,6-47,3$ & 43,6 & 2,0 & \\
\hline Length upper jaw & 50 & $0,0-37,3$ & 2,8 & 9,8 & \\
\hline
\end{tabular}




\section{Lebiasina festae (Boulenger)}

(Figura 89)

Piabucina festae Boulenger, 1899: 1.- Eigenmann, 1912.- Meek \& Hildebrand, 1916: 299 [Key to the species of Piabucina in Panamá]; 300 [synonymy; habits; distribution].Eigenmann, 1920a: 16 [distribution; "Tuyra basin, Panama" - this species occurs from the pacific drainages in San Blas, Panamá to the rio Dagua basin].- Eigenmann, 1923a: 126 [key to the species of Piabucina; synonymy; brief description].- Eigenman, 1923b.Barbour, 1923 [MCZ 32829].- Breder, 1927: 116 [first description of the dark dorsal-fin blotch; habitats; reproductive season based in the juveniles]; 117 [feeding habits]; 145-151 [localities description and other species collected].- Myers, 1928: 4-5 [correction to Eigenmann, 1923a identifications].- Hildebrand, 1938: 286 [L. festae and L. panamensis as closely related species]; 288 [reconsideration of the distribution given in Meek \& Hildebrand, 1916, after Eigenmann, 1923 wrong identifications].- Fowler, 1939: 3 [synonymy; color pattern description].- Weitzman, 1964.- Weitzman, 1966.Loftin, 1966: 115 [distribution; comments on Eigenmann, 1923; biogeographic theory to explain the distribution of the three lebiasinins in Central America].- Bussing, 1967: 220 [comparisons between L. festae and L. boruca].- Machado-Allison, 1974: 582 [diversity of Lebiasininae].- Weitzman \& Cobb, 1975.- Graham et al., 1977 [airbreathing in L.festae].- Graham et al., 1978 [comparisons between breathing phisiology of L. festae and L. panamensis].- Sellick, 1983.- Bussing, 1998: 125-126 [distribution incomplete].- Eschmeyer, 1998: 576 [catalog].- Weitzman \& Weitzman, 2003: 246 [checklist].

Piabucina panamensis (non Gill).- Eigenmann, 1920b: 07 [discussion on the four patterns observed by Eigenmann on the species common to the San Juan and Atrato rivers "B. Those common north of the Atrato which find their furthest south in the San Juan, and which probably migrated south"].- Eigenmann, 1923a: 127 [Eigenmann lists several lots of Piabucina, but all of them are in fact L. festae; except for the syntype depicted in fig. 5, Eigenmann did not examine any specimen of of $L$. panamensis in that occasion]; fig. 4 [large female]. 
Piabucina spp.- Román-Valencia \& Acero, 1992: 122 [even though the authors do not distinguish the species collected in the coast of Antioquia, it is possible to infer those are likely to be L. festae and L. chocoensis, based in their distribution pattern. The coastal rivers seem to be more closely related to the Atrato, since the area seems to be isolated from the remaining systems by the Serrania de Darién and Serrania de Abibe"].

Lebiasina festae.- Géry, 1977: 112 [figure in the bottom, specimen from rio Calima, Colombia]; 127 [key to the species of Lebiasininae].- Román-Valencia, 1990: 204 [checklist].

Série-tipo. MZUT, 1591.

Localidade-tipo. Laguna della Pita, Darien, Panama.

\section{Material examinado.}

ANSP 84264 (2, 95.7-110.5 mm SL), [Colômbia, Chocó] Buenaventura [03²5’44.9”N $77^{\circ}$ 3'10.4’W], río Dagua, Aug 1939, W. S. Thomas;

CAR 15-04-12 (1, 104.5 mm SL), Colombia, Valle del Cauca, Reserva Florestal Escalarete, Rio Escalarete, 18-XI-1975, José Saulo Usma;

CAR 15-04-41 (9, 70.9-138.3 mm SL), Colombia, Chocó, Rio Cabi, próximo à ponte [0540'52”N 7640'15”W], 02-I-2003, C. Ardila-Rodriguez;

CAR 137 (8/10, 30.9-118.0 mm SL), Colombia, Chocó, Andagoya [0506’03.9”N 76²1'43.8”W], Quebrada Afluente Río Condoto, 05-I-2003, C. Ardila-Rodriguez;

CAR 142 (9, 33.2-96.0), Colombia, Chocó, quebrada afluente do Rio Tutunendo [0547’04.4’'N 76³4'6.5”W], 16-VIII-2002, C. Ardila-Rodriguez;

CAR 143 (8, 80.9-130.0), Colombia, Antioquia, Vigia del Fuerte [06 $35^{\prime} 48.8^{\prime \prime} \mathrm{N}$ 7653'10.0”'W], 01-II-2004, J. C. Minota Córdoba;

CAR 148 (2, 78.6-84.4 mm SL), Colombia, Chocó, Yuto, Quebrada la [Doña] Josefa, 18-IX-2005, C. Ardila Rodriguez;

CAR 202 (9/11, 63.6-112.6 mm SL), Colombia, Chocó, Quibdó [0540’52”N 76²'15”W], quebrada afluente do rio Cabi, 06-I-2003, C. Ardila-Rodriguez;

CAR 203 (7, 93.8-139.5 mm SL), Colombia, Chocó, Andagoya [0506’03.9”N $\left.76^{\circ} 41^{\prime} 43.8^{\prime \prime} \mathrm{W}\right]$, quebrada afluente do Río Condoto, 05-I-2003, C. Ardila-Rodriguez; 
CAR 204 (3, 92.9-116.0 mm SL), Colombia, Chocó, Condoto, Quebrada Andrea, Tributário do Río Condoto, 13-VII-2002, C. Ardila-Rodriguez;

CAR 453 (2, 84.6-124.2 mm SL), Colombia, Chocó, Corregimiento de Tutunendo, Quidbó, 2, 14-VII-2002, J. C. Minota Córdoba;

CAR 454 (1, 127.2 mm SL), Colombia, Chocó, Comunidade Munguidó, 1-XII-2002, J. C. Minota Córdoba;

CAR 481 (10/11, 35.8-53.7 mm SL), Colombia, Chocó, Rio Cabi [0540’52”N 76²'15”W], afluente do rio Atrato, 13-XII-2002, J. C. Minota Córdoba;

CAS 66982 (6, 50.5-73.9 mm SL), Panamá, Darién, Yaviza [08¹0’18.4”N 7741'10.3”W], 19-IX-1967, C. Cavalier;

CAS 70961 (4, 33.2-123.1 mm SL), Colombia, Chocó, rio Raspadura [05¹6’00”N 76²'00”W], em Raspadura, ao norte do Río San Juan, bacia do rio Atrato, unknown date, C. H. Wilson;

CAS uncat (IU 13067) (36, 58.8-79.9 mm SL), Truando [rio Truando, Chocó, Colômbia: 0709’02.8”N 77¹2'19.1”W], 1913, C. H. Wilson;

IAvH-P 4731 (2, 110.0-112.9 mm SL), Colombia, Chocó, Condoto, Quebrada Andrea tributario río Condoto, 2, 14-VII-06, C. Ardila-Rodriguez;

IAvH-P 6292 (1, 88.2 mm SL), Colombia, Chocó, Yuto [05³2’52.5”N 76³8’7.5”W], Quebrada cuenca río Atrato, 25-VI-08, Chaverra \& Cuesta;

IAvH-P 6293 (1, 85.3 mm SL), Colombia Chocó, Yuto [05³2’52.5”N 76³8’7.5”W], Poseta de agua Quebrada Doña Josefa, 28-IX-08, Chaverra \& Cuesta;

IAvH-P 6324 (1, 97.1 mm SL), Colombia, Chocó, Yuto [05³2’52.5”N 76³8’7.5”W], Poseta de agua Quebrada Doña Josefa, 28-XI-08, Chaverra \& Cuesta;

IAvH-P 6330 (1, 112.5 mm SL), Colombia, Chocó, Yuto [05³2’52.5’N 76³8’7.5”W], Quebrada cuenca río Atrato, 25-VI-08, Chaverra \& Cuesta;

IAvH-P 6331 (1, $98.1 \mathrm{~mm}$ SL), Colombia, Chocó, Yuto, Río Yuto [05³1’00”N 76³9’00’W], 26-VI-08, Chaverra \& Cuesta;

IAvH-P 6332 (2, 91.3-107.1 mm SL), Colombia, Chocó, Yuto, Quebrada Doña Josefa, 27-IX-08, Chaverra \& Cuesta;

IAvH-P 6333 (1, 99.5 mm SL), Colombia, Chocó, Yuto, Río Yuto [05³1’00”N 76³9’00”W], 24-VIII-08, Chaverra \& Cuesta;

IAvH-P 6334 (5, 108.3-126.6 mm SL), Colombia, Chocó, Yuto, Río Yuto [05³1’00”N 76³9’00’W], 24-VIII-08, Chaverra \& Cuesta; 
IAvH-P 7455 (1, 120.9 mm SL), Colombia, Chocó, Yuto, canal de irrigação e drenagem proveniente da quebrada Tendal, vereda Sautata, unknown date, Maldonado et al.;

ICNMHN 117 (4, 94.6-128.6 mm SL), Colombia, Chocó, Amparraidó [Alto Baudó: 05³2’00”N 7700’00”W], [Rio] Baudó, XI-1959, G. Dahl;

ICNMHN 153 (15, 80.1-110.3), Colombia, Chocó, río San Juan, região Noanamá [0441'24’N 7655'48’W], 30-X-1987, C. Román-Valencia \& E. Puentes;

ICNMHN 225 (1, 54,3 mm SL), Colombia, Chocó, Quebrada pequena, próximo à boca do Sipí [desembocadura do rio Sipí: 0444’56”N 7651'29”W; mun. Sipí: 04³9'11.3”N 76³8'00.4’W], G. Galvis, M. Camargo;

ICNMHN 1603 (6, 52.8-105.3 mm SL), Colombia, Chocó, Quebrada yeasca grande, Cuenca del Río Atrato, Quibdó, 6, 7-IX-1959, G. Dahl;

ICNMHN 2101 (1, 86.7 mm SL), Colombia, Chocó, Rio Cabi, afluente del Rio Atrato, puente Cabi [0540’52”N 7640’15”W], 1, 27-III-1994, L. F. Jimenez \& M. Camargo;

ICNMHN 3604 (5, 70.6-105.5), Valle del Cauca, Colombia, Río Dagua, Cuenca del Pacífico, Buenaventura $\left[03^{\circ} 25^{\prime} 44.9^{\prime} \mathrm{N} 77^{\circ}\right.$ 3'10.4”W], 5, 5-I-2003, C. ArdilaRodriguez;

ICNMHN 5316 [1, 102.1 mm SL), Colombia [Chocó], Río Dagua, unknown date and collector;

MCZ 30940 (ex-IU 13067?) (10, 61.9-70.6 mm SL), Truando [rio Truando, Chocó, Colômbia: $07^{\circ} 09^{\prime} 02.8^{\prime} \mathrm{N} 77^{\circ} 12^{\prime} 19.1$ 'W], unknown date and collector;

MCZ 32829 (5, 52.6-67.0 mm SL), [Panamá, Dárien] río Esnape, afluente do rio Taimiti [Rio Taimati 0808'14.1’N 78¹4'18.1’W], 05-III-1922, T. Barbour \& W. S. Brooks;

MNRJ 14542 (1 c\&s, mm SL), Panamá, Darién, rio Yape [0806’58.7”N 77³4’45.4”W], bacia do rio Tuira, 25-III-1995, E. Birmingham;

MNRJ 14543 (1, 124.6 mm SL), Panamá, Darién, rio Iglesia [08²4’00”N 7800’00”W], bacia do rio Tuira, 28-I-1995, E. Birmingham;

MZUSP 23105 (1, 29.4 mm SL), Panamá, Panamá, Rio Pacora [0901'43.3”N 79¹7'13.1’W], XI-1965, H. A. Bristki;

MZUT 1591 Holótipo (1, 134.4 mm SL), Panamá, Darién, laguna Della Pita [laguna Matusagratí $08^{\circ} 20^{\prime} \mathrm{N} 77^{\circ} 56^{\prime} \mathrm{W}$, ciénega na desembocadura do rio Tuira], unknown collection date, E. Festa;

NRM 35875 (3, 58.5-78.1 mm SL), Panamá, Darién, Yaviza, tributário do rio Tupisa, 8.200556, -77.68806 [08¹1'59.9’N 7741'17.3”W], 7-II-1996, A. Stalsberg; 
NRM NNN/1938809.3687 (1, 83.0 mm SL), [Colombia] Chocó. Río Tadocito [05¹6’00’N 76³2’00”W], afl upper río San Juan, 1938, G. Gerring;

NRM SOK/1989080.6043 (2, 78.4-140.1 mm SL), [Colombia] Chocó, Río Baudó

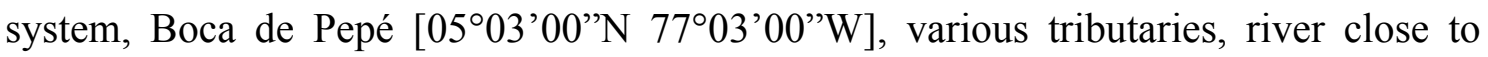
village, unknown date and collector;

USNM 76965 (IU 13067) (24, 50.9-74.3 mm SL) Truando [rio Truando, Chocó, Colômbia: 0709’02.8’'N 77²12'19.1’W], 1913, C. Wilson;

USNM 78641 (1, 107.8 mm SL), [Panama, Dárien] Río Yape [0806’58.7’N 77³4'45.4’W], 6-III-1912, S. E. Meek and S. F. Hildebrand;

USNM 78642 (2, 88.9-90.6 mm SL), [Panama, Dárien] Río Santiganti, Caña, 02III-1912, S. E. Meek and S. F. Hildebrand;

USNM 78643 (1, 130.7 mm SL), [Panama, Dárien] Río Aruza [0806’21.9”N 77³6’00.6’W], Aruza, 26-II-1912, S. E. Meek and S. F. Hildebrand;

USNM 78644 (7, 48.0-84.5 mm SL), [Panama, Dárien] Río Santiganti, Caña, 01III-1912, S. E. Meek and S. F. Hildebrand;

USNM 78645 (1, $125.0 \mathrm{~mm}$ SL), [Panama, Dárien] Río Cupe [0803’00”N 77³5'00’W], Cituro, 25-II-1912, S. E. Meek and S. F. Hildebrand.

USNM 78646 (12/14, 67.8-113.5 mm SL), [Panama, Dárien] Río Aruza [0806’02.8’N 77³6’28.7’'W], Aruza, 27-II-1912, S. E. Meek and S. F. Hildebrand;

USNM 167795 (IU 13067) (7, 59.8-66.3 mm SL), Truando [rio Truando, Chocó, Colômbia: 0709’02.8”N 77²12'19.1”W], 1913, C. Wilson;

USNM 216848 (1, 85.1 mm SL), [Panamá, Panamá] Pequeno riacho próximo ao rio Tocumen [0902'1.23’N 79²3'57.4”W], na Finca Tocuman, a aprox. 20 km E Panama City, 07-IV-1975, D. Kramer;.

USNM 216860 (3, 83.2-108.5 mm SL), [Panamá, Panamá] Pequeno riacho próximo ao rio Tocumen [0902'1.23”N 79²3'57.4”W], na Finca Tocuman, a aprox. $20 \mathrm{~km} \mathrm{E}$ Panama City, 07-IV-1975, D. Kramer;

USNM 293148 (5, 30.8-58.5 mm SL), [Panamá] Darien, Quebrada Corotú [0803'30.43”N 78²3'30”W?] $3 \mathrm{~km}$ from Garachine [08 04'00”N 78²2’00”W] (afl Golfo de San Miguel), 13-II-1985, J. Lundberg et al.;

USNM 293153 (2, 62.9-64.6 mm SL), [Panamá, Dárien] rio Meteti (afl Chucunaque) na rodovia Pan-Americana, aprox. 40 km NW de Yaviza, 08³0’ N 7758’ W, 24-II-1985, W. C. Starnes et al.; 
USNM 310904 (2, 28.9-85.7), [Panama, Dárien] Río Tuira at El Real [0807’48.8’N 7743’38.6”W], $08^{\circ} 11^{\prime} \mathrm{N} 77^{\circ} 41^{\prime} \mathrm{W}, 24-27-\mathrm{II}-1967, \mathrm{~N}$. W. Battelle;

Diagnose. Lebiasina festae diferencia-se de Lebiasina astrigata, L. aureoguttata, L. chocoensis, L. colombia, L. elongata, L. erythrinoides, L. floridablancaensis, L. intermedia, L. multimaculata, L. ortegai, L. panamensis, L. taphorni, L. unitaeniata, L. uruyensis, L. yuruaniensis, L. sp. Azuay, L. sp. “Curuá-Faixa”, L. sp. “Curuá-Pinta” e L. sp. "Parima" pelas seguintes características: parede da câmara posterior da bexiga natatória "celular"; escamas da sexta série longitudinal modificadas em machos adultos, ao menos a quarta escama da linha lateral com intensa deposição de guanina (vs. parede da bexiga natatória não "celular"; modificações nas escamas da quinta série longitudinal nos machos adultos; escamas sem intensa deposição de guanina). A espécie distingue-se de Lebiasina bimaculata, L. aff. bimaculata I e L. aff. bimaculata II por apresentar dentes com a cúspide central distintamente mais longa que as laterais e dentes no endopterigóide ( $v s$. dentes com as cúspides laterais quase tão desenvolvidas quanto a cúspide central e por não apresentar dentes no endopterigóide). Lebiasina festae difere de $L$. boruca e $L$. aff. festae pela ausência do pós-cleitro 3 (vs. pós-cleitro 3 presente). A espécie difere ainda de L. boruca por apresentar apenas a quarta escama da linha lateral com intensa deposição de guanina e uma discreta mancha escura na porção proximal dos raios anteriores da nadadeira dorsal ( $v s$. duas a três séries longitudinais de escamas apresentando depósito de guanina; conspícua mancha escura na porção proximal dos raios posteriores da nadadeira dorsal). L. festae difere ainda de Lebiasina aff. festae pela ausência de uma mancha arredondada na base da nadadeira caudal e a ausência de um processo na porção anterior do opérculo, onde se insere parte do dilatator operculi (vs. mancha caudal presente; margem anterior do opérculo com um processo ósseo onde se insere parte do dilatator operculi).

Descrição. Dados morfométricos apresentados na tabela 10. Corpo comprimido e alongado. Perfil dorsal da cabeça distintamente convexo do lábio superior até até a origem da nadadeira dorsal. Perfil reto na base da dorsal e levemente côncavo posteriormente até a origem dos raios pró-correntes da nadadeira caudal. Perfil ventral da cabeça e tronco convexo desde o lábio inferior até a origem da pélvica, reto deste 
ponto até a origem da nadadeira anal, convexo na base da anal e côncavo do término da anal até a origem dos pró-correntes ventrais da nadadeira caudal.

Espécie discretamente prognata, boca terminal. Maxilar quase alcançando a margem anterior da órbita. Apenas uma série de 11 (8), 12* (22), 13 (6), 14 (9) ou 15 (1) dentes tricúspides decrescendo posteriormente no pré-maxilar. Maxilar com 3 (1), 4 (2), 5 (20), 6 (11), 7* (11), 8 (3) ou 9 (1) dentes tricuspidados. Dentário com duas séries de dentes: 12 (18), 13 (4), 14 (6), 15 (6) ou 16* (4) dentes tricúspides pedunculados com a cúspide central distintamente mais longa que as cúspides laterais na série externa, série interna com dentes diminutos, na maioria, cônicos (podendo ser tricúspides posteriormente) estendendo-se desde a sínfise até próximo ao processo coronóide. Raios-branquiostégios 4, três articulando com o ceratobranquial anterior e 1 com o ceratobranquial posterior.

Escamas ciclóides, circuli restritos à borda da escama, diversos radii (aproximadamente 18) convergindo para o centro da escama, fortemente anastomosados no centro, formando numerosas células. Série longitudinal da linha lateral com $26^{*}$ (2), 27 (4), 28 (21) ou 29 (16) escamas, das quais apenas 4 (3), 5 (23) ou 6 (14) são perfuradas. Séries longitudinais entre a nadadeira dorsal e a pélvica 7. Escamas prédorsais 11 (1), 12 (7) ou 13 (34). Escamas da primeira série longitudinal alcançando a vertical que passa pela origem da nadadeira anal. Escamas circumpedunculares 12.

Nadadeira peitoral i, 12 (3), 13 (22), 14 (17) ou 15 (2). Ponta da peitoral não alcançando a vertical que passa pela origem da pélvica. Raios da nadadeira pélvica i, 7. Supraneurais 9, 10 ou 11 anteriores aos espinhos neurais dos centros 5 a 13 (2), 14 (42) ou 15 (44). Nadadeira dorsal ii, 7 (1) ou ii, 8 (42). Primeiro pterigióforo da nadadeira dorsal inserido posteriormente ao espinho neural do centro 13 (2), 14 (42) ou 15 (44). Margem distal da nadadeira dorsal arredondada quando expandida. Origem da nadadeira dorsal distintamente mais próxima à base da nadadeira caudal que da ponta do focinho. Base do último raio da dorsal distintamente anterior à vertical que passa pela origem da nadadeira anal. Nadadeira anal iii, 8 (42) ou iii, 9 (1), último raio adnato. Margem distal da nadadeira anal arredondada. Primeiro pterigióforo da nadadeira anal inserido posteriormente ao arco hemal do centro 22 (2), 23 (25), 24 (73) ou 25 (6). Nadadeira adiposa presente. Dois epurais. Nadadeira caudal furcada, lóbulo superior discretamente mais longo que o inferior, ambos arredondados. Raios principais da nadadeira caudal i, 9/i, 8. Pró-correntes dorsais 8 (3) ou 9* (3); pró-correntes ventrais 8 
(4) ou 9* (2). Vértebras pré-caudais $22 *(1), 23$ (4) ou 24 (1); vértebras caudais $16^{*}$ (5) ou $17(1)$.

Colorido. Cor de fundo predominantemente amarela. Coloração escura estendendo-se desde o lábio superior até a porção exposta dos parietais e ao longo da série medial e primeira série de escamas até a origem da nadadeira caudal. Maxilar, ossos circumorbitais e série opercular pouco pigmentados próximo à porção dorsal da cabeça, tornando-se gradualmente amarelados ventralmente e com discreta deposição de guanina. Lábio inferior pouco pigmentado; restante da mandíbula e toda porção ventral da cabeça com pigmentação escassa.

Tronco tornando-se gradualmente amarelado ventralmente. Região abdominal amarela, com diminutos cromatóforos entre o istmo e a origem da nadadeira anal. Mancha umeral arredondada, conspícua em indivíduos jovens, porém inconspícua ou ausente em indivíduos adultos. Faixa primária ampla, percorrendo as escamas da terceira, quarta e quinta séries longitudinais, estendendo-se da região umeral até a vertical que passa pela origem dos raios pró-correntes da nadadeira caudal, tornando-se conspícua apenas a partir da oitava escama da série da linha lateral. Faixa secundária estendendo-se ao longo da primeira e segunda séries longitudinais de escamas, desde os epoccipitais à vertical que passa pela metade da nadadeira dorsal. Escamas sem intensa deposição de guanina, com exceção da quinta escama da série da linha lateral. Base da dorsal distintamente mais escura que o dorso. Mancha caudal ausente. Nadadeiras peitoral, pélvica, anal, adiposa e caudal hialinas. Porção proximal dos quatro raios ramificados mais anteriores densamente pigmentados.

Dimorfismo sexual. Exemplares machos de Lebiasina festae apresentam o padrão de dimorfismo sexual semelhante ao descrito para L. bimaculata e L. boruca.

Distribuição. Drenagens costeiras do Oceano Pacífico no Panamá e Colômbia, e no rio Atrato (Figura 82). 
Tabela 10. Dados morfométricos de Lebiasina festae.

\begin{tabular}{lcrccc} 
& $\mathrm{n}$ & Range & Mean & SD & Holotype \\
\cline { 2 - 6 } & 92 & $29,4-139,5$ & 85,3 & & 134,4 \\
Standard length $\quad$ Morphometrics \% of SL & & & & & \\
& 45 & $22,0-30,2$ & 25,7 & 1,5 & 28,0 \\
Depth dorsal fin origin & 46 & $73,2-80,6$ & 78,1 & 1,5 & 77,1 \\
Snout to anal fin origin & 46 & $50,9-56,3$ & 53,9 & 1,3 & 53,6 \\
Snout to pelvic fin origin & 45 & $55,7-61,6$ & 58,5 & 1,2 & 58,8 \\
Snout to dorsal fin origin & 45 & $41,1-47,1$ & 43,4 & 1,0 & 46,4 \\
Dorsal fin origin to caudal base & 46 & $17,1-22,5$ & 20,3 & 1,3 & \\
Dorsal fin length & 46 & $7,6-9,7$ & 8,6 & 0,6 & 9,7 \\
Dorsal fin base & 45 & $10,0-13,4$ & 11,6 & 0,8 & \\
Adipose fin to caudal peduncle & 44 & $12,1-16,0$ & 13,7 & 0,7 & 15,6 \\
Length caudal peduncle & 44 & $12,1-13,8$ & 13,0 & 0,5 & 13,8 \\
Depth caudal peduncle & 45 & $17,9-24,5$ & 20,6 & 1,4 & \\
Anal fin length & 45 & $8,9-14,2$ & 10,6 & 1,2 & 10,9 \\
Anal fin base & 45 & $22,8-28,9$ & 25,0 & 1,3 & 24,5 \\
Pelvic- to anal fin origin & 45 & $14,3-17,3$ & 15,8 & 0,7 & \\
Pelvic fin length & 45 & $26,7-35,0$ & 30,5 & 1,8 & 33,1 \\
Pectoral to pelvic fin origin & 45 & $16,0-21,6$ & 19,9 & 1,3 & \\
Pectoral fin length & 45 & $21,4-26,8$ & 24,5 & 1,4 & 20,8 \\
Snout to pectoral fin origin & 48 & $22,4-28,1$ & 25,9 & 1,3 & 20,0 \\
Bony head length & & & & & \\
& \multicolumn{1}{c}{ Morphometrics \% of HL } & & & & \\
Head width & 48 & $54,5-81,8$ & 61,3 & 4,7 & \\
Horizontal eye diameter & 48 & $20,1-33,0$ & 25,8 & 2,6 & 28,0 \\
Distance snout tip to eye & 48 & $25,6-30,7$ & 28,0 & 1,3 & 23,1 \\
Interorbital distance & 48 & $36,7-45,0$ & 40,2 & 1,4 & \\
Length lower jaw & 48 & $38,3-42,6$ & 40,3 & 1,1 & 44,8 \\
Length upper jaw & 48 & $16,5-35,8$ & 20,9 & 5,4 & 39,2 \\
\hline
\end{tabular}

Lebiasina floridablancaensis Ardila-Rodríguez

(Figura 90)

Lebiasina floridablancaensis Ardila-Rodríguez, 1994.- Ardila-Rodríguez, 1999: 5 [L. provenzanoi description]; 2001 [comparisons between L. floridablancaensis and $L$. chucuriensis].- Maldonado-Ocampo et al., 2005: 94 [field guide; description, biology, ecology, comments and list of specimens in museums].- Mojica et al., 2006: 30 [checklist; museum records].

Lebiasina pleurotaenia (non Regan).- Dahl, 1971: 119-120 [key to the species of Lebiasininae; based in Miles, 1947].

Piabucina pleurotaenia (non Regan).- Miles, 1945: .- Miles, 1947: 166 [color description; habits; sexual dimorphism; common name; collection site; Miles assumed the species invaded the Magdalena drainage from the Maracaibo system, due to the lower altitudes of the Andes near the Magdalena valley].- Loftin, 1966: 115 [inferred 
from distribution; "Still another species, P. pleurotaenia Regan, occurs in the Rio Magdalena.']. Machado-Allison, 1974: 580 [specimens of 'P. pleurotaenia' from the Magdalena system]

Lebiasina chucuriensis Ardila-Rodriguez, 2001.- Maldonado-Ocampo et al., 2005: 92 [field guide; description, biology, ecology, comments and list of specimens in museums].- Mojica et al., 2006: 30 [checklist; museum records].

Série-tipo. Holótipo: CAR 15-04-01. Parátipos: CAR 15-04-02-03 (9); ICN-MHN 1837 (3); ICN-MHN 2605 (4).

Localidade-tipo. El Gaque, Tributário do Rio Aranzoque, Município de Flordablanca, Departamento Santander, Colômbia, elev. 1000 m.

\section{Material examinado.}

BMNH 1947.47.7.1.23-32 (9, 45.9-106.2 mm SL), Colombia. Santander. Bucaramanga, 1000 m elev., vale do rio Magdalena, face leste, unknown collection date, C. Miles;

CAR 15-04-01 holótipo (1, $109.2 \mathrm{~mm}$ SL), Colombia, Santander, Floridablanca [0703'58.9'N 7305'21.3”W], Quebrada el Gaque [alto rio Lebrija], 27-03-1988, C. Ardila-Rodriguez;

CAR 15-04-03 (3, 65.9-86.4 mm SL), Colombia, Santander, Floridablanca [0703'58.9”N 7305’21.3”W], Quebrada el Gaque (Clúsias) [alto rio Lebrija], 05V-1993, C. Ardila-Rodriguez;

CAR 15-04-04 (16, 63.4-138.2 mm SL), Colombia, Santander, Floridablanca [0703'58.9'N 7305'21.3’W], Quebrada los Palmitos, 16, 28-XII-1994, C. ArdilaRodriguez;

CAR 15-04-05 (2, 98.4-105.5 mm SL), Colombia, Santander, Floridablanca $\left[07^{\circ} 03^{\prime} 58.9^{\prime} \mathrm{N} 73^{\circ} 05^{\prime} 21.3^{\prime \prime} \mathrm{W}\right]$, Puente Pantano, margem direita do rio Aranzoque, 06VII-2000, C. Ardila-Rodriguez;

CAR 15-04-23 (2, 105.1-117.9 mm SL), Colombia, Santander, San Vicente de Chucuri [06 53'47.1'N 7325'39.6”'W], quebrada La Carbonera, afluente do rio la Llana, 08VII-2000, C. Ardila-Rodriguez; 
CAR 15-04-24 (1, 114.9 mm SL), Colombia, Santander, San Vicente de Chucuri [06 53'47.1'N 73²5'39.6”'W], quebrada La Carbonera, afluente do rio la Llana, 08VII-2000, C. Ardila-Rodriguez;

CAR 15-04-25 (6, 60.8-122.8 mm SL), Colombia, Santander, San Vicente de Chucuri [0653'47.1'” 73²5’39.6”W], quebrada La Carbonera, afluente do rio la Llana, 6, 3I-2001, C. Ardila-Rodriguez;

CAR 15-04-49 (8/10, 143.4-106.9 mm SL), Colombia, Santander, Girón [0704’18.5”N 73¹0’32.5”W], Quebrada el Palmar, afluente do rio Del oro, 17-XII-2001, C. ArdilaRodriguez, R. Ardila;

CAR 200 (20, 71.1-137.1 mm SL), Colombia, Santander, San Vicente de Chucuri [0653'47.1'N 73²5’39.6”W], quebrada Agua Linda, afluente da Quebrada la Llana, 11-II-2002, C. Ardila-Rodriguez et al.;

CAR 201 (15, 72.0-118.2 mm SL), Colombia, Santander, Quebrada Agua Linda, Afluente da Quebrada la Llana, San Vicente de Chucuri, 11-II-2002, C. ArdilaRodriguez et al.;

CAR 260 (14, 131.2-46.0 mm SL), Colombia, Santander, Lebrija [0707’10.3”N 73¹3'13.6”'W], Vereda Lisboa, afluente do rio Sucio, afluente do rio Lebrija, 03I-2006, C. Ardila-Rodriguez et al.;

CAR 448 (9, 53.2-142.0 mm SL),Colombia, Santander, Quebrada Agua Blanca, afluente da Quebrada la Llana, a 16 km de San Vicente de Chucuri, 11-II-2002, C. Ardila-Rodriguez, Jorge Vera, Javier Castro;

IAvH-P 4729 (2, 90.9-91.0 mm SL), Colombia, Santander, San Vicente de Chucuri [0653'47.1'N 73²5’39.6”W], quebrada Agua Linda, afluente da Quebrada la Llana, 11-II-2002, C. Ardila-Rodriguez et al.;

IAvH-P 4730 (2, 89.2-106.3 mm SL), Colombia, Santander, Girón [0704’18.5”N 73¹0’32.5”W], Quebrada el Palmar, afluente do rio Del oro, 17-XII-2001, C. ArdilaRodriguez, R. Ardila;

ICNMNH 1837 (1, 87.9 mm SL), Colombia, Santander, Floridablanca [0703'58.9'N 7305'21.3”W], Quebrada el Gaque [alto rio Lebrija], 27-III-1988, C. ArdilaRodriguez;

ICNMHN 5313 Paratipos (1/2, Colombia, Santander, San Vicente de Chucuri [06 $53^{\circ} 47.1^{\prime \prime} \mathrm{N} 73^{\circ} 25^{\prime} 39.6^{\prime} \mathrm{W}$, quebrada La Carbonera, afluente do rio la Llana, 1 de 2 , 7-XI-1981, M. Bozeman; 
USNM 123796 (4, 60.7-64.9 mm SL), Colômbia, Santander, Bucaramanga [0706'18.5”N 7307'01.2”W], vertente leste do vale do rio Magdalena, confluência dos rios de Oro e Suratá [0709'31.9”N 7308’35.0”W], tributários do rio Labrija [Lebrija], afluente da margem direita do rio Magdalena. $07^{\circ} 07^{\prime} \mathrm{N} 73^{\circ} 07^{\prime} \mathrm{W}$, unknown date,Cecil Miles;

USNM 88303 (2, 56.6-41.6 mm SL), Colômbia, Santander, Bucaramanga [0706'18.51”N 7307’01.2”W], área alagada, bacia do rio Magdalena, 27-II-1924, H. Hansen;

Diagnose. Lebiasina floridablancaensis difere de Lebiasina bimaculata, L. aff. bimaculata I, L. aff. bimaculata II, L, boruca, L. festae e L. aff. festae por não apresentar a parede da câmara posterior da bexiga natatória "celular", por apresentar as escamas da quinta série longitudinal com tecido epitelial hipertrofiado nos machos adultos e por não apresentar escamas com intensa deposição de guanina ( $v$ s. parede da bexiga natatória "celular", escamas da sexta série longitudinal modificadas em machos adultos, ao menos a quarta escama da linha lateral com intensa deposição de guanina). A espécie difere das demais congêneres (exceto L. erythrinoides) por apresentar a primeira série longitudinal de escamas estendendo-se até a base da nadadeira caudal e 14 escamas circumpedunculares. Adicionalmente, Lebiasina floridablancaensis pode ser diferenciada de Lebiasina sp. "Curuá-Pinta" por apresentar faixas longitudinais e mancha caudal e não apresentar manchas escuras na base das escamas da segunda à quinta séries longitudinais (vs. faixas longitudinais e mancha caudal ausentes; manchas escuras presentes na base das escamas da segunda à quinta séries longitudinais). A espécie difere ainda de Lebiasina elongata, L. erythrinoides, L. intermedia, L. taphorni, L. unitaeniata, L. uruyensis, L. yuruaniensis, L. sp. "Curuá-Faixa" e L. sp. "Parima" por apresentar uma série longitudinal de pequenas manchas arredondadas ( $v s$. série longitudinal de manchas escuras ausente). Lebiasina floridablancaensis difere ainda de L. taphorni, L. unitaeniata, L. uruyensis, L. yuruaniensis e L. sp. "Parima", pela ausência da faixa "intermediária" e pela mancha caudal alcançar o pedúnculo caudal anteriormente ( $v s$. faixa “intermediária” presente; mancha caudal não alcançando o pedúnculo caudal anteriormente). Entre as demais espécies do clado 83, Lebiasina floridablancaensis se diferencia de Lebiasina astrigata, L. aureoguttata, L. colombia, L. chocoensis, L. multimaculata, L. ortegai, L. panamensis e L. sp. Azuay por apresentar 
apenas a porção posterior da faixa primária conspícua ( $v s$. faixa primária conspícua ao longo de todo o corpo em L. ortegai e exemplares adultos de L. panamensis; porção anterior da faixa primária conspícua em L. colombia e exemplares jovens de $L$. panamensis; faixa primária inconspícua em Lebiasina astrigata, L. aureoguttata, L. chocoensis, L. multimaculata e L. sp. Azuay ). A espécie se distingue ainda de $L$. multimaculata e L. chocoensis por apresentar a faixa secundária conspícua, passando pelas escamas da segunda e terceira séries longitudinais (vs. faixa secundária inconspícua estendendo-se ao longo das escamas da primeira e segunda séries longitudinais).

Descrição. Dados morfométricos apresentados na tabela 11. Corpo comprimido e alongado. Perfil dorsal da cabeça e do corpo convexo do lábio superior até até a origem da nadadeira dorsal, tornando-se praticamente reto entre os parietais e a origem da dorsal. Perfil reto na base da dorsal e levemente côncavo posteriormente até a origem dos raios pró-correntes da nadadeira caudal. Perfil ventral da cabeça e tronco convexo desde o lábio inferior até a origem da pélvica, reto deste ponto até a origem da nadadeira anal, convexo na base da anal e côncavo do término da anal até a origem dos pró-correntes ventrais da nadadeira caudal.

Espécie discretamente prognata, boca subsuperior. Maxilar alcançando a margem anterior da órbita. Apenas uma série de 10 (10), 11 (9) ou 12 (2) dentes tricúspides decrescendo posteriormente no pré-maxilar. Maxilar com 5 (2), 6 (6), 7 (6), 8 (4) ou 9 (1) dentes tricuspidados. Dentário com duas séries de dentes: 12 (7), 13, (1), 14 (3), 15 (1) ou 16 (2) dentes tricúspides pedunculados com a cúspide central distintamente mais longa que as cúspides laterais na série externa, série interna com dentes diminutos, na maioria, cônicos (podendo ser tricúspides posteriormente) estendendo-se desde a sínfise até próximo ao processo coronóide. Raiosbranquiostégios 4 , três articulando com o ceratobranquial anterior e 1 com o ceratobranquial posterior.

Escamas ciclóides, circuli restritos à borda da escama, diversos radii convergindo para o centro da escama, fortemente anastomosados no centro, formando numerosas células. Série longitudinal da linha lateral com 30 (5), 31* (10), 32 (15), 33 (9) ou 34 (4) escamas, das quais apenas $4(1), 5^{*}(26)$ ou 6 (16) são perfuradas. Séries longitudinais entre a nadadeira dorsal e a pélvica 7. Escamas pré-dorsais 13 (8), 14* (21) ou 15 (12). 
Primeira série longitudinal geralmente se estendendo por todo o corpo, alcançando o término do pedúnculo caudal, ou pelo menos alcançando a vertical que passa pelo prócorrente dorsal mais anterior. Escamas circumpedunculares 14.

Nadadeira peitoral i, 12 (5), $13(21), 14 *(16)$ ou 15 (1). Ponta da peitoral não alcançando a vertical que passa pela origem da pélvica. Raios da nadadeira pélvica i, 6 (3) ou 1, 7 (40). Supraneurais 11 (12) ou 12 (6) anteriores aos espinhos neurais dos centros 5 a 15 (12) ou 16 (6). Nadadeira dorsal ii, 7 (2), iii, 7 (3), ii, 8* (36) ou iii, 8 (2). Primeiro pterigióforo da nadadeira dorsal inserido posteriormente ao espinho neural do centro 15 (12) ou 16 (6). Margem distal da nadadeira dorsal arredondada quando expandida. Origem da nadadeira dorsal distintamente mais próxima à base da nadadeira caudal que da ponta do focinho. Base do último raio da dorsal distintamente anterior à vertical que passa pela origem da nadadeira anal. Nadadeira anal iii, $8^{*}(42)$ ou iv, 7 (1), último raio adnato. Margem distal da nadadeira anal arredondada. Primeiro pterigióforo da nadadeira anal inserido posteriormente ao arco hemal do centro 24 (1), 25 (8) ou 26 (10). Nadadeira adiposa presente. Epurais 2. Nadadeira caudal furcada, lóbulo superior distintamente mais longo que o inferior, ambos arredondados. Raios principais da nadadeira caudal ii,8/i,8 (5) ou i,9/i,8 (37). Pró-correntes dorsais 9 (3) ou 10 (1); prócorrentes ventrais 8 (1) ou 9 (3) 10 (1). Vértebras pré-caudais 24 (1), 25 (3) ou 26 (1); vértebras caudais 17 (1) ou 18 (4).

Colorido. Cor de fundo predominantemente amarela. Coloração do dorso praticamente de mesma intensidade que o ventre. Maxilar, ossos circumorbitais e série opercular pouco pigmentados próximo à porção dorsal da cabeça, tornando-se gradualmente mais claros ventralmente. Lábio inferior pouco pigmentado; restante da mandíbula e toda porção ventral da cabeça com pigmentação escassa.

Tronco tornando-se gradualmente mais claro ventralmente. Região abdominal amarela, com diminutos cromatóforos entre o istmo e a origem da nadadeira anal. Mancha umeral comparativamente grande, arredondada, conspícua em indivíduos jovens e adultos. Faixa primária difusa, originando-se próximo à vertical que passa pela origem da nadadeira pélvica, percorrendo principalmente as escamas da quarta série longitudinal, até a vertical que passa pela origem da nadadeira adiposa. Faixa primária coberta por 4-5 manchas oblongas, amplas. Manchas anteriores situadas principalmente nas escamas da quarta série longitudinal; última mancha distintamente deslocada 
dorsalmente, situada nas escamas da terceira série longitudinal. Faixa secundária estendendo-se ao longo da terceira série longitudinal de escamas, desde o supracleitro à vertical que passa pela origem da faixa primária. Base da dorsal distintamente mais escura que o dorso. Mancha caudal presente, arredondada, situada na porção distal do pedúnculo, estendendo-se posteriormente, alcançando a base de 4-6 raios medianos da nadadeira caudal. Nadadeiras peitoral, pélvica, anal, adiposa e caudal hialinas. Porção proximal do último raio não ramificado e dos quatro raios ramificados mais anteriores densamente pigmentados; ponto de ramificação dos raios com discreta pigmentação.

Dimorfismo sexual. Exemplares machos de Lebiasina floridablancaensis apresentam o padrão mais difundido de dimorfismo sexual entre as Lebiasina, descrito acima para L. astrigata.

Distribuiçãa. Norte da Colômbia no vale do rio Magdalena. Espécie restrita a pequenos riachos que drenam da Mesa de Ruitoque (Maldonado et al., 2005) no rio Lebrija (alto rio del Oro) e no rio Chucuri (alto rio Sogamoso) (Fig. 88).

Tabela 11. Dados morfométricos de Lebiasina floridablancaensis.

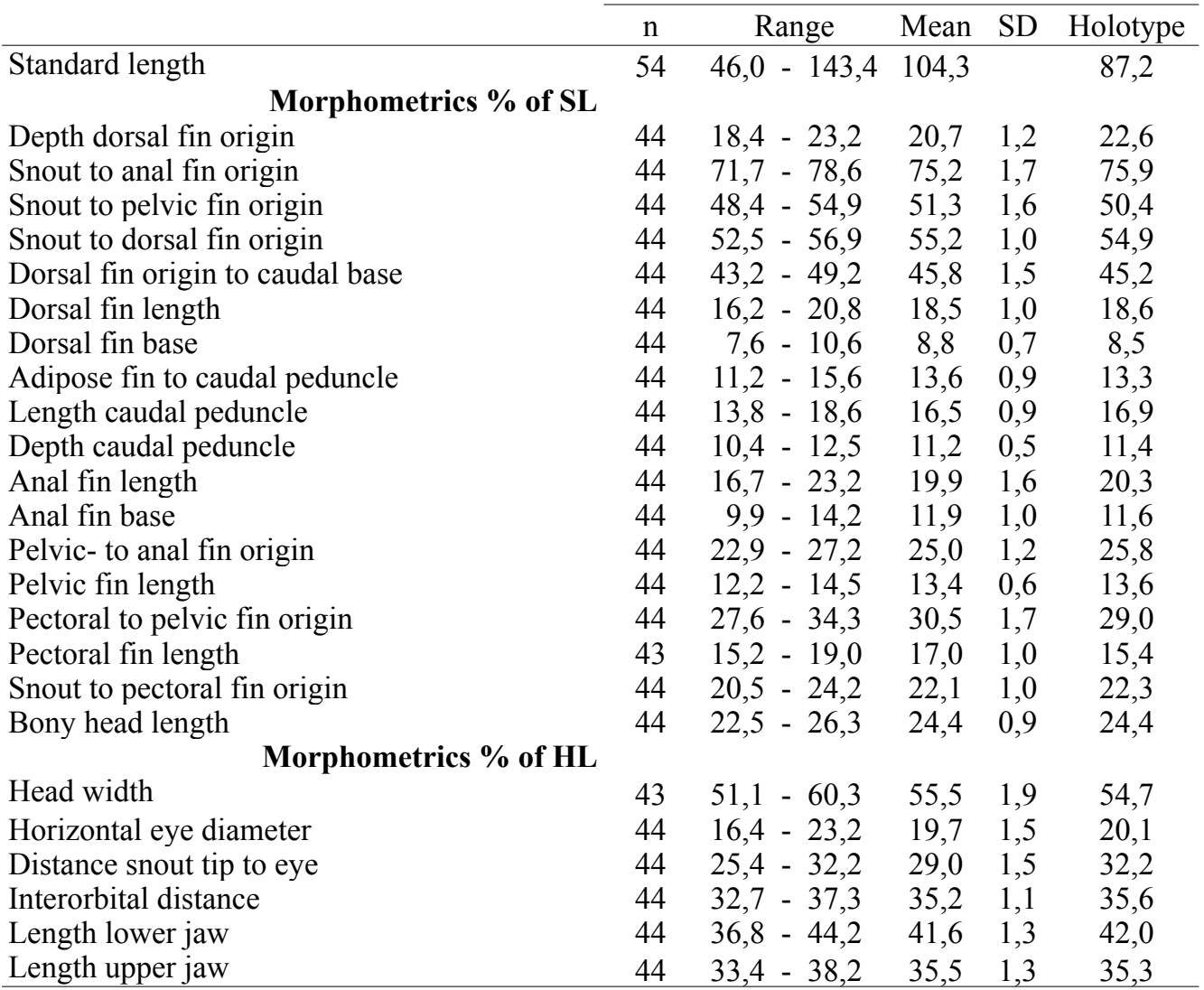




\section{Lebiasina intermedia Meinken}

(Figura 91)

Lebiasina intermedia Meinken, 1937.- Géry, 1977: 123 [distribution pattern of Lebiasininae] Eschmeyer, 1998: 782 [catalog].- Weitzman \& Weitzman, 2003: 243 [checklist]

Série-tipo. Holótipo: KHMM 2156.

Localidade-tipo. Próximo a Santarém, bacia Amazônica, Pará, Brasil. Ver discussão no item "Distribuição".

Material examinado. A espécie era conhecida apenas do holótipo e outros poucos exemplares não depositados em coleção por Meinken. No entanto, o holótipo parece ter sido destruído durante os bombardeios em Magdeburg durante a Segunda Guerra Mundial. Todos os dados acerca desta espécie foram obtidos a partir da descrição original.

Diagnose (Inferida a partir da ilustração original de Meinken e exemplares de $L$. sp. “Curuá-Faixa").

Lebiasina intermedia difere de Lebiasina bimaculata, L. aff. bimaculata I, L. aff. bimaculata II, L, boruca, L. festae e L. aff. festae por não apresentar a parede da câmara posterior da bexiga natatória "celular", por apresentar as escamas da quinta série longitudinal com tecido epitelial hipertrofiado nos machos adultos e por não apresentar escamas com intensa deposição de guanina (vs. parede da bexiga natatória "celular", escamas da sexta série longitudinal modificadas em machos adultos, ao menos a quarta escama da linha lateral com intensa deposição de guanina). A espécie difere de Lebiasina sp. "Curuá-Pinta" por apresentar faixas longitudinais e mancha caudal, e não apresentar manchas escuras na base das escamas da segunda à quinta séries longitudinais (vs. faixas longitudinais e mancha caudal ausentes; manchas escuras presentes na base das escamas da segunda à quinta séries longitudinais). Lebiasina intermedia difere de L. taphorni, L. unitaeniata, L. uruyensis, L. yuruaniensis e L. sp. 
"Parima" pela faixa secundária passando ao longo das escamas da primeira e segunda séries longitudinais, ausência da faixa "intermediária" e pela mancha caudal alcançar o pedúnculo caudal anteriormente ( $v s$. faixa secundária passando ao longo das escamas da segunda e terceira séries longitudinais, faixa "intermediária" presente; mancha caudal não alcançando o pedúnculo caudal anteriormente). A espécie difere de Lebisina astrigata, L. aureoguttata, L. chocoensis, L. colombia, L. floridablancaensis, L. multimaculata, L. ortegai e L. panamensis por não apresentar uma série longitudinal de manchas arredondadas distribuídas ao longo das escamas da quarta série longitudinal (vs. série longitudinal de manchas arredondadas distribuídas ao longo das escamas da quarta série longitudinal). Distingue-se ainda de Lebisina astrigata, L. aureoguttata, L. chocoensis, L. colombia, L. floridablancaensis e L. multimaculata por apresentar a faixa primária conspícua, estendendo-se ao longo de praticamente todo o corpo (vs. faixa primária inconspícua em Lebisina astrigata, L. aureoguttata, L. chocoensis e L. multimaculata; apenas a porção anterior da faixa primária conspícua em L. colombia; apenas a porção posterior da faixa primária conspícua em L. floridablancaensis). Difere de L. elongata, L. erythrinoides e L. sp. "Curuá-Faixa" pela presença de três séries longitudinais de manchas escuras situadas ventralmente à faixa primária (vs. séries longitudinais de manchas escuras ausentes em L. elongata e L. erythrinoides; uma série longitudinal de manchas escuras em $L$. sp. "Curuá-Faixa"). L. intermedia difere ainda de L. elongata e L. erythrinoides por apresentar a faixa primária alcançando a mancha caudal posteriormente (vs. faixa primária não alcançando a mancha caudal) e de $L$. sp. “Curuá-Faixa” pela presença de 32 escamas na série longitudinal e 14 escamas prédorsais, presença da nadadeira adiposa e de manchas escuras no maxilar, infra-orbitais 1 e 2 e na porção proximal dos raios da nadadeira dorsal (vs. 25-26 escamas na série longitudinal da linha lateral; 11 a 12 escamas pré-dorsais; nadadeira adiposa ausente; manchas escuras no maxilar, infra-orbitais e raios da nadadeira dorsal ausentes).

Colorido. Focinho e dorso da cabeça escuros, oliváceos. Opérculo bronze. Próximo à boca os exemplares apresentam uma mancha escura triangular [mancha escura situada no maxilar]. Lábios com bordas escuras, principalmente o inferior. lábio inferior pouco pigmentado, porção ventral da cabeça com brancos. Mancha humeral difusa. Na porção média do corpo está presente uma faixa escura que se estende desde uma mancha escura arredondada até uma mancha escura muito maior na base da caudal. Próximo à 
nadadeira dorsal essa faixa apresenta-se em um ziguezague até a nadadeira adiposa. Raios médios da nadadeira dorsal com uma mancha negra semicircular.

Dimorfismo sexual. Apesar de não serem conhecidos exemplares de Lebiasina intermedia, o padrão de dimorfismo sexual desta espécie possivelmente é o mais difundido entre as espécies de Lebiasininae, já que de acordo com a descrição e a ilustração de Meinken, esta não parece estar proximamente relacionada ao grupo $L$. bimaculata.

Distribuição. Localidade imprecisa "Próximo a Santarém, bacia Amazônica, Pará. Brasil”. Distribuição da espécie desconhecida, entretanto, em recente expedição coleta à Serra do Cachimbo, foram coletados exemplares de Lebiasina sp. Curuá que apresenta padrão de colorido semelhante ao descrito para Lebiasina intermedia, entretanto, esta não apresenta nadadeira adiposa, além de caracteres merísticos e morfométricos. Com base na semelhança entre as duas espécies observada a partir da ilustração fornecida por Meinken, é possível sugerir que L. intermedia e Lebiasina sp. Curuá sejam espéciesirmãs, e os exemplares obtidos por Meinken sejam oriundos de uma drenagem com história geológica compartilhada com a cabeceira do rio Curuá, possivelmente na Serra do Cachimbo (Fig. 92).

Tabela 12. Dados morfométricos de Lebiasina intermedia (retirados de Meinken, 1937).

\begin{tabular}{lc}
\hline Greatest length & 107 \\
Body & 89 \\
Body depth & 20 \\
Width & $13^{1} \frac{1}{2}$ \\
Head & 21 \\
Eye diameter & 4 \\
Snout length & 5 \\
Interorbital & $91 / 2$ \\
Width behind eye & 12 \\
Caudal peduncle length & 13 \\
Caudal peduncle depth & 10 \\
Snout to dorsal fin & 49 \\
Snout to pelvic fin & 46 \\
Snout to anal fin & $681 / 2$
\end{tabular}




\begin{tabular}{lc} 
Snout to pectoral fin & $201 \frac{1}{2}$ \\
Longest dorsal-fin ray & 12 \\
Longest anal-fin ray & $71 \frac{2}{2}$ \\
Longest pelvic-fin ray & 11 \\
Longest pectoral-fin ray & $12^{1} \frac{2}{21}$ \\
Longest ray dorsal caudal lobe & 21 \\
Longest ray ventral caudal lobe & 16 \\
\hline
\end{tabular}

\section{Lebiasina multimaculata Boulenger}

(Figura 93)

Lebiasina multimaculata .- Regan, 1913a: 462 [fish fauna of Río San Juan, Colombia].Eigenmann, 1920a: 16 [ distribution; "Atrato, San Juan basins" - the species does not seem to be in the Atrato river basin, despite the couple specimens from Tambo (CAS 19767)].-Eigenmann, 1920a: 16 [specimens from Río San Juan; those from rio Atrato are Lebiasina chocoensis].- Eigenmann, 1920b: 07 [discussion on the distribution patterns of the species occurring in the San Juan and Atrato basins; Eigenmann considers L. multimaculata as fitting in pattern D: "Those confined to the two (rivers).." although the species does not occur in the Atrato Basin. In addition, L. multimaculata is also present in the Dagua river basin].- Eigenmann, 1922: 123 [key to the species of Lebiasina]; 125 [synonymy; collection records; lots examined herein: IU 12964; IU 12965; brief description; color pattern; discussion on Regan, 1913a, who assigned specimens with adipose to "P. aureoguttata"].- Dahl \& Medem, 1964: 58 [incorrect distribution; L. colombia, Lebiasina chocoensis, L. multimaculata and L. astrigata are the species occurring in that range].- Weitzman, 1962; 1964; 1966.- Dahl, 1971: 119 [key to the species of Lebiasina; distribution (same comment as in Dahl \& Medem, 1964].- Machado-Allison, 1974: 582 [diversity of Lebiasininae].- Weitzman \& Cobb, 1975.- Géry, 1977: 126 [key to the species of Lebiasina].- Eschmeyer, 1998: 1132 [catalog].- Ardila-Rodríguez, 2000: 4 [L. yuruaniensis description].- Weitzman \& Weitzman, 2003: 243 [checklist].- Ardila-Rodríguez, 2008a: 28- 30 [comparisons between L. multimaculata and L. colombia].

Piabucina aureoguttata (non Fowler).- Regan, 1913a: 462 [specimens from Lisa and Tamaná rivers; both belong to the San Juan river basin, to the south of Condoto]. 
Piabucina panamensis (non Regan).-Eigenmann, 1920a: 20 [specimens from Río San Juan].- Fowler, 1944: 227-228 [specimen from Baudó; brief description of color pattern; inferred from distribution].

Série-tipo. Síntipos: BMNH 1910.7.11.167-169 (3).

Localidade-tipo. Río Condoto em Condoto, Departamento Chocó, sudoeste da Colombia, elevação 45 metros.

\section{Material examinado.}

ANSP 45472 (1, 130.9 mm SL), Equador, Guayas, Vinces. [Localidade incorreta], unknown date and collector;

BMNH 1910.7.11:167 Lectótipo (1, 90.4 mm SL), Colômbia, Chocó, Condoto, Río Condoto [0606’00’N 7642’00’W], 45 m elev, III-IV-1909, M. G. Palmer;

CAR 15-04-33 (37, 53.6-90.6 mm SL), Colombia, Chocó, Andagoya [0506’03.9”N $76^{\circ} 41^{\prime} 43.8^{\prime}$ W], Quebrada afluente do Río San Juan, próximo à desembocadura do Río Condoto, 05-I-2003, C. Ardila-Rodriguez;

CAR 15-04-34 (35, 21.6-48.7 mm SL), Colombia, Chocó, Andagoya [0506’03.9’N $76^{\circ} 41^{\prime} 43.8^{\prime \prime W]}$, Quebrada afluente do Río San Juan, próximo à desembocadura do Río Condoto, 05-I-2003, C. Ardila-Rodriguez;

CAR 138 (5, 52.9-103.7 mm SL), Colombia, Chocó, Opogodó [5³’0’N 76³9’0’W], Rio Opogodó, próximo ao balneário, 15-X-2006, C. Ardila-Rodriguez;

CAR 139 (13, 21.7-118.3 mm SL), Colombia, Chocó, a aproximadamente $3 \mathrm{~km}$ depois do povoado de Tadó $\left[05^{\circ} 15^{\prime} 25.2^{\prime} \mathrm{N}\right.$ 76³'12.9'W] pela via Pereira, 14-X-2006, C. Ardila-Rodriguez;

CAR 141 (4, 67.5-134.4 mm SL), Valle del Cauca Colombia, Río San Juan, Puerto Pizário, Buenaventura, 4, 16-VIII-2002, unknown collector;

CAR 144 (6, 42.9-131.3 mm SL), Colômbia, Valle del Cauca, Quebrada Jenaro, tributário da Quebrada Ordoñez, rio Cajambre [03²2’25.6”N, $\left.77^{\circ} 08^{\prime} 9.9^{\prime \prime} \mathrm{W}\right]$, 22VII-2008, G. C. Sánchez;

CAR 207 (9, 57.9-135.0 mm SL), Colombia, Quebrada Patecucho, 01-VI-2002, Comunidad Silinio; 
CAR 451 (2, 110.9-123.8 mm SL), Colombia, Chocó, quebrada Weguerál, Río San Juan, 10-VIII-2002, S. Usma;

CAR 452 (ex-ICNMHN 144) (9, 27.9-56.6 mm SL), Colombia, Chocó, Río San Juan, Localidad Noanamá [0441'24’N 7655’48’W], 05-XI-1959, G.Dahl;

CAR 455 (2, 103.3-130.9 mm SL), Colombia, Chocó, Río San Juan, unknown date and collector;

CAS 19767 (ex-IU 12965) (2, 42.9-63.5 mm SL), Colômbia, Choco, pequeno córrego em Tambo, estação nas cabeceiras da bacia do rio Atrato, ao norte de Istmina [exemplares provavelmente provenientes da bacia do Río San Juan], 1913, C. Wilson; CAS uncat (ex-IU 12964) (15/20, 32.8-79.9 mm SL), Colômbia, Chocó, Condoto, 1913, C. Wilson;

ICNMHN 133 (1, $42.5 \mathrm{~mm}$ SL), Colombia, Chocó, Aparraidó [rio Amparadó: 540’02.4’N 7700’9.5’W], rio Baudó, IX-1985, L. F. Jimenez;

ICNMHN 144 (119, 40.20-137.9 mm SL), Colombia, Chocó, Río San Juan [Localidad Noanamá: 0441'24’N 7655'48”W], 05-XI-1959, George Dahl;

ICNMHN 177 (3, 88.8-99.2 mm SL),Colombia, Chocó, Río San Juan, 27-III-1988, C. Ardila-Rodriguez;

ICNMHN 2281 (1, 87.9 mm SL), Colombia, Chocó, bacia do rio Baudó sobre a via para Pie de Pepé [0507’00’N 7650’00’W], II-1995, M. Camargo \& G. Gálvis;

ICNMHN 6873 (5, 56.3-76.4 mm SL), Colombia, Chocó, Río Condoto, Quebrada afluente del Río San Juan, unknown date and collector;

NRM 10685 (3, 95.0-112.3 mm SL), Chocó, Cabeceras [04²18’N 7709’W], río San Juan, 1939, G. Gerring;

NRM 10686 (1, 103.3 mm SL), Colômbia, Chocó, rio Tadocito [05¹6’00”N 76³2’00”W], 1938, G. Gerring;

NRM 13047 (1, 95.7 mm SL), Colômbia, dados de procedência perdidos, K. Von Sneidern;

NRM 15444 (2, 61.5-111.3 mm SL), Colômbia, dados de procedência perdidos, K. Von Sneidern;

NRM 4365 (1, 88.0 mm SL), dados de procedência perdidos, 1947?, K. von Sneidern; NRM 3416 (9, 60.2-86.2 mm SL), Colômbia, Caldas [Risaralda], La Selva-Pueblo Rico [Pueblo Rico: 05¹4'06.2”N 7602'19.8”W; La Selva: 0455'00”N 7609'00”W, 
localidade provavelmente próxima à cabeceira do Río San Juan, no parque nacional Tatama], 1700 m elev., Jan 1946, K. von Sneidern;

NRM SOK/1989057.5929 (1, 78.1 mm SL), Colômbia, Chocó, Río Condoto, praia na margem direita do Río Condoto, abaixo da ponte, afluente do Río San Juan, 05-II-1989, S. Kullander et al.;

NRM SOK/1989057.5931 (1, 95.3 mm SL), Colômbia, Chocó, quebrada na floresta, na rodovia Condoto-Soledad, a 5 min da estrada para o aeroporto, afluente do Río Condoto [La Soledad: $05^{\circ} 02^{\prime} \mathrm{N} 76^{\circ} 32^{\prime}$ W], 05-II-1989, S. Kullander et al.;

NRM SOK/1989057.5932 (1, 87.8 mm SL), Colômbia, Chocó, Condoto, comprado de crianças pescando no Río Condoto, 05-II-1989, S. Kullander et al.;

NRM SOK/1989080.6044 (5, 73.9-129.8 mm SL), Colômbia, Chocó, rio próximo à vila

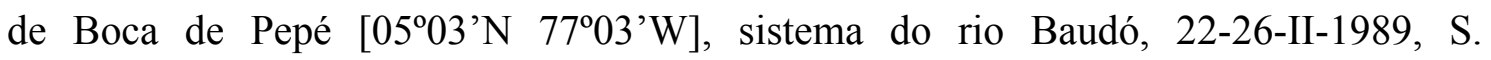
Kullander, A. Silfvergrip.

Diagnose. Lebiasina multimaculata diferencia-se de Lebiasina bimaculata, L. aff. bimaculata I, L. aff. bimaculata II, L, boruca, L. festae e L. aff. festae por não apresentar a parede da câmara posterior da bexiga natatória "celular", por apresentar as escamas da quinta série longitudinal com tecido epitelial hipertrofiado nos machos adultos e por não apresentar escamas com intensa deposição de guanina (vs. parede da bexiga natatória “celular", escamas da sexta série longitudinal modificadas em machos adultos, ao menos a quarta escama da linha lateral com intensa deposição de guanina). A espécie difere de Lebiasina sp. "Curuá-Pinta" por apresentar faixas longitudinais e mancha caudal, e não apresentar manchas escuras na base das escamas da segunda à quinta séries longitudinais (vs. faixas longitudinais e mancha caudal ausentes; manchas escuras presentes na base das escamas da segunda à quinta séries longitudinais). Difere de Lebiasina elongata, L. erythrinoides, L. intermedia, L. taphorni, L. unitaeniata, L. uruyensis, L. yuruaniensis, L. sp. "Curuá-Faixa" e L. sp. "Parima” por apresentar uma série longitudinal de pequenas manchas arredondadas (vs. série longitudinal de manchas escuras ausente). Lebiasina multimaculata difere ainda de L. taphorni, L. unitaeniata, L. uruyensis, L. yuruaniensis e L. sp. "Parima" pela faixa secundária passando ao longo das escamas da primeira e segunda séries longitudinais, ausência da faixa "intermediária" e pela mancha caudal alcançar o pedúnculo caudal anteriormente (vs. faixa secundária passando ao longo das escamas da segunda e terceira séries 
longitudinais, faixa "intermediária" presente; mancha caudal não alcançando o pedúnculo caudal anteriormente). Entre as espécies do clado 83, Lebiasina multimaculata diferencia-se de L. colombia, L. floridablancaensis, L. ortegai e L. panamensis por apresentar faixa primária inconspícua (vs. faixa primária conspícua ao longo de todo o corpo em L. ortegai e exemplares adultos de L. panamensis; porção anterior da faixa primária conspícua em L. colombia e exemplares jovens de $L$. panamensis; porção posterior da faixa primária conspícua em L. floridablancaensis). A espécie difere de Lebiasina astrigata, L. aureoguttata e L. sp. Azuay por apresentar a faixa secundária inconspícua estendendo-se ao longo das escamas da primeira e segunda séries longitudinais (vs. faixa secundária conspícua, passando pelas escamas da segunda e terceira séries longitudinais). Lebiasina multimaculata distingue-se de L. chocoensis por apresentar numerosas manchas pequenas distribuídas ao longo da quarta série longitudinal de escamas, nadadeira adiposa ausente (vs. poucas manchas grandes distribuídas ao longo da quarta série longitudinal e nadadeira adiposa).

Descrição. Dados morfométricos apresentados na tabela 13. Corpo comprimido e alongado. Perfil dorsal da cabeça e do corpo convexo do lábio superior até até a origem da nadadeira dorsal, tornando-se praticamente reto entre os parietais e a origem da dorsal. Perfil reto na base da dorsal e levemente côncavo posteriormente até a origem dos raios pró-correntes da nadadeira caudal. Perfil ventral da cabeça e tronco convexo desde o lábio inferior até a origem da pélvica, reto deste ponto até a origem da nadadeira anal, convexo na base da anal e côncavo do término da anal até a origem dos pró-correntes ventrais da nadadeira caudal.

Espécie discretamente prognata, boca terminal. Maxilar ultrapassando a margem anterior da órbita. Apenas uma série de 8 (2), 9* (10), 10 (15), 11 (34), 12 (25) ou 13 (1) dentes tricúspides decrescendo posteriormente no pré-maxilar. Maxilar com 3 (1), 4 (16), 5 (13), 6 (18), 7 (22), 8 (13), 9* (4) ou 10 (1) dentes tricuspidados. Dentário com duas séries de dentes: 12 (10), 13 (11), 14*(8), 15 (14), 16 (11), 17 (3) ou 18 (1) dentes tricúspides pedunculados com a cúspide central distintamente mais longa que as cúspides laterais na série externa, série interna com dentes diminutos, na maioria, cônicos (podendo ser tricúspides posteriormente) estendendo-se desde a sínfise até próximo ao processo coronóide. Raios-branquiostégios 4, três articulando com o ceratobranquial anterior e 1 com o ceratobranquial posterior. 
Escamas ciclóides, circuli restritos à borda da escama, diversos radii convergindo para o centro da escama, fortemente anastomosados no centro, formando numerosas células. Série longitudinal da linha lateral com 27 (2), 28 (10), 29* (12), 30 (2) ou 31 (1) escamas, das quais apenas 5 (7), 6* (19) ou 7 (1) são perfuradas. Séries longitudinais entre a nadadeira dorsal e a pélvica 7. Escamas pré-dorsais 12 (1), 13 (9) ou 14* (17). Primeira série longitudinal de escamas ultrapassando a vertical que passa pela origem da nadadeira anal. Escamas circumpedunculares 12.

Nadadeira peitoral i, 12 (11), 13 (8), 14 (16) ou 15* (2). Ponta da peitoral não alcançando a vertical que passa pela origem da pélvica. Raios da nadadeira pélvica i, $7 *$ (25) ou i, 8 (2). Supraneurais 10 (10), 11 (41) ou 12* (11) anteriores aos espinhos neurais dos centros 5 a 14 (10), 15 (41) ou 16* (11). Nadadeira dorsal ii, 7 (2), iii, 7 (2) ou ii, $8 *$ (23). Primeiro pterigióforo da nadadeira dorsal inserido posteriormente ao espinho neural do centro 14 (10), 15 (41) ou 16* (11). Margem distal da nadadeira dorsal arredondada quando expandida. Origem da nadadeira dorsal distintamente mais próxima à base da nadadeira caudal que da ponta do focinho. Base do último raio da dorsal distintamente anterior à vertical que passa pela origem da nadadeira anal. Nadadeira anal iii, 7 (1) ou iii, 8* (25). Margem distal da nadadeira anal arredondada. Primeiro pterigióforo da nadadeira anal inserido posteriormente ao arco hemal do centro $24(33), 25^{*}(27)$ ou 26 (1). Nadadeira adiposa ausente. Epurais 2. Nadadeira caudal furcada, lóbulo superior discretamente mais longo que o inferior, ambos arredondados. Raios principais da nadadeira caudal ii,8/i,9 (1) ou i, 9/i, $8^{*}$ (26). Pró-correntes dorsais 8 (2) ou 9(2); pró-correntes ventrais 7 (1), 8 (1) ou 9 (2). Vértebras pré-caudais 23 (8), 24 (1) ou $25 *(1)$; vértebras caudais $17 *(2), 18$ (6) ou 19 (2).

Colorido. Cor de fundo predominantemente amarela. Coloração escura estendendo-se desde o lábio superior até a porção exposta dos parietais e ao longo da série medial e primeira série de escamas até a origem da nadadeira caudal. Maxilar, ossos circumorbitais e série opercular densamente pigmentados próximo à porção dorsal da cabeça, tornando-se gradualmente amarelada ventralmente; opérculo com uma distinta mancha escura na região médio-inferior. Faixa negra estendendo-se da porção dorsal da órbita, passando pelos infra-orbitais 5 e 6 e face dorsal do opérculo, inconspícua. Lábio inferior intensamente pigmentado; restante da mandíbula e toda porção ventral da cabeça com pigmentação escassa. 
Tronco tornando-se gradualmente amarelado ventralmente. Região abdominal amarela, com diminutos cromatóforos entre o istmo e a origem da nadadeira anal. Mancha umeral arredondada, conspícua em indivíduos jovens, porém difusa em adultos. Faixa primária representada por seis a dezoito manchas pequenas e arredondadas, geralmente ocupando amplitude de uma escama da quarta série longitudinal, estando distribuídas entre a mancha umeral e a mancha caudal. Diferentemente de L. astrigata, as manchas mais anteriores, localizadas entre a peitoral e a pélvica, apresentam intensidade similar à das mais posteriores; manchas posteriores não coalescem. Última mancha deslocada dorsalmente, estando situada principalmente na terceira série longitudinal de escamas, podendo estar ausente. Faixa secundária estendendo-se ao longo da primeira e segunda séries longitudinais de escamas, desde os epoccipitais à vertical que passa pelo término da nadadeira dorsal. Terceira, quarta e quinta séries longitudinais de escamas com pequenas manchas escuras próximo à base e na porção mais distal destas. Base da dorsal distintamente mais escura que o dorso. Mancha caudal alongada verticalmente, situada na extremidade do pedúnculo caudal e estendendo-se à base de 9 raios medianos da nadadeira caudal. Nadadeiras peitoral, pélvica e caudal hialinas; raios da nadadeira dorsal com diminutos cromatóforos na base; raios da nadadeira anal com a borda distal densamente pigmentada.

Dimorfismo sexual. Exemplares machos de Lebiasina multimaculata apresentam o padrão mais difundido de dimorfismo sexual entre as Lebiasina, descrito acima para $L$. astrigata.

Distribuição. Sudoeste da Colômbia, nas bacias dos rios Dagua, San Juan e Baudó (fíg. 84).

Tabela 13. Dados morfométricos de Lebiasina multimaculata.

\begin{tabular}{lccccc} 
& $\mathrm{n}$ & Range & Mean & SD & Lectotype \\
\cline { 2 - 6 } Standard length & 43 & $28,0-135,0$ & 95,9 & & 90,4 \\
& & & & & \\
Depth dorsal fin origin & 27 & $19,8-22,9$ & 21,0 & 0,76 & 21,3 \\
Snout to anal fin origin & 28 & $71,9-79,0$ & 75,1 & 1,95 & 73,1 \\
Snout to pelvic fin origin & 27 & $47,3-53,9$ & 50,6 & 1,42 & 50,3 \\
Snout to dorsal fin origin & 28 & $53,4-58,7$ & 56,0 & 1,12 & 57,1 \\
Dorsal fin origin to caudal base & 28 & $42,9-46,9$ & 45,2 & 1,21 & 46,4 \\
Dorsal fin length & 28 & $17,1-20,5$ & 18,8 & 0,86 & 20,5 \\
Dorsal fin base & 28 & $7,3-9,5$ & 8,4 & 0,43 & 8,5 \\
Length caudal peduncle & 28 & $14,0-17,8$ & 16,2 & 0,98 & 17,6
\end{tabular}


Depth caudal peduncle

Anal fin length

Anal fin base

Pelvic- to anal fin origin

Pelvic fin length

Pectoral to pelvic fin origin

Pectoral fin length

Snout to pectoral fin origin

Bony head length

Head width

Morphometrics \% of HL

Horizontal eye diameter

Distance snout tip to eye

Interorbital distance

Length lower jaw

Length upper jaw

\begin{tabular}{rrrr}
$10,9-12,7$ & 11,8 & 0,45 & 12,5 \\
$17,8-24,8$ & 20,5 & 2,14 & 19,9 \\
$9,5-16,1$ & 12,5 & 1,74 & 11,9 \\
$22,1-28,3$ & 25,3 & 1,31 & 24,6 \\
$12,3-16,0$ & 13,9 & 0,97 & 14,7 \\
$28,2-34,1$ & 30,6 & 1,29 & 31,2 \\
$13,8-21,3$ & 16,0 & 1,41 & 16,9 \\
$15,0-23,8$ & 21,1 & 1,57 & 22,6 \\
$21,8-24,0$ & 23,0 & 0,58 & 23,7 \\
& & & \\
$54,3-62,9$ & 58,9 & 2,18 & 62,6 \\
$18,3-23,2$ & 20,5 & 1,24 & 20,6 \\
$26,0-31,2$ & 28,7 & 1,37 & 26,2 \\
$34,7-39,6$ & 36,7 & 1,22 & 36,4 \\
$41,8-47,7$ & 44,5 & 1,45 & 47,7 \\
$35,0-39,8$ & 37,2 & 1,07 & 39,8 \\
\hline
\end{tabular}

\section{Lebiasina ortegai Ardila-Rodriguez}

(Figura 94)

Lebiasina ortegai Ardila-Rodríguez, 2008b

Piabucina sp.- Román-Vallencia et al., 1999: 168-170 [longitudinal distribution of fishes from the Cauca river basin].- Román-Vallencia, 1988 [apud Román-Valencia, 1996]; 1993 [apud Román-Valencia, 1996]; 1995 [apud Román-Valencia, 1996]; 1996 [autoecology]; 1997.

Lebiasina multimaculata (non Boulenger).- Ortega-Lara et al., 2000: 19 [inferred from distribution (CAR 145); illustration; vernacular names; habitat description; distribution]

Lebiasina cf. multimaculata.- Román-Valencia \& Vélez, 1986 [apud Román-Valencia, 1996].

Lebiasina sp.- Géry, 1977: 126 [figure on top].

Série-tipo. Holótipo: IMCN 4200 (104.0 mm SL); Parátipos: IMCN 4201 (3, 107.1-38.1 mm SL), CAR 265 (7, 117.3-35.0 mm LE), IAvH-P 9875 (1, 116.4 mm SL), CZUT-IC 2586, (1, 72 mm SL), CAR 157 (5, 122.0-65,5 mm SL). 
Localidade-tipo. Colômbia, Valle del Cauca, Florida, quebrada afluente do rio Las Cañas, $200 \mathrm{~m}$ antes de cruzar a via Florida-Miranda.

\section{Material examinado.}

CAR 15-04-10 (4, 64.1-119.8 mm SL), Colombia, Valle del Cauca, Florida [03¹8'50.7’’ $\left.76^{\circ} 14^{\prime} 26.8^{\prime} \mathrm{W}\right]$, quebrada afluente do rio Cañas, Vereda el Tambor, 1100 m elev., 31-X-1999, C. Ardila-Rodriguez, A. Ortega-Lara;

CAR 15-04-13 (3, 55.4-103.6 mm SL), Colombia, Valle del Cauca, quebrada afluente do rio Cauca, que atravessa o povoado de La Balsa [0440’37.6”' 7547’18.2”W], 3, 2III-2000, A. Ortega-Lara;

CAR 15-04-45 (1, 72.3 mm SL), Colombia, Quindio, quebrada el Broche, sistema do rio Baragán, estrada para Caicedonia [04²0’07.2”N 7542’02.8”W?] 23-1982 [23IX-1982?], C. Román-Valencia;

CAR 15-04-46 (3, 64.1-70.5 mm SL), Colombia, Quindio, quebrada el Broche, sistema Rio Baragán, estrada para Caicedonia [04²0’07.2”N 7542’02.8”W?], 23-1982 (23IX-1982?), C. Román-Valencia;

CAR 145 (12, 66.3-137.3 mm SL), Colombia, Valle del Cauca, Alcalá [0440’46.3”N 7547'33.7'W], quebrada sem nombre, rio Barbas a $200 \mathrm{~m}$ da confluência como rio La Vieja, 12, 5-VII-2005, C. Ardila-Rodriguez;

CAR 146 (1, 91.0 mm SL), Colombia, Caldas, Viterbo [0503’41.5”N 7552’36.8”W], quebrada Sajonia, 12-IV-1998, M. Peláes;

CAR 147 (2, 76.0-76.4 mm SL), Colombia, Quindio, quebrada el Broche, afluente Rio Baragán, 26-III-1986, C. Román-Valencia;

CAR 265 (13, 34.7-114.8 mm SL), Colombia, Valle del Cauca, afluente do rio las Cañas, $200 \mathrm{~m}$ antes de cruzar a estrada entre Florida e Miranda [0316’41.74”N 76²13'17.9’W?], 07-XI-2004, C. Ardila-Rodriguez, A. Ortega-Lara;

CAR 445 (1, 55.8 mm SL), Colombia, Cauca, quebrada Gemagra, Popayán [02²7’03.5’N 76³7’12.1’W], 1730m elev., 4-II-2003, H. Mueses;

ICNMHN 910 (1, 117.0 mm SL), Colômbia, Quindio, Pijao [04²0’07.2”N 7542’02.8”W], quebrada El Broche, tributário do rio Barragán, passando ao norte de Páramo Barragán no alto rio Cauca, próximo a Cartago, 23-IX-1982, C. RománValencia \& G. Roman-V.; 
ICNMHN 2723 (17, 69.1-88.2 mm SL), Colombia, Quindio, quebrada el Broche, afluente do rio Baragán, Vereda Barragán estrada para Caicedonia [04²0’07.2”N 7542’02.8’W?], X-1960, Unknown collector.

Diagnose. Lebiasina ortegai diferencia-se de Lebiasina bimaculata, L. aff. bimaculata I, L. aff. bimaculata II, L, boruca, L. festae e L. aff. festae por não apresentar a parede da câmara posterior da bexiga natatória "celular", por apresentar as escamas da quinta série longitudinal com tecido epitelial hipertrofiado nos machos adultos e por não apresentar escamas com intensa deposição de guanina (vs. parede da bexiga natatória "celular", escamas da sexta série longitudinal modificadas em machos adultos, ao menos a quarta escama da linha lateral com intensa deposição de guanina). A espécie difere de todas as demais congêneres pelo ramo infra-orbital do canal látero-sensorial cefálico não se estender ao antorbital (vs. antorbital portanto um ramo do canal láterosensorial infra-orbital). Adicionalmente, a espécie distingue-se de Lebiasina sp. "CuruáPinta" por apresentar faixas longitudinais e mancha caudal e não apresentar manchas escuras na base das escamas da segunda à quinta séries longitudinais (vs. faixas longitudinais e mancha caudal ausentes; manchas escuras presentes na base das escamas da segunda à quinta séries longitudinais). Difere de Lebiasina elongata, L. erythrinoides, L. intermedia, L. taphorni, L. unitaeniata, L. uruyensis, L. yuruaniensis, L. sp. "Curuá-Faixa" e L. sp. "Parima" por apresentar uma série longitudinal de pequenas manchas arredondadas (vs. série longitudinal de manchas escuras ausente). Lebiasina ortegai difere ainda de L. taphorni, L. unitaeniata, L. uruyensis, L. yuruaniensis e L. sp. "Parima" pela faixa secundária passando ao longo das escamas da primeira e segunda séries longitudinais, ausência da faixa "intermediária" e pela mancha caudal alcançar o pedúnculo caudal anteriormente (vs. faixa secundária passando ao longo das escamas da segunda e terceira séries longitudinais, faixa "intermediária" presente; mancha caudal não alcançando o pedúnculo caudal anteriormente). Entre as espécies do clado 83, Lebiasina ortegai difere de Lebisina astrigata, L. aureoguttata, L. chocoensis, L. colombia, L. floridablancaensis, L. multimaculata e L. sp. Azuay por apresentar a faixa primária conspícua ao longo de todo o corpo (vs. faixa primária inconspícua em Lebisina astrigata, L. aureoguttata, L. chocoensis, L. multimaculata e L. sp. Azuay; faixa primária conspícua apenas na porção anterior do corpo em L. colombia; apenas a porção posterior da faixa primária 
conspícua em L. floridablancaensis). A espécie distingue-se ainda de Lebiasina astrigata, L. aureoguttata, L. floridablancaensis e L. sp. Azuay por apresentar a faixa secundária inconspícua estendendo-se ao longo das escamas da primeira e segunda séries longitudinais ( $v s$. faixa secundária conspícua, passando pelas escamas da segunda e terceira séries longitudinais) e de L. multimaculata por apresentar grandes manchas arredondadas e nadadeira adiposa ( $v s$. manchas pequenas; nadadeira adiposa ausente). Lebiasina ortegai distingue-se de L. panamensis por apresentar toda a faixa primária conspícua ao longo de sua ontogenia, não alcançando a mancha caudal; mancha umeral similar em tamanho à espessura da faixa primária e às manchas do corpo; mancha caudal verticalmente alongada; endopterigóide apresentando dentes (vs. faixa primária com a porção anterior conspícua em jovens, mas, geralmente, completa em exemplares adultos, estendendo-se posteriormente, alcançando a mancha caudal; mancha umeral distintamente mais espessa que as manchas do corpo e a faixa primária; mancha caudal distintamente triangular).

Descrição. Dados morfométricos apresentados na tabela 14. Corpo comprimido e alongado. Perfil dorsal da cabeça e do corpo convexo do lábio superior até até a origem da nadadeira dorsal, tornando-se praticamente reto entre os parietais e a origem da dorsal. Perfil reto na base da dorsal e levemente côncavo posteriormente até a origem dos raios pró-correntes da nadadeira caudal. Perfil ventral da cabeça e tronco convexo desde o lábio inferior até a origem da pélvica, reto deste ponto até a origem da nadadeira anal, convexo na base da anal e côncavo do término da anal até a origem dos pró-correntes ventrais da nadadeira caudal.

Espécie discretamente prognata, boca subsuperior. Maxilar alcançando a vertical que passa pelo meio da órbita. Apenas uma série de 10 (5), 11 (6) ou 12 (5) dentes tricúspides decrescendo posteriormente no pré-maxilar. Maxilar 6 (3), 7 (9), 8 (1) ou 9 (1) com dentes tricuspidados. Dentário com duas séries de dentes: 13 (5), 14 (3), 15 (1) ou 16 (1) dentes tricúspides pedunculados com a cúspide central distintamente mais longa que as cúspides laterais na série externa, série interna com dentes diminutos, na maioria, cônicos (podendo ser tricúspides posteriormente) estendendo-se desde a sínfise até próximo ao processo coronóide. Raios-branquiostégios 4, três articulando com o ceratobranquial anterior e 1 com o ceratobranquial posterior. 
Escamas ciclóides, circuli restritos à borda da escama, diversos radii (aproximadamente 29) convergindo para o centro da escama, fortemente anastomosados no centro, formando numerosas células. Série longitudinal da linha lateral com 28 (4), 29 (7), 30 (7) ou 31 (4) escamas, das quais apenas 6 ou 7 são perfuradas. Séries longitudinais entre a nadadeira dorsal e a pélvica 7. Escamas pré-dorsais 13 (5), 14 (15) ou 15 (3). Primeira série longitudinal de escamas ultrapassando a vertical que passa pela metade da nadadeira anal, podendo alcançar a origem da nadadeira adiposa. Escamas circumpedunculares 12 .

Nadadeira peitoral i, 12 (5), 13 (8)ou 14 (6). Ponta da peitoral não alcançando a vertical que passa pela origem da pélvica. Raios da nadadeira pélvica i, 7 (19) ou i, 8 (1). Supraneurais 10 (3) ou 11 (4) anteriores aos espinhos neurais dos centros 5 a 14 (3) ou 15 (4). Nadadeira dorsal ii, 7 (1), iii, 7 (1) ou ii, 8 (19). Primeiro pterigióforo da nadadeira dorsal inserido posteriormente ao espinho neural do centro 14 (3) ou 15 (4). Margem distal da nadadeira dorsal arredondada quando expandida. Origem da nadadeira dorsal distintamente mais próxima à base da nadadeira caudal que da ponta do focinho. Base do último raio da dorsal distintamente anterior à vertical que passa pela origem da nadadeira anal. Nadadeira anal iii, 7 (2) ou iii, 8 (19). Margem distal da nadadeira anal arredondada. Primeiro pterigióforo da nadadeira anal inserido posteriormente ao arco hemal do centro 23 (3) ou 24 (4). Nadadeira adiposa presente. Epurais 2. Nadadeira caudal furcada, lóbulo superior discretamente mais longo que o inferior, ambos arredondados. Raios principais da nadadeira caudal i, 9/i, 8 (21). Prócorrentes dorsais 8 (1); pró-correntes ventrais 9 (1). Vértebras pré-caudais 23 (1); vértebras caudais $16(1)$.

Colorido. Cor de fundo predominantemente amarela. Coloração escura estendendo-se desde o lábio superior até a porção exposta dos parietais e ao longo da série medial e primeira série de escamas até a origem da nadadeira caudal. Maxilar, ossos circumorbitais e série opercular densamente pigmentados próximo à porção dorsal da cabeça, tornando-se gradualmente amarelada ventralmente; opérculo com uma distinta mancha escura na região médio-inferior. Estreita faixa negra estendendo-se da porção dorsal da órbita, passando pelos infra-orbitais 5 e 6 e face dorsal do opérculo. Lábio inferior intensamente pigmentado; restante da mandíbula e toda porção ventral da cabeça com pigmentação escassa. 
Tronco tornando-se gradualmente amarelado ventralmente. Região abdominal amarela, com diminutos cromatóforos entre o istmo e a origem da nadadeira anal. Mancha umeral arredondada, conspícua em indivíduos jovens, tornando-se, porém, menos conspícua ao longo da ontogenia, conforme a faixa primária se torna mais espessa. Faixa primária representada por três a sete manchas grandes e arredondadas, distribuídas entre a mancha umeral e a mancha caudal. Ao longo da ontogenia, tais manchas se conectam por meio de uma faixa escura que se torna gradualmente mais larga de acordo com o crescimento do indivíduo. Última mancha, localizada entre a nadadeira adiposa e a mancha caudal, pouco conspícua discretamente deslocada dorsalmente, podendo estar ausente. Faixa secundária inconspícua, estendendo-se ao longo da primeira e segunda séries longitudinais de escamas, desde os epoccipitais à vertical que passa pela metade da nadadeira dorsal. Terceira, quarta e quinta séries longitudinais de escamas com pequenas manchas escuras próximo à base e na porção mais distal destas. Base da dorsal distintamente mais escura que o dorso. Mancha caudal alongada verticalmente, situada na extremidade do pedúnculo caudal e estendendo-se à base de 11 raios medianos da nadadeira caudal. Nadadeiras peitoral, pélvica, anal e caudal hialinas; porção proximal dos raios da nadadeira dorsal com uma distinta mancha escura, bastante intensa em indivíduos jovens, mas gradualmente perdendo intensidade ao longo da ontogenia.

Dimorfismo sexual. Exemplares machos de Lebiasina ortegai apresentam o padrão mais difundido de dimorfismo sexual entre as Lebiasina, descrito acima para $L$. astrigata.

Distribuição. Alto rio Cauca, Colômbia (Fig. 84).

Tabela 14. Dados morfométricos de Lebiasina ortegai.

\begin{tabular}{lcccc}
\cline { 2 - 5 } & $\mathrm{n}$ & Range & Mean & SD \\
\hline Standard length & 26 & $34,7-137,3$ & 91,5 & \\
& & & & \\
Depth dorsal fin origin & 22 & $19,3-23,9$ & 21,5 & 1,2 \\
Snout to anal fin origin & 22 & $71,5-78,6$ & 76,1 & 1,8 \\
Snout to pelvic fin origin & 22 & $48,8-54,6$ & 51,9 & 1,2 \\
Snout to dorsal fin origin & 22 & $53,9-59,1$ & 56,8 & 1,3 \\
Dorsal fin origin to caudal base & 22 & $43,0-48,0$ & 44,8 & 1,2 \\
Dorsal fin length & 22 & $18,0-21,2$ & 19,1 & 0,8 \\
Dorsal fin base & 22 & $7,8-10,4$ & 9,1 & 0,6 \\
Adipose fin to caudal peduncle & 22 & $9,6-13,1$ & 11,4 & 0,9
\end{tabular}




\begin{tabular}{lllll} 
Length caudal peduncle & 22 & $14,5-17,3$ & 15,6 & 0,9 \\
Depth caudal peduncle & 22 & $10,5-12,4$ & 11,4 & 0,4 \\
Anal fin length & 22 & $16,4-25,0$ & 20,4 & 2,1 \\
Anal fin base & 22 & $10,5-15,2$ & 12,4 & 1,4 \\
Pelvic- to anal fin origin & 22 & $22,7-27,3$ & 24,9 & 1,2 \\
Pelvic fin length & 22 & $12,8-15,6$ & 14,0 & 0,9 \\
Pectoral to pelvic fin origin & 22 & $25,0-30,1$ & 27,8 & 1,4 \\
Pectoral fin length & 22 & $12,7-18,7$ & 15,5 & 1,4 \\
Snout to pectoral fin origin & 22 & $23,5-27,2$ & 25,2 & 1,2 \\
Bony head length & 22 & $25,3-30,5$ & 27,5 & 1,0 \\
& & & & \\
Head width & 22 & $52,4-62,7$ & 56,7 & 2,1 \\
Horizontal eye diameter & 22 & $15,9-22,8$ & 18,9 & 1,7 \\
Distance snout tip to eye & 22 & $25,7-29,5$ & 27,1 & 1,0 \\
Interorbital distance & 22 & $33,5-37,3$ & 34,7 & 0,8 \\
Length lower jaw & 22 & $41,7-46,1$ & 43,9 & 1,3 \\
Length upper jaw & 22 & $35,2-39,8$ & 37,3 & 1,5 \\
\hline
\end{tabular}

\section{Lebiasina panamensis (Gill)}

(Figura 95)

Piabucina panamensis Gill, 1877: 336.- Eigenmann \& Eigenmann, 1891: 52 [catalog].Eigenmann, 1910: 439 [catalog].- Meek \& Hildebrand, 1916: 299 [key to the species of Piabucina in Panama]; 300 [synonymy; distribution; brief description; habitat].Eigenmann, 1920a: 16 [distribution; specimens from Chagres and Chepo basins].Eigenmann, 1922: 126 [key to the species of Lebiasininae; none of the specimens listed in p. 127 is L. panamensis].- Breder, 1933: 565 [collection sites].- Hildebrand, 1938: 286-287 [distinguishing characters for L. festae and L. panamensis; habitat description; color pattern; feeding habits and reproductive season; collection sites].- Loftin, 1966: 114-116 [distribution; collection sites; hypothesis to the invasion of Lebiasininae in Central America].- Bussing, 1967: 219-221 [comparissons with L. boruca].- Zaret \& Rand, 1971: [L. panamensis was collected in pools during the dry season. It occupied the bottom area of rocky pools and fed on fruits and seeds and prawns which it attacked rapidly. It was absent from the main stream during the wet season and the authors suggest that it might have gone into adjacent quiet backwaters.].- Machado-Allison, 1974: 582 [diversity of Lebiasininae].- Graham et al., 1978: 279-287 [comparisons between the respiration physiology of L. festae and L. panamensis].- Kramer, 1978a: 976-983 [reproduction seasonality of L. panamensis].- Kramer, 1978b [L. panamensis as a non air-breathing species].- Kramer, 1983 [L. panamensis as a non air-breathing species].- Vari \& Howe, 1991: 33 [type specimens catalog].- Vari, 1995 [representative of Lebiasininae as an out-group for phylogentic study of Ctenoluciidae].- Eschmeyer, 
1998: 1277 [catalog].- Bussing, 1998: 125-126 [distribution].- Weitzman \& Weitzman, 2003: 247 [checklist].

Lebiasina panamensis.- Géry, 1977: 112.- Géry \& Zarske, 2002: 39.

Série-tipo. Síntipos: USNM 16676 (1) Panama. Canal Zone. "Stream emptying into Atlantic"; USNM16677 (2) Panama. Río Frijole. J. F. Bransford. Espécime jovem originalmente catalogado em USNM 16677 foi recatalogado como uma espécie diferente e de uma família diferente. Talvez tenha havido uma troca de exemplares (Eschmeyer, 1998).

Localidade-tipo. Rio Frijole e riacho desembocando no Atlântico, Panamá.

\section{Material examinado.}

ANSP 104114 (5, 102.1-127.3 mm SL), Panamá, Coclé, córrego na cabeceira do rio Índio, próximo de La Mesa [08 $\left.38^{\prime} 00^{\prime} \mathrm{N} 80^{\circ} 07^{\prime} 00^{\prime} \mathrm{W}\right]$, a montante de El Valle [08 36'00”N 8008'00”W], onde três nascentes formam o córrego, 14-IX-1962, H. G. Loftin;

ANSP 104137 (12, 72.8-135.6 mm SL), Panamá, Panamá, córrego cruzando a estrada a $8 \mathrm{Km}$ de Cerro Azul [Cerro Azul: 09¹0’00”N 79²5’00”W], 27-VIII-1962, H. G. Loftin \& W. Kosan;

ANSP 126193 (4, 64.5-134.4 mm SL), Panama, 16 km de Cerro Azul, drenagem do Oceano Pacífico [Cerro Azul 09¹0’00”N 79²5’00”W], 29-I-1971, Abele \& Dressler; CAS 6813 (3, 45.2-102.8 mm SL), Panamá, Panamá, Barro Colorado [0909’47.91’N 7949'43.3”W], 15-II-1935, S. F. Hildebrand;

INHS 68116 (1, 54.3 mm SL), Panamá, Colón, Parque Nacional da Soberania, rio Frijolito, bacia do rio Chagres [09¹0'11.1'N 7946'54.6”W], III a IV-1979, J. R. Karr \& P. L. Angermeier;

INHS 68141 (4, 52.8-65.4 mm SL), Panamá, Colón, Parque Nacional da Soberania, rio Frijolito, bacia do rio Chagres [09¹0'11.1”N 7946’54.6”W], III a IV-1979, J. R. Karr \& P. L. Angermeier; 
INHS 68151 (5, 52.8-87.3 mm SL), Panamá, Colón, Parque Nacional da Soberania, rio Frijolito, bacia do rio Chagres [09¹0'11.1'N 7946'54.6”W], III a IV-1979, J. R. Karr \& P. L. Angermeier;

INHS 68176 (2, 95.6-138.4 mm SL), Panamá, Parque Nacional de Soberania, córrego “Tayra” [09080’0.1”N 7941'43.2”W], bacia do rio Chagres, III-1979, J. R. Karr \& P. L. Angermeier;

MCZ 45820 (1, 118.3 mm SL), Panamá, área do canal, próximo a Gamboa, tributário do Río Chagres, fora da Pipeline Road, 0907’N 7942’W, 06-IV-1967, J. Musick et al.; MCZ 54121 (1, $68.3 \mathrm{~mm}$ SL), Panamá, Panamá, $12 \mathrm{~km}$ a leste da ponte sobre o rio Bayano [0909’24.2”N 7841'59.6”W], sistema do rio Bayano, 31-III-1978, K. Hartel, W. Fink;

MCZ 54122 (3, 95.0-122.7 mm SL), Panamá, rio Tej[?] acampamento de construção a oeste da Ponte sobre o rio Bayano, sistema do rio Bayano, 01-IV-1978, K. Hartel \& W. Fink;

MCZ 80749 (11, 53.3-141.9 mm SL), Panamá, córrego na ilha Barro Colorado [0909’47.91”N 7949’43.3”W], área do canal, III-1977, T. Zaret;

MNRJ 14541 (1, 139.1 mm SL; 1 c\&s, 100.0 mm SL), Panamá, Comarca de San Blas, córrego Bulebgandi, rio Azúcar [09²4’53.1”N 78³8’20.0”W], 17-II-1995, E. Bermingham;

MZUSP 23106 (1, 54.8 mm SL), Panamá, Panamá, Córrego da ilha de Barro Colorado [0909’47.91”N 7949’43.3”W], área do canal, XI-1965, H. A. Britski;

MZUSP 47704 (3, 112.4-138.2 mm SL), Panamá, Panamá, Rio Capira, na estrada em Campana [0842'57.3”N 7953'59.2’W], 24-III-1962, H. G. Loftin et al.;

SU 24291 (1, 120.4 mm SL), Panamá, Panamá, Barro Colorado [0909’47.91”N 7949’43.3”W], lago Gatun, área do canal, 15-XII-1928, A. W. Herre;

SU 50310 (1, 125.7 mm SL), Panamá, Panamá, cerca de 2 milhas a sudeste de Gamboa (prov. Colón), na margem leste do canal [0905’22.3”N 7940’43.9”W], unknown date, T. D. White \& J. B. Coman;

UF 19688 (18, 41.1-109.4 mm SL), Panamá, Zona do canal, córrego Cardenas, atrás do Fort Clayton Hospital [0900’00”N 79³4’00”W], 12-IV-1965, F. W. Brockman \& E. T. Moras; 
UF 19697 (3, 47.2-130.8 mm SL), Panamá, Colón, pequeno córrego a menos de uma milha do mar, na ponte S-8-2 na estrada do Forte San Lorenzo [9¹8'34.5”N 7959’43.9’W], área do canal, 13-IV-1965, F. W. Brockman \& E. T. Moras;

USNM 16676 Lectótipo (1, 65.9 mm SL), Panamá,"córrego desembocando no Atlântico", Área do Canal, 1876?, J. F. Bransford;

USNM 16677 Paralectótipo (1, $65.3 \mathrm{~mm}$ SL), Canal Zone, rio Frijole [Río Frijoles: 0908’24.9’N 7945’43”W], 1876?, J. F. Bransford;

USNM 64770 (1, 45.8 mm SL), Panamá, área do canal, córrego desembocando no lago Gatun [09¹6'07.8”N 7955'24.5”'W; Hildebrand, 1938, 229: “remains situated at the place where the Chagres was dammed to form Gatun Lake"], 15-VIII-1909, A. H. Jennings;

USNM 78647 (3, 131.1-137.8 mm SL), Panamá, Corozal [0859’N 79³4’W], río Cardenas, área do canal, 16-II-1911, S. E. Meek \& S. F. Hildebrand;

USNM 78648 (1, 67.5 mm SL), Panamá, Culebra, vertente atlântica, área do canal, 07II-1911, S. E. Meek \& S. F. Hildebrand;

USNM 78649 (4, 39.8-46.9 mm SL), Panamá, rio Indio [Río Indio 0856’N 7942’W], 25-II-1911, S. E. Meek \& S. F. Hildebrand;

USNM 78650 (3, 55.9-71.5 mm SL), Panamá, Gorgona, córrego do reservatório, área do canal, 29-III-1912, S. E. Meek \& S. F. Hildebrand;

USNM 78651 (1, 95.3 mm SL), Panamá, Colón, Porto Bello [Portobelo 09³3’N 79³9’W], 25-IV-1911, S. E. Meek \& S. F. Hildebrand;

USNM 78652 (1, 103.6 mm SL), Panamá, Empire, Río Missimbi, área do canal, 08II-1911, S. E. Meek \& S. F. Hildebrand;

USNM 78653 (2, 64.3-140.7 mm SL), Panamá, pequeno córrego na trilha ArrijanCharera [Arraiján: $08^{\circ} 57^{\prime} \mathrm{N} 79^{\circ} 39^{\prime} \mathrm{W}$; La Chorrera: 0852’34.5’N 7946’37.1’W], 09IV-1911, S. E. Meek \& S. F. Hildebrand;

USNM 78654 (2, 106.6-141.3 mm SL), Panamá, Toro Point [Toro Point 09²1’37.5’N 7957'03.5”W. Hildebrand, 1938: “across Limón Bay from Colón, now called Fort Sherman"], área do canal, 14-IV-1911, S. E. Meek \& S. F. Hildebrand; USNM 78655 (1, 116.2 mm SL), Panamá. rio Calobre [Río Calobre 09¹0`N 7858`W, tributário da margem esquerda do Río Bayano a montante de Bayano], 18-III-1911, S. E. Meek \& S. F. Hildebrand; 
USNM 78656 (2, 120.1-128.3 mm SL), Panamá, Agua Clara [Hildebrand, 1938, 229: "Agua Clara, situated on the Rio Trinidad, a large tributary of the Rio Chagres west of the route of the Canal, was flooded and abandoned"; Agua Clara 09 $\left.18^{\prime} \mathrm{N} 79^{\circ} 47^{\prime} \mathrm{W}\right]$, área do canal, 10-III-1911, S. E. Meek \& S. F. Hildebrand;

USNM 78657 (1, 145.2 mm SL), Panamá, Agua Clara [09²18’N 7947’W], área do canal, 12-IV-1911, S. E. Meek \& S. F. Hildebrand;

USNM 78658 (7/8, 74.5-116.3 mm SL), Panamá, Canal Zone. Reservoir Creek, Culebra. [Hildebrand, 1938, 229-230: "Beyond Gamboa, and on the west side of the then proposed Canal, were situated the important towns, Empire and Culebra. The latter, at the summit of the divide, was the headquarters of the Isthmian Canal Commission. Though these places are shown on current maps they have virtually been abandoned, having become rather inaccessible when the Panama Railroad was relocated on the east side of the Canal."'], 01-IV-1911, S. E. Meek \& S. F. Hildebrand; USNM 78659 (46, 37.2-122.6 mm SL), Panamá, Arrijan, [Arraiján 0857’N 79³9’W], 18-II-1911, S. E. Meek \& S. F. Hildebrand;

USNM 78660 (1, 134.3 mm SL), Panamá, área do canal, XII-1911, E. D. Christopherson;

USNM 109231 (19, 61.9-127.0 mm SL), Panamá, Loro Point. [Toro Point? 09²2’N 7957’W], área do canal, 27-II-1937, J. B. Shropshire;

USNM 109233 (16, 35.2-115.5 mm SL), Panamá, córrego na ilha Barro Colorado, 04III-1935, S. F. Hildebrand;

USNM 109234 (5, 70.9-87.8 mm SL), Colón. Cativa, [Cativá 09²1’N 7951’W], 02III-1937, S. F. Hildebrand;

USNM 109235 (3, 90.1-137.2 mm SL), Panamá, Campaña, rio Capira, [Río Capira $08^{\circ} 48^{\prime} \mathrm{N} 79^{\circ} 50^{\prime} \mathrm{W}$; Campana $\left.43^{\circ} \mathrm{N} 79^{\circ} 54^{\prime} \mathrm{W}\right]$, 11-II-1937, S. F. Hildebrand;

USNM 217498 (1, 93.7 mm SL), Panamá, Colón, Rio Frijolito, a jusante da rodovia da tubulação na área do canal, 06-V-1975, D. L. Kramer;

USNM 293130 (4, 111.4-132.0 mm SL), Panamá, Comarca Kuna Yola, tributário do rio Cangandí próximo a Cangandí, 09²7’00”N 7907’30”W, VI-1986 (06-II-1986?), S. Charnley com índios Kuna;

USNM 293199 (1, 105.3 mm SL), Panamá, Comarca Kuna Yola, tributário do rio Cangandí próximo a Cangandí 09²7’00”N 7907’30”W, 06-II-1986, S. Charnley; 
USNM 304211 (34, 51.8-120.0 mm SL), Panamá, Río Cardenas atrás da área residencial de Fort Clayton, [Río Cárdenas $08^{\circ} 59^{`} \mathrm{~N} 79^{\circ} 35^{\prime} \mathrm{W}$; Fort Clayton $09^{\circ} 01^{`} \mathrm{~N}$ 79³4'W], 19-IV-1962, H. Loftin \& T. Roberts;

USNM 310908 (1, 157.3 mm SL), Panamá, San Blas, Armila, [Armila 0840`N

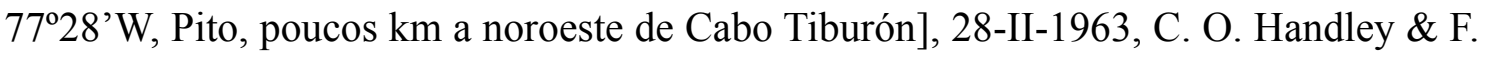
M. Greenwell;

USNM 310909 (5/8, 49.3-138.8 mm SL), Panamá, Río Capira próximo de Campana na rodovia, 24-III-1962, H. Loftin \& T. Roberts;

USNM 310910 (4, 88.9-111.8 mm SL), Panamá, ilha Barro Colorado, área do canal, VIII-1962, H. Loftin et al.;

USNM 310911 (4, 95.0-154.4 mm SL), Panamá, cavernas em Buena Vista, “Transisthmian Highway” [Buena Vista 09¹6’29.2”N 7941'42.9”W], 24-I-1963, H. Loftin \& Olson.

Diagnose. Lebiasina panamensis diferencia-se de Lebiasina bimaculata, L. aff. bimaculata I, L. aff. bimaculata II, L, boruca, L. festae e $L$. aff. festae por não apresentar a parede da câmara posterior da bexiga natatória "celular", por apresentar as escamas da quinta série longitudinal com tecido epitelial hipertrofiado nos machos adultos e por não apresentar escamas com intensa deposição de guanina ( $v s$. parede da bexiga natatória “celular", escamas da sexta série longitudinal modificadas em machos adultos, ao menos a quarta escama da linha lateral com intensa deposição de guanina). A espécie distingue-se de Lebiasina sp. "Curuá-Pinta" por apresentar faixas longitudinais e mancha caudal e não apresentar manchas escuras na base das escamas da segunda à quinta séries longitudinais (vs. faixas longitudinais e mancha caudal ausentes; manchas escuras presentes na base das escamas da segunda à quinta séries longitudinais). Difere de Lebiasina elongata, L. erythrinoides, L. intermedia, L. taphorni, L. unitaeniata, L. uruyensis, L. yuruaniensis, L. sp. "Curuá-Faixa” e L. sp. "Parima" por apresentar uma série longitudinal de pequenas manchas arredondadas (vs. série longitudinal de manchas escuras ausente). Lebiasina panamensis difere ainda de $L$. taphorni, L. unitaeniata, L. uruyensis, L. yuruaniensis e L. sp. "Parima" pela faixa secundária passando ao longo das escamas da primeira e segunda séries longitudinais, ausência da faixa "intermediária" e pela mancha caudal alcançar o pedúnculo caudal anteriormente (vs. faixa secundária passando ao longo das escamas da segunda e 
terceira séries longitudinais, faixa "intermediária" presente; mancha caudal não alcançando o pedúnculo caudal anteriormente). Entre as espécies do clado 83, Lebiasina panamensis difere de Lebisina astrigata, L. aureoguttata, L. chocoensis, L. colombia, L. floridablancaensis, L. multimaculata e L. sp. Azuay por apresentar a faixa primária conspícua ao longo de todo o corpo quando adultos (vs. faixa primária inconspícua em Lebisina astrigata, L. aureoguttata, L. chocoensis, L. multimaculata e L. sp. Azuay; faixa primária conspícua apenas na porção anterior do corpo em L. colombia; apenas a porção posterior da faixa primária conspícua em L. floridablancaensis). A espécie distingue-se de Lebiasina astrigata, L. aureoguttata, L. floridablancaensis e L. sp. Azuay por apresentar a faixa secundária inconspícua estendendo-se ao longo das escamas da primeira e segunda séries longitudinais (vs. faixa secundária conspícua, passando pelas escamas da segunda e terceira séries longitudinais) e de $L$. multimaculata por apresentar nadadeira adiposa (vs. nadadeira adiposa ausente). Lebiasina panamensis distingue-se de L. ortegai por apresentar a faixa primária com a porção anterior conspícua em jovens, mas, geralmente, completa em exemplares adultos, estendendo-se posteriormente, alcançando a mancha caudal; mancha umeral distintamente mais espessa que as manchas do corpo e a faixa primária; mancha caudal distintamente triangular (vs. toda a faixa primária conspícua ao longo de sua ontogenia, não alcançando a mancha caudal; mancha umeral similar em tamanho à espessura da faixa primária e às manchas do corpo; mancha caudal verticalmente alongada; endopterigóide apresentando dentes).

Descrição. Dados morfométricos apresentados na tabela 15. Corpo comprimido e alongado. Perfil dorsal da cabeça e do corpo convexo do lábio superior até até a origem da nadadeira dorsal, tornando-se praticamente reto entre os parietais e a origem da dorsal. Perfil reto na base da dorsal e levemente côncavo posteriormente até a origem dos raios pró-correntes da nadadeira caudal. Perfil ventral da cabeça e tronco convexo desde o lábio inferior até a origem da pélvica, reto deste ponto até a origem da nadadeira anal, convexo na base da anal e côncavo do término da anal até a origem dos pró-correntes ventrais da nadadeira caudal.

Espécie discretamente prognata, boca subsuperior. Maxilar alcançando a margem anterior da órbita. Apenas uma série de 9 (2), 10* (5), 11 (6), 12 (3) ou 13 (2) dentes tricúspides decrescendo posteriormente no pré-maxilar. Maxilar com 4 (3), 5 (7), 
$6(2), 7^{*}(7)$ ou 8 (1) dentes tricuspidados. Dentário com duas séries de dentes: 10 (2), 12* (3), 13 (4), 14 (4) ou 15 (1) dentes tricúspides pedunculados com a cúspide central distintamente mais longa que as cúspides laterais na série externa, série interna com dentes diminutos, na maioria, cônicos (podendo ser tricúspides posteriormente) estendendo-se desde a sínfise até próximo ao processo coronóide. Raiosbranquiostégios 4, três articulando com o ceratobranquial anterior e 1 com o ceratobranquial posterior.

Escamas ciclóides, circuli restritos à borda da escama, diversos radii (aproximadamente 21) convergindo para o centro da escama, fortemente anastomosados no centro, formando numerosas células. Série longitudinal da linha lateral com 28 (1), 29 (11), 30* (27), ou 31 (6) escamas, das quais apenas 5 (15) ou 6* (32) são perfuradas. Séries longitudinais entre a nadadeira dorsal e a pélvica 7. Escamas pré-dorsais 12 (3), 13* (25) ou 14 (18). Primeira série longitudinal de escamas alcançando a vertical que passa pela origem da nadadeira anal. Escamas circumpedunculares 12.

Nadadeira peitoral i, $11(1), 12 *(13), 13(15), 14$ (17) ou 15 (1). Ponta da peitoral não alcançando a vertical que passa pela origem da pélvica. Raios da nadadeira pélvica i, 7. Supraneurais 9 (1), 10* (37) ou 11 (29), anteriores aos espinhos neurais dos centros 5 a 13 (1), 14* (37) ou 15 (29). Nadadeira dorsal ii, 7 (1) ou ii, 8* (46). Primeiro pterigióforo da nadadeira dorsal inserido posteriormente ao espinho neural do centro 13 (1), 14* (37) ou 15 (29). Margem distal da nadadeira dorsal arredondada quando expandida. Origem da nadadeira dorsal distintamente mais próxima à base da nadadeira caudal que da ponta do focinho. Base do último raio da dorsal distintamente anterior à vertical que passa pela origem da nadadeira anal. Nadadeira anal iii, 8* (45) ou iii, 9 (2), último raio adnato. Margem distal da nadadeira anal arredondada. Primeiro pterigióforo da nadadeira anal inserido posteriormente ao arco hemal do centro 23 (5), 24 (47) ou 25* (15). Nadadeira adiposa presente. Um único epural. Nadadeira caudal furcada, lóbulo superior discretamente mais longo que o inferior, ambos arredondados. Raios principais da nadadeira caudal i, 8/i, 8 (2) ou i, 9/i, 8 (45). Pró-correntes dorsais 7 (2), 8 (2) 9(1); pró-correntes ventrais 8 (3) 9 (2). Vértebras pré-caudais 23 (3), 24 (2) 25 (1); vértebras caudais 17 (4), 18 (1) 19 (1).

Colorido. Cor de fundo predominantemente amarela. Coloração escura estendendo-se desde o lábio superior até a porção exposta dos parietais e ao longo da série medial e 
primeira série de escamas até a origem da nadadeira caudal. Maxilar, ossos circumorbitais e série opercular densamente pigmentados próximo à porção dorsal da cabeça, tornando-se gradualmente amarelada ventralmente; opérculo com uma distinta mancha escura na região médio-inferior. Estreita faixa escura estendendo-se da porção dorsal da órbita, passando pelos infra-orbitais 5 e 6 e face dorsal do opérculo. Lábio inferior intensamente pigmentado; restante da mandíbula e toda porção ventral da cabeça com pigmentação escassa.

Tronco tornando-se gradualmente amarelado ventralmente. Região abdominal amarela, com diminutos cromatóforos entre o istmo e a origem da nadadeira anal. Mancha umeral trapezoidal, se estendendo por sete escamas da série da linha lateral, conspícua em indivíduos jovens e adultos. Faixa primária representada por seis a nove manchas longas e estreitas, distribuídas entre a mancha umeral e a mancha caudal. Ao longo da ontogenia, tais manchas se conectam por meio de uma faixa escura de espessura similar. Faixa secundária inconspícua, estendendo-se ao longo da primeira e segunda séries longitudinais de escamas, desde os epoccipitais à vertical que passa pelo término da nadadeira dorsal. Segunda e terceira séries longitudinais de escamas com pigmentação na borda posterior, criando um padrão reticulado. Na porção posterior do corpo, as escamas da terceira série longitudinal podem apresentar pequenas manchas escuras na base, no meio das quais se deposita o pigmento carotenóide da primeira série de manchas claras. Base da dorsal distintamente mais escura que o dorso. Mancha caudal triangular, originando-se próximo à vertical que passa pela ponta da adiposa quando adpressa ao corpo, estendendo-se à base de 11 raios medianos da nadadeira caudal. Nadadeiras peitoral, pélvica e anal hialinas; membranas interradiais entre o segundo raio indiviso e o quinto raio ramificado da nadadeira dorsal com uma distinta mancha escura; porção proximal dos raios da nadadeira dorsal com uma distinta mancha escura, bastante intensa em indivíduos jovens, mas gradualmente perdendo intensidade ao longo da ontogenia; ponto de ramificação dos raios da nadadeira dorsal com uma distinta mancha escura; membrana interradial dos raios da nadadeira caudal com pequenas manchas escuras, na borda da bainha de escamas que recobre parte dos lóbulos da nadadeira. 
Dimorfismo sexual. Exemplares machos de Lebiasina panamensis apresentam o padrão mais difundido de dimorfismo sexual entre as Lebiasina, descrito acima para $L$. astrigata.

Distribuição. Bacia dos rios Indio, Chagres, Cangandí, Azucar e Bayano, no Panamá.

Tabela 15. Dados morfométricos de Lebiasina panamensis.

\begin{tabular}{lccccc} 
& $\mathrm{n}$ & Range & Mean & SD & Lectotype \\
\cline { 2 - 6 } & 53 & $45,2-139,1$ & 93,4 & & 65,9 \\
Standard length Morphometrics \% of SL & & & & & \\
Depth dorsal fin origin & 45 & $19,9-23,2$ & 21,7 & 0,9 & 22,6 \\
Snout to anal fin origin & 46 & $71,5-78,2$ & 75,2 & 1,4 & 78,2 \\
Snout to pelvic fin origin & 46 & $48,8-56,0$ & 52,4 & 1,3 & 56,0 \\
Snout to dorsal fin origin & 46 & $52,0-56,9$ & 55,1 & 1,0 & 56,6 \\
Dorsal fin origin to caudal base & 46 & $44,8-50,1$ & 46,5 & 1,1 & 46,1 \\
Dorsal fin length & 46 & $15,4-20,9$ & 18,9 & 1,2 & 19,1 \\
Dorsal fin base & 46 & $7,9-10,4$ & 8,8 & 0,6 & 8,3 \\
Adipose fin to caudal peduncle & 46 & $11,8-16,4$ & 13,7 & 0,8 & 12,9 \\
Length caudal peduncle & 46 & $13,3-17,5$ & 15,9 & 0,8 & 13,3 \\
Depth caudal peduncle & 46 & $10,3-12,4$ & 11,3 & 0,5 & 12,0 \\
Anal fin length & 46 & $16,8-24,7$ & 19,6 & 1,9 & 19,3 \\
Anal fin base & 46 & $9,4-16,8$ & 11,3 & 1,4 & 10,6 \\
Pelvic- to anal fin origin & 46 & $20,8-26,3$ & 23,1 & 1,2 & 22,5 \\
Pelvic fin length & 46 & $12,3-15,0$ & 13,7 & 0,6 & 14,0 \\
Pectoral to pelvic fin origin & 46 & $26,0-33,5$ & 29,7 & 1,4 & 32,4 \\
Pectoral fin length & 46 & $13,3-18,0$ & 16,3 & 1,0 & 17,6 \\
Snout to pectoral fin origin & 46 & $20,9-24,5$ & 23,0 & 0,9 & 23,6 \\
Bony head length & 46 & $22,3-26,9$ & 25,2 & 0,9 & 26,9 \\
& & & & & \\
Head width & 46 & $51,0-63,6$ & 55,3 & 3,1 & 53,8 \\
Horizontal eye diameter & 46 & $17,9-25,2$ & 21,8 & 1,8 & 25,2 \\
Distance snout tip to eye & 46 & $25,9-31,9$ & 28,9 & 1,4 & 25,9 \\
Interorbital distance & 46 & $33,2-37,7$ & 34,6 & 1,0 & 34,3 \\
Length lower jaw & 46 & $42,1-46,9$ & 44,6 & 1,0 & 43,8 \\
Length upper jaw & 46 & $20,0-40,1$ & 22,8 & 4,1 & 37,2 \\
\hline
\end{tabular}

Lebiasina taphorni Ardila-Rodriguez

(Figura 96)

Série-tipo. Holótipo: CAR 15-04-47. Parátipos: CAR 15-04-48 (2)

Localidade-tipo. Rio Caura, Estado Bolívar, Venezuela. 


\section{Material examinado.}

CAR 15-04-15 (ex-MCNG 18817) (3, 106.6-123.7 mm SL), Venezuela, Bolívar, Cedeño, Guanajuja [0509'00”N 6409'00’W], arroio em quebrada na selva úmida, a jusante de uma pequena cachoeira, 13-V-1988, B. Stergios et al.;

CAR 15-04-47 holótipo (ex-MCNG 19939) (1, $87.1 \mathrm{~mm}$ SL), Venezuela, Bolívar, quebrada no médio rio Caura, IV-1989, L. Nico et al.;

CAR 15-04-48 parátipos (ex-MCNG 19939) (6, 34.0-62.4 mm SL), Venezuela, Bolívar, quebrada no médio rio Caura, IV-1989, L. Nico et al.;

MCNG 18814 (5, 61.3-123.0 mm SL; 1 c\&s, 67.9 mm SL, Venezuela, Bolívar, Cedeño,

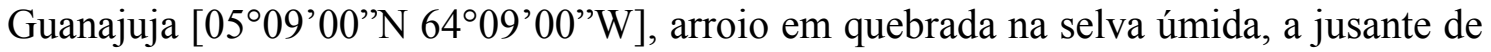
uma pequena cachoeira, 13-V-1988, B. Stergios et al.;

MCNG 18817 (15, 70.0-142.3 mm SL), Venezuela, Bolívar, Cedeño, Guanajuja [0509'00”N 6409'00”W], arroio em quebrada na selva úmida, a jusante de uma pequena cachoeira, 13-V-1988, B. Stergios et al.;

MCNG 18910 (5, 94.3-140.3 mm SL), Venezuela, Bolívar, Cedeño, Guanajuja [0509’00”N 6409'00”W], arroyo pequeño en rio Caura, 13-V-1988, B. Stergios et al.; MCNG 19939 (21, 76.4-133.7 mm SL), Venezuela, Bolívar, Guanajuja [0509’00’N 6409'00’W], afluente del Rio Caura (a 450 m. NE del helipuerto), 00-00-1989, L. Nico;

MNRJ 14229 (5, 81.2-116.9 mm SL), Venezuela, Bolívar, Cedeño, Guanajuja [0509'00”N 6409’00”W], arroio em quebrada na selva úmida, a jusante de uma pequena cachoeira, 13-V-1988, B. Stergios et al.

Diagnose. Lebiasina taphorni difere de Lebiasina bimaculata, L. aff. bimaculata I, L. aff. bimaculata II, L, boruca, L. festae e L. aff. festae por não apresentar a parede da câmara posterior da bexiga natatória "celular", por apresentar as escamas da quinta série longitudinal com tecido epitelial hipertrofiado nos machos adultos e por não apresentar escamas com intensa deposição de guanina (vs. parede da bexiga natatória "celular", escamas da sexta série longitudinal modificadas em machos adultos, ao menos a quarta escama da linha lateral com intensa deposição de guanina). A espécie difere de Lebiasina sp. "Curuá-Pinta" por apresentar faixas longitudinais e mancha caudal, e não apresentar manchas escuras na base das escamas da segunda à quinta séries longitudinais (vs. faixas longitudinais e mancha caudal ausentes; manchas escuras 
presentes na base das escamas da segunda à quinta séries longitudinais). Lebiasina taphorni difere de Lebisina astrigata, L. aureoguttata, L. chocoensis, L. colombia, L. elongata, L. erythrinoides, L. floridablancaensis, L. intermedia, L. multimaculata, L. ortegai, L. panamensis, L. sp. Azuay e L. sp. "Curuá-Faixa” pela seguinte combinação de caracteres: faixa primária inconspícua em adultos; faixa secundária passando ao longo das escamas da segunda e terceira séries longitudinais; série longitudinal de manchas arredondadas distribuídas ao longo das escamas da quarta série longitudinal ausente; presença da faixa "intermediária"; mancha caudal não alcançando o pedúnculo caudal anteriormente. Entre as espécies do clado 93, Lebiasina taphorni difere de L. unitaeniata, L. yuruaniensis e L. sp. "Parima" pela faixa primária inconspícua em exemplares adultos, a faixa secundária conspícua e a ausência da nadadeira adiposa ( $v s$. faixa primária conspícua; faixa secundária inconspícua; nadadeira adiposa presente). A espécie difere ainda de $L$. sp. "Parima" pela faixa "intermediária" restrita aos infraorbitais e ausência da faixa terciária ( $v s$. faixa "intermediária" estendendo-se ao longo das escamas da quinta série longitudinal, alcançando a origem da nadadeira anal; faixa terciária presente). Lebiasina taphorni difere de L. uruyensis pela intensa pigmentação nas escamas do dorso, formando células e pela conspícua faixa "intermediária" ( $v s$. escamas do dorso discretamente pigmentadas; faixa “intermediária” inconspícua).

Descrição. Dados morfométricos apresentados na tabela 16. Corpo comprimido e alongado. Perfil dorsal da cabeça e do corpo convexo do lábio superior até até a origem da nadadeira dorsal, tornando-se praticamente reto entre os parietais e a origem da dorsal. Perfil reto na base da dorsal e levemente côncavo posteriormente até a origem dos raios pró-correntes da nadadeira caudal. Perfil ventral da cabeça e tronco convexo desde o lábio inferior até a origem da pélvica, reto deste ponto até a origem da nadadeira anal, convexo na base da anal e côncavo do término da anal até a origem dos pró-correntes ventrais da nadadeira caudal.

Espécie discretamente prognata, boca subsuperior. Maxilar ultrapassando a margem anterior da órbita. Apenas uma série de 11 (2) dentes tricúspides decrescendo posteriormente no pré-maxilar. Maxilar com 6 (2) dentes tricuspidados. Dentário com duas séries de dentes: 15 (2) dentes tricúspides pedunculados com a cúspide central distintamente mais longa que as cúspides laterais na série externa, série interna com dentes diminutos, na maioria, cônicos (podendo ser tricúspides posteriormente) 
estendendo-se desde a sínfise até próximo ao processo coronóide. Raiosbranquiostégios 4, três articulando com o ceratobranquial anterior e 1 com o ceratobranquial posterior.

Escamas ciclóides, circuli restritos à borda da escama, diversos radii (aproximadamente 26) convergindo para o centro da escama, fortemente anastomosados no centro, formando numerosas células. Série longitudinal da linha lateral com 30 (2), 31 (11) ou 32* (8) escamas, das quais apenas 5 (6) ou 6* (15) são perfuradas. Séries longitudinais entre a nadadeira dorsal e a pélvica 7. Escamas pré-dorsais 12 (1), 13 (13) ou 14* (7). Primeira série longitudinal de escamas se estendendo apenas à vertical que passa pelo término da nadadeira dorsal, ou estendendo-se posteriormente por uma ou duas escamas, nunca alcançando a vertical que passa pelo ânus. Escamas circumpedunculares 12 .

Supraneurais 10 anteriores aos espinhos neurais dos centros 5 a 14 (1). Nadadeira dorsal ii, 8. Primeiro pterigióforo da nadadeira dorsal inserido posteriormente ao espinho neural do centro 14 (1). Margem distal da nadadeira dorsal arredondada quando expandida. Origem da nadadeira dorsal distintamente mais próxima à base da nadadeira caudal que da ponta do focinho. Base do último raio da dorsal distintamente anterior à vertical que passa pela origem da nadadeira anal. Nadadeira anal iii, 8 (16) ou iii, 9*(5). Margem distal da nadadeira anal arredondada. Primeiro pterigióforo da nadadeira anal inserido posteriormente ao arco hemal do centro 25 (1). Nadadeira adiposa ausente. Epurais dois. Nadadeira caudal furcada, lóbulo superior discretamente mais longo que o inferior, ambos arredondados. Raios principais da nadadeira caudal i, 8/i, 8 (1) ou i, 9/i, 8 (20). Pró-correntes dorsais 8 (1); pró-correntes ventrais 7 (1). Vértebras pré-caudais 23 (1); vértebras caudais 19 (1).

Colorido. Cor de fundo predominantemente amarela. Coloração do dorso discretamente mais escura que o ventre. Maxilar, ossos circumorbitais e série opercular pouco pigmentados próximo à porção dorsal da cabeça, tornando-se gradualmente mais claros ventralmente. Porção ventral do infra-orbital 3 com uma discreta mancha horizontalmente alongada, contínua a uma mancha difusa no opéculo. Lábio inferior pouco pigmentado; restante da mandíbula e toda porção ventral da cabeça com pigmentação escassa. 
Tronco tornando-se gradualmente mais claro ventralmente. Região abdominal amarela, com diminutos cromatóforos entre o istmo e a origem da nadadeira anal. Mancha umeral arredondada, conspícua em indivíduos jovens e adultos. Faixa primária difusa, representada apenas por manchas irregulares ao longo das escamas da quarta série longitudinal. Faixa secundária estendendo-se ao longo da segunda e terceira séries longitudinais de escamas, desde os epoccipitais à vertical que passa pela metade da nadadeira dorsal. Inconspícua faixa longitudinal passando ao longo da margem ventral da quinta e margem dorsal da sexta séries longitudinais (visível apenas em exemplares com o colorido muito bem preservado); tal faixa parece contínua à mancha presente no infra-orbital 3 e o opérculo. Base da dorsal distintamente mais escura que o dorso; ao longo da ontogenia, as escamas da série medial, bem como as da primeira e a borda dorsal das escamas da segunda série longitudinal se tornam escuras, apenas com a porção anterior despigmentada; tal processo ocorre tanto na porção anterior do corpo quanto na posterior, e se inicia a partir da base da nadadeira dorsal. Mancha caudal diminuta, arredondada em indivíduos jovens, situada na porção proximal de cinco raios medianos da nadadeira caudal; difusa e inconspícua em exemplares adultos, representada apenas por grupos de cromatóforos; borda anterior da mancha caudal não alcançando o pedúnculo caudal. Nadadeiras peitoral e pélvica hialinas. Pontos de ramificação dos raios da nadadeira dorsal com acúmulo de cromatóforos; base dos raios anteriores densamente pigmentados em jovens, diminuindo gradualmente ao longo da ontogenia até não ser perceptível em adultos. Raio mais posterior da nadadeira anal com pequenas manchas irregulares. Porção proximal do último raio não ramificado e dos quatro raios ramificados mais anteriores densamente pigmentados; ponto de ramificação dos raios com discreta pigmentação. Raios principais da nadadeira caudal com pequenas manchas escuras no ponto de ramificação.

Dimorfismo sexual. Exemplares machos de Lebiasina taphorni apresentam o padrão mais difundido de dimorfismo sexual entre as Lebiasina, descrito acima para $L$. astrigata.

Distribuição. Conhecida apenas do rio Caura, Estado Bolívar, Venezuela (Fig. 97). 
Tabela 16. Dados morfométricos de Lebiasina taphorni.

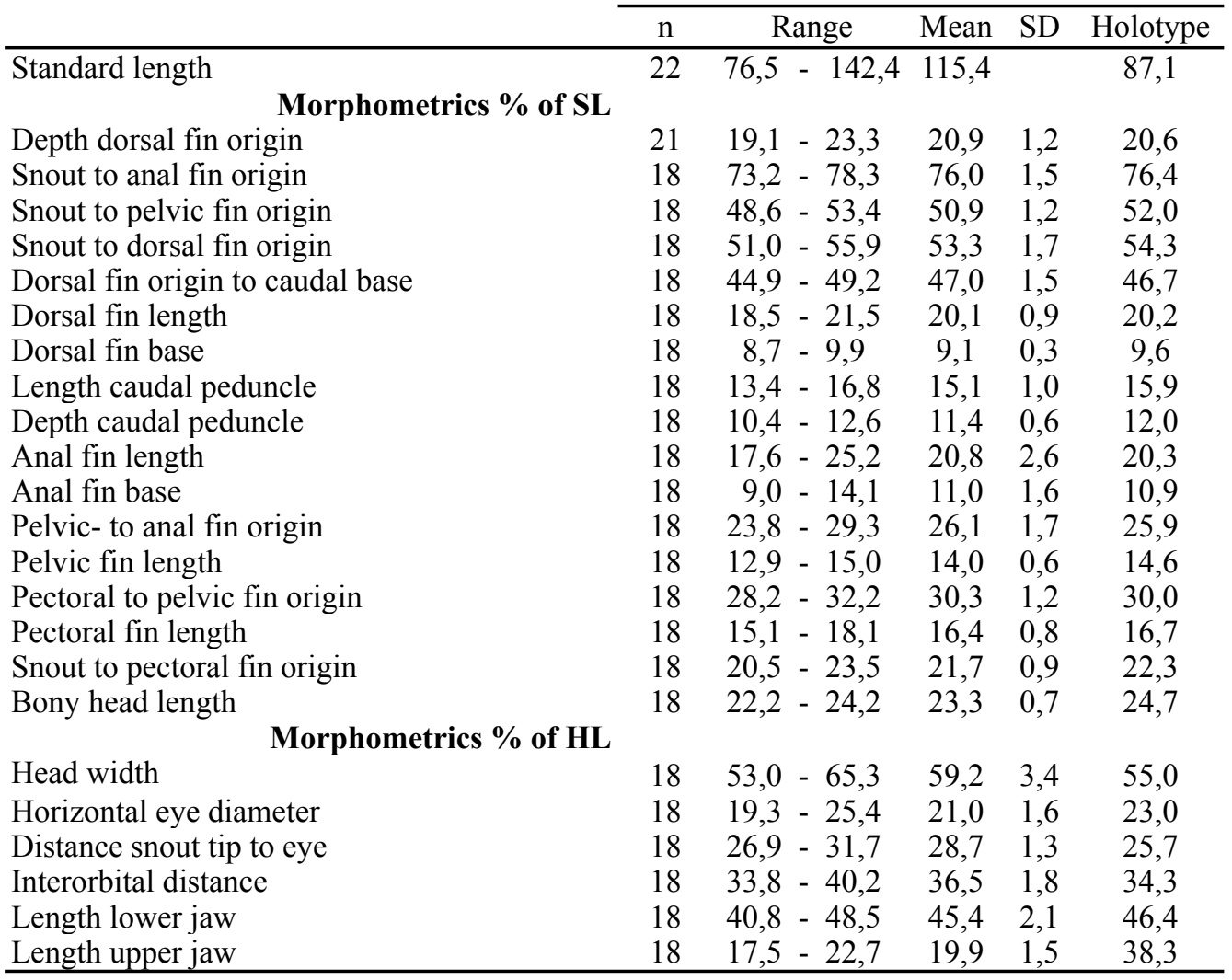

\section{Lebiasina unitaeniata (Günther)}

(Figura 98)

Piabucina unitaeniata Günther, 1864: 311-312 [even though Günther briefly describes L. unitaeniata, the author did not appoint that species as new in his catalog].Eigenmann, \& Eigenmann, 1891: 52 [catalog; incorrect distribution; authors misidentified L. elongata and L. unitaeniata].- Eigenmann, 1910: 439 [catalog; incorrect distribution].- Eigenmann \& Allen, 1942: 278 [incorrect distribution].- Fowler, 1950: 365 [synonymy; incorrect distribution].- Machado-Allison, 1974: 582 [diversity of Lebiasininae]; 583 [suggests a high similarity between the descriptions of $L$. unitaeniata and L. erythrinoides, and that both species would be only distinguishable by their distribution].- Taphorn et al., 1997: 78 [checklist].- Weitzman \& Weitzman, 2003: 246 [checklist].

Lebiasina unitaeniata.- Géry, 1977: 126-127 [key to the species of Lebiasininae].Ardila-Rodríguez, 1999: 3 [description of L. provenzanoi].- Ardila-Rodríguez, 2000: 4 [L. yuruaniensis description].- Géry \& Zarske, 2002: 45. 
Lebiasina sp.- Lasso et al., 1992: 302 [L. unitaeniata as potential predator of Rivulus gransabanae Lasso et al. in the upper Caroni drainage].

Lebiasina uruyensis (non Fernández-Yépez).- Colonello, 1986: 26 [results from the "Estación Hidrobiológica de Guayana" Expedition to the Gran Sabana].

Lebiasina provenzanoi Ardila-Rodriguez, 1999: 2.- Ardila-Rodríguez, 2000: 4 [L. yuruaniensis description].

Série-tipo. Holótipo: BMNH 1988.2.16.1.

Localidade-tipo. "British Guiana".

Nota. Devido a disputas territoriais entre a Venezuela e a Inglaterra, a coroa Inglesa contratou Robert H. Schomburgk e seu irmão R. Schomburgk para realizar um levantamento da região entre 1835 e 1844 (Huber, 1995) e propor uma nova fronteira entre a colônia e o país vizinho. Na ocasião das expedições, os irmãos Schomburgk fizeram extensas coletas ao longo das cabeceiras do Essequibo, Rupununi e Branco. Posteriormente a estas expedições, Robert Schomburgk atravessou a região que atualmente corresponde à Gran Sabana, desde o monte Roraima até as serras Parima e Pakaraima. Apesar de não haver encontrado registros que permitissem precisar os locais de coleta de Schomburgk, é possível que a coleta tenha ocorrido em território venezuelano na região da bacia do rio Apon Wao, que fazia parte da colônia inglesa, uma vez que o tipo de L. yuruaniensis, apesar de encontrar-se mal preservado, é bastante semelhante aos exemplares coletados naquela região.

\section{Material examinado.}

AMNH 199331 (6, 103.4-131.8 mm SL), Venezuela, Bolívar, Soropan-tepuí, 5600’ elev. [Sororopán-tepuí $05^{\circ} 45^{\prime} \mathrm{N} 61^{\circ} 43^{\prime} \mathrm{W}$, quebrada Sororopán tributário da margem esquerda do rio Parupá, tributário do alto Apon wao], XII-1952, E. McGuire (Wetherby Venezuela Expedition); 
BMNH 1988.2.16.1 Holótipo (1, 100.4 mm SL), Guyana [Venezuela, Bolívar?], unknown date, R. H. Schomburgk;

CAR 485 (ex-MBUCV-V 22331) (7, 44.5-98.4 mm SL), Venezuela, Bolívar, Gran Sabana, quebrada Tarotá, sistema do rio Apon Wao, 04-II-1984, M. E. Cabre \& A. Cabre;

MZUSP 73090 (ex-MBUCV-V 29376) (10, 51.2-102.6 mm SL), Venezuela, Bolívar, Gran Sabana, rio Tarota, sistema do rio Apon Wao, 4-II-1984, M. E. Antonio;

USNM 163426 (5, 102.0-129.1 mm SL), Venezuela, Bolívar, Soropan-tepuí, 5600’ elev. [Sororopán-tepuí $05^{\circ} 45^{\prime} \mathrm{N} 61^{\circ} 43^{\prime} \mathrm{W}$, quebrada Sororopán tributário da margem esquerda do rio Parupá, tributário do alto Apon wao], XII-1952, E. McGuire (Wetherby Venezuela Expedition);

USNM 307215 (9, 50.6-110.4 mm SL), Venezuela, Bolívar, Río Tarota, afluente do rio Aponguao [=rio Apon Wao], 04-II-1984, M. E. Antonio C.

Diagnose. Lebiasina unitaeniata difere de Lebiasina bimaculata, L. aff. bimaculata I, L. aff. bimaculata II, L, boruca, L. festae e L. aff. festae por não apresentar a parede da câmara posterior da bexiga natatória “celular", por apresentar as escamas da quinta série longitudinal com tecido epitelial hipertrofiado nos machos adultos e por não apresentar escamas com intensa deposição de guanina (vs. parede da bexiga natatória "celular", escamas da sexta série longitudinal modificadas em machos adultos, ao menos a quarta escama da linha lateral com intensa deposição de guanina). A espécie de Lebiasina sp. "Curuá-Pinta" por apresentar faixas longitudinais e mancha caudal e não apresentar manchas escuras na base das escamas da segunda à quinta séries longitudinais (vs. faixas longitudinais e mancha caudal ausentes; manchas escuras presentes na base das escamas da segunda à quinta séries longitudinais). Difere de Lebisina astrigata, L. aureoguttata, L. chocoensis, L. colombia, L. elongata, L. erythrinoides, L. floridablancaensis, L. intermedia, L. multimaculata, L. ortegai, L. panamensis, L. sp. Azuay e $L$. sp. "Curuá-Faixa” pela seguinte combinação de caracteres: faixa secundária passando ao longo das escamas da segunda e terceira séries longitudinais; série longitudinal de manchas arredondadas distribuídas ao longo das escamas da quarta série longitudinal ausente; presença da faixa "intermediária"; mancha caudal não alcançando o pedúnculo caudal anteriormente. Lebiasina yuruaniensis difere ainda de Lebisina astrigata, L. aureoguttata, L. chocoensis, L. colombia, L. floridablancaensis, L. 
multimaculata e L. sp. Azuay por apresentar a faixa primária conspícua (vs. faixa primária inconspícua em Lebisina astrigata, L. aureoguttata, L. chocoensis, L. multimaculata e L. sp. Azuay; faixa primária conspícua apenas na porção anterior do corpo em L. colombia; apenas a porção posterior da faixa primária conspícua em $L$. floridablancaensis). Entre as espécies do clado 93, Lebiasina unitaeniata difere de $L$. taphorni e L. uruyensis pela faixa primária conspícua, a faixa secundária inconspícua e a presença da nadadeira adiposa ( $v s$. faixa primária inconspícua; faixa secundária conspícua em exemplares adultos; nadadeira adiposa ausente). A espécie difere de $L$. sp. Parima pela faixa "intermediária" restrita aos infra-orbitais e ausência da faixa terciária (vs. faixa "intermediária" estendendo-se ao longo das escamas da quinta série longitudinal, alcançando a origem da nadadeira anal; faixa terciária presente). Lebiasina unitaeniata difere de L. yuruaniensis por apresentar a boca sub-superior, a faixa primária contígua por toda sua extensão, margem posterior do opérculo aproximadamente reta e a borda ventral do cerato-hial anterior com distintas reentrâncias ( $v s$. boca terminal, faixa primária intermitente, margem posterior do opérculo distintamente côncava, borda ventral do cerato-hial anterior com distintas reentrâncias).

Descrição. Dados morfométricos apresentados na tabela 17. Corpo comprimido e alongado. Perfil dorsal da cabeça e do corpo convexo do lábio superior até até a origem da nadadeira dorsal, tornando-se praticamente reto entre os parietais e a origem da dorsal. Perfil reto na base da dorsal e levemente côncavo posteriormente até a origem dos raios pró-correntes da nadadeira caudal. Perfil ventral da cabeça e tronco convexo desde o lábio inferior até a origem da pélvica, reto deste ponto até a origem da nadadeira anal, convexo na base da anal e côncavo do término da anal até a origem dos pró-correntes ventrais da nadadeira caudal.

Espécie discretamente prognata, boca sub-superior. Maxilar alcançando a margem anterior da órbita. Apenas uma série de 9 (1), 10 (3), 11* (14) ou 12 (4) dentes tricúspides decrescendo posteriormente no pré-maxilar. Maxilar com $5^{*}(1), 7(6), 8$ (5), 9 (5) ou 10 (7) dentes tricuspidados. Dentário com duas séries de dentes: 12 (8), 13 (8), 14 (5), 15 (5) ou 16* (2) dentes tricúspides pedunculados com a cúspide central distintamente mais longa que as cúspides laterais na série externa, série interna com dentes diminutos, na maioria, cônicos (podendo ser tricúspides posteriormente) 
estendendo-se desde a sínfise até próximo ao processo coronóide. Raiosbranquiostégios 4 , três articulando com o ceratobranquial anterior e 1 com o ceratobranquial posterior.

Escamas ciclóides, circuli restritos à borda da escama, diversos radii (aproximadamente 30) convergindo para o centro da escama, fortemente anastomosados no centro, formando numerosas células. Série longitudinal da linha lateral com 29 (4), 30 (16) ou 31* (6) escamas, das quais apenas 5 (3), 6 (20) ou $7^{*}$ (2) são perfuradas. Séries longitudinais entre a nadadeira dorsal e a pélvica 7. Escamas pré-dorsais 12 (11), 13 (33), 14* (9) ou 15 (1). Primeira série longitudinal de escamas se estendendo apenas à vertical que passa pelo término da nadadeira dorsal, ou estendendo-se posteriormente por uma ou duas escamas, nunca alcançando a vertical que passa pelo ânus. Escamas circumpedunculares 12 .

Nadadeira peitoral i, 11 (1), 12 (10), 13* (13) ou 14 (2). Ponta da peitoral não alcançando a vertical que passa pela origem da pélvica. Raios da nadadeira pélvica i, 7. Supraneurais $9(6), 10 *(23)$ ou 11 (9) anteriores aos espinhos neurais dos centros 5 a 13 (6), 14* (23) ou 15 (9). Nadadeira dorsal ii, 8. Primeiro pterigióforo da nadadeira dorsal inserido posteriormente ao espinho neural do centro 13 (6), 14*(23) ou 15 (9). Margem distal da nadadeira dorsal arredondada quando expandida. Origem da nadadeira dorsal distintamente mais próxima à base da nadadeira caudal que da ponta do focinho. Base do último raio da dorsal distintamente anterior à vertical que passa pela origem da nadadeira anal. Nadadeira anal iii, 8. Margem distal da nadadeira anal arredondada. Primeiro pterigióforo da nadadeira anal inserido posteriormente ao arco hemal do centro 22 (1), 23* (23) ou 24 (14). Nadadeira adiposa presente. Epurais dois. Nadadeira caudal furcada, lóbulo superior discretamente mais longo que o inferior, ambos arredondados. Raios principais da nadadeira caudal i, 9/i, 8. Pró-correntes dorsais 7 (1), 8 (4) ou 9 (1); pró-correntes ventrais 7 (2), 8 (4) ou 9 (1). Vértebras pré-caudais 21 (1) ou 22 (7); vértebras caudais 17 (3), 18 (4) ou 19 (1).

Colorido. Cor de fundo escura. Coloração do dorso distintamente mais escura que o ventre. Maxilar, ossos circumorbitais e série opercular intensamente pigmentados próximo à porção dorsal da cabeça, tornando-se gradualmente mais claros ventralmente. Porção ventral do infra-orbital 3 com uma discreta mancha horizontalmente alongada, contínua a uma mancha difusa no opéculo. Lábio inferior bastante pigmentado; restante 
da mandíbula e toda porção ventral da cabeça escuros, tornando-se gradualmente mais claros posteriormente.

Tronco tornando-se gradualmente mais claro ventralmente. Região abdominal amarela, com diminutos cromatóforos entre o istmo e a origem da nadadeira anal. Mancha umeral arredondada, conspícua em indivíduos jovens, tornando-se inconspícua ao longo da ontogenia, na medida em que a faixa primária se sobrepõe a esta. Faixa primária conspícua, estendendo-se desde o supracleitro até a vertical que passa pela origem dos raios pró-correntes da nadadeira caudal, sendo mais conspícua a partir da vertical que passa pela ponta dos raios da peitoral, quando adpressa ao corpo. Faixa secundária inconspícua, estendendo-se por todo o corpo, ao longo da segunda e terceira séries longitudinais de escamas, também se estendendo pelos raios principais mais dorsais do lóbulo superior da nadadeira caudal. Base da dorsal distintamente mais escura que o dorso. Inconspícua faixa longitudinal passando ao longo da margem ventral da quinta e margem dorsal da sexta séries longitudinais (visível apenas em exemplares com o colorido muito bem preservado; aparentemente ausente em exemplares com mais de $100.0 \mathrm{~mm} \mathrm{SL}$ ); tal faixa parece contínua à mancha presente no infra-orbital 3 e o opérculo. Mancha caudal diminuta, arredondada em indivíduos jovens, situada na porção proximal de cinco raios medianos da nadadeira caudal; difusa e inconspícua em exemplares adultos, representada apenas por grupos de cromatóforos; borda anterior da mancha caudal não alcançando o pedúnculo caudal. Nadadeira peitoral hialina. Ponto de ramificação dos raios da nadadeira pélvica com discretas manchas escuras. Porção proximal dos raios da nadadeira dorsal densamente pigmentados em jovens e adultos; ponto de ramificação com distintas manchas escuras, também observados nas nadadeiras anal e caudal. Raio mais posterior da nadadeira anal com pequenas manchas irregulares; porção distal dos raios densamente pigmentada. Membrana inter-radial dos raios principais da nadadeira caudal com distintas manchas escuras no término da bainha de escamas que recobre parte dos raios.

Dimorfismo sexual. Exemplares machos de Lebiasina unitaeniata apresentam o padrão mais difundido de dimorfismo sexual entre as Lebiasina, descrito acima para $L$. astrigata. Adicionalmente, exemplares machos de L. unitaeniata apresentam a faixa primária distintamente mais escura que as fêmeas. 
Distribuição. Espécie endêmica do alto rio Caroni, Bolívar, Venezuela (Fig. 97).

Tabela 17. Dados morfométricos de Lebiasina unitaeniata.

\begin{tabular}{|c|c|c|c|c|c|}
\hline & $\mathrm{n}$ & Range & Mean & SD & Holotype \\
\hline Standard length & 26 & $27,5-131,8$ & 95,5 & & 100,0 \\
\hline \multicolumn{6}{|c|}{ Morphometrics \% of SL } \\
\hline Depth dorsal fin origin & 21 & $20,3-24,2$ & 22,7 & 1,1 & 23,2 \\
\hline Snout to anal fin origin & 21 & $72,6-77,1$ & 75,2 & 1,2 & 72,6 \\
\hline Snout to pelvic fin origin & 21 & $47,4-51,8$ & 50,5 & 0,8 & 47,4 \\
\hline Snout to dorsal fin origin & 21 & $53,8-57,8$ & 56,4 & 1,0 & 53,8 \\
\hline Dorsal fin origin to caudal base & 21 & $43,8-48,7$ & 45,3 & 0,8 & 48,7 \\
\hline Dorsal fin length & 21 & $18,1-21,3$ & 19,8 & 1,0 & 21,1 \\
\hline Dorsal fin base & 21 & $8,3-10,5$ & 9,2 & 0,5 & 10,5 \\
\hline Adipose fin to caudal ped & 21 & $10,1-14,3$ & 12,7 & 1,0 & 12,1 \\
\hline Length caudal peduncle & 21 & $12,9-17,7$ & 15,1 & 1,3 & 17,0 \\
\hline Depth caudal peduncle & 21 & $9,8-11,5$ & 10,7 & 0,4 & 10,0 \\
\hline Anal fin length & 21 & $18,6-24,7$ & 19,9 & 1,6 & 21,0 \\
\hline Anal fin base & 21 & $8,7-13,6$ & 10,9 & 1,0 & 13,0 \\
\hline Pelvic- to anal fin origin & 21 & $22,7-28,6$ & 25,8 & 1,5 & 25,5 \\
\hline Pelvic fin length & 21 & $12,5-15,2$ & 13,9 & 0,8 & 13,4 \\
\hline Pectoral to pelvic fin origin & 21 & $25,7-30,8$ & 27,5 & 1,1 & 26,0 \\
\hline Pectoral fin length & 21 & $15,4-19,6$ & 17,0 & 1,0 & 18,0 \\
\hline Snout to pectoral fin origin & 21 & $21,0-25,0$ & 23,5 & 0,9 & 23,0 \\
\hline \multirow{2}{*}{\multicolumn{6}{|c|}{ Morphometrics \% of $\mathrm{HL}$}} \\
\hline & & & & & \\
\hline Head width & 21 & $45,2-54,8$ & 48,9 & 2,0 & 49,8 \\
\hline Horizontal e & 21 & $17,2-25,3$ & 21,1 & 2,1 & 22,2 \\
\hline Distance snout tip to eye & 21 & $25,1-29,6$ & 27,1 & 1,3 & 25,5 \\
\hline Interorbital distance & 20 & $30,0-36,7$ & 32,4 & 1,5 & 36,6 \\
\hline Length lower jaw & 21 & $42,7-49,0$ & 45,0 & 1,7 & 48,1 \\
\hline Length upper jaw & 20 & $34,4-40,8$ & 37,8 & 1,7 & 38,3 \\
\hline
\end{tabular}

\section{Lebiasina uruyensis Fernández-Yépez}

(Figura 99)

Lebiasina uruyensis Fernández-Yépez, 1967: 173.- Mago-Leccia, 1970: 74 [checklist].Fernández-Yépez, 1972: 13 [“hace algunos años describí una especie que colecté en la región del Auyantepuy, propiamente en el Uruyen medio"].- [Taphorn \& Tenía, 1991: fig. 5 [fishes from the rio Caroni in the MCNG collection].- Lasso et al. 1997:43 [type catalog MHNLS].- Taphorn et al., 1997: 78 [checklist].- Provenzano et al., 1998:12 [type catalog of MBUCV].- Eschmeyer, 1998: 1732 [catalog].-Ardila-Rodríguez 1999: 4 [description of L. provenzanoi]; 2000: 4 [L. yuruaniensis description].- Géry \& Zarske 2002: 45 [description of Derhamia].- Weitzman \& Weitzman 2003: 243 [checklist].Ardila-Rodríguez 2004: 60 [description of L. taphorni].

Série-tipo. Holótipo: MHNLS 789. Parátipos: MBUCV-V-2601 (1). 


\section{Material examinado.}

AMNH 14262 (1, 114.5 mm SL), Venezuela, Bolívar, rio Haicha [rio Haicha não consta em nenhum Gazetteer consultado. De acordo com os relatórios da Phelps Venezuela Expedition, esta localidade estaria próxima do acampamento, cerca de $05^{\circ} 44^{\prime} 41^{\prime \prime} \mathrm{N}$ 62²7’37’W], sopé do Auyán-tepui, III-1938, G. H. H. Tate, Dillon;

AMNH 14263 (1, 82.1 mm SL), Venezuela, Bolívar, rio Haicha [0544’41'N 62²7’37’W], sopé do Auyán-tepui, 450 m elev., III-1938, Phelps Venezuela Expedition;

AMNH 14264 (1, 93.9 mm SL), Venezuela, Bolívar, Río Haicha [0544’41”N 62²7’37’W], sopé do Auyán-tepui, 600 m elev., 06-XII-1937, Phelps Venezuela Expedition;

AMNH 59048 (20/52, 41.7-127.9 mm SL), Cerro Guaiquinima [0549’00”N 6340’00”W], riacho na floresta, próximo ao acampamento I, 27-II-1990, M. A. Donnelly \& R. Prum;

AMNH 59049 (4, 63.0-111.9 mm SL), Venezuela, Bolívar, tributário da margem esquerda do rio Carapo, entre a segunda e terceira corredeiras [Río Carapo 05³9'N $63^{\circ} 40^{\prime} \mathrm{W}$ afl. margem direita do rio Paragua, 450-550 m elev., encosta sul e leste do Cerro Guaiquinima], 28-II-1990, C. J. Ferraris \& R. Royero L.;

CAR 15-04-14 (ex-MHNLS 787) (3, 87.4-90.4 mm SL), Venezuela, Bolívar, rio Guayaraca [Campo Guayaraca $05^{\circ} 41^{\prime} \mathrm{N} 62^{\circ} 32^{\prime} \mathrm{W}$ ], ao sul de Auyan Tepuy, $980 \mathrm{~m}$ elev., 24-IV-1956, A. Fernandez-Yépez;

CAR 449 (ex-MHNLS AV-53) (8, 132.5-35.2 mm SL), Venezuela, unknown date and collector;

CAR 456 (ex-MHNLS 14458) (4, 64.4-81.4 mm SL), Venezuela, Bolívar, Parque Nacional Canaima, rio Wareipita, braços marginais, Wareipa, 0600’32”N 6246'52”W, 27-IX-2000, C. Lasso et al.;

MBUCV-V 2601 parátipo (1,83.1 mm SL), médio rio Uruyén [Uruyén: 0540’53”N 62²5’33”W], IV-1956, A. Fernández-Yépez;

MBUCV V-3981 (16, 89.5-132.5 mm SL), Venezuela, Bolívar, Gran Sabana, 'La Mejicana', no km 105 da rodovia El Dorado-Santa Elena de Uairén [0558'58’N $61^{\circ} 24^{\prime} 54^{\prime} \mathrm{W}$ rótulo provavelmente trocado. Localidade nas cabeceiras do rio Cuyuni, onde a espécie não ocorre], 26-IV-1966, J. Moscó et al. 
MHNLS 789 holótipo (1, 110.9 mm SL), Venezuela, Bolívar, rio Guayaraca, ao sul de Auyán-tepui, $980 \mathrm{~m}$ elev. [Campo Guayaraca $05^{\circ} 41^{\prime} \mathrm{N} 62^{\circ} 32^{\prime} \mathrm{W}$, cabeceiras do rio Uraima, afl. margem direita do rio Aprada, afl. margem direita do rio Caroní], 24IV-1956, A. Fernández-Yépez et al.;

MHNLS 789 parátipos $(9,96.6-118.0 \mathrm{~mm}$ SL), Venezuela, Bolívar, Río Guayaraca, ao sul de Auyán-tepui, $980 \mathrm{~m}$ elev. [Campo Guayaraca $05^{\circ} 41^{\prime} \mathrm{N} 62^{\circ} 32^{\prime} \mathrm{W}$, cabeceiras do rio Uraima, afl. margem direita do rio Aprada, afl. margem direita do rio Caroní], 24IV-1956, A. Fernández-Yépez et al.;

MNRJ 14228 (5, 29.8-97.3 mm SL; 2 c\&s, 49.4-77.5 mm SL), Venezuela, Bolívar, Roscio, riacho na mata a $4 \mathrm{Km}$ do rio Parapapoy [na estrada para Manteco, tributário do rio Supamo, sistema Cuyuni-Essequibo, 6³5'0”'N, 6242’0”W], 30-XI-1992, L. Nico \& V. Muñoz;

UF 97900 (7, 34.4-96.3 mm SL), Venezuela, Bolívar, Roscio, riacho na mata, a aprox. 4 $\mathrm{km}$ do rio Parapapoy, na estrada para Manteco, tributário do rio Supamo, 06³5’00”N, 6242’00”'W, 30-XI-1992, L. Nico \& V. Muñoz.

Localidade-tipo. Rio Uruyén, região do Auyan tepui, bacia do Caroní, Estado Bolívar, Venezuela.

Diagnose. Lebiasina uruyensis difere de Lebiasina bimaculata, L. aff. bimaculata I, L. aff. bimaculata II, L, boruca, L. festae e L. aff. festae por não apresentar a parede da câmara posterior da bexiga natatória “celular", por apresentar as escamas da quinta série longitudinal com tecido epitelial hipertrofiado nos machos adultos e por não apresentar escamas com intensa deposição de guanina (vs. parede da bexiga natatória "celular", escamas da sexta série longitudinal modificadas em machos adultos, ao menos a quarta escama da linha lateral com intensa deposição de guanina). A espécie difere de Lebiasina sp. "Curuá-Pinta" por apresentar faixas longitudinais e mancha caudal, e não apresentar manchas escuras na base das escamas da segunda à quinta séries longitudinais (vs. faixas longitudinais e mancha caudal ausentes; manchas escuras presentes na base das escamas da segunda à quinta séries longitudinais). Lebiasina uruyensis difere de Lebisina astrigata, L. aureoguttata, L. chocoensis, L. colombia, L. elongata, L. erythrinoides, L. floridablancaensis, L. intermedia, L. multimaculata, L. ortegai, L. panamensis, L. sp. Azuay e L. sp. “Curuá-Faixa” pela seguinte combinação 
de caracteres: faixa primária inconspícua em adultos; faixa secundária passando ao longo das escamas da segunda e terceira séries longitudinais; série longitudinal de manchas arredondadas distribuídas ao longo das escamas da quarta série longitudinal ausente; presença da faixa "intermediária"; mancha caudal não alcançando o pedúnculo caudal anteriormente. Lebiasina uruyensis difere de L. unitaeniata, L. yuruaniensis e L. sp. "Parima" pela faixa primária inconspícua em exemplares adultos, a faixa secundária conspícua e a ausência da nadadeira adiposa ( $v s$. faixa primária conspícua; faixa secundária inconspícua; nadadeira adiposa presente). A espécie difere ainda de $L$. sp. "Parima" pela faixa "intermediária" restrita aos infra-orbitais e ausência da faixa terciária (vs. faixa "intermediária" estendendo-se ao longo das escamas da quinta série longitudinal, alcançando a origem da nadadeira anal; faixa terciária presente). Lebiasina uruyensis difere de L. taphorni pela discreta pigmentação nas escamas do dorso, não formando células e pela faixa "intermediária" inconspícua (vs. escamas do dorso intensamente pigmentadas; faixa "intermediária” conspícua).

Descrição. Dados morfométricos apresentados na tabela 18. Corpo comprimido e alongado. Perfil dorsal da cabeça e do corpo convexo do lábio superior até até a origem da nadadeira dorsal, tornando-se praticamente reto entre os parietais e a origem da dorsal. Perfil reto na base da dorsal e levemente côncavo posteriormente até a origem dos raios pró-correntes da nadadeira caudal. Perfil ventral da cabeça e tronco convexo desde o lábio inferior até a origem da pélvica, reto deste ponto até a origem da nadadeira anal, convexo na base da anal e côncavo do término da anal até a origem dos pró-correntes ventrais da nadadeira caudal.

Espécie discretamente prognata, boca subsuperior. Maxilar ultrapassando a margem anterior da órbita. Apenas uma série de 10 (10), 11 (36), 12* (15) ou 13 (3) dentes tricúspides decrescendo posteriormente no pré-maxilar. Maxilar com 5 (1), 6 (7), $7(19), 8(16), 9 *(10), 10(8), 11$ (1) ou 12 (1) dentes tricuspidados. Dentário com duas séries de dentes: 12 (13), 13 (10), 14* (13), 15 (3), 16 (1) ou 17 (1) dentes tricúspides pedunculados com a cúspide central distintamente mais longa que as cúspides laterais na série externa, série interna com dentes diminutos, na maioria, cônicos (podendo ser tricúspides posteriormente) estendendo-se desde a sínfise até próximo ao processo coronóide. Raios-branquiostégios 4 , três articulando com o ceratobranquial anterior e 1 com o ceratobranquial posterior. 
Escamas ciclóides, circuli restritos à borda da escama, diversos radii (aproximadamente 21) convergindo para o centro da escama, fortemente anastomosados no centro, formando numerosas células. Série longitudinal da linha lateral com 29 (3), 30 (17), 31 (16) ou 32* (6) escamas, das quais apenas 5 (7), 6* (23) ou 7 (8) são perfuradas. Séries longitudinais entre a nadadeira dorsal e a pélvica 7. Escamas prédorsais 12 (4), 13 (13), 14 (20) ou 15 (1). Primeira série longitudinal de escamas se estendendo apenas à vertical que passa pelo término da nadadeira dorsal, ou estendendo-se posteriormente por uma ou duas escamas, nunca alcançando a vertical que passa pelo ânus. Escamas circumpedunculares 12 .

Nadadeira peitoral i, $12(8), 13 *(22)$ ou 14 (8). Ponta da peitoral não alcançando a vertical que passa pela origem da pélvica. Raios da nadadeira pélvica i, $7^{*}$ (36) ou i, 6 (2). Supraneurais $10(13)$ ou 11*(15) anteriores aos espinhos neurais dos centros 5 a 14 (12) ou 15* (15). Nadadeira dorsal ii, 8* (37) ou i, 9 (1). Primeiro pterigióforo da nadadeira dorsal inserido posteriormente ao espinho neural do centro 14 (12) ou $15^{*}$ (15). Margem distal da nadadeira dorsal arredondada quando expandida. Origem da nadadeira dorsal distintamente mais próxima à base da nadadeira caudal que da ponta do focinho. Base do último raio da dorsal distintamente anterior à vertical que passa pela origem da nadadeira anal. Nadadeira anal iii, 7 (1), iii, 8 (35) ou iii, 9 (2). Margem distal da nadadeira anal arredondada. Primeiro pterigióforo da nadadeira anal inserido posteriormente ao arco hemal do centro 24 (1), 25* (21) ou 26 (7). Nadadeira adiposa presente em apenas quatro dos exemplares examinados. Epurais dois. Nadadeira caudal furcada, lóbulo superior discretamente mais longo que o inferior, ambos arredondados. Raios principais da nadadeira caudal ii, 8/i, 8 (1), i, 8/ i, 7 (1) ou i, 9/i, 8* (36). Prócorrentes dorsais 8 (2) ou 9 (3); pró-correntes ventrais 9 (6). Vértebras pré-caudais 23 (1), 24* (7), 25 (2) ; vértebras caudais 16 (1), 17 (5) 18* (4).

Colorido. Cor de fundo predominantemente amarela. Coloração do dorso discretamente mais escura que o ventre. Maxilar, ossos circumorbitais e série opercular pouco pigmentados próximo à porção dorsal da cabeça, tornando-se gradualmente mais claros ventralmente. Porção ventral do infra-orbital 3 com uma discreta mancha horizontalmente alongada, contínua a uma mancha difusa no opéculo. Lábio inferior pouco pigmentado; restante da mandíbula e toda porção ventral da cabeça com pigmentação escassa. 
Tronco tornando-se gradualmente mais claro ventralmente. Região abdominal amarela, com diminutos cromatóforos entre o istmo e a origem da nadadeira anal. Mancha umeral arredondada, conspícua em indivíduos jovens e adultos. Faixa primária difusa, representada apenas por manchas irregulares ao longo das escamas da quarta série longitudinal. Faixa secundária estendendo-se ao longo da segunda e terceira séries longitudinais de escamas, desde os epoccipitais à vertical que passa pela origem da nadadeira anal. Inconspícua faixa longitudinal passando ao longo da margem ventral da quinta e margem dorsal da sexta séries longitudinais (visível apenas em exemplares com o colorido muito bem preservado); tal faixa parece contínua à mancha presente no infraorbital 3 e o opérculo. Base da dorsal distintamente mais escura que o dorso; ao longo da ontogenia, a porção mediana da borda posterior das escamas da série medial, bem como as da primeira e a borda dorsal das escamas da segunda série longitudinal se torna escura, formando pequenas manchas escuras; tal processo ocorre tanto na porção anterior do corpo quanto na posterior, e se inicia a partir da base da nadadeira dorsal. Mancha caudal diminuta, arredondada em indivíduos jovens, situada na porção proximal de cinco raios medianos da nadadeira caudal; difusa e inconspícua em exemplares adultos, representada apenas por grupos de cromatóforos; borda anterior da mancha caudal não alcançando o pedúnculo caudal. Nadadeiras peitoral e pélvica hialinas. Pontos de ramificação dos raios da nadadeira dorsal com acúmulo de cromatóforos; base dos raios anteriores densamente pigmentados em jovens, diminuindo gradualmente ao longo da ontogenia até não ser perceptível em adultos. Raio mais posterior da nadadeira anal com pequenas manchas irregulares. Porção proximal do último raio não ramificado e dos quatro raios ramificados mais anteriores densamente pigmentados; ponto de ramificação dos raios com discreta pigmentação. Raios principais da nadadeira caudal com pequenas manchas escuras no ponto de ramificação.

Dimorfismo sexual. Exemplares machos de Lebiasina uruyensis apresentam o padrão mais difundido de dimorfismo sexual entre as Lebiasina, descrito acima para $L$. astrigata.

Distribuição. Porção superior da bacia do rio Caroni no oeste da Gran Sabana, estado Bolívar, Venezuela (Fig. 97). 
Tabela 18. Dados morfométricos de Lebiasina uruyensis.

\begin{tabular}{lccccc} 
& $\mathrm{n}$ & Range & Mean & SD & Holotype \\
\cline { 2 - 6 } Standard length & 32 & $64,4-132,5$ & 106,5 & & 110,9 \\
& & & & \\
Depth dorsal fin origin & 29 & $17,8-24,5$ & 20,7 & 1,9 & 19,7 \\
Snout to anal fin origin & 29 & $71,5-78,2$ & 76,2 & 1,5 & 78,1 \\
Snout to pelvic fin origin & 29 & $47,4-53,0$ & 50,6 & 1,3 & 51,2 \\
Snout to dorsal fin origin & 29 & $53,1-57,2$ & 54,6 & 1,0 & 54,1 \\
Dorsal fin origin to caudal base & 29 & $44,3-48,8$ & 46,4 & 1,2 & 44,8 \\
Dorsal fin length & 29 & $18,6-22,3$ & 20,2 & 0,9 & 19,2 \\
Dorsal fin base & 29 & $8,7-10,3$ & 9,5 & 0,4 & 9,5 \\
Adipose fin to caudal peduncle & 4 & $11,9-12,9$ & 12,2 & 0,5 & 0,0 \\
Length caudal peduncle & 29 & $13,1-18,1$ & 15,3 & 1,2 & 14,5 \\
Depth caudal peduncle & 29 & $10,1-13,3$ & 11,6 & 0,8 & 11,4 \\
Anal fin length & 29 & $17,5-24,0$ & 20,4 & 2,0 & 22,9 \\
Anal fin base & 29 & $9,2-14,3$ & 11,4 & 1,5 & 13,0 \\
Pelvic- to anal fin origin & 29 & $23,6-29,4$ & 26,3 & 1,3 & 27,7 \\
Pelvic fin length & 29 & $13,1-16,1$ & 14,3 & 0,7 & 14,5 \\
Pectoral to pelvic fin origin & 28 & $27,4-33,1$ & 29,4 & 1,2 & 30,9 \\
Pectoral fin length & 29 & $15,0-19,1$ & 16,9 & 1,0 & 17,1 \\
Snout to pectoral fin origin & 29 & $20,7-23,8$ & 22,1 & 0,9 & 20,7 \\
Bony head length & 28 & $22,6-26,4$ & 24,3 & 1,0 & 23,1 \\
& & & & & \\
Head width & & & & \\
Horizontal eye diameter & 28 & $48,1-64,7$ & 53,8 & 3,1 & 51,0 \\
Distance snout tip to eye & 28 & $18,2-25,5$ & 21,1 & 1,5 & 20,8 \\
Interorbital distance & 28 & $24,9-31,1$ & 28,0 & 1,4 & 28,5 \\
Length lower jaw & 28 & $31,3-37,3$ & 34,2 & 1,4 & 33,1 \\
Length upper jaw & 28 & $42,2-49,1$ & 44,5 & 1,5 & 46,1 \\
\hline & 28 & $34,4-40,9$ & 38,4 & 1,5 & 38,3 \\
\hline
\end{tabular}

\section{Lebiasina yuruaniensis}

(Figura 100)

Série-tipo. Holótipo: MHNLS 7469. Parátipos: MHNLS 7467 (17); MHNLS 7468 (3).

\section{Material examinado.}

AMNH 1536 (1, 70.7 mm SL), Venezuela, Bolívar, córrego Erkin, braço do rio Arabopo [rio Arabopó $\left.04^{\circ} 47^{\prime} \mathrm{N} 60^{\circ} 52^{\prime} \mathrm{W}\right]$, cabeceiras do rio rio Caroni, VIII-1911, H. E. Crampton, et al.;

AMNH 9662 (3, 82.3-118.5 mm SL), Venezuela, Bolívar, Arabupu, 4200’, Mt. Roraima [Arabopó 0506’N 6044’W, 1200-1300 m elev., 13 Km SE Monte Roraima], XII-1927, J. A. Samuels, et al.;

AUM 36649 (4, 27.7-77.7 mm SL), Venezuela, Bolívar, tributário do rio Waiparú, km 77, no Waipan-Tepuy, sistema do rio Caroní, $04.5^{\circ} \mathrm{N} 61.6^{\circ} \mathrm{W}, 13-\mathrm{VI}-2003$, J.W. Armbruster et al.; 
AUM 36650 (3, 27.5-55.7 mm SL), Venezuela, Bolívar, tributário do rio Waiparú, km 77, no Waipan-Tepuy, sistema do rio Caroní, $04.5^{\circ} \mathrm{N} 61.6^{\circ} \mathrm{W}, 13-\mathrm{VI}-2003$, J.W. Armbruster et al.;

AUM 36651 (2, 80.1-83.9 mm SL), Venezuela, Bolívar, Fundo Cantarrana, rio Ikabaru, afl rio Caroní, km 95, 04.4 N 61.7 W,13-VI-2003, J.W. Armbruster et al.;

CAR 285 (19, 44.4-92.6 mm SL), Venezuela, Bolívar, Gran Sabana, El Pauji, Pozo Esmeralda [04²7’59.1’N 61³6’5.5’W], 30-VI-2006, C. Ardila-Rodriguez;

CAR 286 (7, 51.8-116.8 mm SL), Venezuela, Bolívar, Gran Sabana, rio El Pauji, antes do salto el Pauji, 29-VI-2006, C. Ardila-Rodriguez;

CAR 287 (20, 22.3-94.5 mm SL), Venezuela, Bolívar, Gran Sabana, El Pauji, afluente do rio Chaberú [=rio Waiparú?, 4³0’ $\mathrm{N}, 61^{\circ} 36^{\prime} \mathrm{W}$ coordenada obtida em Moran, 2000], 01-VII-2006, C. Ardila-Rodríguez;

CAR 289 (9, 65.0-78.9 mm SL), Venezuela, Bolívar, Gran Sabana, rio El Pauji, antes do salto El Pauji, 06-VII-2006, C. Ardila-Rodríguez;

CAR 290 (24, 69.9-94.1 mm SL), Venezuela, Bolívar, Quebrada La Burra, Gran Sabana, El Pauji, antes de chegar ao Tepui el Altar, 07-VII-2006, C. Ardila-Rodríguez;

CAR 291 (19, 27.4-94.5 mm SL), Venezuela, Bolívar, Gran Sabana, El Pauji, quebrada La Burra, antes de chegar ao Tepui el Altar, 10-VII-2006, C. Ardila-Rodríguez;

CAR 457 (ex-MBUCV-V 17426) (6, 30.5-85.1 mm SL), Venezuela, Bolívar, Quebrada Cantarrana, aprox. $30 \mathrm{Km}$ ao norte de Icabarú, Gran Sabana, 6, 20-III-1986, Carlos Lasso, G. Marrero;

CAR 477 (ex-MBUCV-V 17453) (5, 37.9-69.9 mm SL), Venezuela, Bolívar, Gran Sabana, quebrada Aropán, entre rio Anavaic e Kamoirán, 23-III-1986, Carlos Lasso, G. Marrero;

CAR 478 (ex-MHNLS 4470) (9, 86.3-87.6 mm SL) Venezuela, Bolívar, Cantarrana, entre el Pauji e Icabarú 600 m elev., 20-III-1986, Carlos Lasso, G. Marrero e J. Medina; MBUCV-V 15285 (38, 95.5-58.0 mm SL), Venezuela, Bolívar, quebrada Cantarrana

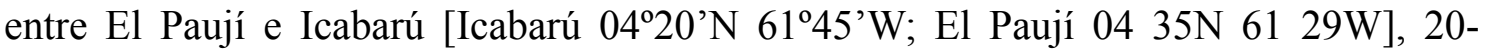
III-1986, C. Lasso et al.;

MBUCV-V 15286 (1, 126.2 mm SL), Venezuela, Bolívar, rio Kakopauri entre Santa Elena y San Ignacio de Yuruaní, 22-III-1986, C. Marrero et al.;

MCNG 18992 (4, 41.5-69.3 mm SL), Venezuela, Bolívar, estrada El Dorado-Gran Sabana, Km 149 [05³9’16.9”N 61²6’12.1’W], 25-VI-1988, L. Nico; 
MCNG 19006 (7, 46.7-68.9 mm SL), Venezuela, Bolívar, Gran Sabana, 22 km ao sul de Whao-whao, 26-VII-1988, L. Nico;

MCNG 44957 (4, 25.0-67.1 mm SL), Venezuela, Bolívar, Gran Sabana, riacho entre os Km 217 e 218 na rodovia para Luepa [Luepa: 544’37.8”N 61³1'8.6”W], 2001, O. L. M.;

MCNG 48089 (3, 24.5-70.1 mm SL), Venezuela, Bolívar, Heres, próximo ao Salto Catedral [em Carucú-maru: 04³4’29.8”N 61¹2’58.8”W], 4,6 Km a Oeste de Santa Elena, 2003, unknown collector;

MCNG 48091 (1, 71.4 mm SL), Venezuela, Bolívar, Heres, Fundo Cantarrana, rio Ikabaru, Km 95 en el Fundo Cantarrana;

MCNG 48103 (33, 15.3-66.1 mm SL; 1 c\&s, 49.0 mm SL), Venezuela, Bolívar, rio Chirima $\left[05^{\circ} 09^{\prime} 00^{\prime} \mathrm{N} 61^{\circ} 00^{\prime} 00^{\prime} \mathrm{W}\right]$ no mirante do vale do rio Chirima, 2003, unknown collector;

MHNLS 4471 (7, 20.6-55.8 mm SL), Venezuela, Bolívar, rio Tuperere entre os rios

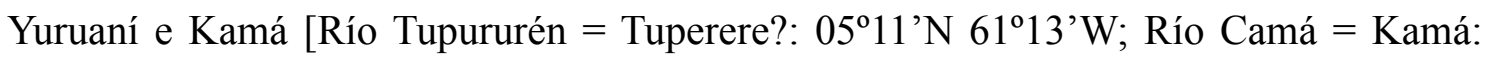
$\left.05^{\circ} 16^{\prime} \mathrm{N} 61^{\circ} 17^{\prime} \mathrm{W}\right], 23-\mathrm{III}-1986, \mathrm{C}$. Lasso et al.;

MZUSP 73092 (6, 40.5-110.0 mm SL; 1 c\&s, 59.7 mm SL), Venezuela, Bolívar, Gran Sabana, quebrada Cantarrana, a aproximadamente $30 \mathrm{Km}$ ao norte de Icabarú [04²7’12.63”N 61³8’11.2”W], 20-III-1986, C. Lasso \& C. Marrero;

NRM THO/1985045.8140 (9, 17.6-50.0 mm SL), Venezuela, Bolívar, Perai Tepui, El Polaco, mina próxima a La Faisca, entre Santa Elena and Icabarú [Perai-Tepuí $04^{\circ} 35^{\prime} \mathrm{N}$ $61^{\circ} 29^{\prime} \mathrm{W}$; Quebrada La Faisca $04^{\circ} 31^{\prime} \mathrm{N} 61^{\circ} 25^{\prime} \mathrm{W}$, afluente da margem esquerda do rio Surucán, afluente da margem esquerda do rio Caroní], 25-I-1985, T. Hongslo;

Localidade-tipo. Río Yuruaní, Gran Sabana, Estado Bolívar, Venezuela.

Diagnose. Lebiasina yuruaniensis difere de Lebiasina bimaculata, L. aff. bimaculata I, L. aff. bimaculata II, L, boruca, L. festae e $L$. aff. festae por não apresentar a parede da câmara posterior da bexiga natatória “celular", por apresentar as escamas da quinta série longitudinal com tecido epitelial hipertrofiado nos machos adultos e por não apresentar escamas com intensa deposição de guanina (vs. parede da bexiga natatória "celular", escamas da sexta série longitudinal modificadas em machos adultos, ao menos a quarta escama da linha lateral com intensa deposição de guanina). A espécie de Lebiasina sp. 
"Curuá-Pinta" por apresentar faixas longitudinais e mancha caudal e não apresentar manchas escuras na base das escamas da segunda à quinta séries longitudinais (vs. faixas longitudinais e mancha caudal ausentes; manchas escuras presentes na base das escamas da segunda à quinta séries longitudinais). Difere de Lebisina astrigata, L. aureoguttata, L. chocoensis, L. colombia, L. elongata, L. erythrinoides, L. floridablancaensis, L. intermedia, L. multimaculata, L. ortegai, L. panamensis, L. sp. Azuay e $L$. sp. "Curuá-Faixa” pela seguinte combinação de caracteres: faixa secundária passando ao longo das escamas da segunda e terceira séries longitudinais; série longitudinal de manchas arredondadas distribuídas ao longo das escamas da quarta série longitudinal ausente; presença da faixa "intermediária"; mancha caudal não alcançando o pedúnculo caudal anteriormente. Lebiasina yuruaniensis difere ainda de Lebisina astrigata, L. aureoguttata, L. chocoensis, L. colombia, L. floridablancaensis, L. multimaculata e L. sp. Azuay por apresentar a faixa primária conspícua (vs. faixa primária inconspícua em Lebisina astrigata, L. aureoguttata, L. chocoensis, L. multimaculata e L. sp. Azuay; faixa primária conspícua apenas na porção anterior do corpo em L. colombia; apenas a porção posterior da faixa primária conspícua em $L$. floridablancaensis). Entre as espécies do clado 93, Lebiasina yuruaniensis difere de L. taphorni e L. uruyensis pela faixa primária conspícua, a faixa secundária inconspícua e a presença da nadadeira adiposa ( $v s$. faixa primária inconspícua; faixa secundária conspícua em exemplares adultos; nadadeira adiposa ausente). A espécie difere de $L$. sp. Parima pela faixa "intermediária" restrita aos infra-orbitais e ausência da faixa terciária (vs. faixa "intermediária" estendendo-se ao longo das escamas da quinta série longitudinal, alcançando a origem da nadadeira anal; faixa terciária presente). Lebiasina yuruaniensis difere de L. unitaeniata por apresentar a boca terminal, a faixa primária intermitente, a margem posterior do opérculo distintamente côncava e a borda ventral do cerato-hial anterior com distintas reentrâncias ( $v s$. boca sub-superior, a faixa primária contígua por toda sua extensão, margem posterior do opérculo aproximadamente reta e a borda ventral do cerato-hial anterior com distintas reentrâncias).

Descrição. Dados morfométricos apresentados na tabela 19. Corpo comprimido e alongado. Perfil dorsal da cabeça e do corpo convexo do lábio superior até até a origem da nadadeira dorsal, tornando-se praticamente reto entre os parietais e a origem da dorsal. Perfil reto na base da dorsal e levemente côncavo posteriormente até a origem 
dos raios pró-correntes da nadadeira caudal. Perfil ventral da cabeça e tronco convexo desde o lábio inferior até a origem da pélvica, reto deste ponto até a origem da nadadeira anal, convexo na base da anal e côncavo do término da anal até a origem dos pró-correntes ventrais da nadadeira caudal.

Espécie discretamente prognata, boca terminal. Maxilar alcançando a margem anterior da órbita. Apenas uma série de 9 (3), 10 (17), 11 (32) ou 12 (4) dentes tricúspides decrescendo posteriormente no pré-maxilar. Maxilar com 5 (5), 6 (11), 7 (19), 8 (12), 9 (4) ou 10 (7) dentes tricuspidados. Dentário com duas séries de dentes: 12 (15), 13 (6), 14 (5), 15 (1) ou 17 (1) dentes tricúspides pedunculados com a cúspide central distintamente mais longa que as cúspides laterais na série externa, série interna com dentes diminutos, na maioria, cônicos (podendo ser tricúspides posteriormente) estendendo-se desde a sínfise até próximo ao processo coronóide. Raiosbranquiostégios 4, três articulando com o ceratobranquial anterior e 1 com o ceratobranquial posterior.

Escamas ciclóides, circuli restritos à borda da escama, diversos radii (aproximadamente 30) convergindo para o centro da escama, fortemente anastomosados no centro, formando numerosas células. Série longitudinal da linha lateral com 27 (2), 28 (17), 29 (12), 30 (17) ou 31 (6) escamas, das quais apenas 4 (3), 5 (24), 6 (25) ou 7 (2) são perfuradas. Séries longitudinais entre a nadadeira dorsal e a pélvica 7. Escamas pré-dorsais 12 (11), 13 (33), 14 (9) ou 15 (1). Primeira série longitudinal de escamas se estendendo apenas à vertical que passa pelo término da nadadeira dorsal, ou estendendo-se posteriormente por uma ou duas escamas, nunca alcançando a vertical que passa pelo ânus. Escamas circumpedunculares 12 .

Nadadeira peitoral i, 12 (12), 13 (32) ou 14 (9). Ponta da peitoral não alcançando a vertical que passa pela origem da pélvica. Raios da nadadeira pélvica i, 7. Supraneurais , 10 (1) anteriores aos espinhos neurais dos centros 5 a 14 (1). Nadadeira dorsal ii, 8. Primeiro pterigióforo da nadadeira dorsal inserido posteriormente ao espinho neural do centro 14 (1). Margem distal da nadadeira dorsal arredondada quando expandida. Origem da nadadeira dorsal distintamente mais próxima à base da nadadeira caudal que da ponta do focinho. Base do último raio da dorsal distintamente anterior à vertical que passa pela origem da nadadeira anal. Nadadeira anal iii, 8. Margem distal da nadadeira anal arredondada. Primeiro pterigióforo da nadadeira anal inserido posteriormente ao arco hemal do centro 23 (1). Nadadeira adiposa presente. Epurais 
dois. Nadadeira caudal furcada, lóbulo superior discretamente mais longo que o inferior, ambos arredondados. Raios principais da nadadeira caudal i, 9/i, 8. Pró-correntes dorsais $8(1)$; pró-correntes ventrais 8 (1). Vértebras pré-caudais 22 (1); vértebras caudais $18(1)$.

Colorido. Cor de fundo escura. Coloração do dorso distintamente mais escura que o ventre. Maxilar, ossos circumorbitais e série opercular intensamente pigmentados próximo à porção dorsal da cabeça, tornando-se gradualmente mais claros ventralmente. Porção ventral do infra-orbital 3 com uma discreta mancha horizontalmente alongada, contínua a uma mancha difusa no opéculo. Lábio inferior bastante pigmentado; restante da mandíbula e toda porção ventral da cabeça escuros, tornando-se gradualmente mais claros posteriormente.

Tronco tornando-se gradualmente mais claro ventralmente. Região abdominal amarela, com diminutos cromatóforos entre o istmo e a origem da nadadeira anal. Mancha umeral arredondada, conspícua em indivíduos jovens, tornando-se inconspícua ao longo da ontogenia, na medida em que a faixa primária se sobrepõe a esta. Faixa primária conspícua, estendendo-se desde o supracleitro até a vertical que passa pela origem dos raios pró-correntes da nadadeira caudal, sendo mais conspícua a partir da vertical que passa pela ponta dos raios da peitoral, quando adpressa ao corpo. Faixa secundária inconspícua, estendendo-se por todo o corpo, ao longo da segunda e terceira séries longitudinais de escamas, também se estendendo pelos raios principais mais dorsais do lóbulo superior da nadadeira caudal. Base da dorsal distintamente mais escura que o dorso. Inconspícua faixa longitudinal passando ao longo da margem ventral da quinta e margem dorsal da sexta séries longitudinais (visível apenas em exemplares com o colorido muito bem preservado; aparentemente ausente em exemplares com mais de $100.0 \mathrm{~mm} \mathrm{SL}$ ); tal faixa parece contínua à faixa "intermediária" presente no infra-orbital 3 e o opérculo. Mancha caudal diminuta, arredondada em indivíduos jovens, situada na porção proximal de cinco raios medianos da nadadeira caudal; difusa e inconspícua em exemplares adultos, representada apenas por grupos de cromatóforos; borda anterior da mancha caudal não alcançando o pedúnculo caudal. Nadadeira peitoral hialina. Ponto de ramificação dos raios da nadadeira pélvica com discretas manchas escuras. Porção proximal dos raios da nadadeira dorsal densamente pigmentados em jovens e adultos; ponto de ramificação 
com distintas manchas escuras, também observados nas nadadeiras anal e caudal. Raio mais posterior da nadadeira anal com pequenas manchas irregulares; porção distal dos raios densamente pigmentada. Membrana inter-radial dos raios principais da nadadeira caudal com distintas manchas escuras no término da bainha de escamas que recobre parte dos raios.

Dimorfismo sexual. Exemplares machos de Lebiasina yuruaniensis apresentam o padrão mais difundido de dimorfismo sexual entre as Lebiasina, descrito acima para $L$. astrigata. Assim como em L. unitaeniata, exemplares machos de L. yuruaniensis apresentam a faixa primária distintamente mais escura que as fêmeas.

Distribuição. Espécie endêmica do alto rio Caroni, Bolívar, Venezuela (Fig. 97).

Tabela 19. Dados morfométricos de Lebiasina yuruaniensis.

\begin{tabular}{lcccc} 
& $\mathrm{n}$ & Range & Mean & SD \\
\cline { 2 - 5 } Standard length & 32 & $46,7-124,7$ & 84,8 & \\
& & & & \\
Depth dorsal fin origin & 26 & $20,8-24,2$ & 22,2 & 0,8 \\
Snout to anal fin origin & 26 & $70,8-77,3$ & 73,6 & 1,5 \\
Snout to pelvic fin origin & 26 & $47,1-51,0$ & 49,4 & 0,9 \\
Snout to dorsal fin origin & 26 & $52,0-56,0$ & 54,1 & 0,9 \\
Dorsal fin origin to caudal base & 26 & $45,5-49,2$ & 47,6 & 1,1 \\
Dorsal fin length & 26 & $19,1-22,2$ & 20,3 & 0,7 \\
Dorsal fin base & 26 & $8,6-10,5$ & 9,6 & 0,4 \\
Adipose fin to caudal peduncle & 26 & $12,1-16,3$ & 14,0 & 1,0 \\
Length caudal peduncle & 26 & $14,7-20,0$ & 17,3 & 1,2 \\
Depth caudal peduncle & 26 & $10,0-12,2$ & 11,1 & 0,4 \\
Anal fin length & 26 & $17,5-24,9$ & 20,9 & 2,2 \\
Anal fin base & 26 & $10,2-14,2$ & 12,0 & 1,3 \\
Pelvic- to anal fin origin & 26 & $22,2-26,8$ & 24,7 & 1,1 \\
Pelvic fin length & 26 & $11,7-14,7$ & 13,4 & 0,8 \\
Pectoral to pelvic fin origin & 26 & $26,0-29,0$ & 27,6 & 1,0 \\
Pectoral fin length & 26 & $13,7-18,7$ & 16,7 & 1,0 \\
Snout to pectoral fin origin & 26 & $20,7-29,6$ & 22,5 & 1,6 \\
Bony head length & 25 & $23,0-25,7$ & 24,4 & 0,8 \\
& & & & \\
Head width $\div$ Morphod length & 25 & $47,8-56,7$ & 51,7 & 1,9 \\
Horizontal eye diameter & 25 & $20,4-25,3$ & 22,5 & 1,3 \\
Distance snout tip to eye & 25 & $25,4-30,3$ & 27,7 & 1,3 \\
Interorbital distance & 25 & $30,7-36,6$ & 33,3 & 1,3 \\
Length lower jaw & 25 & $42,4-48,1$ & 44,4 & 1,3 \\
Length upper jaw & 25 & $34,3-39,5$ & 37,4 & 1,3 \\
\hline
\end{tabular}




\section{Lebiasina sp. "Curuá Pinta”}

(Figura 101)

Lebiasina sp.- Sabaj, 2009: [Trip report].

\section{Material examinado.}

MNRJ 13487 (2 c\&s, 45.2-50.1 mm SL) Brasil, Pará, Cachimbo, unknown date, L. Travassos;

MNRJ 28257 (24, 32.1-47.6 mm SL), Brasil, Pará, Cachimbo, 17-VI-1955, L. Travassos;

MZUSP 99609 (1, 85.89 mm SL), Brasil, Pará, Altamira, tributário do rio Curuá, bacia do rio Iriri (drenagem do rio Xingu), próximo à BR-163, 0849'12”S 5458'11'W, 29X-2007, J. L. O. Birindelli, L. M. Sousa, A. L. Netto-Ferreira, M. H. Sabaj-Pérez, N. K. Lujan;

MZUSP 99610 (27, 41.73-93.53 mm SL; 3 c\&s, 72.51-89.41 mm SL), Brasil, Pará, Altamira, tributário do rio Curuá, bacia do rio Iriri (drenagem do rio Xingu), próximo à BR-163, 0849'12’S 5458'11’'W, 29-X-2007, J. L. O. Birindelli, L. M. Sousa, A. L. Netto-Ferreira, M. H. Sabaj-Pérez, N. K. Lujan;

MZUSP 99611 (12, 6.17-32.26 mm SL), Brasil, Pará, Altamira, tributário do rio Curuá, bacia do rio Iriri (drenagem do rio Xingu), próximo à BR-163, 0847’03”S, 5458'29’W, 29-X-2007, A. L. Netto-Ferreira, L. M. Sousa, J. L. O. Birindelli, M. H. Sabaj Pérez, N. K. Lujan;

MZUSP 101382 (9, 43.1-110.2 mm SL), Brasil, Pará, Altamira, tributário do rio Curuá, bacia do rio Iriri (drenagem do rio Xingu), próximo à BR-163, 0849'12” S 05458'11" W, 22-I-2009, A. L. Netto-Ferreira, L. M. Sousa, J. L. O. Birindelli, P. HollandaCarvalho;

MZUSP 101412 (102, -68.4 mm SL), Brasil, Pará, Altamira, rio Treze de Maio (sistema do rio Iriri, bacia do rio Xingu), próximo à BR-163, 0847'03'S, 05458'29'W, 22I-2009, A. L. Netto-Ferreira, J. L. O. Birindelli, L. M. Sousa, P. Hollanda-Carvalho; MZUSP 101423 (1, 54.4 mm SL), Brasil, Pará, Altamira, rio Treze de Maio (sistema do rio Iriri, bacia do rio Xingu), próximo à BR163, a montante da barragem, 0845'06”S, 05502’05’W, 23-I-2009, A. L. Netto-Ferreira, J. L. O. Birindelli, L. M. Sousa, P. Hollanda-Carvalho. 
Diagnose. Lebiasina sp. "Curuá Pinta" difere de Lebiasina bimaculata, L. aff. bimaculata I, L. aff. bimaculata II, L, boruca, L. festae e L. aff. festae por não apresentar a parede da câmara posterior da bexiga natatória "celular", por apresentar as escamas da quinta série longitudinal com tecido epitelial hipertrofiado nos machos adultos e por não apresentar escamas com intensa deposição de guanina ( $v$ s. parede da bexiga natatória "celular", escamas da sexta série longitudinal modificadas em machos adultos, ao menos a quarta escama da linha lateral com intensa deposição de guanina). A espécie difere de todas as demais congêneres por não apresentar faixas longitudinais e mancha caudal, além de apresentar manchas escuras na base das escamas da segunda à quinta séries longitudinais (vs. faixas longitudinais e mancha caudal presentes; manchas escuras na base das escamas da segunda à quinta séries longitudinais ausentes).

Descrição. Dados morfométricos apresentados na tabela 20. Vista lateral do holótipo em vivo na figura 101-A. Corpo cilíndrico, moderadamente alongado. Maior altura do corpo anterior à origem da nadadeira dorsal, entre as nadadeiras peitoral e pélvica. Perfil dorsal da cabeça convexo da extremidade do lábio superior à narina anterior, e praticamente reto deste ponto à base das escamas encobrindo a metade posterior dos parietais. Perfil do corpo reto ou praticamente convexo da cabeça à base da nadadeira dorsal e distintamente côncavo deste ponto à origem dos raios pró-correntes dorsais. Perfil ventral da cabeça e tronco distintamente convexo do lábio inferior à origem da pélvica, praticamente reto deste ponto à origem da nadadeira anal, convexo ao longo da nadadeira anal e levemente côncavo do término da nadadeira anal à origem dos raios pró-correntes ventrais.

Espécie prognata, boca subsuperior. Maxilar alcançando ou ultrapassando discretamente a margem anterior da órbita. Única série de 11 dentes tricúspides no prémaxilar. Maxilar com quatro dentes tricúspides. Dentário com duas series de dentes. Série externa com 14 dentes tricúspides pedunculados com cúspide central distintamente mais desenvolvida; série interna com diversos dentes diminutos, distribuídos desde a sínfise até próximo ao processo coronóide. Quatro raiosbranquiostégios, 3 se originando no ceratohial anterior e 1 no ceratohial posterior.

Escamas ciclóides, circuli restritos à borda da escama, com diversos (aproximadamente 32) radii, estando estes praticamente paralelos na borda das 
escamas, mas fortemente anastomosados no centro destas, formando células. Série longitudinal da linha lateral com 26 (1), 27 (12) ou 28 (8) escamas, das quais apenas 4 (1), 5 (18) ou 6 (2) são perfuradas. Séries longitudinais de escamas entre a nadadeira dorsal e pélvica 7. Escamas pré-dorsais 12 (4), 13 (14) ou 14 (3). Primeira série longitudinal de escamas alcançando a vertical que passa pela metade da nadadeira dorsal. Escamas circumpedunculares 12.

Raios da peitoral i, 11 (4), 12 (9), 13 (6) ou 14 (1). Ponta do raio mais longo da peitoral nunca alcançando a origem da pélvica. Raios da pélvica i, 7. Supraneurais 10 (2) ou 11 (1), anteriores aos centros 5 a 14 (1) ou 15 (2). Nadadeira dorsal iv, 6 (1), iii, 7 (1) ou ii, 8 (19). Primeiro pterigióforo da nadadeira doral inserido atrás do espinho neural do centro 14 (1) ou 15 (2). Margem distal da nadadeira dorsal arredondada quando expandida. Origem da nadadeira dorsal distintamente poterior ao meio do corpo. Base do último raio da dorsal distintamente anterior à origem da nadadeira anal. Nadadeira anal iii,8, raramente iii,9, último raio adnato. Margem distal da nadadeira anal arredondada. Primeiro pterigióforo da nadadeira anal inserido posteriormente ao arco hemal do centro 22 (2) ou 23 (1). Nadadeira adiposa ausente. Dois epurais. Nadadeira caudal furcada, lóbulos com praticamente o mesmo comprimento, com o dorsal discretamente mais longo que o ventral, ambos arredondados. Diversas escamas menores que as presentes no corpo encobrindo o quarto proximal dos raios da nadadeira caudal. Raios principais geralmente ii,8/i,8, raramente i,9/i,8 (condição mais difundida entre os Characiformes). Raios pró-correntes dorsais 6 (1) ou 7 (2); pró-correntes ventrais 7 (2) ou 8 (1). Vértebras pré-caudais 21 (3); vértebras caudais 15 (2) ou 16 (1).

Colorido. Cor de fundo predominantemente marrom. Cabeça densamente pigmentada desde o lábio superior até a porção exposta dos parietais e posteriormente até a inserção da nadadeira caudal. Maxilar, ossos circumorbitais e série opercular densamente pigmentados próximo à porção dorsal da cabeça, tornando-se gradualmente amarelada ventralmente. Lábio inferior fortemente pigmentado próximo à abertura da boca. Porção ventral da cabeça com pigmentação escassa. Membrana opercular com pequenos cromatóforos esparsos.

Tronco tornando-se gradualmente amarelado ventralmente. Região abdominal amarela, com diminutos cromatóforos entre o istmo e a origem da nadadeira anal. Mancha umeral arredondada, mais conspícua em indivíduos jovens e adultos de menor 
tamanho, tornando-se praticamente indistinta em exemplares adultos muito grandes, devido à pigmentação mais escura do corpo. Faixas longitudinais primária, secundária, terciária ou quaternária ausentes; manchas arredondadas ao longo da porção mediana do corpo também ausentes. Quatro séries longitudinais de manchas escuras na base das escamas das séries longitudinais 2, 3, 4 e 5. Mancha caudal ausente. Nadadeiras peitoral, pélvica, dorsal, anal e caudal hialinas.

Dimorfismo sexual. Exemplares machos de Lebiasina sp. "Curuá Pinta” apresentam o mesmo padrão de dimorfismo sexual observado em Lebiasina astrigata.

Distribuição. Conhecida do rio denominado por Travassos como rio Cachimbo, que possivelmente se trata do rio Braço Norte, afluente do rio Teles Pires, bacia do Tapajós (Birindelli et al., 2009), ou um de seus afluentes na base aérea da Serra do Cachimbo (Fig. 92).

Tabela 20. Dados morfométricos de Lebiasina sp. "Curuá Pinta".

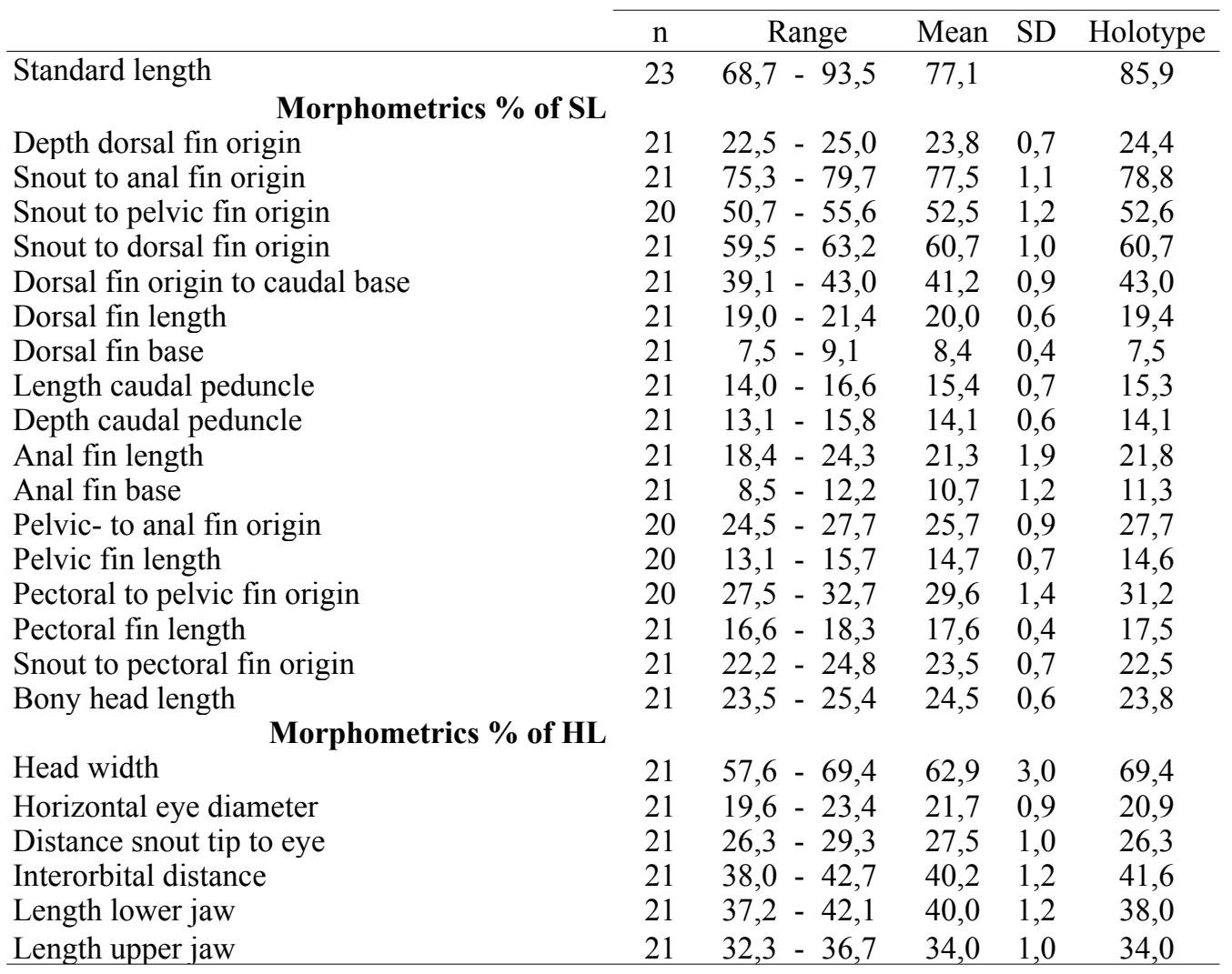




\section{Lebiasina sp. "Curuá Faixa"}

(Figura 102)

\section{Material examinado.}

MZUSP 99608 (1, 31.80 mm SL) Brasil, Pará, Altamira, tributário do rio Curuá, bacia do rio Iriri (drenagem do rio Xingu), próximo à BR-163, 0849'12” S 05458'11” W, 29-X-2007, J. L. O. Birindelli, L. M. Sousa, A. L. Netto-Ferreira, M. H. Sabaj-Pérez, N. K. Lujan;

MZUSP 99607 (3, 31.63-33.68 mm SL) Brasil, Pará, Altamira, tributário do rio Curuá, bacia do rio Iriri (drenagem do rio Xingu), próximo à BR-163, 0849'12" S 05458'11" W, 29-X-2007, J. L. O. Birindelli, L. M. Sousa, A. L. Netto-Ferreira, M. H. Sabaj-Pérez, N. K. Lujan;

MZUSP 101375 (1, 88.8 mm SL), Brasil, Pará, Altamira, tributário do rio Curuá, bacia do rio Iriri (drenagem do rio Xingu), próximo à BR-163, 0849'12” S 05458'11” W, 22-I-2009, A. L. Netto-Ferreira, L. M. Sousa, J. L. O. Birindelli, P. Hollanda-Carvalho.

Diagnose. Lebiasina sp. "Curuá-Faixa" difere de Lebiasina bimaculata, L. aff. bimaculata I, L. aff. bimaculata II, L, boruca, L. festae e L. aff. festae por não apresentar a parede da câmara posterior da bexiga natatória "celular", por apresentar as escamas da quinta série longitudinal com tecido epitelial hipertrofiado nos machos adultos e por não apresentar escamas com intensa deposição de guanina ( $v s$. parede da bexiga natatória "celular", escamas da sexta série longitudinal modificadas em machos adultos, ao menos a quarta escama da linha lateral com intensa deposição de guanina). A espécie de todos os demais congêneres (exceto Lebiasina sp. "Parima") por apresentar a lâmina dorsal do mesetmóide arredondada e por apresentar o ramo palatino do nervo facial transpassando o vômer (exceto em L. sp. "Curuá-Pinta") (vs. mesetmóide em forma de " $T$ "; ramo palatino percorrendo a margem lateral do vômer). Lebiasina sp. "Curuá-faixa" difere ainda difere de Lebiasina sp. "Curuá-Pinta" por apresentar faixas longitudinais e mancha caudal, e não apresentar manchas escuras na base das escamas da segunda à quinta séries longitudinais (vs. faixas longitudinais e mancha caudal ausentes; manchas escuras presentes na base das escamas da segunda à quinta séries longitudinais). Lebiasina sp. "Curuá-Faixa" difere de L. taphorni, L. unitaeniata, L. uruyensis, L. yuruaniensis e L. sp. "Parima" pela faixa secundária 
passando ao longo das escamas da primeira e segunda séries longitudinais, ausência da faixa "intermediária" e pela mancha caudal alcançar o pedúnculo caudal anteriormente (vs. faixa secundária passando ao longo das escamas da segunda e terceira séries longitudinais, faixa "intermediária" presente; mancha caudal não alcançando o pedúnculo caudal anteriormente). A espécie difere de Lebisina astrigata, L. aureoguttata, L. chocoensis, L. colombia, L. floridablancaensis, L. multimaculata, L. ortegai e L. panamensis por não apresentar uma série longitudinal de manchas arredondadas distribuídas ao longo das escamas da quarta série longitudinal (vs. série longitudinal de manchas arredondadas distribuídas ao longo das escamas da quarta série longitudinal). Distingue-se ainda de Lebisina astrigata, L. aureoguttata, L. chocoensis, L. colombia, L. floridablancaensis e L. multimaculata por apresentar a faixa primária conspícua, estendendo-se ao longo de praticamente todo o corpo (vs. faixa primária inconspícua em Lebisina astrigata, L. aureoguttata, L. chocoensis e L. multimaculata; apenas a porção anterior da faixa primária conspícua em L. colombia; apenas a porção posterior da faixa primária conspícua em L. floridablancaensis). Difere de L. elongata, L. erythrinoides e L. intermedia pela presença de uma séries longitudinais de manchas escuras situadas ventralmente à faixa primária e a ausência da nadadeira adiposa (vs. séries longitudinais de manchas escuras ausentes em L. elongata e L. erythrinoides; três séries longitudinais de manchas escuras em L. intermedia). L. sp. "Curuá-Faixa” difere ainda de L. elongata e L. erythrinoides por apresentar a faixa primária alcançando a mancha caudal posteriormente (vs. faixa primária não alcançando a mancha caudal) e de L. erythrinoides por apresentar 12 escamas circumpedunculares (vs. 14 escamas circumpedunculares). Lebiasina sp. "Curuá-Faixa" difere de L. intermedia pela ausência de manchas escuras no maxilar, infra-orbitais 1 e 2 e na porção proximal dos raios da nadadeira dorsal (vs. manchas escuras no maxilar, infra-orbitais e raios da nadadeira dorsal presentes).

Descrição. Dados morfométricos apresentados na tabela 21. Vista lateral do holótipo e $\mathrm{m}$ vivo na figura 102. Corpo cilíndrico, moderadamente alongado. Maior altura do corpo anterior à origem da nadadeira dorsal, entre as nadadeiras peitoral e pélvica. Perfil dorsal da cabeça convexo do lábio superior à origem da nadadeira dorsal, reto deste ponto até o término da dorsal e posteriormente côncavo até a origem dos raios prócorrentes dorsais. Perfil ventral da cabeça e tronco distintamente convexo do lábio 
inferior até a origem da nadadeira pélvica, côncavo entre a origem das nadadeiras pélvica e da anal, base da nadadeira anal convexo, perfil do pedúnculo caudal levemente côncavo, quase reto, até a origem dos raios pró-correntes ventrais da nadadeira caudal.

Espécie prognata, boca subsuperior. Maxilar alcançando ou discretamente ultrapassando a margem anterior da órbita. Apenas uma série de 9 dentes tricúspides decrescendo posteriormente no pré-maxilar. Maxilar com 5 dentes tricúspides ou cônicos. Dentário com duas séries de dentes: 12 dentes tricúspides pedunculados com a cúspide central distintamente mais longa que as cúspides laterais na série externa, dentes decrescendo gradualmente posteriormente; dentes diminutos cônicos na série interna estendendo-se desde a sínfise até próximo ao processo coronóide. Raiosbranquiostégios 4, três articulando com o ceratobranquial anterior e 1 com o ceratobranquial posterior.

Escamas ciclóides, circuli restritos à borda da escama, diversos radii (aproximadamente 24), estando os mesmos quase paralelos próximo à borda da escama e fortemente anastomosados no centro, formando diversas células. Série longitudinal da linha lateral com 25 (2) ou 26 (3) escamas, das quais apenas 6 são perfuradas. Séries longitudinais entre a nadadeira dorsal e a pélvica 7. Escamas pré-dorsais 11 (3) ou 12 (2). Primeira série longitudinal de escamas estendendo-se até a vertical que passa pelo término da nadadeira dorsal. Escamas circumpedunculares 12.

Nadadeira peitoral i, 11 (1) ou 12 (4). Ponta da peitoral não alcançando a vertical que passa pela origem da pélvica. Raios da nadadeira pélvica i, 7. Supraneurais 9 (1), anteriores aos espinhos neurais dos centros 5 a 13 (1). Nadadeira dorsal ii, 8 (3), iii, 8 (1) ou ii, 9 (1). Primeiro pterigióforo da nadadeira dorsal inserido posteriormente ao espinho neural do centro 13 (1). Margem distal da nadadeira dorsal arredondada quando expandida. Origem da nadadeira dorsal distintamente mais próxima à base da nadadeira caudal que da ponta do focinho. Base do último raio da dorsal distintamente anterior à vertical que passa pela origem da nadadeira anal. Nadadeira anal iii, 8, último raio adnato. Margem distal da nadadeira anal arredondada. Primeiro pterigióforo da nadadeira anal inserido posteriormente ao arco hemal do centro 22. Nadadeira adiposa ausente. Dois epurais. Nadadeira caudal furcada, lóbulo superior distintamente mais longo que o inferior, ambos arredondados. Raios principais da nadadeira caudal ii, 8/i, 8 (1) ou i, 9/i, 8 (4). Pró-correntes dorsais 10 (1); pró-correntes ventrais 9 (1). Vértebras pré-caudais 21 (1); vértebras caudais 15 (1). 
Colorido. Cor de fundo amarela. Cabeça densamente pigmentada do lábio superior até a porção posterior exposta dos parietais. Pigmentação densa se estendendo posteriormente pela série médio-dorsal e duas séries adjacentes, dos parietais até a inserção da nadadeira caudal. Ossos da série circumorbital e série opercular apenas com pequenos cromatóforos, exceto nos infra-orbitais e série opercular, por onde passa a faixa primária. Lábio inferior densamente pigmentado próximo à abertura da boca. Porção ventral da cabeça escassamente pigmentada. Membranas operculares com pequenos cromatóforos esparsos.

Tronco tornando-se gradualmente mais claro ventralmente. Região abdominal amarela, com diminutos cromatóforos entre o istmo e a origem da nadadeira anal. Mancha umeral arredondada, conspícua em indivíduos jovens, porém indistinguível da faixa primária em exemplares adultos. Faixa primária conspícua e ampla, estendendo-se desde a ponta do focinho até a mancha caudal. Faixa secundária ausente. Escamas da terceira, quarta e quinta séries longitudinais com a porção central despigmentadas, onde se encontram as manchas alaranjadas em vida. Base das escamas da sexta série longitudinal com manchas escuras, que, ao longo da ontogenia, de expandem e coalescem, formando uma faixa escura, paralela à faixa primária, se estendendo desde o cleitro até a vertical que passa pelo término da nadadeira anal, onde a faixa converge em direção à faixa primária. Mancha caudal conspícua, alongada verticalmente, situada na porção distal do pedúnculo caudal, estendendo-se à base de nove a onze raios medianos da nadadeira caudal. Nadadeiras peitoral, pélvica, dorsal e anal hialinas.

Dimorfismo sexual. Não são conhecidos exemplares machos adultos de Lebiasina sp. “Curuá Faixa”, entretanto, dada sua relação com os demais Lebiasininae (figura XX), é possível sugerir que esta espécie possivelmente apresenta o padrão de dimorfismo sexual mais difundido na subfamília Lebiasininae, descrito acima para L. astrigata.

Distribuição. Espécie conhecida apenas do rio Curuá, onde o mesmo cruza a Rodovia Cuiabá-Santarém na Serra do Cachimbo, estado do Pará, Brasil. 
Tabela 21. Dados morfométricos de Lebiasina sp. "Curuá Faixa".

\begin{tabular}{|c|c|c|c|c|c|}
\hline & $\mathrm{n}$ & Range & Mean & SD & Holotype \\
\hline Standard length & 5 & $31,6-88,8$ & 43,7 & & 88,8 \\
\hline \multicolumn{6}{|c|}{ Morphometrics \% of SL } \\
\hline Depth dorsal fin origin & 5 & $21,9-27,1$ & 24,1 & 1,9 & 27,1 \\
\hline Snout to anal fin origin & 5 & $75,9-78,1$ & 77,1 & 0,8 & 78,1 \\
\hline Snout to pelvic fin origin & 5 & $52,4-55,7$ & 53,7 & 1,2 & 53,5 \\
\hline Snout to dorsal fin origin & 5 & $57,1-58,0$ & 57,6 & 0,4 & 58,0 \\
\hline Dorsal fin origin to caudal base & 5 & $42,6-45,9$ & 43,9 & 1,3 & 45,9 \\
\hline Dorsal fin length & 5 & $22,0-24,5$ & 23,3 & 1,0 & 22,7 \\
\hline Dorsal fin base & 5 & $8,5-11,1$ & 9,4 & 1,1 & 11,1 \\
\hline Length caudal peduncle & 5 & $13,4-14,8$ & 14,0 & 0,6 & 14,6 \\
\hline Depth caudal peduncle & 5 & $11,8-14,0$ & 12,4 & 0,9 & 14,0 \\
\hline Anal fin length & 5 & $19,7-21,2$ & 20,5 & 0,6 & 19,7 \\
\hline Anal fin base & 5 & $9,6-11,1$ & 10,2 & 0,6 & 11,1 \\
\hline Pelvic- to anal fin origin & 5 & $23,2-25,2$ & 23,8 & 0,8 & 25,2 \\
\hline Pelvic fin length & 5 & $14,4-17,6$ & 16,3 & 1,2 & 14,4 \\
\hline Pectoral to pelvic fin origin & 5 & $26,4-29,4$ & 27,7 & 1,2 & 29,4 \\
\hline Pectoral fin length & 5 & $17,7-20,6$ & 19,1 & 1,2 & 17,7 \\
\hline Snout to pectoral fin origin & 5 & $25,2-28,1$ & 26,6 & 1,2 & 25,2 \\
\hline Bony head length & 5 & $27,6-28,9$ & 28,2 & 0,5 & 28,1 \\
\hline \multicolumn{6}{|c|}{ Morphometrics \% of HL } \\
\hline Head width & 5 & $47,8-52,4$ & 50,0 & 1,9 & 52,4 \\
\hline Horizontal eye diameter & 5 & $19,2-31,1$ & 28,5 & 5,2 & 19,2 \\
\hline Distance snout tip to eye & 5 & $23,6-27,7$ & 25,8 & 1,5 & 27,7 \\
\hline Interorbital distance & 5 & $29,0-33,6$ & 31,1 & 1,8 & 33,6 \\
\hline Length lower jaw & 5 & $37,9-43,6$ & 39,8 & 2,2 & 43,6 \\
\hline Length upper jaw & 5 & $25,5-34,1$ & 29,1 & 3,2 & 34,1 \\
\hline
\end{tabular}

\section{Lebiasina sp. "Parima"}

(Figura 103)

Lebiasina sp. -Géry \& Zarske, 2002: 44-45 ["When young, individuals of Derhamia hoffmannorum gen. et sp. n. resemble juveniles of a still undescribed, allopatric, species from the southern slope of the Roraima in Brazil, labelled: 'unidentified characoid, possibly near Nannostomus or Pyrrhulina' (Géry 1978 p. 567 [sic]), which were only known from a photograph at that time. The senior author was able to study an adult specimen of the same species, preserved in the Museu Goeldi, Belem, under the Nr. 539. This specimen was collected in a tributary of the Rio Uraricoera in the Serra Parima at 1200m altitude by Sr. Hidasi, March, 1962.”].

carpa criolla.- Fernández-Yépez, 1972: 13 [“tengo otra especie por describir correspondiente a las altas aguas del Rio Orinoco"].

Nannostomus or Pyrrhulina (?). -Géry, 1977: 588, figure; Parima mountains in northern Brazil.- Géry, 1977: 588 [figure on top of page, USNM 306560]. 


\section{Material examinado.}

INPA 15091 (2, 21.8-40.5 mm SL), Brasil, Roraima, Igarapé das Irmãs, Rio Parima, tributário do rio Branco, 21-IX-1998, Equipe Oncocercose;

INPA 15742 (1, 88.2 mm SL), Brasil, Roraima, rio Parima, tributário do rio Branco, Xitei-Xidea, 2³6’29’N, 6352’18’W, 17-IV-1979, U. Barbosa (Equipe Oncocercose); INPA 15743 (9/18, 14.6-22.6 mm SL), Brasil, Roraima, Irmãs Xiteí, 09-XII-1997, Equipe Oncocercose;

INPA 20518 (1, 93.6 mm SL), Brasil, Roraima, Rio Mucajaí, tributário do rio Branco, área indígena Yanomami, IV-2002, M. William;

MAC-PAY 0619 (3, 27.3-40.00 mm SL), Venezuela, Amazonas, Cañito Jopajewä que desemboca no Río Padamo, em sua margem esquerda, a aprox. 10 min. a montante de Coshilowäteri [Río Padamo $02^{\circ} 54^{\prime} \mathrm{N} 65^{\circ} 17^{\prime} \mathrm{W}$ afl margem direita do rio Orinoco], 22X-1982, J. Fernández;

MAC-PAY 0591 (8, 37.1-134.9 mm SL), Venezuela, Amazonas, rio Niyayobä, Sierra Parima, $02^{\circ} 45^{\prime} \mathrm{N} 64^{\circ} 18^{\prime} \mathrm{W}, 17-\mathrm{X}-1982$, J. Fernández;

MBUCV-V 11000 (2, 114.3-145.8 mm SL), Venezuela, Amazonas, Atabapo, Caño Herita $\left[64^{\circ} 35^{\prime} \mathrm{W} 03^{\circ} 45^{\prime} \mathrm{N}\right]$, Río Ocamo, afl margem direita do alto rio Orinoco, XI-1975, J. Lizot;

MHNLS 797 (2, 40.8-83.8 mm SL), Venezuela, Amazonas, corredeira Culebra [Raudal Culebra 0336’N 654’'W], XII-1951, A. Fernández-Yepez;

MHNLS 4160 (1, 106.7 mm SL), Venezuela, Amazonas, Mavaca, Alto Orinoco [boca do Río Mavaca $\left.02^{\circ} 31^{\prime} \mathrm{N} 65^{\circ} 11^{\prime} \mathrm{W}\right]$, XI-1981, J. Finkers;

MNRJ uncat (25, 23.7-152.9 mm SL), Brasil, Amazonas, Rio Marari, acampamento entre 700 e $1000 \mathrm{~m}$ a montante da Missão Marari da aldeia Ianomami, na Serra Tapirapecó, afluente do rio Padauari, 12-IV a 20-V-2004, U. Caramaschi \& D. F. Moraes;

MPEG 1830 (1, 94.5 mm SL), Brasil, Roraima, Serra Parima, tributário do rio Urar8icoera, 1200 m elev., III-1962, M. Hidasi [specimen examined by Géry, in Géry \& Zarske, 2002: 45];

MZUSP 62916 (1, 96.5 mm SL), Brasil, Roraima, rio Parima, tributário do rio Branco, Xitei-Xidea, 2³6’29’'N, 6352’18’W, 17-IV-1979, U. Barbosa (Equipe Oncocercose); 
MZUSP 62917 (8, 12.0-38.2 mm SL), Brasil, Roraima, Irmãs Xiteí, 09-XII-1997, Equipe Oncocercose;

MZUSP 62918 (3, 31.9-81.5 mm SL), Brasil, Roraima, Igarapé das Irmãs, Rio Parima, tributário do rio Branco, 21-IX-1998, Equipe Oncocercose;

MZUSP 81128 ( 1 c\&s, 42.8 mm SL), Brasil, Roraima, Igarapé das Irmãs, Rio Parima, tributário do rio Branco, 21-IX-1998, Equipe Oncocercose;

MZUSP 81129 (1, $90.2 \mathrm{~mm}$ SL), Brasil, Roraima, Rio Mucajaí, tributário do rio Branco, área indígena Yanomami, IV-2002, M. William;

USNM 306560 (3, 21.8-27.0 mm SL), Río Parima, H. Axelrod, III-1963 [1 fotografado e ilustrado em Géry, 1975].

Diagnose. Lebiasina sp. "Parima" difere de Lebiasina bimaculata, L. aff. bimaculata I, L. aff. bimaculata II, L, boruca, L. festae e L. aff. festae por não apresentar a parede da câmara posterior da bexiga natatória “celular", por apresentar as escamas da quinta série longitudinal com tecido epitelial hipertrofiado nos machos adultos e por não apresentar escamas com intensa deposição de guanina (vs. parede da bexiga natatória "celular", escamas da sexta série longitudinal modificadas em machos adultos, ao menos a quarta escama da linha lateral com intensa deposição de guanina). A espécie de todos os demais congêneres (exceto Lebiasina sp. "Curuá-Faixa") por apresentar a lâmina dorsal do mesetmóide arredondada ( $v$ s. mesetmóide em forma de "T"). Lebiasina sp. "Parima" difere ainda de Lebiasina sp. "Curuá-Pinta" por apresentar faixas longitudinais e mancha caudal, e não apresentar manchas escuras na base das escamas da segunda à quinta séries longitudinais (vs. faixas longitudinais e mancha caudal ausentes; manchas escuras presentes na base das escamas da segunda à quinta séries longitudinais). Difere de Lebisina astrigata, L. aureoguttata, L. chocoensis, L. colombia, L. elongata, L. erythrinoides, L. floridablancaensis, L. intermedia, L. multimaculata, L. ortegai, L. panamensis, L. sp. Azuay e L. sp. "Curuá-Faixa" pela seguinte combinação de caracteres: faixa secundária passando ao longo das escamas da segunda e terceira séries longitudinais; série longitudinal de manchas arredondadas distribuídas ao longo das escamas da quarta série longitudinal ausente; presença da faixa "intermediária"; mancha caudal não alcançando o pedúnculo caudal anteriormente. Lebiasina sp. "Parima" difere ainda de Lebisina astrigata, L. aureoguttata, L. chocoensis, L. colombia, L. floridablancaensis, L. multimaculata e L. sp. Azuay por apresentar a faixa primária 
conspícua (vs. faixa primária inconspícua em Lebisina astrigata, L. aureoguttata, L. chocoensis, L. multimaculata e L. sp. Azuay; faixa primária conspícua apenas na porção anterior do corpo em L. colombia; apenas a porção posterior da faixa primária conspícua em L. floridablancaensis). Entre as espécies do clado 93, L. sp. "Parima" difere de L. taphorni, L. unitaeniata, L. uruyensis e L. yuruaniensis por apresentar a faixa "intermediária" estendendo-se ao longo das escamas da quinta série longitudinal, alcançando a origem da nadadeira anal, e a faixa terciária (vs. faixa "intermediária" restrita aos infra-orbitais; faixa terciária ausente). Lebiasina sp. "Parima" difere ainda de L. taphorni e L. uruyensis pela faixa primária conspícua, a faixa secundária inconspícua e a presença da nadadeira adiposa ( $v s$. faixa primária inconspícua; faixa secundária conspícua em exemplares adultos; nadadeira adiposa ausente).

Descrição. Dados morfométricos apresentados na tabela 22. Corpo comprimido e alongado. Perfil dorsal da cabeça distintamente convexo do lábio superior até os parietais, tornando-se levemente convexo, quase reto, deste ponto até a origem da nadadeira dorsal. Perfil levemente côncavo desde a base da dorsal até a origem dos raios pró-correntes da nadadeira caudal. Perfil ventral da cabeça e tronco convexo desde o lábio inferior até a origem da pélvica, reto deste ponto até a origem da nadadeira anal, convexo na base da anal e côncavo do término da anal até a origem dos pró-correntes ventrais da nadadeira caudal.

Espécie prognata, boca terminal. Maxilar distintamente ultrapassando a margem anterior da órbita. Apenas uma série de 9 (1) ou 11 (1) dentes tricúspides decrescendo posteriormente no pré-maxilar. Maxilar com 5 (1) ou 7 (1) dentes tricuspidados. Dentário com duas séries de dentes: 12 (1) ou 18 (1) dentes tricúspides pedunculados com a cúspide central distintamente mais longa que as cúspides laterais na série externa, dentes decrescendo gradualmente posteriormente; dentes diminutos cônicos na série interna estendendo-se desde a sínfise até próximo ao processo coronóide. Raiosbranquiostégios 4 , três articulando com o ceratobranquial anterior e 1 com o ceratobranquial posterior.

Escamas ciclóides, circuli restritos à borda da escama, diversos radii (aproximadamente 25) convergindo para o centro da escama, fortemente anastomosados no centro, formando numerosas células. Série longitudinal da linha lateral com 26 (1), 27 (5), 28 (4) ou 29 (1) escamas, das quais apenas 3 (3), 4 (1), 5 (9) ou 6 (1) são 
perfuradas. Séries longitudinais entre a nadadeira dorsal e a pélvica 7. Escamas prédorsais 12 (7) ou 13 (7). Primeira série longitudinal de escamas alcançando a vertical que passa pelo término da nadadeira dorsal, podendo se estender por uma ou duas escamas além deste ponto. Escamas circumpedunculares 12.

Nadadeira peitoral i, 13 (1), 14 (4), 15 (5) ou 16 (2). Ponta da peitoral não alcançando a vertical que passa pela origem da pélvica. Raios da nadadeira pélvica i, 7. Supraneurais 10 (8), anteriores aos espinhos neurais dos centros 5 a 14 (8). Nadadeira dorsal ii, 8 (8) ou ii,9 (4). Primeiro pterigióforo da nadadeira dorsal inserido posteriormente ao espinho neural do centro 14 (8). Margem distal da nadadeira dorsal arredondada quando expandida. Origem da nadadeira dorsal distintamente mais próxima à base da nadadeira caudal que da ponta do focinho. Base do último raio da dorsal distintamente anterior à vertical que passa pela origem da nadadeira anal. Nadadeira anal iii,8 (9) ou iii, 11(1), último raio adnato. Margem distal da nadadeira anal arredondada. Primeiro pterigióforo da nadadeira anal inserido posteriormente ao arco hemal do centro 24. Nadadeira adiposa sempre presente. Dois epurais. Nadadeira caudal furcada, lóbulo superior distintamente mais longo que o inferior, ambos arredondados. Raios principais da nadadeira caudal i, 9/i, 8. Pró-correntes dorsais 9 (2); pró-correntes ventrais 8 (1) ou 9 (1). Vértebras pré-caudais 23 (2); vértebras caudais 19 (2).

Colorido. Cor de fundo amarela. Cabeça densamente pigmentada do lábio superior até a porção posterior exposta dos parietais. Pigmentação densa se estendendo posteriormente pela série médio-dorsal e duas séries adjacentes, dos parietais até a inserção da nadadeira caudal. Ossos da série circumorbital e série opercular com elaborado padrão de pigmentação. Lábio inferior densamente pigmentado próximo à abertura da boca. Porção ventral da cabeça escassamente pigmentada.

Tronco tornando-se gradualmente mais claro ventralmente. Região abdominal amarela, com diminutos cromatóforos entre o istmo e a origem da nadadeira anal. Mancha umeral arredondada, sobreposta pela faixa primária em exemplares adultos. Faixa primária originando-se posteriormente ao olho, passando pelo quarto e quinto infra-orbitais, opérculo e se estendendo por todo o corpo, até o término do pedúnculo caudal, sendo que na vertical que passa pelo término da nadadeira dorsal, a faixa se fragmenta, sendo representada por 10 as 12 manchas arredondadas, uma em cada 
escama da quarta série longitudinal. Faixa secundária pouco conspícua, estendendo-se por todo o corpo, desde o supracleitro até a porção medial dos raios do lóbulo superior da nadadeira caudal. Faixa conspícua estendendo-se desde a boca podendo alcançar a vertical que passa pelo meio da nadadeira anal, passando pela quinta série longitudinal de escamas. Faixa terciária estendendo-se da origem da peitoral aos raios do lóbulo inferior da nadadeira caudal, ao longo das escamas da sexta série longitudinal; faixa terciária densamente pigmentada ao longo da base da nadadeira anal, tornando-se inconspícua na porção proximal do pedúnculo caudal. Mancha caudal difusa, arredondada em indivíduos jovens, situada na porção proximal de cinco raios medianos da nadadeira caudal; inconspícua ou ausente em exemplares adultos maiores que 123.0 mm SL, representada apenas por grupos de cromatóforos; borda anterior da mancha caudal não alcançando o pedúnculo caudal. Nadadeiras pélvica e dorsal hialinas. Base dos raios da nadadeira peitoral densamente pigmentados, formando uma mancha negra arredondada. Raios da nadadeira anal discretamente pigmentados, formando um padrão acinzentado, com as bordas distais hialinas. Base dos dois últimos raios da nadadeira anal densamente pigmentados. Raios da nadadeira caudal densamente pigmentados.

Dimorfismo sexual. Exemplares machos de Lebiasina sp. Parima apresentam o mesmo padrão de dimorfismo sexual observado em L. astrigata, exceto pelos músculos da anal não se apresentarem hipertrofiados e de não ocorrer o entumescimento do tecido epitelial sobre as escamas da quinta série de escamas acima da nadadeira anal. Adicionalmente, exemplares machos de Lebiasina sp. Parima apresentam tubérculos nupciais nos raios das nadadeiras anal, dorsal e caudal, e nas escamas, além de apresentar tais estruturas nos raios das nadadeiras peitoral e pélvica, e na lateral da cabeça, como as demais espécies de Lebiasina.

Distribuição. Conhecida da bacia do rio Branco, nos rios Parima (Mucajaí) e Uracicoera, estado de Roraima, do rio Marari, sistema do rio Padaurai, estado do Amazonas, Brasil e na bacia do alto rio Orinoco, a montante de La Esmeralda, Estado Amazonas, Venezuela (Fig. 97). 
Tabela 22. Dados morfométricos de Lebiasina sp. "Parima".

\begin{tabular}{lccccc} 
& $\mathrm{n}$ & Range & Mean & SD & Holotype \\
\cline { 2 - 6 } Standard length & 22 & $12,0-152,9$ & 80,7 & & 152,9 \\
& & & & \\
Depth dorsal fin origin & 12 & $18,6-23,2$ & 21,3 & 1,4 & 20,9 \\
Snout to anal fin origin & 12 & $73,5-79,3$ & 76,0 & 1,8 & 73,5 \\
Snout to pelvic fin origin & 12 & $49,8-53,9$ & 51,8 & 1,4 & 50,2 \\
Snout to dorsal fin origin & 12 & $53,5-57,0$ & 54,8 & 1,2 & 53,5 \\
Dorsal fin origin to caudal base & 12 & $45,0-48,3$ & 46,5 & 1,1 & 47,7 \\
Dorsal fin length & 11 & $18,2-19,6$ & 18,9 & 0,5 & 18,5 \\
Dorsal fin base & 12 & $9,0-10,9$ & 9,9 & 0,5 & 9,9 \\
Adipose fin to caudal peduncle & 12 & $11,5-13,4$ & 12,5 & 0,7 & 12,5 \\
Length caudal peduncle & 12 & $14,2-16,3$ & 15,2 & 0,6 & 14,8 \\
Depth caudal peduncle & 12 & $8,7-10,6$ & 9,5 & 0,7 & 9,9 \\
Anal fin length & 12 & $18,1-21,3$ & 19,7 & 1,0 & 19,9 \\
Anal fin base & 12 & $9,3-12,3$ & 10,5 & 1,1 & 10,7 \\
Pelvic- to anal fin origin & 12 & $22,3-25,9$ & 24,8 & 1,1 & 24,6 \\
Pelvic fin length & 12 & $12,0-15,1$ & 12,9 & 0,9 & 12,2 \\
Pectoral to pelvic fin origin & 12 & $27,9-31,3$ & 29,5 & 1,1 & 28,5 \\
Pectoral fin length & 12 & $15,5-17,7$ & 16,4 & 0,7 & 15,9 \\
Snout to pectoral fin origin & 12 & $21,2-25,9$ & 23,1 & 1,4 & 21,2 \\
Bony head length & 12 & $23,4-26,6$ & 25,2 & 1,0 & 23,6 \\
& & & & & \\
Head width & & & & \\
Horizontal eye diameter & 12 & $12,7-14,6$ & 13,4 & 0,6 & 13,0 \\
Distance snout tip to eye & 12 & $4,5-6,3$ & 5,4 & 0,6 & 4,5 \\
Interorbital distance & 12 & $6,7-8,1$ & 7,6 & 0,4 & 6,7 \\
Length lower jaw & 12 & $9,1-9,7$ & 9,3 & 0,2 & 9,1 \\
Length maxilla & 12 & $10,1-12,2$ & 11,2 & 0,7 & 10,3 \\
\hline & 12 & $5,1-10,3$ & 7,0 & 2,1 & 5,1 \\
\hline
\end{tabular}

\section{Lebiasina aff. bimaculata I}

(Figura 104)

Lebiasina bimaculata (non Valenciennes, in Cuvier \& Valenciennes).- Evermann \& Radcliffe, 1917: 29 [specimens “from a 'pozo' a little short of half-way between Amotape and Tumbes"; brief description of specimens and habitat].

Eigenmann, 1920a: 16 - in allusion to the specimens from the Piura river basin.

\section{Material examinado.}

ANSP 124144 (7, 23.6-48.9 mm SL), Peru, Piura, Porta Chuelo, próximo ao rio Chira, unknown collection date, A.G. Fisher;

IAvH-P 2125 (2, 47.2-47.3 mm SL), Peru, Piura, Cato El ansolo, 10-IX-1981, J. Hernández;

MCNG 19381 (1, 84.7 mm SL), Equador, Loja, rio Alamor (acampamento próximo à cabeceira: $\left.04^{\circ} 02^{\prime} \mathrm{S} 80^{\circ} 02^{\prime} \mathrm{W}\right), 1991, \mathrm{D} . \mathrm{C}$. Taphorn; 
MCNG 19382 (4, 56.8-71.9 mm SL), Equador, quebrada San José, 1991, D. C. Taphorn;

MCNG 19383 (1, 76.8 mm SL), Equador, Azuay, quebrada Limón [03¹9’06"S 79¹8’09"W] próximo a Girón, 1200m, afl Jubones., 1991, D. C. Taphorn;

MCNG 19384 (3, 85.0-100.1 mm SL), Equador, Azuay, quebrada Limón [03¹9’06"S 79¹8’09"W] próximo a Girón, 1200m, afl. Jubones., 1991, D. C. Taphorn;

MEPN 1909, (34, 33.2-90.7 mm SL), Equador, Loja, quebrada Vulcancocha, afluente do rio Calvas, SE de Cariamanga, 1500m elev., 04²2's $79^{\circ} 27^{\prime} \mathrm{W}, 05-\mathrm{IV}-1979$, R. Barriga;

MEPN 1910 (90.5 mm SL), Equador, Zamora-Chinchipe, rio Malacatos, $1250 \mathrm{~m}$ elev., 0403'34”S 7956’25”W, 7-IV-1979, R. Barriga;

MEPN 1992 (2, 56.7-72.2 mm SL), Equador, Loja, Quebrada Limón, 1500 m elev., $04^{\circ} 27^{\prime} 05^{\prime}$ S 79²6’20’W, 01-IV-1979, R. Barriga et al.;

MEPN 2889 (1, 39.3 mm SL), Equador, Loja, Quebrada Limón, 1500 m elev., 04²7’05’'S 79²6’20’W, 21-VIII-1978, R.Barriga;

MEPN 4632 (18, 33.8-79.3 mm SL), Equador, Loja, quebrada Flores, afluente do rio Maracá, afluente do rio Alamor, ao norte de Saucillo, $04^{\circ} 16^{\prime} \mathrm{S} 80^{\circ} 12^{\prime} \mathrm{W}, 300 \mathrm{~m}$ elev., 01-IV-1979, R. Barriga et al.;

MEPN 4633 (12, 53.2-76.6 mm SL), Equador, Loja, Quebrada Flores, afluente do rio

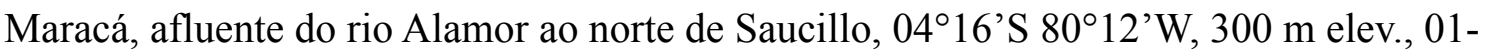
IV-1979, R. Barriga et al.;

MEPN 5926 (12, 26.0-79.5 mm SL), Equador, Loja, Quebrada Yaguarcochao, rio Catamayo, 1500 m elev., 0403'50”S 79²2’40”W, 14-IV-1979, R. Barriga et al.;

MEPN 6955 (1, $84.1 \mathrm{~mm}$ SL), Equador, Loja, río Malacatos [04¹3’S 79²18'W], afluente do rio Solanda, afluente do rio Catamayo , 7-IV-1979, R. Barriga;

MEPN 6956, (3/6, 43.0-94.0 mm SL), Equador, El Oro, rio Pindo, afluente do rio Puyango [tributário da margem direita do rio Tumbes], próximo à desembocadura, a sudoeste de Zaruma, 650m elev., 03ํ7'’ 7942’W, 05-IV-1979, R. Barriga;

MEPN 7023 (5, 42.4-54.2 mm SL), Equador, rio Catamayo próximo a El Tingo, unknown date, M. Olalla;

MEPN 8495 (2, 80.2-83.2 mm SL), Equador, Loja, rio La Florida afluente do rio Catamayo, bacia do rio Chira, 1218 m. elev., 04¹8’29”S 7947’08”W, 28-VIII-2008, R. Barriga et al.; 
MEPN 9491 (35, 18.8-55.3 mm SL), Equador, Loja, Quebrada Indiucho, cuenca del Río Catamayo, próximo ao Río Vilcabamba, 1200 m elev., 0407’24”S 79¹8'19”W, 15VIII-1978, R. Barriga;

MEPN uncat (4, 46.5-73.9 mm SL), Equador, Loja, quebrada Flores, afluente do rio Maracá, afluente do rio Alamor ao norte de Saucillo, $04^{\circ} 16^{\prime}$ 'S $80^{\circ} 12^{\prime} \mathrm{W}, 300 \mathrm{~m}$ elev., 01IV-1979, R. Barriga et al.;

MEPN uncat. (5/10, 35.1-90.7 mm SL), Equador, Loja, quebrada Vulcancocha, afluente do rio Calvas, SE do cantón Cariamanga, 1500m elev., 04²8’'S 79²7’ W, 05-IV-1979, R. Barriga;

MUSM 348 (3, 82.5-85.6 mm SL), Peru, Tumbes, Río Tumbes [3³4’22"S $\left.80^{\circ} 27^{\prime} 44^{\prime \prime} \mathrm{W}\right], 18-X I-1978$, W. Gutierrez;

MUSM 351 (3, 75.6-80.2 mm SL), Peru, Tumbes, quebrada Ucumares [0352’56"S 80³0’22"W], 01-XI-1977, IMARPE;

MUSM 352 (2, 41.6-59.3), Peru, Tumbes, Cazaderos, 0405’00”S 80³0’00”W, 29X-1977, IMARPE;

MUSM 3265 (1, 65.0 mm SL), Peru, Tumbes, Ucumares, Quebrada Honda [0354’33"S 80¹9’46"W], 04-VII-1992, F. Chang et al.;

MUSM 3268 (1, 60.8 mm SL), Peru, Tumbes, Ucumares, Rio Tumbes, Quebrada Honda [0354'33"S 80¹9’46"W], 04-VII-1992, F. Chang et al.;

MUSM 3287 (1, 64.10 mm SL), Peru, Tumbes, Rica Playa [0348’23"S 80²9’55"W], Quebrada El Huaco , 03-VII-1992, F. Chang, C. Palma \& F. Rodriguez;

MUSM 5754 (8, 31.0-73.2 mm SL), Peru, Piura, Sullana, Mallares, Puente Samán [0451’31"S 8045’35"W], Brazo Río Chira, 18-VIII-1994 P. de Rham \& F. Chang;

MUSM 5835 (11, 33.8-88.1 mm SL), Peru, Tumbes, PNCA, El Huásimo, rio Tumbes, Quebrada el Huásimo [035’03"S 80³0’50"W], 12-XII-1993 F. Chang;

MUSM 7327 (22, 56.3-98.4 mm SL), Peru, Piura, Alto Río Piura, 15-VIII-1995, P. Guerrero;

MUSM 11548 (1/3, 106.3 mm SL), Peru, Tumbes, El Gaucho, Quebrada Faical, 23II-1996, M.Napravnik-Choy;

MUSM 15786 (2, 44.6-47.3 mm SL), Peru, Piura, Ayabaca, rio Quiroz, 4³2’ S 8001’ W, 18-IV-1956, H. W. Koepke;

MUSM 22217 (1, 59.1 mm SL), Peru, Piura, Sullana [0453’24"S 8041’23"W], Cerca de Caza el Angolo, Quebrada El Espino, 16-II-2004, J. Barrio; 
USNM 77551 (3, 79.6-87.1 mm SL), Peru, Tumbes?, poço entre Amotape [?] e Tumbes

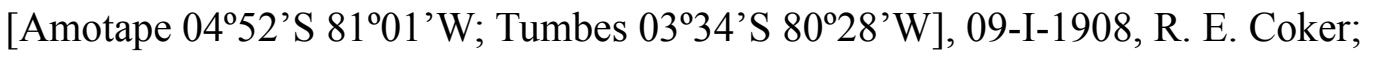
USNM 83025 (2, 64.4-67.9 mm SL), Peru, unknown collection date, Wilkes Exped; USNM 83628 (ex-IU 15171) (14, 53.4-67.9 mm SL), Peru, Piura, Piura [Piura 05²'’S $\left.80^{\circ} 38^{\prime} \mathrm{W}\right], 11-\mathrm{I}-1919$, C. H. Eigenmann;

USNM uncat. (2, 62.8-86.5 mm SL), Peru, Tumbes, Rica Playa [0348’23"S 80²9’55"W], 21-V-1978, W. Gutierrez.

Diagnose. Lebiasina aff. bimaculata I diferencia-se de Lebiasina astrigata, L. aureoguttata, L. chocoensis, L. colombia, L. elongata, L. erythrinoides, $L$. floridablancaensis, L. intermedia, L. multimaculata, L. ortegai, L. panamensis, L. taphorni, L. unitaeniata, L. uruyensis, L. yuruaniensis, L. sp. Azuay, L. sp. "CuruáFaixa", L. sp. "Curuá-Pinta" e L. sp. "Parima" pelas seguintes características: parede da câmara posterior da bexiga natatória "celular"; escamas da sexta série longitudinal modificadas em machos adultos; três ou quatro séries longitudinais de escamas com intensa deposição de guanina ( $v s$. parede da bexiga natatória não "celular"; modificações nas escamas da quinta série longitudinal nos machos adultos; escamas sem intensa deposição de guanina). Lebiasina aff. bimaculata I diferencia-se de $L$. boruca, L. festae e $L$. aff. festae por apresentar dentes com as cúspides laterais quase tão desenvolvidas quanto a cúspide central e por não apresentar dentes no endopterigóide (vs. dentes com cúspide central distintamente mais longa que as laterais; endopterigóide apresentando dentes). A espécie diferencia-se de L. bimaculata e L. aff. bimaculata II por apresentar uma inflexão no maxilar, dentes do pré-maxilar e maxilar formando uma única superfície cortante (vs. porção dentígera do maxilar não flexionada anteriormente). A espécie difere ainda de L. bimaculata por apresentar moldura do forame escapular com uma porção cartilaginosa entre a escápula e o cleitro e não apresentar o pós-cleitro 3 (vs. moldura do forame escapular com uma porção cartilaginosa entre a escápula e o cleitro; pós-cleitro 3 presente). A espécie diferencia-se ainda de L. aff. bimaculata II por não apresentar redução do pré-maxilar (vs. prémaxilar reduzido).

Descrição. Dados morfométricos apresentados na tabela 23. Corpo comprimido e alongado. Perfil dorsal da cabeça distintamente convexo do lábio superior até até a 
origem da nadadeira dorsal. Perfil reto na base da dorsal e levemente côncavo posteriormente até a origem dos raios pró-correntes da nadadeira caudal. Perfil ventral da cabeça e tronco convexo desde o lábio inferior até a origem da pélvica, reto deste ponto até a origem da nadadeira anal, convexo na base da anal e côncavo do término da anal até a origem dos pró-correntes ventrais da nadadeira caudal.

Espécie discretamente prognata, boca terminal. Maxilar quase alcançando a margem anterior da órbita. Apenas uma série de 11 (1) ou 12 (3) dentes tricúspides decrescendo posteriormente no pré-maxilar. Maxilar com 4 (3) ou 5 (1) dentes tricuspidados. Dentário com duas séries de dentes: 14 (3) 15 (1) dentes tricúspides pedunculados com a cúspide central distintamente mais longa que as cúspides laterais na série externa, série interna com dentes diminutos, na maioria, cônicos (podendo ser tricúspides posteriormente) estendendo-se desde a sínfise até próximo ao processo coronóide. Raios-branquiostégios 4 , três articulando com o ceratobranquial anterior e 1 com o ceratobranquial posterior.

Escamas ciclóides, circuli restritos à borda da escama, diversos radii (aproximadamente 26) convergindo para o centro da escama, fortemente anastomosados no centro, formando numerosas células. Série longitudinal da linha lateral com 27 (3), 28 (6), 29 (11) ou 30 (2) escamas, das quais apenas 5 (4) ou 6 (19) são perfuradas. Séries longitudinais entre a nadadeira dorsal e a pélvica 7. Escamas pré-dorsais 12 (8) ou 13 (12). Primeira série longitudinal de escamas ultrapassando discretamente a vertical que passa pela origem da nadadeira anal. Escamas circumpedunculares 12.

Nadadeira peitoral i, 12 (5), 13 (9), 14 (7) ou 15 (2). Ponta da peitoral não alcançando a vertical que passa pela origem da pélvica. Raios da nadadeira pélvica i, 7 (22) ou i, 8 (1). Supraneurais 9 (1) ou 10 (2) anteriores aos espinhos neurais dos centros 5 a 13 (1) ou 14 (2). Nadadeira dorsal ii, 8. Primeiro pterigióforo da nadadeira dorsal inserido posteriormente ao espinho neural do centro 13 (2) ou 14 (1). Margem distal da nadadeira dorsal arredondada quando expandida. Origem da nadadeira dorsal distintamente mais próxima à base da nadadeira caudal que da ponta do focinho. Base do último raio da dorsal distintamente anterior à vertical que passa pela origem da nadadeira anal. Nadadeira anal iii, 8, último raio adnato. Margem distal da nadadeira anal arredondada. Primeiro pterigióforo da nadadeira anal inserido posteriormente ao arco hemal do centro 22 (2) ou 23 (1). Nadadeira adiposa ausente. Epurais 2. Nadadeira caudal furcada, lóbulo superior discretamente mais longo que o inferior, ambos 
arredondados. Raios principais da nadadeira caudal geralmente i, 9/i, 8 (raramente i, 8/i, 8). Pró-correntes dorsais 8 (1) ou 9 (1); pró-correntes ventrais 9 (2). Vértebras précaudais 21 (2)ou 22 (1); vértebras caudais 15 (1), 16 (1) ou 17 (1).

Colorido. Cor de fundo predominantemente amarela. Coloração escura estendendo-se desde o lábio superior até a porção exposta dos parietais e ao longo da série medial e primeira série de escamas até a origem da nadadeira caudal. Maxilar, ossos circumorbitais e série opercular densamente pigmentados próximo à porção dorsal da cabeça, tornando-se gradualmente amarelada ventralmente e com sutil deposição de guanina. Lábio inferior pouco pigmentado; restante da mandíbula e toda porção ventral da cabeça com pigmentação escassa.

Tronco tornando-se gradualmente amarelado ventralmente. Região abdominal amarela, com diminutos cromatóforos entre o istmo e a origem da nadadeira anal. Mancha umeral arredondada, conspícua em indivíduos jovens, porém inconspícua ou ausente em indivíduos adultos. Faixa primária ampla, percorrendo as escamas da terceira, quarta e quinta séries longitudinais, estendendo-se da região umeral até a vertical que passa pela origem dos raios pró-correntes da nadadeira caudal, não alcançando a mancha caudal. Faixa secundária estendendo-se ao longo da primeira e segunda séries longitudinais de escamas, desde os epoccipitais à vertical que passa pela origem da nadadeira anal. Base das escamas da segunda, terceira, quarta, quinta e sexta séries longitudinais de escamas com deposição de guanina, que em exemplares vivos é coberta por pigmentos que variam do rosa ao vermelho intenso; deposição de guanina na quinta escama da linha lateral mais intensa. Mancha caudal arredondada, situada na extremidade do pedúnculo caudal e estendendo-se à base de seis raios medianos da nadadeira caudal. Nadadeiras peitoral, pélvica, dorsal, anal e caudal hialinas.

Dimorfismo sexual. Exemplares machos de Lebiasina aff. bimaculata I apresentam o padrão de dimorfismo sexual exclusivo do grupo de espécies próximas a L. bimaculata (incluindo L. boruca e L. festae) descrito acima.

Distribuição. Lebiasina aff. bimaculata I é conhecida das bacias dos rios Tumbes, Catamayo, Piura e Quiroz, no Peru e Equador (Fig. 80). 
Tabela 23. Dados morfométricos de Lebiasina aff. bimaculata I.

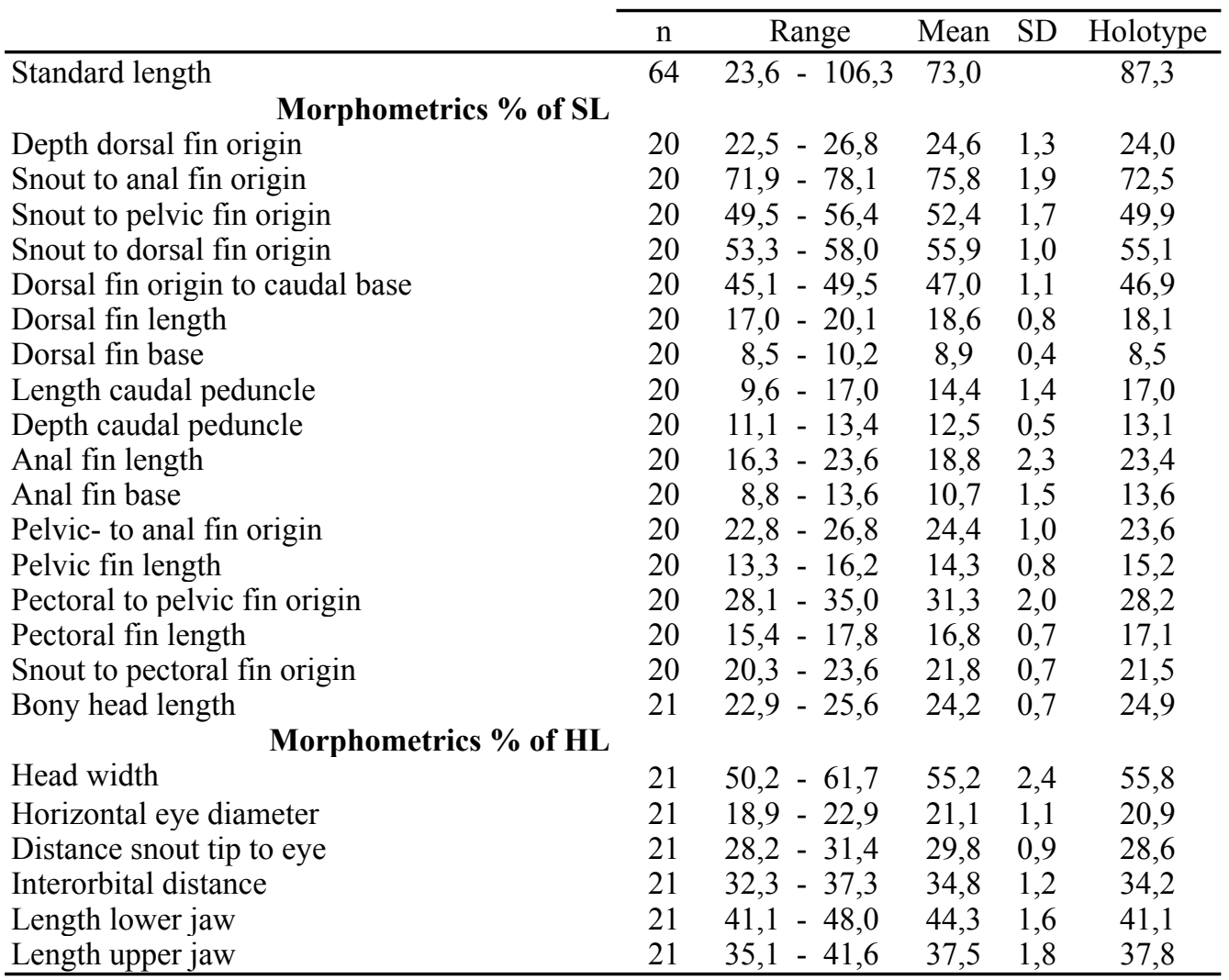

\section{Lebiasina aff. bimaculata II}

(Figura 105)

\section{Material examinado.}

MUSM 13270 (10, 77.4-96.7 mm SL), Peru, Piura, Sullana, Quebrada Salado [04³8’24’S 80¹8’58’W], 18-VI-1998, G. Mejía.

Diagnose. Lebiasina aff. bimaculata II diferencia-se de Lebiasina astrigata, L. aureoguttata, L. chocoensis, L. colombia, L. elongata, L. erythrinoides, $L$. floridablancaensis, L. intermedia, L. multimaculata, L. ortegai, L. panamensis, L. taphorni, L. unitaeniata, L. uruyensis, L. yuruaniensis, L. sp. Azuay, L. sp. "CuruáFaixa", L. sp. "Curuá-Pinta" e $L$. sp. "Parima" pelas seguintes características: parede da câmara posterior da bexiga natatória "celular"; escamas da sexta série longitudinal modificadas em machos adultos; três ou quatro séries longitudinais de escamas com intensa deposição de guanina (vs. parede da bexiga natatória não "celular"; modificações nas escamas da quinta série longitudinal nos machos adultos; escamas sem intensa deposição de guanina). Lebiasina aff. bimaculata II diferencia-se de $L$. 
boruca, L. festae e L. aff. festae por apresentar dentes com as cúspides laterais quase tão desenvolvidas quanto a cúspide central e por não apresentar dentes no endopterigóide (vs. dentes com cúspide central distintamente mais longa que as laterais; endopterigóide apresentando dentes). A espécie diferencia-se de L. bimaculata e L. aff. bimaculata I por apresentar uma distinta redução dos pré-maxilares, resultando em um forte prognatismo (vs. exemplares discretamente prognatos). A espécie difere ainda de L. bimaculata por apresentar moldura do forame escapular com uma porção cartilaginosa entre a escápula e o cleitro e não apresentar o pós-cleitro 3 (vs. moldura do forame escapular com uma porção cartilaginosa entre a escápula e o cleitro; pós-cleitro 3 presente) e de $L$. aff. bimaculata II por não apresentar uma inflexão na porção dentígera do maxilar (vs. porção dentígera do maxilar flexionada anteriormente, dentes do pré-maxilar e maxilar formando uma única superfície cortante).

Descrição. Dados morfométricos apresentados na tabela 24. Corpo comprimido e alongado. Perfil dorsal da cabeça distintamente convexo do lábio superior até até a origem da nadadeira dorsal. Perfil reto na base da dorsal e levemente côncavo posteriormente até a origem dos raios pró-correntes da nadadeira caudal. Perfil ventral da cabeça e tronco convexo desde o lábio inferior até a origem da pélvica, reto deste ponto até a origem da nadadeira anal, convexo na base da anal e côncavo do término da anal até a origem dos pró-correntes ventrais da nadadeira caudal.

Espécie discretamente prognata, boca terminal. Maxilar quase alcançando a margem anterior da órbita. Apenas uma série de 10 (2) ou 11 (2) dentes tricúspides decrescendo posteriormente no pré-maxilar. Maxilar com 4 (1) ou /5 (3) dentes tricuspidados. Dentário com duas séries de dentes: 12 (1) 14 (1) ou 15 (2) dentes tricúspides pedunculados com a cúspide central distintamente mais longa que as cúspides laterais na série externa, série interna com dentes diminutos, na maioria, cônicos (podendo ser tricúspides posteriormente) estendendo-se desde a sínfise até próximo ao processo coronóide. Raios-branquiostégios 4, três articulando com o ceratobranquial anterior e 1 com o ceratobranquial posterior.

Escamas ciclóides, circuli restritos à borda da escama, diversos radii (aproximadamente 23) convergindo para o centro da escama, fortemente anastomosados no centro, formando numerosas células. Série longitudinal da linha lateral com 27 (2) ou 28 (8) escamas, das quais apenas 5 ou 6 são perfuradas. Séries longitudinais entre a 
nadadeira dorsal e a pélvica 7. Escamas pré-dorsais 12. Escamas circumpedunculares 12.

Nadadeira peitoral i, 12 (1), 13 (5) ou 14 (4). Ponta da peitoral não alcançando a vertical que passa pela origem da pélvica. Raios da nadadeira pélvica i, 6 (1) ou i, 7 (9). Supraneurais 9 (2) anteriores aos espinhos neurais dos centros 5 a 13 (2). Nadadeira dorsal iii, 7 (1) ii, 8 (9). Primeiro pterigióforo da nadadeira dorsal inserido posteriormente ao espinho neural do centro 12 (2). Margem distal da nadadeira dorsal arredondada quando expandida. Origem da nadadeira dorsal distintamente mais próxima à base da nadadeira caudal que da ponta do focinho. Base do último raio da dorsal distintamente anterior à vertical que passa pela origem da nadadeira anal. Nadadeira anal iii, 8 (10), último raio adnato. Margem distal da nadadeira anal arredondada. Primeiro pterigióforo da nadadeira anal inserido posteriormente ao arco hemal do centro 22 (2). Nadadeira adiposa ausente. Dois epurais. Nadadeira caudal furcada, lóbulo superior discretamente mais longo que o inferior, ambos arredondados. Raios principais da nadadeira caudal geralmente i, 9/i, 8 (10). Pró-correntes dorsais 8 (1) ou 9 (1); pró-correntes ventrais 8 (2). Vértebras pré-caudais 22 (2); vértebras caudais 15 (1) ou 16 (1).

Colorido. Cor de fundo predominantemente amarela. Coloração escura estendendo-se desde o lábio superior até a porção exposta dos parietais e ao longo da série medial e primeira série de escamas até a origem da nadadeira caudal. Maxilar, ossos circumorbitais e série opercular densamente pigmentados próximo à porção dorsal da cabeça, tornando-se gradualmente amarelada ventralmente e com sutil deposição de guanina. Lábio inferior pouco pigmentado; restante da mandíbula e toda porção ventral da cabeça com pigmentação escassa.

Tronco tornando-se gradualmente amarelado ventralmente. Região abdominal amarela, com diminutos cromatóforos entre o istmo e a origem da nadadeira anal. Mancha umeral arredondada, conspícua em indivíduos jovens, porém inconspícua ou ausente em indivíduos adultos. Faixa primária ampla, percorrendo as escamas da terceira, quarta e quinta séries longitudinais, estendendo-se da região umeral até a vertical que passa pela origem dos raios pró-correntes da nadadeira caudal, não alcançando a mancha caudal. Faixa secundária estendendo-se ao longo da primeira e segunda séries longitudinais de escamas, desde os epoccipitais à vertical que passa pela 
origem da nadadeira anal. Base das escamas da segunda, terceira, quarta, quinta e sexta séries longitudinais de escamas com deposição de guanina, que em exemplares vivos é coberta por pigmentos que variam do rosa ao vermelho intenso; deposição de guanina na quinta escama da linha lateral mais intensa. Mancha caudal arredondada, situada na extremidade do pedúnculo caudal e estendendo-se à base de seis raios medianos da nadadeira caudal. Nadadeiras peitoral, pélvica, dorsal, anal e caudal hialinas.

Dimorfismo sexual. Exemplares machos de Lebiasina aff. bimaculata II apresentam o padrão de dimorfismo sexual exclusivo do grupo de espécies próximas a L. bimaculata (incluindo L. boruca e L. festae) já descrito acima.

Distribuição. Conhecida somente de Sullana, distrito de Piura, Quebrada Salado, bacia do rio Catamayo (Fig. 80).

Tabela 24. Dados morfométricos de Lebiasina aff. bimaculata II.

\begin{tabular}{lccccc} 
& $\mathrm{n}$ & Range & Mean & SD & Holotype \\
\cline { 2 - 6 } & 10 & $77,4-96,7$ & 85,4 & & 85,8 \\
Standard length & \multicolumn{1}{c}{ Morphometrics \% of SL } & & & & \\
& 10 & $22,2-24,7$ & 23,6 & 0,8 & 22,5 \\
Depth dorsal fin origin & 10 & $71,5-77,3$ & 75,0 & 1,7 & 74,4 \\
Snout to anal fin origin & 10 & $50,0-53,8$ & 51,3 & 1,0 & 50,9 \\
Snout to pelvic fin origin & 10 & $51,3-55,6$ & 53,4 & 1,3 & 52,1 \\
Snout to dorsal fin origin & 10 & $46,6-48,8$ & 48,1 & 0,6 & 48,0 \\
Dorsal fin origin to caudal base & 10 & $17,0-20,9$ & 19,5 & 1,1 & 18,9 \\
Dorsal fin length & 10 & $8,8-10,5$ & 9,5 & 0,5 & 9,2 \\
Dorsal fin base & 10 & $13,3-16,8$ & 15,4 & 1,0 & 16,8 \\
Length caudal peduncle & 10 & $12,0-12,8$ & 12,4 & 0,3 & 12,3 \\
Depth caudal peduncle & 10 & $17,0-25,4$ & 20,3 & 3,2 & 23,4 \\
Anal fin length & 10 & $10,0-13,9$ & 11,7 & 1,6 & 12,9 \\
Anal fin base & 10 & $22,3-27,0$ & 24,6 & 1,4 & 24,0 \\
Pelvic- to anal fin origin & 10 & $13,2-15,8$ & 14,7 & 0,9 & 15,8 \\
Pelvic fin length & 10 & $28,7-31,4$ & 29,8 & 0,9 & 28,9 \\
Pectoral to pelvic fin origin & 10 & $15,9-17,9$ & 17,0 & 0,6 & 17,9 \\
Pectoral fin length & 10 & $21,1-23,4$ & 22,2 & 0,8 & 22,6 \\
Snout to pectoral fin origin & 10 & $23,5-25,7$ & 24,8 & 0,7 & 24,9 \\
Bony head length & & & & & \\
& \multicolumn{1}{c}{ Morphometrics \% of HL } & & & & \\
Head width & 10 & $53,2-58,5$ & 55,7 & 2,1 & 53,7 \\
Horizontal eye diameter & 10 & $18,9-22,0$ & 20,0 & 0,9 & 18,9 \\
Distance snout tip to eye & 10 & $29,0-33,5$ & 30,5 & 1,5 & 33,5 \\
Interorbital distance & 10 & $34,8-40,1$ & 36,5 & 1,7 & 35,3 \\
Length lower jaw & 10 & $41,2-44,8$ & 42,6 & 1,2 & 42,1 \\
Length upper jaw & 10 & $34,6-38,6$ & 36,5 & 1,4 & 37,3 \\
\hline
\end{tabular}




\section{Lebiasina aff. festae}

(Figura 106)

Lebiasina bimaculata (non Valenciennes, in Cuvier \& Valenciennes).- Günther, 1860: 234 [inferred from distribution - "The third collection of Reptiles and Fishes sent by Mr. Fraser contains specimens from Guayaquil and from Esmeraldas."]; 240 [color pattern: "This species has, during life, a red spot in the third scale of the fourth longitudinal series." - the red spot is actually in the fifth scale of the fourth series, and the other species which has been traditionally identified as $L$. bimaculata presents 3-5 longitudinal rows of redish spots].- Starks, 1906 [distribution, specimens from Santa Rosa (Ecuador) only].- Eigenmann, 1914:28-29 [Among a large number of specimens of Lebiasina, recently collected by Mr. Henn, in Ecuador, a few are found which have the adipose - specimens collected in 1913 during the Landon Expedition, represented herein by ANSP 45473-76, CAS 11618, IU 13527, 13532, 13533, SU 22756, USNM 76963, 76964].- Eigenmann, 1920a: 16 [specimens from Guayas river basin].Eigenmann, 1923a: 123 [key to the species and synonymy]; 124-125 [examined material (of which lots IU 13526, 13527, 13528, 13529, 13530, 13531, 13532, 13533 and 13069 may be attributed to this species)]; 125 [overall morphology and color pattern descriptions]; plate XXI, fig. 2; 1923b: 446 [“'Liza de agua dulce and Huaija of Guayaquil are different names for the same fish - Lebiasina bimaculata." (specimens from Guayaquill)].- Myers, 1925: 28 [Lebiasina as a biological control of mosquito larvae; inferred from distribution].- Böhlke, 1958:94 [none of the specimens examined by Böhlke is L. bimaculata (ANSP 75950, USNM 164027, SU 49784)]; plate 6, fig. 1 [specimen from ANSP 75950].-Glodek, 1978: 5, table 1 [inferred from distribution].

Lebiasina (Lebiasina) bimaculata.- Géry, 1972: 92 [synonymy; brief description].

\section{Comentários}

Günther (1859: 418; 1864: 285) lista exemplares de "Lebiasina bimaculata" coletados no Ecuador por Fraser, no entanto, este registro não pode ser atribuído a Lebiasina aff. festae ou L. aff. bimaculata I pela falta de referências geográficas ou de colorido que permita o detalhamento em nível específico, diferentemente do estudo de 
Günther (1860: 233, 240), onde o autor fornece dados suficientes para atribuir a referência a Lebiasina aff. festae. Entretanto, pode-se afirmar que em ambos os casos não se tratam de exemplares de Lebiasina bimaculata propriamente dita (exceto pelo único exemplare da bacia de Callao, listado em Günther, 1864).

\section{Material examinado.}

ANSP 45473-45476 (3, 79.9-121.8 mm SL), Equador, Pichincha, Mindo [Mindo $00^{\circ} 02^{\prime}$ S 7848'W], VIII a IX-1913, A. Henn;

ANSP 75950 (2, 78.0-92.7 mm SL), Equador, Guayas, rio Chimbo, próximo a Bucay, IV-1954, G. Herrera;

CAS uncat (ex-IU 13527) (5, 48.5-75.3 mm SL), Equador, Manabi, Porto Viejo [Portoviejo $01^{\circ} 03$ 'S 80²7'W], 1913, A. Henn;

CAS uncat (ex-IU 13532) (17, 39.9-59.7 mm SL), Equador, Guayas. Colimes, Río Daule [Colimes $01^{\circ} 33^{\prime} \mathrm{S} 80^{\circ} 01^{\prime} \mathrm{W}$; Río Daule $00^{\circ} 25^{\prime} \mathrm{N} 80^{\circ} 01^{\prime} \mathrm{W}, 02^{\circ} 10^{\prime} \mathrm{S} 79^{\circ} 52^{\prime} \mathrm{W}$, rio Daule afl da margem esquerda do rio Guayas, a montante de Guayaquil], 1913, A. Henn, Landon Expedition;

CAS uncat (ex-IU 13533) (4, 40.9-52.8 mm SL), Equador, Guayas, Colimes, Río Daule [Colimes $01^{\circ} 33^{\prime} \mathrm{S} 80^{\circ} 01^{\prime} \mathrm{W}$; Río Daule $00^{\circ} 25^{\prime} \mathrm{N} 80^{\circ} 01^{\prime} \mathrm{W}, 02^{\circ} 10^{\prime} \mathrm{S} 79^{\circ} 52^{\prime} \mathrm{W}$, rio Daule afl da margem esquerda do rio Guayas, a montante de Guayaquil], 1913, A. Henn, Landon Exped;

CAS 11618 (2, 67.5-65.5 mm SL), Equador, Los Rios, rio Vinces, bacia do rio Guayas, 1913, A.W. Henn;

CAS 70426 (4, 78.6-97.8 mm SL), Equador, Manabi, Chone, Rio Chone, próximo à costa oeste de Colimes [Landon Expedition?];

CAS 72057 (1, 89.3 mm SL) Equador, “oeste do Equador”, unknown date and collector; MEPN uncat. (1, $26.0 \mathrm{~mm}$ SL), Equador, El Oro, rio Huisho, afluente do rio Jubones, próximo à sua desembocadura a leste de Pasaje, $400 \mathrm{~m}$ elev., $03^{\circ} 19^{\prime} \mathrm{S} 79^{\circ} 45^{\prime} \mathrm{W}, 01$ VI-1979, R. Barriga et al.;

FMNH 93152 (10, 44.5-90.3 mm SL), Equador, Los Rios, Río Palenque, poça de um pequeno riacho no Centro Cientifico [Río Palenque 01²2’S 79²2’W], 09-IX-1978, G. S. Glodek;

MCNG 19385 (6, 57.3-124.5 mm SL), Equador, Bolívar, Río Chimbo, 1991, D. C. Taphorn; 
MCNG 19386 (3, 84.0-90.8 mm SL), Equador, rio Changui [Río Changuil 0153'S 79²5’W], 1991, D. C. Taphorn;

MCNG 19387 (2, 95.5-113.5 mm SL), Equador, Guayas, rio Balao [rio Balao 0255'S 7949’W], 1991, D. C. Taphorn;

MEPN 1902 (2, 40.2-50.3 mm SL), Equador, Loja, Quebrada San Jose, 04²8'00”S 79³6’05’W, 750 m elev., 26-VIII-1978, R. Barriga;

MEPN 2103 (6, 66.5-107.8 mm SL), Equador, Zamora Chinchipe, rio Paquintza, 100m a montante da confluência com o rio Chumbletza [Chuchumbletza] [03³1'49.2"S 78³1'50.3"W], 710 m elev., 03-X-2005, R. Barriga et al.;

MEPN 2605 (2, 66.1-69.1 mm SL), Equador, El Oro, La Cuca 03³8’10”S 7955’40”W, 280 m elev., R. Barrigaet al.;

MEPN 321 (2, 103.7-124.5 mm SL), Equador, Guayas, rio Balao [rio Balao 0255'S 7949’W], I-1949, unknown collector [Melina?];

MEPN 3782 (3, 89.2-99.2 mm SL), Equador, Esmeraldas, Estero El Salto afluente do rio Chinca [=rio Quinindé] a $2 \mathrm{Km}$ da desembocadura no rio Esmeraldas, 046’33' $\mathrm{N}$ 79³3’12”W, 14-X-1985, R. Barriga et al.;

MEPN 3783 (2, 44.4-62.3 mm SL), Equador, Esmeraldas, rio Qunindé [Quinindé?] praia na margem esquerda 10 minutos a montante do povoado, $0^{\circ} 18^{\prime} 0^{\prime} \mathrm{N} 79^{\circ} 28^{\prime} 0^{\prime \prime} \mathrm{W}$, 14-X-1985, R. Barriga et al.;

MEPN 3784 (2, 91.7-97.8 mm SL), Equador, Esmeraldas, estero Mutile [baixo rio Esmeraldas], próximo a San Mateo, $00^{\circ} 53^{\prime}$ N 79³7’W, 20-III-1985, R. Barriga et al.; MEPN 3785 (1, 83.2 mm SL), Equador, Esmeraldas, braço do rio Guayllabamba a 500 $\mathrm{m}$ de Ronca Tigre, $00^{\circ} 23$ '16”N 79²3'18”W, 10-XII-1985, R. Barriga et al.;

MEPN 3786 (2/3, 42.1-87.6 mm SL), Equador, Esmeraldas, Estero Mendoza em frente ao Estero Cole a $1 \mathrm{Km}$ do povoamento [Río Cole afl Esmeraldas, próximo à desembocadura do rio Guayllabamba], 00²7’N 79²4’09’'W, 10-III-1985, R. Barriga et al.;

MEPN 3787 (2, 71.6-92.2 mm SL), Equador, Esmeraldas, Estero La Bocana del Cupa, 100 m a jusante de Puerto Cupa no rio Blanco, 00²6’36”N 79²5'0”'W, 14-X-1985, R. Barriga et al.;

MEPN 3788 (1/4, 94.6 mm SL), Equador, Esmeraldas. Estero Tatica, $2 \mathrm{Km}$ do recinto Timbre, 050'26”N 79³7'7’W [próximo a San Mateo], 14-X-1985, R. Barriga et al.; 
MEPN 3789 (2, 84.1-85.5 mm SL), Equador, Esmeraldas, estero El Male $2 \mathrm{~km}$ a jusante do recinto Male [baixo rio Esmeraldas], 00³7’52”N 79³1’36”W, 14-X-1985, R. Barriga et al.;

MEPN 3793 (1, 75.8 mm SL), Equador, Esmeraldas, Estero San Pablo a 2 Km de Santa Elvira, afluente do rio Quinindé, $00^{\circ} 13$ '52'N 79²5'38'W, 14-XI-1985, R. Barriga et al.;

MEPN 4628 (6, 121.3-183.5 mm SL), Equador, El Oro, Granja "La Cuca," canal do rio Arenillas, ao sudoeste de Santa Rosa, 0330’'S 8004’W, 30m elev., 02-VIII-1978, R. Barriga \& M. Ibarra;

MEPN 4630 (8, 58.4-112.4 mm SL), Equador, Manabi, $1 \mathrm{Km}$ a montante do acampamento de Poza Honda, D. Coopmann;

MEPN 4634 (6/7, 52.380 .9 mm SL), Equador, El Oro, Granja "La Cuca," canal del río Arenillas, a sudeste de Santa Rosa, 30m. 03³0’S 8004’W, 02-VIII-1978, R. Barriga \& M. Ibarra;

MEPN 4738 (1, 72.7 mm SL), Equador, El Oro, Pasaje, Huisho, 400 m elev., 03¹9’40” S 7944’53” W, 04-I-1979, R.Barrigaet al.;

MEPN 6100 (2, 88.9-116.9 mm SL), Equador, Guayas, Rio Balao, 1949, Molina;

MEPN 6161 (21, 40.1-89.3 mm SL), Equador, Guayas, Rio Borbón acampamento do Departamento de Forestacion, unknown date, F. Leon;

MEPN 6174 (2, 72.8-101.7 mm SL), Equador, Guayas, rio Canayacu a $7 \mathrm{~km}$ ao sul de Naranjal [0240’23"S 79³6’52"W], na cooperativa La Nueva Union, 24-IX-1992, R. Barriga;

MEPN 6178 (19, 46.3-93.7 mm SL), Equador, Guayas, rio Minas cruzando a cooperativa 23 de Noviembre, $9 \mathrm{Km}$ ao sul de Naranjal, $110 \mathrm{~m}$ elev., 0241'26”S 79³8'16”W, 22-IX-1992, R. Barriga;

MEPN 6194 (22, 40.1-87.0 mm SL), Equador, El Oro, Estero Viernes Santo (Canal do rio Arenillas), 16-XII-1993, R. Barriga;

MEPN 6218 (1, 95.6 mm SL), Equador, Los Ríos, Quevedo, rio Quevedo aflluente do rio Babahoyo, bacia do rio Guayas, X-1955, G. Herrera;

MEPN 6239 (3, 97.1-106.1 mm SL), Equador, Esmeraldas, Quinindé-La Unión, estero no Km 180, R. Barriga;

MEPN 6263 (4, 73.5-85.0 mm SL), Equador, Esmeraldas [Los Ríos], Bucay, rio Chagui [Río Chagui=Río Chaguil?: 153’0” S 79²5’0” W], IV-1954, G. Herrera; 
MEPN 6405 (10, 61.5-112.1 mm SL), unknown data;

MEPN 6994 (1, 74.2 mm SL), Equador, Azuay, rio Fermin, La Independencia, 0303'11'S 7942'48”'W, 03-IX-2007, R. Barriga;

MEPN 8970 (4, 42.4-54.8 mm SL), Equador, Los Rios, Estero sem nome entre San Pedro e o rio Lulú, 150 m elev., 00²7’16”S 79²1’18”W, 6-XII-2003, R. Barriga;

MEPN 9072 (3, 58.6-78.6 mm SL), Equador, Los Rios, estero Choyo afluente do rio Lulú [0054’0’S 79²6’0’W], setor Hamburgo, 125 m elev., R. Barriga;

MEPN 9079 (5, 57.9-75.4 mm SL), Equador, Manabí, Rio Portoviejo sector Higuerón, 50 m elev., $01^{\circ} 02^{\prime} 18^{\prime}$ S 8008'15’W, 02-VI-1993, R. Barriga;

MEPN 9242 (10, 37.8-115.4 mm SL), Equador, Guayas, rio Minas, cruzando a Cooperativa 23 de Noviembre, a $9 \mathrm{Km}$ ao Sul de Naranjal, $110 \mathrm{~m}$ elev., 0241'26”S 79³8'16’W, 28-IX-1992, R. Barriga;

MEPN 9307 (1, 75,7 mm SL), Equador, Azuay, rio Fermin via para Minas 12 de octubre rio Siete, $100 \mathrm{~m}$ elev., 0302’06”S 7941’52’W, 09-III-2007, R. Barriga;

MEPN 9308 (8, 58.2-111.2 mm SL), Equador, Zamora-Chinchipe, pântano lateral junto à vía Los Encuentros-Paquisha, destacamento, 0546’09”S 78³6’06” W, 790 m elev., 27-III-2008, R. Barriga et al.;

MEPN 9343 (1, 65.0 mm SL), Equador, Los Rios, rio Lulú, Ada-San Simón a 9km do povoado de San Pedro, 140 m elev., 12-VI-2003, R.Barriga \& A. Farfán;

MEPN 9493 (1, $91.9 \mathrm{~mm}$ SL), Equador, Guayas, rio Culebra [02¹8'11"S 7943'57"W], 6-VII-1980, unknown collector;

MEPN uncat (5, 24,27-83,67), no data;

MEPN uncat (2, 57.8-58.4 mm SL), Equador, Manabi, rio Chico, afluente do río

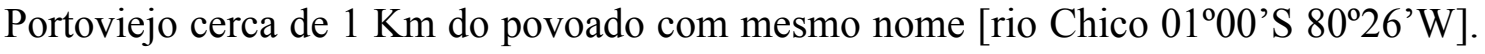
29-IX-1988, C. Zarubrons;

MEPN uncat (4, 53.2-95.4 mm SL), Equador, Guayas, rio Chimbo [Río Chimbo 02 $06^{\prime}$ 'S 79² $42^{\prime} \mathrm{W}$, afl. margem esquerda do rio Babahoyo, a montante de Guayaquil], unknown date and collector;

MUSM 11542 (2, 59.49-116.35 mm SL), Peru, Tumbes, El Gaucho, Quebrada Faical, 13-V-1994, M.Napravnik-Choy;

MUSM 11548 (2/3, 126.95-139.33 mm SL), Peru, Tumbes, El Gaucho, Quebrada Faical, 23-II-1996, M.Napravnik-Choy;

MUSM 12775 (2, 81.32-98.87 mm SL), Equador, rio Chone; 
SU 9302 (17, 37.7-63.0 mm SL), Equador, rio em Santa Rosa, unknown date, P. O. Simons;

MUSM 1917 (1, 62.73 mm SL), Peru, Amazonas, aprox. 14 km de Bágua, Rio Marañon, 10-VII-1986, E. Holm;

MUSM 1917, 1, Peru, Amazonas, aprox. 14 Km de Bágua, rio Marañon, 10-VII-1986, E. Holm;

MUSM 5741 (3, 55.14-69.97 mm SL), Peru, Tumbes, Zarumilla, Matapalo, Quebrada Faical, 17-VIII-1994, P. de Rham \& F. Chang;

MUSM 5841 (1, 107.28 mm SL), Peru, Tumbes, Bosque Nacional de Tumbes (BNT), El Gaucho, Qda Faical, 0359’ S 80³1’ W, 09-XII-1993, F. Chang;

MUSM 6530 (10, 107.22-121.27 mm SL), Peru, Tumbes, BNT, El Gaucho, Quebrada Faical, 550 m elev., 0359' S 80³1' W, 07-XII-1993, F. Chang;

MUSM 6537 (1, 112.29 mm SL), Peru, Tumbes, BNT, El Gaucho, Qda Faical, 0359’ S $80^{\circ} 31^{\prime}$ W, 550 m elev., 08-XII-1993, F. Chang;

MUSM 6543 (3, 109.72-121.55 mm SL), Peru, Tumbes, BNT, El Gaucho, quebrada Faical 550 m elev., 0359’ S 80³1’ W, 03-XII-1993, F. Chang;

MUSM 9980 (2, 110.79-133.07 mm SL), Peru, Tumbes, BNT, El Gaucho, Qda Faical, 0359’ S 80³1’ W, 2 VII-1994, F. Chang;

NRM 10362 (4, 06.55-125.6 mm SL), [possivelmente bacia do rio Guayas], 1934, Hammarlund;

SU 22756 (7, 54.4-76.4 mm SL), Equador, Los Rios, rio Vinces, bacia do rio Guayas, 1913, A.W. Henn;

SU 49784 (2, 101.5-108.9 mm SL), Equador, Guayas, na boca do rio balao, unknown collection date, R. Molina;

USNM 53502 (7, 36.4-50.8 mm SL), Equador, El Oro, rio em Santa Rosa, unknown date, P. O. Simons;

USNM 76963 (ex-IU 13533) (40, 40.7-57.4 mm SL), Equador, Guayas, Colimes, Río Daule [Colimes $01^{\circ} 33^{\prime} \mathrm{S} 80^{\circ} 01^{\prime} \mathrm{W}$; Río Daule $00^{\circ} 25^{\prime} \mathrm{N} 80^{\circ} 01^{\prime} \mathrm{W}, 02^{\circ} 10^{\prime} \mathrm{S} 79^{\circ} 52^{\prime} \mathrm{W}$, rio Daule afl da margem esquerda do rio Guayas, a montante de Guayaquil], 1913, A. Henn, Landon Exped;

USNM 76964 (15, 76.8-106.1 mm SL), Equador, Manabi. Chone [Chone 0041's 8004’W], 1913, A. Henn, Landon Exped; 
USNM 164027 (4/6, 74.2-99.7 mm SL), Equador, Guayas. Rio Chimbo, próximo a Bucay [Bucay $02^{\circ} 10^{\prime} \mathrm{S} 7^{\circ} 06^{\prime} \mathrm{W}$; rio Chimbo, afl margem esquerda do rio Guayas; Böhlke, 1958:115, Bucay - vila próximo à confluência dos rios Chimbo e Chanchán], IV-1954, G. Herrera;

USNM 280468 (1, 53.6 mm SL), Peru, Tumbes, rio Tumbes a montante de Rica Playa [034'23"S 80²9'55"W], 11-VIII-1986, R. P. Vari et al.;

USNM 280469 (6, 50.9-81.5 mm SL), Peru, Tumbes, alto rio Zarumilla em Pozo Lajas, (na fronteira Equador/Peru) [Quebrada Lajas 0340’S 80¹3’W], 12-VIII-1986, R. P. Vari et al.;

USNM 280470 (1, $56.4 \mathrm{~mm}$ SL), Peru, Tumbes, rio Tumbes próximo ao projeto de irrigação Boca Tumba, a jusante de Francos [Francos 03²4'S 80²8'W], 10-VIII-1986, R. P. Vari et al.;

USNM 287748 (ex-MEPN 3787) (1, 95.7 mm SL), Equador, Esmeraldas, Estero La Bocana del Cupa, $100 \mathrm{~m}$ a jusante de Puerto Cupa no rio Blanco, 00²6’36”N 79²5'0’W, 14-X-1985, R. Barriga et al.;

USNM 326205 (1, 102.0 mm SL), Equador, Esmeraldas, unknown date and collector; USNM 326206 (1, 95.8 mm SL), Equador, Esmeraldas, unknown date and collector.

Diagnose. Lebiasina aff. festae diferencia-se de Lebiasina astrigata, L. aureoguttata, L. chocoensis, L. colombia, L. elongata, L. erythrinoides, L. floridablancaensis, L. intermedia, L. multimaculata, L. ortegai, L. panamensis, L. taphorni, L. unitaeniata, L. uruyensis, L. yuruaniensis, L. sp. Azuay, L. sp. “Curuá-Faixa”, L. sp. “Curuá-Pinta” e $L$. sp. "Parima" pelas seguintes características: parede da câmara posterior da bexiga natatória "celular"; escamas da sexta série longitudinal modificadas em machos adultos, ao menos a quarta escama da linha lateral com intensa deposição de guanina (vs. parede da bexiga natatória não "celular”; modificações nas escamas da quinta série longitudinal nos machos adultos; escamas sem intensa deposição de guanina). A espécie distingue-se de Lebiasina bimaculata, L. aff. bimaculata I e L. aff. bimaculata II por apresentar dentes com a cúspide central distintamente mais longa que as laterais e dentes no endopterigóide ( $v s$. dentes com as cúspides laterais quase tão desenvolvidas quanto a cúspide central e por não apresentar dentes no endopterigóide). Lebiasina aff. festae difere de L. boruca e L. festae pela presença da mancha caudal (vs. mancha caudal ausente). A espécie difere ainda de L. boruca por apresentar apenas a quarta escama da 
linha lateral com intensa deposição de guanina e uma discreta mancha escura na porção proximal dos raios anteriores da nadadeira dorsal (vs. duas a três séries longitudinais de escamas apresentando depósito de guanina; conspícua mancha escura na porção proximal dos raios posteriores da nadadeira dorsal). Lebiasina aff. festae difere ainda de L. festae pela presença do pós-cleitro 3 e de um processo na porção anterior do opérculo, onde se insere parte do dilatator operculi (vs. pós-cleitro 3 ausente; margem anterior do opérculo sem um processo ósseo onde se insere parte do dilatator operculi).

Descrição. Dados morfométricos apresentados na tabela 25. Corpo comprimido e alongado. Perfil dorsal da cabeça distintamente convexo do lábio superior até até a origem da nadadeira dorsal. Perfil reto na base da dorsal e levemente côncavo posteriormente até a origem dos raios pró-correntes da nadadeira caudal. Perfil ventral da cabeça e tronco convexo desde o lábio inferior até a origem da pélvica, reto deste ponto até a origem da nadadeira anal, convexo na base da anal e côncavo do término da anal até a origem dos pró-correntes ventrais da nadadeira caudal.

Espécie discretamente prognata, boca terminal. Maxilar quase alcançando a margem anterior da órbita. Apenas uma série de 11 (3) dentes tricúspides decrescendo posteriormente no pré-maxilar. Maxilar com 4 (1) 5 (1) 6 (1) 8 (1)dentes tricuspidados. Dentário com duas séries de dentes: 13 (1) 15 (2) 16 (1)dentes tricúspides pedunculados com a cúspide central distintamente mais longa que as cúspides laterais na série externa, série interna com dentes diminutos, na maioria, cônicos (podendo ser tricúspides posteriormente) estendendo-se desde a sínfise até próximo ao processo coronóide. Raios-branquiostégios 4, três articulando com o ceratobranquial anterior e 1 com o ceratobranquial posterior.

Escamas ciclóides, circuli restritos à borda da escama, diversos radii (aproximadamente 22) convergindo para o centro da escama, fortemente anastomosados no centro, formando numerosas células. Série longitudinal da linha lateral com 27 (3), 28 (27), 29 (17) ou 30 (2) escamas, das quais apenas 5 (13) ou 6 (47) são perfuradas. Séries longitudinais entre a nadadeira dorsal e a pélvica 7. Escamas pré-dorsais 12 (7), 13 (40) ou 14 (1). Primeira série longitudinal de escamas alcançando a vertical que passa pela origem da nadadeira anal. Escamas circumpedunculares 12.

Nadadeira peitoral i, 12 (3), 13 (22), 14 (18) ou 15 (6). Ponta da peitoral não alcançando a vertical que passa pela origem da pélvica. Raios da nadadeira pélvica i, 7 
(59) ou i, 8 (1). Supraneurais 10 (2) anteriores aos espinhos neurais dos centros 5 a 14. Nadadeira dorsal ii, 8 (62) iii, 7 (1). Primeiro pterigióforo da nadadeira dorsal inserido posteriormente ao espinho neural do centro 13 (1) ou 14 (1). Margem distal da nadadeira dorsal arredondada quando expandida. Origem da nadadeira dorsal distintamente mais próxima à base da nadadeira caudal que da ponta do focinho. Base do último raio da dorsal distintamente anterior à vertical que passa pela origem da nadadeira anal. Nadadeira anal iii, 8 (raramente iii, 9), último raio adnato. Margem distal da nadadeira anal arredondada. Primeiro pterigióforo da nadadeira anal inserido posteriormente ao arco hemal do centro 23. Nadadeira adiposa presente em apenas oito exemplares examinados. Dois epurais. Nadadeira caudal furcada, lóbulo superior discretamente mais longo que o inferior, ambos arredondados. Raios principais da nadadeira caudal geralmente i, 9/i, 8 (raramente i, 8/i, 8). Pró-correntes dorsais 9 (2); pró-correntes ventrais 8 (1) ou 9 (1). Vértebras pré-caudais 23; vértebras caudais 15 .

Colorido. Coloração de fundo amarelada. Cabeça densamente pigmentada do lábio superior até a porção posterior exposta dos parietais. Pigmentação densa se estendendo posteriormente pela série médio-dorsal e duas séries adjacentes, dos parietais até a inserção da nadadeira caudal, tornando-se gradualmente amarelada ventralmente. Ossos da série circumorbital e série opercular levemente pigmentados. Lábio inferior discretamente pigmentado próximo à abertura da boca. Porção ventral da cabeça escassamente pigmentada.

Faixa primária ampla, porém pouco conspícua, estendendo-se desde a região umeral até próximo ao término do pedúnculo caudal ao longo da terceira e quarta séries longitudinais de escamas, não estando conectada à mancha caudal. Faixa secundária praticamente indistinta, estendendo-se ao longo primeira e segunda séries longitudinais de escamas, alcançando ao menos a a vertical que passa pela origem da nadadeira anal. Mancha umeral presente, mais distinta em exemplares jovens e adultos de menor tamanho, estando praticamente indistinta da faixa primária em exemplares maiores que $90 \mathrm{~mm}$ SL. Séries longitudinais de manchas formadas por deposição de guanina na base das escamas raramente distintas, exceto por uma mancha situada na quinta escama da série da linha lateral. Nadadeiras peitoral, pélvica, anal e caudal hialinas. Membranas inter-radiais na porção média dos raios da nadadeira dorsal variavelmente pigmentadas; pigmentação mais distinta em juvenis que em adultos. 
Dimorfismo sexual. Exemplares machos de Lebiasina aff. festae apresentam o padrão de dimorfismo sexual exclusivo do grupo de espécies próximas a L. bimaculata (incluindo L. boruca e L. festae) já descrito acima.

Distribuição. A oeste dos Andes desde a bacia do rio Esmeraldas (norte do Equador) até a bacia do rio Tumbes (Peru) e a leste dos Andes (Figura 80).

Tabela 25. Dados morfométricos de Lebiasina aff. festae.

\begin{tabular}{|c|c|c|c|c|c|}
\hline & $\mathrm{n}$ & Range & Mean & SD & Holotype \\
\hline Standard length & 49 & $46,6-139,3$ & 90,3 & & 120,1 \\
\hline \multicolumn{6}{|c|}{ Morphometrics \% of SL } \\
\hline Depth dorsal fin origin & 47 & $21,8-27,5$ & 25,0 & 1,4 & 24,0 \\
\hline Snout to anal fin origin & 47 & $71,6-80,4$ & 77,1 & 1,9 & 75,9 \\
\hline Snout to pelvic fin origin & 47 & $50,4-58,9$ & 53,5 & 1,7 & 51,2 \\
\hline Snout to dorsal fin origin & 47 & $55,6-61,4$ & 57,8 & 1,3 & 56,8 \\
\hline Dorsal fin origin to caudal base & 47 & $42,9-49,1$ & 45,2 & 1,4 & 45,2 \\
\hline Dorsal fin length & 47 & $17,4-21,8$ & 19,6 & 1,2 & 18,3 \\
\hline Dorsal fin base & 47 & $7,9-10,0$ & 9,1 & 0,5 & 9,1 \\
\hline Adipose fin to caudal peduncle & 8 & $12,5-18,2$ & 13,5 & 1,9 & 0,0 \\
\hline Length caudal peduncle & 46 & $10,6-16,0$ & 13,4 & 1,2 & 15,3 \\
\hline Depth caudal peduncle & 47 & $11,7-13,6$ & 12,6 & 0,4 & 12,9 \\
\hline Anal fin length & 47 & $15,9-24,2$ & 19,1 & 1,8 & 20,6 \\
\hline Anal fin base & 47 & $8,3-14,2$ & 11,0 & 1,3 & 13,3 \\
\hline Pelvic- to anal fin origin & 47 & $21,1-26,7$ & 24,5 & 1,3 & 25,8 \\
\hline Pelvic fin length & 47 & $13,0-16,6$ & 14,9 & 1,0 & 15,4 \\
\hline Pectoral to pelvic fin origin & 47 & $28,7-33,9$ & 31,1 & 1,3 & 31,0 \\
\hline Pectoral fin length & 47 & $14,2-19,6$ & 17,3 & 1,5 & 16,0 \\
\hline Snout to pectoral fin origin & 47 & $21,5-27,6$ & 23,5 & 1,6 & 21,8 \\
\hline Bony head length & 47 & $23,0-27,9$ & 24,9 & 1,3 & 23,3 \\
\hline \multicolumn{6}{|c|}{ Morphometrics \% of HL } \\
\hline Head width & 47 & $55,4-68,0$ & 60,2 & 3,3 & 59,2 \\
\hline Horizontal eye diameter & 47 & $18,3-29,3$ & 22,9 & 3,1 & 20,4 \\
\hline Distance snout tip to eye & 47 & $23,5-30,9$ & 27,1 & 2,0 & 30,1 \\
\hline Interorbital distance & 47 & $34,8-42,0$ & 38,0 & 1,5 & 37,6 \\
\hline Length lower jaw & 47 & $35,1-43,1$ & 38,6 & 2,1 & 38,2 \\
\hline Length upper jaw & 21 & $31,3-38,3$ & 33,4 & 1,6 & 33,4 \\
\hline
\end{tabular}

\section{Lebiasina sp. "Azuay"}

(Figura 107)

\section{Material examinado.}

MEPN 5982 (6, 84.1-126.0 mm SL), Equador, Azuay, rio Pulga Guerrero afluente do rio Fermín, 160 m elev., 0301'47’S 7943’00”W, 25-V-2007, R. Barriga et al.; 
MEPN 5985 (2, 86.7-98.1 mm SL), Equador, Azuay, quebrada Tama entre as minas de Santa Martha e Santa Martha, 170m elev., 0301'45”S 7942’43”W, 26-VIII-2007, R. Barriga et al.;

MEPN 6001 (4, 97.8-120.00 mm SL), Equador, Azuay, quebrada sem nome, afluente do rio Guanache, 200m elev., 0303’38’S 7943’50”W, 25-VII-2007, R. Barriga et al.; MEPN 6988 (4, 69.8-114.5 mm SL), Equador, Azuay, rio Fermin via para Minas 12 de octubre, rio Siete, $03^{\circ} 02^{\prime} 06^{\prime}$ S 7941'52”W, 09-III-2007, R. Barriga;

MEPN 6994 (3, 63.9-79.8 mm SL), Equador, Azuay, Rio Fermin, La Independencia, 0303'11’S 7942’48”W, 09-III-2007, R. Barriga;

MEPN 7011 (2, 76.5-124.7 mm SL), Equador, Azuay, Cabeceira do Rio Fermin antes de La Independencia, 0302’12’S, 7942’48’W, 09-III-2007, R. Barriga;

MEPN 9307 (1, 77.6 mm SL), Equador, Azuay, Rio Fermin, via para Minas 12 de octubre, rio Siete, $100 \mathrm{~m}$ elev., 0302’06”S 7941’52”W, 9-III-2007, R. Barriga.

Diagnose. Lebiasina sp. Azuay difere das espécies de Lebiasina bimaculata, L. aff. bimaculata I, L. aff. bimaculata II, L, boruca, L. festae e $L$. aff. festae por não apresentar a parede da câmara posterior da bexiga natatória "celular", por apresentar as escamas da quinta série longitudinal com tecido epitelial hipertrofiado nos machos adultos e por não apresentar escamas com intensa deposição de guanina (vs. parede da bexiga natatória "celular", escamas da sexta série longitudinal modificadas em machos adultos, ao menos a quarta escama da linha lateral com intensa deposição de guanina). A espécie difere de Lebiasina sp. "Curuá-Pinta" por apresentar faixas longitudinais e mancha caudal, e não apresentar manchas escuras na base das escamas da segunda à quinta séries longitudinais (vs. faixas longitudinais e mancha caudal ausentes; manchas escuras presentes na base das escamas da segunda à quinta séries longitudinais). Difere de Lebiasina elongata, L. erythrinoides, L. intermedia, L. taphorni, L. unitaeniata, L. uruyensis, L. yuruaniensis, L. sp. "Curuá-Faixa" e L. sp. "Parima” por apresentar uma série longitudinal de pequenas manchas arredondadas (vs. série longitudinal de manchas escuras ausente). Lebiasina sp. Azuay difere ainda de L. taphorni, L. unitaeniata, L. uruyensis, L. yuruaniensis e L. sp. "Parima", pela ausência da faixa "intermediária" e pela mancha caudal alcançar o pedúnculo caudal anteriormente ( $v s$. faixa "intermediária" presente; mancha caudal não alcançando o pedúnculo caudal anteriormente). Entre as espécies do clado 83, Lebiasina sp. Azuay se diferencia de $L$. 
colombia, L. floridablancaensis, L. ortegai e L. panamensis por apresentar faixa primária inconspícua (vs. faixa primária conspícua ao longo de todo o corpo em $L$. ortegai e exemplares adultos de L. panamensis; porção anterior da faixa primária conspícua em L. colombia e exemplares jovens de L. panamensis; porção posterior da faixa primária conspícua em L. floridablancaensis). A espécie se distingue de $L$. multimaculata e L. chocoensis por apresentar a faixa secundária conspícua, passando pelas escamas da segunda e terceira séries longitudinais (vs. faixa secundária inconspícua estendendo-se ao longo das escamas da primeira e segunda séries longitudinais). A espécie se diferencia de L. aureoguttata por apresentar numerosas manchas pequenas distribuídas ao longo da quarta série longitudinal de escamas e a faixa secundária alcançando o término da nadadeira dorsal (vs. poucas manchas grandes distribuídas ao longo da quarta série longitudinal, faixa secundária alcançando a vertical que passa pela origem da nadadeira adiposa). Lebiasina sp. Azuay se diferencia de Lebiasina astrigata pelos seguintes caracteres: faringo-branquial 2 apresentando dentes; nasal não alcançando o ramo lateral do pré-maxilar; espinho do supra-occipital ultrapassando o ponto de contato entre o complexo neural e o supra-occipital; faixa primária alcançando a nadadeira caudal ( $v s$. faringo-branquial 2 edêntulo; nasal estendendo-se anteriormente, alcançando o ramo lateral do pré-maxilar; espinho do supra-occipital curto, não alcançando o ponto de contato entre o complexo neural e o supra-occipital; faixa primária alcançando a vertical que passa pelo término da nadadeira dorsal).

Descrição. Dados morfométricos apresentados na tabela 26. Corpo comprimido e alongado. Perfil dorsal da cabeça e do corpo convexo do lábio superior até até a origem da nadadeira dorsal, tornando-se praticamente reto entre os parietais e a origem da dorsal. Perfil reto na base da dorsal e levemente côncavo posteriormente até a origem dos raios pró-correntes da nadadeira caudal. Perfil ventral da cabeça e tronco convexo desde o lábio inferior até a origem da pélvica, reto deste ponto até a origem da nadadeira anal, convexo na base da anal e côncavo do término da anal até a origem dos pró-correntes ventrais da nadadeira caudal.

Espécie discretamente prognata, boca subsuperior. Maxilar alcançando o meio da órbita. Apenas uma série de x dentes tricúspides decrescendo posteriormente no prémaxilar. Maxilar com x dentes tricuspidados. Dentário com duas séries de dentes; $\mathrm{x}$ 
dentes tricúspides pedunculados com a cúspide central distintamente mais longa que as cúspides laterais na série externa, série interna com dentes diminutos, na maioria, cônicos (podendo ser tricúspides posteriormente) estendendo-se desde a sínfise até próximo ao processo coronóide. Raios-branquiostégios 4, três articulando com o ceratobranquial anterior e um com o ceratobranquial posterior.

Escamas ciclóides, circuli restritos à borda da escama, diversos radii convergindo para o centro da escama, estando intensamente anastomosados no centro, formando diversas células. Série longitudinal da linha lateral com 27 (3), 28 (10) ou 29* (5) escamas, 4 (1), 5 (3) ou 6 (14) perfuradas. Séries longitudinais entre a nadadeira dorsal e a pélvica 7. Escamas pré-dorsais 13 (14) ou 14 (4). Escamas da primeira série longitudinal alcançando a vertical que passa pelo ânus. Escamas circumpedunculares 12.

Nadadeira peitoral i, 14 (7), 15 (10) ou 16 (1). Ponta da peitoral não alcançando a vertical que passa pela origem da pélvica. Raios da nadadeira pélvica i, 7. Supraneurais 10, anteriores aos espinhos neurais dos centros 5 ao 14 (1). Nadadeira dorsal ii, 7 (1) ou ii, 8* (17). Primeiro pterigióforo da nadadeira dorsal inserido posteriormente ao espinho neural do centro 14 (1). Margem distal da nadadeira dorsal arredondada quando expandida. Origem da nadadeira dorsal distintamente mais próxima à base da nadadeira caudal que da ponta do focinho. Base do último raio da dorsal distintamente anterior à vertical que passa pela origem da nadadeira anal. Nadadeira anal iii, 8, último raio adnato. Margem distal da nadadeira anal arredondada. Primeiro pterigióforo da nadadeira anal inserido posteriormente ao arco hemal do centro 25 (1). Nadadeira adiposa presente. Epurais 2. Nadadeira caudal furcada, lóbulo superior distintamente mais longo que o inferior, ambos arredondados. Raios principais da nadadeira caudal ii, 8/i, 8 (4) i, 9/i, 8 (14). Pró-correntes dorsais 7; pró-correntes ventrais 8 . Vértebras précaudais 24; vértebras caudais 17.

Colorido. Cor de fundo predominantemente amarela. Coloração escura estendendo-se desde o lábio superior até a porção exposta dos parietais e ao longo da série medial e primeira série de escamas até a origem da nadadeira caudal. Maxilar, ossos circumorbitais e série opercular densamente pigmentados próximo à porção dorsal da cabeça, tornando-se gradualmente amarelada ventralmente; opérculo com uma distinta mancha escura na região médio-inferior. Estreita faixa negra estendendo-se da porção 
dorsal da órbita, passando pelos infra-orbitais 5 e 6 , alcançando a face dorsal do opérculo. Lábio inferior intensamente pigmentado; restante da mandíbula e toda porção ventral da cabeça com pigmentação escassa.

Tronco tornando-se gradualmente amarelado ventralmente. Região abdominal amarela, com diminutos cromatóforos entre o istmo e a origem da nadadeira anal. Mancha umeral arredondada, conspícua em indivíduos jovens, porém difusa em adultos. Faixa primária representada por sete a doze manchas pequenas anteriormente, restritas às escamas da quarta série longitudinal, amplas e alongadas horizontalmente, posteriormente à vertical que passa pela origem da nadadeira pélvica, estando distribuídas entre a mancha umeral e a mancha caudal. Ao longo da ontogenia, todas as manchas, tornam-se mais difusas, podem estar representadas apenas por uma banda acinzentada ao longo da terceira, quarta e quinta séries longitudinais. Última mancha deslocada dorsalmente, estando situada principalmente na terceira série longitudinal de escamas, podendo estar ausente. Faixa secundária estendendo-se ao longo da segunda e terceira séries longitudinais de escamas, desde os epoccipitais à extremidade do pedúnculo caudal, estando geralmente fragmentada em pequenas manchas irregulares posteriormente à vertical que passa pelo término da nadadeira dorsal. Terceira, quarta e quinta séries longitudinais de escamas com pequenas manchas escuras próximo à base. Base da dorsal distintamente mais escura que o dorso. Mancha caudal alongada verticalmente, situada na extremidade do pedúnculo caudal e estendendo-se à base de 9 raios medianos da nadadeira caudal. Nadadeiras peitoral, pélvica, anal, adiposa e caudal hialinas; raios da nadadeira dorsal com cromatóforos nos primeiro ponto de ramificação na porção média dos raios; base dos raios com uma mancha conspícua.

Dimorfismo sexual. Exemplares machos de Lebiasina sp. "Azuay" apresentam o padrão mais difundido de dimorfismo sexual entre as Lebiasina, descrito anteriorente para L. astrigata.

Distribuição. Sul do Equador, a oeste dos Andes, nas bacias dos rios Guanache e San Fermín (Figura 77). 
Tabela 26. Dados morfométricos de Lebiasina sp. Azuay.

\begin{tabular}{lccccc} 
& $\mathrm{n}$ & Range & Mean & SD & Holotype \\
\cline { 2 - 6 } & 19 & $69,8-126,0$ & 99,1 & & 120,0 \\
Standard length & Morphometrics \% of SL & & & & \\
& 16 & $17,7-22,2$ & 20,4 & 1,2 & 19,3 \\
Depth dorsal fin origin & 16 & $73,3-76,8$ & 74,7 & 1,1 & 73,4 \\
Snout to anal fin origin & 16 & $50,0-53,9$ & 51,9 & 1,1 & 50,0 \\
Snout to pelvic fin origin & 16 & $54,2-57,0$ & 56,0 & 0,9 & 54,4 \\
Snout to dorsal fin origin & 16 & $43,4-47,3$ & 45,2 & 0,9 & 46,1 \\
Dorsal fin origin to caudal base & 16 & $17,2-20,3$ & 18,6 & 0,8 & 17,2 \\
Dorsal fin length & 16 & $8,1-9,8$ & 8,9 & 0,5 & 8,6 \\
Dorsal fin base & 16 & $11,1-13,0$ & 12,3 & 0,5 & 12,3 \\
Adipose fin to caudal peduncle & 16 & $15,0-18,1$ & 16,4 & 0,7 & 16,8 \\
Length caudal peduncle & 16 & $10,4-11,6$ & 11,1 & 0,3 & 10,4 \\
Depth caudal peduncle & 16 & $18,7-24,5$ & 20,9 & 1,7 & 23,5 \\
Anal fin length & 16 & $10,6-14,8$ & 12,2 & 1,3 & 13,9 \\
Anal fin base & 16 & $22,1-25,3$ & 23,5 & 0,9 & 24,2 \\
Pelvic- to anal fin origin & 16 & $12,6-15,4$ & 13,8 & 0,8 & 13,2 \\
Pelvic fin length & 16 & $28,2-32,1$ & 30,6 & 1,3 & 29,8 \\
Pectoral to pelvic fin origin & 16 & $14,6-17,0$ & 15,7 & 0,7 & 14,6 \\
Pectoral fin length & 16 & $20,7-24,1$ & 22,4 & 0,8 & 20,7 \\
Snout to pectoral fin origin & 16 & $22,8-26,3$ & 25,1 & 0,9 & 22,8 \\
Bony head length & & & & & \\
& $\quad$ Morphometrics \% of HL & & & & \\
& 16 & $55,2-60,9$ & 57,5 & 1,7 & 59,9 \\
Head width & 16 & $18,8-22,1$ & 20,4 & 1,1 & 20,8 \\
Horizontal eye diameter & 16 & $26,2-30,8$ & 27,8 & 1,2 & 27,5 \\
Distance snout tip to eye & 16 & $34,1-38,3$ & 36,2 & 1,2 & 35,3 \\
Interorbital distance & 16 & $42,9-49,5$ & 45,8 & 1,5 & 49,5 \\
Length lower jaw & 16 & $38,0-41,5$ & 39,5 & 1,2 & 39,6 \\
Length upper jaw & & & & & \\
\hline & & & &
\end{tabular}




\section{Chave artificial de identificação para as espécies de Lebiasininae.}

1. Faixas primária, secundária, terciária ou "intermediária” ausentes; três ou quatro séries de pequenas manchas na base das escamas da segunda, terceira, quarta e quinta séries longitudinais; mancha caudal ausente (cabeceiras do rio Braço Norte - bacia do Tapajós - e rio Curuá - bacia do Xingu) ...............................ebiasina sp. "Curuá Pinta" 1'. Ao menos uma faixa longitudinal ao longo do corpo; três ou quatro séries longitudinais de manchas variando entre o amarelo e o vermelho; faixa primária geralmente se estendendo da mancha umeral e terminando próximo à mancha caudal; mancha caudal geralmente presente

2. Faixa primária ampla, passando, pelo menos parcialmente, pelas escamas da segunda, terceira e quarta séries longitudinais; séries longitudinais de manchas escuras arredondadas ausentes; pelo menos uma mancha vermelha com intensa deposição de guanina subjacentemente na quarta escama da linha lateral; lóbulos da nadadeira caudal geralmente simétricos; machos adultos com modificações nas escamas da sexta série longitudinal; câmara posterior da bexiga natatória com parede celular 3

(Lebiasina bimaculata + L. festae group of species)

2’. Faixa primária geralmente estreita; uma série de 5-18 manchas escuras arredondadas variavelmente desenvolvidas pode estar presente, podendo coalescer durante a ontogenia; discreta deposição de guanina nas escamas; lóbulo superior da nadadeira caudal distintamente mais longo que o inferior; machos adultos com modificações nas escamas da quinta série longitudinal; parede da câmara posterior da bexiga-natatória não apresentando "células"

3. Nadadeira dorsal com distinta pigmentação escura nas membranas inter-radiais dos raios ramificados (mais conspícua em jovens); cúspide central dos dentes distintamente mais desenvolvida que as cúspides laterais; focinho truncado em vista dorsal 4 3'. Nadadeira dorsal hialina, sem pigmentação escura (mesmo em exemplares jovens); cúspides laterais dos dentes similares em forma e tamanho às centrais; focinho arredondado, quase cônico em vista dorsal

4. Mancha caudal presente (da bacia do Río Piura, nordeste do Peru, ao Río Esmeraldas, nordeste do Equador) Lebiasina aff. festae 
5. Espécie com coloração geral escura, faixas primária e secundária bem marcadas; faixa primária não alcançando a mancha umeral anteriormente; apenas a quarta escama da linha lateral com uma distinta mancha vermelha (ou prateada quando preservado) pós-cleitro 3 ausente (sul do Panamá e bacias dos rios Cauca, Atrato, Baudó e San Juan na Colômbia) Lebiasina festae

5'. Espécie com coloração relativamente clara, faixas primária e secundária inconspícuas; faixa primária alcançando a mancha umeral anteriormente; duas ou três séries longitudinais de manchas vermelhas (ou prateadas quando preservado) distribuídas ao longo da terceira, quarta e quinta séries longitudinais; pós-cleitro 3 presente (sudoeste da Costa Rica e Chiriqui, noroeste do Panamá)........Lebiasina boruca

6. Pós-cleitro 3 presente (sudoeste do Peru, do Río Lurin ao Río Chira) Lebiasina bimaculata 6’. Pós-cleitro 3 ausente .7

7. Porção dentígera do maxilar flexionada anteriormente, dentes formando uma única superfície cortante com os do pré-maxilar, uma condição semelhante à observada em Deuterodon; mesetmóide e pré-maxilar bem desenvolvidos; espécie discretamente prognata (desde a bacia do Río Piura, norte do Peru até pequenas bacias costeiras no sul do Equador) Lebiasina aff. bimaculata I

7'. Porção dentígera do maxilar não flexionada anteriormente, dentes do maxilar e prémaxilar não formam uma única superfície cortante; mesetmóide e pré-maxilar reduzidos; espécie distintamente prognata (alto Río Piura, Peru) Lebiasina aff. bimaculata II

8. Série de 5-18 manchas arredondadas variavelmente desenvolvidas ao longo das escamas da quarta série longitudinal.

8'. Série de manchas arredondadas ao longo das escamas da quarta série longitudinal ausente. 
10. Faixa secundária estendendo-se ao longo de 7-12 escamas da terceira série longitudinal; faixa primária estendendo-se desde a origem da nadadeira pélvica até a porção distal do pedúnculo caudal; primeira série longitudinal de escamas estendendose da cabeça à nadadeira caudal; escamas circumpedunculares 14 (alto Río Magdalena) Lebiasina floridablancaensis 10'. Faixa secundária estendendo-se ao longo das escamas da primeira e segunda séries longitudinais por todo corpo; faixa primária restrita à porção anterior do corpo, ou alcançando a porção distal do pedúnculo caudal; primeira série longitudinal de escamas não ultrapassando a origem da nadadeira adiposa; 12 escamas circumpedunculares .....11

11. Mancha caudal alongada verticalmente; primeira série longitudinal de escamas alcançando a vertical que passa pelo terceiro raio ramificado da nadadeira anal (bacia do Río Cauca) Lebiasina ortegai 11'. Mancha caudal triangular ou distintamente arredondada; primeira série longitudinal de escamas não alcançando a vertical que passa pela origem da nadadeira anal .12

12. Faixa primária intermitente em jovens, mas geralmente coalescendo completamente em exemplares adultos, estendendo-se ao longo de todo o corpo; mancha caudal triangular (sistema do canal do Panamá e bacia do Río Bayano)....Lebiasina panamensis 12'. Faixa primária passando apenas pela mancha umeral e as quatro manchas mais anteriores, geralmente inconspícua posteriormente à origem da nadadeira pélvica; mancha caudal arredondada (bacias do Río Pito, Panamá e do Río Sinu, Colômbia) Lebiasina colombia

13. Faixa secundária passando pelas escamas da primeira e segunda séries longitudinais

13'. Faixa secundária passando pelas escamas da segunda e terceira séries longitudinais 15

14. 10 a 18 manchas arredondadas com a altura de uma escama ou menor; nadadeira adiposa ausente (rios San Juan e Baudó, Colômbia) Lebiasina multimaculata 
14'. Cinco a nove manchas, crescentes ântero-posteriormente; nadadeira adiposa presente (rios Atrato e Jurudidá, Colômbia) Lebiasina chocoensis

15. Cinco a sete manchas alongadas e altas, passando por 2 a 3 escamas da quarta série longitudinal, não coalescendo ao longo da ontogenia (bacia dos rios Guayas e Esmeraldas, Ecuador) Lebiasina aureoguttata 15'. Nove a onze manchas crescentes ântero-posteriormente, geralmente coalescendo ao longo da ontogenia entre a origem da nadadeira pélvica e o término da nadadeira dorsal .16

16. Faixa secundária alcançando a vertical que passa pelo término da nadadeira dorsal; mancha caudal diminuta, sobre seis raios principais da nadadeira caudal (bacias dos rios Santiago e Mira) Lebiasina astrigata 16'. Faixa secundária alcançando a vertical que passa pela origem da nadadeira caudal; mancha caudal ampla, sobre 12 raios principais da nadadeira caudal (bacias dos rios Guanache e Fermín, Equador) Lebiasina sp. Azuay

17. Faixa secundária estendendo-se pelas escamas da segunda e terceira séries longitudinais; faixa "intermediária" presente, pelo menos no infra-orbital 3; mancha caudal deslocada posteriormente, não alcançando o pedúnculo caudal anteriormente...18 17'. Faixa secundária estendendo-se pelas escamas da primeira e segunda séries longitudinais; faixa "intermediária" ausente; margem anterior da mancha caudal alcançando a porção posterior do pedúnculo caudal .

18. Faixa terciária passando pelas escamas da sexta série longitudinal; faixa “intermediária" estendendo-se posteriormente, alcançando a origem da nadadeira anal; superfície dorsal do mesetmóide arredondada (cabeceiras do alto Orinoco e Branco) Lebiasina sp. "Parima" 18'. Faixa terciária ausente; faixa "intermediária” restrita aos infra-orbitais; superfície dorsal do mestmóide em forma de "T". .19

19. Faixa secundária inconspícua; faixa primária conspícua, estendendo-se do supracleitro à nadadeira caudal (alto Río Caroni) .20 
19'. Faixa secundária conspícua; faixa primária geralmente inconspícua, quase ausente em alguns exemplares, representada apenas por manchas irregulares .21

20. Boca terminal; faixa primária intermitente; margem posterior do opérculo distintamente côncava Lebiasina yuruaniensis 20'. Boca sub-superior; faixa primária contínua; margem posterior do opérculo aproximadamente reta . Lebiasina unitaeniata

21. Faixa intermediária distinta na porção ventral dos infra-orbitais 3 e 4; bordas das escamas densamente pigmentadas entre o crânio e a origem da nadadeira dorsal, formando células ( sistema do Río Caura). Lebiasina taphorni 21'. Faixa intermediária inconspícua; bordas das escamas do dorso discretamente pigmentadas, não formando células (sistema do Río Caroni) Lebiasina uruyensis

22. Primeira série longitudinal de escamas alcançando a nadadeira caudal; escamas circumpedunculares geralmente 14 (sistema do lago Maracaibo, tributários do Orinoco adjacentes à cordilheira oriental na Venezuela e na Colombia e baixo Río Magdalena) Lebiasina erythrinoides 22'. Primeira série longitudinal de escamas não ultrapassando a vertical que passa pela origem da nadadeira anal; 12 escamas circumpedunculares

23. Faixa primária estreita, não alcaçando a mancha caudal; séries de pequenas manchas escuras situadas ventralmente à faixa primária ausentes (cabeceiras dos rios Marañon, Napo, Putumayo e Caquetá) Lebiasina elongata 23'. Faixa primária ampla, sobreposta à mancha caudal; uma ou três séries longitudinais de manchas escuras presentes

24.Apenas uma série de aproximadamente 14 manchas escuras; maxilar, primeiros infra-orbitais e raios ramificados posteriores da nadadeira dorsal sem manchas escuras; nadadeira adiposa ausente (alto rio Curuá, bacia Xingu)..........Lebiasina sp. Curuá-Faixa 24'. Três séries longitudinais com diversas manchas escuras na base das escamas da quarta à sexta séries; maxilar, infra-orbitais 1 (e 2?), e raios ramificados posteriores da nadadeira dorsal com manchas escuras; nadadeira adiposa presente (distribuição desconhecida). Lebiasina intermedia 


\section{$\underline{\text { Referências bibliográficas }}$}

Alexander, R. McN. 1964. Adaptation in the skulls and cranial muscles of South American characinoid fish. Journal of the Linnean Society (Zoology), 45: 169-190.

Alpírez Q, O. 1985. Ictiofauna de la vertiente pacifica de Costa Rica. Brenesia, (24): 292-318.

Ardila-Rodríguez, C. A. 1978. Contribución al estudio de la ictiogeografia venezolana de la Piabucina pleurotaenia (Regan). Memoria de la Sociedad de Ciencias Naturales La Salle, 38 (109): 77-84.

Ardila-Rodríguez, C. A. 1994. Lebiasina floridablancaensis, una nueva especie de pez para Colombia (Telesotei: Characiformes: Lebiasinidae). Revista Unimetro, 10 (19): $8 \mathrm{pp}$.

Ardila-Rodríguez, C. A. 1999. Lebiasina provenzanoi, una nueva especie de pez para Venezuela (Teleostei: Characiformes: Lebiasinidae). Revista Unimetro, 13 (5\& 6): $10 \mathrm{pp}$.

Ardila-Rodríguez, C. A. 2000. Lebiasina yuruaniensis, una nueva especie de pez para Venezuela (Teleostei: Characiformes: Lebiasinidae). Revista Unimetro, Separata Especial No. 2, 13, (25 \& 26): 16 pp.

Ardila-Rodríguez, C. A. 2002. Lebiasina nariñensis, una nueva especie de pez para Colombia (Teleostei: Characiformes, Lebiasinidae). Dahlia, 5: 11-18.

Ardila-Rodríguez, C. A. 2004. Lebiasina taphorni (Pisces: Characiformes, Lebiasinidae), una nueva especie. Dahlia, 7: 57-65.

Ardila-Rodríguez, C. A. 2008a. Lebiasina colombia (Characiformes: Lebiasinidae), nueva especie cuenca del Río Sinú, Colombia. Dahlia, 10: 27-32.

Ardila-Rodríguez, C. A. 2008b. Lebiasina ortegai (Characiformes: Lebiasinidae), nueva especie, sistema del Río Cauca, Colombia. Dahlia, 10: 17-25.

Ardila-Rodríguez, C. A. 2010a. Lebiasina chocoensis, una nueva especie de pex para Colombia (Teleostei: Characiformes: Lebiasinidae: Lebiasininae). Peces del Departamento del Chocó, 1: 20 pp.

Arnold, J. P. \& E. Ahl. 1936. Fremdländische Süsswasserfische. Gustav Wenzel \& Sohn, Braunschweig. 592 pp. 
Arratia, G. 1992. Development and variation of the suspensorium of primitive Catfishes (Teleostei: Ostariophysi) and their phylogenetic relationships. Bonner Zoologische Monographien 32: 1-149.

Barbour, T. 1923. Notes on Reptiles and Amphibians from Panama. Occasional Papers of the Museum of Zoology, 129: 1-6.

Birindelli, J. L. O., Zanata, A. M., Sousa, L. M. \& A. L. Netto-Ferreira. 2009. New species of Jupiaba Zanata (Characiformes: Characidae) from Serra do Cachimbo, with comments on the endemism of upper rio Curuá, rio Xingu basin, Brazil. Neotropical Ichthyology, 7(1): 11-18.

Böhlke, J. 1958. Studies of fishes of the family Characidae - No. 14. A report on several extensive recent collections from Equador. Proc. Acad. Nat. Sci. Philadelphia, vol. 110: pp. 1-121, pranchas 1-7.

Breder, C. M, Jr. 1927. The fishes of the Chucunaque drainage, eastern Panama. Bulletin of the American Museum of Natural History, 57 (3): 91-176.

Bremer, K. 1994. Branch support and tree stability. Cladistics, 10: 295-304.

Britto, M. R. 2002. Análise filogenética da ordem Siluriformes com ênfase nas relações da superfamília Loricarioidea (Teleostei: Ostariophysi). Tese de Doutorado, Universidade de São Paulo, São Paulo, 512 pp.

Boulenger, G. A. 1887. An account of the fishes collected by Mr. C. Buckley in eastern Ecuador. Proceedings of the General Meetings for Scientific Business of the Zoological Society of London, 1887 (pt 2): 274-283.

Boulenger, G. A. 1895. Viaggio del dottor Alfredo Borelli nella Repubblica Argentina e nel Paraguay. XII. Poissons. Bull. Mus. Zool. Anat. Comp. Torino, 10 (196): 1-3.

Boulenger, G. A. 1899. Viaggio del Dott. Enrico Festa nel Darien e regioni vicine. Poissons de l'Amérique Centrale. Teleostei. Bollettino dei Musei di Zoologia ed Anatomia Comparata della R. Università di Torino, 14 (346): 1-4.

Boulenger, G. A. 1904. Fishes (Systematic account of Teleostei). In Harmer, S. F. \& A. E. Shipley, The Cambridge Natural History, 539-727. vol. 7760 p.

Buckup, P.A. 1993. Phylogenetic interrelationships and reductive evolution in Neotropical characidiin fishes (Characiformes, Ostariophysi). Cladistics, 9: $305-341$ 
Buckup, P.A. 1998. Relationships of the Characidiinae and Phylogeny of Characiform Fishes (Teleostei: Ostariophysi). In: Phylogeny and Classification of Neotropical Fishes, 123-144-. Porto Alegre, Edipucrs, 603p.

Bussing, W. A. 1967. New Species and New Records of Costa Rican Freshwater Fishes with a Tentative List of Species. Revista de Biologia Tropical, 14(2): 205-249.

Bussing, W. A. 1987. Peces de las aguas continentales de Costa Rica. Editorial de la Universidad de Costa Rica, $271 \mathrm{pp}$.

Bussing, W. A.1998. Peces de las aguas continentales de Costa Rica. [Freshwater Fishes of Costa Rica.]. Revista de Biologia Tropical, 46 (Suppl. 2): 1-468.

Castro, R. M. C. \& M. M. C. Castro. 1987. Proposta de uma nomenclatura osteológica para Characiformes (Pisces: Ostariophysi). Boletim do Museu Paraense Emílio Goeldi, série Zoologia 3: 25-32.

Castro, E., O. Huamán, \& H. Ortega. 1998. Ictiofauna de los Pantanos de Villa: composicion, abundancia y aspectos ecologicos. In: Los Pantanos de Villa biologia y conservation, Cano, A. and K. Young (eds). Museo de Historia natural, UNMSM. Serie de Divulgación No. 11, Lima: pp. 78-83.

Cockerell, T. D. A. 1914. The Scales of the South American Characinid Fishes. Annals of the Carnegie Museum, 9(1-2): 92-113.

Colonello, G. 1986. El Abismo, una región inexplorada en el confín sur-este de Venezuela. Natura, Revista de Divulgación Científica de la Sociedad de Ciencias Naturalles La Salle, Caracas 78 (20): 22-28.

Cuvier, G. L. C. F. D. \& A., Valenciennes. 1846. Histoire naturelle des poisons. vol. 19, 549 pp.

Cuvier, G. L. C. F. D. \& A., Valenciennes. 1849. Histoire naturelle des poisson. vol, 22, $395 \mathrm{pp}$.

Dahl, G. 1971. Los Peces del norte de Colombia. Instituto de Desarrollo de Los Recursos Naturales Renovables (INDERENA), Bogotá, 1-391.

Dahl, G. \& F. Medem. 1964. Informe sobre la fauna acuatica del río Sinu. Corporacion autonoma Regional de los Valles del Magdalena y del Sinu. CVM Departamento de Investigaciones ictiologocas y Faunisticas, $160 \mathrm{pp}$.

Datovo, A. \& F. A. Bockmann. 2010. Dorsolateral headmuscles of the catfish families Nematogenyidae e Trichomycteridae (Siluriformes: Loricarioidei): comparative anatomy and phylogenetic analysis. Neotropical Ichthyology, 8 (2): 193-246. 
Daugeron, C. 1997. Evolution of feeding and mating behaviors in the Empidoidea (Diptera: Eremoneura). 163-182. In: Grandcolas, P. (ed.), The origin of biodiversity in insects: phylogenetic tests of evolutionary scenarios. Mém. Mus. Natn. Hist. Nat., 173. 329 pp. Paris

Diogo, R. \& Chardon, M. 2000. Homologies among different adductor mandibulae sections of teleostean fishes, with special regards to catfishes (Teleostei: Siluriformes). Journal of Morphology, 243: 193-208.

Eigenmann, C.H 1909. Some new genera and species of fishes from British Guiana. (Repts. of the Exped. to B. Guiana of the Ind. Univ. and Carn. Museum 1908). Ann. Carn. Mus., 6:4-54.

Eigenmann, C. H. 1910. IV. Catalogue and Bibliography of the Fresh Water Fishes of the Americas South of the Tropic of Cancer. Reports of the Princeton University Expedition to Patagonia, 1896-1899. 3(4): 375-511.

Eigenmann, C. H. 1914. Some results from studies of South American fishes. I. Lines and methods of evolution in some characid fishes. Indiana Univ. Bull., 12(1): 4-48.

Eigenmann, C. H. 1920a. South America West of the Maracaibo, Orinoco, Amazon, and Titicaca Basins, and the Horizontal Distribution of its Fresh-Water Fishes. Indiana Univ. Studies, 7(45): 1-24.

Eigenmann, C. H. 1920b. The Irwin Expedition to Peru, Bolivia, and Chili. Indiana University Alumni Quarterly Jan, 1920: 1-16.

Eigenmann, C. H. 1923a. The Fishes of Western South America, Part I. The Fresh-water Fishes of Northwestern South America, Including Colombia, Panama, and the Pacific slopes of Ecuador and Peru, Together with an Appendix Upon the Fishes of the Rio Meta in Colombia. Memoirs of the Carnegie Museum, 9 (l):1-349.

Eigenmann, C. H. 1923b. Yellow fever and its fishes. The American Naturalist, 57: 443-448.

Eigenmann, C. H. \& W. R. Allen. 1942. Fishes of western South America. I. The Intercordilleran and Amazonian lowlands of Peru. II. The high pampas of Peru, Bolivia and northern Chile. Univ. of Kentucky, Lexington: 494 pp.

Eigenmann, C. H. \& R. S. Eigenmann. 1889. Review of the Erythrininae. Proceedings of the California Academy of Sciences, 2nd series, 2: 100-116. 
Eigenmann, C. H. \& R. S. Eigenmann. 1891. A Catalogue of the Fresh-Water Fishes of South America. Proceedings of the United States National Museum for the Year 1891, 14(842): 1-81.

Eldredge, N. \& J. Cracraft. 1980. Phylogenetic patterns and the evolutionary process. Columbia University Press, New York, 349 pp.

Eschmeyer, W. N. 1998. Catalog of Fishes. 3 vol. California Academy of Sciences, Anaheim, California, 2905 pp.

Farris, J. S. 1970. Methods for computing Wagner trees. Syst. Zool., 19: 83-92.

Farris, J. S. 1988. Hennig86, version 1.5.

Farris, J. S. 1989. The retention index and the rescaled consistency index. Cladistics, 5: 417-419.

Farris, J. S. 1991. Excess homoplasy ratios. Cladistics 7: 81-91.

Felsenstein, J. 1985. Confidence limits on phylogenies: an approach using the bootstrap. Evolution 39 (4): 783-791.

Fernández-Yépez, A. 1972. Analisís Ictiológico del Complejo Hidrográfico (04) "Río Yaracuy". Dirección de Obras Hidraúlicas, Ministerio de Obras Públicas, Republica de Venezuela. 25 pp.

Fernández-Yépez, A. \& F. Martin S. 1953. Apuntes Sobre la Ictiologia de Perijá. Memoria de la Sociedad de Ciencias Naturales La Salle, 13 (35): 227-243.

Fink, W. L. \& Weitzman, S. H. (1974) The so-called cheirodontin fishes of Central America with description of two new species (Pisces, Characidae). Smithsonian Contributions to Zoology, 172: 1-46.

Fowler, H. W. 1911. New fresh-water fishes from western Ecuador. Proceedings of the Academy of Natural Sciences Philadelphia, 63:493-520.

Fowler, H. W. 1939. Fishes from the Pacific slope of Colombia, Ecuador and Peru. Notulae Naturae, Academy of Natural Sciences of Philadelphia, 33:1-7.

Fowler, H. W. 1944. Fresh-water Fishes from Northwestern Colombia. Proceedings of the Academy of Natural Sciences of Philadelphia, 46: 227-248.

Fowler, H. W. 1945. Los Peces del Peru. Catálogo sistemático de los peces que habitan en aguas peruanas. Museo de Historia Natural "Javier Prado" Universidad Nacional Mayor de San Marcos. Lima. 298 pp

Fowler, H. W. 1950. Os peixes de agua doce do Brasil. Arquivos de Zoologia do Estado de São Paulo, 6, 2a. entrega.: 205-404. 
Freihofer, W. F. 1978. Cranial nerves of a percoid fish Polycentrus schomburgkii (family Nandidae), a contribution to the morphology and classification of the order Perciformes. Occ. Papers California Acad. Sci., 128: 1-78.

Fritts, T. H., Riz, A. A. \& S. Samec, 2002. A new species of Echinosaura (Gymnophthalmidae) from Equador and Colombia with comments on other members of the genus and Teuchocercus keyi. Journal of Herpetology, 36 (3): 349-355.

Fromm, D. 1977. Expedition nach Costa Rica II. DATZ 30 (8): 262-265.

Fryer, G., Greenwood, P. H. \& J. F. Peake. 1983 Punctuated equilibria, morphological stasis and the palaeontological documentation of speciation: a biological appraisal of a case history in an African lake. Biological Journal of the Linnean Society, 20: 195-205.

Galvis, G., J. I. Mojica \& M. Camargo. 1997. Peces del Catatumbo. Asociación Cravo Norte. Santafé de Bogotá, D.C. 118 pp

Géry, J. 1972. Contribution à l'étude des Poissons characoïdes de l'Equateur. Acta Humboldtiana, Wiesbaden, Series Geologica, Palaeontologica et Biologia Nr. 2: $1-110$.

Géry, J. 1977. Characoids of the world. New Jersey, T.F.H. Publications, Inc. 672 p.

Géry, J. \& A. Zarske. 2002. Derhamia hoffmannorum gen. et sp. n.- A new pencil fish (Teleostei, Characiformes,Lebiasinidae), Endemic from the Mazaruni River in Guyana. Zoologische Abhandlungen 52: 35-47.

Gill, T. 1877. Notes on fishes from the Isthmus of Panama, collected by Dr. J. F. Bransford, U. S. N. Proceedings of the Academy of Natural Sciences of Philadelphia, 28: 335-339.

Gill, T. 1895. The differential characters of characinoid and erythrinoid fishes. Proceedings of the United States National Museum, 18 (1056): 205-209.

Glodek, G. S. 1978. The Importance of Catfish Burrows in Maintaining Fish Populations of Tropical Freshwater Streams in Western Ecuador. Fieldiana, Zool., 73(1):1-8

Goloboff, P. A., J. Farris \& K. Nixon. 2003. Tree analysis using New Techonology. Program and documentation available from the authors at www.zmuc.dk/public/ phylogeny. 
Gosline, W.A. 1989. Two patterns of differentiation in the jaw musculature of teleostean fishes. Journal of Zoology, 218: 649-661.

Graham, J. B., D. L. Kramer, \& E. Pineda. 1977. Respiration of the Air Breathing Fish Piabucina festae. Journal of Comparative Physiology, 122: 295-310.

Graham, J. B., D. L. Kramer, \& E. Pineda. 1978. Comparative respiration of an airbreathing and a non-air-breathing characoid fish and the evolution of aerial respiration in characins. Physiological Zoology, 51(3): 279-288.

Günther, A. C. L. G. 1859. Second list of cold-blooded vertebrates collected by Mr. Fraser in the Andes of Western Ecuador. Proceedings Zoological Society of London, 27: 402-420, pl. 2.

Günther, A. C. L. G. 1860. Third list of cold-blooded vertebrata collected by Mr. Fraser in Ecuador. Proceedings of the Zoological Society of London, 28: 233-240.

Günther, A. C. L. G. 1864. Catalogue of fishes in the British Museum. Catalogue of the Physostomi, containing the families Siluridae, Characinidae, Haplochitonidae, Sternoptychidae, Scopelidae, Stomiatidae in the collection of the British Museum. Vol. 5: xxii +455 pp.

Hall, B. K. 1994. Homology - The hierarchical basis of comparative biology. Academic Press, San Diego, xvi + 483 pp.

Harvey, P. H., A. J. L. Brown, J. M. Smith \& S. Nee. 1996. New uses for new phylogenies. Oxford University Press, Oxford, xi +349pp.

Hennig, W. 1950. Grundzüge einer Theorie der phylogenetischen Systematik. Deutsche Zentralverlag, Berlin, 370 pp.

Hennig, W. 1966. Phylogenetic Systematics. University of Illinois Press, Urbana, 263 pp.

Hennig, W. 1968. Elementos de una sistemática filogenética. Editorial Universitaria de Buenos Aires, Buenos Aires, 353 pp.

Hildebrand, S. F. 1938. A New Catalogue of the Fresh-Water Fishes of Panama. Zoological Series, Field Museum of Natural History, 22(4): 215-359.

Hoedeman, J. J. 1954. Notes ond the ichthyology of Suruinam (Dutch Guiana). 3. A new species and teo new subspecies of Nannostomidi from the Surinam River. Beufortia, 4 (39): 81-89. 
Howes, G.J. 1976. The cranial musculature and taxonomy of characoid fishes of the tribes Cynodontini and Characini. Bulletin of the British Museum of Natural History, Zoology, 29: 201-248.

Hoyer, R. 2008. Bemerkungen zu einem Vorkommen von Piabucina boruca (Bussing, 1967). BSSW-Report, 20 (4): 5-9.

Huber, O. 1995. History of Botanical Exploration. In: Flora of the Venezuelan Guayana. Vol. 1: Introduction, Paul E. Berry, Bruce K. Holst, and Kay Yatskievych editors. Missouri Botanical Garden, St Louis. 320 pp : 63-95

ICZN, 1999. versão on-line. Disponível em http://www.iczn.org/iczn/index.jsp.

Kitching, I. J., P. L. Forey, C. J. Humphries \& D. M. Williams. 1998. Cladistics - The theory and practice of parsimony analyis. Oxford University Press, Oxford, xiii $+228 \mathrm{pp}$

Kluge, A. G. \& J. S. Farris, 1969. Quantitative phyletics and the evolution of anurans. Syst. Zool. 29 (4): 203-248.

Kramer, D. L. 1978a. Reproductive seasonality in the fishes of a tropical stream. Ecology, 59 (5):976-985

Kramer, D. L. 1978b. Ventilation of the respiratory gas bladder in Hoplerythrinus unitaeniatus (Pisces, Characoidei, Erythrinidae). Canadian Journal of Zoology, 56 (4): 931-938.

Kramer, D. L. 1983. The evolutionary ecology of respiratory mode in fishes: an analysis based on the costs of breathing. Environmental Biology of Fishes, 9 (2):145-158.

Lasso, C. A., V. Ponte \& O. M. Lasso. 1997. Catálogo de la colección de tipos de peces de la Fundación La Salle de Ciencias naturales. Parte I: Museo de Historia Natural la Salle (MHNLS). Memoria de la Sociedad de Ciencias Naturales La Salle, 57 (147): 37-52.

Lasso, C., D. C. Taphorn \& J. E. Thomerson. 1992. Rivulus gransabanae, a new species of killifish from Venezuela (Cyprinodontiformes: Rivulidae). Ichthyol. Explor. Freshwaters, 2 (4):297-303.

Leviton, A. E., R. H. Gibbs Jr., E. Heal \& C. E. Dawson. 1985. Standards in herpetology and ichthyology: Part I. Standard symbolic codes for institutional resource collections in herpetology and ichthyology. Copeia, 1985 (3): 802-832. 
Machado-Allison, A. 1974. Etapas del desarrollo del pez Piabucina pleurotaenia Regan 1903 (Characiformes: Lebiasinidae). Acta Biol.Venez., 8(3-4): 579-622.

Mago-Leccia, F. 1970. Lista de los Peces de Venezuela Incluyendo un Estudio Preliminar sobre la Ictiogeografia del País. Ministerio de Agricultura y Cria, Oficina Nacional de Pesca, Caracas, Venezuela, 283 pp.

Malabarba, L. R. \& S. H. Weitzman (2003) Description of a new genus with six new species from southern Brazil, Uruguay and Argentina, with a discussion of a putative characid clade (Teleostei: Characiformes: Characidae). Comunicações do Museu de Ciências e Tecnologia da PUCRS, série Zoologia, 16 (1): 67-151.

Maldonado-Ocampo, J. A., A. Ortega-Lara, J. S. Usma Oviedo, G. Galvis Vergara, F. A. Villa-Navarro, L. Vásquez Gamboa, S. Prada-Pedreros, C. Ardila Rodríguez. 2005. Peces de los Andes de Colombia. Guía de campo. Instituto de Investigación de Recursos Biológicos Alexander von Humboldt Bogotá, D.C. $356 \mathrm{pp}$.

Mattox, G. M. T. 2010. Estudo filogenético de Characinae (Teleostei: Characiformes: Characidae). Tese de Doutorado. Universidade de São Paulo, São Paulo, 260 pp.

Meek, S. E. \& S. F. Hildebrand. 1916. The fishes of the fresh waters of Panama. Field Museum of Natural History, Zoological Series, Publication 191, 10(15): 217-374.

Meinken, H. 1936. Über einige in letzter Zeit eingeführte Fische. Blätter für Aquärien und Terrarkunde, 47(3):49-51.

Miles, C. 1945. Some newly recorded fishes from the Magdalena River system. Caldasia, 3: 453-464

Miles, C. 1947. Los peces del Rio Magdalena. Ministerio de la Economía Nacional, Sección de Piscicultura, Pesca y Caza, Bogotá Colombia. xxviii, 214.

Mojica, J. I., G. Galvis, P. Sánchez-Duarte, C. Castellanos \& F. A. Villa-Navarro, 2006. Peces del valle medio del río Magdalena, Colombia. Biota Colombiana 7 (1): 23-38.

Moran, R. C. 2000. Trichomanes resinosum (Hymenophyllaceae), a new species from Southern Venezuela and adjacent Guyana. Brittonia, 52 (3): 238-240. 
Moreira, C. L. R. 2007. Relações filogenéticas na ordem Characiformes (Teleostei: Ostariophysi). Tese de doutorado, Universidade de São Paulo, São Paulo, xvii + 468.

Myers, G. S. 1925. Fishes and Human Disease. The Fish Culturist, Philadelphia, 5(4): 27-29

Myers, G. S. 1928. The species of Piabucina inhabiting Colombia. Copeia, 166: 4-5.

Nelson, G. J. \& N. I. Platnick. 1981. Systematics and Biogeography. Cladistics and Vicariance. New York, columbia University Press. 567 p.

Netto-Ferreira, A. L. 2006. Relações filogenéticas dos gêneros de Lebiasinidae (Ostariophysi, Characiformes). Dissertação de mestrado, Universidade Federal do Rio de Janeiro, Rio de Janeiro, xx + 374.

Nixon, K. C. 2002. WinClada, version 1.00.08.

Nixon, K. C. \& J. M. Carpenter. 1993. On outgroups. Cladistics, 9: 413-426.

Novacek, M. J. \& Q. D. Wheeler. 1992. Extinction and phylogeny. Columbia University Press, New York, vi +253 pp.

Oyakawa, O. T. 1998. Relações filogenéticas da famílias Pyrrhulinidae, Lebiasinidae e Erythrinidae (Osteichthyes: Characiformes). Tese de Doutorado. Universidade de São Paulo, São Paulo, 200 pp.

Ortega Lara, A., O. E. M. García, M. C. P. Idrobo, J. E. Sterling. 2000. Peces de la Cuenca Alta del Río Cauca. Corporación Autónoma Regional del Valle del Cauca, Subdirección de Patrimonio Ambiental, Grupo Hidrobiología, Santiago de Cali. 68 pp.

Page, R. D. M. \& E. C. Holmes. 1998. Molecular evolution - A phylogenetic approach. Blackwell Sciences, Oxford, 346 pp.

Pearson, N. E. 1937. The fishes of the Atlantic and Pacific slopes near Cajamarca, Peru. Proceedings California Academy of Sciences, 23(7): 87-98.

Persson, C. 2003. Agouticarpa, a new Neotropical genus of Tribe Gardenieae (Rubiaceae)._Brittonia, 55 (2): 176-201.

de Pinna, M. C. C. 1991. Concepts and tests of homology in the cladistic paradigm. Cladistics, 7: 367-394. 
de Pinna, M. C. C. 1996. A phylogenetic analysis of the asian catfish families Sisoridae, Akysidae and Amblycipitidae, with a hypothesis on the relationships of the Neotropical Aspredinidae (Teleostei, Ostariophysi). Fieldiana, 84: 1-83.

de Pinna, M. C. C. 1999. Species concepts and phylogenetics. Rev. Fish Biol. Fisheries, $9(4): 353-373$.

Planquette, P.; Keith, P. \& P. Y. Le Bail. 1996. Atlas des Poissons D'eau Douce de Guyane(tome I). Service du Patrimoine Naturel, Instutut d'Ecologie et de Gestion de la Biodiversité. 430p.

Provenzano, F., A. Marcano \& P. Mondaca. 1998. Catálogo de ejemplares tipos en la colección de peces del Museo de Biología de la Universidad Central de Venezuela (MBUCV-V). Acta Biologica Venezuelica, 18 (1): 1-24.

Regan, C. T. 1903. Descriptions of new South-American Fishes in the Collection of the British Museum. Annals and Magazine of Natural History, Series 7, 12:621-630.

Regan, C. T. 1911. The classification of the teleostean fishes of the order Ostariophysi.-1. Cyprinoidea. An. Mag. Nat. Hist. London 8 (8):13-32.

Regan, C. T. 1913a. The fishes of the San Juan River, Colombia. Annals and Magazine of Natural History, Series 8, 12: 462-473.

Regan, C. T. 1913b. Fishes from Peru, collected by Dr. H. O. Forbes. Annals and Magazine of Natural History, Series 8, 12: 278-280.

Roberts, T. R. 1969. Osteology and relationships of characoid fishes, particularly the genera Hepsetus, Salminus, Hoplias, Ctenolucius, and Acestrorhynchus. Proceedings of the California Academy of Sciences, 36: 391-500.

Roberts, T. R.1973. The Glandulocaudine characid fishes of the Guayas Basin in western Ecuador. Bulletin of the Museum of Comparative Zoology 144, 8: 489-514.

Roberts, T. 1974. Osteology and classification of the neotropical characoid fishes of the families Hemiodontidae (including Anodontinae) and Parodontidae. Bull. Mus. Comp. Zool., 146 (9):411-472.

Román-Valencia, C. 1988. Clave taxonomica para determinación de peces nativos de Quindío, subsistema alto Río Cauca, Colombia. Actual. Biol., 17 (64): 107-114.

Román-Valencia, C. 1993. Composición y estructura de las comunidades de peces de la cuenca del Río La Vieja, alto Cauca. Bio. y Educ., 3 (5): 107-114. 
Román-Valencia, C. 1995. Lista anotada de los peces de lacuenca del río La Vieja, Alto Cauca, Colombia. Boletín Ecotrópica, 29: 11-20.

Román-Valencia, C. 1996. Historia natural del rollizo, Piabucina sp. (Pisces, Lebiasinidae) en la cuenca del Río La Vieja, alto Cauca. Dahlia, 1: 89-96.

Román-Valencia, C. 1997. Dieta de una especie nueva de Piabucina (Pisces, Lebiasinidae) en alto Cauca, Colombia. Rev. Biol. Tropical, 45 (3): 1255-1256.

Román-Valencia, C. 2004. Sobre la bioecologia de Lebiasina panamensis (Pisces: Lebiasinidae) en la cuenca del Río León, Caribe colombiano. Dahlia, 7: 33-35.

Román-Valencia, C. \& A. Acero. 1992. Notas sobre las comunidades de peces del norte de Antioquia, Colombia. An. Inst. Inv. Mar. Punta de Betín, 21: 117-125.

Román-Valencia, C. \& M. C. Vélez. 1986. Estudio sobre las escamas del pez rollizo, Lebiasina cf. multimaculata Boulenger, 1911 (Characiformes, Lebiasinidae), observaciones sobre su biologia en el Quindío. Rev. Invest. Univ. del Quindio, 1 (2): $1-24$.

Sabaj P., M. H. 2009. PIPE-Expedition in die Serra do Cachimbo. Amazonas, 25: 36-43.

Saul, W. G. 1975. An Ecological Study of Fishes at a Site in Upper Amazonian Ecuador. Proceedings of the Academy of Natural Sciences of Philadelphia, 127(12): 93-134.

Schuh, R. T. 2000. Biological Systematics: Principles and Applications. Cornell University Press, 236 pp.

Schultz, L. P. 1944. The fishes of the family Characinidae from Venezuela, with Descriptions of Seventeen New Forms. Proceedings of the U.S. National Museum, 95(3181): 235-367.

Scotland, R. W., D. J. Siebert \& D. M. Williams. 1994. Models in phylogeny reconstruction. Oxford University Press, Oxford, xi + 360 pp.

Scotland, R., \& T. Pennington. 2000. Homology and Systematics: Coding Characters for Phylogenetic Analysis. The Systematic Association Special Volume Series 58. Taylor \& Francis 217 pp.

Secioso. H. R. 1997. Monofiletismo de Erythrinidae (Teleostei, Characiformes): Discussão das sinapomorfias e outros caracteres diagnósticos. Dissertação de mestrado, Universidade Federal do Rio de Janeiro, Rio de Janeiro, 147p.

Sellick, I. C. 1983. Fishes of Darién. Aquarist and Pondkeeper, 48(5): 42-47. 
Steindachner, F. 1879. Beiträge zur Kentniss der Flussfische Südamerika's. III. Über einige von Herrn Stolzmann in Peru gesammelte Süsswasserfische. Denkschriften der Mathematisch-Naturwissen- schaftlichen Classe der Kaiserlichen Akademie der Wissenschaften, Band XLI, Wien: 21-23[169-171].

Stewart, D., Barriga S., R. \& M. Ibarra. 1987. Ictiofauna de la Cuenca del Río Napo, Ecuador Oriental: Lista Anotada de Especies. Politecnica, 12(4): 9-64.

Swofford, D. L. \& W. P. Maddison. 1987. Reconstructing ancestral character states under Wagner parsimony. Mathematical Biosciences 87:199-229.

Swofford, D. L. \& G. J. Olsen. 1990. Phylogeny reconstruction, pp. 411-501 in D. M. Hillis \& C. Moritz. Molecular Systematics. Sinauer, Sunderland.

Taphorn, D. 1992. Characiform fishes of the Apure River drainage, Venezuela. BioLlania. UNELLEZ, Guanare, Venezuela. 537p.

Taphorn, D. C. \& C. G. Lilyestrom. 1980. Piabucina pleurotaenia Regan, a synonym of P. erythrinoides Valenciennes (Pisces: Lebiasinidae); its distribution, diet and habitat the lake Maracaibo basin, Venezuela. Copeia, 1980 (2): 335-340.

Taphorn, D. C. \& C. G. Lilyestrom. 1984. Claves para los peces de água dulce de Venezuela. Revista UNELLEZ de Ciencia y Tecnologia, 2 (2): 5-30.

Taphorn, D. C., R. Royero, A. Machado-Allison \& F. Mago-Leccia. 1997. Lista Actualizada de los peces de agua dulce de Venezuela. In: E. La Marca. Vertebrados actuales y fósiles de Venezuela. Série Catálogo Zoológico de Venezuela, Vol. 1. Museo de Ciencia y Tecnologia de Mérida, Venezuela. pp 55-100.

Taphorn, D. C. \& J. G. C. Tenía. 1991. El Rio Claro y Sus Peces, con Consideraciones de los Impactos Ambientales de las Preses sobre la Ictiofauna del Bajo Rio Caroni. BioLlania, 8: 23-45.

Taylor, R. \& C. C. Van Dyke. 1985. Revised procedures for staining and clearing small fishes and other vertebrates for bone and cartilage study. Cybium, 9: 107-119.

Toledo-Piza, M. 2007. Phylogenetic relationships among Acestrorhynchus species (Ostariophysi: Characiformes: Acestrorhynchidae). Zoological Journal of the Linnean Society, 151: 691-757.

Vari, R. P. 1979. Anatomy, relationships and classification of the families Citharinidae and Distichodontidae (Pisces, Characoidea). Bulletin of the British Museum of Natural History, 36: 261-344. 
Vari, R. P. 1995. The Neotropical fish family Ctenoluciidae (Teleostei: Ostariophysi: Characiformes): supra and intrafamilial phylogenetic relationships, with a revisionary study. Smithsonian Contributions to Zoology, 564: 1-97.

Vari, R. P. \& J. C. Howe. 1991. Catalog of Type Specimens of Recent Fishes in the National Museum of Natural History, Smithsonian Institution, 1: Characiformes (Teleostei: Ostariophysi). Smithsonian Contributions to Zoology, 517:1-52.

Weitzman, S. H. 1962. The osteology of Brycon meeki, a generalized characid fish, with an osteological definition of the family. Stanford Ichthyol. Bull. 8: 1-77.

Weitzman, S.H. 1964. Osteology and relationships of South American characid fishes of subfamilies Lebiasinidae and Erythrinidae with special references to subtribe Nannoatomina. Proc. U. S. Natl. Mus., 116 (3538):1-56.

Weitzman, S. H. 1966. Review of South American characid fishes of the subtribe Nannostomina. Proc. U. S. Natl. Mus., 119 (3538): 1-56.

Weitzman, S. H. 1974. Osteology and evolutionary relationships of the Sternoptychidae, with a new classification of stomiatoid families. Bull. Am. Mus. Nat. Hist. 153: $327-478$.

Weitzman, S. H. \& J. S. Cobb, 1975. A revision of the South American fishes of the genus Nannostomus Günther (Family Lebiasinidae). Smithson. Contrib. Zool. 186: $36 \mathrm{p}$.

Weitzman, S. H. \& R. P. Vari. 1988. Miniaturization in South American freshwater fishes: an overview and discussion. Proc Biol. Soc. Washington 101: 444-465.

Weitzman, M. \& S.H. Weitzman, 2003. Family Lebiasinidae. p. 241-250. In: Check List of freshwater fishes of South and Central America (CLOFFSCA). Reis, R. E.; S. O. Kullander \& C. J. Ferraris, Jr. (eds.). Porto Alegre, Edipucrs. 729p.

Wiens, J. J., 2000. Phylogenetic Analysis of Morphological Data. Smithsonian Institution Press, $220 \mathrm{pp}$.

Wiley, E. O. 1981. Phylogenetics - the theory and practice of phylogenetic systematics. Wiley, New York, 439 pp.

Wiley, E. O., D. Siegel-Causey, D. R. Brooks \& V. Funk. 1991. The complete cladist: A primer of phylogenetic procedures. Special Publication 19. The University of Kansas, Museum of Natural History, Lawrence, ix +158 pp. 
Wiley, M. L. \& B. B. Collette 1970. Breeding tubercles and contact organs in fishes: their occurrence,structure, and significance. Bull. Am. Mus. Nat. Hist., 143 (3): 143-216.

Winterbottom, R. 1974. A descriptive synonymy of the striated muscles of the Teleostei. Proceedings of the Academy of Natural Sciences of Philadelphia, 125 (12): 225-317.

Zanata, A. M. 2000. Estudo das relações filogenéticas do gênero Brycon Müller \& Troschel, 1844 (Characidae; Characiformes). Tese de doutorado. Universidade de São Paulo. 358p.

Zanata, A. M. \& Vari, R.P. 2005. The family Alestidae (Ostariophysi, Characiformes): a phylogenetic analysis of a trans-Atlantic clade. Zool. J. Lin. Soc., 145: 1-144.

Zaret, T. M. \& R. S. Rand. 1971. Competition in tropical stream fishes: support for the competitive exclusion principle. Ecology, 52: 336-342.

Zarske, A. 2009. Nannostomus rubrocaudatus sp. n. - ein neuer Ziersalmler aus Peru (Teleostei: Characiformes: Lebiasinidae). Vertebrate Zoology, 59 (1): 11-23.

Zarske, A. \& J. Géry, 2006. Zur Identität von Copella nattereri (Steindachner, 1876) einschließlich der Beschreibung einer neuen Art (Teleostei: Characiformes: Lebiasinidae). Zoologische Abhandlungen, 56: 15-46. 
Tabela 1. Matriz de dados utilizada no estudo filogenético. Caracteres polimórficos foram codificados como: $[01]=\mathrm{A} ;[02]=\mathrm{B} ;[12]=\mathrm{C}$.

Acestrorhynchus pantane iro Boulengerella lateristriga

Brycon obry gnianus Hepsetus odoe

Hoplerythrinus unitaeniatus Lebiasina bimaculata

Lebiasina aff. bimaculata I Lebiasina aff. bimaculata II Lebiasina chocoensis Lebiasina colombia Lebiasina foridablancaensis Lebiasina multimaculata Lebiasina orte gai Lebiasina provenzanoi Lebiasina sp. azuay Lebiasina sp. Cachimbo Lebiasina sp. Curuá faixa Lebiasina sp. Curuá pinta Lebiasina sp. XIII de maio Lebiasina taphorni Lebiasina uruyensis Piabucina astrigata Piabucina aureogutatta Piabucina boruca Piabucina elongata Piabucina erythrinoides Piabucina f estae Piabucina aff. $f$ estae Piabucina panamensis Piabucina sp. Parima Piabucina unitaeniata Copeina guttata Copella arnoldi Copella carsevennensis Copella cf compta Copella eigenmanni MG8305 Copella gr eigenmanni $\mathrm{MZ}$ sur$$
1-10
$$$$
11-20
$$

21-30

$31-40$

41-50

$51-60$

61-70

$71-80$

$81-90$ $0010001000 \quad 0010100200 \quad 0001210100 \quad 2000000100 \quad 0001010002 \quad 0210001010 \quad 0001042000 \quad 00000 ? 1012 \quad 0001201000$ ?01000?001 01101002?0 0011110002 2001001101 $1002 ? 10001 \quad 22100010110003032000 \quad 0010000110 \quad 0001201000$ $0220000000 \quad 0000000000 \quad 0000100000 \quad 0000000000 \quad 0020010202 \quad 2210001010 \quad 1000 ? 01000 \quad 0000101000 \quad 1100011011$ $0000001001 \quad 01101002 ? 00001100001 \quad 0001000101 \quad 0001010002 \quad 0210001001 \quad 0000 ? 02000 \quad 0010001111 \quad 0001001000$ ?300000001 $11201011110001211002 \quad 2001001101 \quad 0000110002 \quad 2211001010 \quad 0003042000 \quad 1010101100 \quad 1101102001$ $\begin{array}{lllllllll}0110111001 & 1000102111 & 0002111001 & 1001001101 & 1010110011 & 2111001000 & 1011101010 & 1020101102 & 1111101011\end{array}$ $\begin{array}{lllllllll}0110121001 & 1000102111 & 0002111001 & 1001001101 & 1010110011 & 2111001000 & 1011102010 & 1020101102 & 1111101011\end{array}$ $\begin{array}{lllllllll}0111111001 & 1000102111 & 0002111001 & 1001001101 & 1010110011 & 2111001000 & 1012102010 & 1020101102 & 1111101011\end{array}$

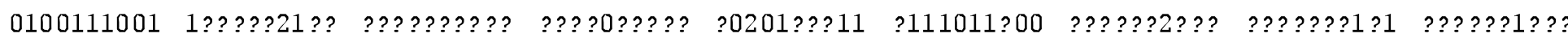

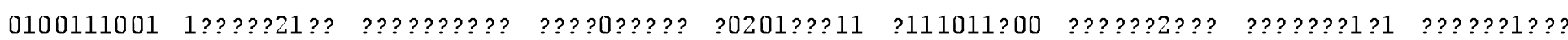

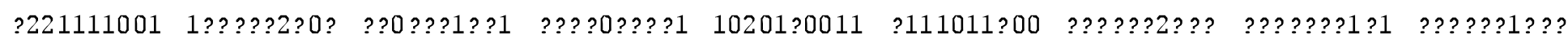
0100121001 1????21?? ??0???1??1 ????0???, 00201 ??0011 2111011 ?? ?????2??? ??????1?2 ?????1??? $022 ? 111001 \quad 1100102101 \quad 0002111001 \quad 1001001101 \quad 0020110011 \quad 2111011000 \quad 1011102010 \quad 1120101101 \quad 1111101011$ $\begin{array}{lllllllll}021111001 & 1000102111 & 0002111101 & 1001001101 & 1020110011 & 2111011000 & 1011102010 & 1020101101 & 1111111011\end{array}$ $\begin{array}{lllllllll}0100111001 & 1100102111 & 0002111001 & 1000000101 & 0020110011 & 2111011000 & 1012102010 & 1020100101 & 1111101011\end{array}$ $\begin{array}{lllllllll}0220111001 & 1010102101 & 0002111001 & 1001000101 & 0020110011 & 2111011000 & 1011101010 & 1020101101 & 1111101011\end{array}$ $\begin{array}{lllllllll}1221111001 & 1000101101 & 00021110 ? 1 & 1001000101 & 1020110011 & 2111001000 & 1012101010 & 1020101112 & 1111101011\end{array}$ $\begin{array}{lllllllll}0220111001 & 1010102101 & 0002111001 & 1001000101 & 1020110011 & 2111011000 & 1012101010 & 1020101101 & 1111101011\end{array}$ $\begin{array}{lllllllll}0220111001 & 1010102101 & 0002111001 & 1001000101 & 0020110011 & 2111011000 & 1011101010 & 1020101101 & 1111101011\end{array}$ $\begin{array}{lllllllll}0221111001 & 1000102111 & 0002111101 & 1000001101 & 1020110011 & 2111011000 & 1011102010 & 0020101112 & 1111101011\end{array}$ $\begin{array}{lllllllll}0221111001 & 1000102111 & 0002111001 & 1001001101 & 1020110011 & 2111011000 & 1011102010 & 0020101102 & 1111101011\end{array}$ $\begin{array}{lllllllll}0100111001 & 1120102111 & 0002111001 & 1000000101 & 1020110011 & 2111011001 & 1012102010 & 1020100101 & 1111101011\end{array}$ $\begin{array}{lllllllll}0100111001 & 1110101111 & 0002111001 & 1000000101 & 0020110011 & 2111011001 & 1012102010 & 1020100102 & 1111101011\end{array}$ $\begin{array}{llllllllll}0111111001 & 1100102111 & 0002111001 & 1001001101 & 1020110011 & 2111001000 & 1012111010 & 1020101101 & 1111101011\end{array}$ $\begin{array}{llllllllll}1210111001 & 1100102111 & 0002111001 & 1001000101 & 1020110011 & 2111011000 & 1001102110 & 1020101102 & 1111101011\end{array}$ $\begin{array}{lllllllll}0220111001 & 1000102101 & 0002111001 & 1000000101 & 1020110011 & 2111011000 & 1011102010 & 1020100102 & 1111101011\end{array}$ $\begin{array}{lllllllll}0111111001 & 1100102111 & 0002111001 & 1001001101 & 1020110011 & 2111001000 & 1012011010 & 1020100101 & 1111101011\end{array}$ $\begin{array}{lllllllll}0111111001 & 1100102111 & 0002111001 & 1000001101 & 0020110011 & 2111001000 & 1012111010 & 1020101112 & 1111101011\end{array}$ $\begin{array}{lllllllll}0220111001 & 1110102111 & 0002111001 & 1000001101 & 0020110011 & 2111011000 & 1002022010 & 0020101102 & 1111101011\end{array}$ $\begin{array}{lllllllll}021111001 & 1000101111 & 0002111001 & 1001000 ? 01 & 1020110011 & 2111011000 & 1011101010 & 1020101102 & 0111101011\end{array}$ $\begin{array}{lllllllll}021111001 & 1000102111 & 00021 \mathrm{~A} 1101 & 0001001101 & 1020110011 & 2111011000 & 1011102110 & 0020101102 & 1111101011\end{array}$ $\begin{array}{lllllllll}1230101111 & 1120101101 & 1202111111 & 0100010111 & 0101010010 & 0212110001 & 1010 ? 01011 & 1110111110 & 1111000011\end{array}$ $2230101111 \quad 1111101100 \quad 1202111130 \quad 0111210011 \quad 0101010010 \quad 0212110002 \quad 1020 ? 01111 \quad 0020113111 \quad 1111010210$ $\begin{array}{lllllllll}2230101111 & 1101101100 & 1202111130 & 0111210011 & 1101010010 & 0212110002 & 1020 ? 01011 & 1120113101 & 0111000210\end{array}$ $\begin{array}{lllllllll}2230101111 & 1101101100 & 1202111120 & 0111110011 & 0101010010 & 0212110000 & 1030 ? 01111 & 1120113112 & 0111010210\end{array}$ $\begin{array}{lllllllll}2230101111 & 1111101100 & 1202111130 & 0111210011 & 0101010010 & 0212110002 & 1020 ? 01011 & 0120113110 & 1111010210\end{array}$ $\begin{array}{lllllllll}2230101111 & 1111101100 & 1202111130 & 0110210011 & 0101010010 & 0212110002 & 1020 ? 01011 & 0120112110 & 1111010110\end{array}$ 
Tabela 1 (continuação).

Copella cf metae

Copella nattereri

Copella nigrof asciata

Derhamia hof $f$ mannorum

Nannostomusbeckf ordPará

Nannostomus beckf ords uriname

Nannostomus britskii

Nannostomus digrammus

Nannostomus eques

Nannostomus harrisoni

Nannostomus limatus

Nannostomus marginatus

Nannostomus marilynae

Nannostomus nitidus

Nannostomus trif asciatus

Nannostomus unif asciatus

Pyrrhulina australis

Pyrrhulina brevis

Pyrrhulina capim

Pyrrhulina semif asciata

Pyrrhulina vittata

Pyrrhulina zigzag

Pyrrhulina sp. Solimões

Pyrrhulina sp. Tapajós I

Pyrrhulina sp. Tapajós II
$1-10$

$2230101111 \quad 1111101100 \quad 1202111120 \quad 0111110011 \quad 1101010010$

$\begin{array}{llllll}2230101111 & 1101101100 & 1202111120 & 0111110011 & 1101010010\end{array}$

$2230101111 \quad 1101101100 \quad 1202111120 \quad 0111110011 \quad 1101010010$

$\begin{array}{lllll}1230101101 & 1000101110 & 0002111100 & 0001000101 & 1120110010\end{array}$

$\begin{array}{llllll}12 ? 0101101 & 1000101100 & 1112111110 & 0011000101 & 0021001010\end{array}$

$12 ? 0101101 \quad 1000101100 \quad 1112111110 \quad 0011000101 \quad 0021001010$

$22 ? 0101101 \quad 12 ? ? 101110 \quad 1012111110 \quad 0011000101 \quad 1021001010$

$12 ? 0101101 \quad 1 B 00111110 \quad 1112111110 \quad 0011000101 \quad 1021001010$

$22 ? 0101101$ 1B01101110 $1012111100 \quad 0010000101 \quad 0021001010$

$22 ? 0101101 \quad 1000101110 \quad 1112211100 \quad 0010000101 \quad 0021001010$

$22 ? 0101101 \quad 1000101100 \quad 1112111100 \quad 0011000101 \quad 0021001010$

$12 ? 0101101 \quad 1000101100 \quad 1112111110 \quad 0011000121 \quad 1021001010$

$12 ? 0101101 \quad 12 ? ? 111110 \quad 1112211100 \quad 0011000101 \quad 1021001010$

$\begin{array}{llllll}12 ? 0101101 & 1000101100 & 1112111110 & 0011000101 & 1021001010\end{array}$

$22 ? 0101101 \quad 1000101110 \quad 1112211110 \quad 0011000101 \quad 1021001010$

$12 ? 0101101 \quad 1000101110 \quad 1112111100 \quad 0010000101 \quad 0021001010$

$\begin{array}{llllll}1230101111 & 1110101101 & 1202111110 & 0111010111 & 1101010110\end{array}$

$\begin{array}{llllll}1230101111 & 1110101101 & 1202111110 & 0111010111 & 1101010110\end{array}$

$\begin{array}{llllll}1230101111 & 1110101101 & 1202111100 & 0111010111 & 1101010110\end{array}$

$\begin{array}{llllll}1230101111 & 1110101101 & 1202111100 & 0111010111 & 1101010110\end{array}$

$\begin{array}{llllll}1230101111 & 1110101101 & 1202011110 & 0111010111 & 0101010110\end{array}$

$\begin{array}{lllllll}1230101111 & 1110101101 & 1202111110 & 0111010111 & 1101010110\end{array}$

$\begin{array}{llllll}1230101111 & 1110101101 & 1202111100 & 0111010111 & 1101010110\end{array}$

$1230101111 \quad 1110101101 \quad 1202011110$

$1230101111 \quad 1110101101 \quad 1202111110$
$51-60$

$61-70$

$71-80$

$81-90$

$\begin{array}{llll} & 1030 ? 01111 & 1120112111 & 0111010110\end{array}$

$0212110002 \quad 1020 ? 011110020112111 \quad 1111010210$

$\begin{array}{llll} & 1030 ? 01111 & 1120113111 & 0111010210\end{array}$

$2112010000 \quad 0010 ? 00011 \quad 00201 ? 31120111011011$

$\begin{array}{llll}1102011112 & 1130 ? 00111 & 0021112100 & 0111010111\end{array}$

$\begin{array}{llll}1102011112 & 1131100111 & 0021112110 & 0111010211\end{array}$

$11020111021130 ? 0011100211 ? 21110111000 \mathrm{C} 11$

$1102011112 \quad 1130 ? 001110021112102 \quad 0111000 \mathrm{C} 11$

$\begin{array}{llll}1102011102 & 1131100011 & 0021112112 & 0111010111\end{array}$

$1102011102 \quad 1130 ? 00011 \quad 0021113110 \quad 0011010011$

$11020111121130 ? 001110021112100 \quad 0111010211$

$1102011102 \quad 1130 ? 00111 \quad 0021112102 \quad 1111010111$

$1102011112 \quad 11311001110021111100 \quad 0111000 \mathrm{C} 11$

$\begin{array}{lllll}1102011112 & 1130 ? 00111 & 0021112100 & 0111010211\end{array}$

$\begin{array}{lllll}1102011102 & 1130 ? 00111 & 0021112112 & 0111010111\end{array}$

$1102011112 \quad 1130 ? 001110021113100 \quad 0011000111$

$0112010000 \quad 0020 ? 01011 \quad 1120113110 \quad 1111010111$

$0212010002 \quad 0020 ? 01011 \quad 1120112112 \quad 1111010111$

$1212010001 \quad 0010 ? 01011 \quad 1120113112 \quad 1111010111$

$12120100010010 ? 01011 \quad 1120112112 \quad 1111010111$

$01120100010010 ? 01011 \quad 1120113112 \quad 1111010111$

$0112010000 \quad 0010 ? 01011 \quad 1120113110 \quad 1111010111$

$12120100010020 ? 01011 \quad 1120112111 \quad 1111010111$

$\begin{array}{lllllll}0111010111 & 0101010110 & 1112010000 & 0020 ? 01011 & 1120113102 & 1111010111\end{array}$

$\begin{array}{llllll}0111010111 & 1101010110 & 1112010000 & 0020 ? 01011 & 1120113110 & 0111010111\end{array}$ 
Tabela 1 (continuação).

Acestrorhynchus pantane iro Boulengerella lateristriga Brycon obry gnianus Hepsetus odoe Hoplerythrinus unitaeniatus Lebiasina bimaculata

Lebiasina aff bimaculata I Lebiasina aff bimaculata II Lebiasina chocoensis Lebiasina colombia Lebiasinaf loridablanc aensis Lebiasina multimaculata Lebiasina orte gai

Lebiasina provenzanoi Lebiasina sp. azuay Lebiasina sp. Cachimbo Lebiasina sp. Curuá faixa Lebiasina sp. Curuá pinta Lebiasina sp. XIII de maio Lebiasina taphorni

Lebiasina uruyensis

Piabucina astrigata

Piabucina aureogutatta

Piabucina boruca

Piabucina elongata

Piabucina erythrinoides

Piabucinaf estae

Piabucina aff $f$ estae

Piabucina panamensis

Piabucina sp. Parima

Piabucina unitaeniata

Copeina guttata

Copella arnoldi

Copella carsevennensis

Copella cf compta

Copella eigenmanni MG8305

Copella gr eigenmanni MZ
91-100

101-110

111-120

121-130

131-140

141-150

$151-160$

161-170

171-180

(1) $0002000000 \quad 0000002000 \quad 0000001100 \quad 0110000200$ $0000011020 \quad 000201 ? 000 \quad 0000011110 \quad 0000010100 \quad 0112211200$ $0100000020 \quad 0002000000 \quad 0000003000 \quad 0000001100 \quad 0000000100$ $0000011020 \quad 0002010000 \quad 0000013000 \quad 0000010100 \quad 0112000200$ $00001001 ? 0 \quad 100200 ? 000 \quad 0000013100 \quad 0201001110 \quad 0111011100$ $0112100000 \quad 0011011000 \quad 0001002101 \quad 0001101110 \quad 1011000101$ $0001101110 \quad 0011011000 \quad 0001002101 \quad 0001101110 \quad 1001000101$ $0002101110 \quad 0011011000 \quad 0001002101 \quad 0001101110 \quad 1111000101$ ??0??????? ??1?011000 000100210100011 ????? ?????????? ??0??????? ??1?011000 $000100210100011 ? ? ? ? ?$ ????????? ??0?100??? 0?1?011000 $000100210100011 ? ? ? ? 0100 ? 000101$ ??0?100??? 0?1?011000 0001002101 00011????0 $100 ? 000101$ $1000100000 \quad 0011010000 \quad 0001002101 \quad 0001101110 \quad 10010 ? 0101$ $\begin{array}{llllll}1100100000 & 0012011000 & 0001002101 & 0001101110 & 1001000101\end{array}$ $0000100000 \quad 0001011000 \quad 0001002101 \quad 0001101110 \quad 1011000101$ $\begin{array}{llllll}1010100001 & 0012011000 & 0001002101 & 0001101110 & 1001000101\end{array}$ $\begin{array}{llllll}1010100001 & 0012011000 & 0001002101 & 0001101110 & 1001000101\end{array}$ $0010100000 \quad 0012011000 \quad 0001002101 \quad 0001101110 \quad 1011000101$ $1010100001 \quad 0012011000 \quad 0001002101 \quad 0001101110 \quad 1001000101$ $\begin{array}{llllll}0100100000 & 0012011000 & 0001002101 & 0001101110 & 1001000101\end{array}$ $1000100010 \quad 0012011000 \quad 0001002101 \quad 0001101110 \quad 1001000101$ $\begin{array}{llllll}1100100100 & 0011011000 & 0001002101 & 0001101110 & 1011000101\end{array}$ $1100100000 \quad 0002011000 \quad 0001002101 \quad 0001101110 \quad 1111000101$ $0012100100 \quad 0012011000 \quad 0001002101 \quad 0001101110 \quad 1001000101$ $\begin{array}{llllll}1100100000 & 0011011000 & 0001002101 & 0001101100 & 1011000101\end{array}$ $1000100000 \quad 0012011000 \quad 0001002101 \quad 0001101110 \quad 1011000101$ $\begin{array}{llllll}0112101100 & 0012011000 & 0001002101 & 0001101110 & 1011000101\end{array}$ $\begin{array}{lllll}0112100100 & 0012011000 & 0001002101 & 0001101110 & 1001000101\end{array}$ $\begin{array}{llllll}1100100000 & 0011011000 & 0001002101 & 0001101110 & 1001000101\end{array}$ $0100100100 \quad 0001011000 \quad 0001002101 \quad 0001101110 \quad 1001000101$ $\begin{array}{lllll}A 100100000 & 0002011000 & 0001002101 & 0001101110 & 1001000101\end{array}$ $0101100120 \quad 0111020001 \quad 00 ? ? 002111 \quad 1200100111 \quad 1011010100$ 11211101210111120111 11??2?012? ?21?210011 1011011100 11211101210111120111 11??2?012? ?21?201011 1001010010 10211101210111120111 11??3?012? ?21?211011 1011010110 11211101210111120111 11??2?012? ?21?210011 1011011100 11211101210111120111 11??2?012? ?21?210011 1011011100
1000011000 $0000000000 \quad 1000000000 \quad 00010100 ? 0$ $100112000000111000000000000 ? 00 \quad 00020111 ? 0$ $1000002000 \quad 00000000001000000000 \quad 0001010000$ $1100011000 \quad 0000100000 \quad 0000000000 \quad 00020111 ? 0$ $101010211100001 ? 01112000101100 \quad 1002102101$ $10100021110000110111 \quad 1000000100 \quad 1002102010$ $10100021110000110111 \quad 1000000100 \quad 1002102010$ $10100021110000110111 \quad 1000000100 \quad 1002102010$ $1 ? 1 ? ? 201 ?$ ????1?0111 $1000000100 \quad 0002102011$ $1 ? 1$ ??201? ????1?0111 $1000000100 \quad 0002102011$ $101 ? ? 20110000110111 \quad 1000000100 \quad 0002102001$ $101 ? ? 21110000110111 \quad 1000000100 \quad 0002102011$ $1 ? 100020110000110111 \quad 1000000100 \quad 0002102011$ $10100020110000110111 \quad 1000000100 \quad 0002102021$ $101000201100001101112000000100 \quad 0002102011$ 101000211 ? $00001 ? 0111 \quad 1000000100 \quad 0002102021$ $101 ? 00211$ ? 00??1?0111 $1000000100 \quad 000210202$ ? $1010002110 \quad 0000100111 \quad 1000000100 \quad 0002102021$ $1010002110 \quad 0000100111 \quad 1000000100 \quad 0002102021$ $10100021110000110111 \quad 1000000100 \quad 0002102021$ $10100021110000110111 \quad 1000000100 \quad 0002102021$ $101000201100001101112000000100 \quad 0002102011$ $10100020110000110111 \quad 1000000100 \quad 0002102011$ $10100020110000110111 \quad 1000000100 \quad 1002102010$ $10100020110000110111 \quad 1000000100 \quad 0002102021$ $10100020110000110111 \quad 1000000100 \quad 0002102001$ $10100020110000110111 \quad 1000000100 \quad 1002102010$ $1010002 \mathrm{~A} 11 \quad 0000110111 \quad 1000000100 \quad 1002102010$ $101000201100001101112000000100 \quad 0002102011$ $10100020110000110111 \quad 1000000100 \quad 0002102021$ $\begin{array}{lllll}1110002011 & 0000110111 & 1000000100 & 0002102021\end{array}$ $2021002112 \quad 11111101112111010100 \quad 0002002120$ $2021111112 \quad 21111101112112021100 \quad 0012012130$ $2021111112 \quad 2111110111 \quad 2112011100 \quad 0012012130$ $2021111112 \quad 21111101112111021100 \quad 0012012130$ $\begin{array}{llll}2021111112 & 2111110111 & 2112021100 & 0012012130\end{array}$ $2021111112 \quad 21111201112112021100 \quad 0012012130$ 
Tabela 1 (continuação).

Copella of metae

Copella nattere ri

Copella nigrof asciata

Derhamia hoff mannorum

Nannostomusbeckf ordPará

Nannostomus beckf ordb uriname

Nannostomus britskii

Nannostomus digrammus

Nannostomus eques

Nannostomus harrisoni

Nannostomus limatus

Nannostomus marginatus

Nannostomus marilynae

Nannostomus nitidus

Nannostomus trif asciatus

Nannostomus unif asciatus

Pyrrhulina australis

Pyrrhulina brevis

Pyrrhulina capim

Pyrrhulina semif asciata

Pyrrhulina vittata

Pyrrhulina zigzag

Pyrrhulina sp. Solimões

Pyrrhulina sp. Tapajós I

Pyrrhulina sp. Tapajós II $\begin{array}{rrrrrrrr}91-100 & 101-110 & 111-120 & 121-130 & 131-140 & 141-150 & 151-160 & 161-170\end{array}$

$11211101210111120111 \quad 11 ? ? 2 ? 012 ? \quad$ ?21?201011 $1001011100 \quad 2021111112 \quad 21111101112112011100 \quad 0012012130$

$11211101210111120111 \quad 11 ? ? 4 ? 012 ? \quad ? 21 ? 201011 \quad 1001011000 \quad 2021111112 \quad 2111110111 \quad 2112021100 \quad 0012012130$

$11211101210111120111 \quad 11$ ??3?012? ?21?201011 $10110101002021111112 \quad 21111101112112011100 \quad 0012012140$

$1100100111001101000111110021010001101011 \quad 1011000101 \quad 101002001 ?$ ??00?00??? 2000000100 01020020?0

$0101000121 \quad 1011020011 \quad 11112 ? 012$ ? $121 ? 101011 \quad 1001100101 \quad 0111002111 \quad 1000121101 \quad 1001011001 \quad 0102003000$

$0101000121 \quad 1011020011 \quad 11112 ? 012$ ? $121 ? 101011 \quad 10111001010111002111 \quad 1000121101 \quad 10010110010102003000$

$0021000110 \quad 0011020011 \quad 11113 ? 012 ?$ ? 21?100011 $10111000010110002110 \quad 0000100000 \quad 1001011010 \quad 0102003000$

10B $10001201011020011 \quad 11111$ ?012? $121 ? 100011 \quad 1001100101 \quad 0 A 11002012 \quad 2000110101 \quad 1001011010 \quad 0102003000$

$10010001210011020001 \quad 11113$ ?012? 121 ? 100001 $10111001010110002011 \quad 1000120101 \quad 1001011010 \quad 0102003000$

$10010001201011020001 \quad 11111 ? 012 ? \quad 121 ? 101001 \quad 10112001010110002011 \quad 1000120101 \quad 1001011010 \quad 0102003000$

$01210001210011020011 \quad 11111 ? 012 ?$ ?21?101011 $1001100101 \quad 0 A 10002111 \quad 1001120101 \quad 1001011001 \quad 0102003000$

$01010001210011020011 \quad 11111 ? 012$ ? $121 ? 101011 \quad 1011100001 \quad 0 A 10102111 \quad 1000121101 \quad 10010110010102003000$

$1021000120101102001111111 ? 012$ ? ?21?100011 $1011100101 \quad 0 A 11102011 \quad 1000120101 \quad 1001011010 \quad 0102003000$

$00210001210011020011 \quad 11111 ? 012$ ? ?21?101011 $1001100101 \quad 0 A 10002011 \quad 1001120101 \quad 10010110010102003000$

0001000120 A011020011 111111112? 021?101001 1011100101 OA10102011 $1000120101 \quad 1001011010 \quad 0102003000$

$00010001200011020001 \quad 111131112$ ? $121 ? 100001 \quad 10112001010110002011 \quad 1000120101 \quad 1001011010 \quad 0102003000$

$11211011210111020001 \quad 11 ? ? 0 ? 012$ ? ?21?201011 $1111011000 \quad 2 \mathrm{~A} 21112112 \quad 21111101112112120100 \quad 0002002140$

$11211011210111020001 \quad 11 ? ? 0 ? 012 ? \quad ? 21 ? 201011 \quad 1011011100 \quad 2021112112 \quad 21111101112112020100 \quad 0012002150$

$11211011210111020001 \quad 11 ? ? 0 ? 012 ? ? 21 ? 201011 \quad 1111011100 \quad 2021112112 \quad 21111101112112020100 \quad 0002002150$

$11211011210111020001 \quad 11 ? ? 0 ? 012 ? \quad ? 21 ? 200011 \quad 1011011100 \quad 2021112112 \quad 2111110111 \quad 2112020100 \quad 0012002150$

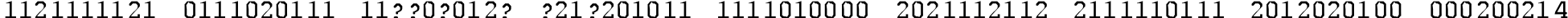

$11211011210111020011 \quad 11 ? ? 0 ? 012 ? \quad ? 21 ? 201011 \quad 1011011100 \quad 2021112112 \quad 2111110111 \quad 2112020100 \quad 0012002150$

$11211011210111020001 \quad 11 ? ? 0 ? 012 ? ? 21 ? 201011 \quad 1111011100 \quad 2021112112 \quad 2111110111 \quad 2112020100 \quad 0012002140$

$11211111210111020001 \quad 11 ? ? 0 ? 012$ ? ?21?201011 $1011011000 \quad 2021112112 \quad 21111101112112120100 \quad 0002002140$

$10211011210111020001 \quad 11 ? ? 0 ? 012 ?$ ?21?201011 $1011011000 \quad 2 \mathrm{~A} 21112112 \quad 2111110111 \quad 2112120100 \quad 0002002150$ 
Tabela 1 (continuação).

Acestrorhynchus pantane iro

Boulengerella lateristriga

Brycon obry gnianus

Hepsetus odoe

Hoplery thrinus unitaeniatus

Lebiasina bimac ulata

Lebiasina aff bimaculata I

Lebiasina aff bimaculata II

Lebiasina chocoensis

Lebiasina colombia

Lebiasina foridablancaensis

Lebiasina multimaculata

Lebiasina orte gai

Lebiasina provenzanoi

Lebiasina sp. azuay

Lebiasina sp. Cachimbo

Lebiasina sp. Curuá faixa

Lebiasina sp. Curuá pinta

Lebiasina sp. XIII de maio

Lebiasina taphorni

Lebiasina uruyensis

Piabucina astrigata

Piabucina aureogutatta

Piabucina boruca

Piabucina elongata

Piabucina ery thrinoides

Piabucina $f$ estae

Piabucina aff. $f$ estae

Piabucina panamensis

Piabucina sp. Parima

Piabucina unitaeniata

Copeina guttata

Copella arnoldi

Copella carsevennensis

Copella cf compta

$181-190 \quad 191-200$

201-208

??00?? 000000100100332110

000 ???00?? 000000000102300110

$0010 ? ? 00 ? ? 00000000100 ? 3 ? 0100$

0000??00?? 000000000? 0???0?0?

00011100 ?? 000000000102300110

$1111010100 \quad 0000201000 \quad 02300110$

$1111010100 \quad 0000201000 \quad 02300110$

$1111010100 \quad 0000201000 \quad 02300110$

$0111112100 \quad 0000011000 \quad 0230011$ ?

$0111112100 \quad 0000011000 \quad 0230011$ ?

0111112210000001100 ? 0230011?

$0111112100 \quad 0000011000 \quad 0230011$ ?

$0111112100 \quad 0000011001 \quad 02300110$

$0111110200 \quad 1000012000 \quad 02300110$

$0111111210 \quad 0000011001 \quad 02300111$

01101100 ?? $0000000000 \quad 02300110$

?111010100 $0000001000 \quad 02300110$

01101100 ?? $0000000000 \quad 02300110$

01101100 ?? 000001000002300110

$0112110210 \quad 1000012001 \quad 02300110$

$0112110210 \quad 1000012001 \quad 02300110$

$0111111210 \quad 0000011000 \quad 02300111$

$0111112210 \quad 0000011000 \quad 02300111$

$1111010100 \quad 0000210000 \quad 02300110$

$0111110100 \quad 0000011000 \quad 02300110$

$0111110100 \quad 0000011001 \quad 02300110$

$1111010100 \quad 0000110000 \quad 02300110$

$1111010100 \quad 0000111000 \quad 02300110$

$0111111100 \quad 0000011001 \quad 02300110$

$0101110200 \quad 2100002001 \quad 02300110$

$0111110200 \quad 1000012000 \quad 02300110$

01011400 ?? 000001000011210000

$00011400 ?$ ? 000001000011111000

00011400 ?? 000001000011111000

00011000 ?? $0000010100 \quad 11111000$ 
Tabela 1 (continuação).

$\begin{array}{lccc} & 181-190 & 191-200 & 201-208 \\ \text { Copella cf metae } & 00011000 ? ? & 0000010100 & 11111000 \\ \text { Copella nattereri } & 0001 \mathrm{~A} 000 \text { ?? } & 0000010100 & 11111000 \\ \text { Copella nigrof asciata } & 00011000 ? ? & 0000010100 & 11111000 \\ \text { Derhamia hof f mannorum } & 0101100111 & 0000000000 & 11210000 \\ \text { Nannostomusbeckf ordPará } & 0001100110 & 0001000002 & 10022000 \\ \text { Nannostomus beckf ords uriname } & 0001100110 & 0001000002 & 10022000 \\ \text { Nannostomus britskii } & 0001100110 & 0111000012 & 10022000 \\ \text { Nannostomus digrammus } & 0001100110 & 0001000002 & 10022000 \\ \text { Nannostomus eques } & 0001100110 & 0111000012 & 10022000 \\ \text { Nannostomus harrisoni } & 0001100110 & 0001000012 & 10022000 \\ \text { Nannostomus limatus } & 0001100111 & 0101000002 & 10022000 \\ \text { Nannostomus marginatus } & 0001100110 & 0101010002 & 10022000 \\ \text { Nannostomus marilynae } & 0001100110 & 0101000002 & 10022000 \\ \text { Nannostomus nitidus } & 0001100111 & 0001000002 & 10022000 \\ \text { Nannostomus trif asciatus } & 0001100110 & 0101000002 & 10022000 \\ \text { Nannostomus unif asciatus } & 00011000 ? ? & 0001000012 & 10022000 \\ \text { Pyrrhulina australis } & 00011400 ? ? & 0000010000 & 11111000 \\ \text { Pyrrhulina brevis } & 00011400 ? ? & 0000010000 & 11111000 \\ \text { Pyrrhulina capim } & 00011400 ? ? & 0000010000 & 11111000 \\ \text { Pyrrhulina semif asciata } & 00011200 ? ? & 0000010000 & 11111000 \\ \text { Pyrrhulina vittata } & 00011400 ? ? & 0000010000 & 11111000 \\ \text { Pyrrhulina zigzag } & 00011000 ? ? & 0000010000 & 11111000 \\ \text { Pynhulina sp. Solimões } & 00011300 ? ? & 0000010000 & 11111000 \\ \text { Pynhulina sp. Tapajós I } & 00011000 ? ? & 0000010000 & 11111000 \\ \text { Pynhulina sp. Tapajós II } & 00011000 ? ? & 0000010000 & 11111000\end{array}$




\section{ANEXO}

Diagnoses:

Lebiasinidae

05* Infra-orbital 3 participando amplamente da margem inferior do anel orbital;

24* Porção posterior do paresfenóide sem uma bifurcação;

41 Espinho do supra-occipital não alcançando o ponto de contato entre o complexo neural e o supraoccipital;

49* Margem antero-ventral do maxilar com uma distinta porção de cartilaginosa, se estendendo da porção postero-ventral à porção dentígera do osso;

50 Maxilar não se estendendo além da borda anterior do infra-orbital 3;

52 Dentes do maxilar restritos à porção médio-anterior do osso;

59 Série interna de dentes do dentário completa;

63 Ectopterigóide atingindo apenas a porção posterior do palatino e uma pequena porção do quadrado; 65* Dentes do ectopterigóide restritos à porção anterior do osso;

69* Fenestra quadrado-metapterigóide obliterada principalmente por projeções lamelares do metapterigóide;

73* Simplético bastante longo, apresentando-se quase tão longo quanto o metapterigóide;

83* Parte óssea do basi-hial formada apenas pelo elemento autógeno; elemento dérmico ausente;

103 Menos de 15 raios ramificados na nadadeira peitoral;

106 Ramo parietal do canal látero-sensorial supra-orbital não alcançando os parietais;

114* Ramo póstero-dorsal do canal látero-sensorial do infra-orbital 6 ausente;

120* Canal supratemporal estendendo-se transversalmente ao longo da região média dos parietais;

125 Linha lateral curta, restrita à porção anterior do corpo;

$131 *$ Costelas da quarta vértebra lamelares, direcionadas posteriormente;

140* Pré-zigapófises das vértebras pré-caudais distintamente mais longas que as pós-zigapófises e praticamente retilíneas, estando discretamente deslocadas distalmente no espinho neural;

188* Faixa secundária presente.

Pyrrhulininae

01 Antorbital tão largo quanto longo

03* Maxilar sobreposto ao infra-orbital 2

08* Infra-orbital 5 com um processo direcionado internamente

28 Processo lamelar na face ventral do órbito-esfenóide 
31 Espinho do esfenótico aproximadamente vertical, com a porção dorsal próxima à porção principal do osso e contínua à superfície ventral do frontal

50* Maxilar não alcançando o infra-orbital 3

54* Dentários com uma depressão conspícua localizada posteriormente à sínfise mandibular

64 Ectopterigóide edêntulo

70 Metapterigóide distintamente mais longo que alto

77 Processo lamelar na porção dorso-posterior do hiomandibular curto, próximo da articulação como o opérculo

79 Margem anterior do opérculo apresentando um distinto processo

85 Superfície lateral dos cerato-hiais anterior e posterior sem interdigitações

86 Borda ventral do cerato-hial anterior apresentando distintas reentrâncias onde se inserem os raios branquiostégios anteriores

110* Tubo ósseo do canal sensorial no infra-orbital 3 ausente

111* Tubo ósseo do canal sensorial no infra-orbital 4 ausente

112* Tubo ósseo do canal sensorial no infra-orbital 5 ausente

113* Tubo ósseo do canal sensorial no infra-orbital 6 ausente

128* Processo ventral na face mesial da base do processo transformador do tripus ausente

130* Complexo neural do aparelho de Weber curto, apresentando-se tão alto quanto longo.

201* Seção A2' do adductor mandibulae ligado principalmente ao ligamentum primordiale e ao maxilar.

202* Seção A2' do adductor mandibulae se estendendo posteriormente, inserida na porção horizontal do pré-opérculo, encobrindo a A2" em grande parte

203 Origem dorsal da seção A2'" do Adductor mandibulae encobrindo grande parte do LAP e alcançando o EE

204* Seção A2", do Adductor mandibulae representada por pequenos feixes espaçados, inseridos no metapterigóide e face lateral da porção lamelar do hiomandibular

206* Margem dorsal do metapterigóide sem uma quilha onde se insere a margem posterior do adductor arcus palatini

207 Origem do dilatator operculi limitada à superfície lateral do frontal e superfície do espinho do esfenótico

\section{Derhamia}

77 Processo lamelar na porção dorso-posterior do hiomandibular ausente; 
91 Faringo-branquial 2 edêntulo;

146 Nadadeira dorsal situada no quarto posterior do corpo;

147 Base do último raio da nadadeira dorsal alcançando a vertical que passa pela origem do quinto raio ramificado da nadadeira anal;

190 Faixa secundária fragmentada, representada por uma série de pequenas manchas escuras.

Pyrrhulinini

$21 *$ Margem posterior do vômer truncada ou arredondada;

22* Porção anterior do paresfenóide com um par de projeções direcionadas anteriormente;

29* Margem ventral do pterosfenóide com uma discreta projeção direcionada medialmente ao neurocrânio;

44 Ramo ascendente do pré-maxilar inconspícuo;

45 Ramo ascendente do pré-maxilar curto, não atingindo a narina anterior;

51 Processo ascendente do maxilar relativamente longo, alcançando o elemento cartilaginoso lateral do palatino;

60 Margem posterior do dentário, onde se encaixa o ângulo-articular, com a concavidade reduzida, praticamente reta;

87* Três raios branquistégios;

94 Face ventral do pós-temporal sem um processo derivado da ossificação do ligamento que conecta o osso ao pterótico;

106* Ramo parietal do canal látero-sensorial supra-orbital ausente;

119 Canal supratemporal ausente;

$121 *$ Canal látero-sensorial no extra-escapular ausente;

122 Pós-temporal sem um ramo do canal látero-sensorial;

164 Seis ou cinco raios pró-correntes do lóbulo superior da nadadeira caudal;

166* Seis ou cinco raios pró-correntes do lóbulo inferior da nadadeira caudal.

Nannostomina (= Nannostomus)

23 Perfil do paresfenóide com uma distinta curvatura ventral entre a articulação com o vômer e o proótico;

46* Pré-maxilar não apresentando um sulcona sua face mesial;

47* Pré-maxilar com uma projeção, situada ventralmente ao ramo ascendente, que se articula com a face ventral de uma projeção laminar da porção antero-lateral do mesetmóide; 
53* Dentários unidos por uma simples faceta articular;

58* Fossa dos dentes de reposição da série externa do dentário profunda e larga;

62* Cartilagem de Meckel curva no terço anterior;

63 Ectopterigóide muito curto, sendo menor que o palatino;

68 Ectopterigóide não articulando diretamente com o quadrado;

74* Pré-opérculo curto, alcançando apenas o processo póstero-ventral do quadrado;

95 Margem póstero-ventral do cleitro entalhada próximo à origem da nadadeira peitoral;

109 Tubo ósseo do canal sensorial no infra-orbital 2 ausente;

115* Ramo supra-orbital do canal látero-sensorial cefálico ultrapassando a barra epfiseana, mas não alcançando os infra-orbitais posteriormente;

135* Supraneurais alargadas em sua porção distal;

141 * Espinhos neurais das vértebras pré-caudais não associados às pós-zigapófises;

142 Espinho neural da última vértebra distintamente mais curto que o espinho neural da vértebra anterior;

159 Músculos inclinadores do último raio da nadadeira anal associados à porção proximal da primeira lepidotríquea;

167 Narina anterior e posterior distantes entre si, separadas por uma larga membrana;

168 Narina anterior não tubular;

$177 *$ Escamas encobrindo grande parte dos parietais;

194* Bandas oblíquas associadas à coloração noturna presentes;

200* Perfil do adductor mandibulae aproximadamente elíptico;

202 Adductor mandibulae restrito à porção anterior da face, inserido apenas na porção horizontal do pré-opérculo e encobrindo apenas uma pequena fração do ramo A2';

203* Origem dorsal da seção A2" do adductor mandibulae não encobrindo, ou encobrindo apenas a porção ventral, do Levator arcus palatini;

204 Seção A2',' do adductor mandibulae representado por um diminuto feixe muscular, ligado apenas ao metapterigóide;

205 Adductor arcus palatini restrito à porção posterior do palato.

Pyrrhulinina

09* Infra-orbital 6 ausente;

12 Nasais com amplas lamelas laterais e mediais;

22* Porção anterior do paresfenóide com um par de longas projeções que margeiam a face lateral do 
vômer;

32* Pterótico com um processo onde se liga um tendão do pós-temporal;

36* Ramo médio do epoccipital ausente;

39* Sulco formado pelas projeções ventrais do basioccipital profundo, expandido lateralmente;

43 Dentes cônicos;

51 Processo ascendente do maxilar curto, alcançando o elemento cartilaginoso lateral do palatino;

52 Dentes do maxilar distribuídos por toda a margem anterior do osso;

72 Vaso transpassando a porção médio-posterior do metapterigóide por meio de um canal curto;

102* Radial proximal 4 tão largo quanto o radial proximal 1;

136 Supraneural da quinta vértebra ausente;

140 Pré-zigapófise das vértebras pré-caudais tão desenvolvidas quanto as pós-zigapófises;

141* Espinhos neurais das vértebras pré-caudais associados à porção médio-distal das pós-zigapófises;

143* Raios mediais da nadadeira pélvica mais longos que os laterais; pélvicas com formato lanceolado;

144 Radiais mediais da nadadeira dorsal ausentes;

150 Radiais proximais da nadadeira anal distintamente mais robustos, porção proximal destes convergentes entre si em relação ao esqueleto axial, discretamente rotacionados anteriormente;

152* Lamelas transversais dos radiais proximais da nadadeira anal alongadas, estendendo-se ventralmente e sobrepondo-se lateralmente à primeira lepidotríquea;

153 Radiais mediais da nadadeira anal ausentes;

154 Peça terminal ou suporte da nadadeira anal ausente;

162* Porção distal do hipural 5 expandida e direcionada ventralmente, em direção ao hipural 4;

163* Hipural 6 ausente;

178 Escamas inseridas em uma concavidade na porção posterior dos parietais;

179 Escamas da primeira série longitudinal estendendo-se desde o crânio até o término da nadadeira dorsal;

186 Faixa primária estendendo-se desde o focinho até a margem posterior do opérculo;

188 Faixa secundária ausente;

196 Mancha ovalada na nadadeira dorsal presente.

\section{Copeina}

13 Margem anterior do nasal distintamente sobreposta ao ramo lateral do pré-maxilar;

30 Margem lateral do frontal com uma projeção lateral que encapsula a porção dorsal do dilatator operculi, mas não atinge o espinho do esfenótico; 
34 Espinho do pterótico longo;

41 Espinho do supra-occipital alcançando ou ultrapassando o ponto de contato entre o complexo neural e o supra-occipital;

73 Simplético longo; expandido dorso-ventralmente;

77 Processo lamelar na porção dorso-posterior do hiomandibular curto, contíguo à articulação do hiomandibular, mas sim próximo à área de articulação do hiomandibular com o pterótico;

80 Margem posterior do opérculo convexa;

86 Borda ventral do cerato-hial anterior relativamente lisa;

111 Canal sensorial do Infra-orbital 4 totalmente incluído no tubo ósseo;

112 Canal sensorial do Infra-orbital 5 totalmente incluído no tubo ósseo;

127 Processo laminar na margem anterior do tripus reduzido ou ausente;

128 Processo ventral na face mesial da base do processo transformador do tripus ausente.

Clado 100 (Copella + Pyrrhulina)

91 Faringo-branquial 2 edêntulo;

93 Extra-escapular ausente;

125* Linha lateral sem escamas perfuradas;

137 Supraneural da sexta vértebra ausente;

145 Peça terminal da nadadeira dorsal ausente;

146 Nadadeira dorsal situada no terço posterior do corpo;

151 Radiais proximais da nadadeira anal dos machos em contato direto, fortemente anquilosados;

164* Três ou quatro raios pró-correntes no lóbulo superior da nadadeira caudal;

173* Presença de raios "filamentosos";

179* Primeira série longitudinal de escamas alcançando apenas a origem da nadadeira dorsal.

\section{Copella}

01 Antorbital mais longo que alto;

14 Nasal não alcançando o frontal posteriormente;

29* Margem póstero-ventral do orbitosfenóide com uma discreta projeção lamelar em direção à margem ventral do pterosfenóide;

35* Margem póstero-ventral do pterosfenóide com um distinto processo direcionado medialmente ao neurocrânio, não contatando sua contraparte;

38 Forames occipitais laterais ocupando uma grande área da superfície posterior dos exoccipitais; 
88 Margem anterior do raio branquiostégio articulado com a face medial do cerato-hial anterior reta, sem uma projeção direcionada anteriormente;

90 Lamelas laterais do uro-hial ausentes;

96 Pós-cleitro 2 ausente;

105* Osso nasal representado apenas pela lamela óssea, não formando o tubo por onde passa o ramo do canal látero-sensorial;

108 Tubo ósseo do canal sensorial no infra-orbital 1 ausente;

109 Tubo ósseo do canal sensorial no infra-orbital 2 ausente;

115 Tubo ósseo do ramo supra-orbital do canal látero-sensorial cefálico estendendo-se desde os nasais até o ramo epifisiano;

147 Base do último raio da nadadeira dorsal atingindo ou ultrapassando discretamente a vertical que passa pela origem da nadadeira anal;

167 Narina anterior e posterior distantes entre si, separadas por uma larga membrana;

176 Borda anterior das escamas lisa ou com ondulações inconspícuas.

Clado 98 (Copella gr. arnoldi)

29* Margem póstero-ventral do orbitosfenóide com uma distinta projeção lamelar em direção à margem ventral do pterosfenóide;

35* Margem póstero-ventral do pterosfenóide com um distinto processo direcionado medialmente ao neurocrânio, contatando sua contraparte;

77 Porção dorso-posterior do hiomandibular sem um processo lamelar.

Clado 103 (Copella gr. compta)

68 Ectopterigóide não articulando com o quadrado;

186 Faixa primária estendendo-se desde o focinho até os raios mediais da nadadeira caudal;

198* Raios pró-correntes do lóbulo superior e inferior da nadadeira caudal fortemente pigmentados em machos adultos.

Pyrrhulina

48 Pré-maxilar com duas séries funcionais de dentes;

61 Osso corono-meckeliano aproximadamente dez vezes mais curto que a cartilagem de Meckel;

97 Pós-cleitro 3 ausente;

179 Primeira série longitudinal de escamas não alcançando a origem da nadadeira dorsal, podendo não 
alcançar a origem da nadadeira pélvica.

Lebiasininae (= Lebiasina)

06* Margem póstero-dorsal do infra-orbital 3 com uma projeção que exclui parcial- ou totalmente o infra-orbital 4 do anel orbital;

17* Lâmina dorsal do mesetmóide em forma de "T";

99* Margem póstero-ventral do coracóide truncada, sem uma projeção direcionada posteriormente;

107* Ramo infra-orbital do canal látero-sensorial cefálico se estendendo ao antorbital;

197 Mancha na base dos raios médios da nadadeira caudal presente.

Clado 69 ("Eulebiasina”)

02 Infra-orbital 1 sobrepondo-se a grande parte da porção látero-posterior do maxilar;

37 Margem posterior do epoccipital com uma discreta projeção onde se insere a musculatura epaxial;

94* Face ventral do pós-temporal sem um processo ósseo derivado da ossificação do ligamento que conecta esse osso ao pterótico;

171 Parede da câmara posterior da bexiga natatória apresentando um complexo sistema de alvéolos;

181 * Escama da sexta série longitudinal situada na vertical que passa pela origem da anal distintamente hipertrofiada, oblonga, demais escamas da série com epitélio entumecido ao longo da base da nadadeira anal;

185 Faixa primária composta apenas de pigmento dérmico, subjacente à pele;

195* Quarta escama da linha lateral com uma distinta mancha prateada (quando fixados, em vida o pigmento varia do amarelo ao vermelho).

Clado 68 (Lebiasina gr. bimaculata)

43 Dentes tricúspides com cúspides simétricas;

148 Nadadeira adiposa ausente;

195 Deposição de guanina na base das escamas da terceira, quarta e quinta séries longitudinais, formando séries longitudinais de manchas prateadas.

\section{Lebiasina bimaculata}

98 Moldura do forame escapular totalmente ossificada.

Clado 74 
92 Margem lateral do quinto cerato-branquial sem um processo;

97 Pós-cleitro 3 ausente;

99 Margem lateral do coracóide com uma discreta projeção.

\section{Lebiasina aff. bimaculata I}

06 Margem póstero-dorsal do infra-orbital 3 com uma projeção que exclui o infra-orbital 4 do anel orbital;

94 Face ventral do pós-temporal com uma discreta projeção derivada da ossificação do ligamento que conecta este osso ao pterótico;

133 Pré-zigapófise da quinta vértebra ausente.

\section{Lebiasina aff. bimaculata II}

04 Margem póstero-ventral do infra-orbital 2 não contígua à margem antero-ventral do infra-orbital 3;

64 Duas séries irregulares de dentes ectopterigóide;

132 Pós-zigapófise da quarta vértebra presente.

Clado 73 (Lebiasina gr.festae)

04 Margem póstero-ventral do infra-orbital 2 não contígua à margem antero-ventral do infra-orbital 3;

12 Nasal com lamelas ósseas desenvolvidas;

64 Duas séries de irregulares de dentes no ectopterigóide;

66 Dentes na porção posterior do endopterigóide;

\section{Lebiasina aff. festae}

34 Espinho do pterótico longo;

41 Espinho do supra-occipital alcançando ou ultrapassando o ponto de contato entre o complexo neural e o supra-occipital;

79 Margem anterior do opérculo com um processo ósseo onde se insere parte do dilatator operculi.

Clado 72

80 Margem posterior do opérculo aproximadamente reta;

197 Mancha na base dos raios médios da nadadeira caudal ausente;

\section{Lebiasina festae}


65 Dentes do ectopterigóide distribuídos ao longo de grande extensão do osso;

77 Processo lamelar na porção dorso-posterior do hiomandibular longo, ultrapassando a área de articulação do hiomandibular com o pterótico e o esfenótico;

97 Pós-cleitro 3 ausente.

\section{Lebiasina boruca}

92 Margem lateral do quinto cerato-branquial sem um processo lateral;

195 Base das escamas da terceira, quarta e quinta séries com manchas prateadas, formando séries longitudinais.

Clado 78 ('Piabucina')

91 Faringo-branquial 2 edêntulo;

98 Forame escapular totalmente ossificado;

179 Primeira série de escamas alcançando apenas o término da nadadeira dorsal;

180 Escamas da quinta série longitudinal apresentando-se alongadas posteriormente, com tecido epitelial entumecido, desde a vertical que passa pela origem da nadadeira anal, podendo estender-se posteriormente por quase todo o pedúnculo caudal.

\section{Lebiasina elongata}

01 Antorbital tão longo quanto alto;

12 Nasal com lamelas ósseas desenvolvidas;

63 Ectopterigóide longo;

68 Ectopterigóide não articulando diretamente com o quadrado;

129 Porção lamelar do complexo neural estendendo-se posteriormente, alcançando a porção não modificada do espinho neural da quarta vértebra.

\section{Clado 77}

03 Infra-orbital 2 encobrindo apenas a porção posterior do maxilar;

133 Pré-zigapófise da quinta vértebra ausente.

\section{Clado 93}

04 Margem póstero-ventral do infra-orbital 2 não contígua à margem antero-ventral do infra-orbital 3; 188 Faixa secundária estendendo-se ao longo das escamas da segunda e terceira séries longitudinais; 
191* Faixa "intermediária” restrita ao infra-orbital 3;

197* Mancha caudal geralmente pouco conspícua, situada somente sobre os raios da nadadeira caudal, não alcançando o pedúnculo caudal anteriormente.

\section{Lebiasina sp. Parima}

17 Lâmina dorsal do mesetmóide arredondada;

81 Basi-hial longo;

91 Faringo-branquial 2 apresentando dentículos viliformes;

98 Moldura do forame escapular com uma porção cartilaginosa entre a escápula e o cleitro;

103 Nadadeira peitoral com mais de 15 raios ramificados;

183 Mancha umeral ausente;

191* Faixa intermediária estendendo-se do infra-orbital 3 à vertical que passa pela origem da nadadeira anal, ao longo da quinta série longitudinal de escamas;

192 Faixa terciária presente;

200 Perfil do adductor mandibulae aproximadamente quadrangular.

Clado 92

28 Processo lamelar na face ventral do órbito-esfenóide presente;

37 Projeção posterior do epoccipital presente.

\section{Lebiasina unitaeniata}

80 Margem posterior do opérculo aproximadamente reta;

86 Borda ventral do cerato-hial anterior apresentando distintas reentrâncias.

\section{Clado 91}

71 Porção posterior do metapterigóide com um forame delimitado posteriormente pelo hiomandibular.

\section{Lebiasina yuruaniensis}

31 Margem lateral do frontal sem uma projeção lateral que encapsula parte do dilatator operculi; 68 Ectopterigóide não articulando diretamente com o quadrado;

103 Mais de 15 raios ramificados na nadadeira peitoral;

142 Espinho neural da última vértebra distintamente reduzido. 
Clado 90

148 Nadadeira adiposa ausente;

184* Faixa primária distinta em exemplares jovens, porém difusa (ou ausente) em exemplares adultos; 189 Faixa secundária conspícua, representada tanto por pigmento dérmico quanto epidérmico; 200 Perfil do adductor mandibulae aproximadamente quadrangular.

\section{Lebiasnia taphorni}

34 Espinho do pterótico longo;

79 Margem anterior do opérculo um processo ósseo onde se insere parte do dilatator operculi;

91 Faringo-branquial 2 apresentando dentículos viliformes;

\section{Lebiasina uruyensis}

28 Processo lamelar na face ventral do órbito-esfenóide;

92 Margem lateral do cerato-branquial 5 sem um processo lateral;

99 Margem póstero-ventral do coracóide com uma discreta projeção posterior.

Clado 76

19 Crista óssea longitudinal na face dorsal do vômer curta;

92 Margem lateral do cerato-branquial 5 sem um processo lateral.

Clado 75

93 Extra-escapular sobrepondo-se lateralmente à margem dorsal do opérculo;

148 Nadadeira adiposa ausente.

\section{Lebiasina sp. Curuá-Faixa}

01 Antorbital tão longo quanto alto;

04 Margem póstero-ventral do infra-orbital 2 não contígua à margem antero-ventral do infra-orbital 3;

17 Lâmina dorsal do mesetmóide arredondada;

56 Margem mesial dos dentários não se projetadas medialmente, encobrindo parte do istmo; margens quase paralelas, convergindo pouco em direção à sínfise mandibular;

79 Margem anterior do opérculo com um processo ósseo onde se insere parte do dilatator operculi;

Clado 80 
13 Margem anterior do nasal alcançando ou sobrepondo-se discretamente ao ramo lateral do prémaxilar;

80 Margem posterior do opérculo aproximadamente reta;

184 Faixa primária ausente;

188 Faixa secundária ausente;

197 Mancha caudal ausente.

Lebiasina sp. Curuá-Pinta

91 Faringo-branquial 2 com dentículos viliformes;

133 Pré-zigapófise da quinta vértebra presente.

Clado 79

41 Espinho do supra-occipital alcançando ou ultrapassando o ponto de contato entre o complexo neural e o supra-occipital.

Lebiasina sp. Cachimbo

Sem autapomorfias.

Lebiasina sp. XIII de maio

196 Mancha ovalada na base dos raios da nadadeira dorsal presente.

Clado 81

179 Primeira série longitudinal de escamas estendendo-se desde o crânio até a base da nadadeira caudal;

200 Perfil do adductor mandibulae aproximadamente quadrangular.

\section{Lebiasina erythrinoides}

77 Processo lamelar na porção dorso-posterior do hiomandibular longo, ultrapassando a área de articulação do hiomandibular com o pterótico e o esfenótico;

133 Pré-zigapófise da quinta vértebra presente.

clado 83

80 Margem posterior do opérculo aproximadamente reta; 
187* Série longitudinal de manchas arredondadas presente.

\section{Lebiasina floridablancaensis}

04 Margem póstero-ventral do infra-orbital 2 não contígua à margem antero-ventral do infra-orbital 3; 188 Faixa secundária estendendo-se ao longo das escamas da segunda e terceira séries longitudinais; 189 Faixa secundária conspícua, representada tanto por pigmento dérmico quanto epidérmico.

\section{Clado 84}

41 Espinho do supra-occipital alcançando ou ultrapassando o ponto de contato entre o complexo neural e o supra-occipital.

\section{Lebiasina ortegai}

72 Vaso que transpassa a porção médio-posterior do metapterigóide percorrendo um canal curto no osso;

107 Ramo infra-orbital do canal látero-sensorial cefálico se estendendo ao antorbital;

\section{Clado 85}

13 Margem anterior do nasal alcançando ou sobrepondo-se discretamente ao ramo lateral do prémaxilar;

19 Crista óssea longitudinal na face dorsal do vômer desenvolvida, quase atingindo a porção ventral do mesetmóide;

64 Ectopterigóide com duas séries irregulares de dentes;

92 Margem lateral do cerato-branquial 5 com um processo espiniforme lateral.

\section{Lebiasina panamensis}

63 Ectopterigóide longo;

65 Dentes do ectopterigóide distribuídos ao longo de grande extensão do osso;

66 Endopterigóide com dentes na porção mediana do osso;

71 Porção médio-posterior do metapterigóide com um forame delimitado posteriormente pelo hiomandibular;

80 Margem posterior do opérculo côncava;

161 Um epural;

187 Série longitudinal de pequenas manchas, geralmente ocupando a área de uma única escama. 
Clado 86

02 Infra-orbital 1 sobrepondo-se a grande parte da porção látero-posterior do maxilar;

03 Infra-orbital 2 encobrindo grande parte do maxilar;

200 Perfil do adductor mandibulae aproximadamente triangular.

\section{Lebiasina chocoensis}

Sem autapomorfias.

\section{Lebiasina colombia}

Sem autapomorfias.

\section{Lebiasina multimaculata}

06 Margem póstero-dorsal do infra-orbital 3 com uma projeção que exclui o infra-orbital 4 do anel orbital;

80 Margem posterior do opérculo côncava;

148 Nadadeira adiposa ausente.

Clado 88

133 Pré-zigapófise da quinta vértebra presente;

188 Faixa secundária estendendo-se ao longo das escamas da segunda e terceira séries longitudinais de escamas;

189 Faixa secundária conspícua, representada tanto por pigmento dérmico quanto epidérmico.

\section{Lebiasina aureoguttata}

80 Margem posterior do opérculo côncava;

104 Canal do maxilar estendendo-se por grande parte do osso;

132 Pós-zigapófise da quarta vértebra presente.

Clado 89

161 Um epural;

187 série longitudinal de pequenas manchas, geralmente ocupando a área de uma única escama. 


\section{Lebiasina astrigata}

13 Margem anterior do nasal alcançando o ramo lateral do pré-maxilar;

41 Espinho do supra-occipital não alcançando o ponto de contato entre o complexo neural e o supraoccipital;

98 Moldura do forame escapular com uma porção cartilaginosa entre a escápula e o cleitro.

\section{Lebiasina sp. Azuay}

13 Margem anterior do nasal não alcançando o ramo lateral do pré-maxilar;

91 Faringo-branquial 2 apresentando dentículos viliformes;

92 Margem lateral do cerato-branquial 5 sem um processo espiniforme lateral;

200 Perfil do adductor mandibulae aproximadamente quadrangular. 


\section{LEBIASINIDAE}

- Copeina guttata: MZUSP 27088, 216 al., 02 C\&S.

- Copella arnoldi: MPEG 7182

- Copella carsevennensis: MPEG 10398

- Copella cf. compta: MZUSP 64615

- Copella eigenmanni: MZUSP 23064; MPEG 8305

- Copella metae: MCNG 6685, 13 al.; MCNG 6842, 22 al.; MCNG 6897, 03 al.; MCNG 17689;

33 al.; MCNG 20213, 20 al.; MCNG 21606, 03 al.; MCNG 21622, 01 ex. al.; MCNG 21682, 14 al., 01 C\&S.; MCNG 2219, 37 al.; MCNG 22239, 03 al.; MCNG 23057, 01 al.; MCNG 23286, 05 al.; MCNG 26093, 12 al.; MCNG 26413, 17 al.; MCNG 26444, 43 al.; MCNG 26984, 21 al.; MCNG 51138, 03 al.

- Copella nattereri: MCNG 35088, 05 al.; MCNG 42122, 29 al.; MCNG 42286, 17 al.; MCNG 50642, 17 al.; MNRJ 28250, 102 al., 02 C\&S.

- Copella nigrofasciata: DEPRJ 104, 16 al., 04 C\&S.; DEPRJ 105, 34 al.; DEPRJ 106, 06 al.; MNRJ 28272, 06 al.

- Derhamia hoffmannorum MHNG 1553.98, 01 al.; MTD F 26 492, 01 C\&S Parátipo; MTD F 26 495, 01 al.; MTD F 26 496, 01 al. Parátipo.

- Nannostomus anduzei: MZUSP 40330, 656 al., 03 C\&S.

- Nannostomus beckfordi: MZUSP 22910, 19 al., 03 C\&S.; MZUSP 65454, 02 C\&S.

- Nannostomus bifasciatus: MZUSP 23160, 02 al.

- Nannostomus britskii: MZUSP 25414, 23 al., 03 C\&S.

- Nannostomus digrammus: MCNG 27106, 46 al.; MCNG 23440, 23 al.; MCNG 39392, 08 al.; MZUSP 5575, 75 al., 03 C\&S.

- Nannostomus eques: MCNG 12088, 01 al.; MCNG 37932, 23 al.; MCNG 38140, 01 al.; MCNG 38351, 13 al.; MCNG 45272, 42 al.; MPEG 6114, 03 al.; MPEG 6193, 03 al.; MNRJ 28251, 02 al.; MNRJ 20023, 13 al., 03 C\&S.; MZUSP 6423, 60 al., 02 C\&S.; MZUSP 15221, 04 al.

- Nannostomus harissoni: MNRJ 26689, 02 al., 01 C\&S.

- Nannostomus limatus: MPEG 6115, 10 al.; MPEG 6226, 05 al.; MNRJ 21088, 35 al., 04 C\&S.

- Nannostomus marginatus: MCNG 25669, 31 al.; MCNG 30391, 04 al.; MCNG 38350, 10 al.; MNRJ 28266, 03 al.; MZUSP 23512, 32 al., 03 C\&S.; DEPRJ 103, 19 al.; 03 C\&S.

- Nannostomus marylinae: MCNG 38140, 369 al.; MCNG 45710, 06 al.; MCNG 45734, 111 al.; MCNG 46261, 09 al.; MCNG 46353, 32 al.; MCNG 47431, 99 al.; MCNG 50368, 16 al.; MZUSP 7926, 183 al., 03 C\&S.

- Nannostomus nitidus: MNRJ 21105, 03 al., 02 C\&S. 
- Nannostomus trifasciatus: MCNG 20977, 05 al.; MCNG 21734, 15 al.; MCNG 23440, 23 al.; MZUSP 29294, 240 al., 03 C\&S.; MZUSP 43634, 02 al.; DEPRJ 101, 01 C\&S.; DEPRJ 102, 04 al.

- Nannostomus unifasciatus: MCNG 38139, 44 al.; MZUSP 29285, 616 al., 02 C\&S.; MZUSP 74767; 07 al.

- Pyrrhulina australis: MZUSP 59567, 40 al., 02 C\&S.

- Pyrrhulina brevis: MZUSP 24328, 13 al., 02 C\&S.

- Pyrrhulina filamentosa: INHS 49609; USMN 226856, 01 C\&S.

- Pyrrhulina semifasciata: MZUSP 23230, 19 al., 02 C\&S.

- Pyrrhulina vittata: MZUSP 22397, 01 al.; MZUSP 29347, 03 al.; MZUSP 31423, 01 al.

- Pyrrhulina zigzag: MUSM 5008, 02 C\&S

- Pyrrhulina sp. “Capim”: MZUSP 23816, 51 al., 02 ex. C\&S.

- Pyrrhulina sp. "Solimões"

MZUSP 74236; 09 al., 01 C\&S.

- Pyrrhulina sp. Tapajós I: MNRJ 23298, 03 al.; MNRJ 23690, 01 al.; MZUSP 61130, 23 al., 02 $\mathrm{C} \& \mathrm{~S}$.

- Pyrrhulina sp. Tapajós II: MCP 39180, 04 C\&S.

- Pyrrhulina sp. "Tiquié": MZUSP 81983, 02 C\&S.

- Pyrrhulina sp. “Trombetas": MZUSP 52656, 01 al.; DEPRJ 107, 08 al., 02 C\&S.; DEPRJ 108, 17 al.; DEPRJ 109, 05 al.

\section{ERYTHRINIDAE}

- Erythrinus erythrinus: MNRJ 4012; MNRJ 4145; MNRJ 4378; MNRJ 14741; MNRJ 15041.Hoplerythrinus unitaeniatus: MNRJ 13486; MNRJ 17514; MNRJ 19263; MNRJ 21735; MNRJ 28258; MZUSP 47695

- Hoplias malabaricus: MNRJ 12586; MNRJ 14133; MNRJ 14135.

\section{CTENOLUCiIDaE}

- Boulengerella cuvieri: MZUSP 47711

- Boulengerella lateristriga: MZUSP 32133

- Boulengerella maculata: MZUSP 47709

- Ctenolucius beani: MNRJ 14539

- Ctenolucius hujetaMZUSP 47728; USNM, 310450

\section{HEPSETIDAE}


- Hepsetus odoe MNRJ 13404; MNRJ 13405; MNRJ 13452; MNRJ 14071; MZUSP 48372; MZUSP 84469

\section{ACESTRORHYNCHIDAE}

- Acestrorhynchus sp.: MNRJ 13493; MNRJ 13494

- Acestrorhynchus falcatus: MZUSP 27896

- Acestrorhynchus pantaneiro: MZUSP 83435

\section{Crenuchidae}

- Characidium lauroi MZUSP 49110

- Crenuchus spilurus MNRJ 26053; MZUSP 20015

\section{Characidae}

- Brycon orbygnianus: MZUSP 3378; MZUSP 17169

- Brycon orthotaenia: MNRJ 14226

\section{ALESTIDAE}

- Bricynus lateralis:MNRJ 13407

- Chalceus spilogyros: MZUSP 76069

- Hydrocynus vittatus: MNRJ 13411; MNRJ 13412

\section{HEMIODONTIDAE}

- Hemiodus ternetzi: MNRJ 13038

\section{PARODONTIDAE}

-Apareiodon affinis: MCP 11062

\section{Curimatidae}

-Cyphocharax gilbert MNRJ 12845; MNRJ 26036

\section{Prochilodontidae}

-Prochilodus sp. MNRJ 14208

\section{ANOSTOMIDAE}

-Leporinus reinhardtii: MNRJ 14211 


\section{Citharinidae}

- Xenocharax spilurus MZUSP 50358;

- Hemigrammocharax multifasciatus: MNRJ 14096 


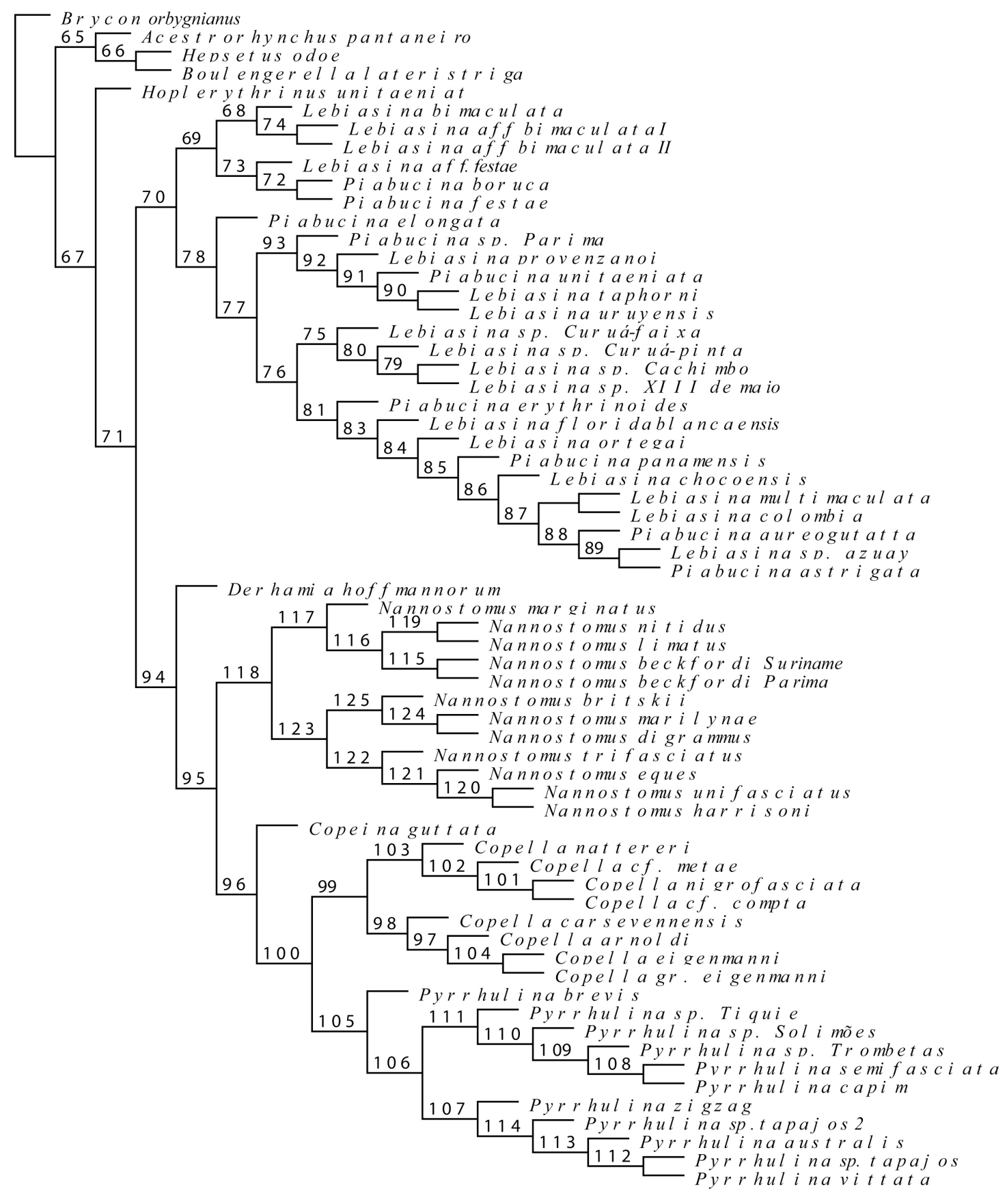

Figura 1. Diagrama não enraizado com 800 passos da hipótese de relacionamento das espécies de Lebiasininae. 


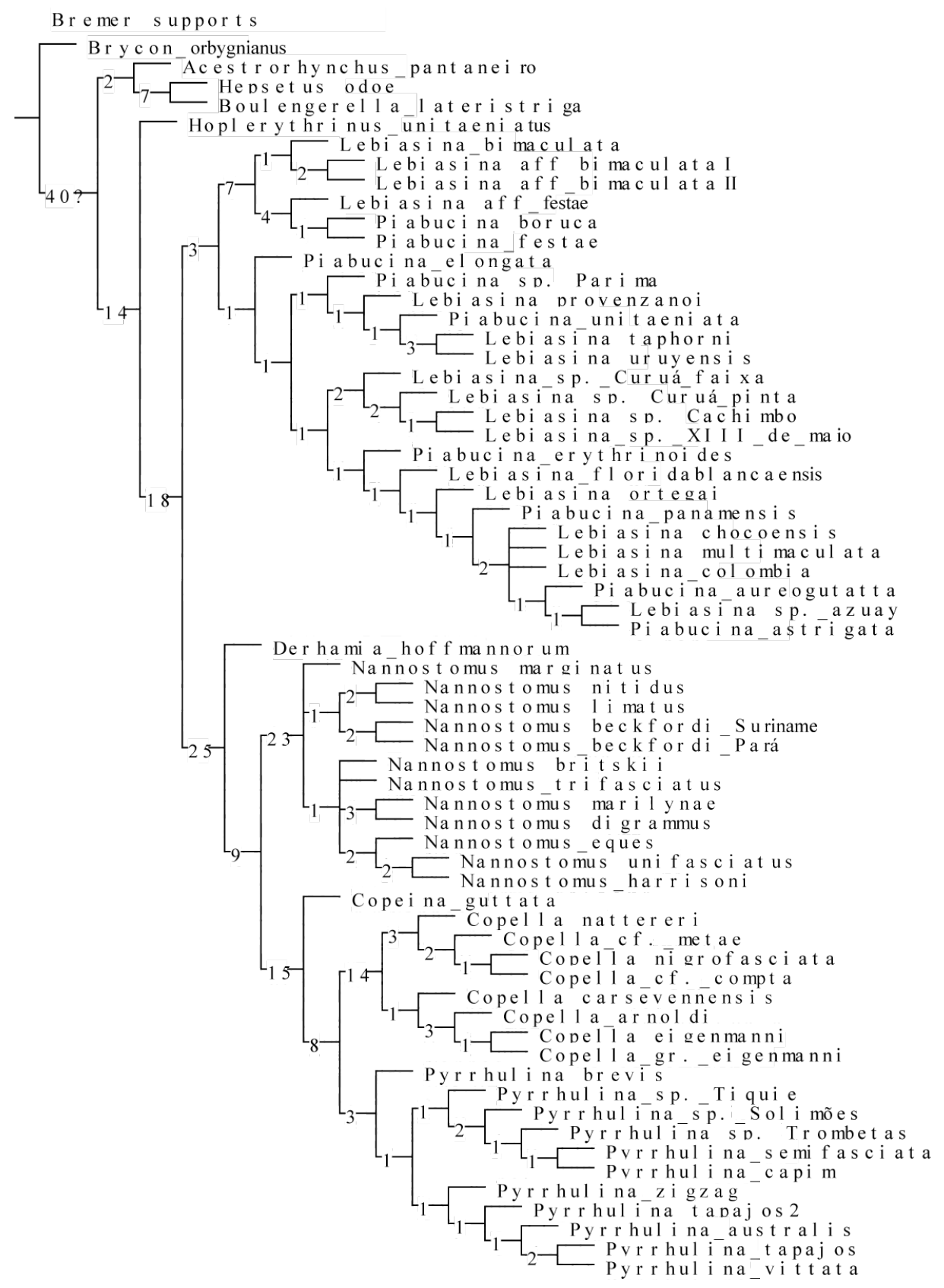

Figura 2. Consenso estrito das seis árvores fundamentais. Algarismos em cada ramo indicam os valores do índice de Bremer $(\geq 1)$ e o Bootstrap $(\geq 50)$. 


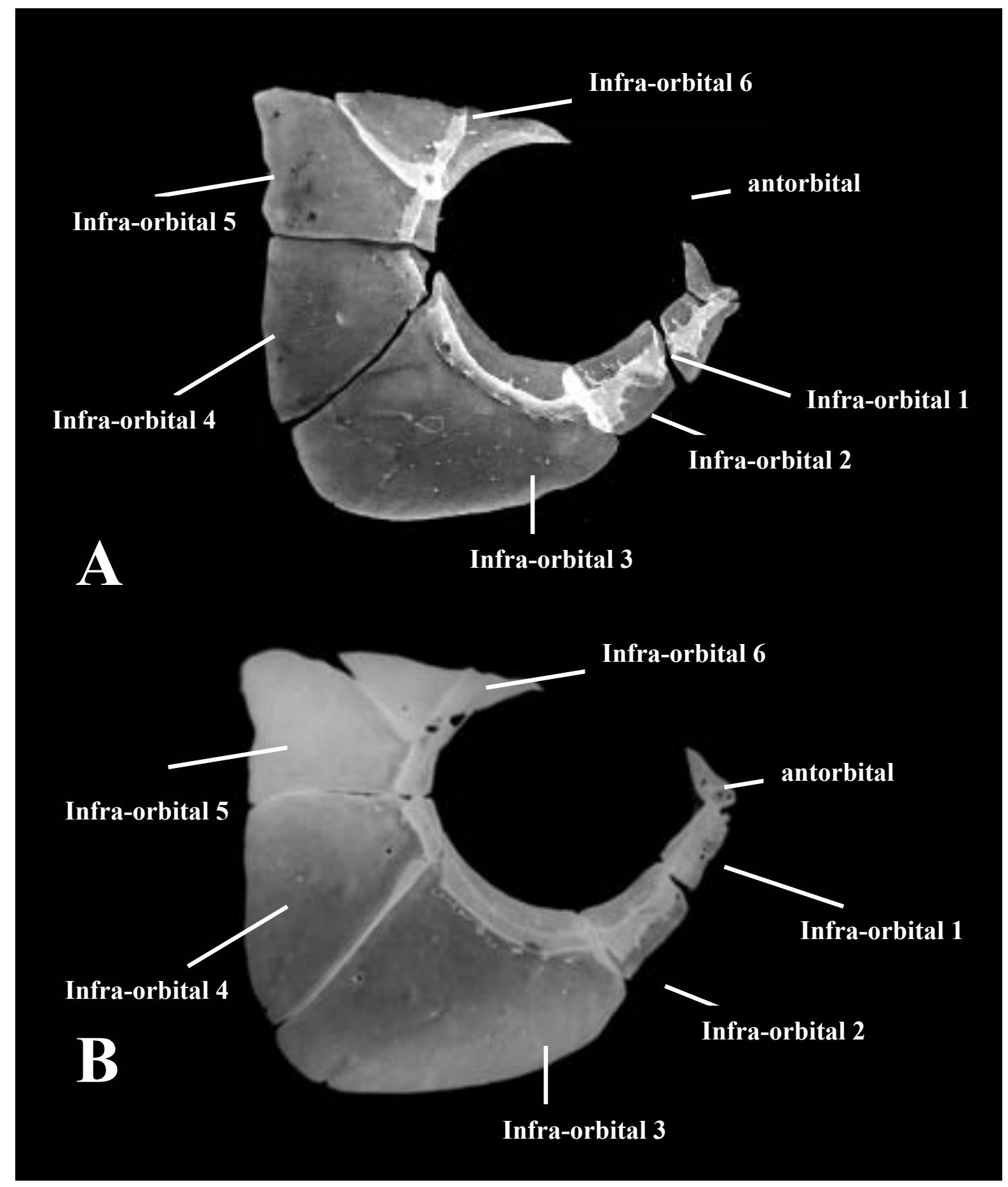

Figura 03. Série circum-orbital de (A) Lebiasina bimaculata MZUSP 80085, 70,1 mm CP e (B) Lebiasina erythrinoides MNRJ 14232, 64,8 mm CP. 


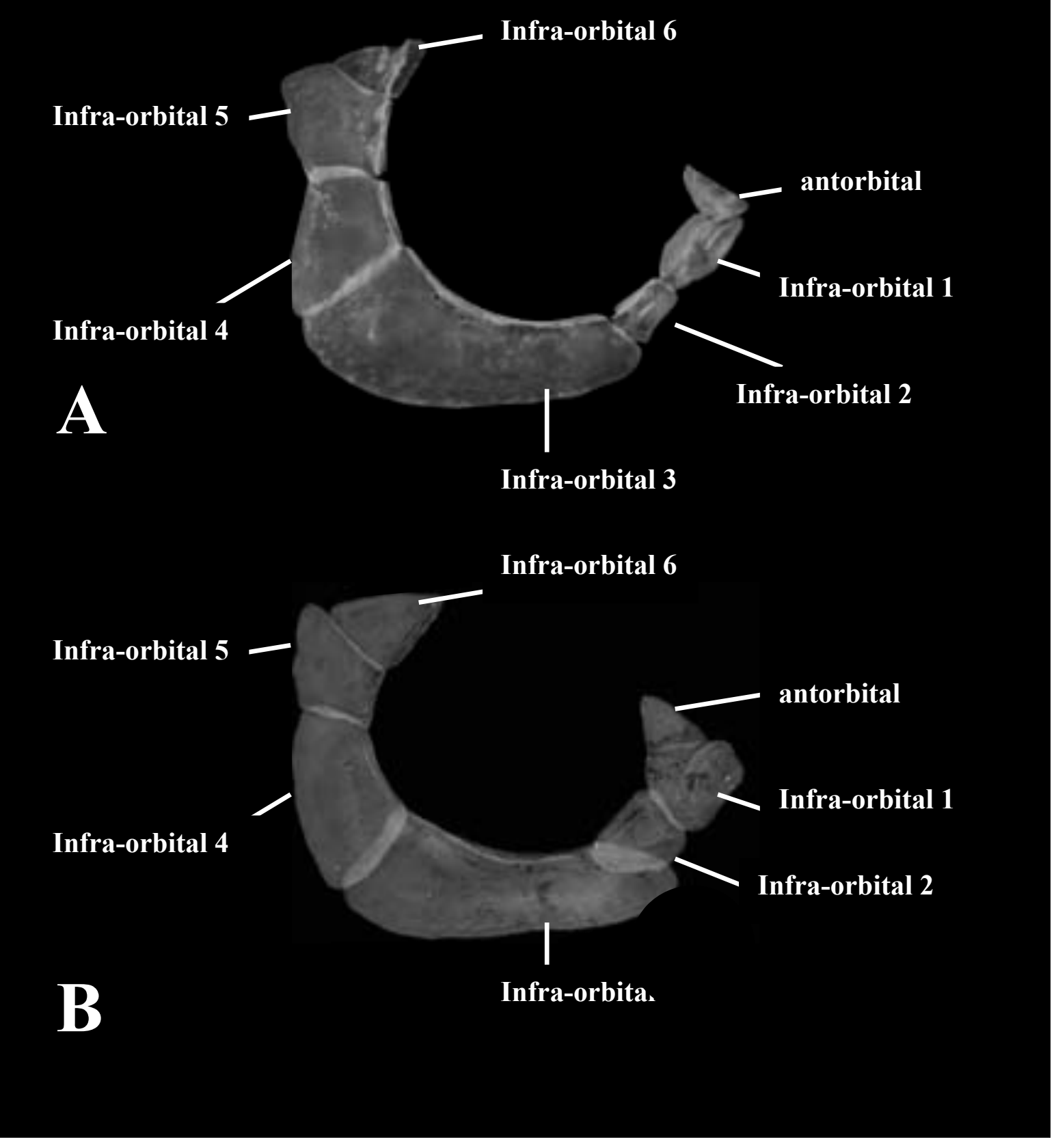

Figura 04. Série circum-orbital de (A) Derhamia hoffmannorum MTD F 26 492, 28 mm CP e (B) Nannostomus beckfordi MZUSP 22910, 26,9 mm CP. 


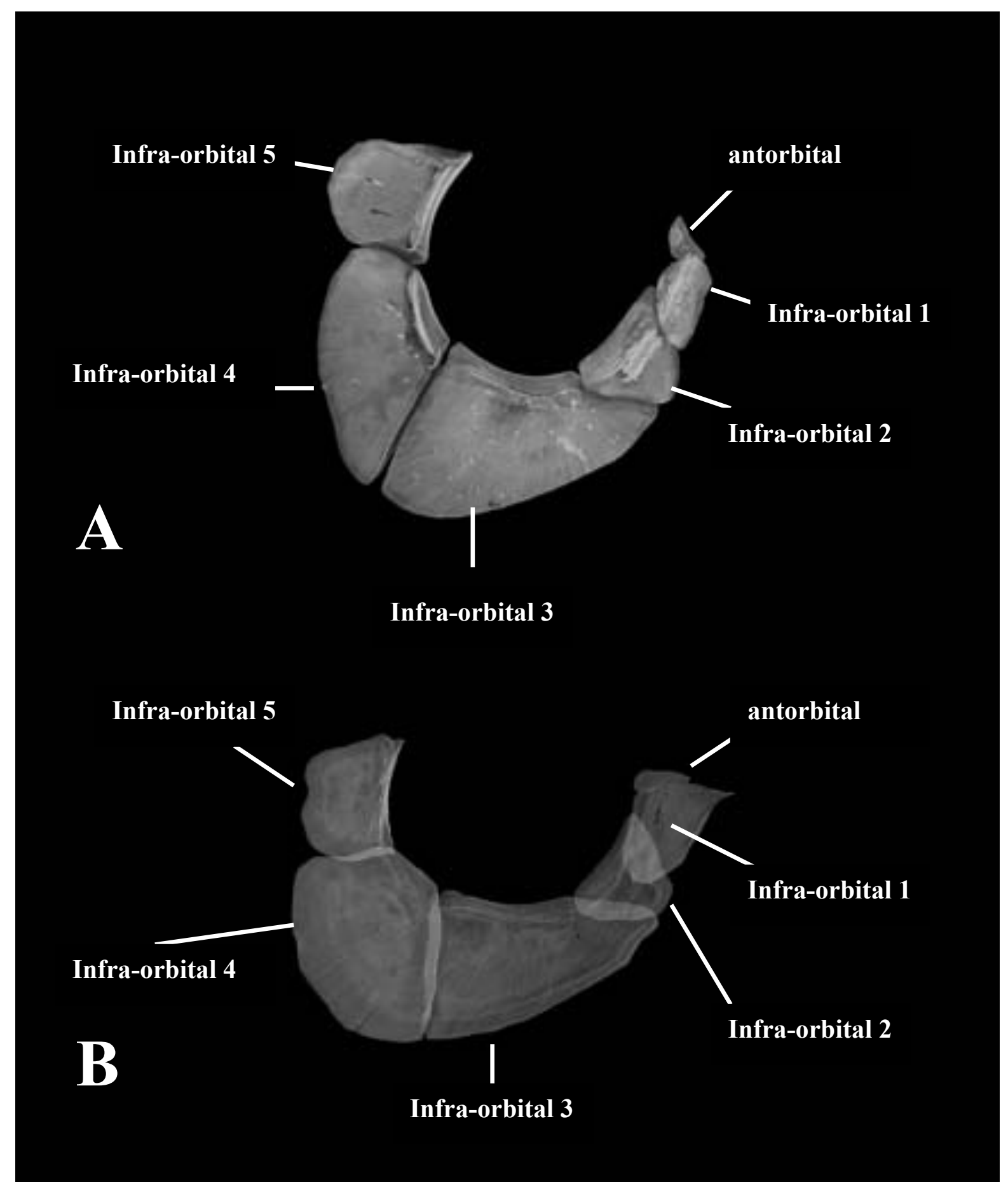

Figura 05. Série circum-orbital de (A) Copeina guttata MZUSP 27088, 65,3mm CP e (B) Copella nigrofasciata DEPRJ 104, 43,4 mm CP. 


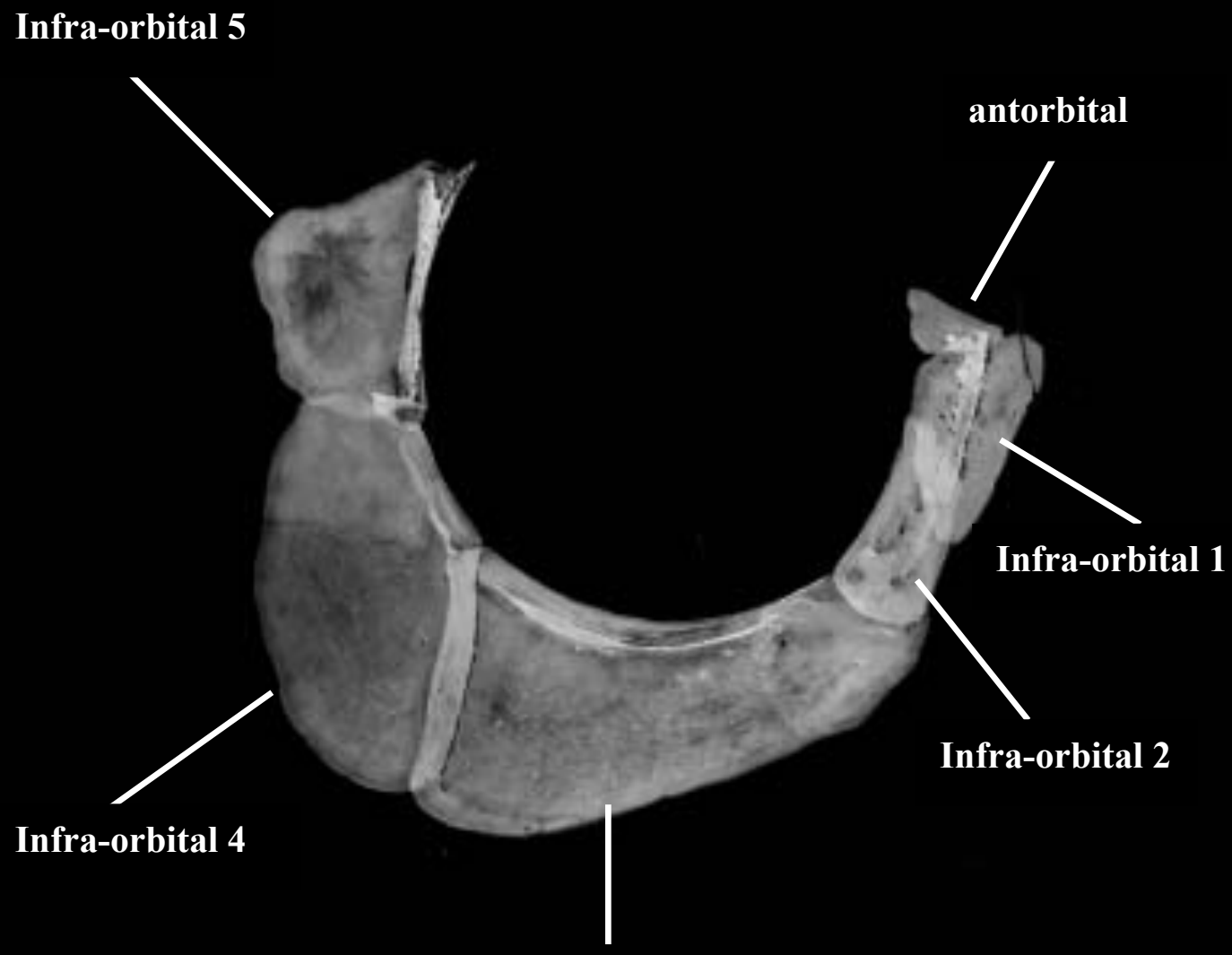

Infra-orbital 3

Figura 06. Série circum-orbital de Pyrrhulina australis MZUSP 59567, 31,8 mm CP. 

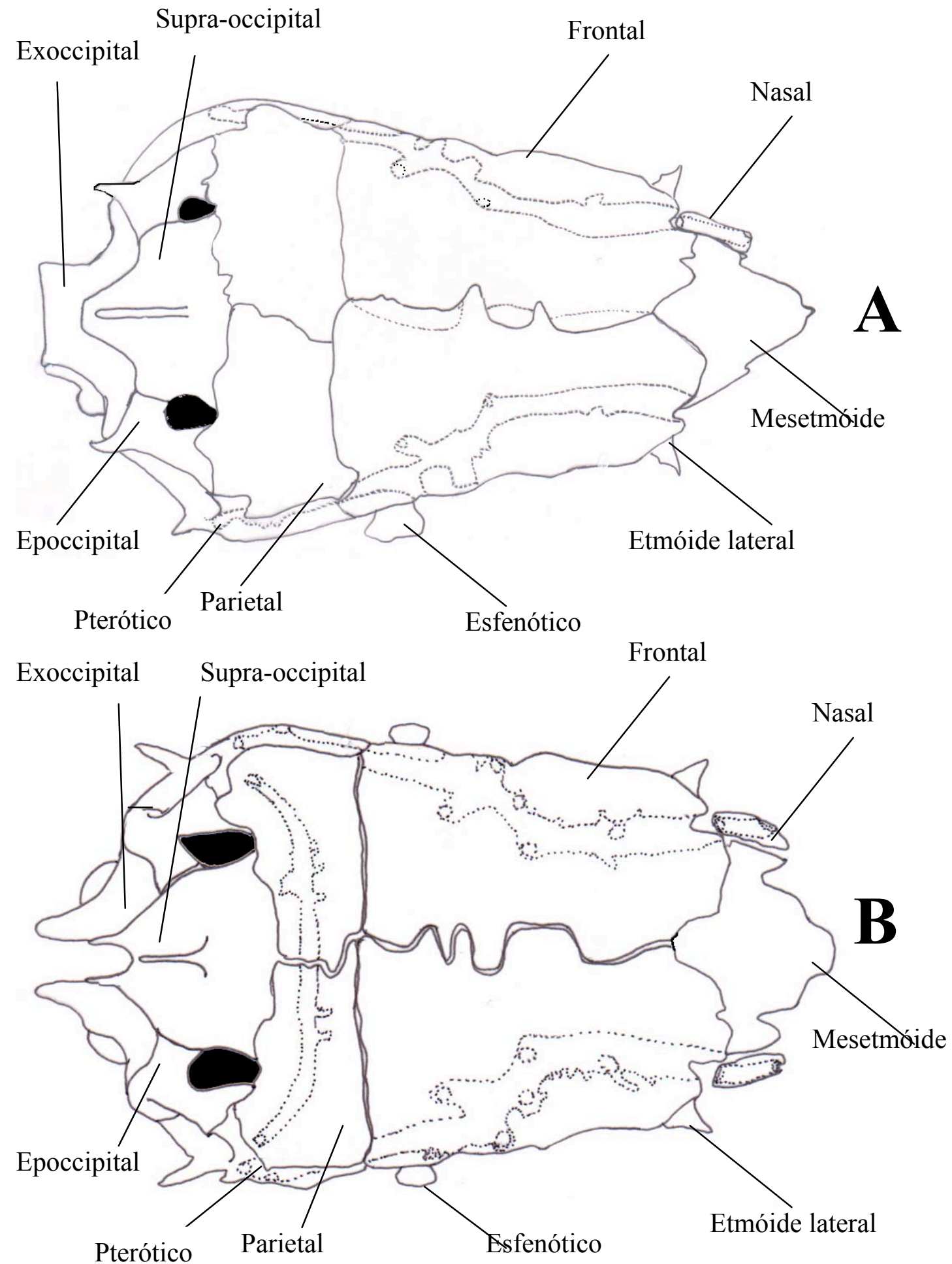

Figura 07. Vista dorsal do crânio de (A) Lebiasina bimaculata MZUSP 80085, 70,1 mm CP e (B) Lebiasina erythrinoides MNRJ 14232, 64,8 mm CP. 

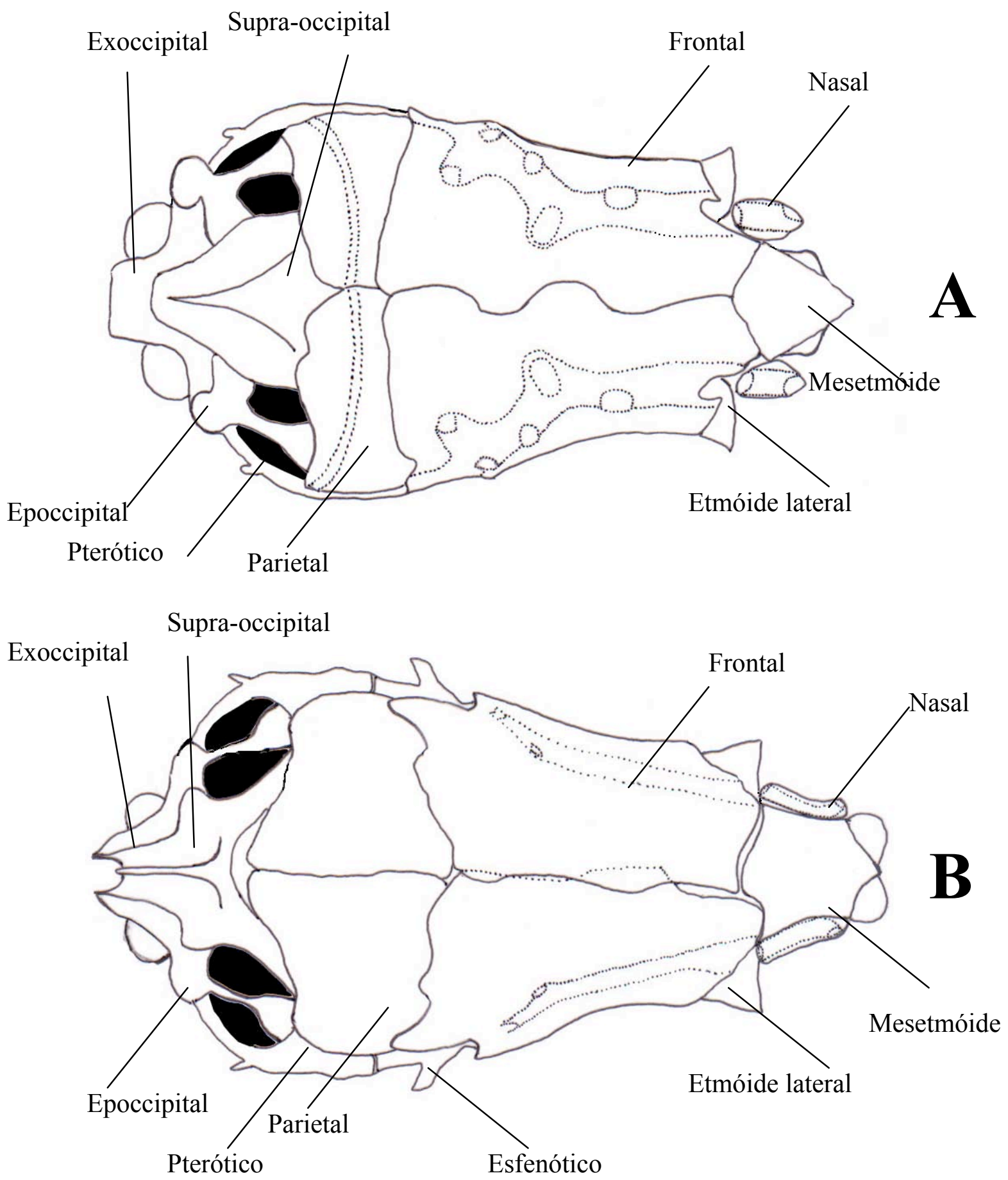

Figura 08. Vista dorsal do crânio de (A) Derhamia hoffmannorum MTD F 26 492, 28 mm CP e (B) Nannostomus beckfordi MZUSP 22910, 26,9 mm CP. 
Supra-occipital

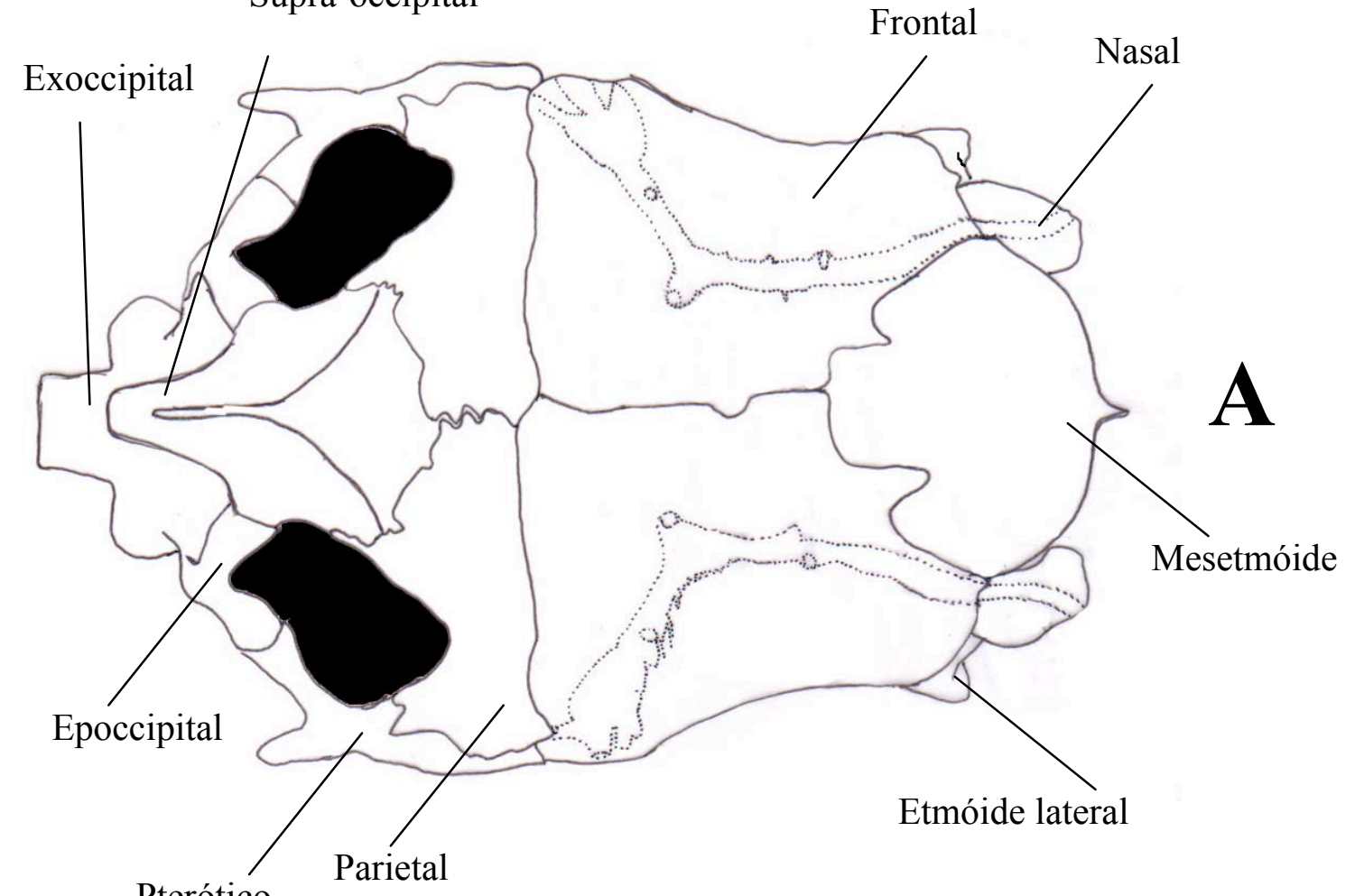

Pterótico

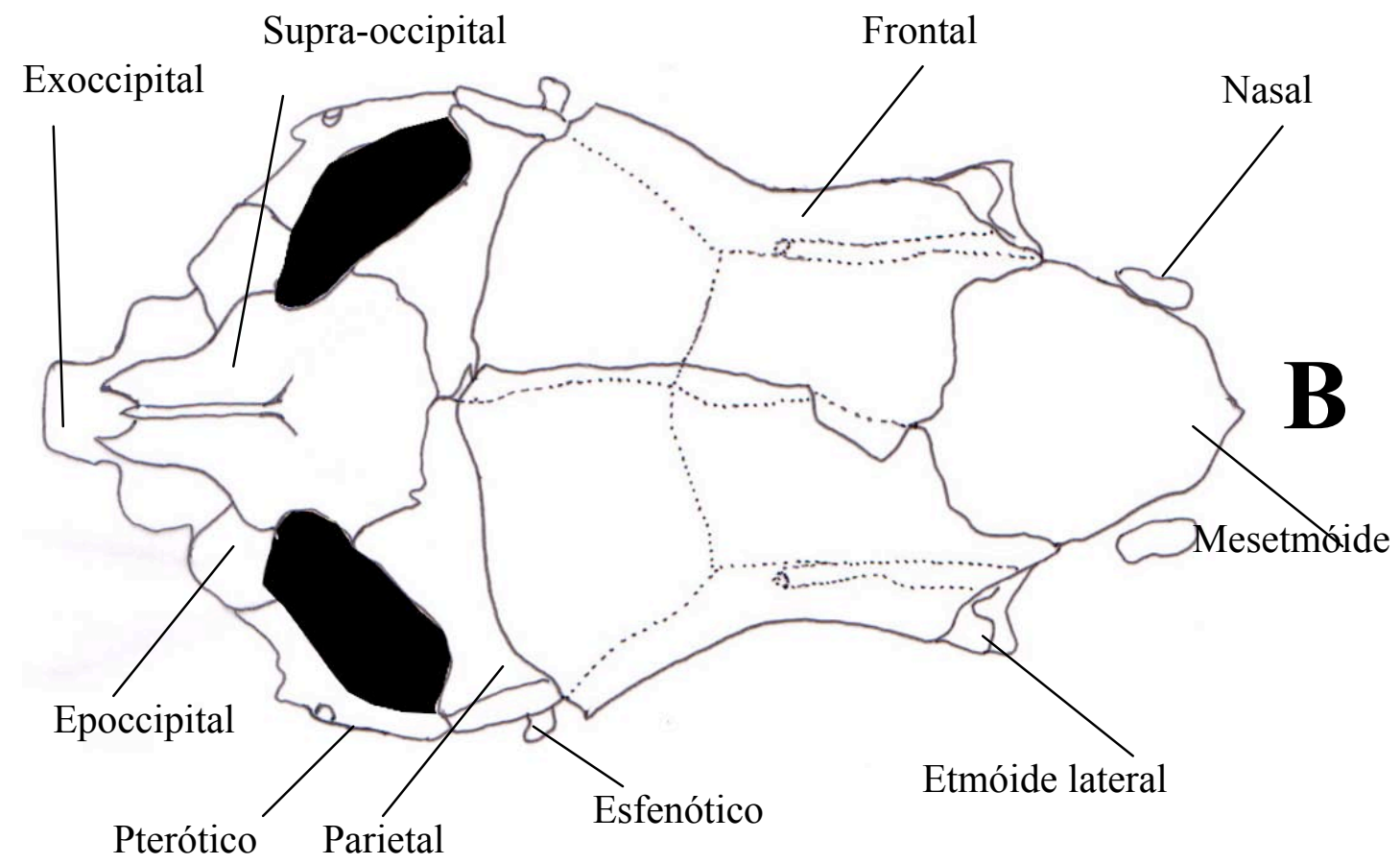

Figura 09. Vista dorsal do crânio de (A) Copeina guttata MZUSP 27088, 65,3mm CP e (B) Copella nigrofasciata DEPRJ 104, 43,4 mm CP. 


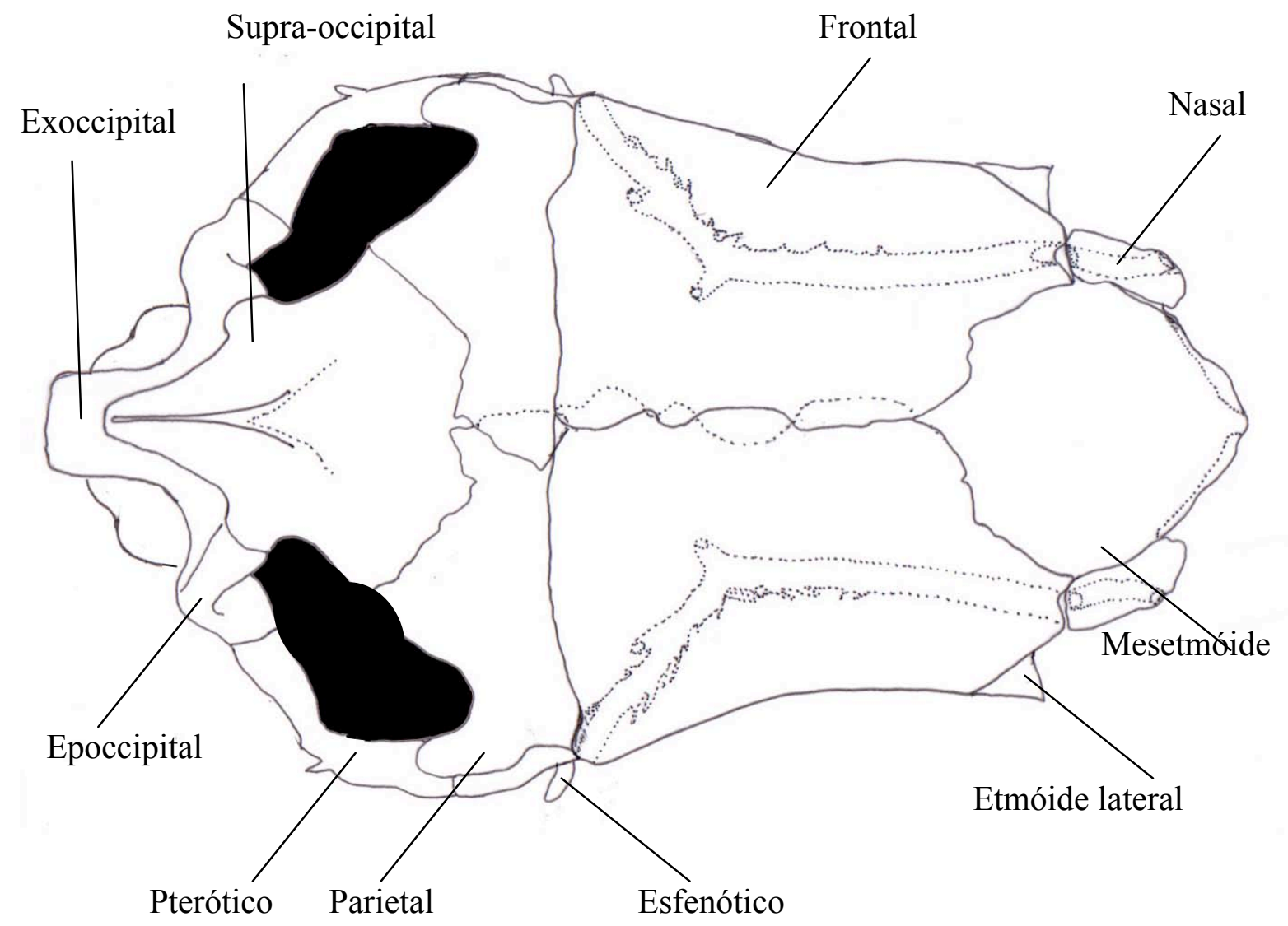

Figura 10. Vista dorsal do crânio de Pyrrhulina sp. Capim MZUSP 23816, 37,3 mm CP. 

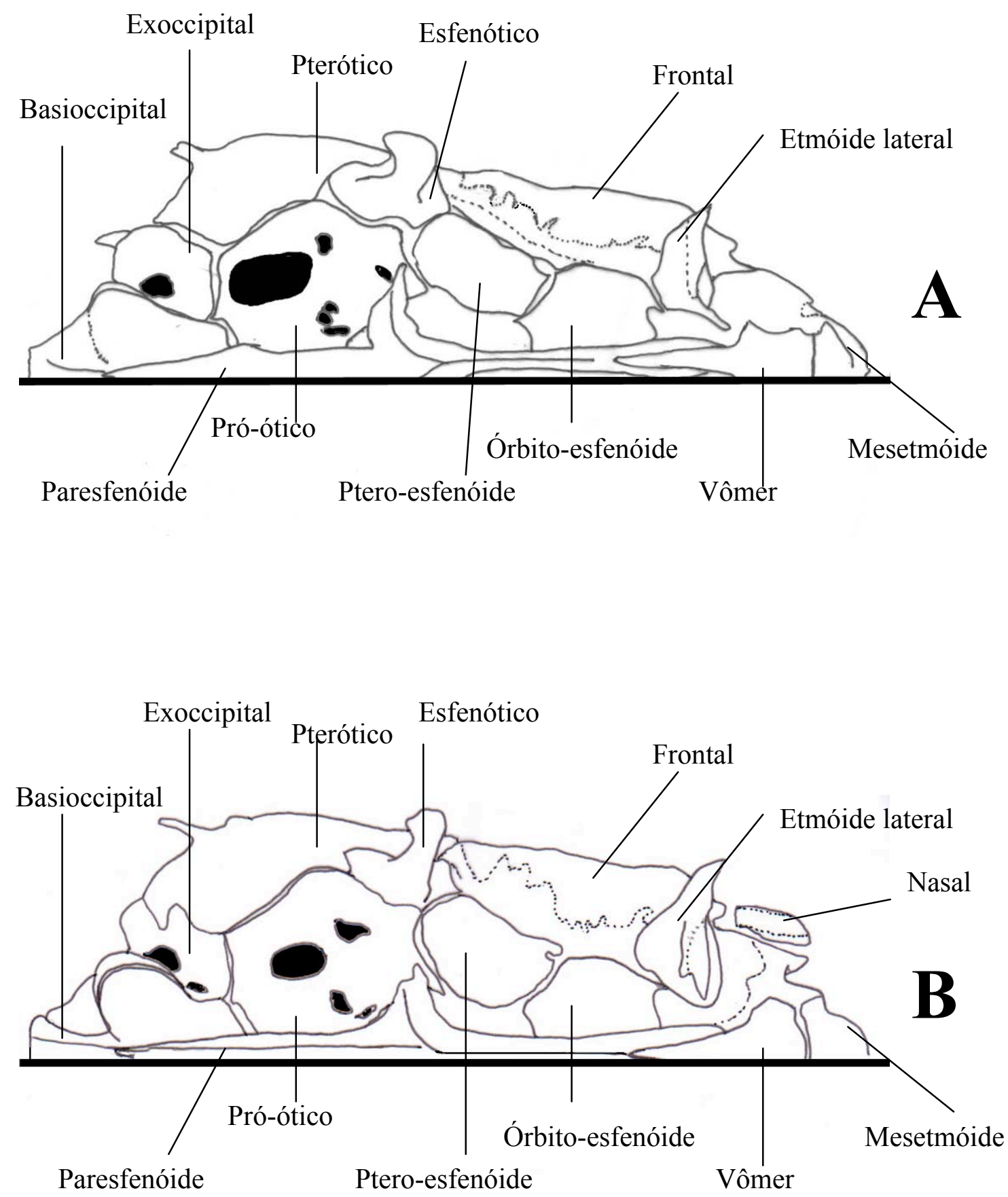

Figura 11. Vista ventral do crânio de (A) Lebiasina bimaculata MZUSP 80085, 70,1 mm CP e (B) Lebiasina erythrinoides MNRJ 14232, 64,8 mm CP. 


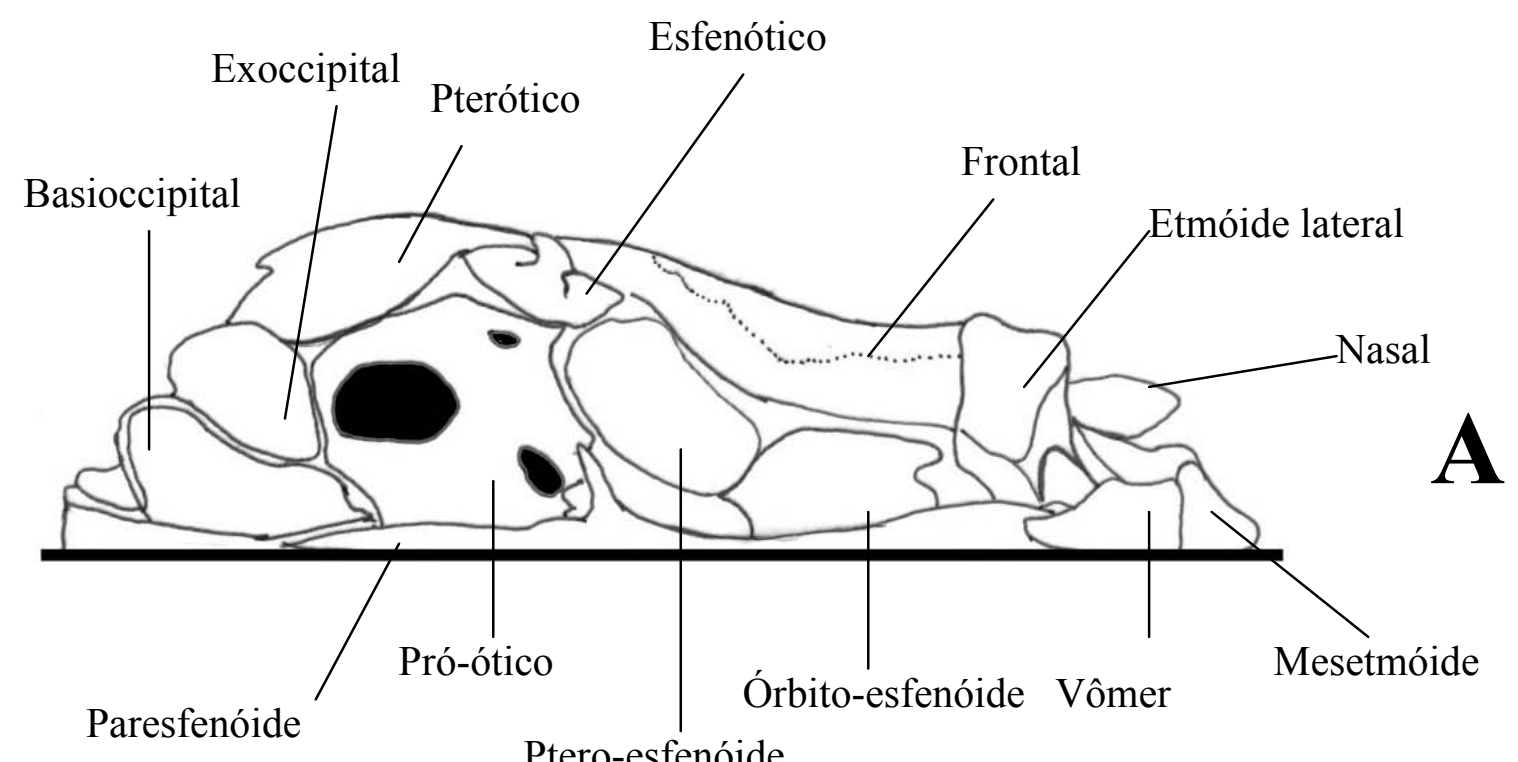

Ptero-esfenóide

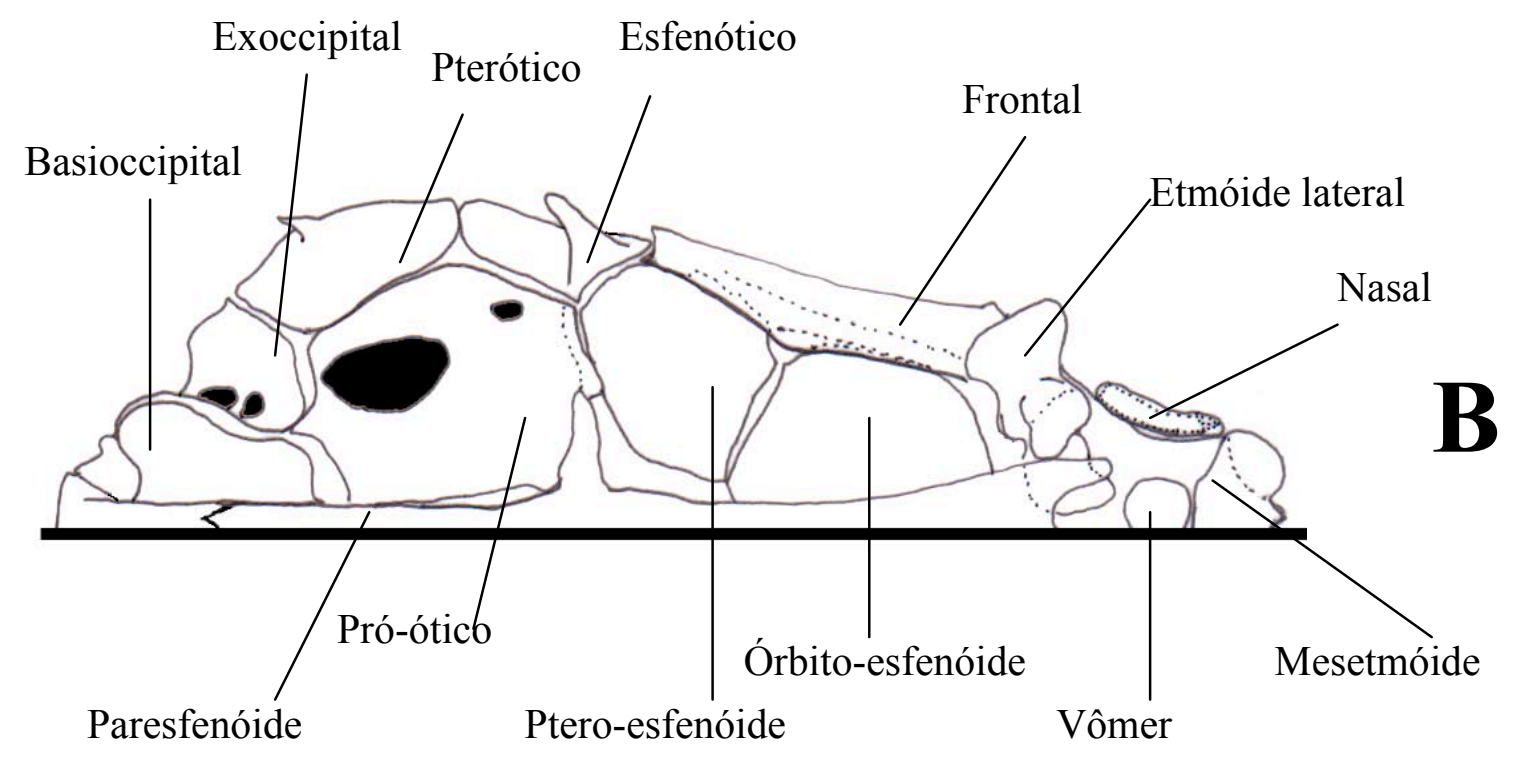

Figura 12. Vista dorsal do crânio de (A) Derhamia hoffmannorum MTD F 26 492, 28 mm CP e (B) Nannostomus beckfordi MZUSP 22910, 26,9 mm CP. 

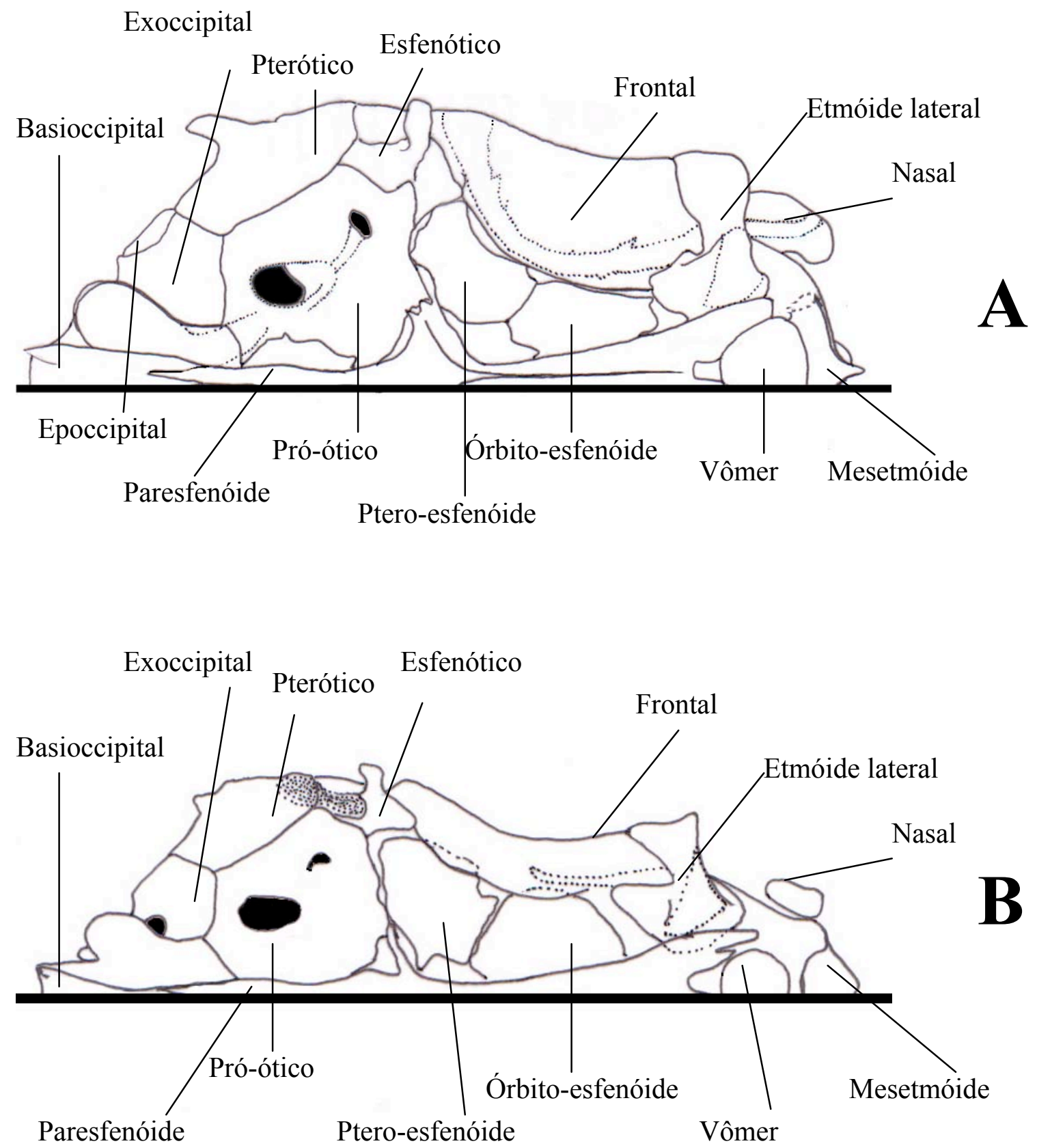

Figura 13. Vista ventral do crânio de (A) Copeina guttata MZUSP 27088, 65,3mm CP e (B) Copella nigrofasciata DEPRJ 104, 43,4 mm CP. 


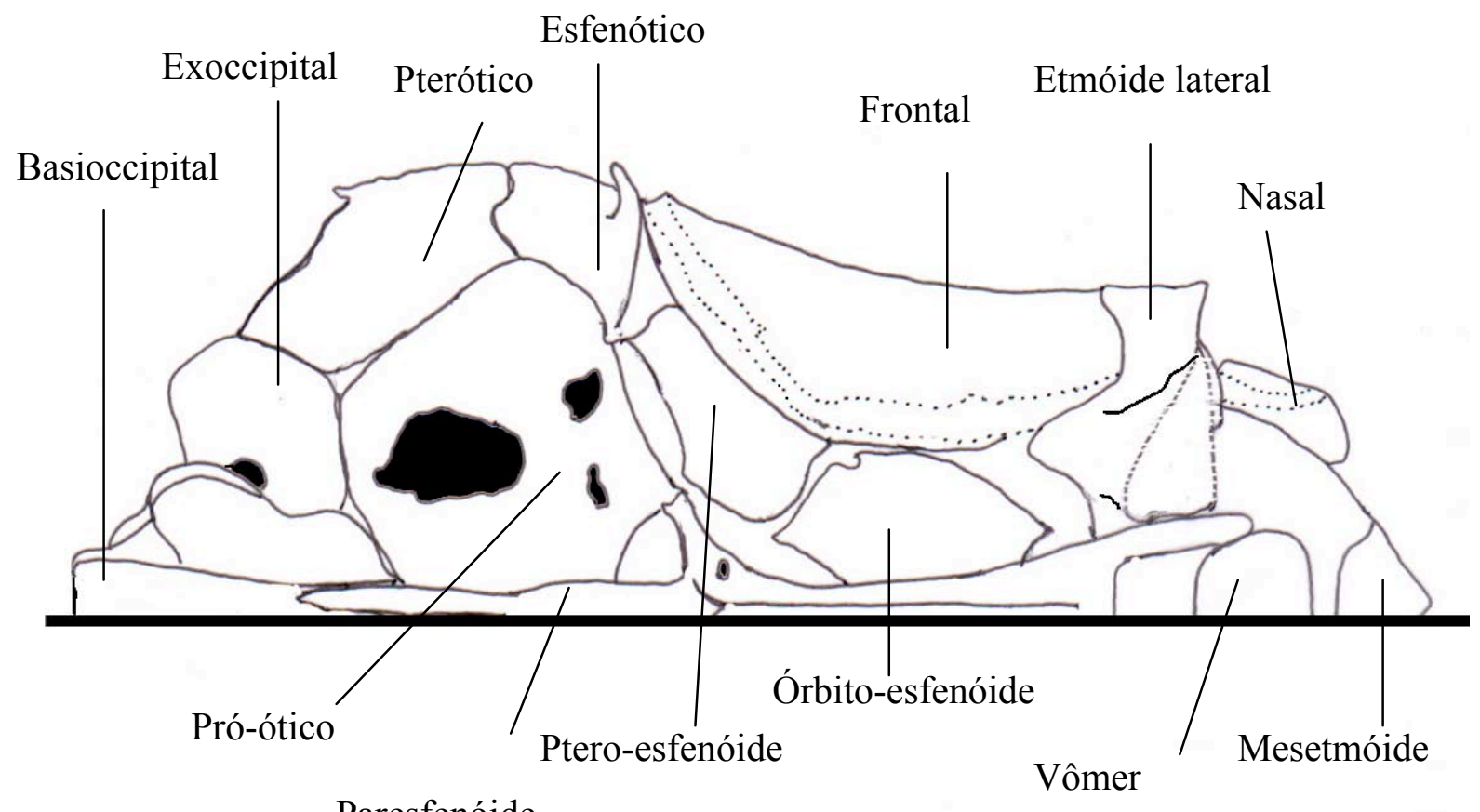

Paresfenóide

Figura 14. Vista ventral do crânio de Pyrrhulina sp. Capim MZUSP 23816, 37,3 mm CP. 


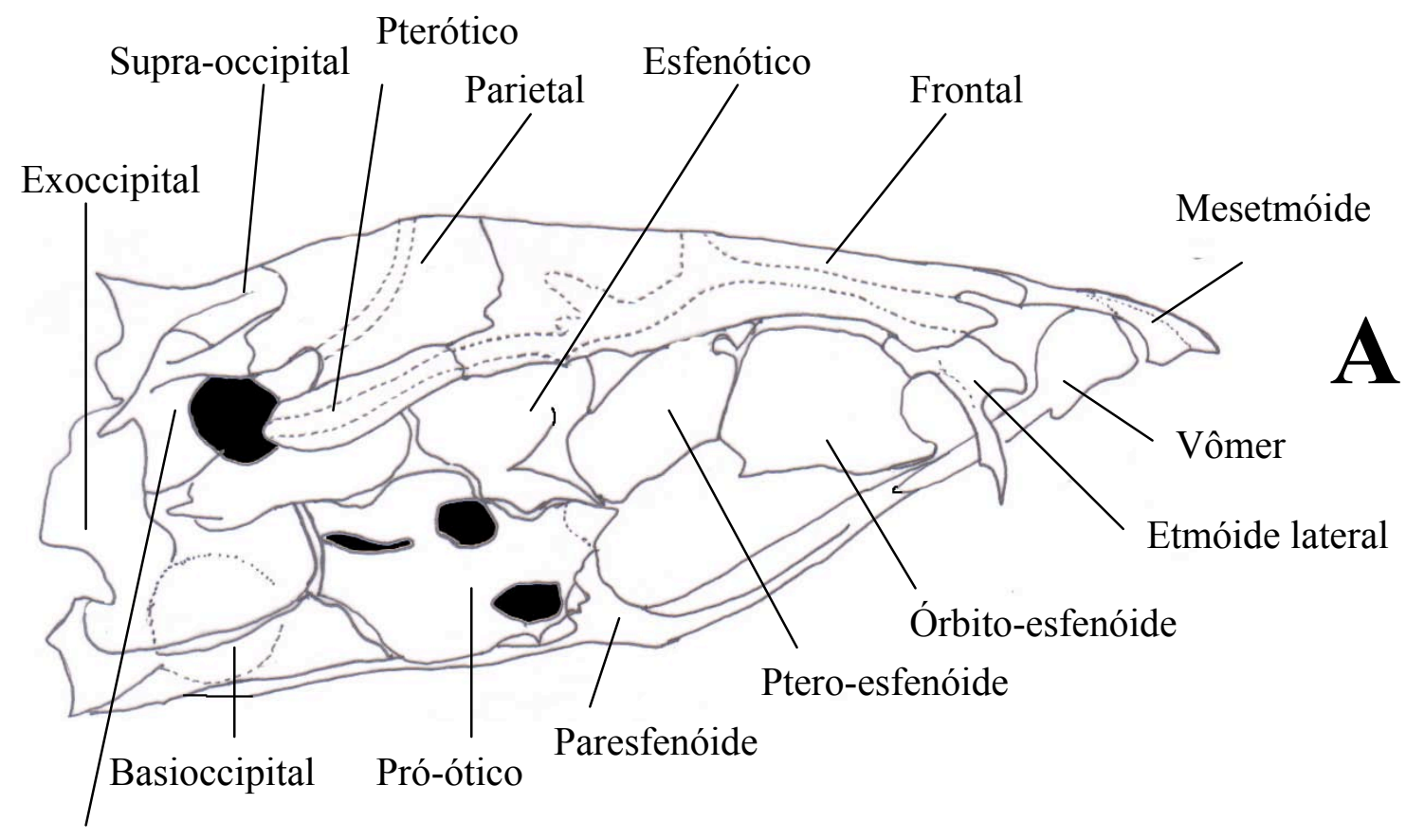

Epoccipital

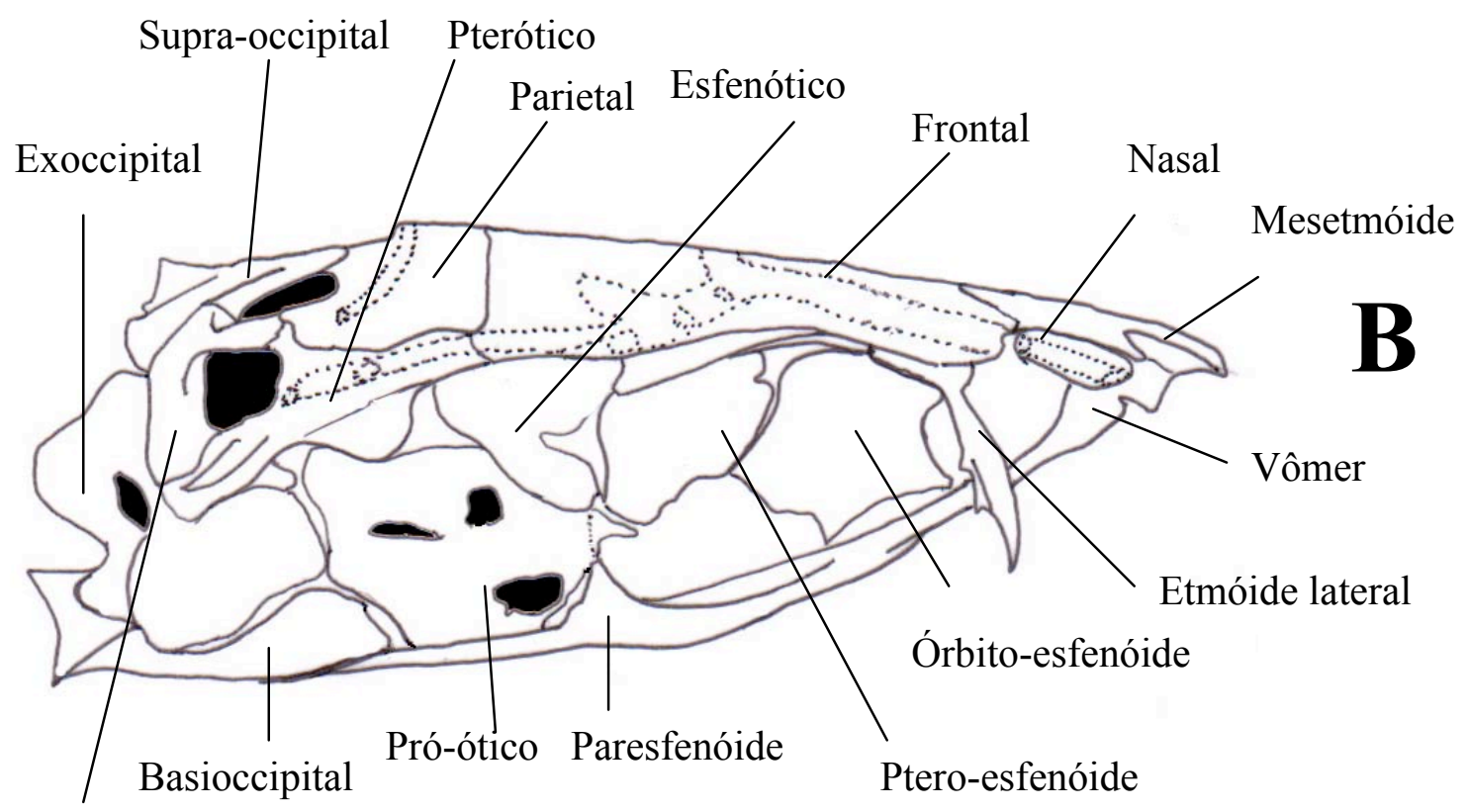

Epoccipital

Figura 15. Vista lateral do crânio de (A) Lebiasina bimaculata MZUSP 80085, 70,1 mm CP e (B) Lebiasina erythrinoides MNRJ 14232, 64,8 mm CP). 

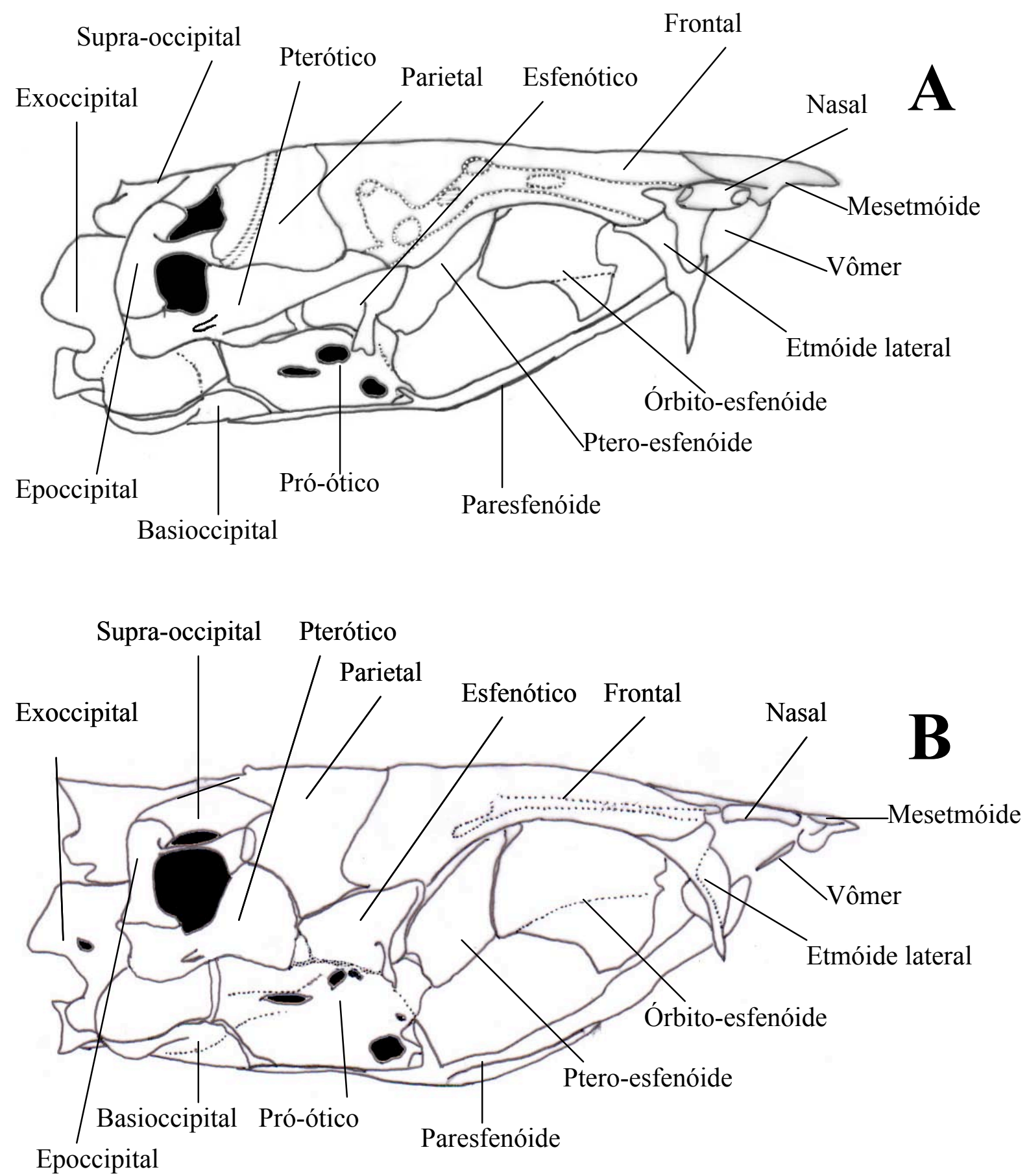

Figura 16. Vista lateral do crânio de (A) Derhamia hoffmannorum MTD F 26 492, 28 mm CP e (B) Nannostomus beckfordi MZUSP 22910, 26,9 mm CP. 

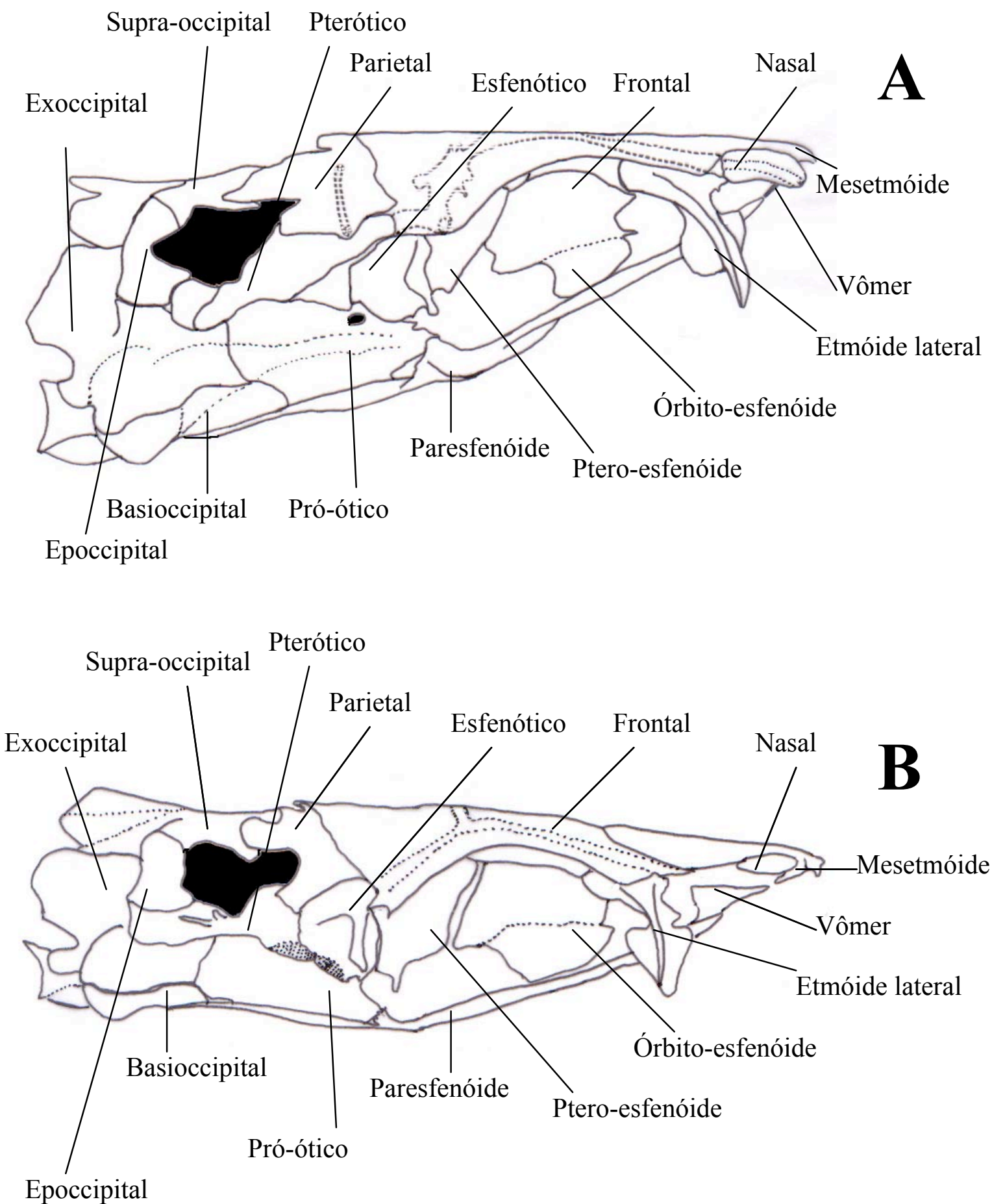

Figura 17. Vista lateral do crânio de (A) Copeina guttata MZUSP 27088, 65,3mm CP e (B) Copella nigrofasciata DEPRJ 104, 43,4 mm CP. 


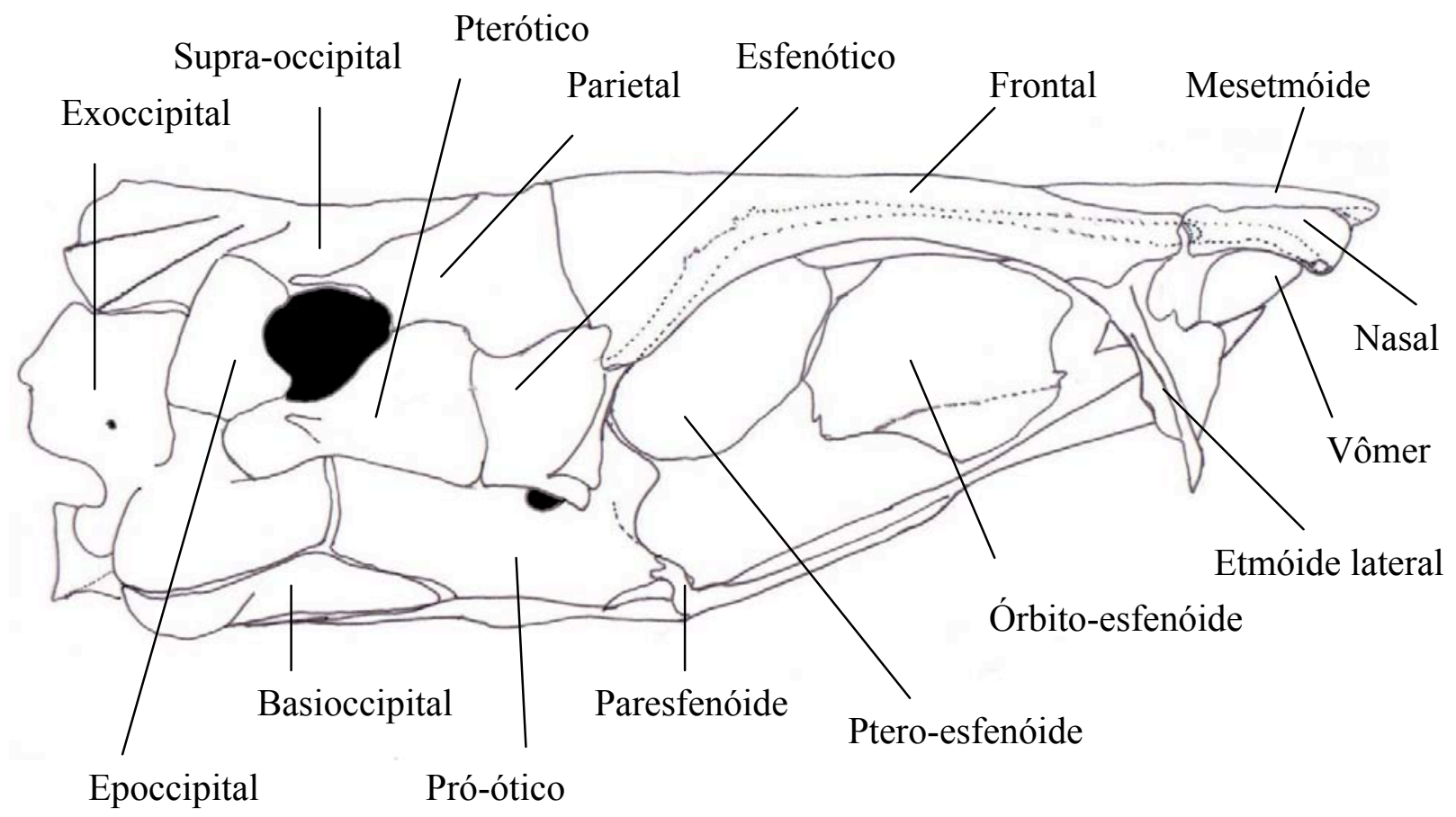

Figura 18. Vista lateral do crânio de Pyrrhulina australis MZUSP 59567, 31,8 mm CP. 


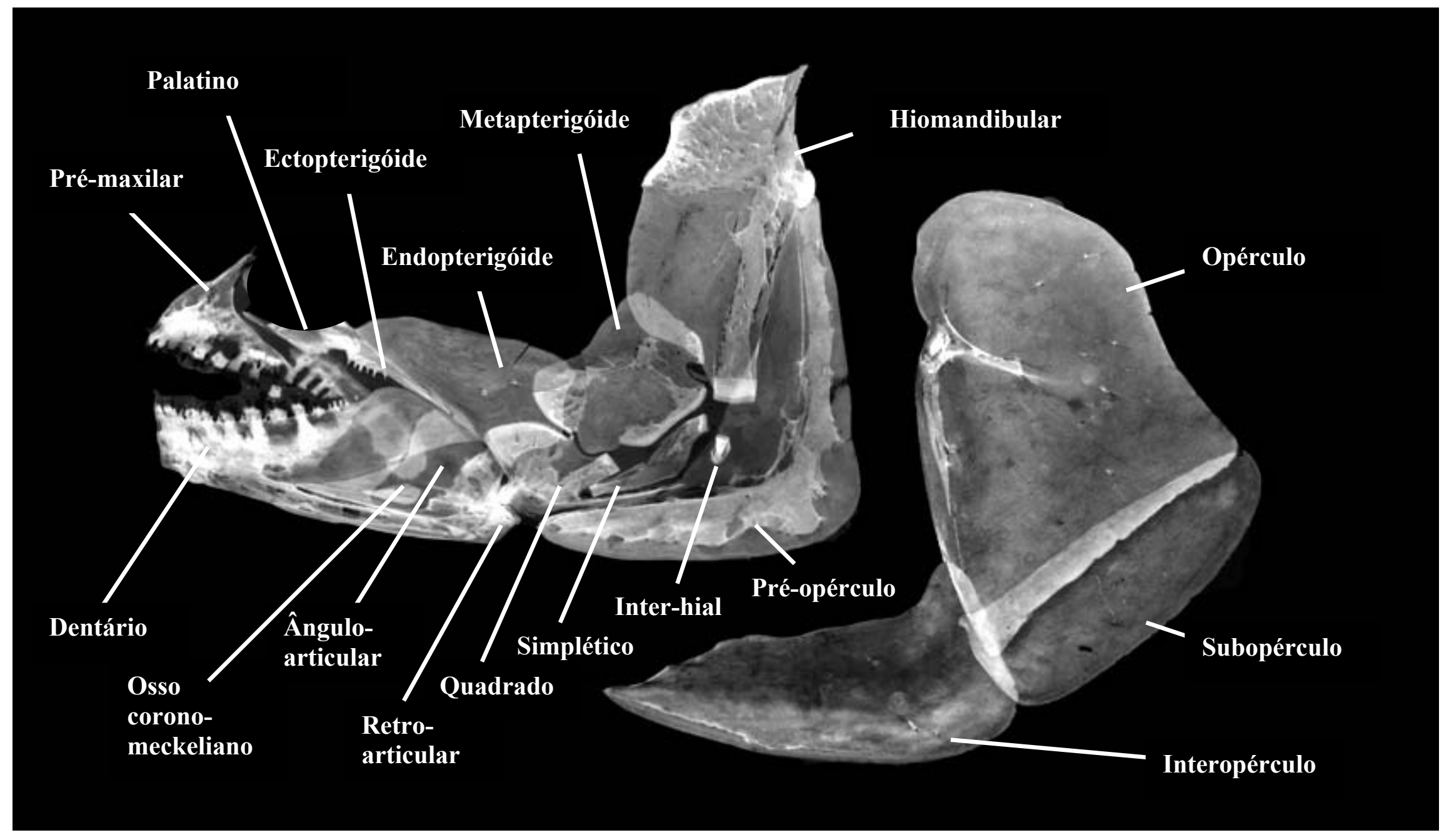

Figura 19. Vista medial do suspensório de Lebiasina bimaculata MZUSP 80085, 70,1 mm CP. 


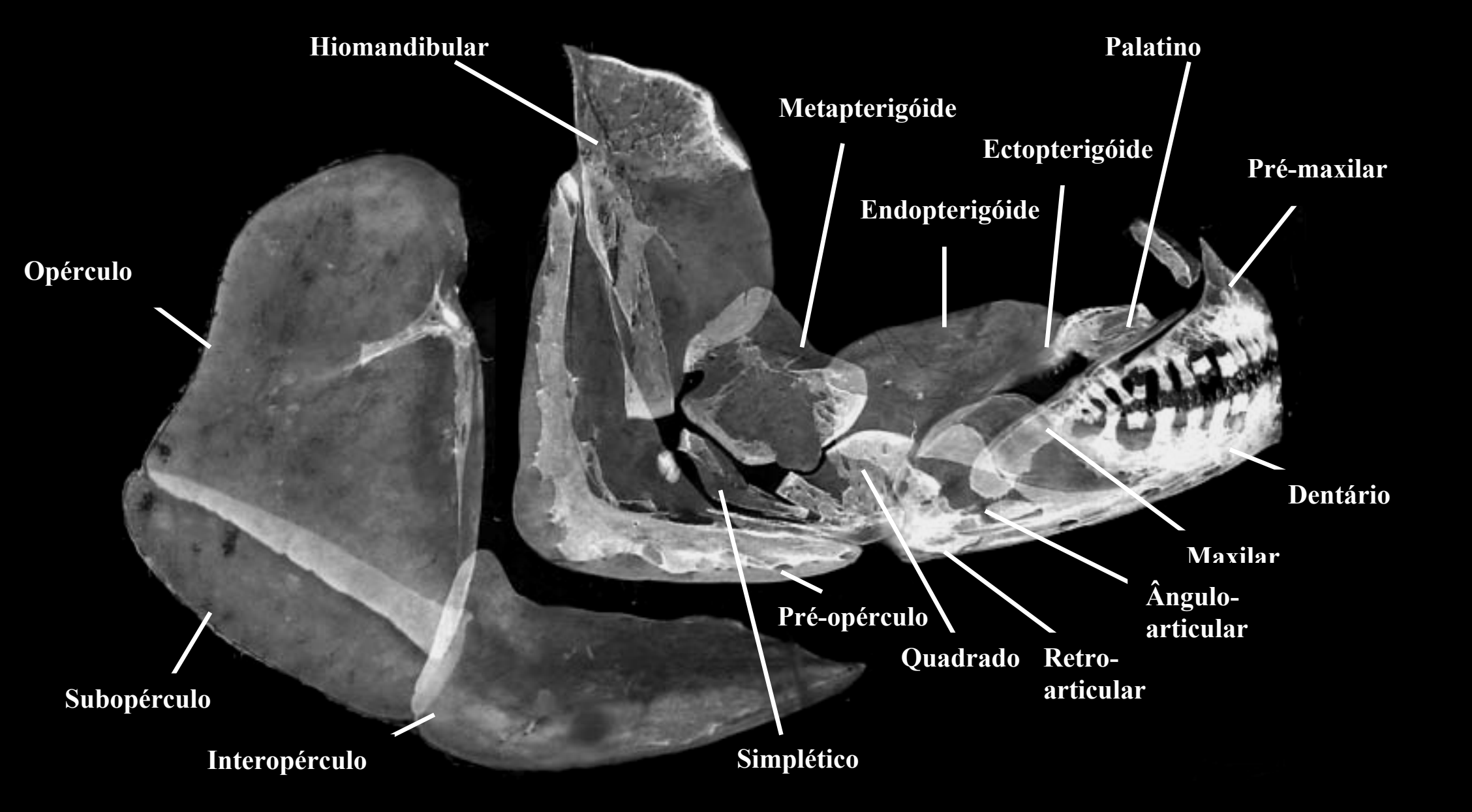

Figura 20. Vista lateral do suspensório de Lebiasina bimaculata MZUSP 80085, 70,1 mm CP. 


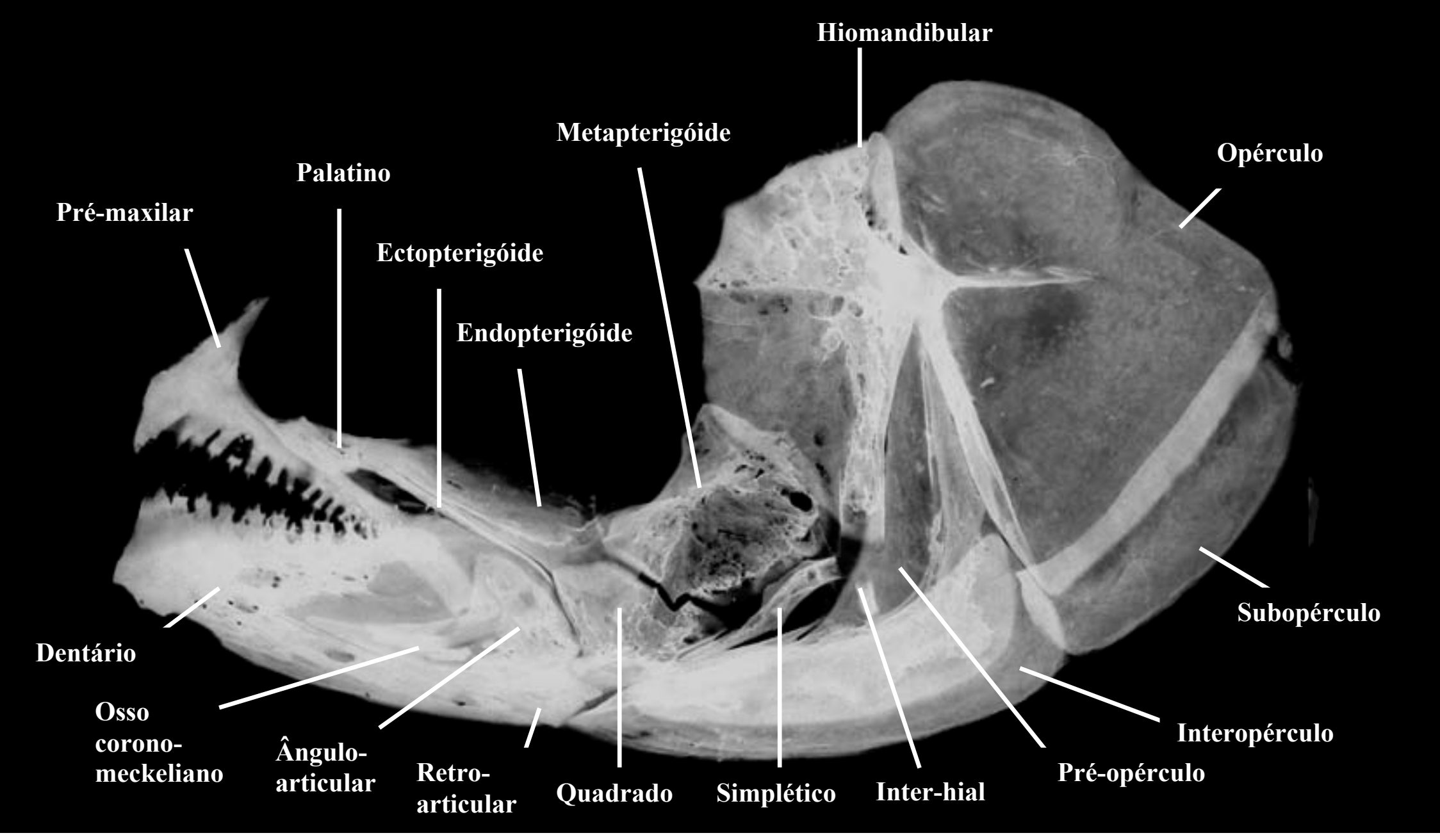

Figura 21. Vista medial do suspensório de Lebiasina erythrinoides MNRJ 14232, 64,8 mm CP. 


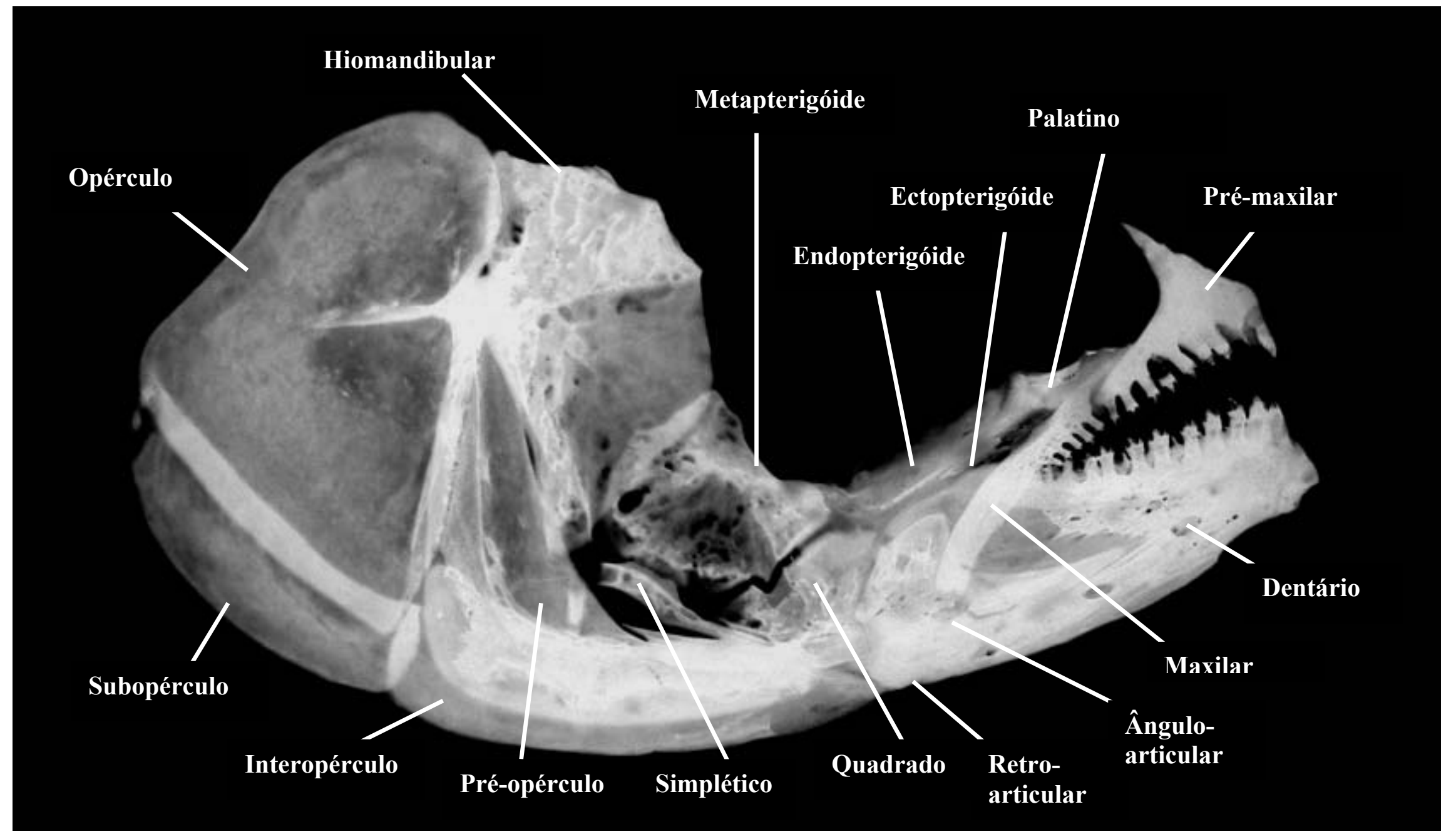

Figura 22. Vista lateral do suspensório de Lebiasina erythrinoides MNRJ 14232, 64,8 mm CP. 


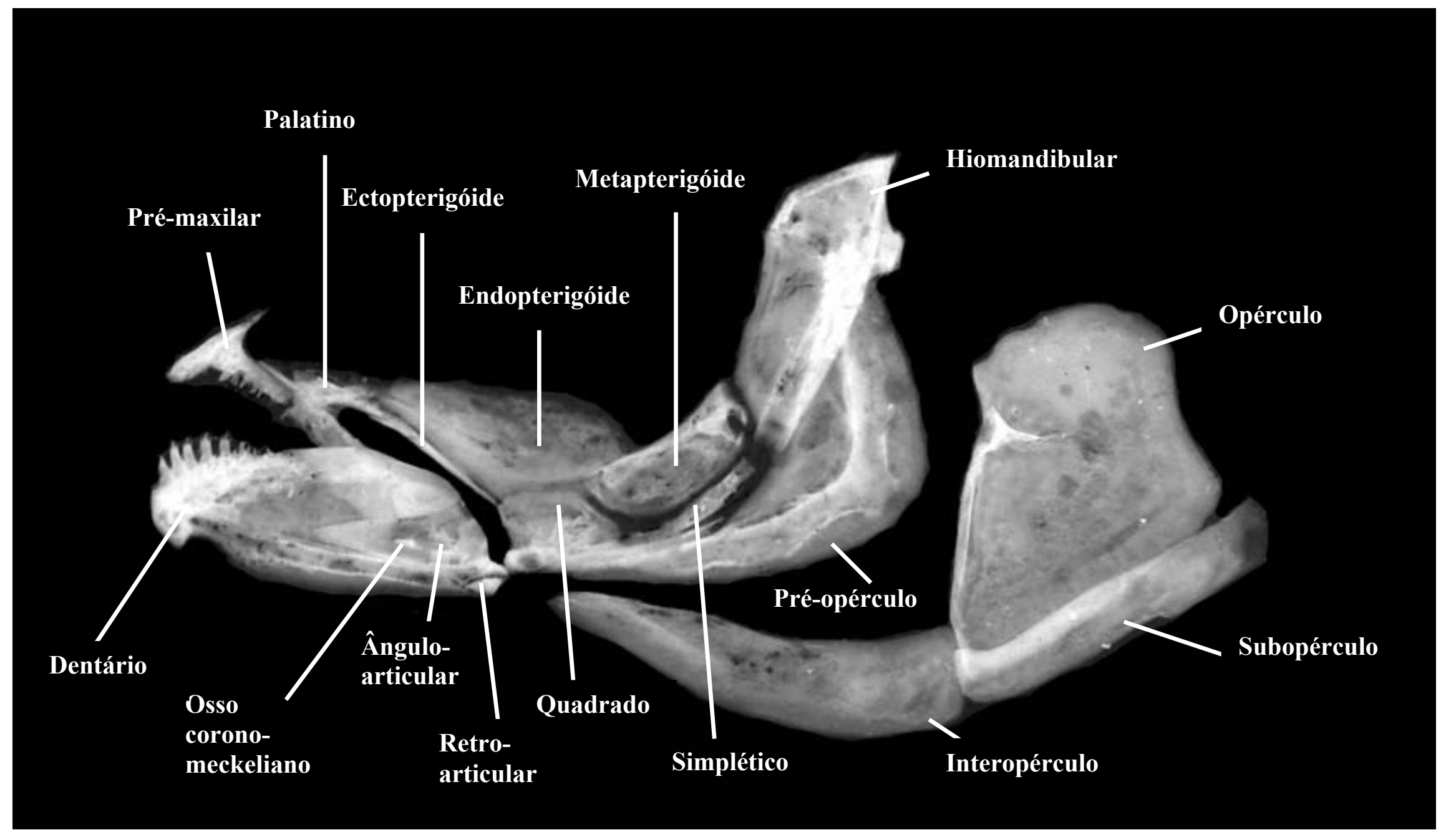

Figura 23. Vista medial do suspensório de Derhamia hoffmannorum MTD F 26 492, 28 mm CP. 


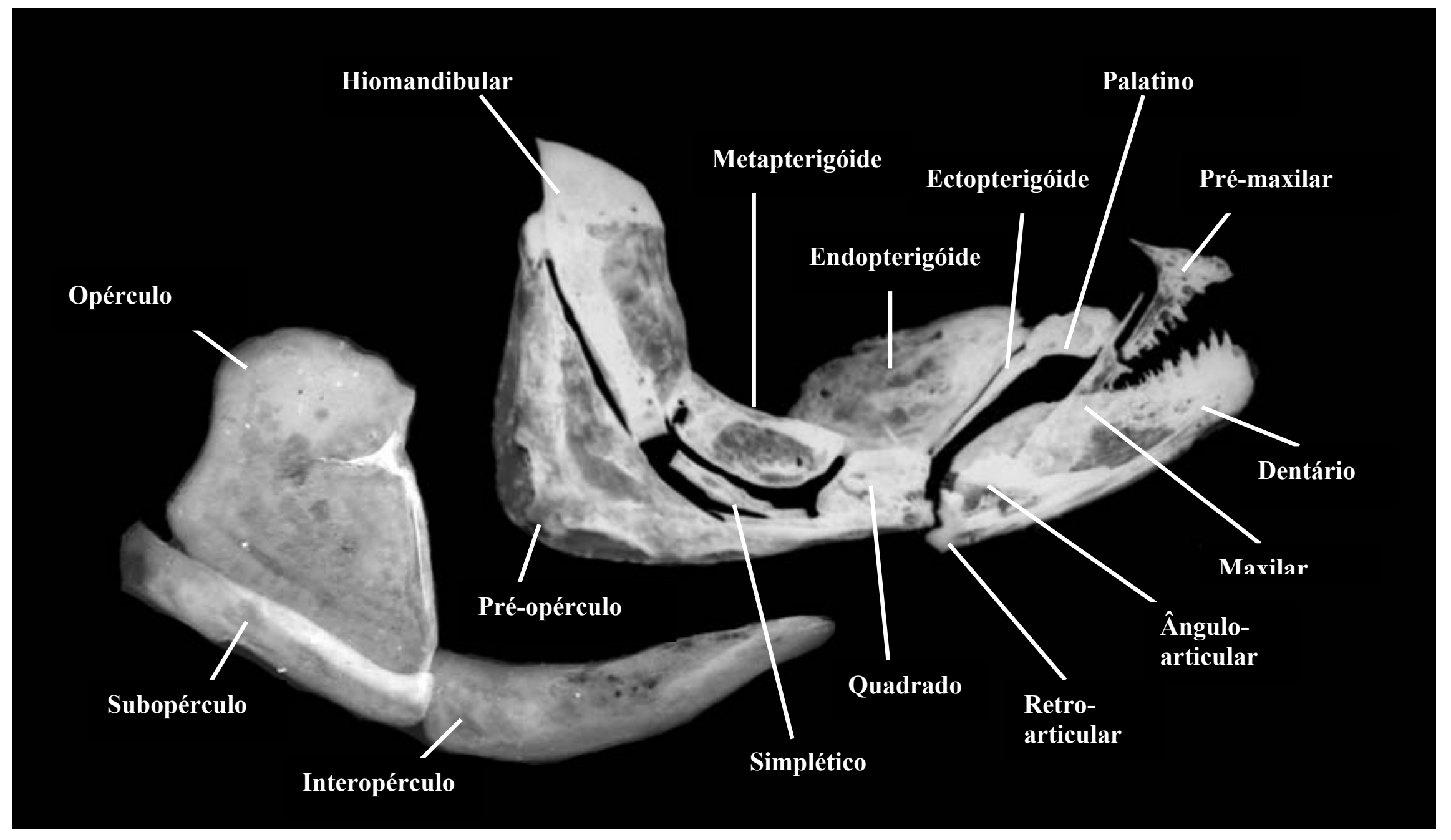

Figura 24. Vista lateral do suspensório de Derhamia hoffmannorum MTD F 26 492, 28 mm CP. 


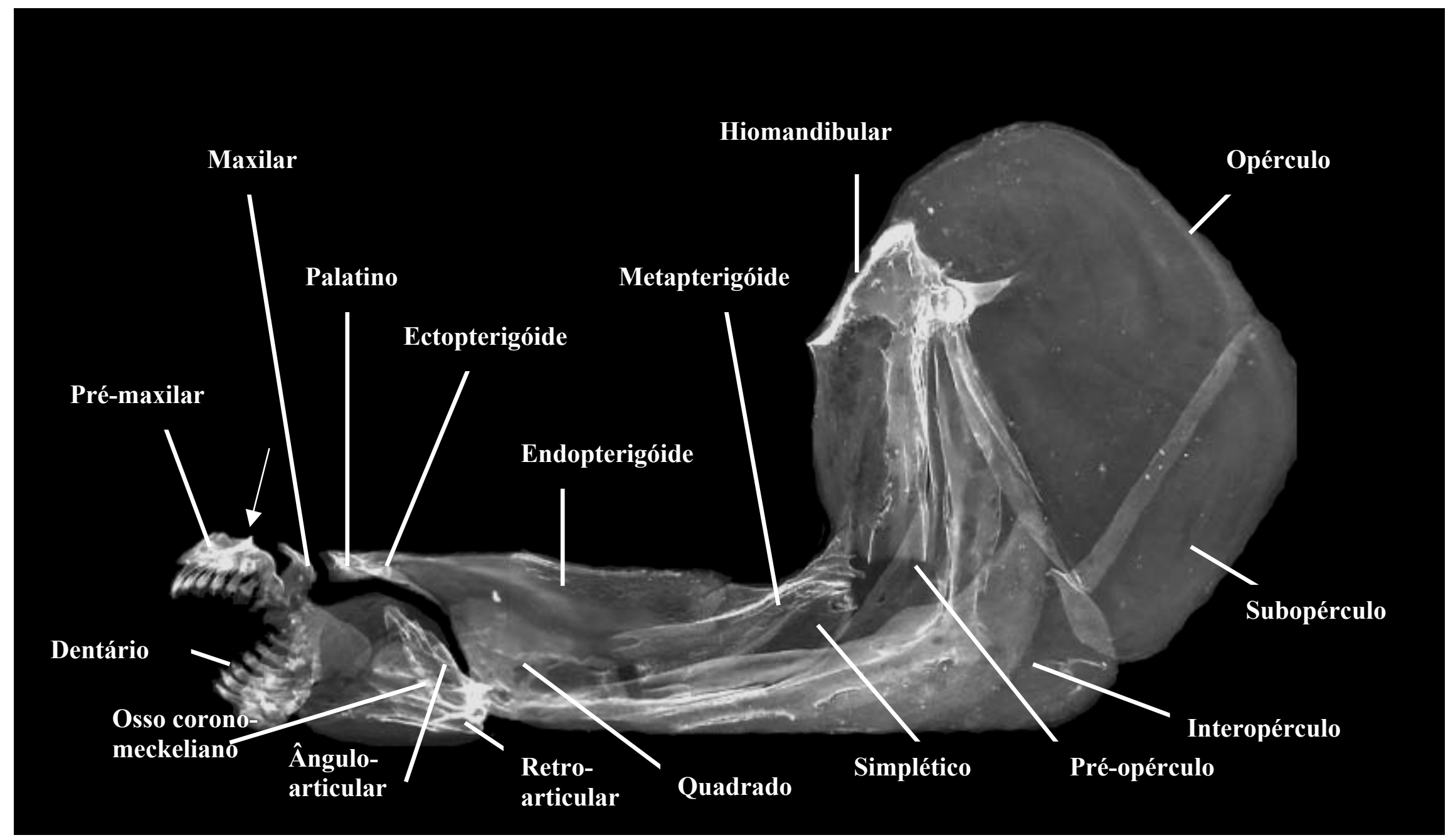

Figura 25. Vista medial do suspensório de Nannostomus beckfordi MZUSP 22910, 26,9 mm CP. $\rightarrow$ Indica o processo que se articula ventralmente com o mesetmóide. 


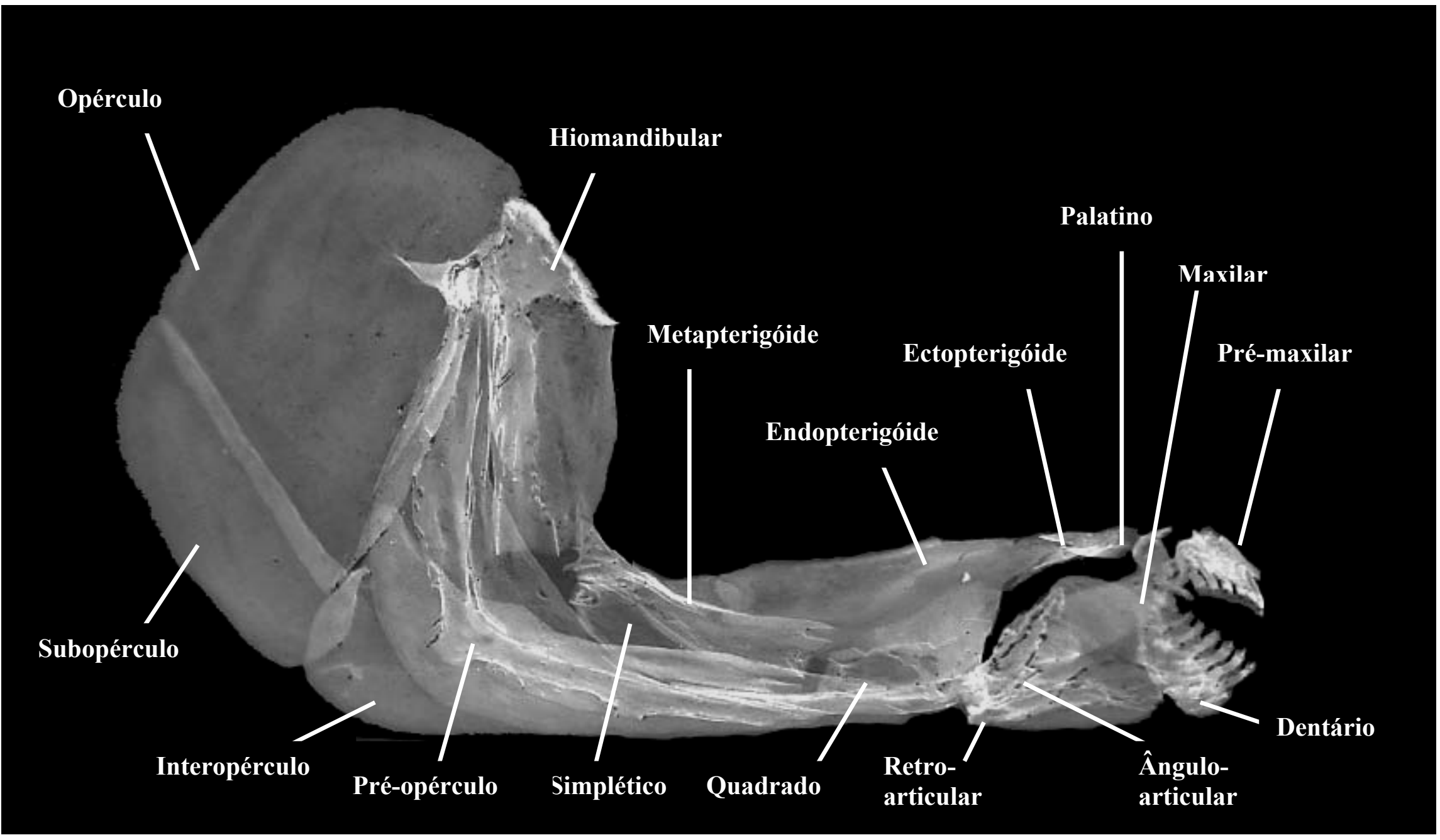

Figura 26. Vista lateral do suspensório de Nannostomus beckfordi MZUSP 22910, 26,9 mm CP. 


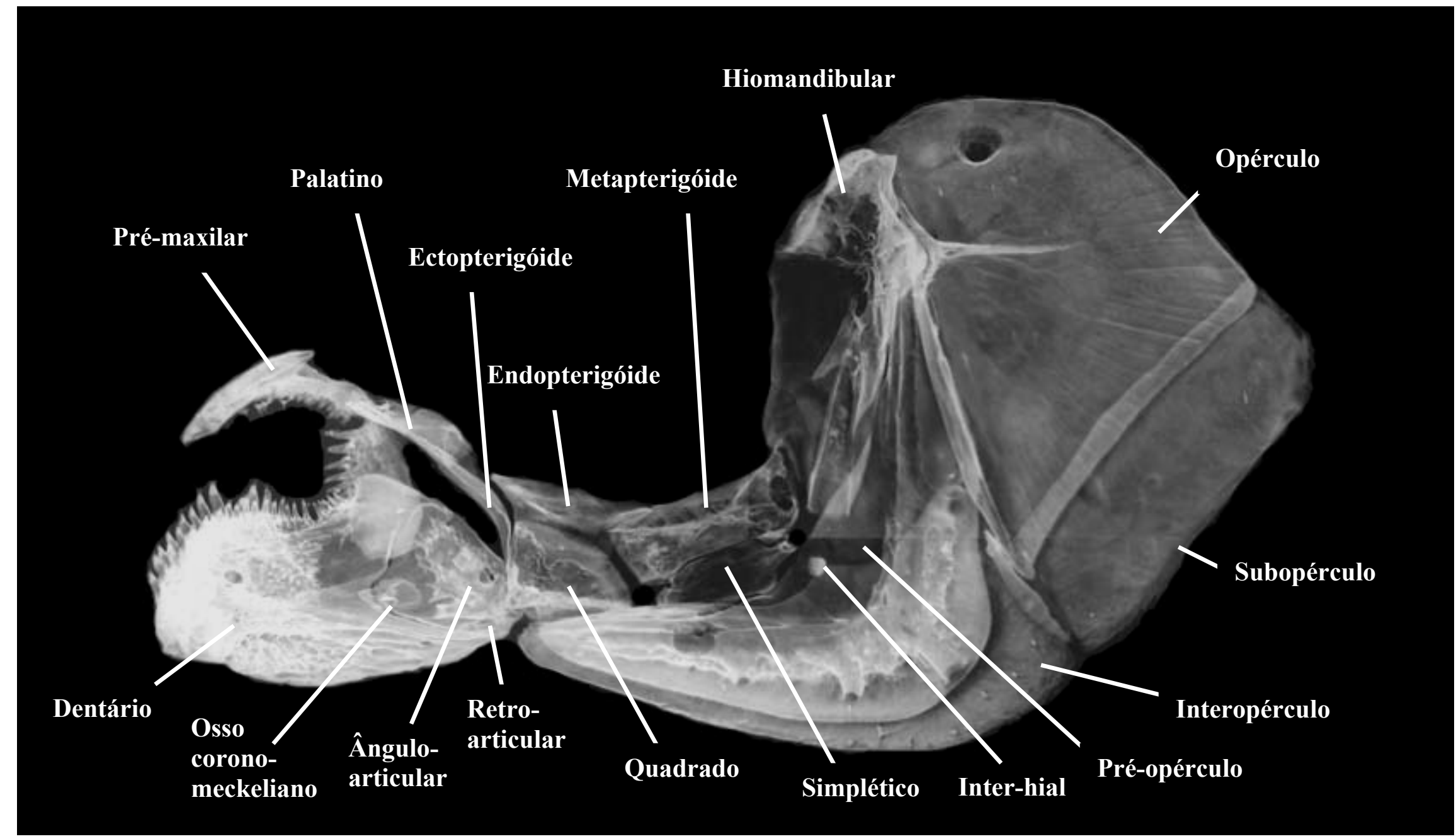

Figura 27. Vista medial do suspensório de Copeina guttata MZUSP 27088, 65,3mm CP. 


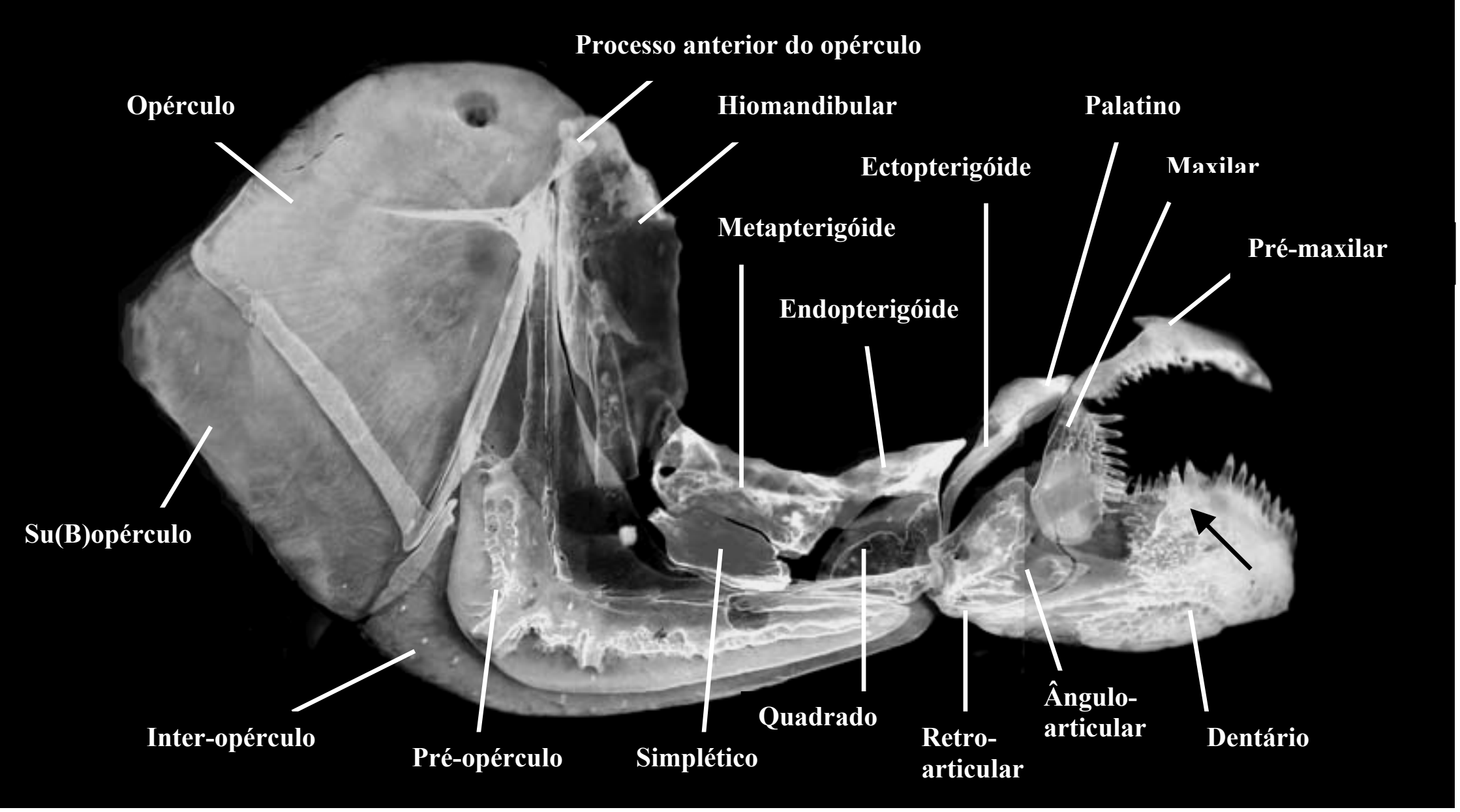

Figura 28. Vista lateral do suspensório de Copeina guttata MZUSP 27088, 65,3mm CP. $\rightarrow$ Indica o processo lateral do dentário. 


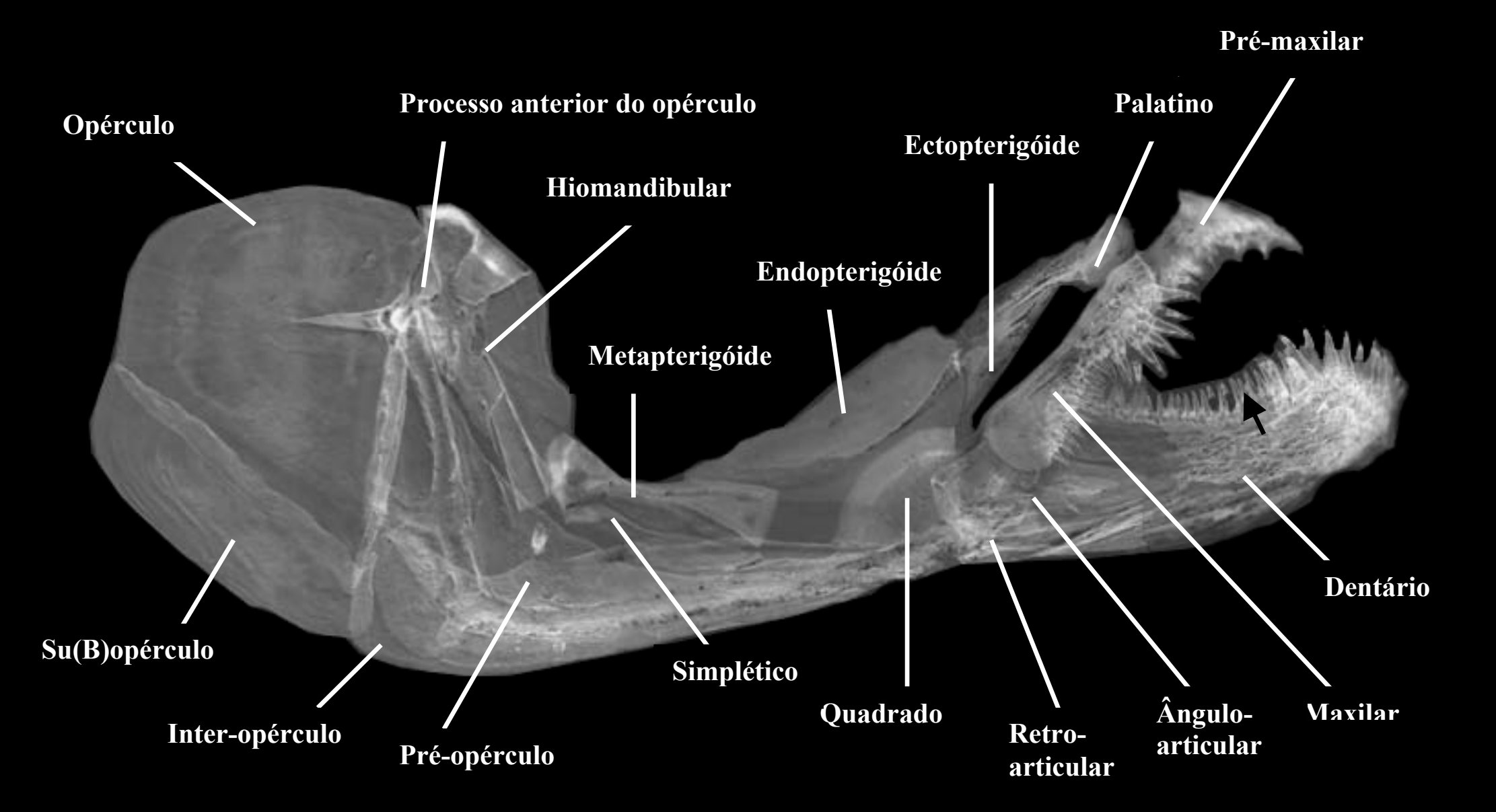

Figura 29. Vista lateral do suspensório de Copella nigrofasciata DEPRJ 104, 43,4 mm CP. $\rightarrow$ Indica o processo lateral do dentário. 


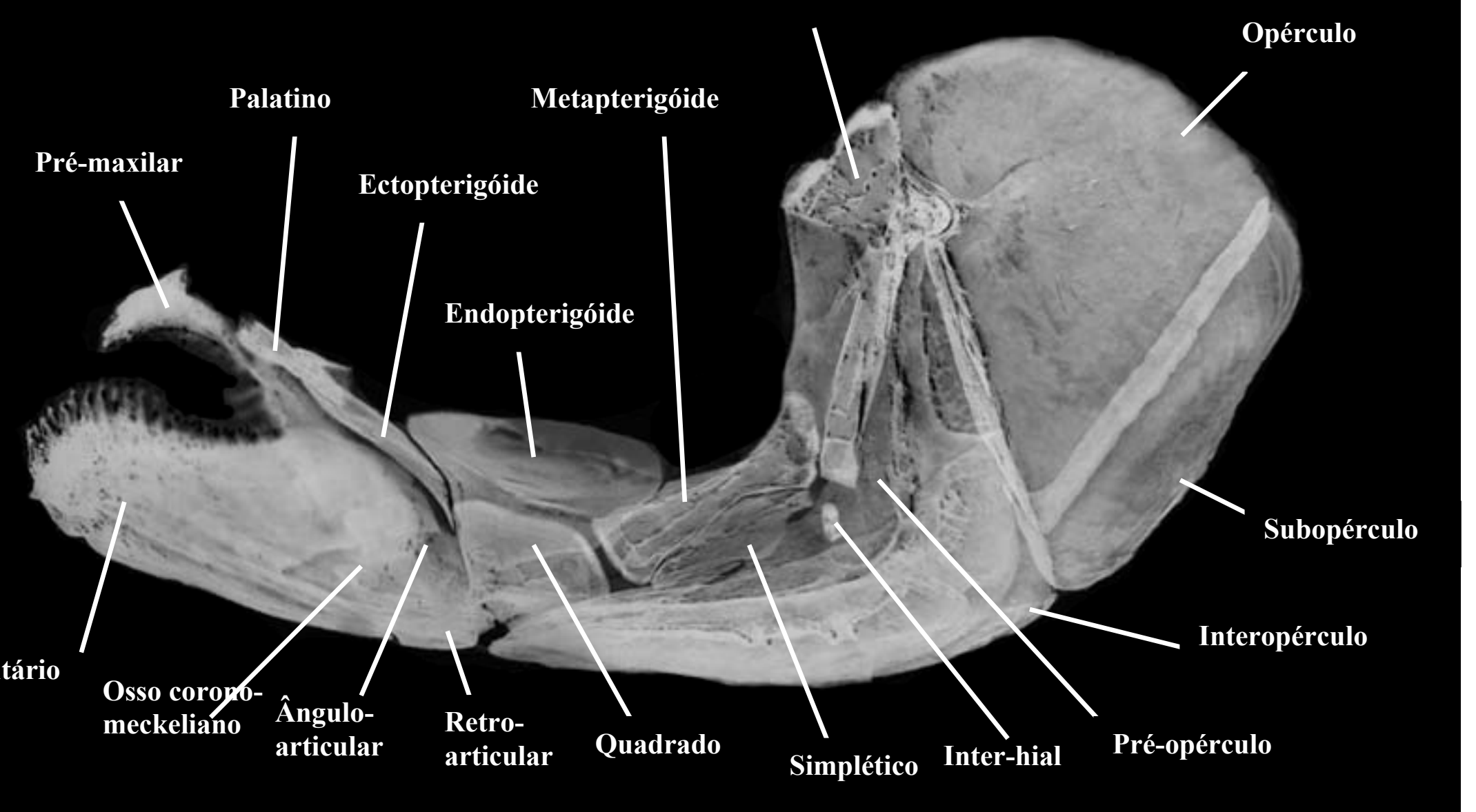

Figura 30. Vista medial do suspensório de Pyrrhulina australis MZUSP 59567, 31,8 mm CP. 


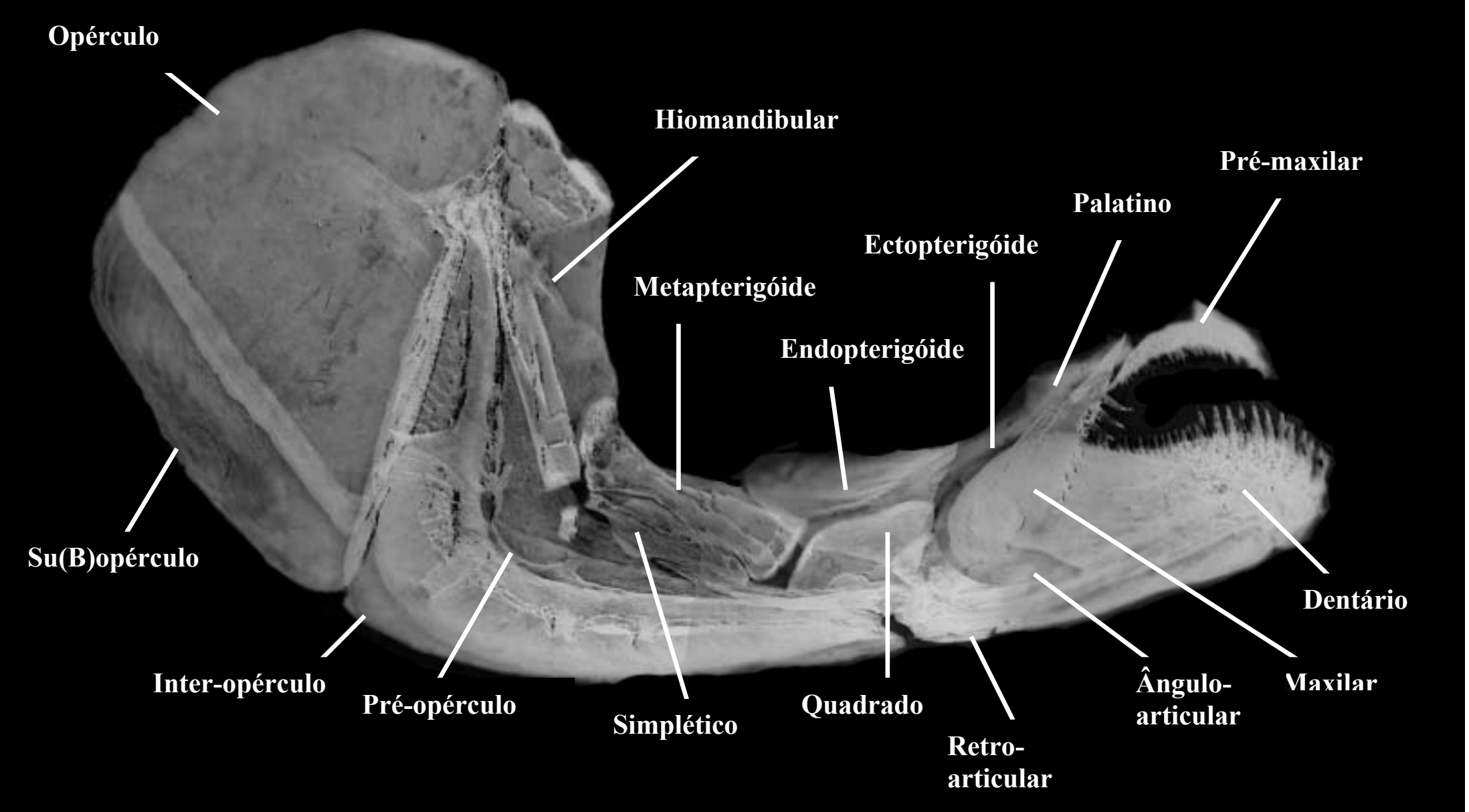

Figura 31. Vista lateral do suspensório de Pyrrhulina australis MZUSP 59567, 31,8 mm CP. 

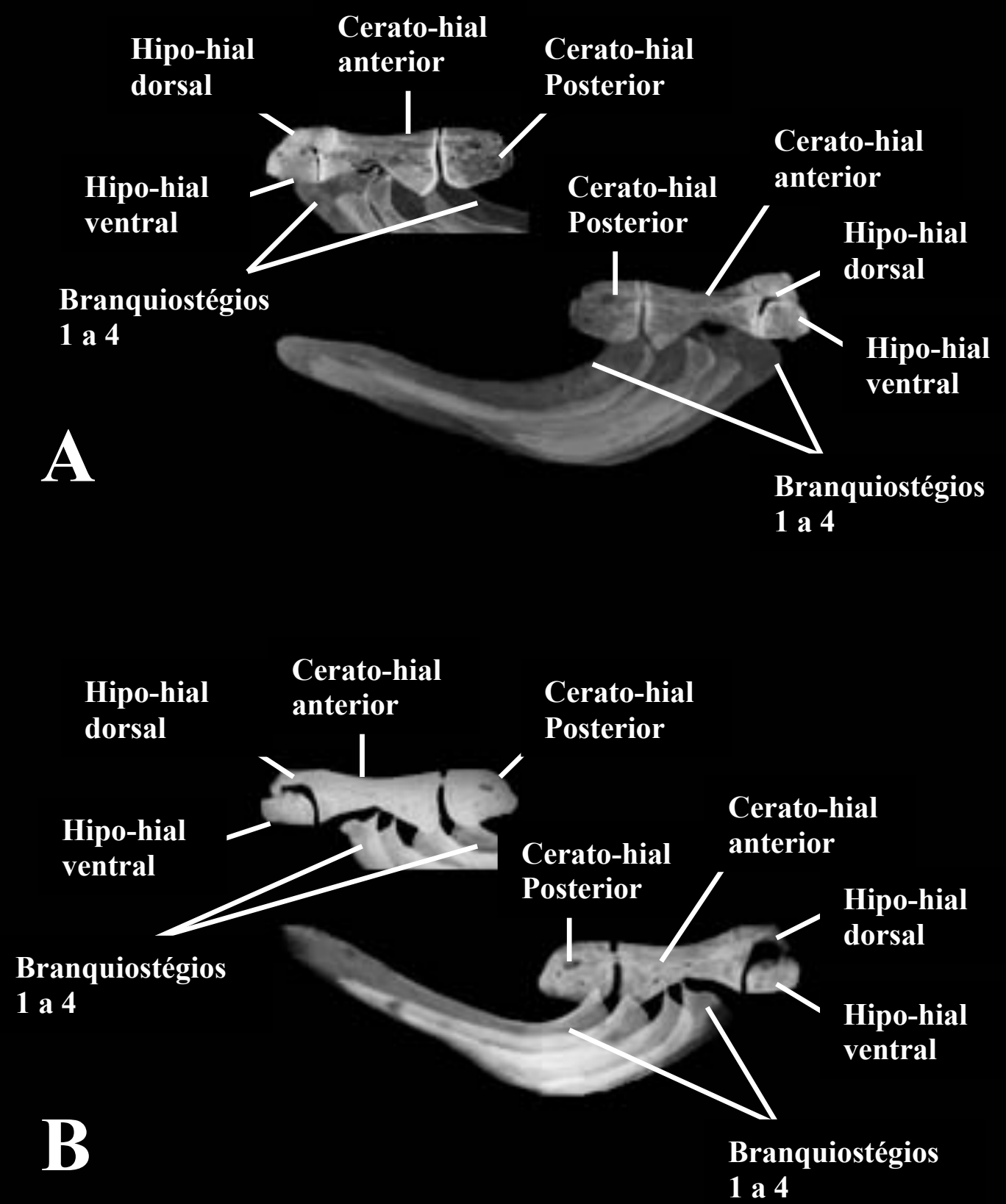

Figura 32. Vista medial (à esquerda) e lateral (à direita) do arco hióide (parte) de (A) Lebiasina bimaculata MZUSP 80085, 70,1 mm CP e (B) Lebiasina erythrinoides MNRJ 14232, 64,8 mm CP. 

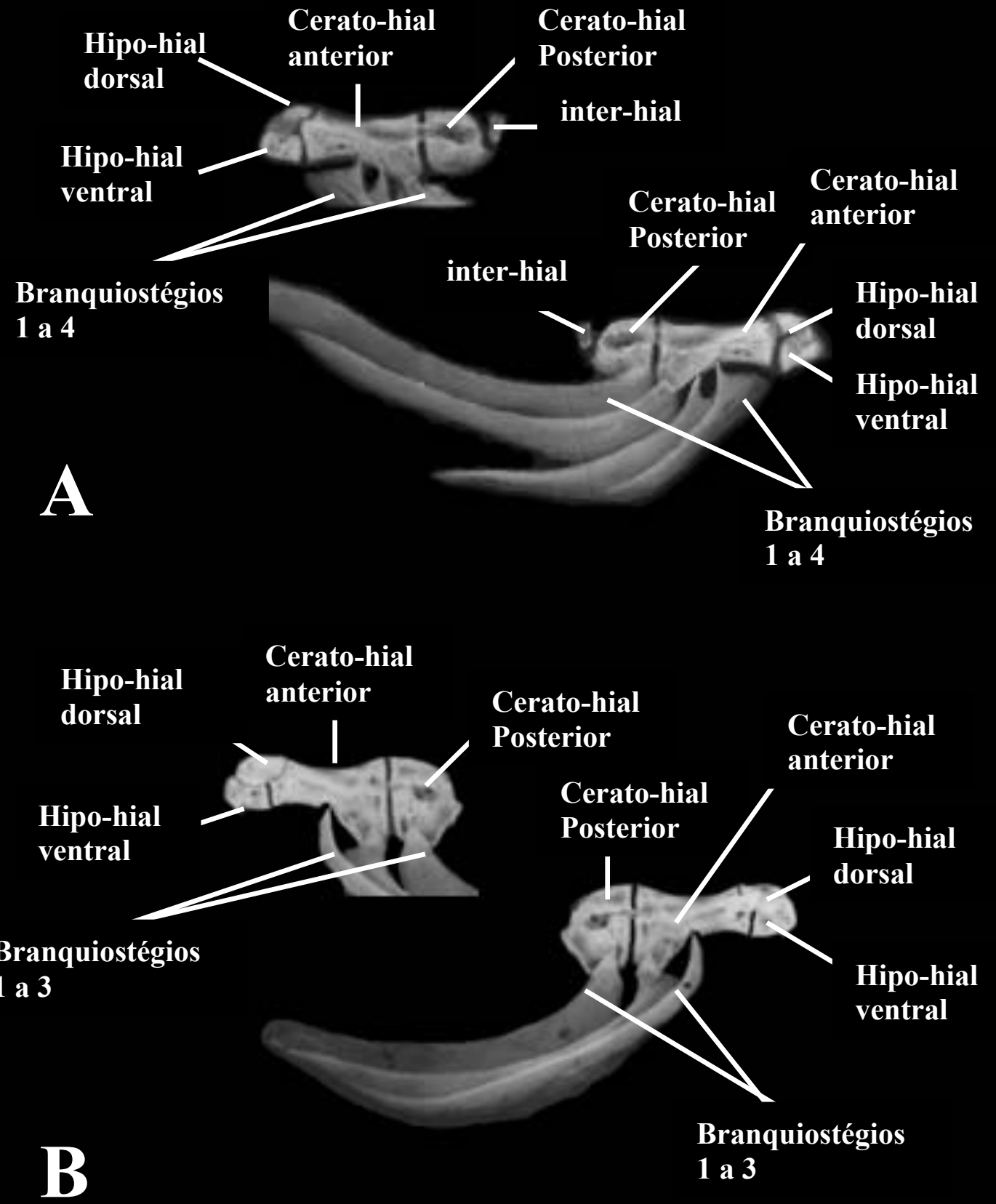

Figura 33. Vista (à esquerda) e lateral (à direita) do arco hióide (parte) de (A) Derhamia hoffmannorum MTD F 26 492, 28 mm CP, (B) Nannostomus beckfordi MZUSP 22910, 26,9 mm CP. 

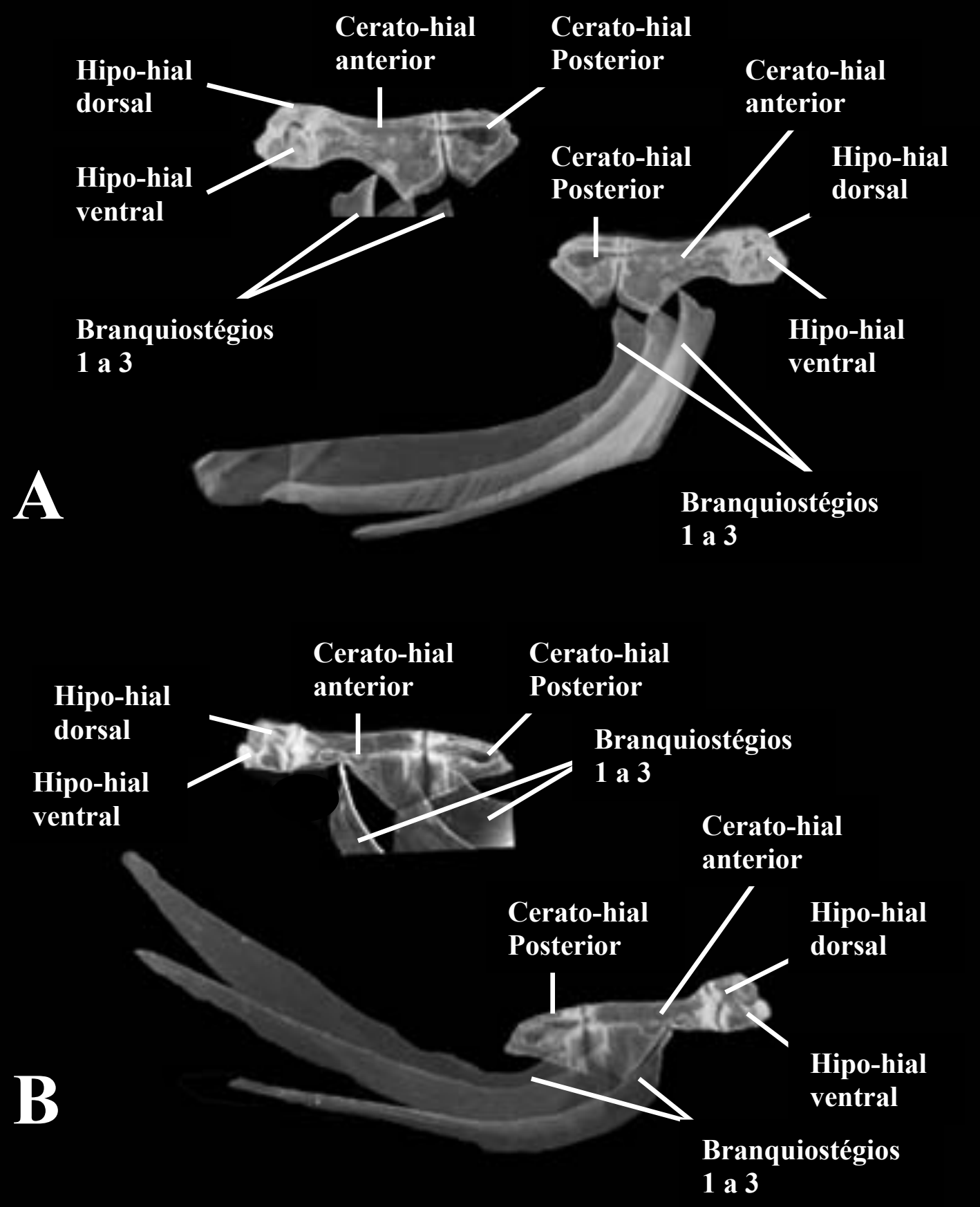

Figura 34. Vista (à esquerda) e lateral (à direita) do arco hióide (parte) de (A) Copeina guttata MZUSP 27088, 65,3mm CP e (B) Copella nigrofasciata DEPRJ 104, 43,4 mm CP. 


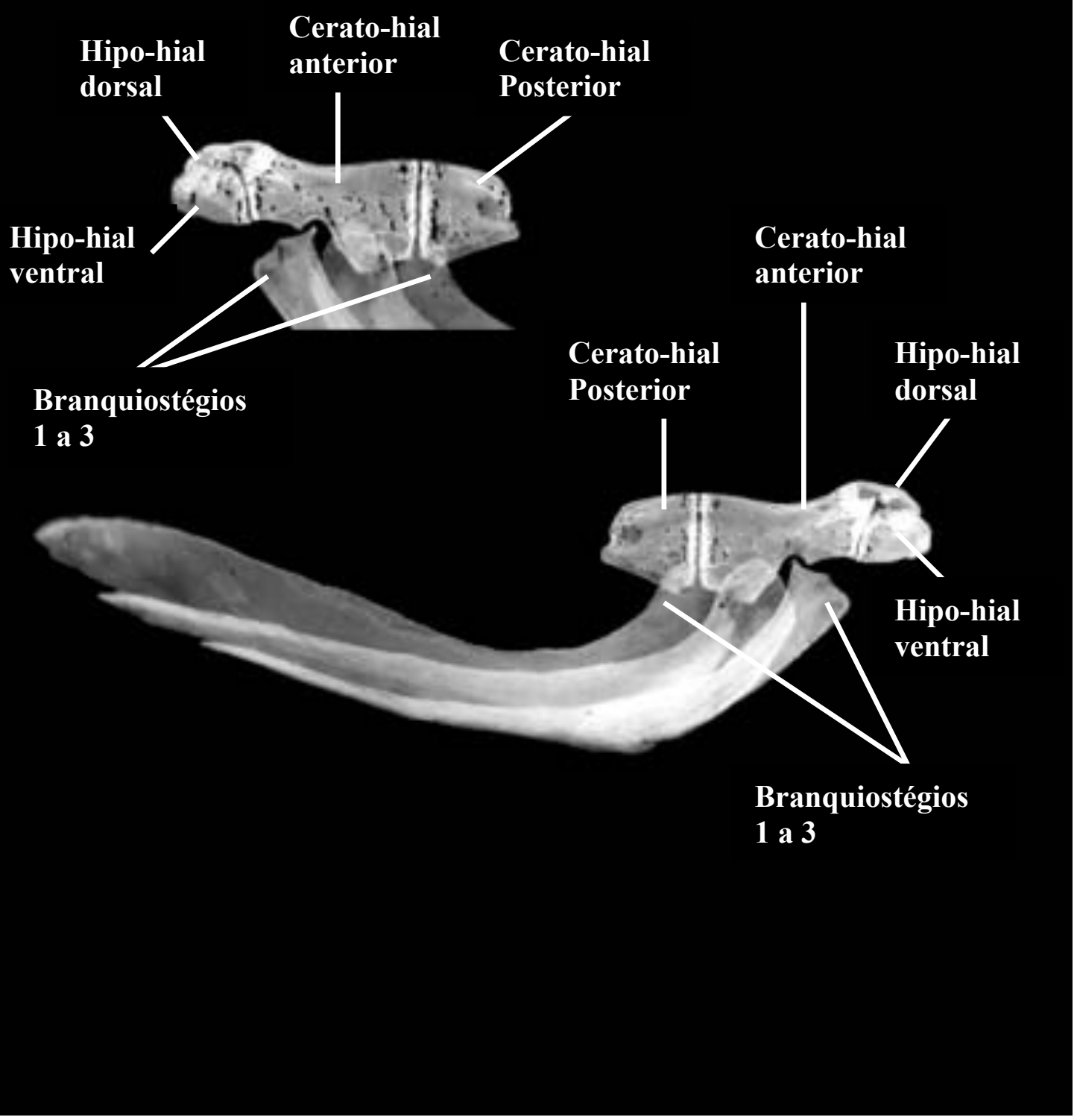

Figura 35. Vista (à esquerda) e lateral (à direita) do arco hióide (parte) de Pyrrhulina australis MZUSP 59567, 31,8 mm CP. 


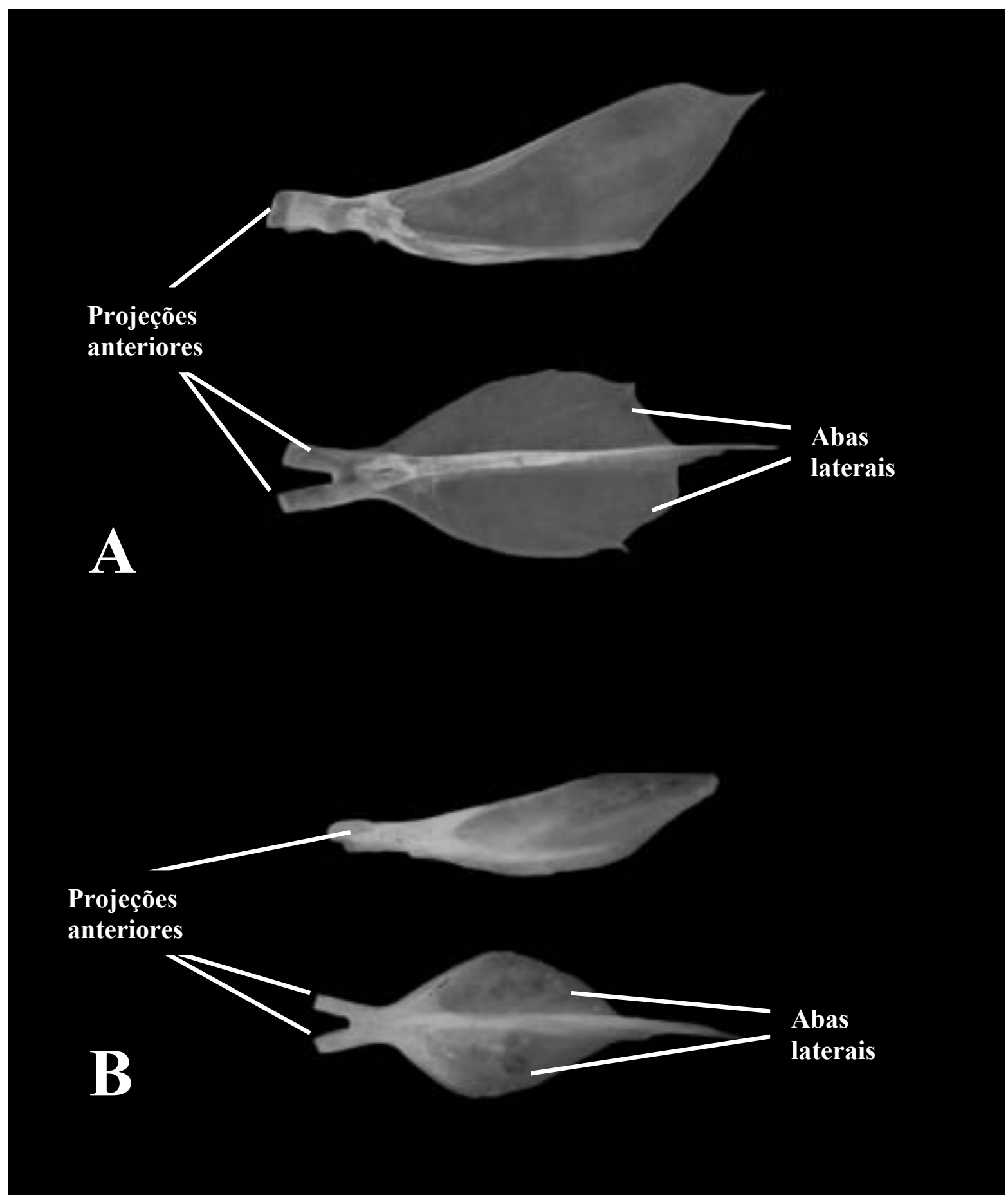

Figura 36. Uro-hial de (A) Lebiasina bimaculata MZUSP 80085, 70,1 mm CP e (B) Derhamia hoffmannorum MTD F 26 492, 28 mm CP em vista lateral e dorsal. 


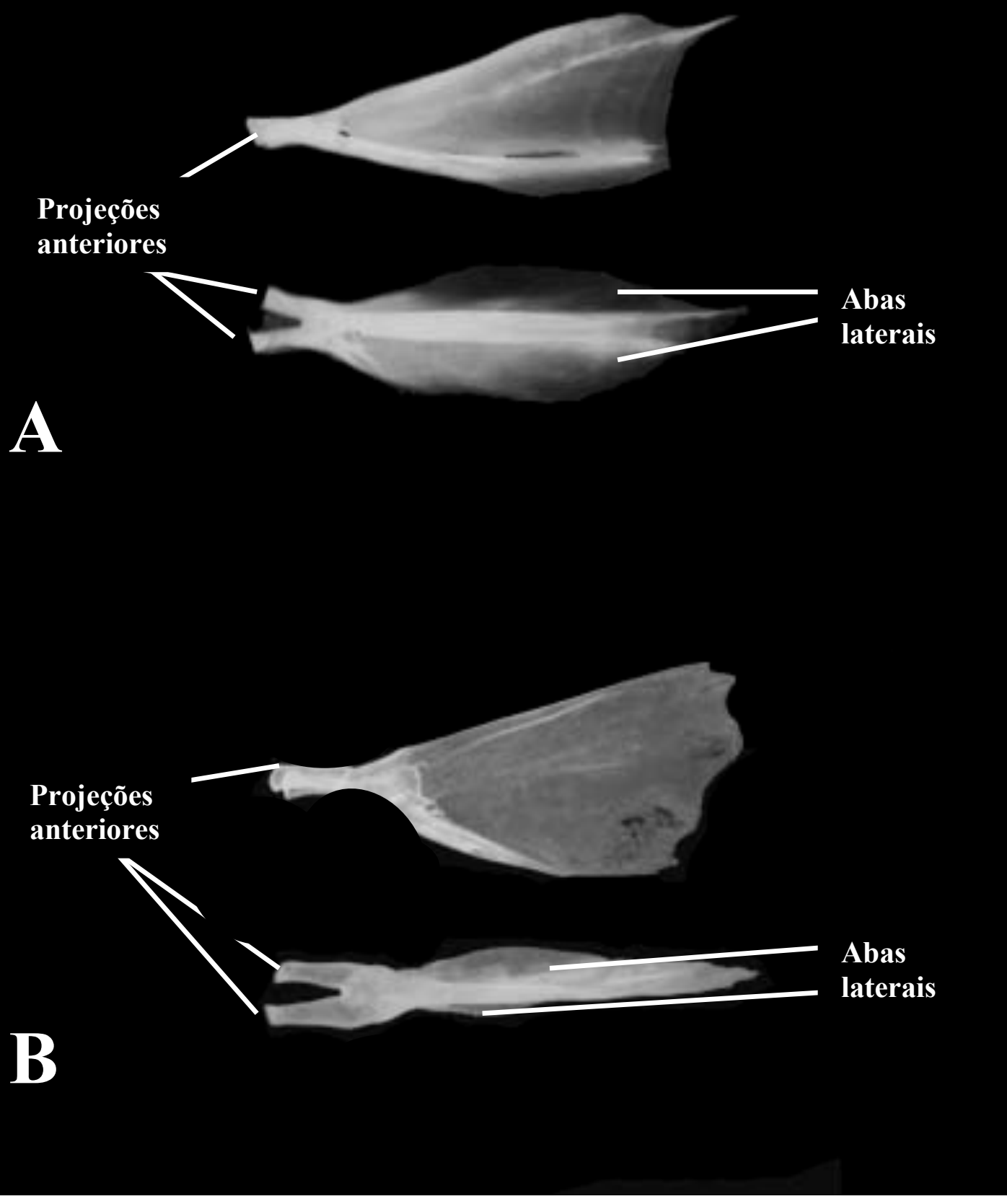

Figura 37. Uro-hial de (A) Nannostomus beckfordi MZUSP 22910, 26,9 mm CP e (B) Copeina guttata MZUSP 27088, 65,3mm CP em vista lateral e dorsal. 


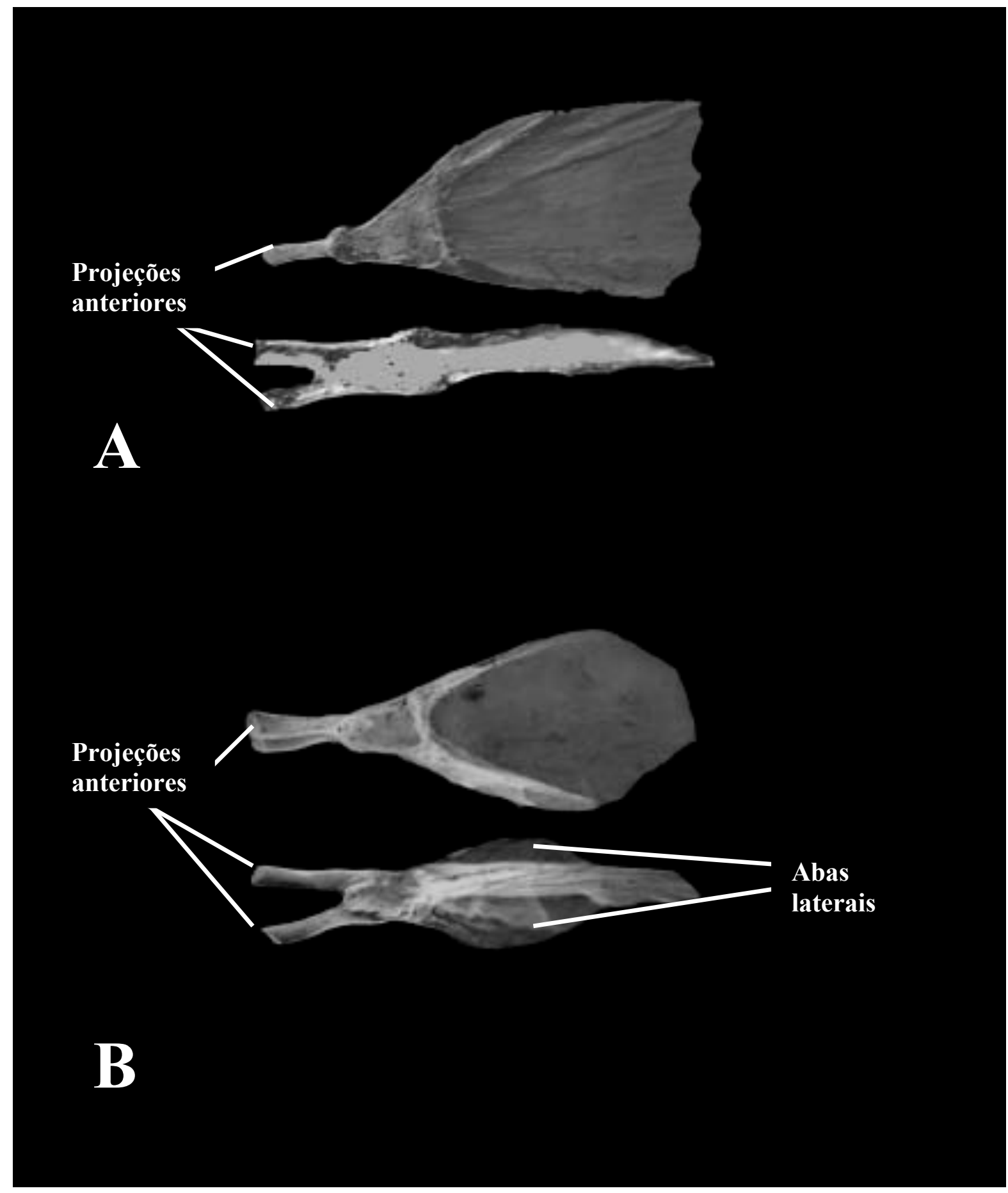

Figura 38. Uro-hial de (A) Copella nigrofasciata DEPRJ 104, 43,4 mm CP e (B) Pyrrhulina australis MZUSP 59567, 31,8 mm CP em vista lateral e dorsal. 


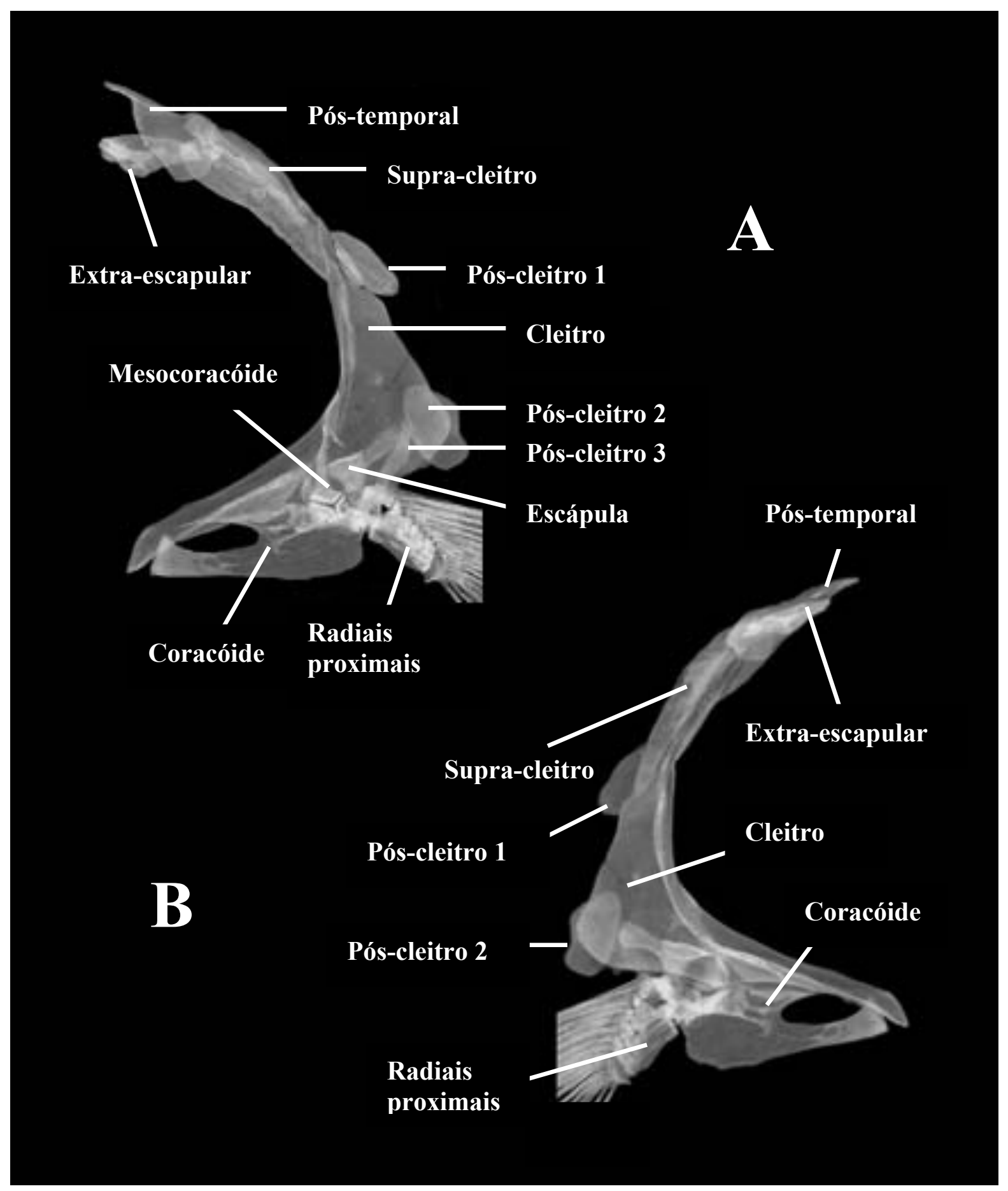

Figura 39. Vista medial (A) e lateral (B) da cintura peitoral de Lebiasina bimaculata MZUSP 80085, 70,1 mm CP. 


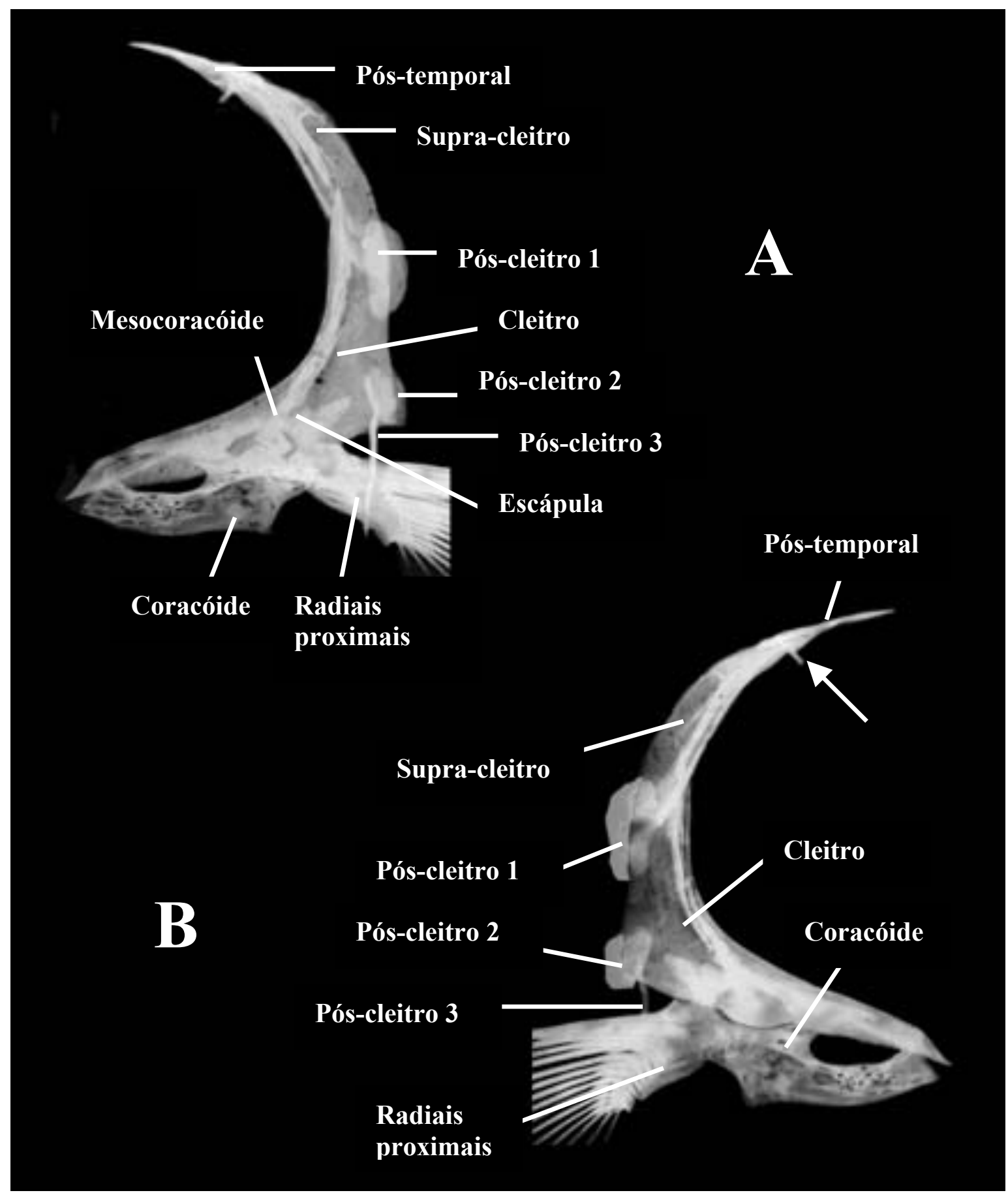

Figura 40. Vista medial (A) e lateral (B) da cintura peitoral de Lebiasina erythrinoides MNRJ 14232, 64,8 mm CP. $\rightarrow$ Indica o processo ventral do pós-temporal. 


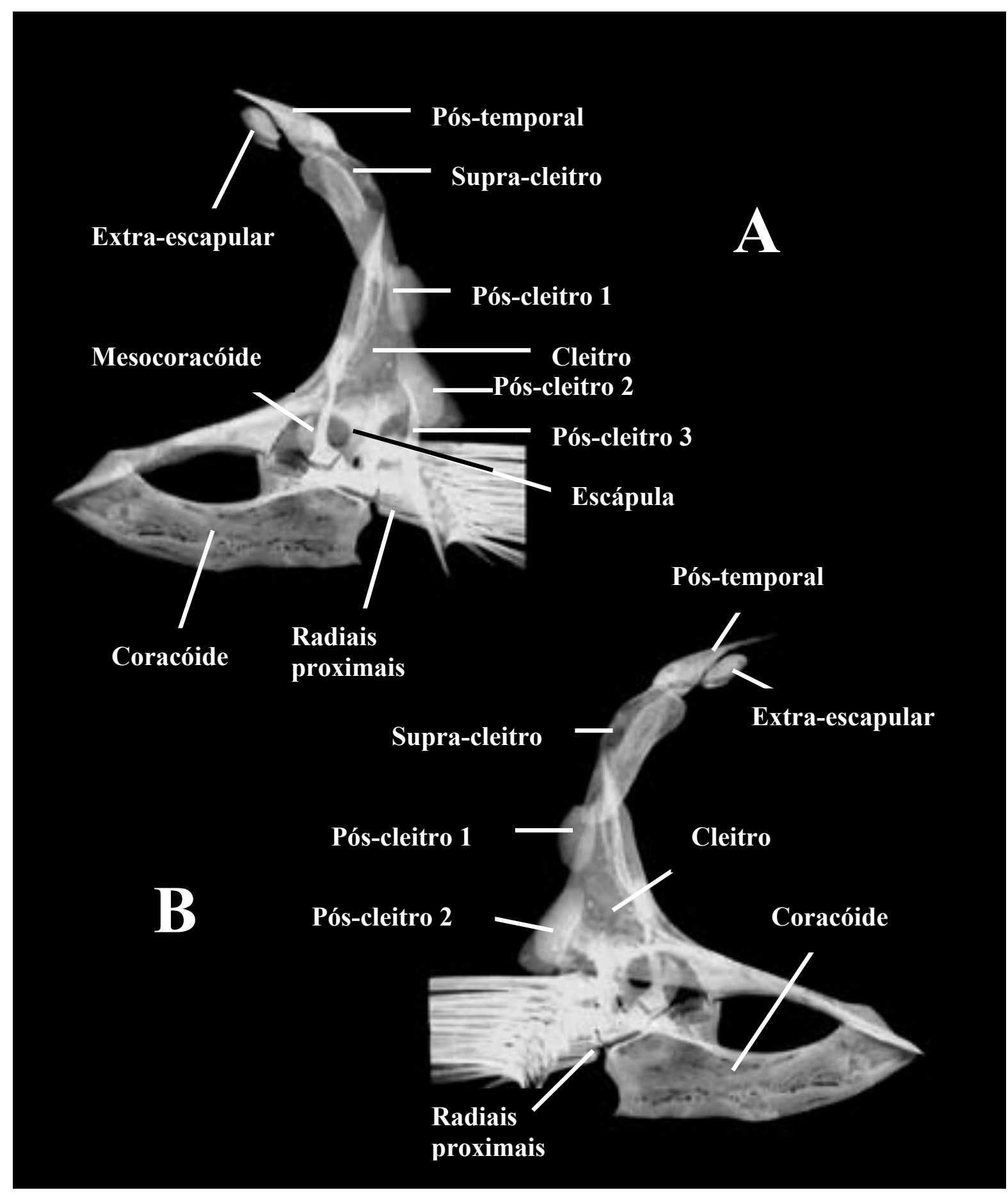

Figura 41. Vista medial (A) e lateral (B) da cintura peitoral de Derhamia hoffmannorum MTD F 26 492, 28 mm CP. 


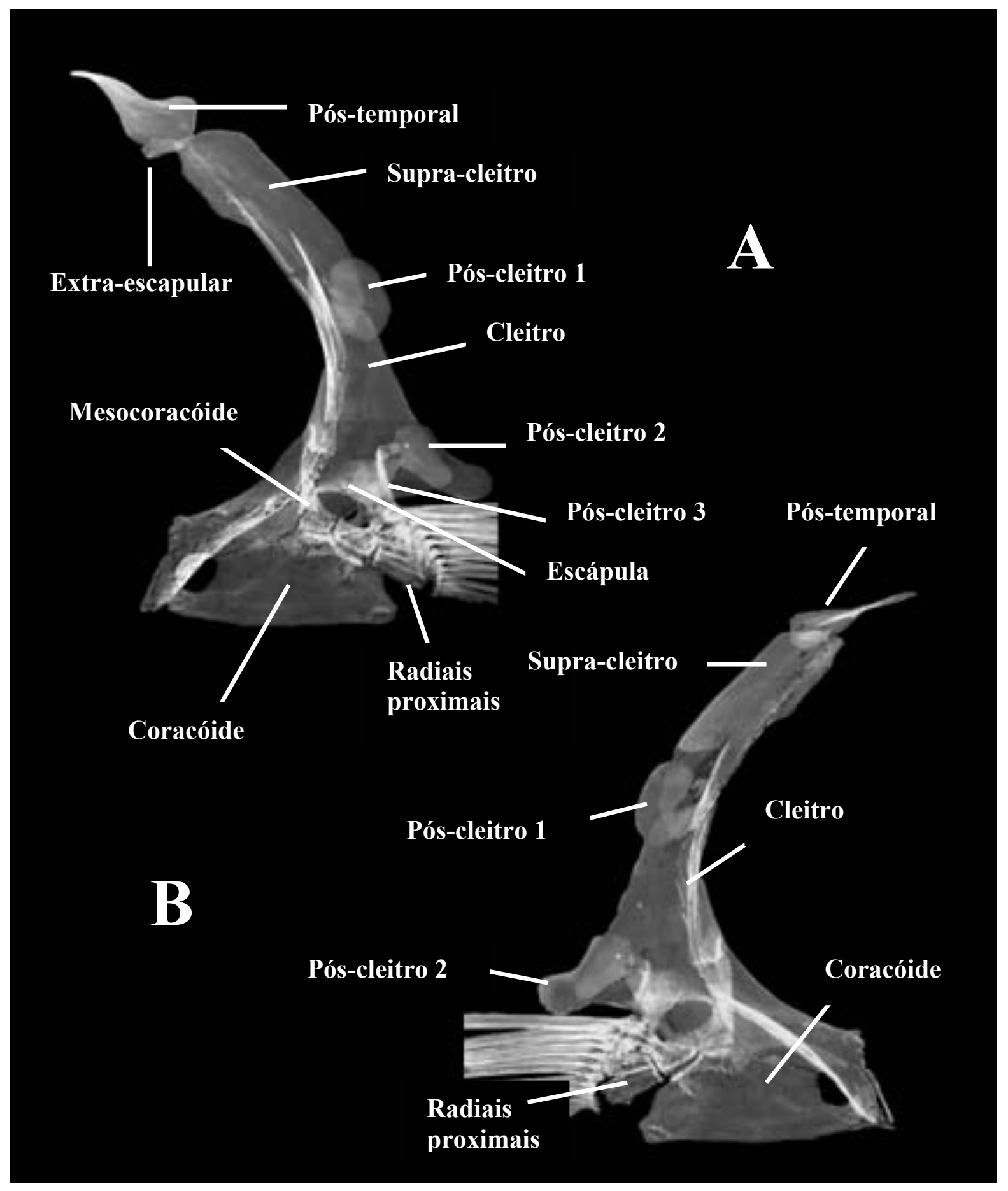

Figura 42. Vista medial (A) e lateral (B) da cintura peitoral de Nannostomus beckfordi MZUSP 22910, 26,9 mm CP. 


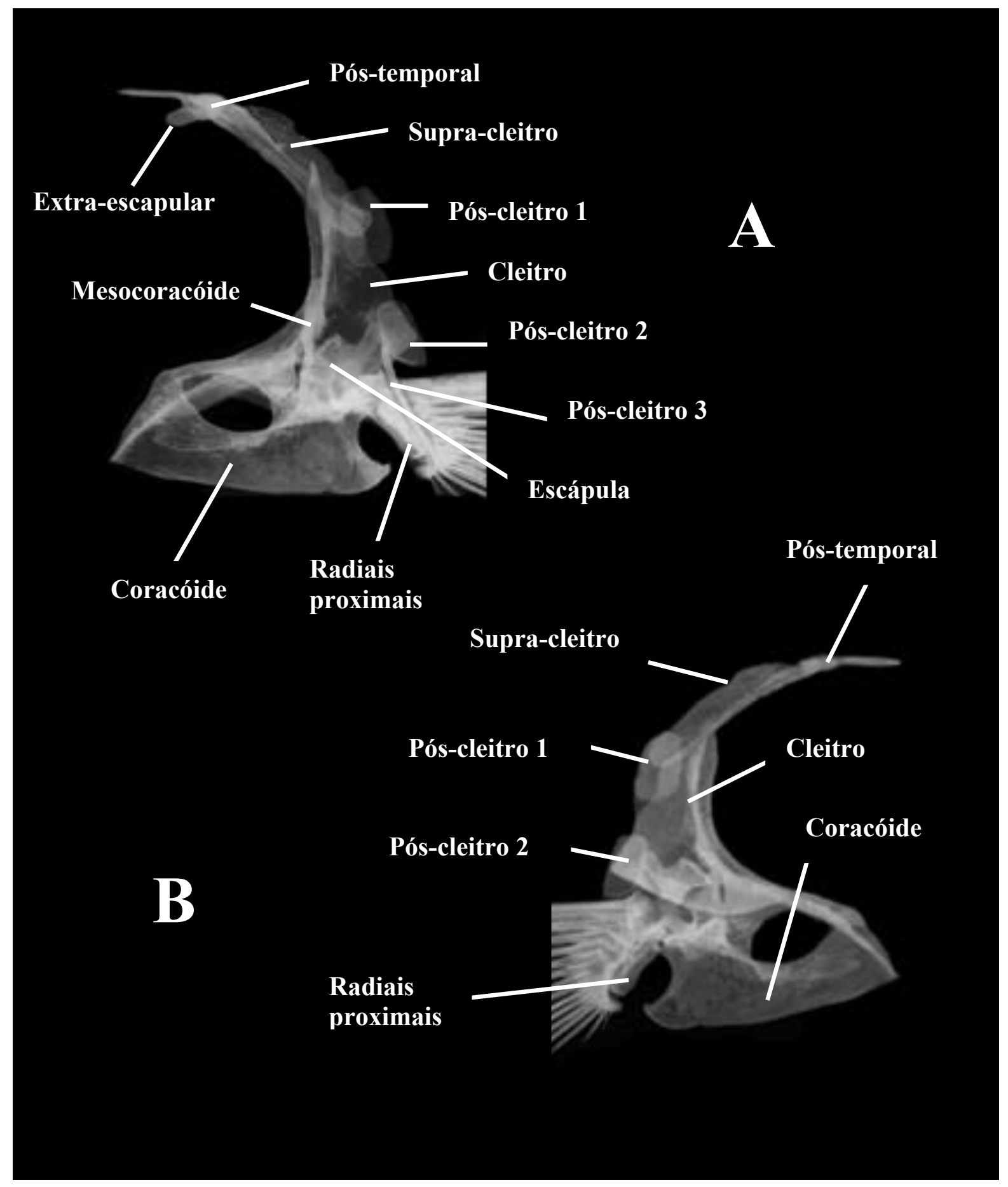

Figura 43. Vista medial (A) e lateral (B) da cintura peitoral de Copeina guttata MZUSP 27088, 65,3mm CP. 


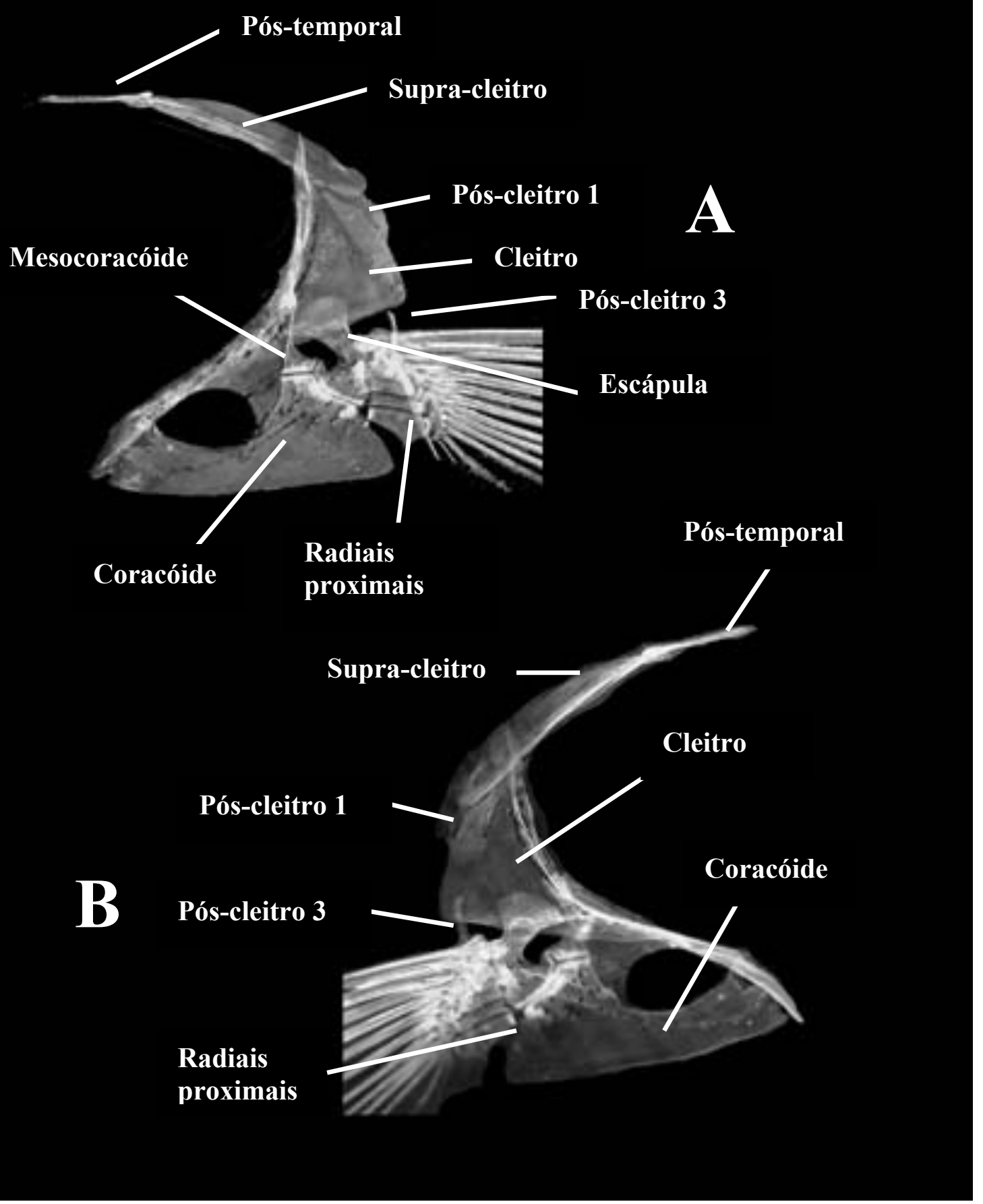

Figura 44. Vista medial (A) e lateral (B) da cintura peitoral de Copella nigrofasciata DEPRJ 104, 43,4 mm CP. 


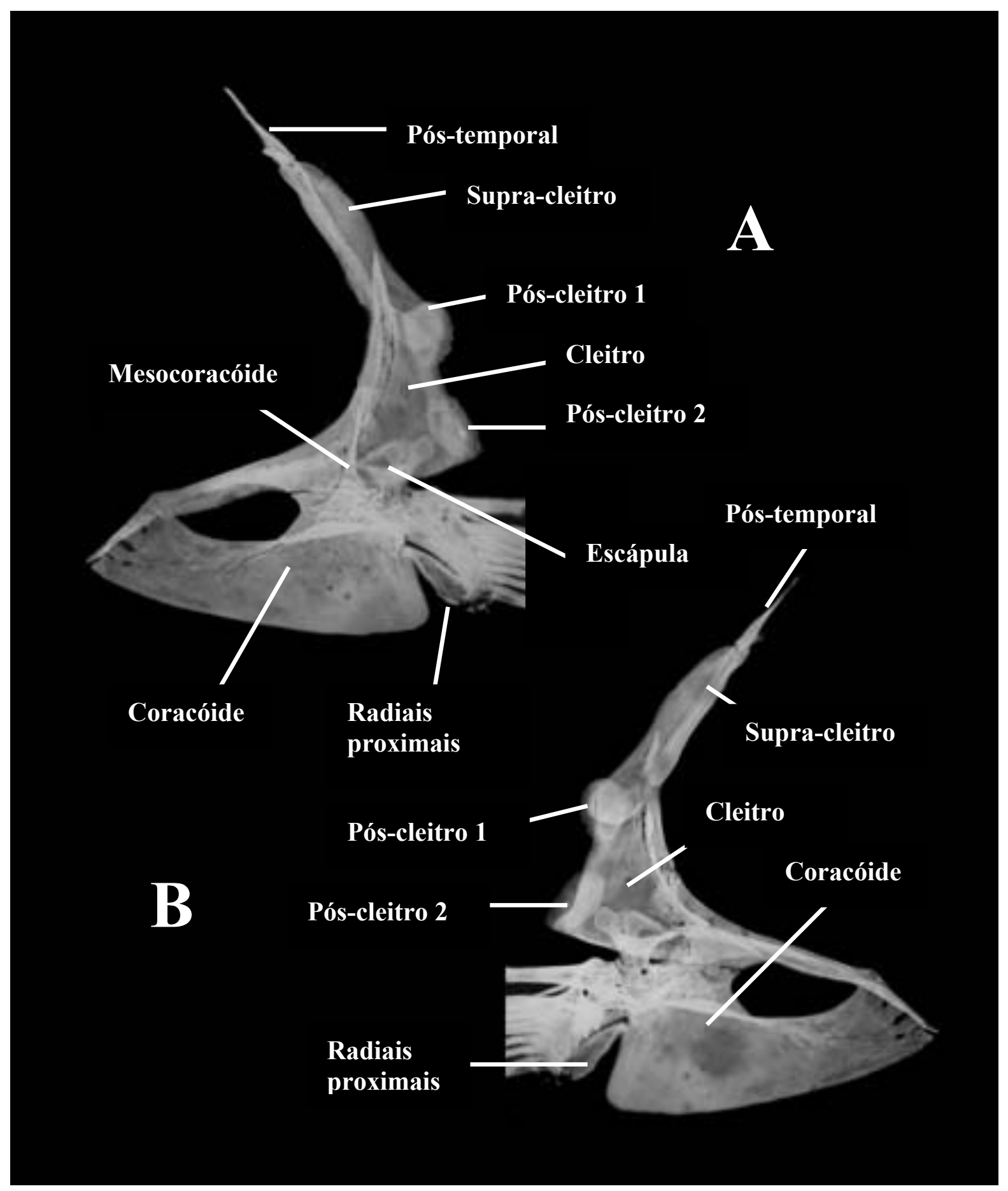

Figura 45. Vista medial (A) e lateral (B) da cintura peitoral de Pyrrhulina australis MZUSP 59567, 31,8 mm CP. 


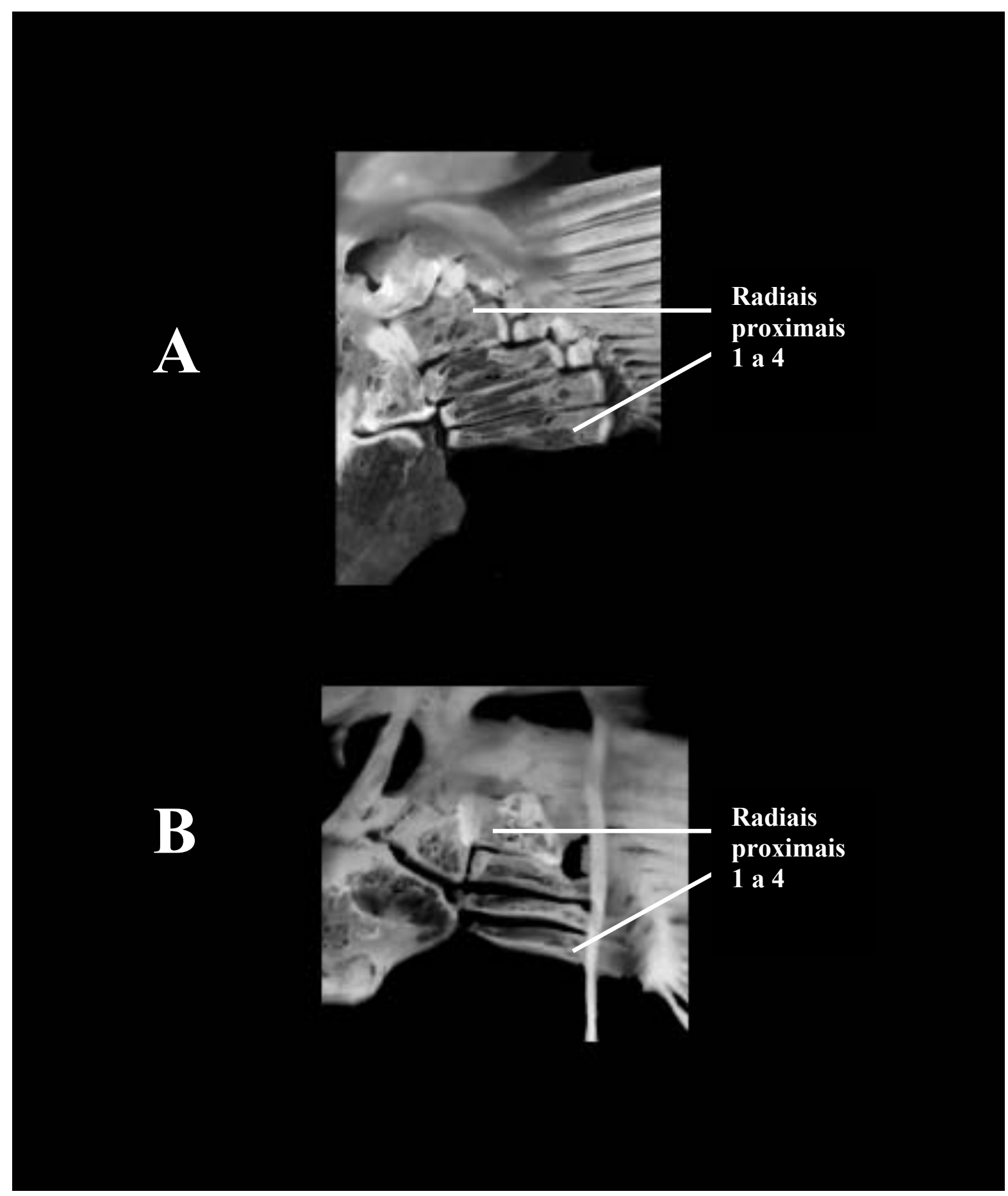

Figura 46. Vista dorsal da cintura peitoral (parte) de (A) Lebiasina bimaculata MZUSP 80085, 70,1 mm CP e (B) Lebiasina erythrinoides MNRJ 14232, 64,8 mm CP, evidenciando os radiais proximais da nadadeira peitoral. 

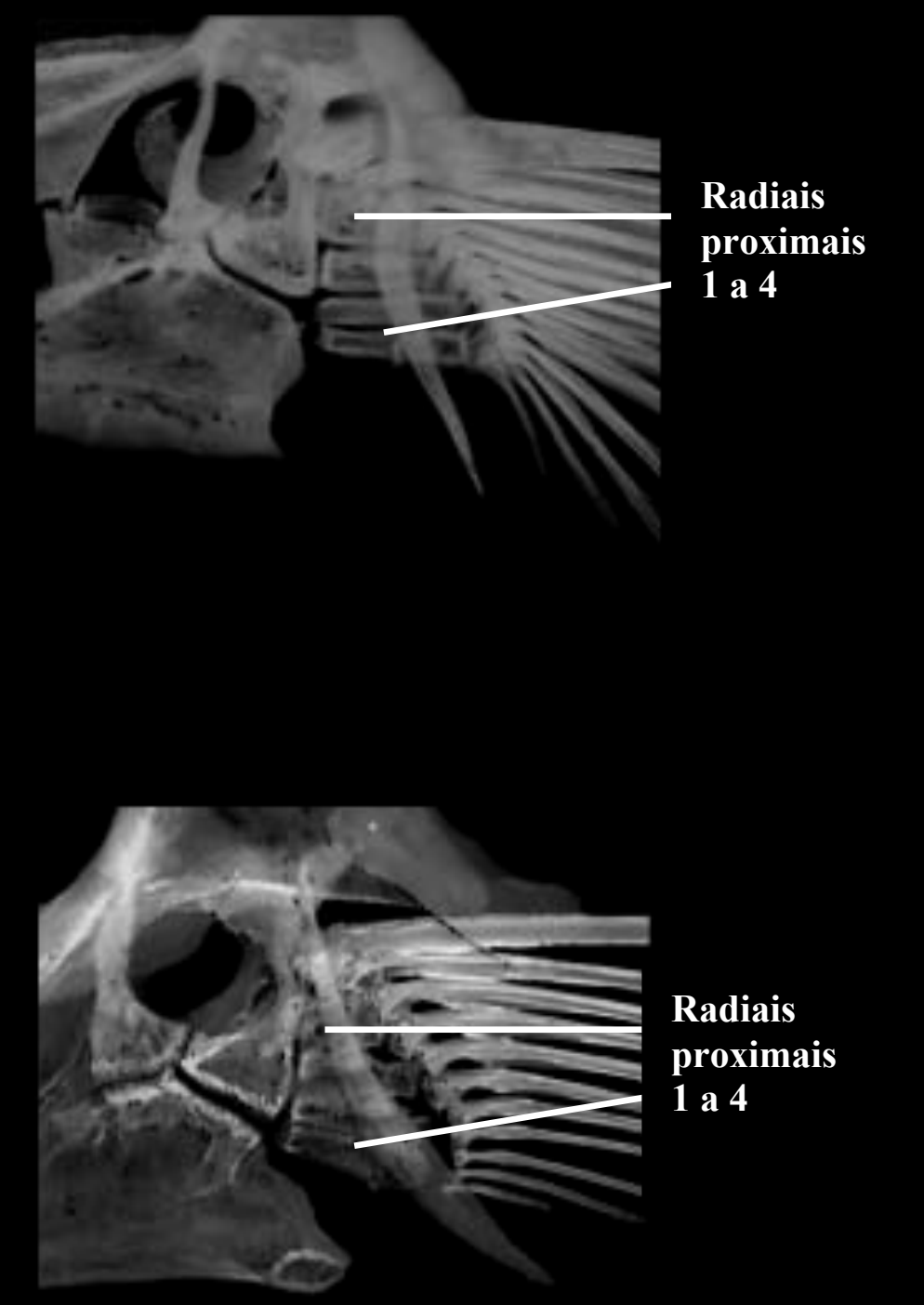

Figura 47. Vista dorsal da cintura peitoral (parte) de (A) Derhamia hoffmannorum MTD F 26 492, 28 mm CP, (B) Nannostomus beckfordi MZUSP 22910, 26,9 mm CP, evidenciando os radiais proximais da nadadeira peitoral. 


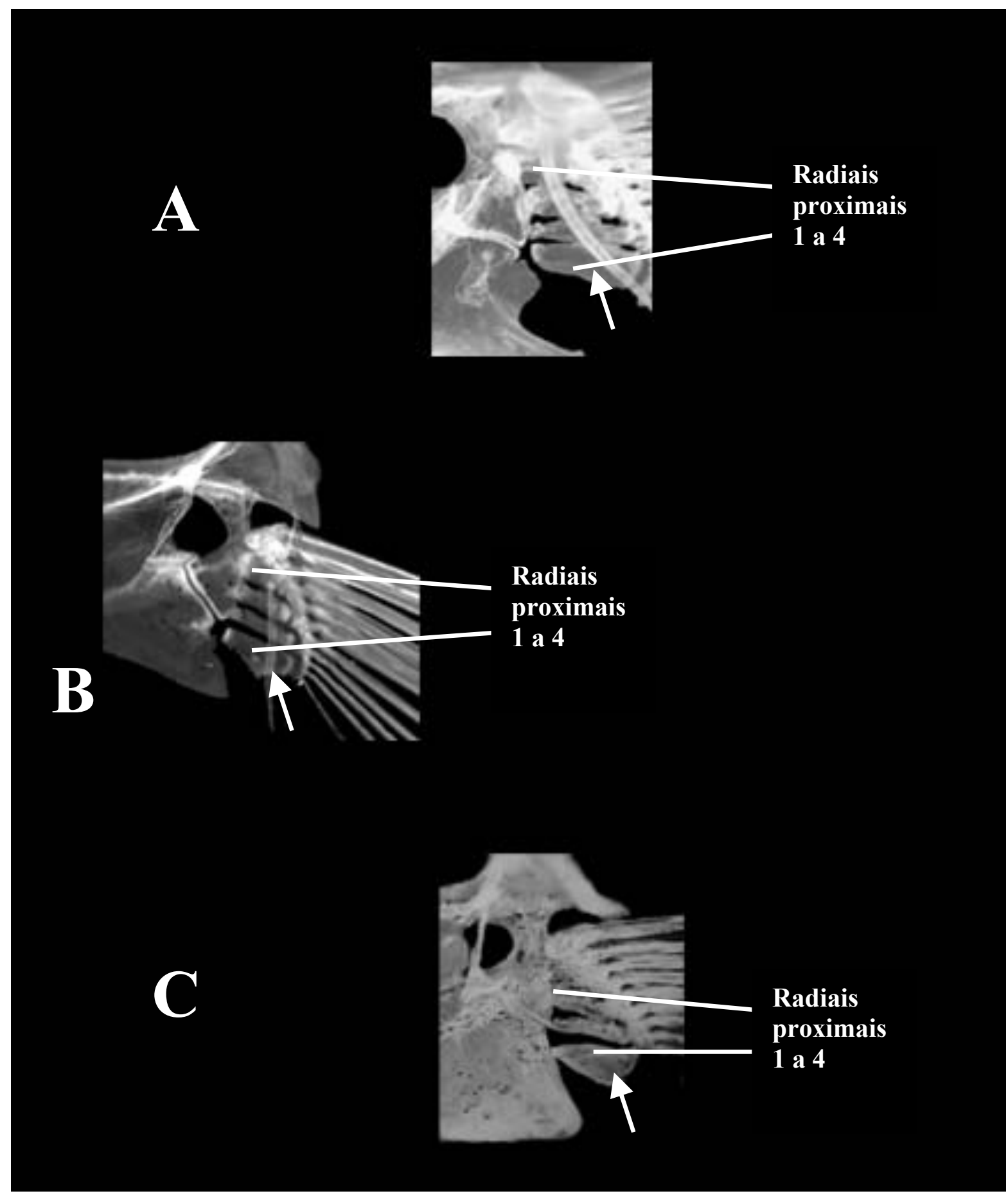

Figura 48. Vista dorsal da cintura peitoral (parte) de (A) Copeina guttata MZUSP 27088, 65,3mm CP, (B) Copella nigrofasciata DEPRJ 104, 43,4 mm CP e (C) Pyrrhulina australis MZUSP 59567, 31,8 mm CP, evidenciando os radiais proximais da nadadeira peitoral. $\rightarrow$ Indicam o radial proximal 1 expandido lateralmente em Copeina, Copella e Pyrrhulina. 

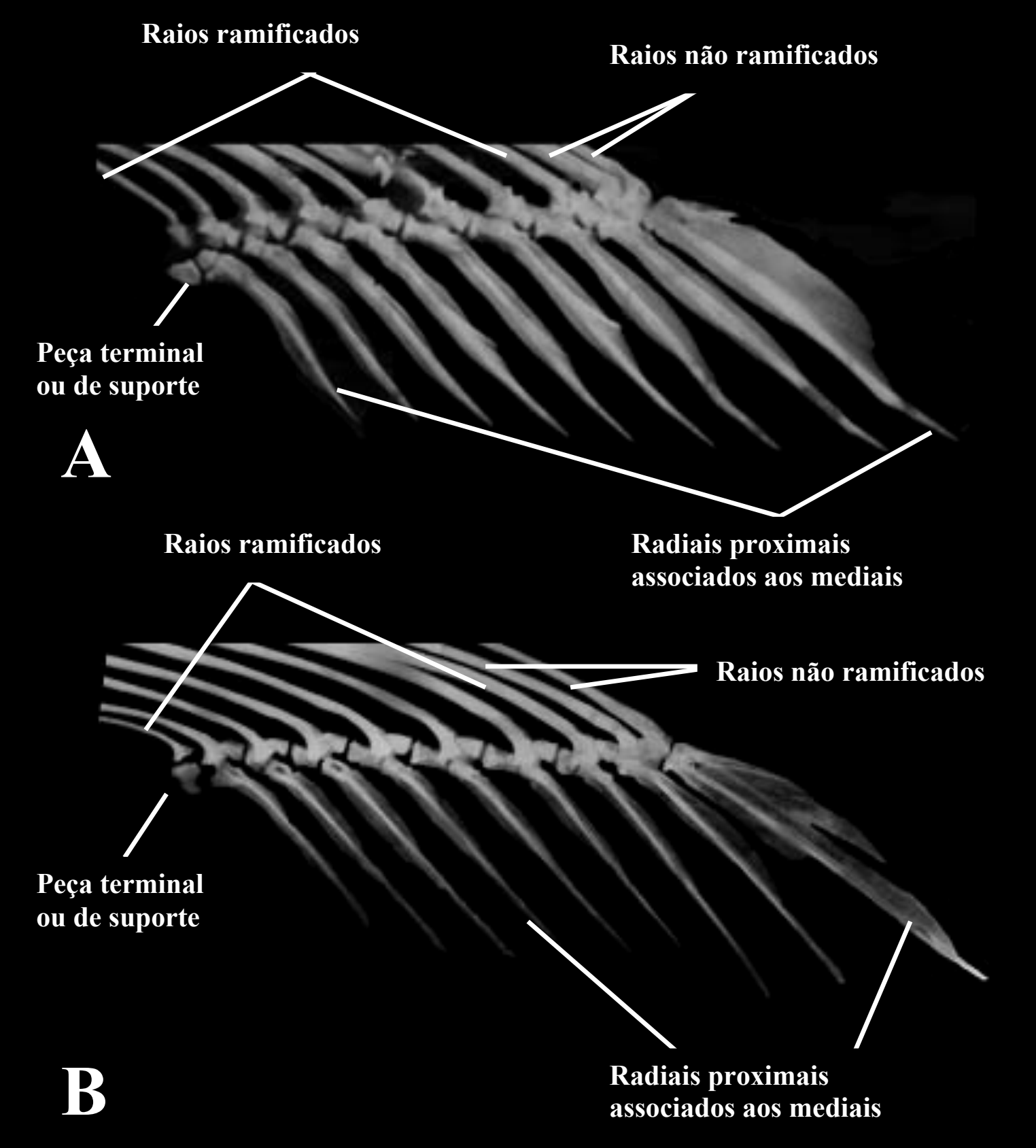

Figura 49. Vista lateral da nadadeira dorsal de (A) Lebiasina bimaculata MZUSP 80085 , 70,1 mm CP e (B) Lebiasina erythrinoides MNRJ 14232, 64,8 mm CP. 


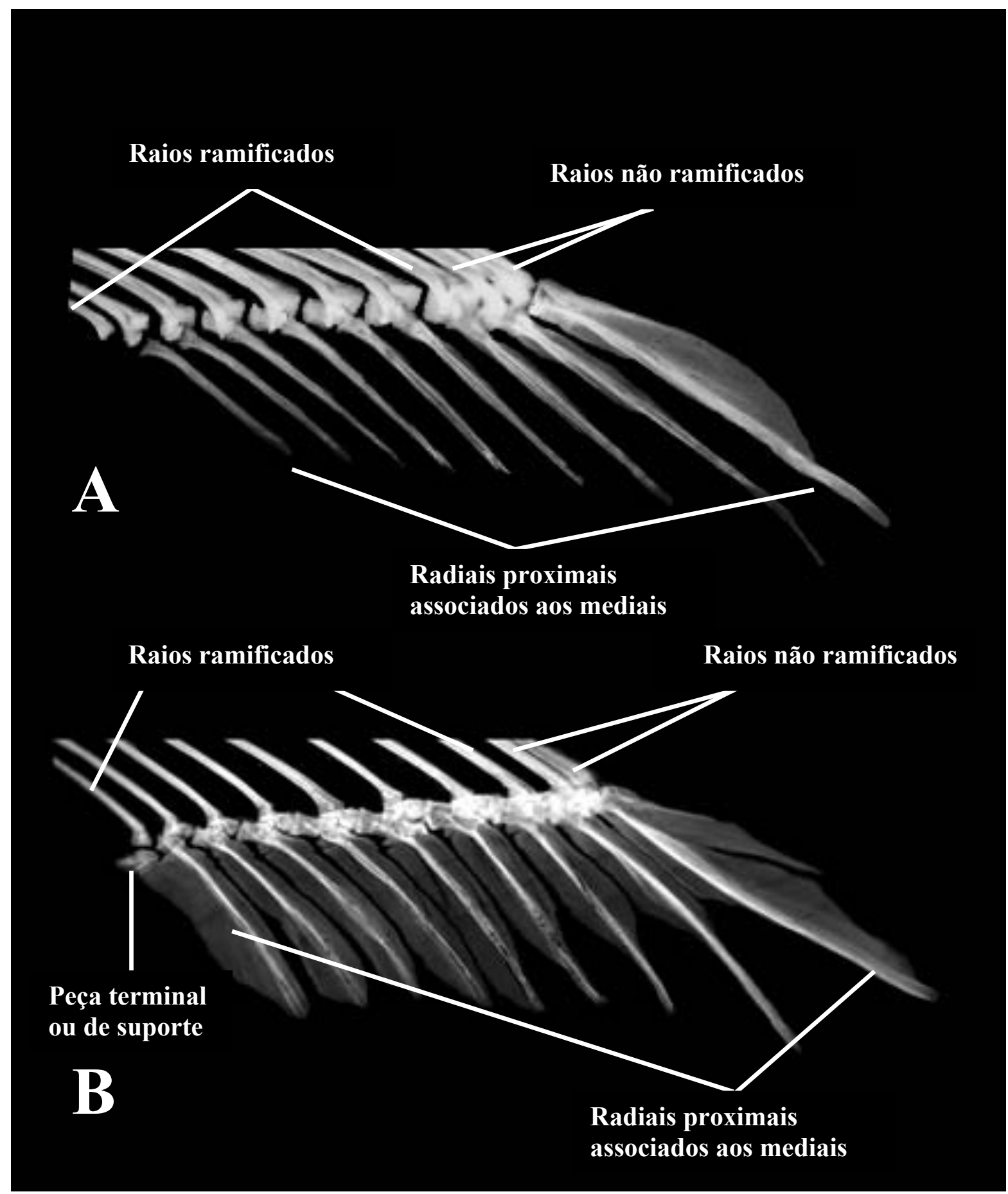

Figura 50. Vista lateral da nadadeira dorsal de (A) Derhamia hoffmannorum MTD F 26 492, 28 mm CP e (B) Nannostomus beckfordi MZUSP 22910, 26,9 mm CP. 


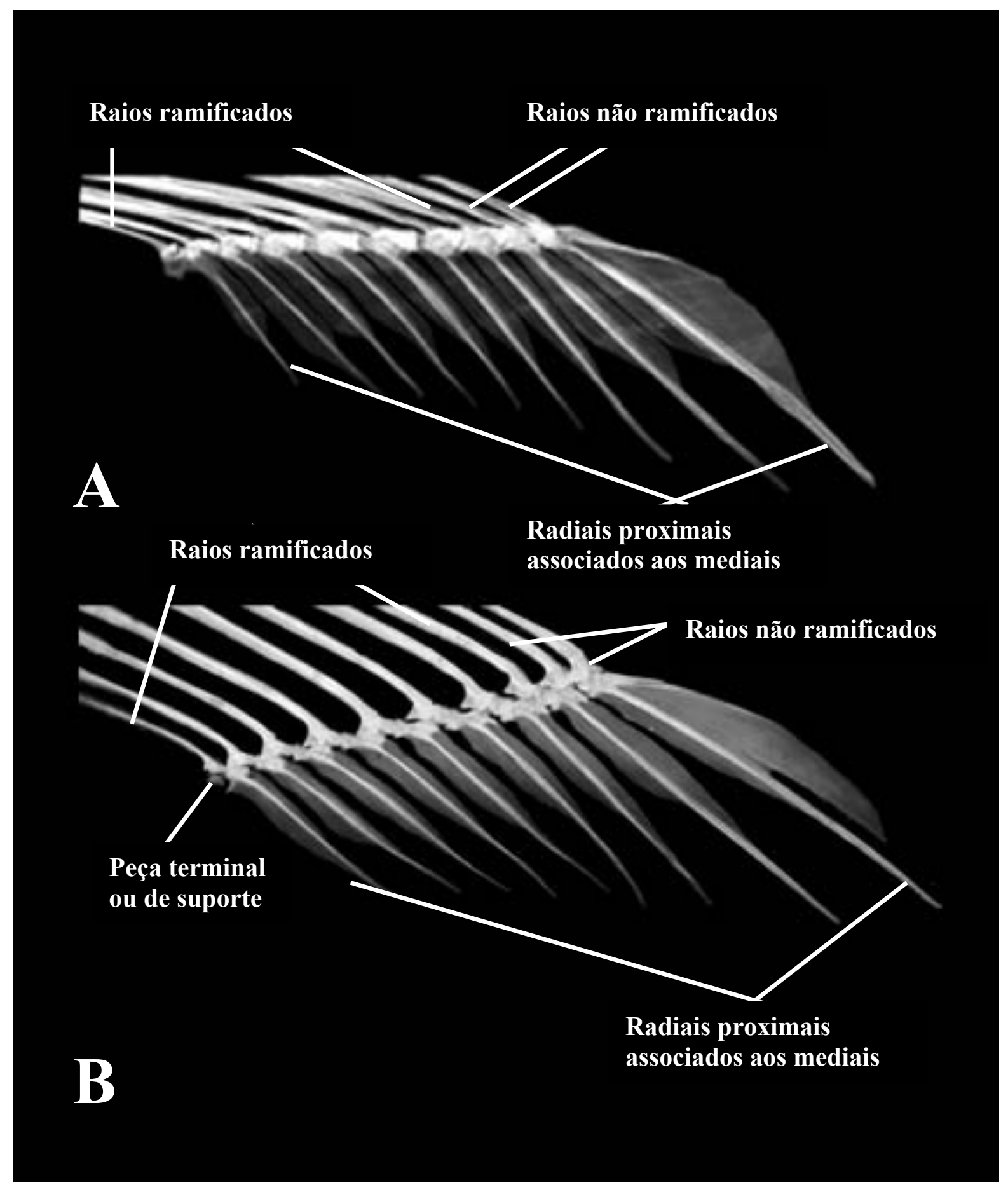

Figura 51. Vista lateral da nadadeira dorsal de (A) Copella nigrofasciata DEPRJ 104, 43,4 mm CP e (B) Copeina guttata MZUSP 27088, 65,3mm CP. 


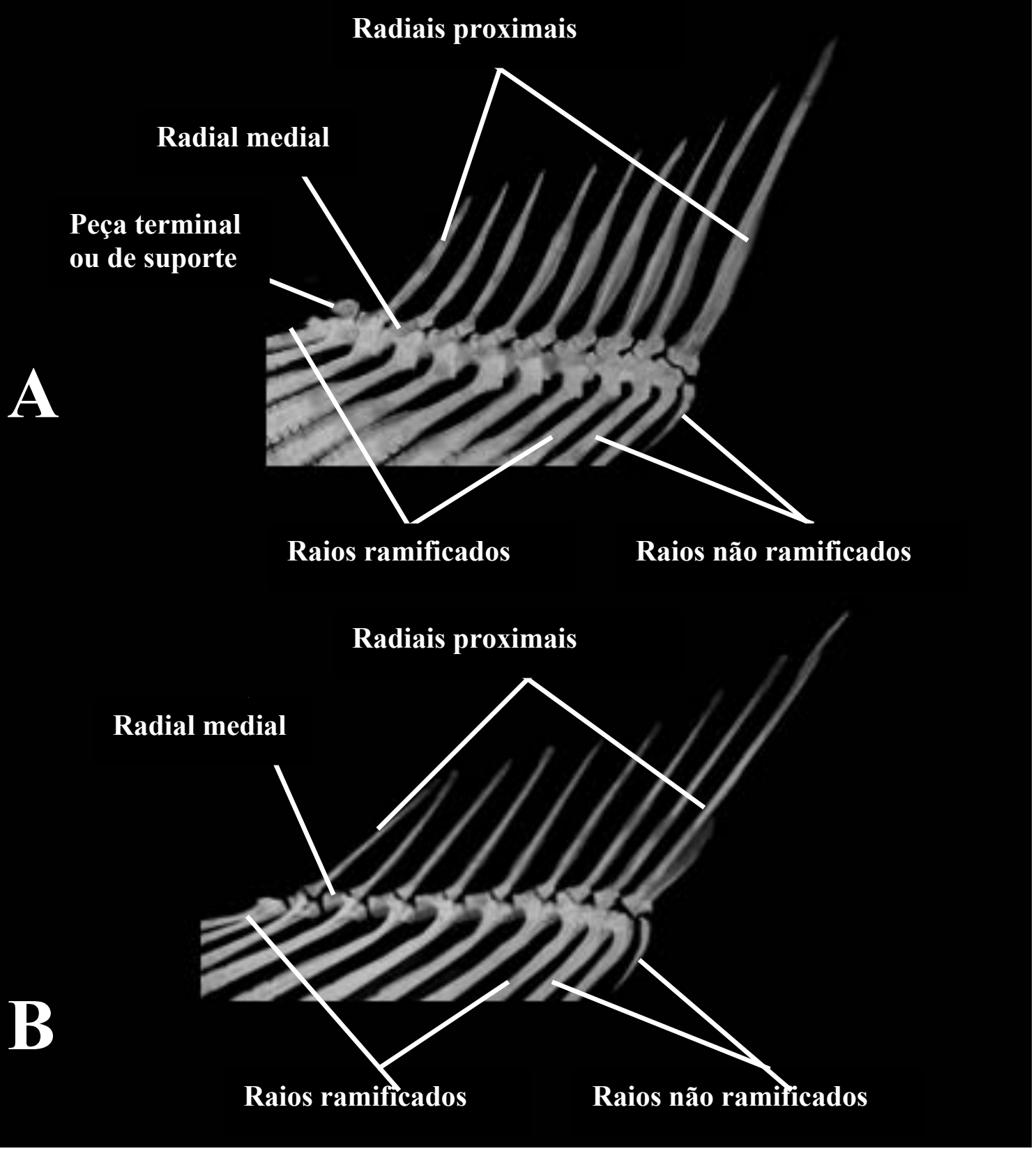

Figura 52. Vista lateral da nadadeira anal de (A) Lebiasina bimaculata MZUSP 80085 , 70,1 mm CP e (B) Lebiasina erythrinoides MNRJ 14232, 64,8 mm CP. 


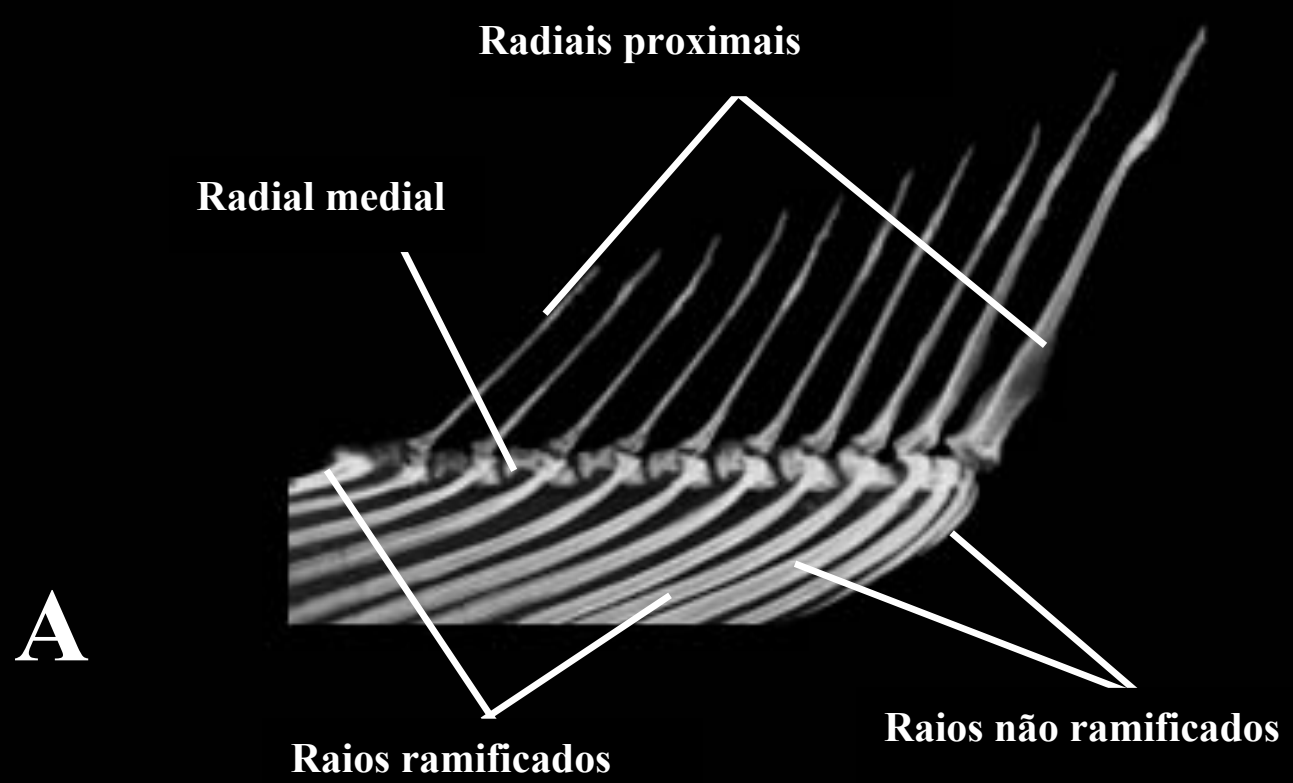

Peça terminal ou de suporte

Radiais proximais

B

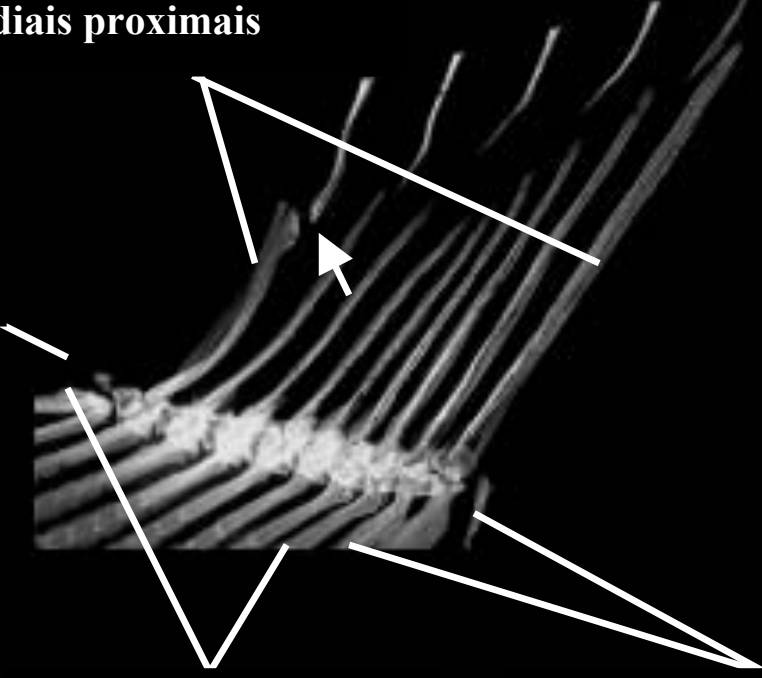

Raios ramificados

Raios não ramificados

Figura 53. Vista lateral da nadadeira anal de (A) Derhamia hoffmannorum MTD F 26492 , $28 \mathrm{~mm}$ CP e (B) Nannostomus beckfordi MZUSP 22910, 26,9 mm CP. $\rightarrow$ Indica a articulação do último radial proximal com o espinho hemal. 

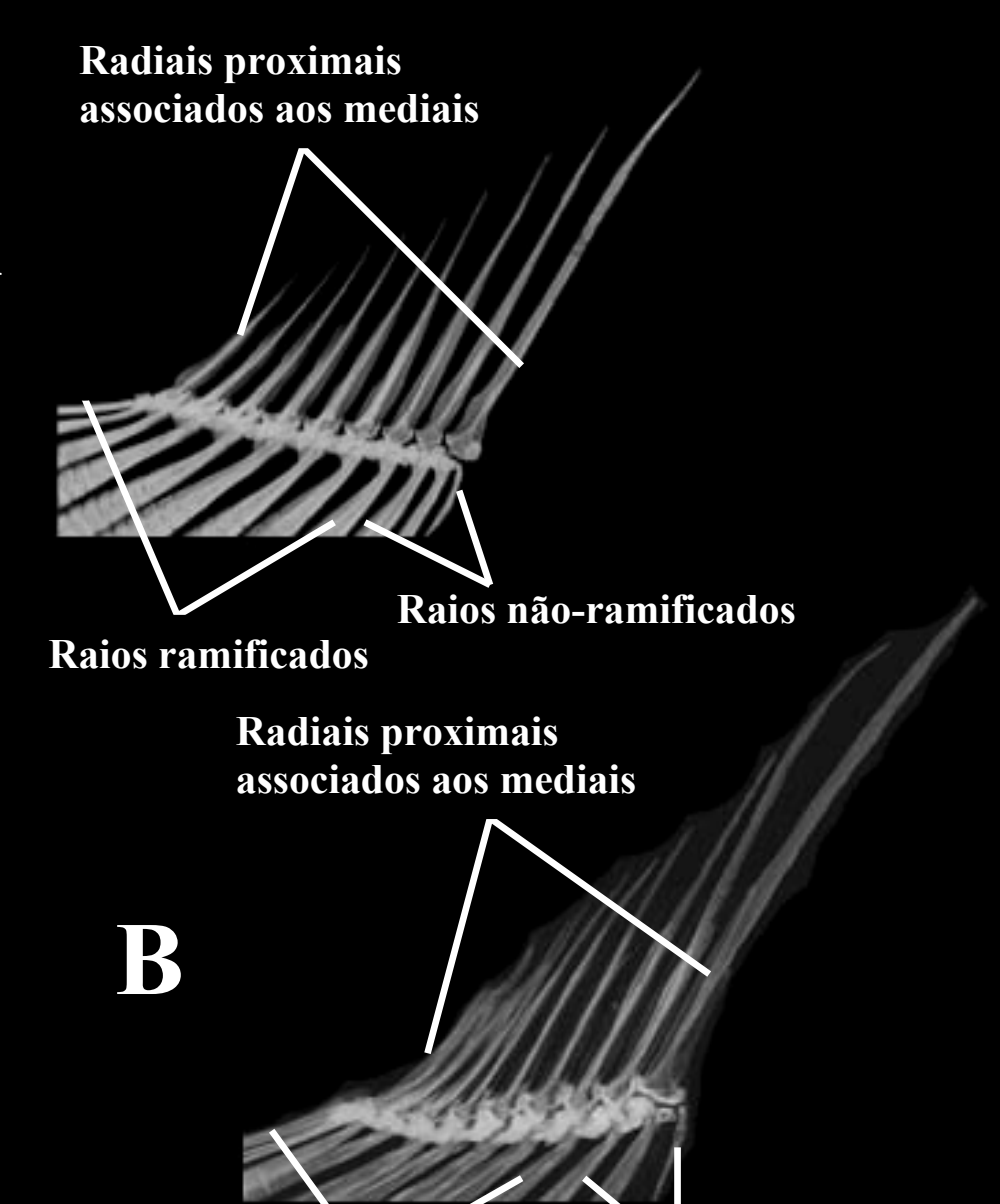

Raios ramificados

Radiais proximais associados aos mediais

\section{Rains ramificados}

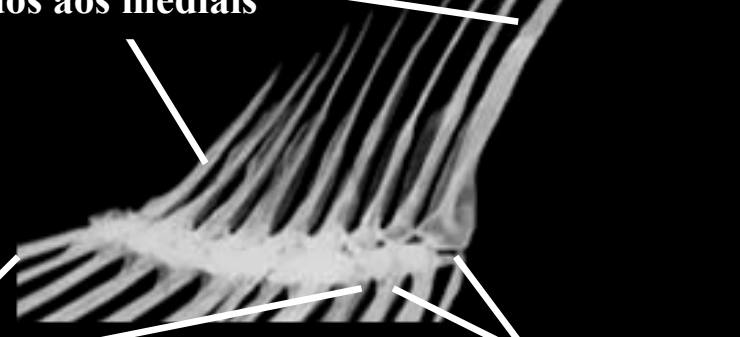

Figura 54. Vista lateral da nadadeira anal de (A) Copeina guttata MZUSP 27088, 65,3mm CP, (B) Copella nigrofasciata DEPRJ 104, 43,4 mm CP e (C) Pyrrhulina australis MZUSP 59567, 31,8 mm CP. 


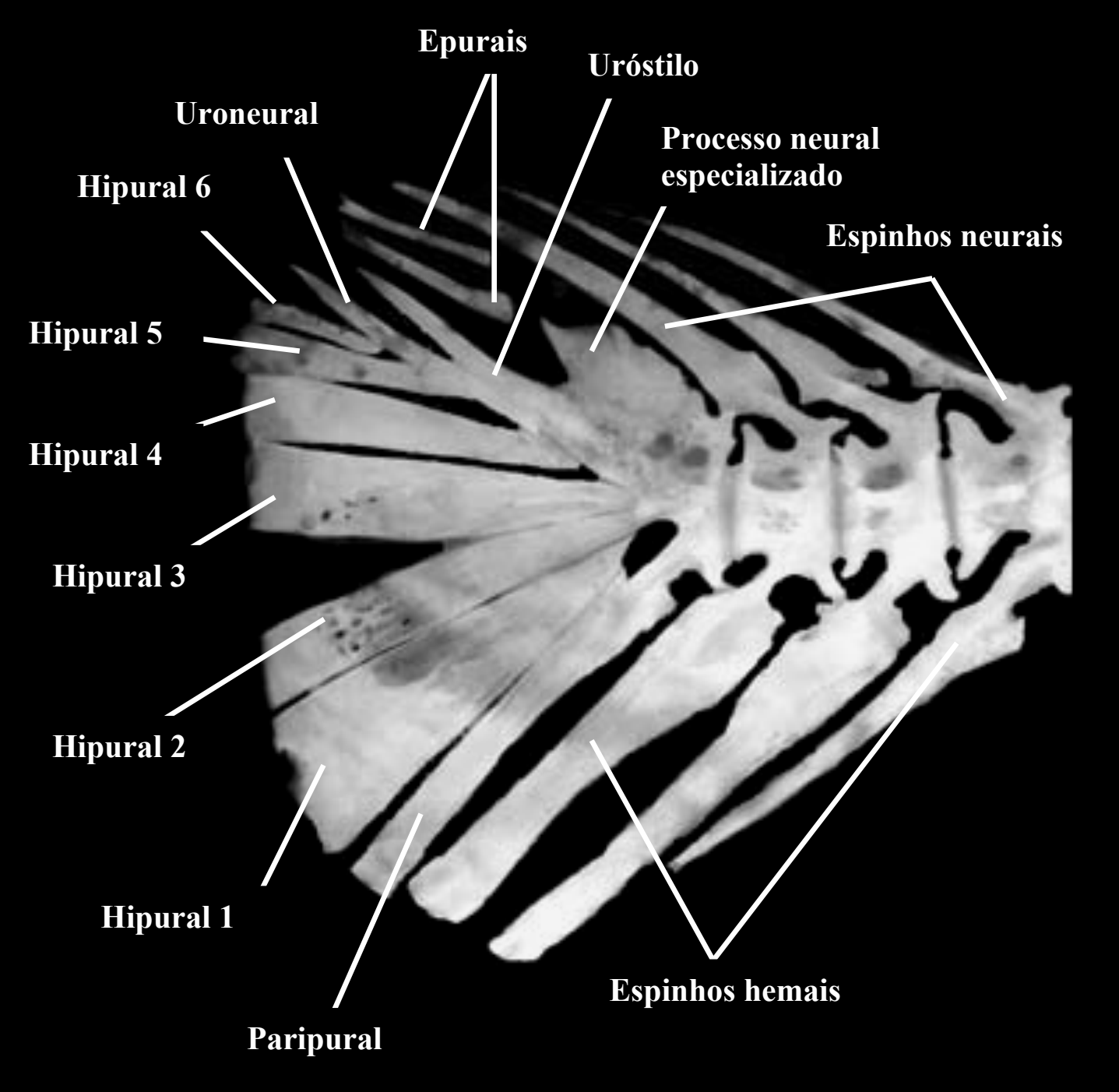

Figura 55. Vista lateral do esqueleto caudal de Lebiasina bimaculata MZUSP 80085, 70,1 $\mathrm{mm} \mathrm{CP.}$ 


\section{Pró-correntes dorsais}

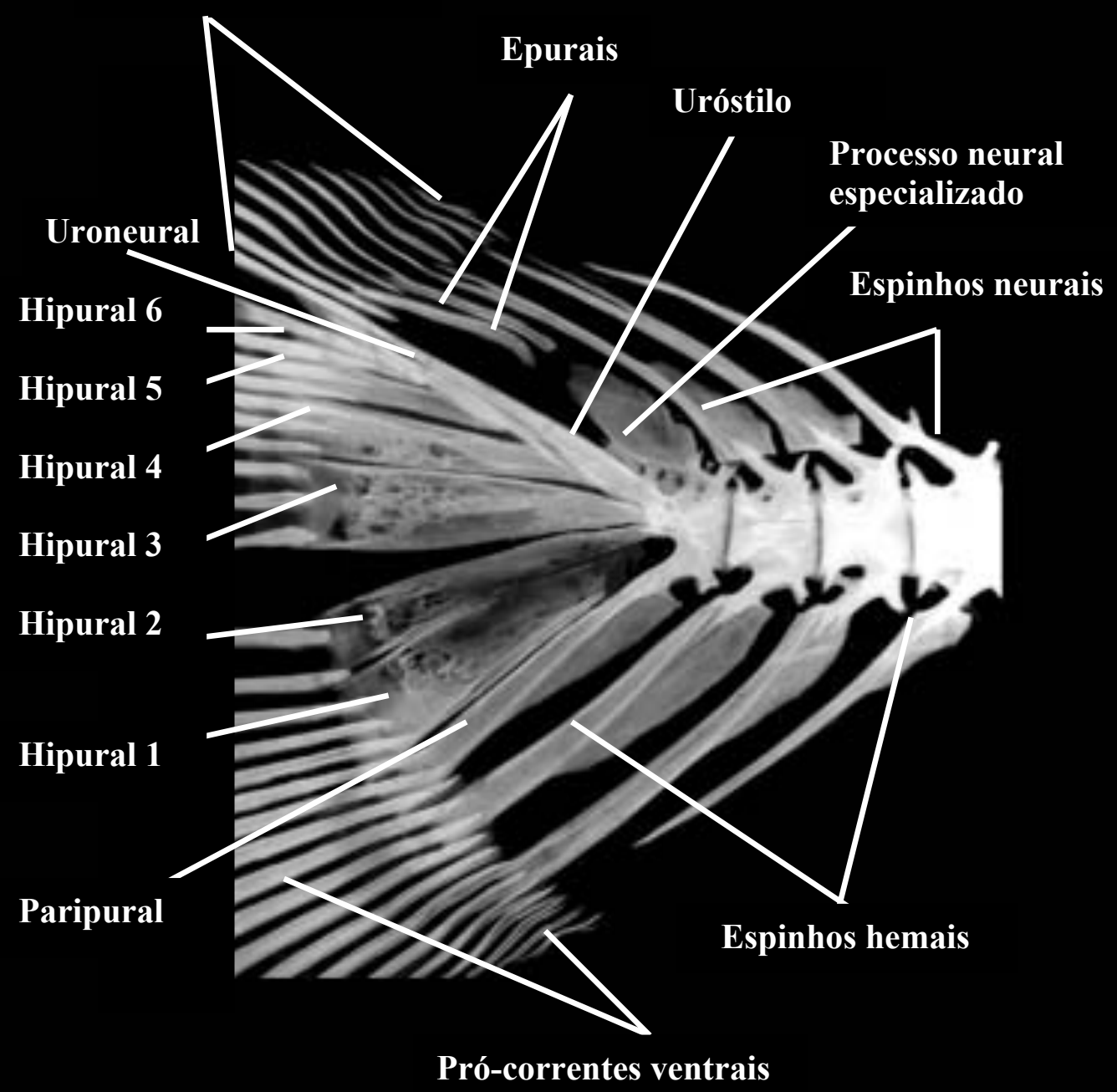

Figura 56. Vista lateral do esqueleto caudal de Lebiasina erythrinoides MNRJ 14232, 64,8 $\mathrm{mm} \mathrm{CP}$. 


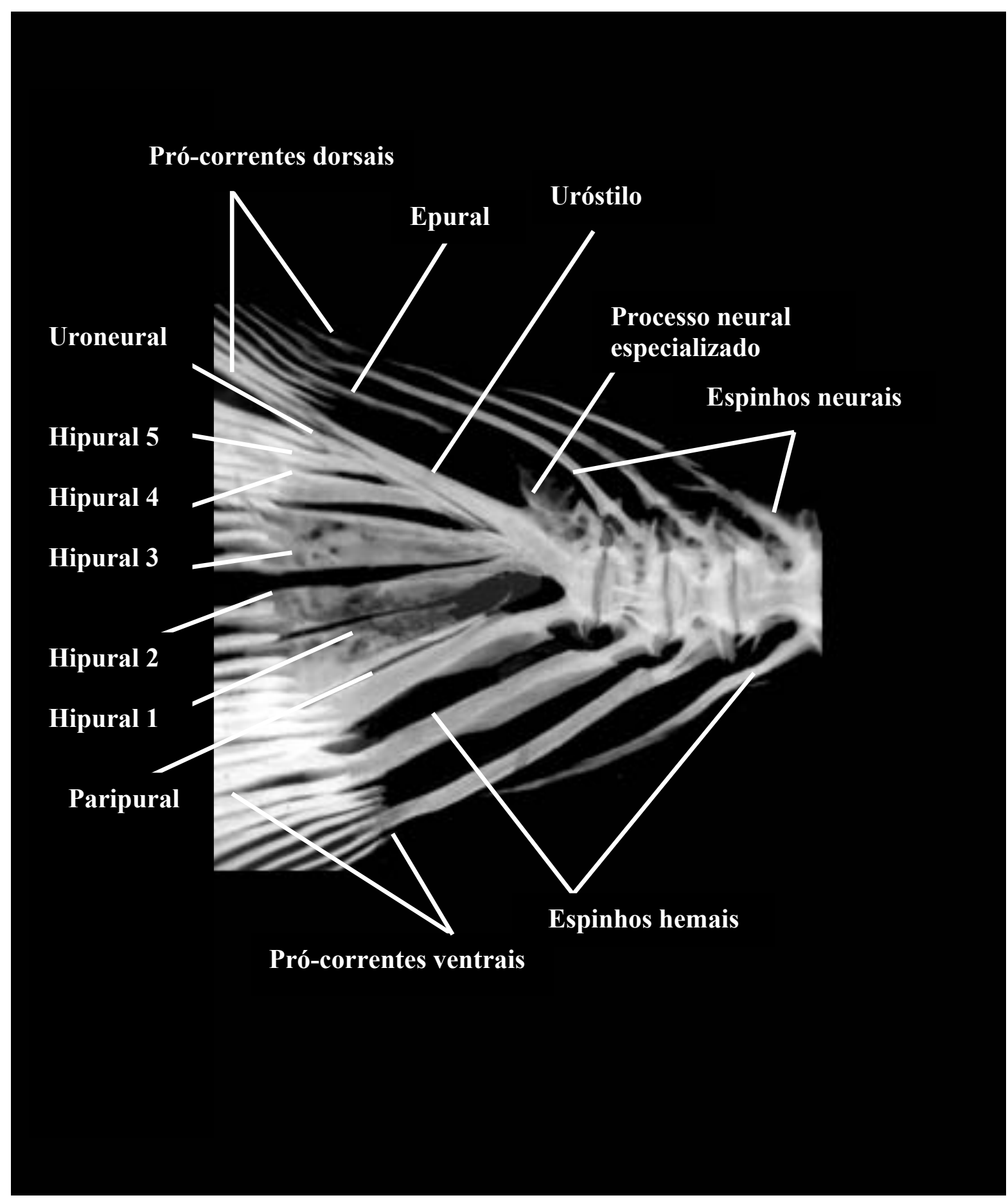

Figura 57. Vista lateral do esqueleto caudal de Derhamia hoffmannorum MTD F 26 492, $28 \mathrm{~mm} \mathrm{CP}$. 


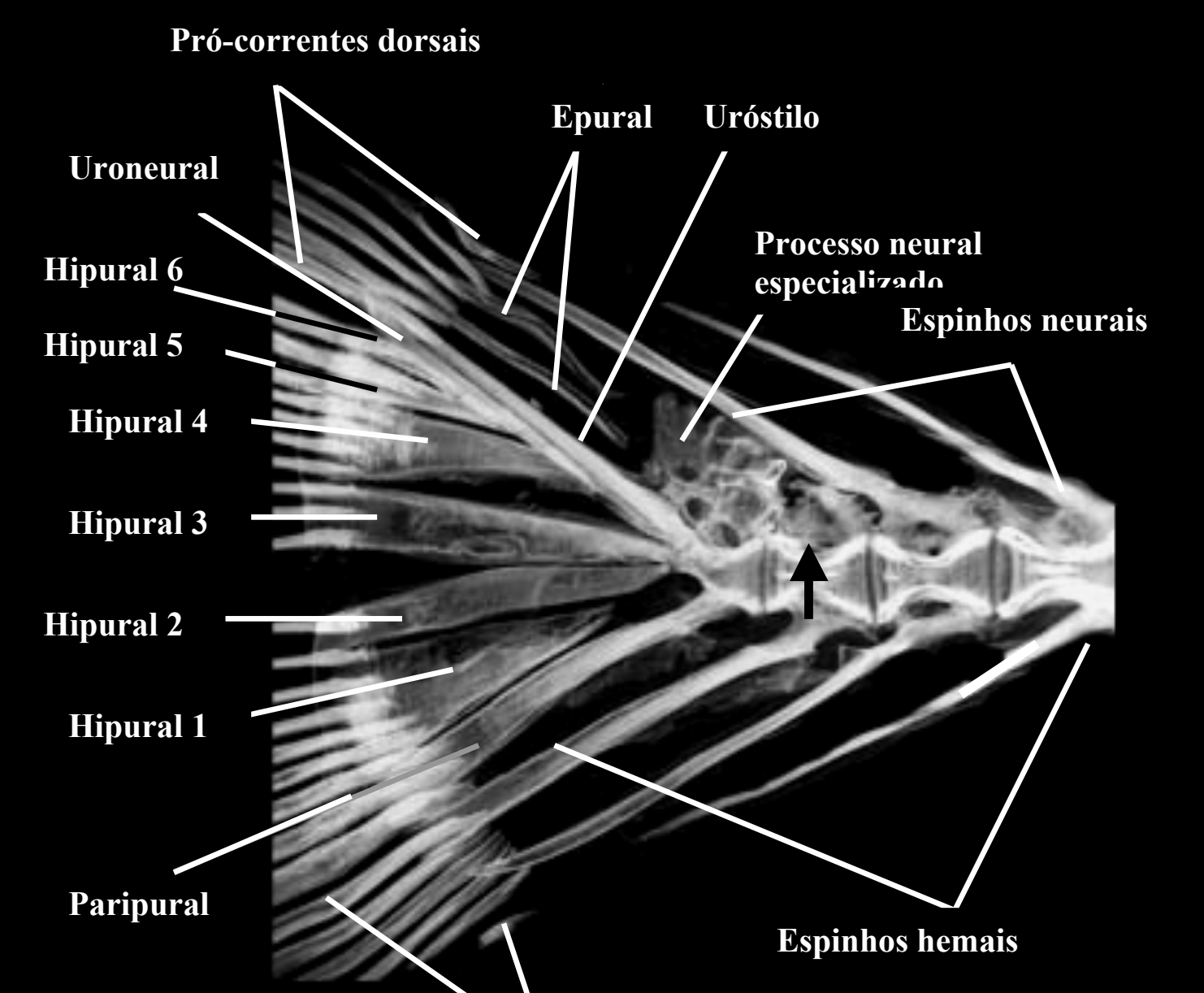

Pró-correntes ventrais

Figura 58. Vista lateral do esqueleto caudal de Nannostomus beckfordi MZUSP 22910, $26,9 \mathrm{~mm} \mathrm{CP.} \rightarrow$ Indica o último espinho neural, que encontra-se reduzido nos representantes do gênero Nannostomus. 


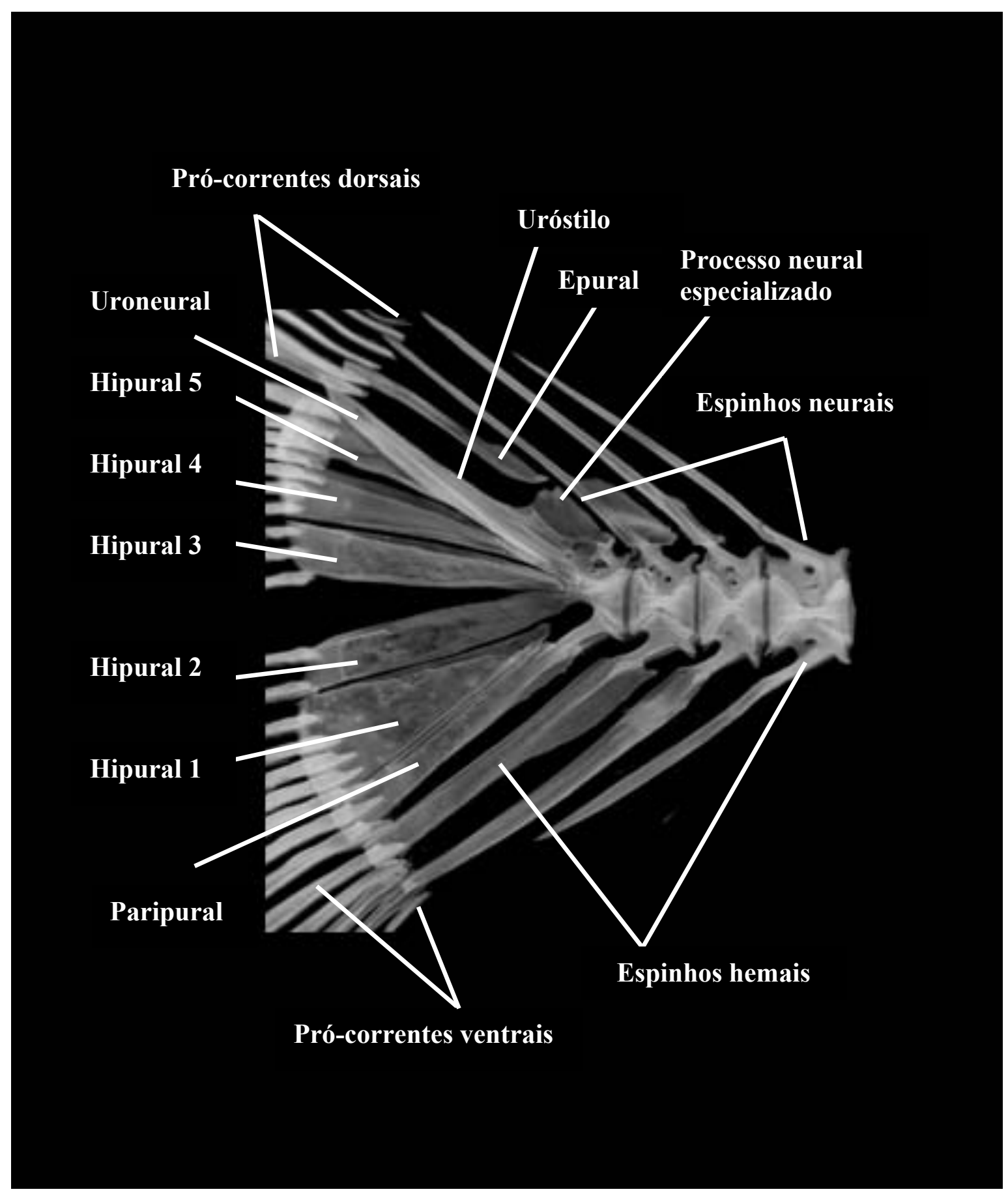

Figura 59. Vista lateral do esqueleto caudal de Copeina guttata MZUSP 27088, 65,3mm CP. 


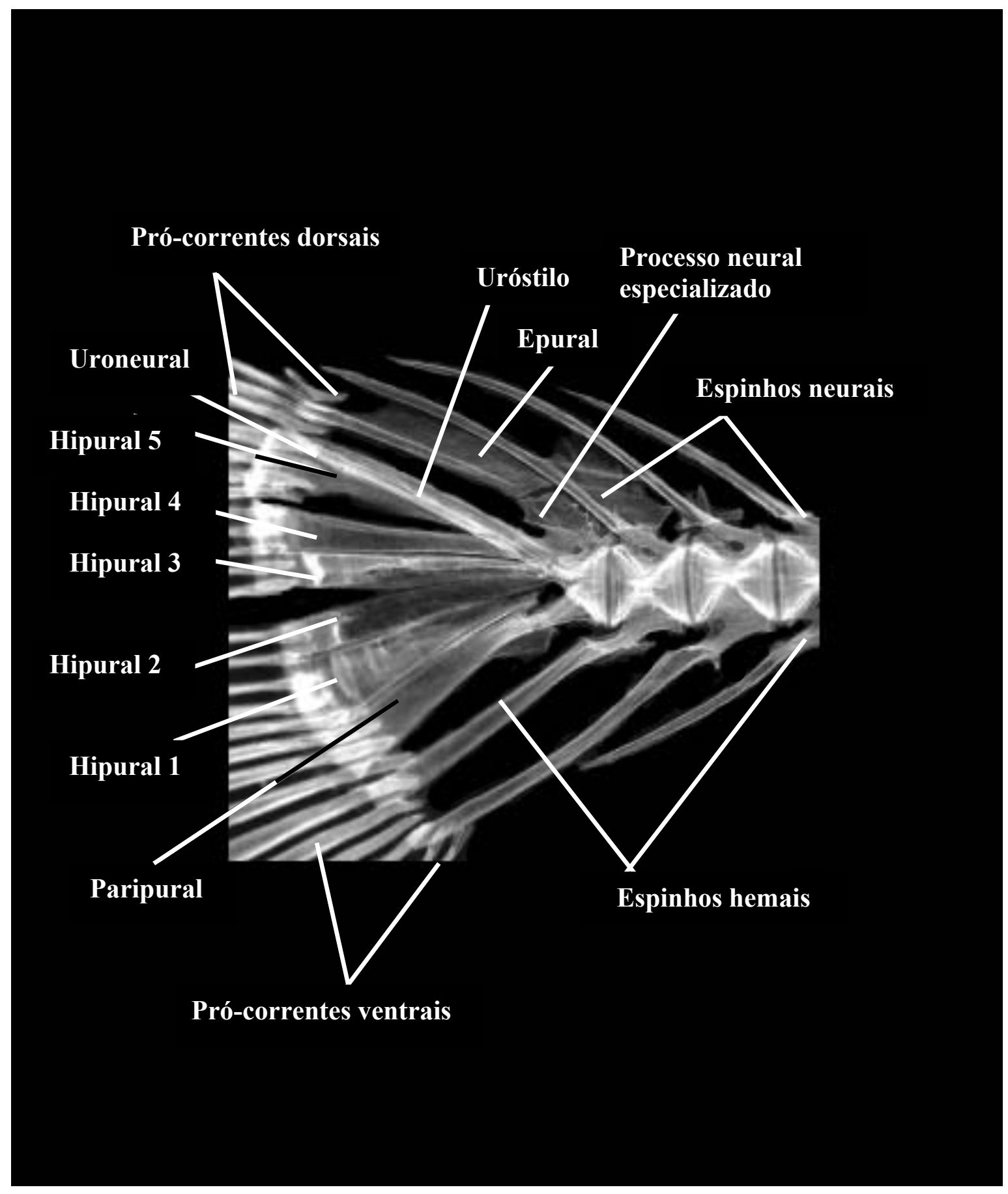

Figura 60. Vista lateral do esqueleto caudal de Copella nigrofasciata DEPRJ 104, 43,4 $\mathrm{mm}$ CP. 


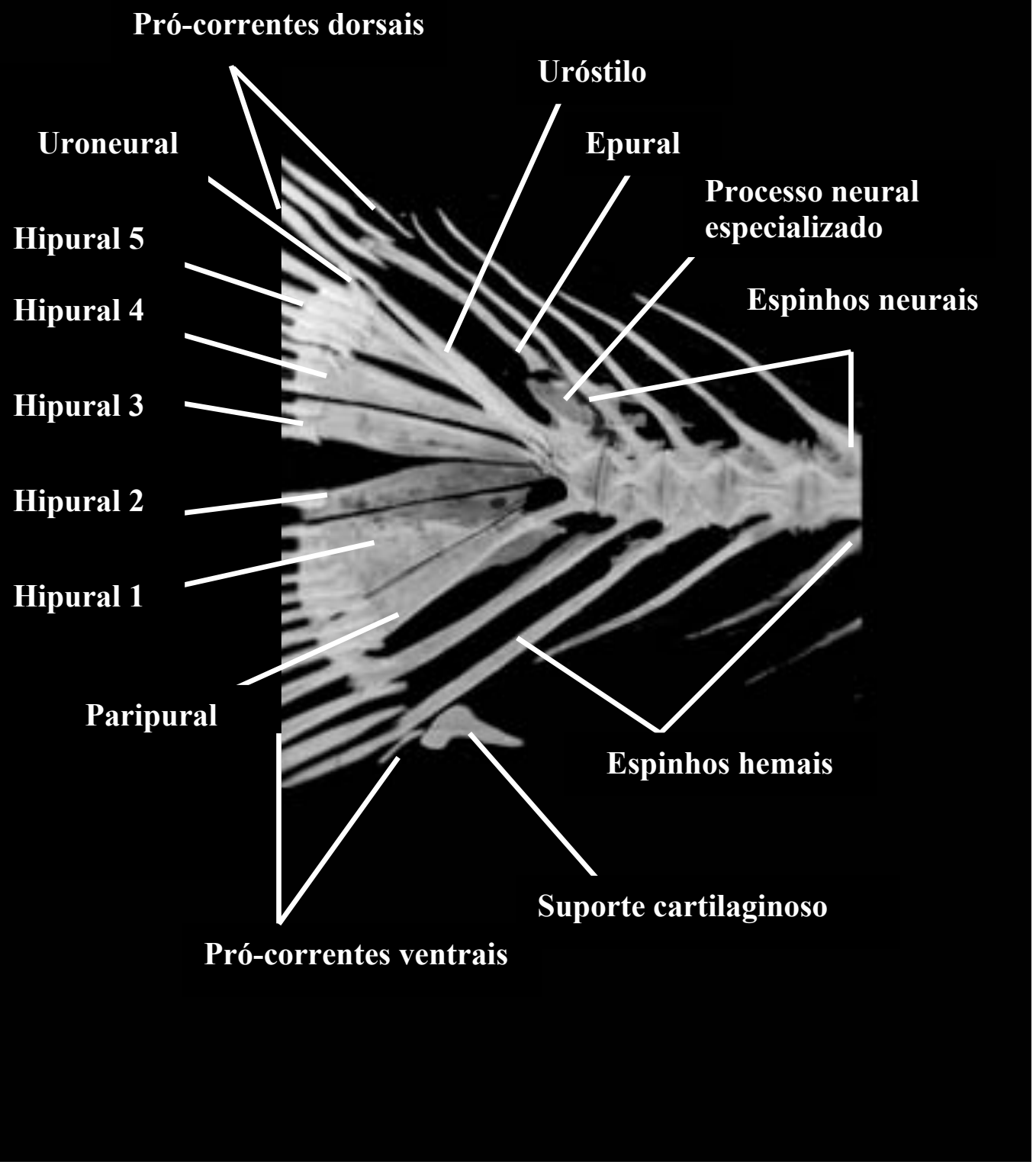

Figura 61. Vista lateral do esqueleto caudal de Pyrrhulina zigzag MZUSP 61130, 30,7 mm CP. 


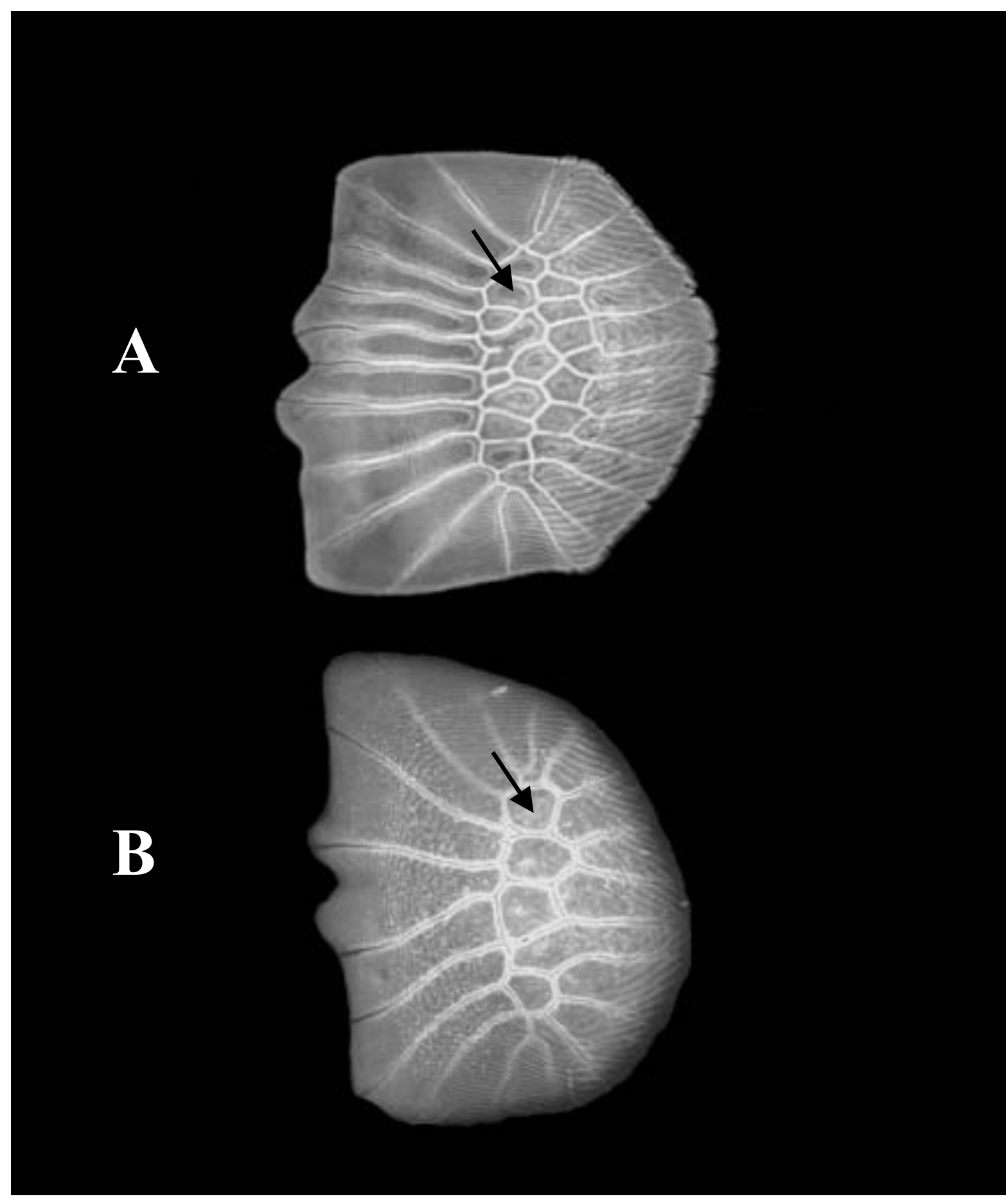

Figura 62. Escamas de (A) Lebiasina bimaculata MZUSP 80085, 70,1 mm CP e (B) Lebiasina erythrinoides MNRJ 14232, 64,8 $\mathrm{mm} \mathrm{CP.} \rightarrow$ Indicam as células formadas pela anastomose dos radii. 


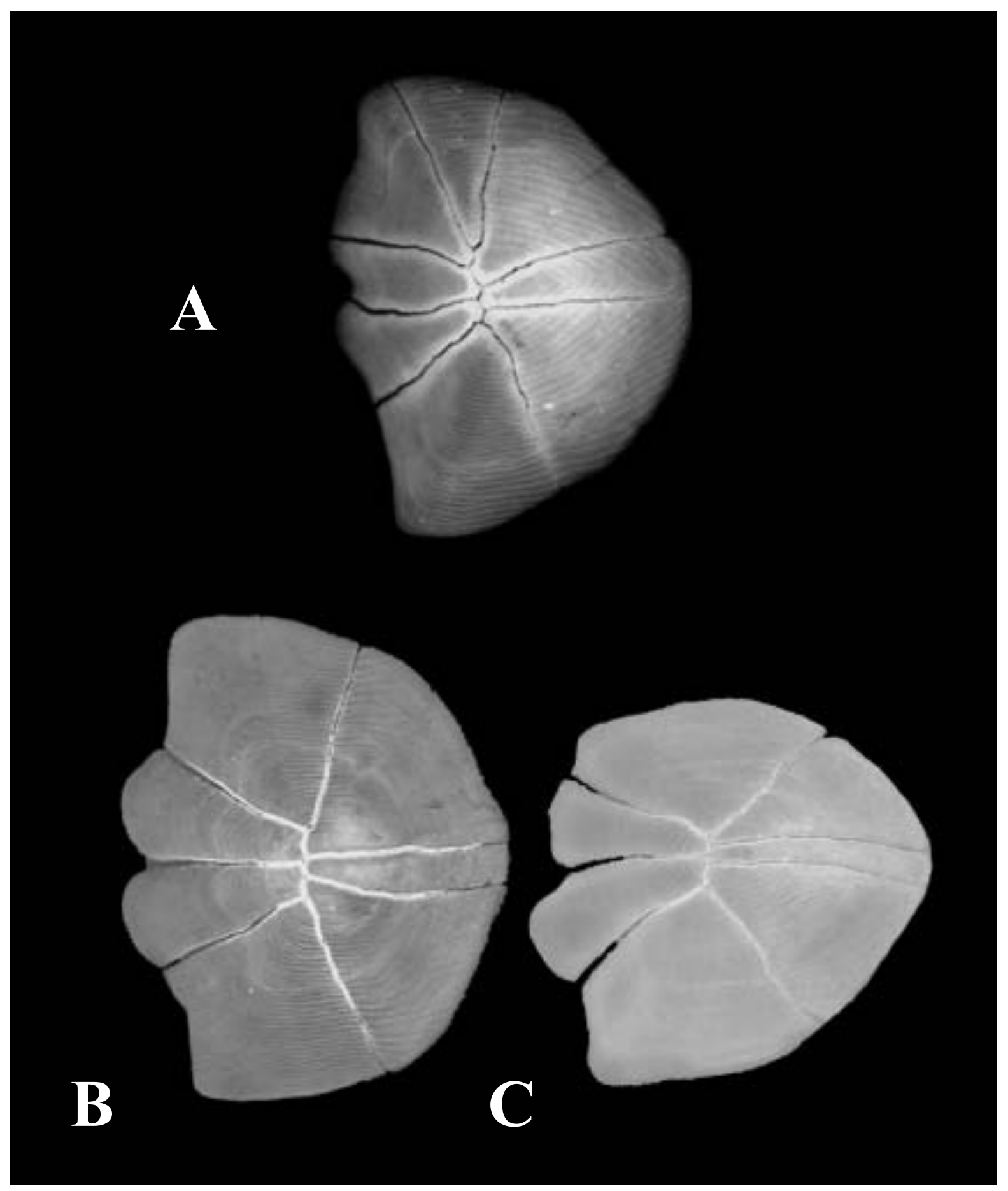

Figura 63. Escamas de (A) Derhamia hoffmannorum MTD F 26 492, 28 mm CP, (B) Nannostomus beckfordi MZUSP 22910, 26,9 mm CP e (C) Nannostomus eques MZUSP 6423, 33,9 mm CP. 


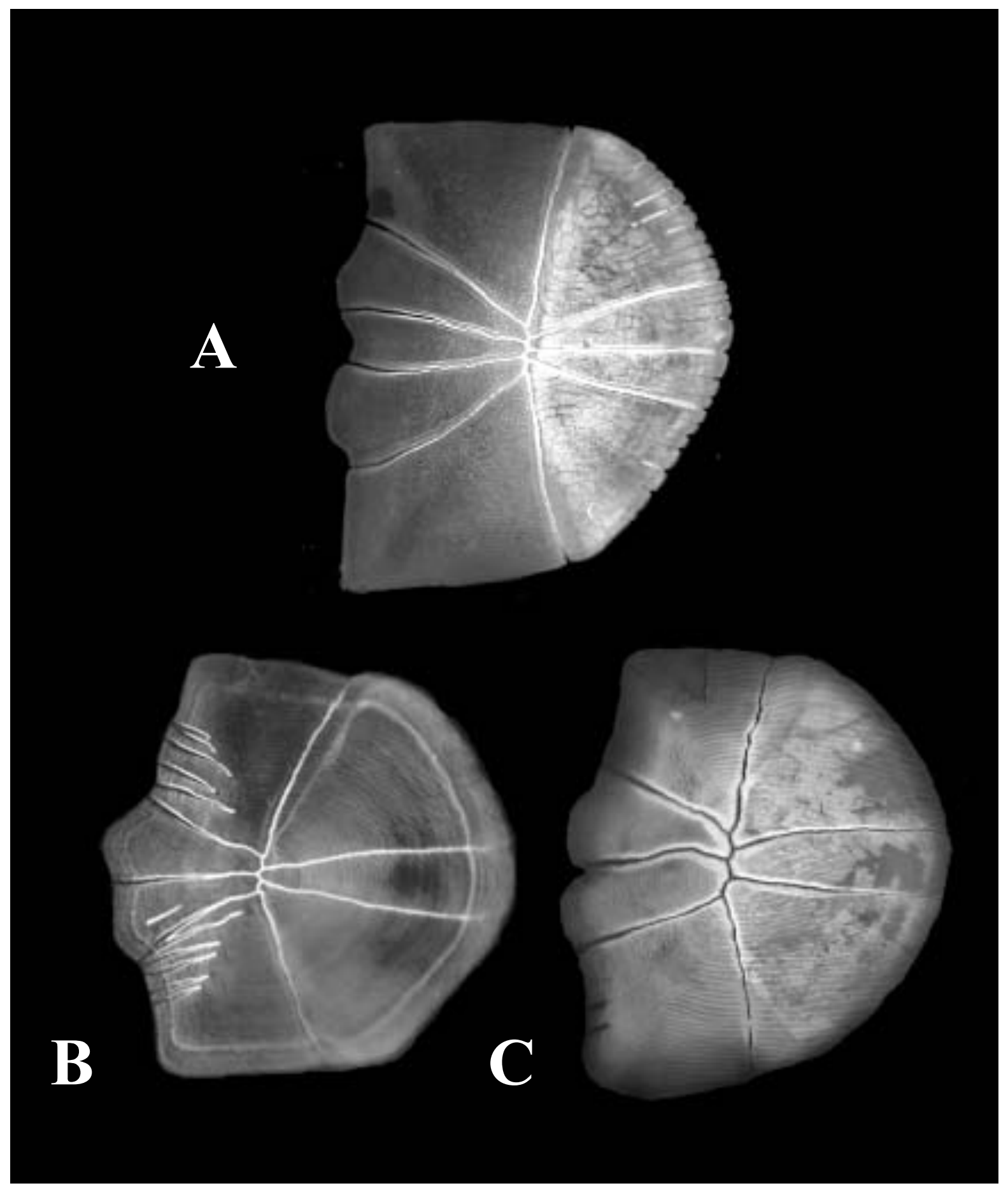

Figura 64. Escamas de (A) Copeina guttata MZUSP 27088, 65,3mm CP, (B) Copella nigrofasciata DEPRJ 104, 43,4 mm CP e (C) Pyrrhulina zigzag MZUSP 61130, 30,7 mm CP. 


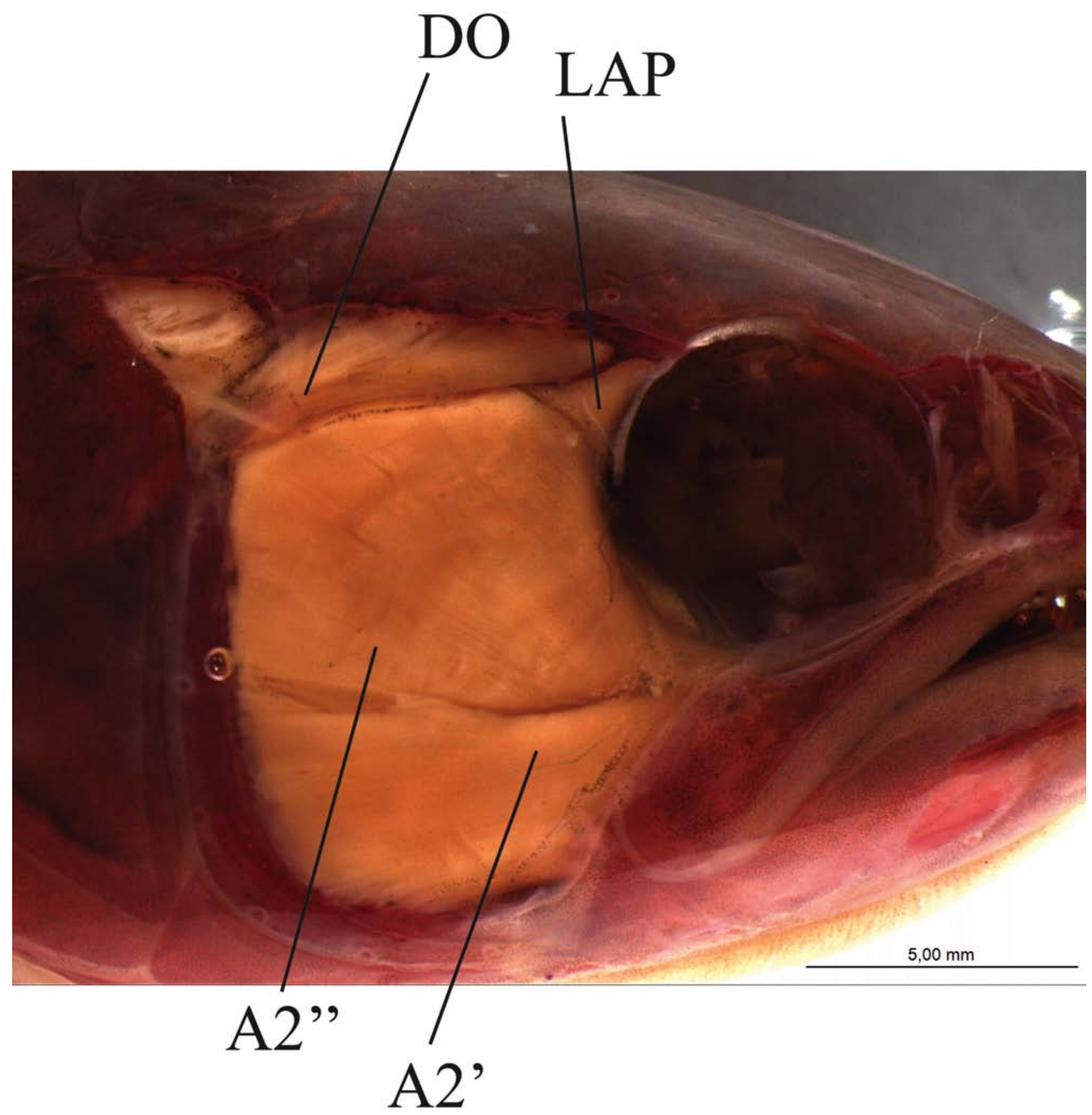

Figura 65. Vista lateral de Hoplerythrinus unitaeniatus (MZUSP 22310, 80.1 mm CP), evidenciando a musculatura facial (A2' e A2" correspondem a seções do adductor mandibulae; $\mathrm{AAP}=$ adductor arcus palatini $; \mathrm{DO}=$ dilatator operculi $; \mathrm{LAP}=$ levator arcus palatini $)$ 


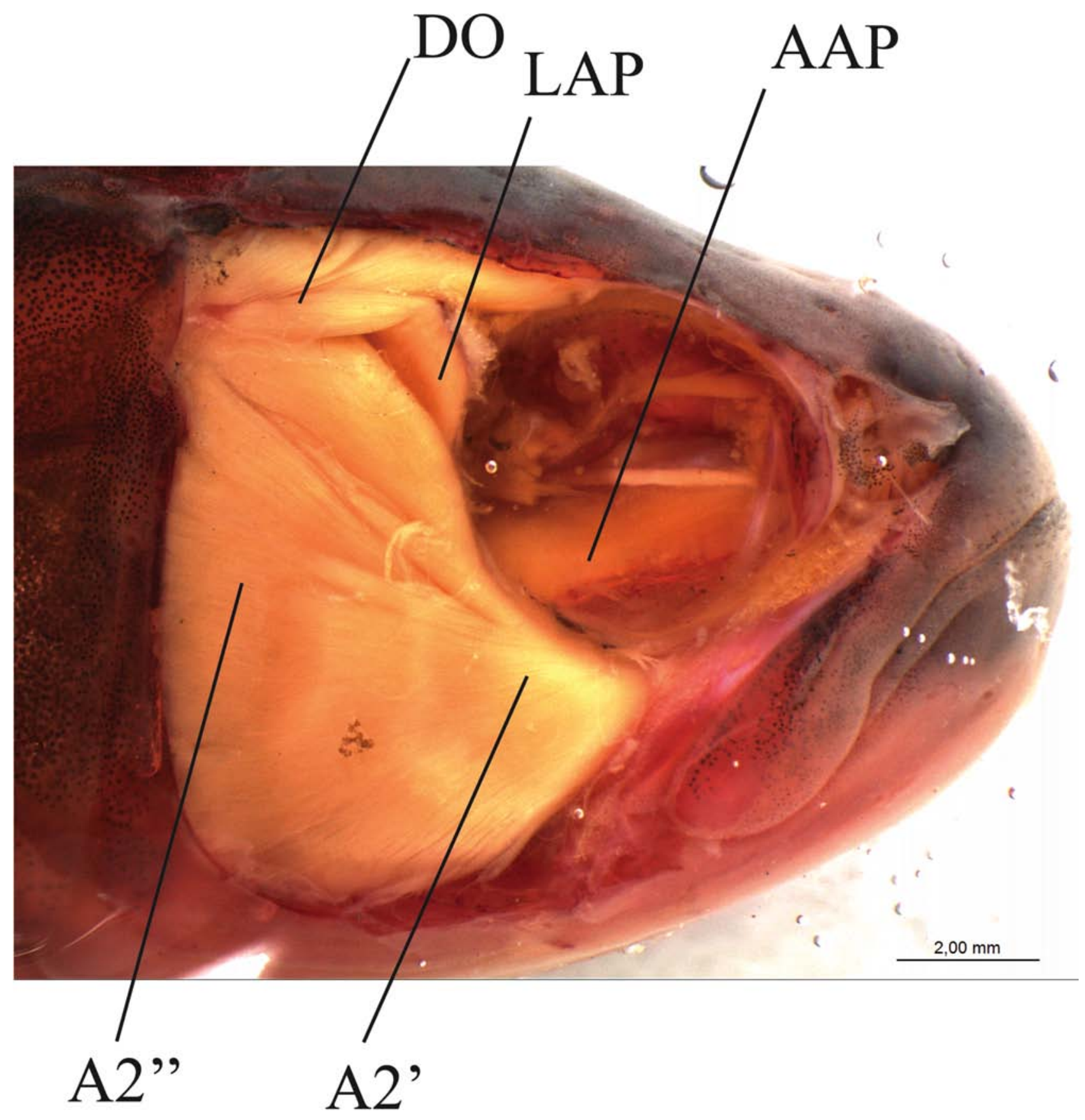

Figura 66. Vista lateral de Lebiasina elongata (MUSM 21356, $76.7 \mathrm{~mm} \mathrm{CP}$ ), evidenciando a musculatura facial (A2' e A2'" correspondem a seções do adductor mandibulae; $\mathrm{AAP}=$ adductor arcus palatini; $\mathrm{DO}=$ dilatator operculi; $\mathrm{LAP}=$ levator arcus palatini $)$. 


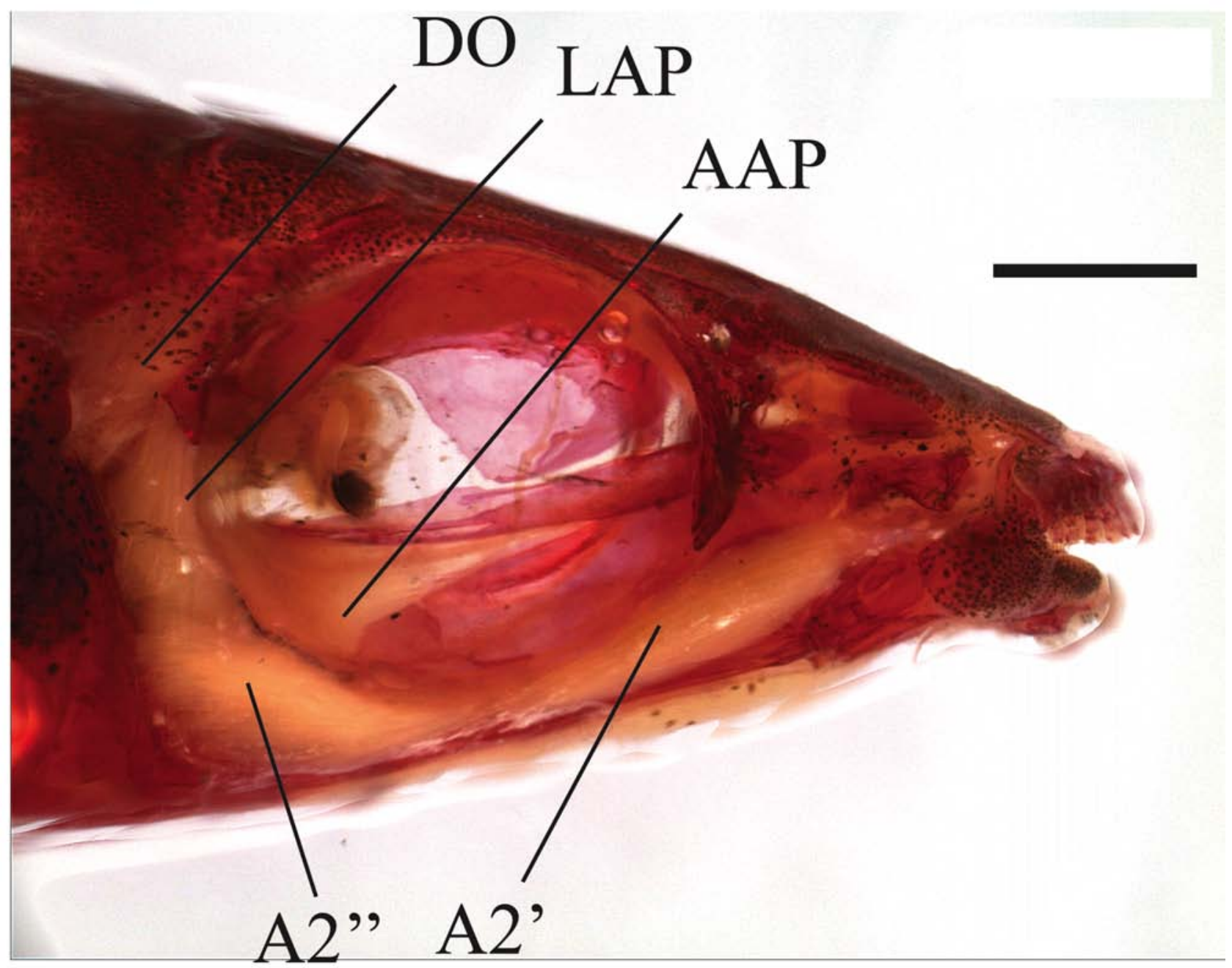

Figura 67. Vista lateral de Nannostomus unifasciatus (MZUSP 29290, $28.4 \mathrm{~mm} \mathrm{CP}$ ), evidenciando a musculatura facial (A2' e A2"' correspondem a seções do adductor mandibulae; AAP= adductor arcus palatini; $\mathrm{DO}=$ dilatator operculi; $\mathrm{LAP}=$ levator arcus palatini $)$. 


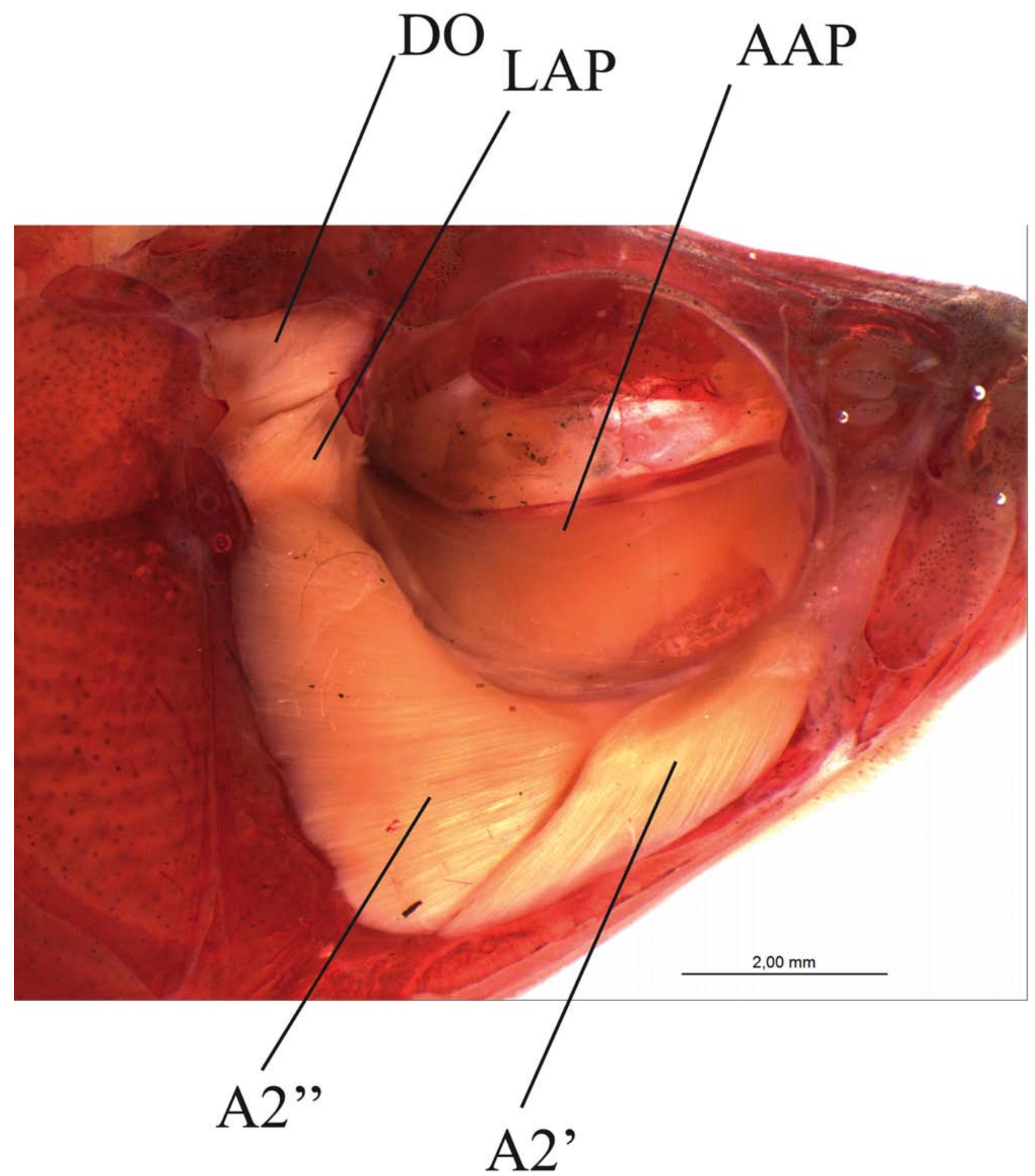

Figura 68. Vista lateral de Copeina guttata (MZUSP 27088, $61.2 \mathrm{~mm} \mathrm{CP}$ ), evidenciando a musculatura facial (A2' e A2' correspondem a seções do adductor mandibulae; AAP=adductor arcus palatini; $\mathrm{DO}=$ dilatator operculi; $\mathrm{LAP}=$ levator arcus palatini). 


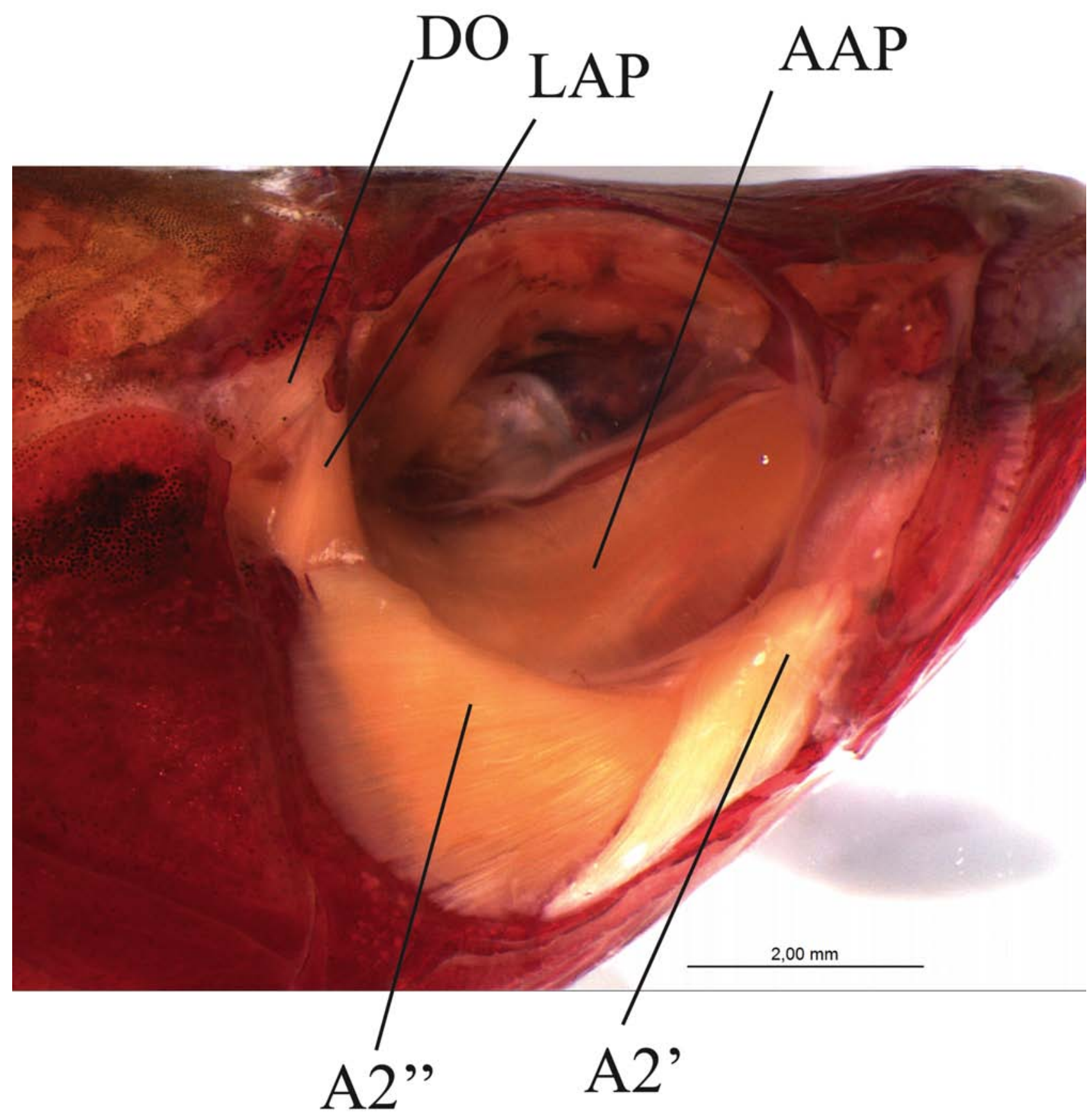

Figura 69. Vista lateral de Pyrrhulina semifasciata (MZUSP 24154, $45.9 \mathrm{~mm} \mathrm{CP}$ ), evidenciando a musculatura facial (A2' e A2"' correspondem a seções do adductor mandibulae; AAP= adductor arcus palatini; $\mathrm{DO}=$ dilatator operculi $\mathrm{LAP}=$ levator arcus palatini $)$. 


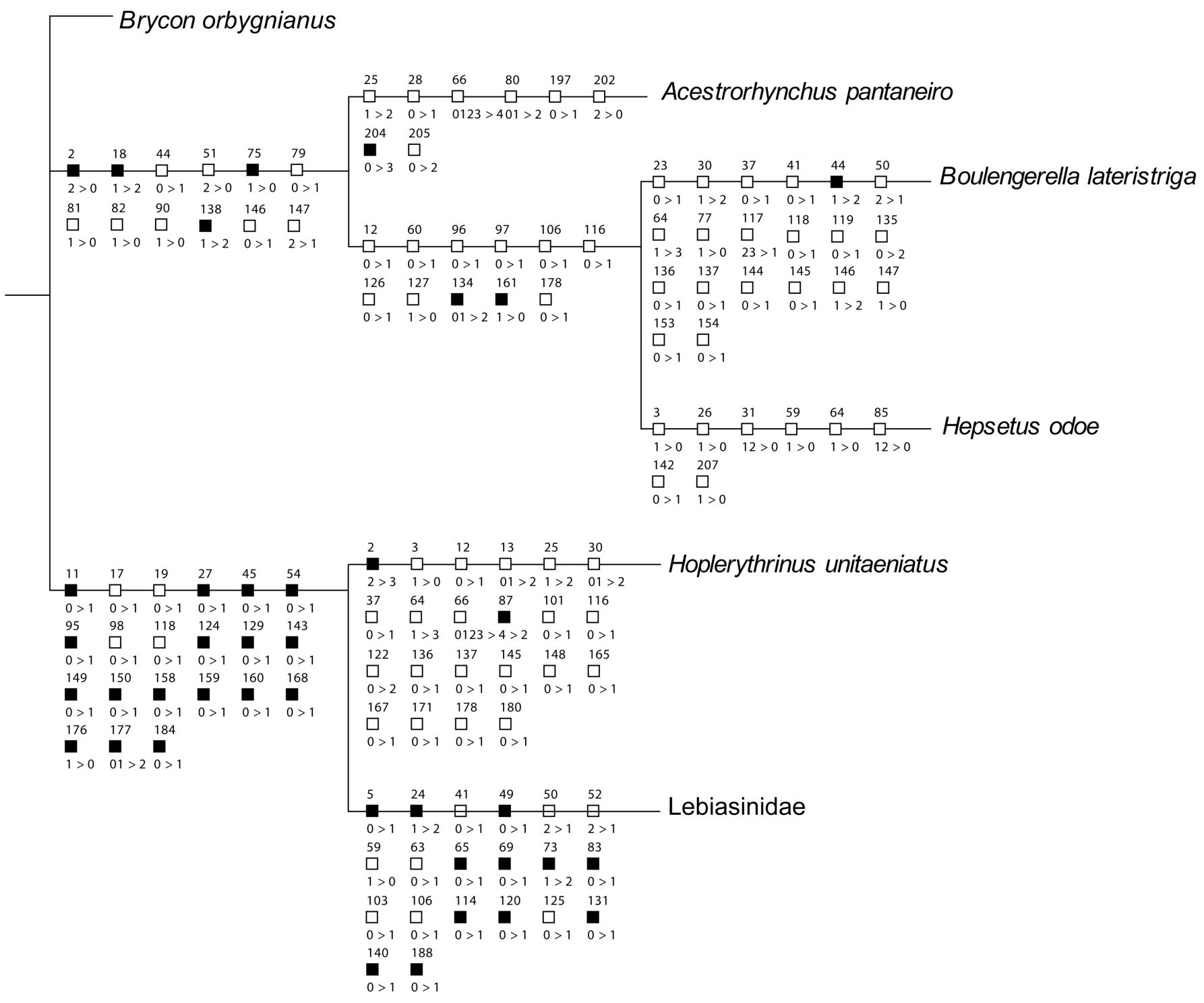

Figura 70. Sinapomorfias do grupo externo referentes à topologia da árvore fundamental resultante da análise de parcimônia. Símbolos claros representam transformações com homoplasia, símbolos escuros representam transformações exclusivas. Apenas transformações não ambíguas demonstradas (continua nas figuras 71-75). 


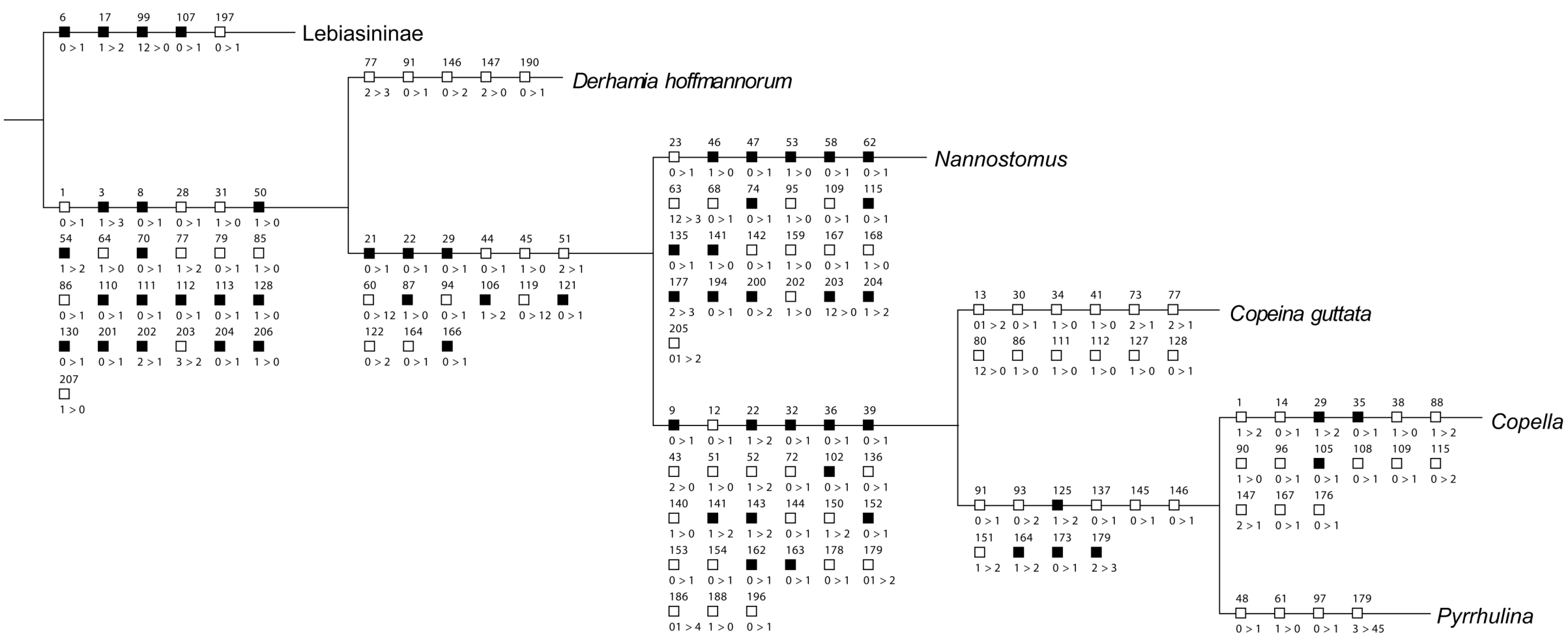

Figura 71. Sinapomorfias do grupo-externo referentes à topologia da árvore fundamental resultante da análise de parcimônia. Símbolos claros representam transformações com homoplasia, símbolos escuros representam transformações exclusivas. Apenas transformações não ambíguas demonstradas (continua nas figuras 72-75). 


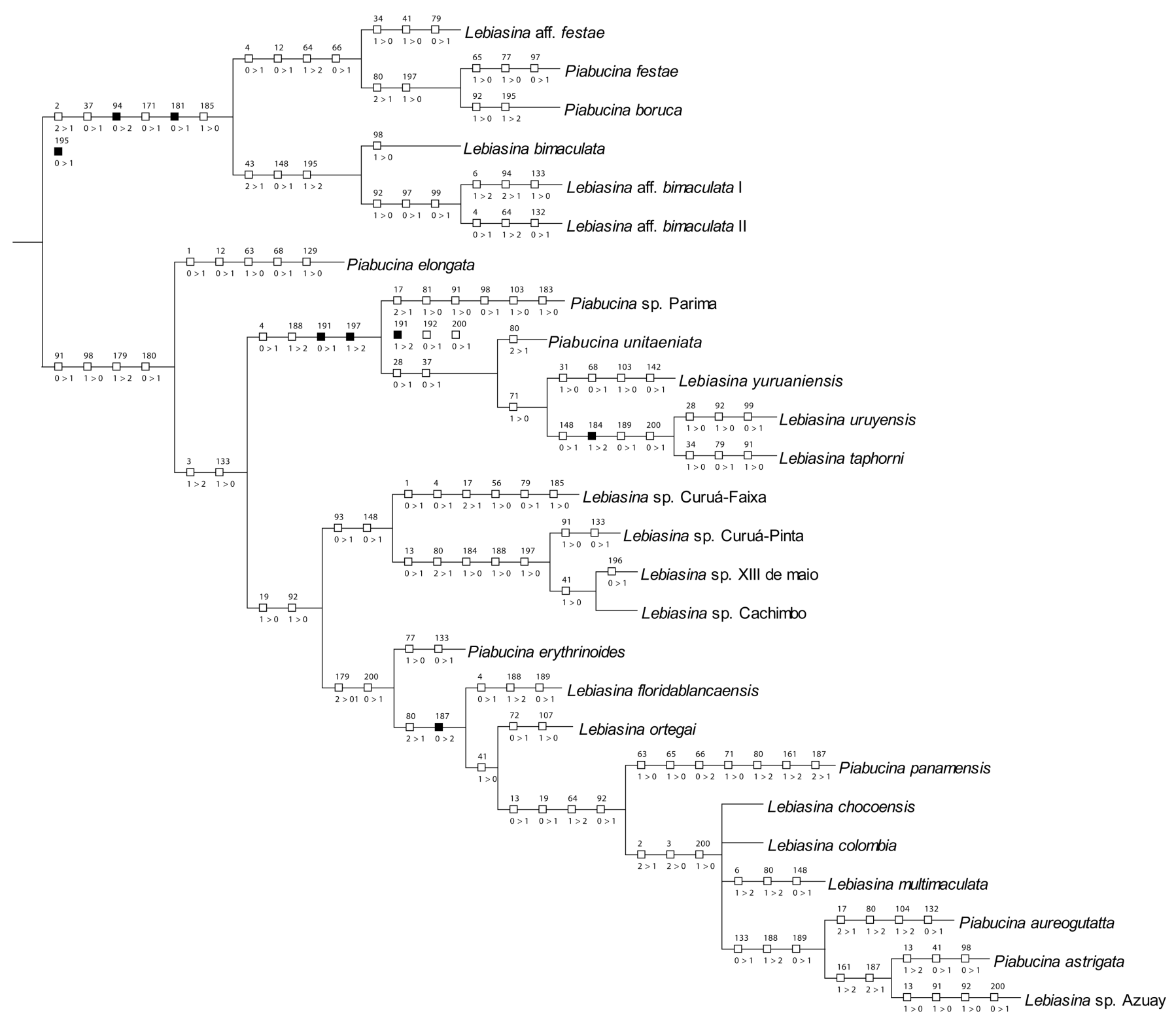

Figura 72. Sinapomorfias do grupo-interno referentes à topologia da árvore fundamental resultante da análise de parcimônia. Símbolos claros representam transformações com homoplasia, símbolos escuros representam transformações exclusivas. Apenas transformações não ambíguas demonstradas (continua nas figuras 73-75). 


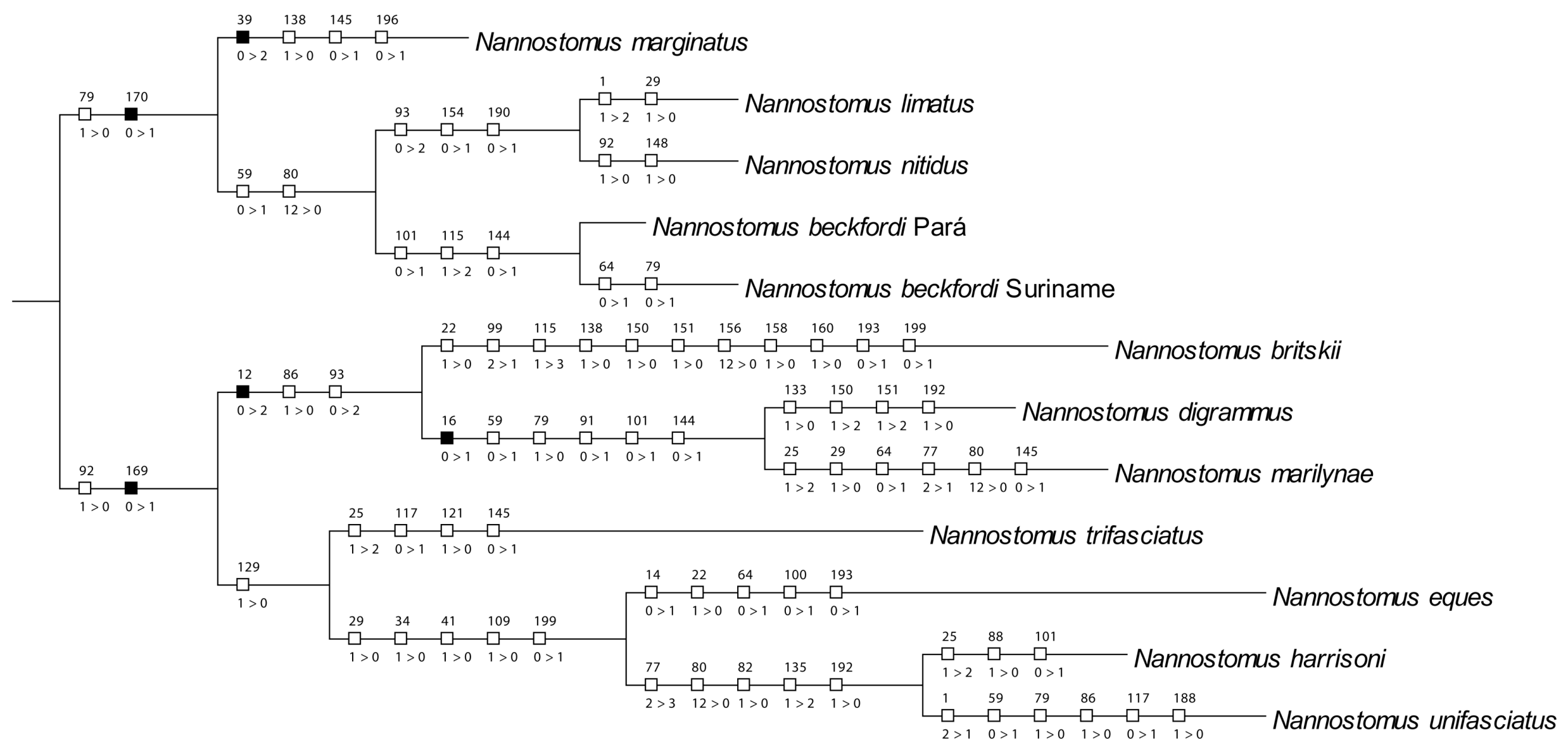

Figura 73. Sinapomorfias do grupo-interno referentes à topologia da árvore fundamental resultante da análise de parcimônia. Símbolos claros representam transformações com homoplasia, símbolos escuros representam transformações exclusivas. Apenas transformações não ambíguas demonstradas (continua nas figuras 74-75). 


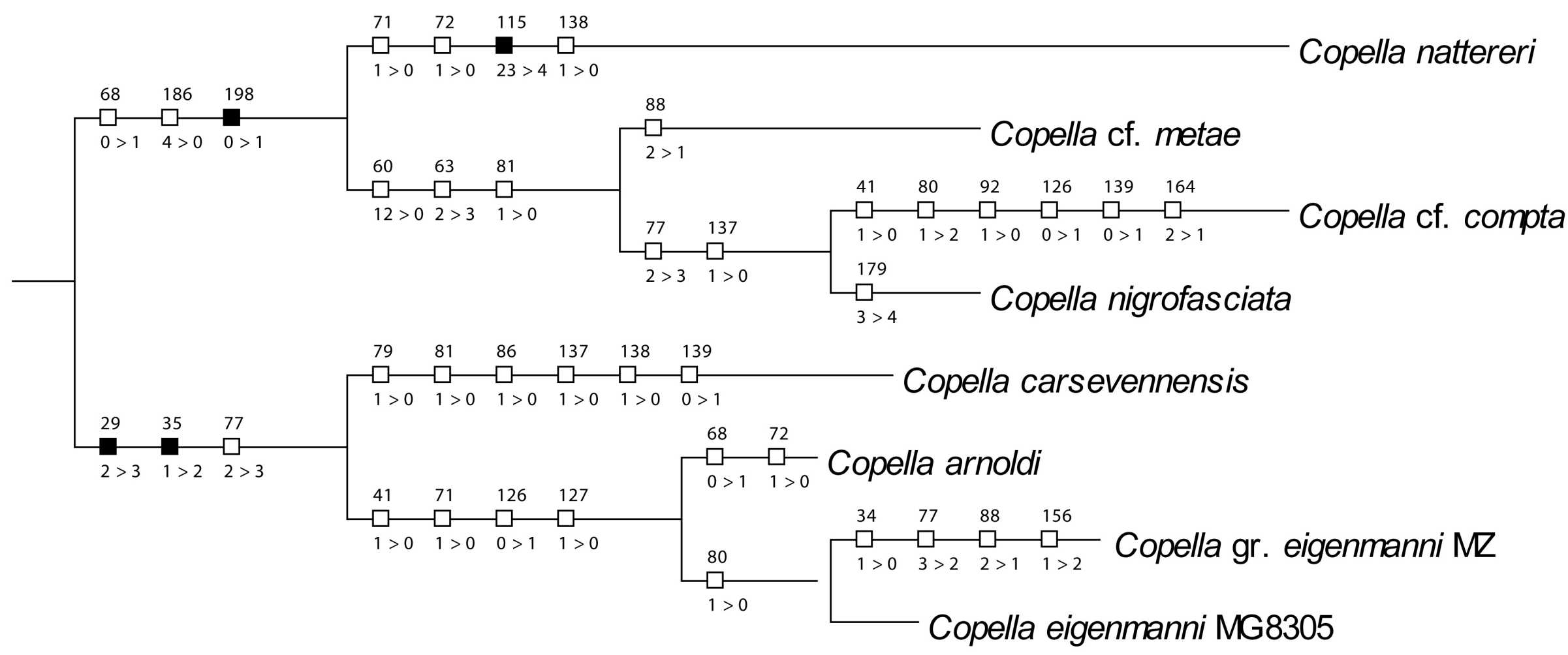

Figura 74. Sinapomorfias do grupo-externo referentes à topologia da árvore fundamental resultante da análise de parcimônia. Símbolos claros representam transformações com homoplasia, símbolos escuros representam transformações exclusivas. Apenas transformações não ambíguas demonstradas (continua na figura 75). 


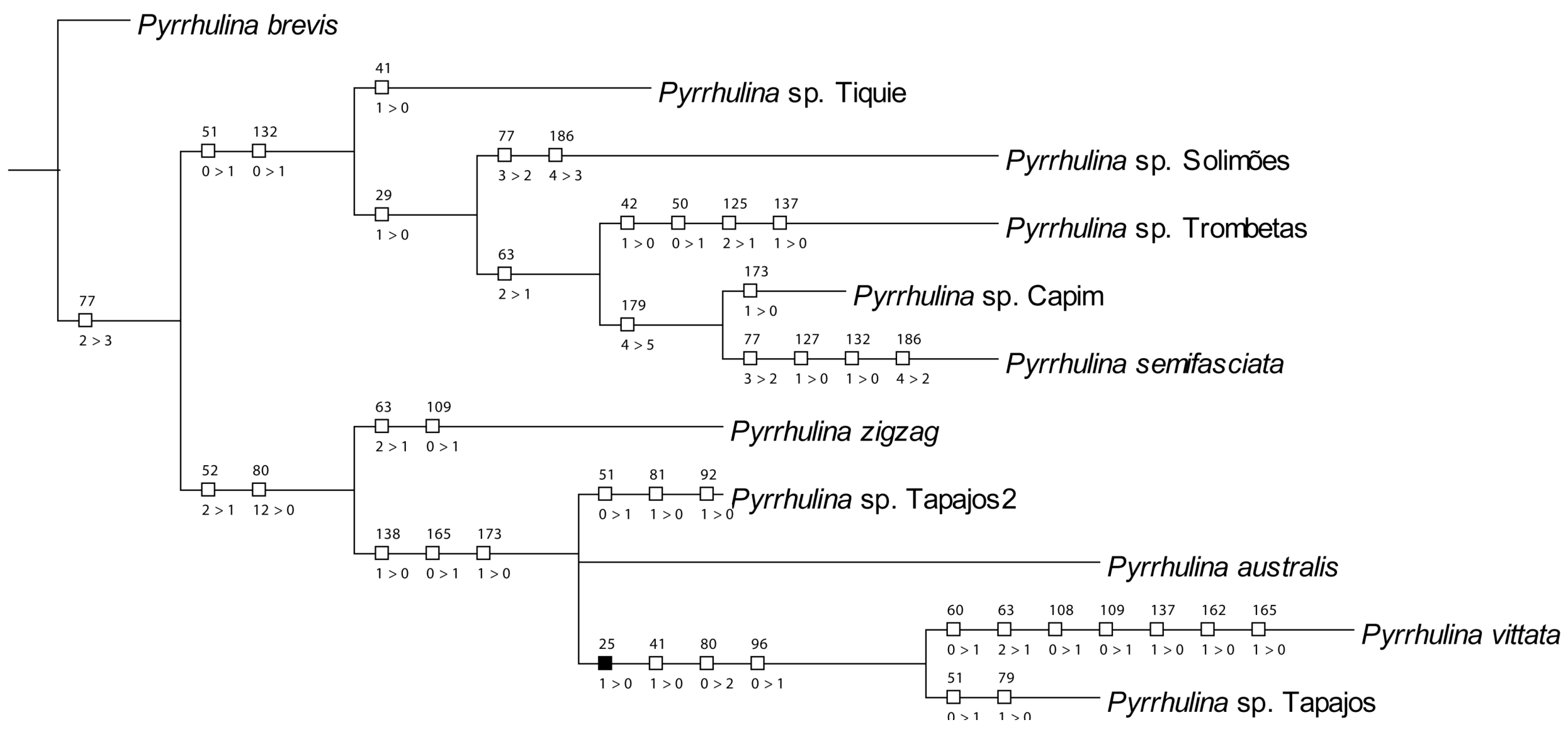

Figura 75. Sinapomorfias do grupo-externo referentes à topologia da árvore fundamental resultante da análise de parcimônia. Símbolos claros representam transformações com homoplasia, símbolos escuros representam transformações exclusivas. Apenas transformações não ambíguas demonstradas. 


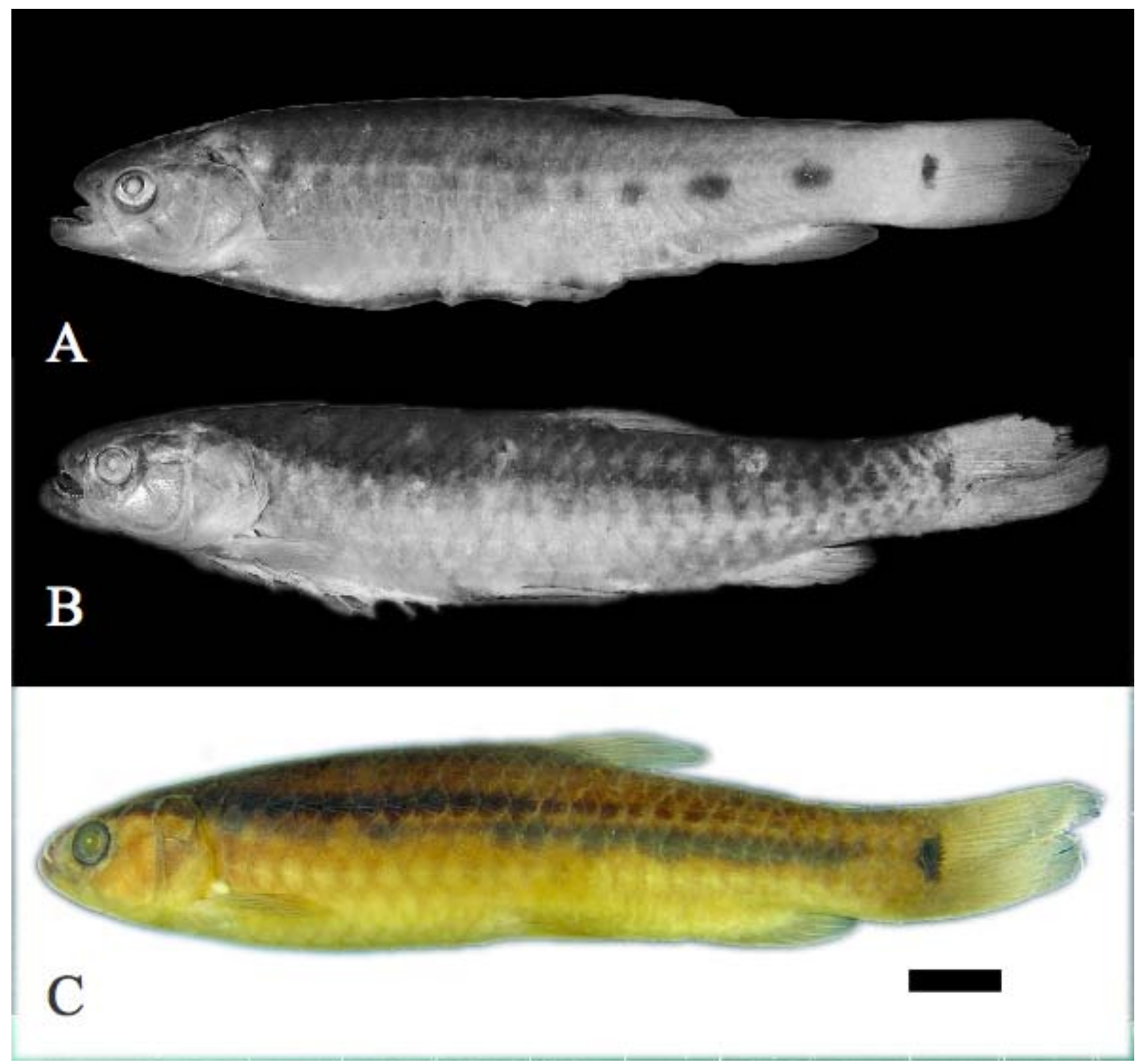

Figura 76. Lebiasina astrigata: A- BMNH 1898.4.28:164-6 síntipo (69.0 mm SL), Equador, Carchi/Imbabura, Paramba; B- BMNH 1902.7.29:59 lectótipo (160 mm SL), Esmeraldas, Río Sapayo; C- ICNMHN 2340 holótipo de L. narinensis (101.8 mm SL), Colômbia, Nariño, 

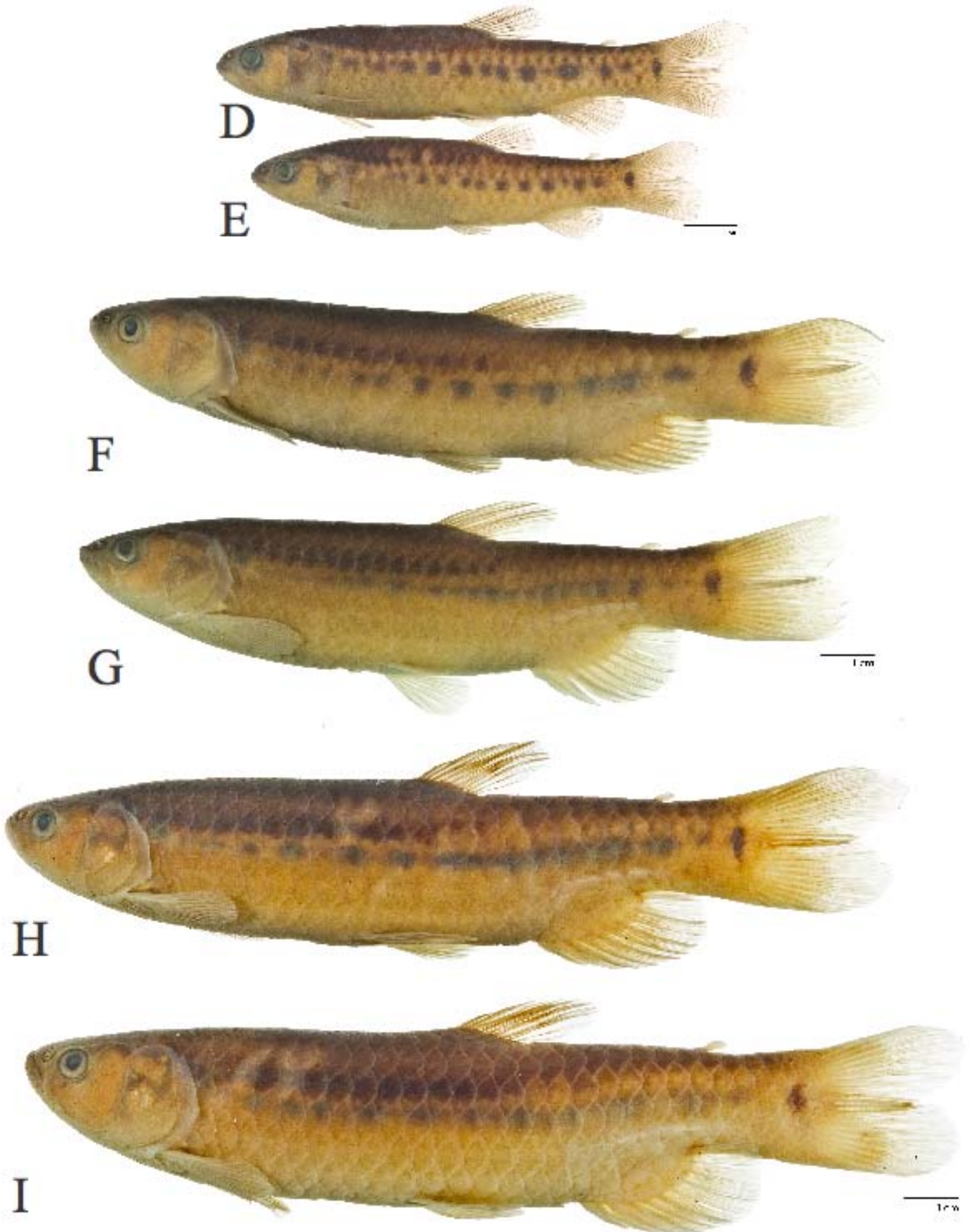

Figura 76 (continuação). 


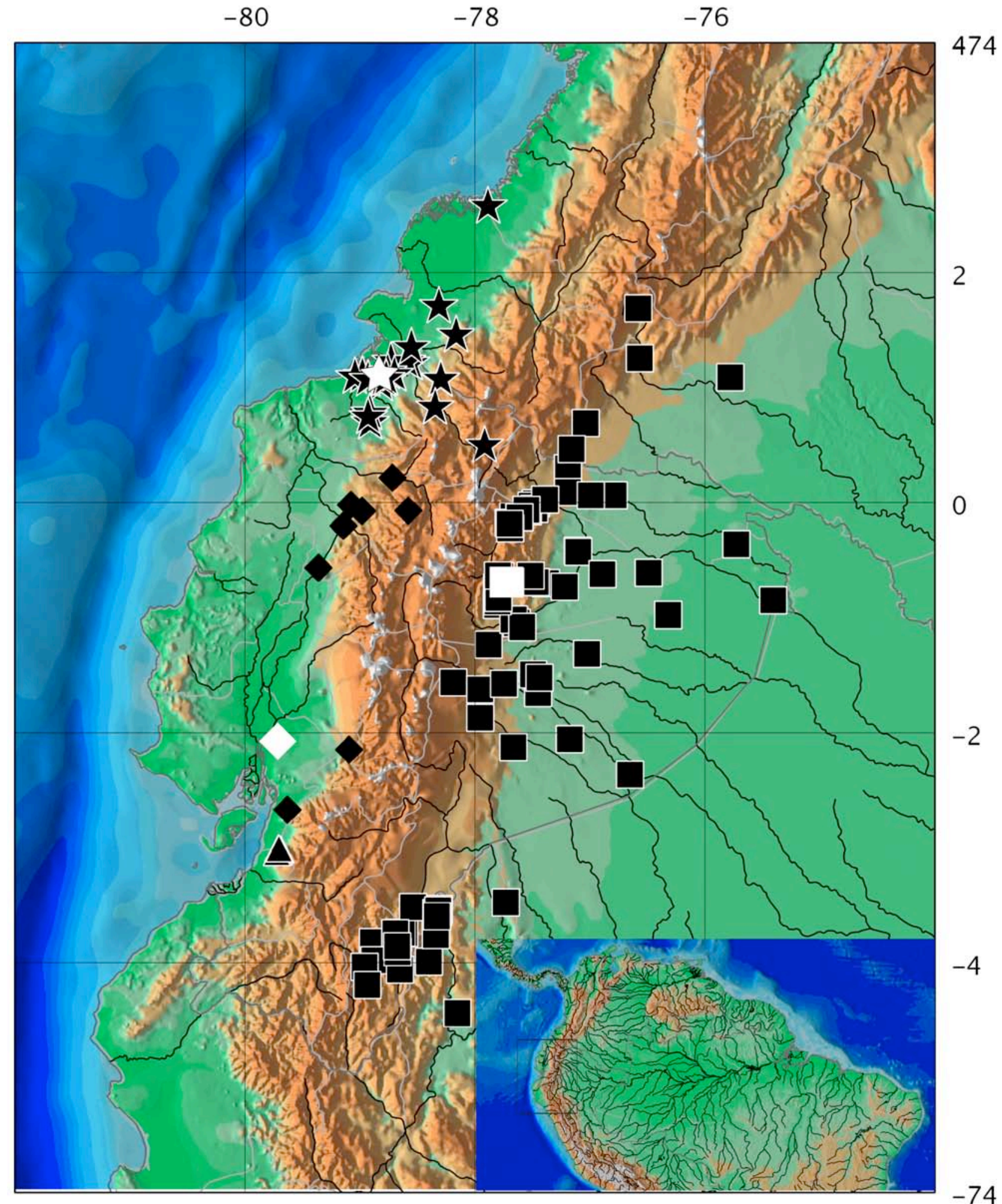

Figura 77. Mapa do noroeste da América do Sul com a distribuição de: Lebiasina astrigata (estrelas), L. aureogutatta (losangos); L. elongata (quadrados) e L. sp. Azuay (triângulos). Localidades-tipo representadas por polígonos brancos. 

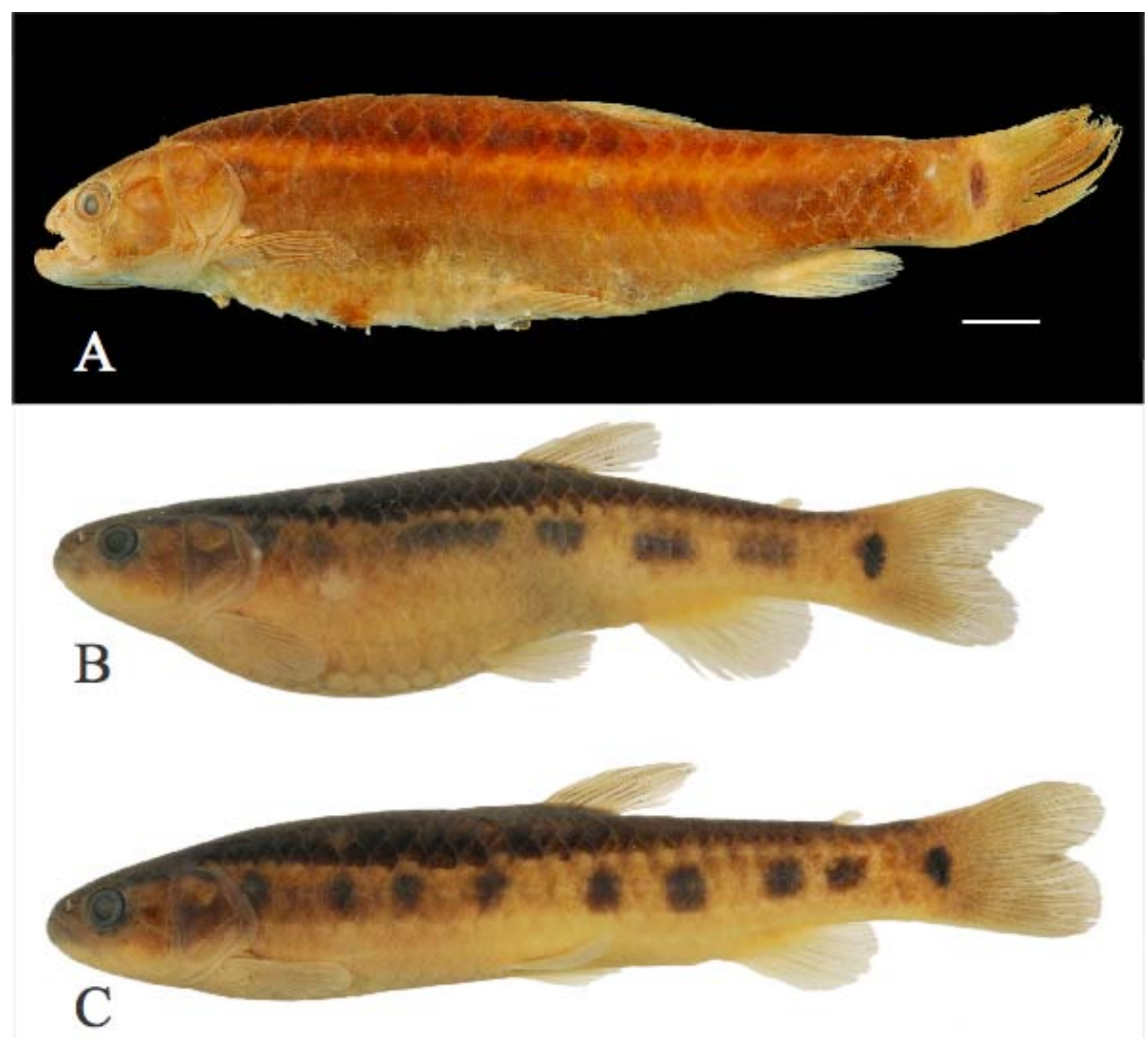

Figura 78. Lebiasina aureoguttata: 

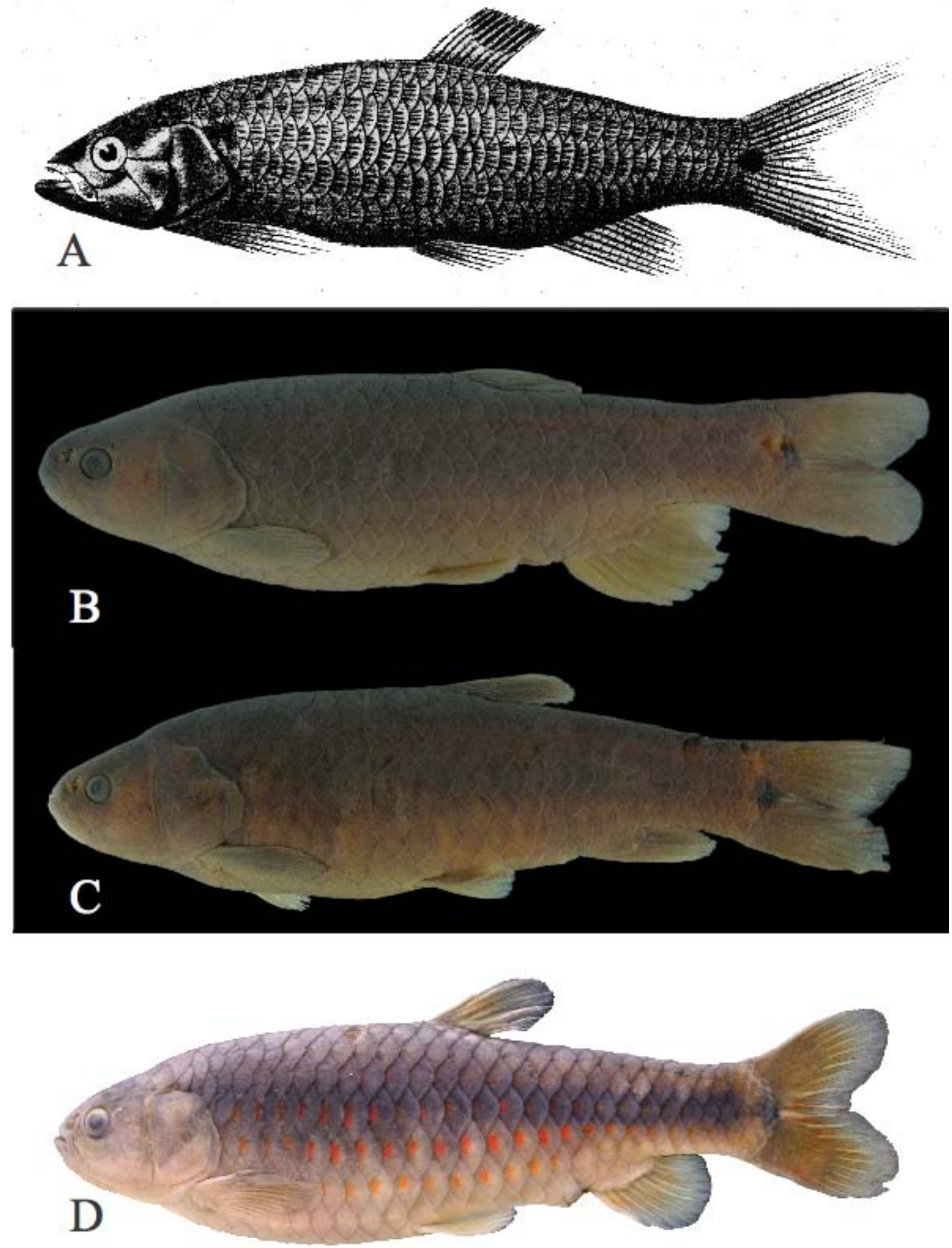

Figura 79. Lebiasina bimaculata: 


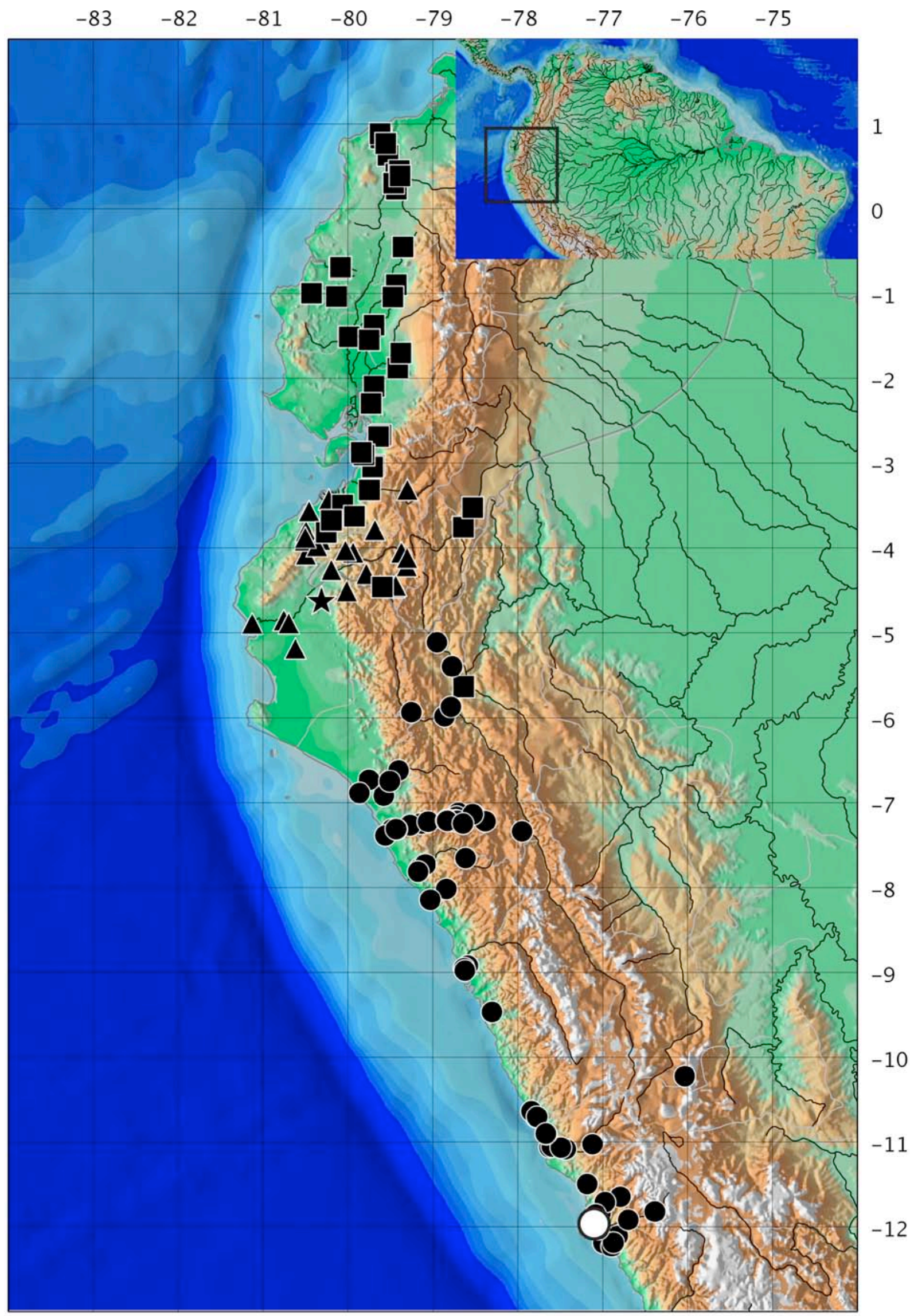

Figura 80. Mapa do noroeste da América do Sul com a distribuição de: Lebiasina bimaculata (círculos), Lebiasina aff. bimaculata I (triângulos), Lebiasina aff. bimaculata II (estrela) e Lebiasina aff. festae (quadrados). Localidades-tipo representadas por polígonos brancos 

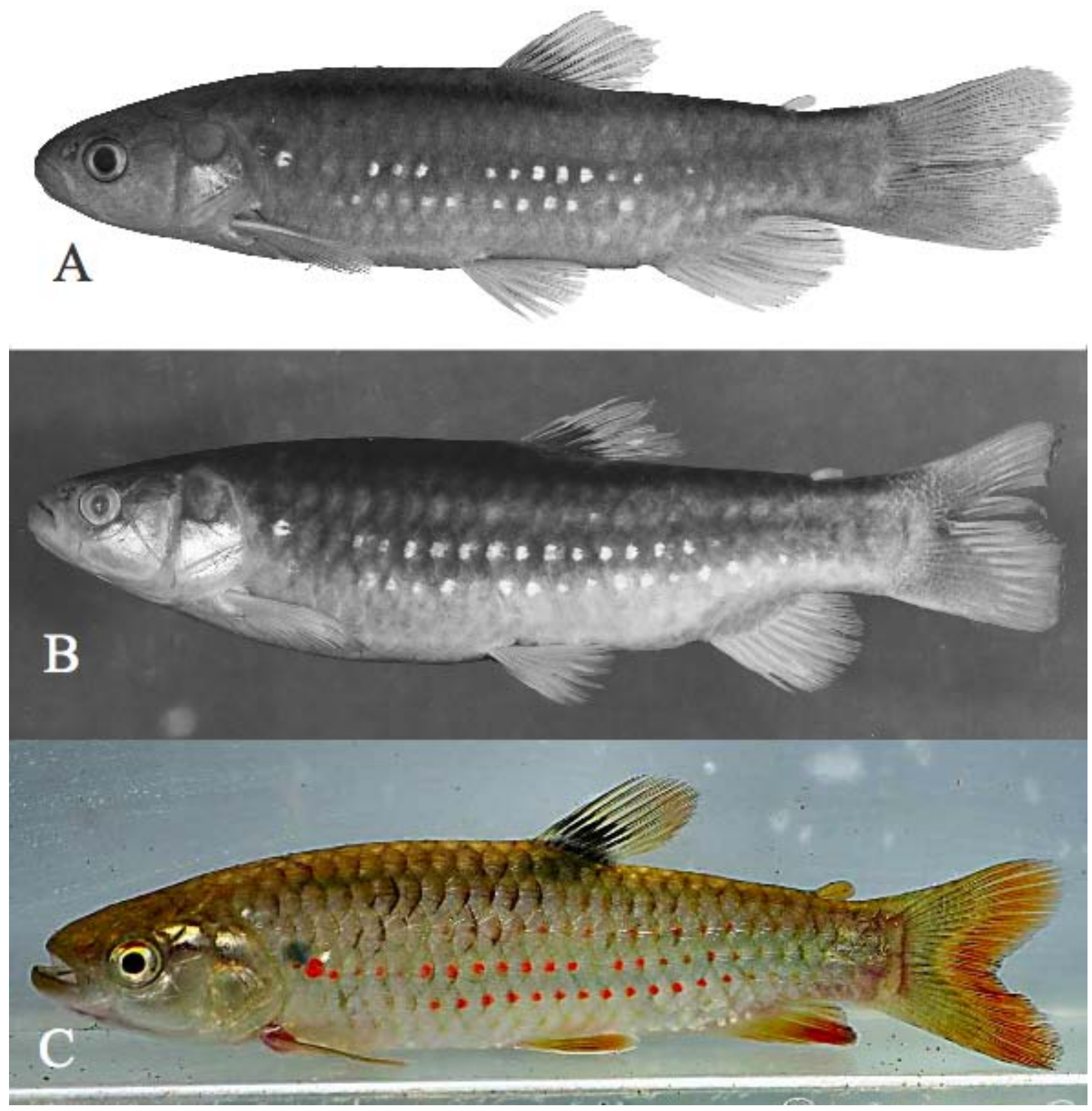

Figura 81. Lebiasina boruca: 


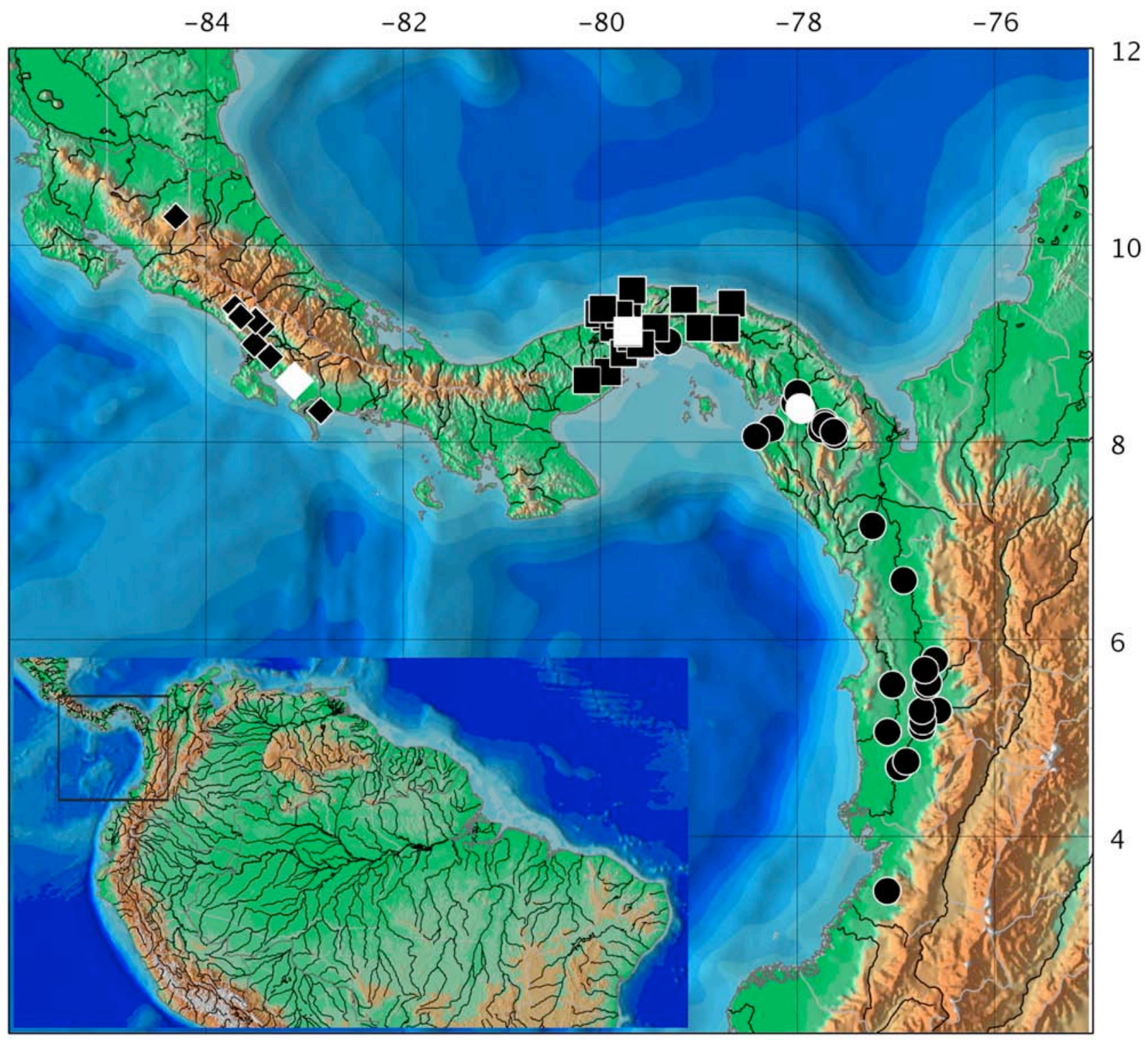

Figura 82. Mapa do noroeste da América do Sul e sul da América com a distribuição de: Lebiasina boruca (losangos), L. festae (círculos) e L. panamensis (quadrados). Localidades-tipo representada por polígonos brancos. 


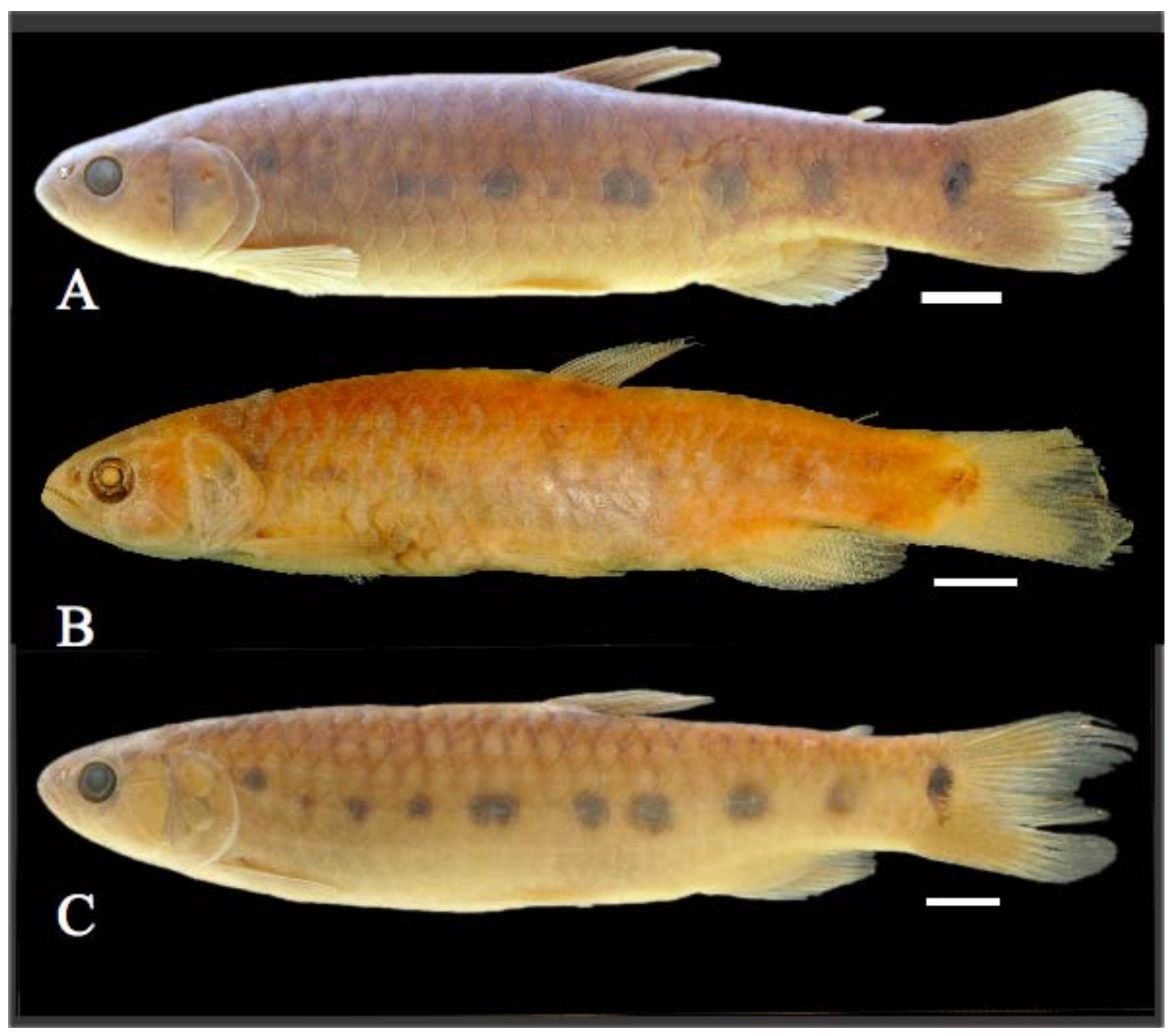

Figura 83. Lebiasina chocoensis: 


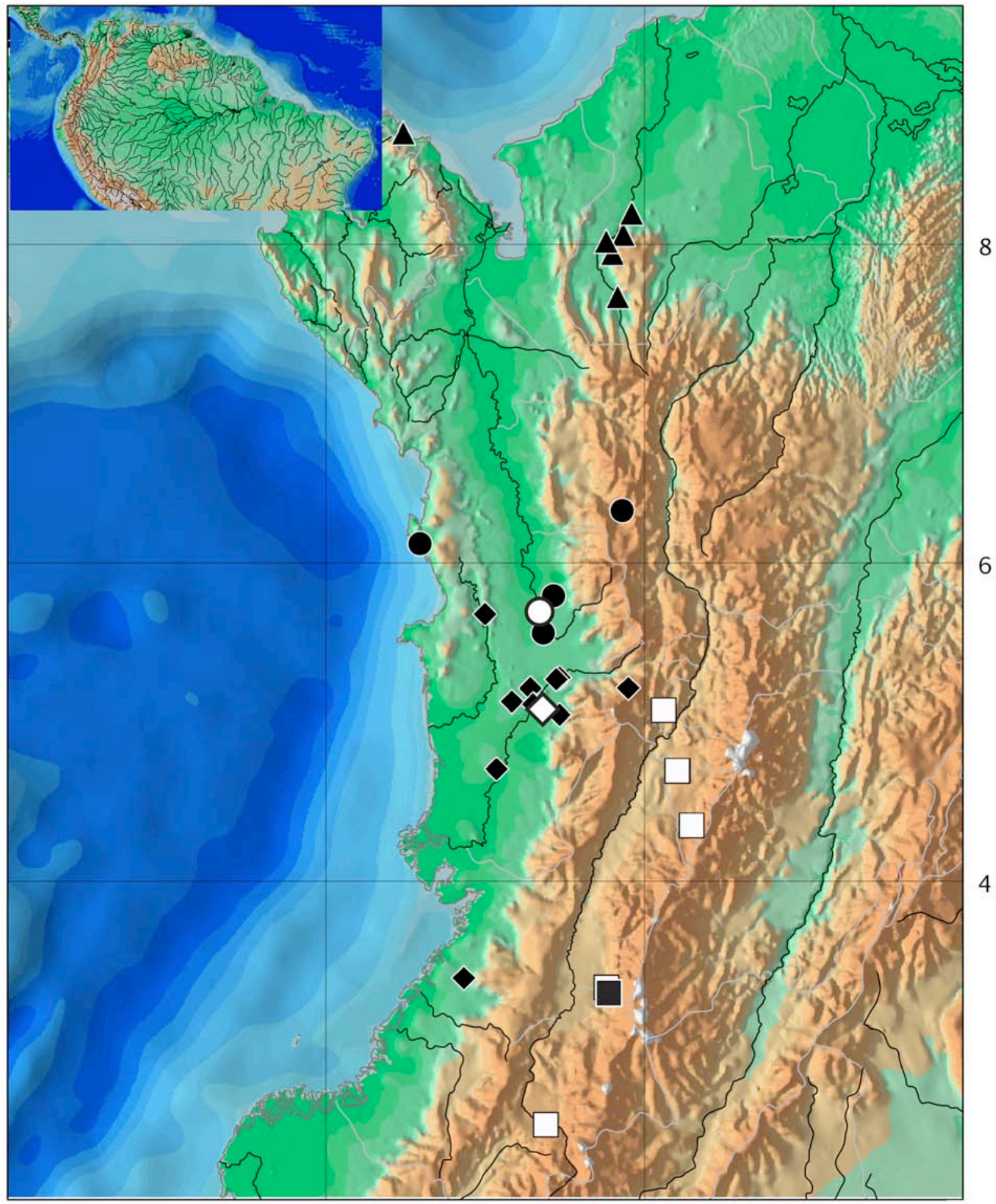

Figura 84. Mapa do noroeste da América do Sul com a distribuição de: Lebiasina chocoensis (círculos), L. colombia (triângulos), L. multimaculata (losangos), L. ortegai (quadrados). Localidades-tipo representada por polígonos brancos 

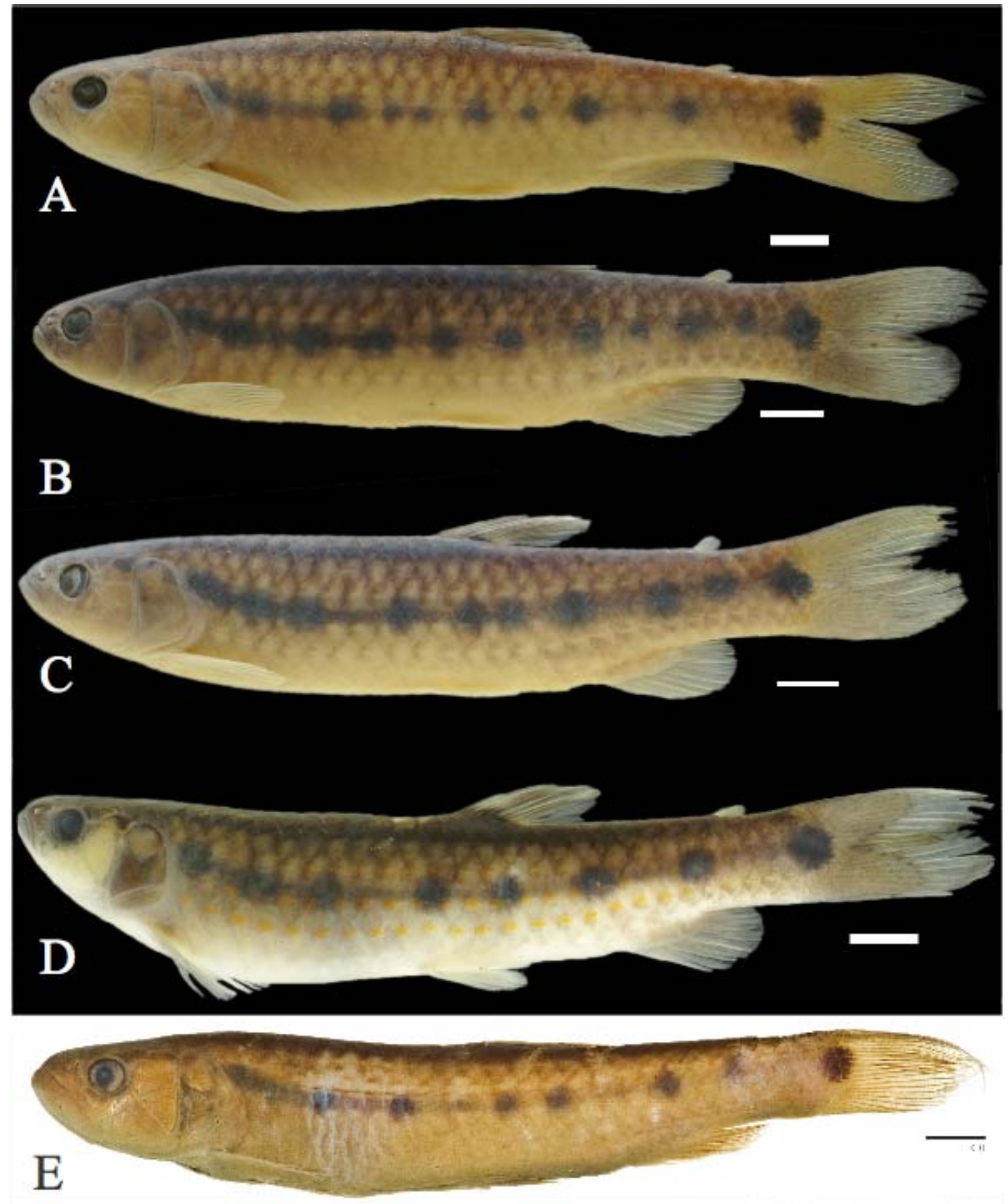

Figura 85. Lebiasina colombia: 

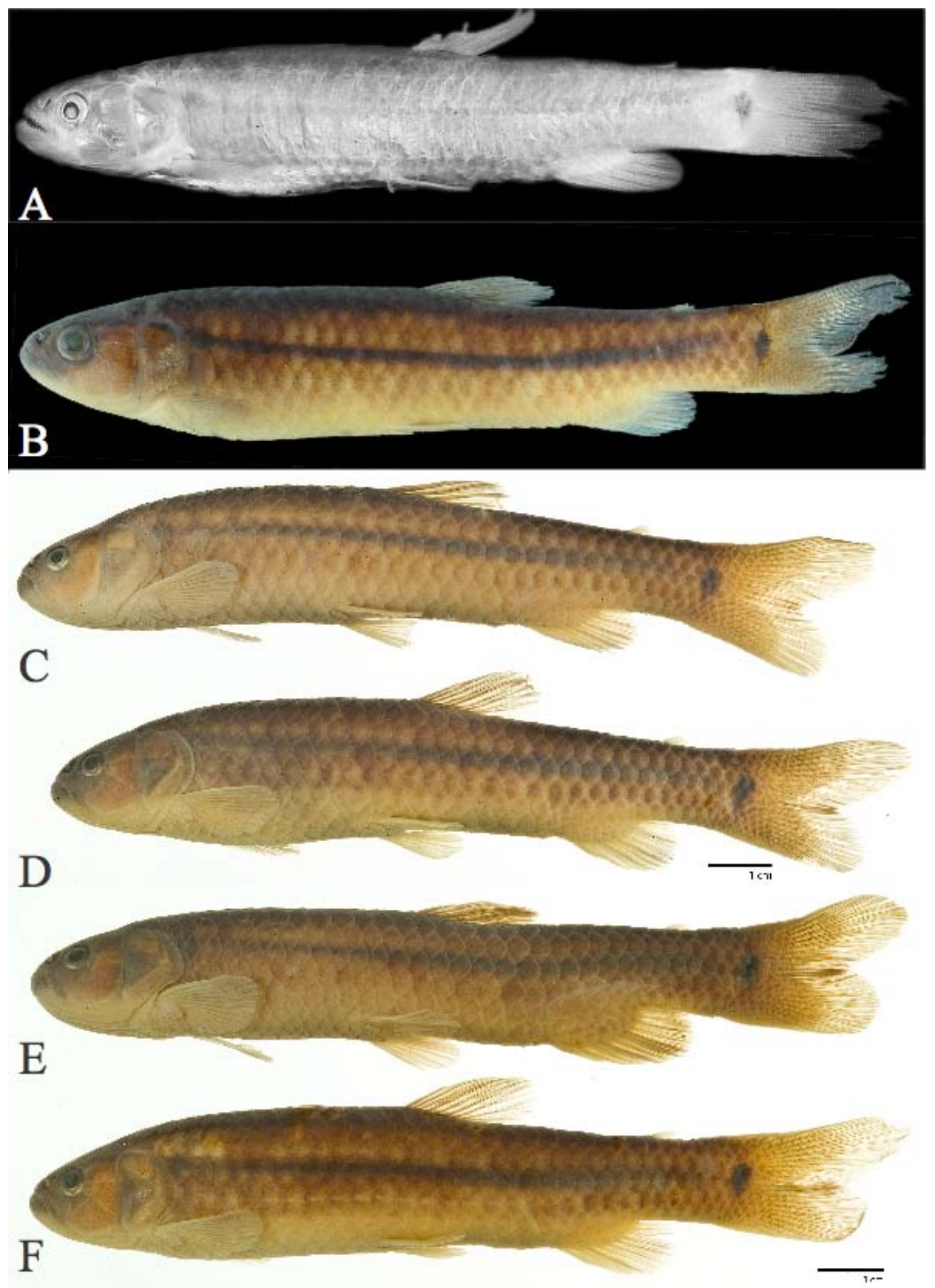

Figura 86. Lebiasina elongata: 


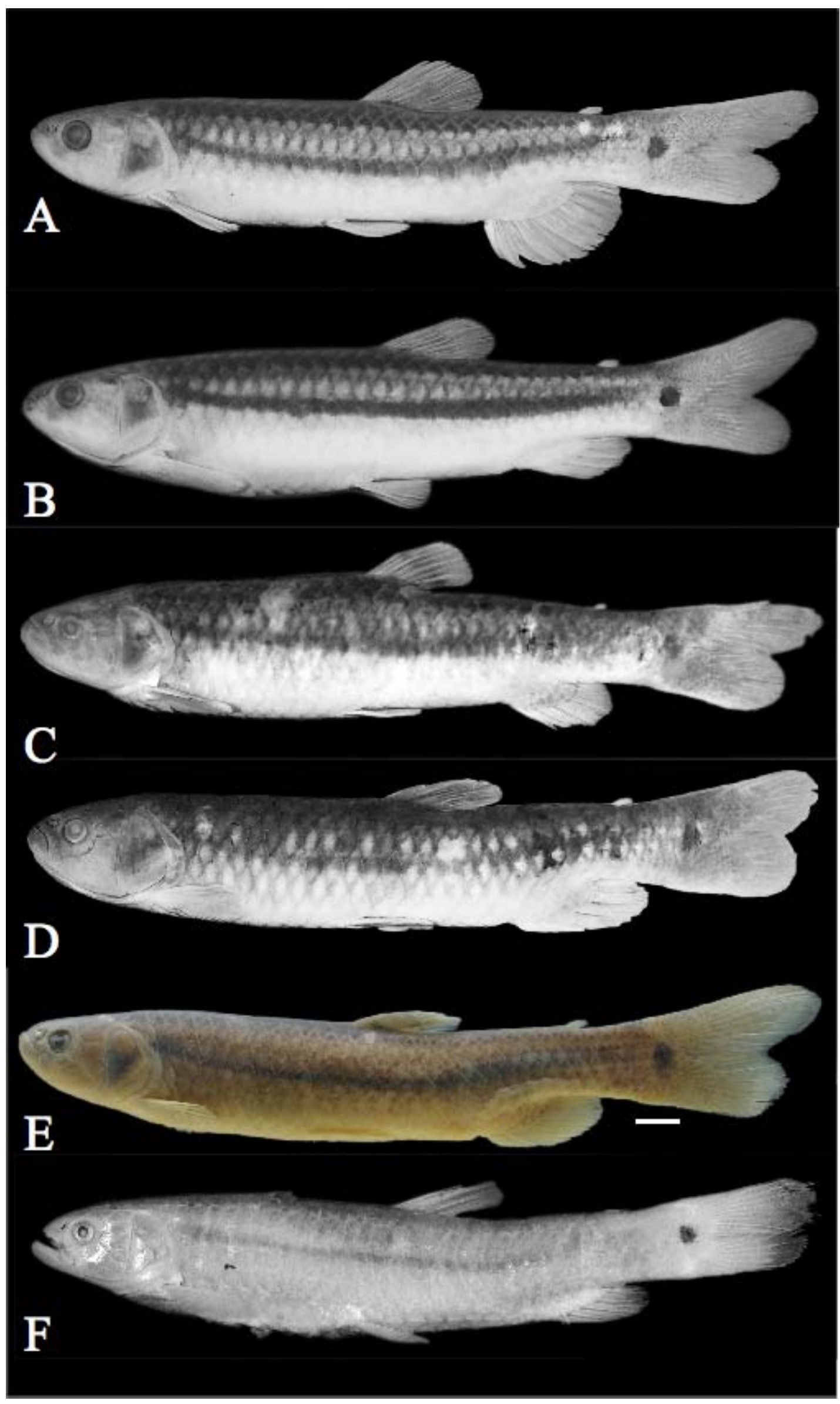

Figura 87. Lebiasina erythrinoides: 
$-74.0$

$-72.0$

$-70.0$

$-68.0$

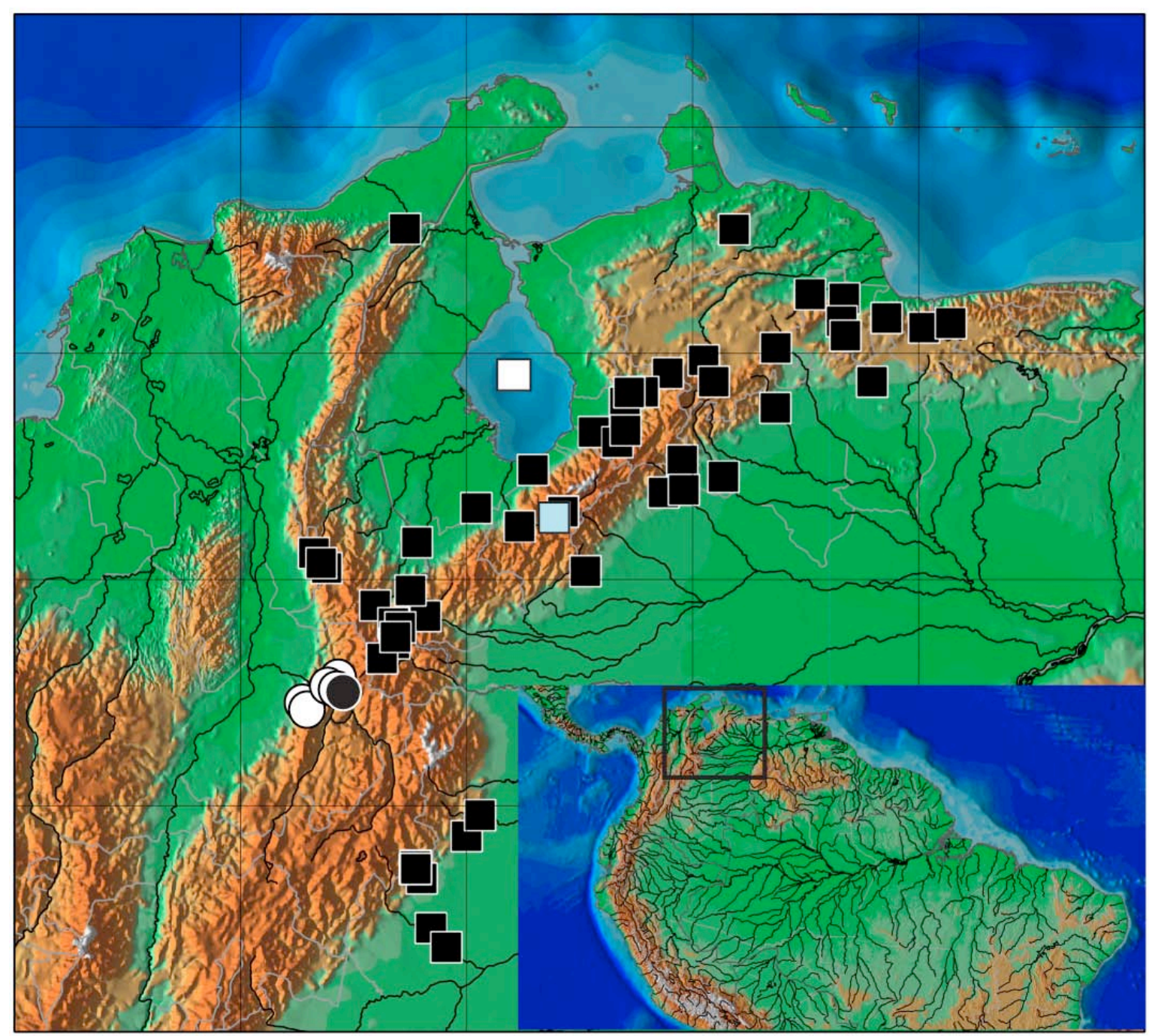

$-66.0$

12.0

10.0

8.0

6.0

Figura 88. Mapa do norte da América do Sul com a distribuição de: Lebiasina erythrinoides (quadrados) e Lebiasina floridablancaensis (círculos). Localidades-tipo representadas por quadrado branco e círculo escuro. Localidade-tipo de L. pleurotaenia apontada em cinza. 


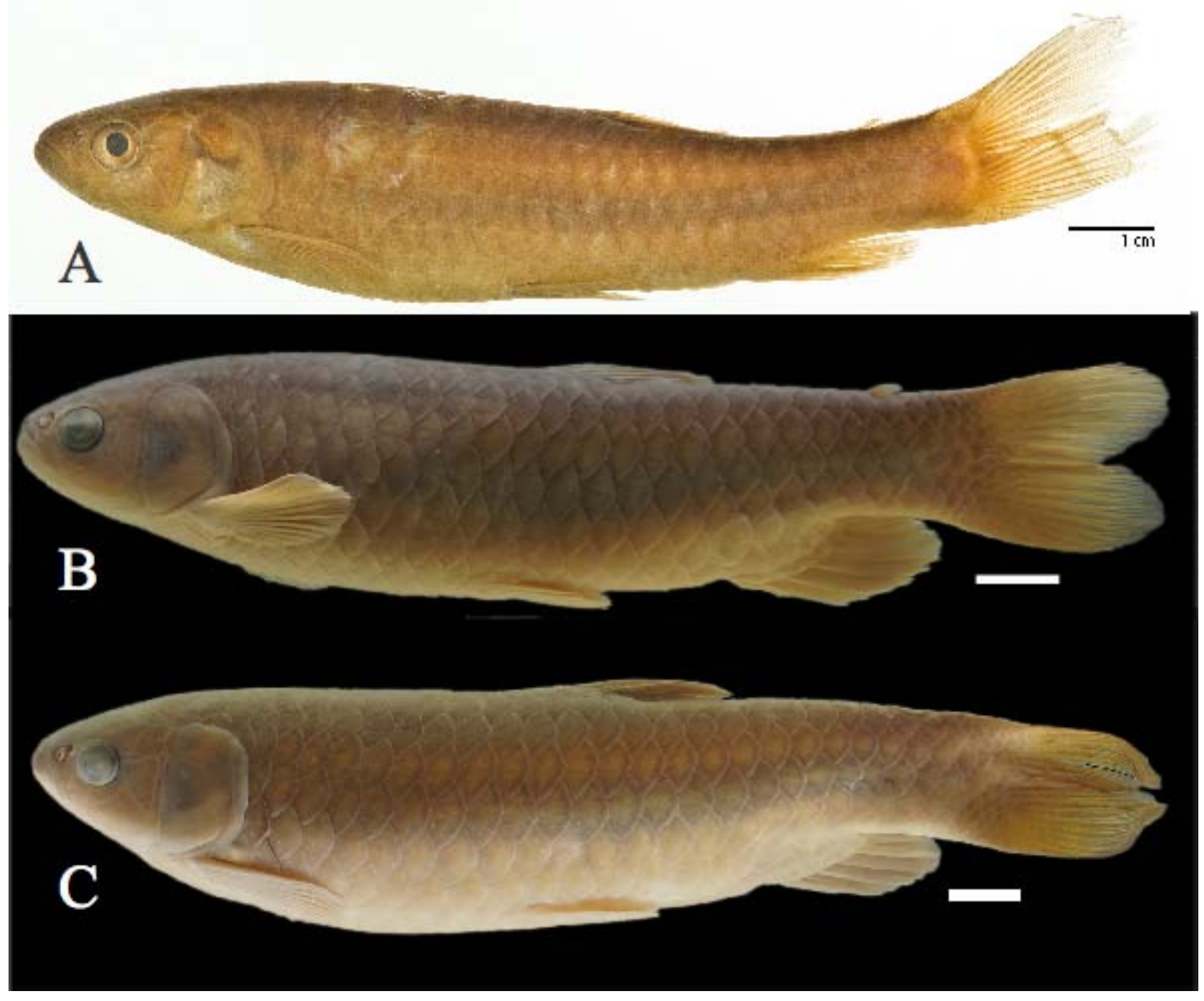

Figura 89. Lebiasina festae 


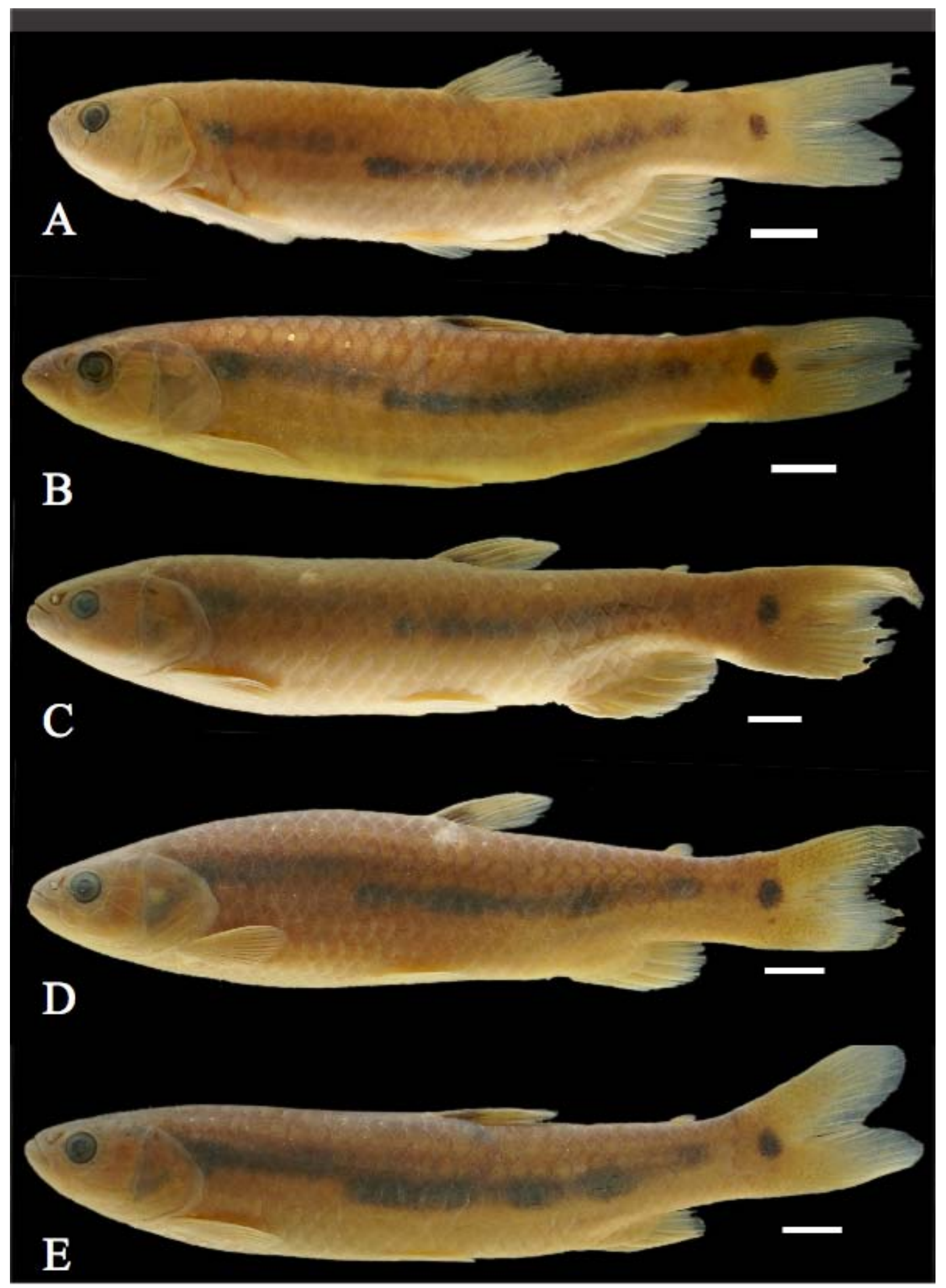

Figura 90. Lebiasina floridablancaensis: 
Figura 91. Ilustração original de Lebiasina intermedia, retirada de Meinken (1937). 


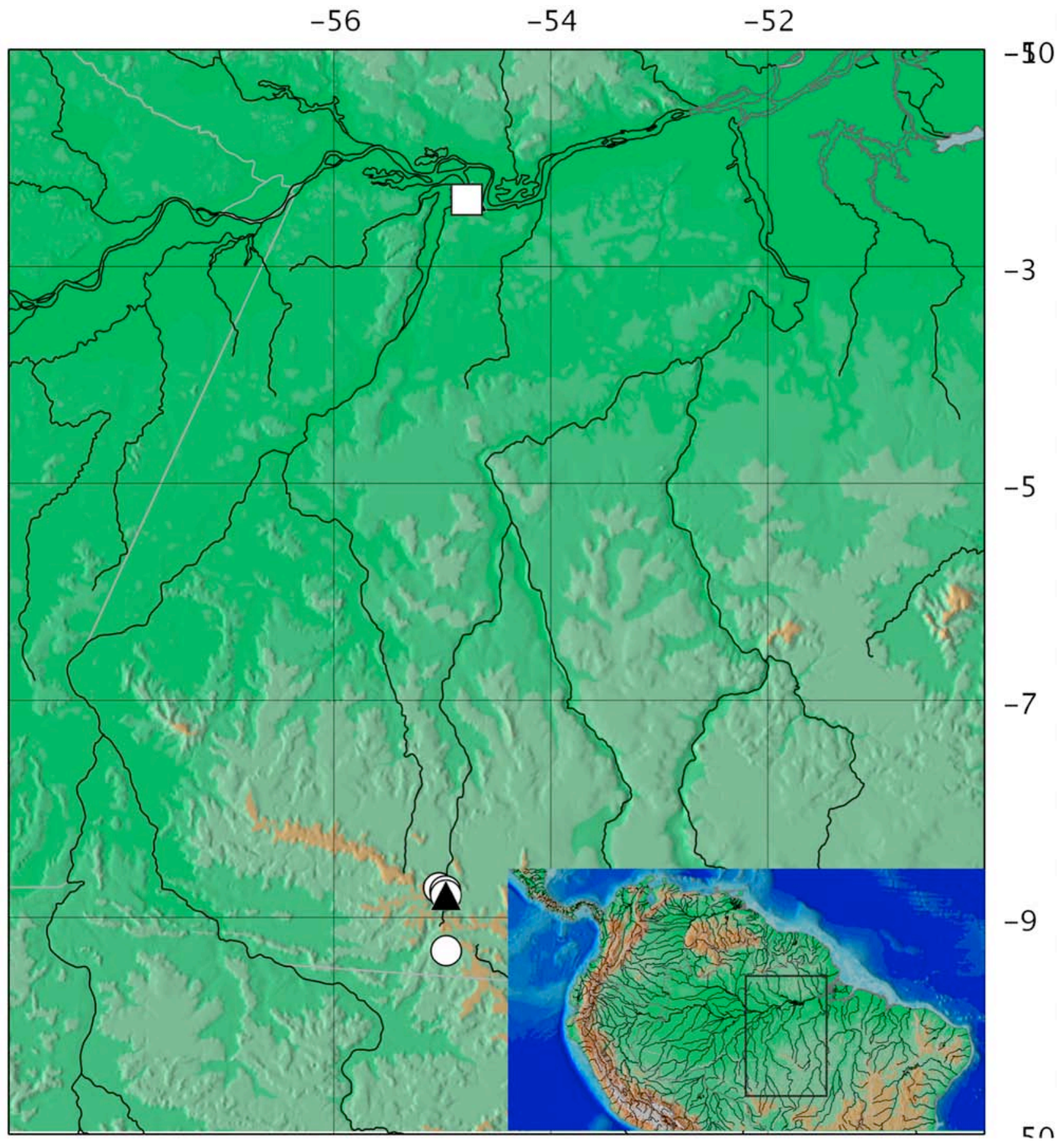

Figura 92. Mapa do Brasil-Central e parte da bacia do rio Amazonas com a distribuição de: Lebiasina sp. "Curuá-Faixa" (triângulo), L. sp. "Curuá-Pinta" (círculos) e a suposta localidade-tipo de L. intermedia ("próximo a Santarém”). 

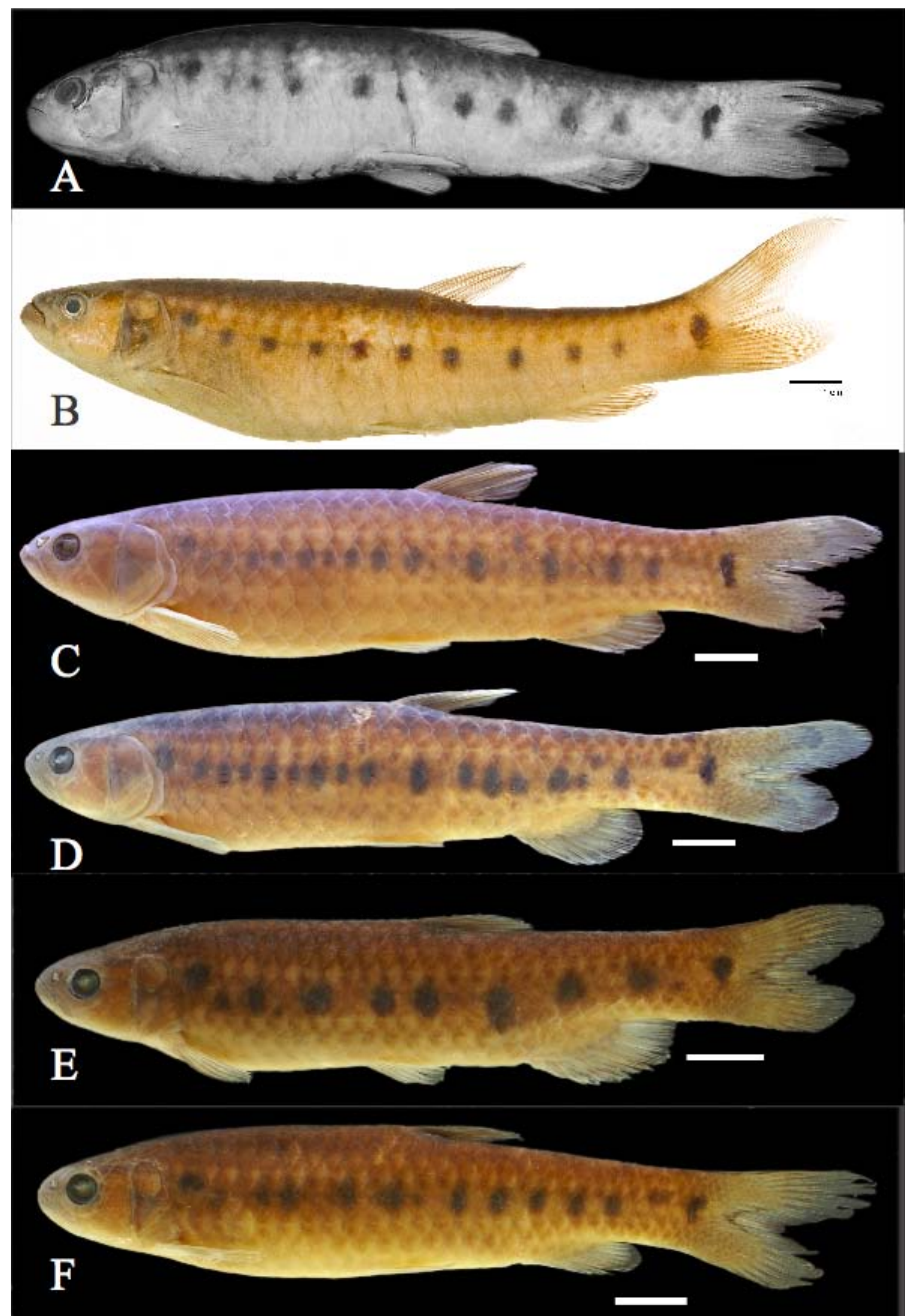

Figura 93. Lebiasina multimaculata: 

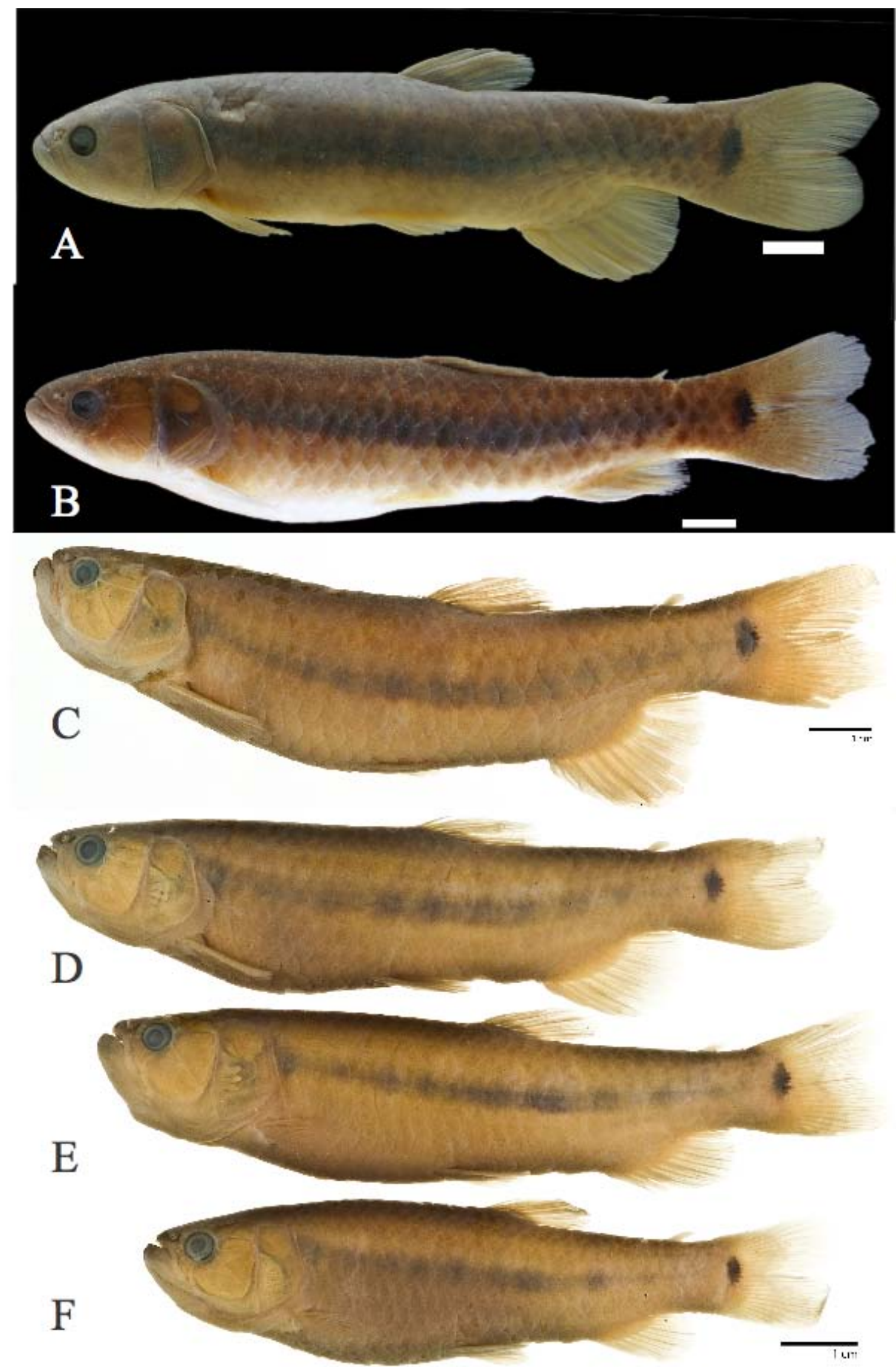

Figura 94. Lebiasina ortegai: 

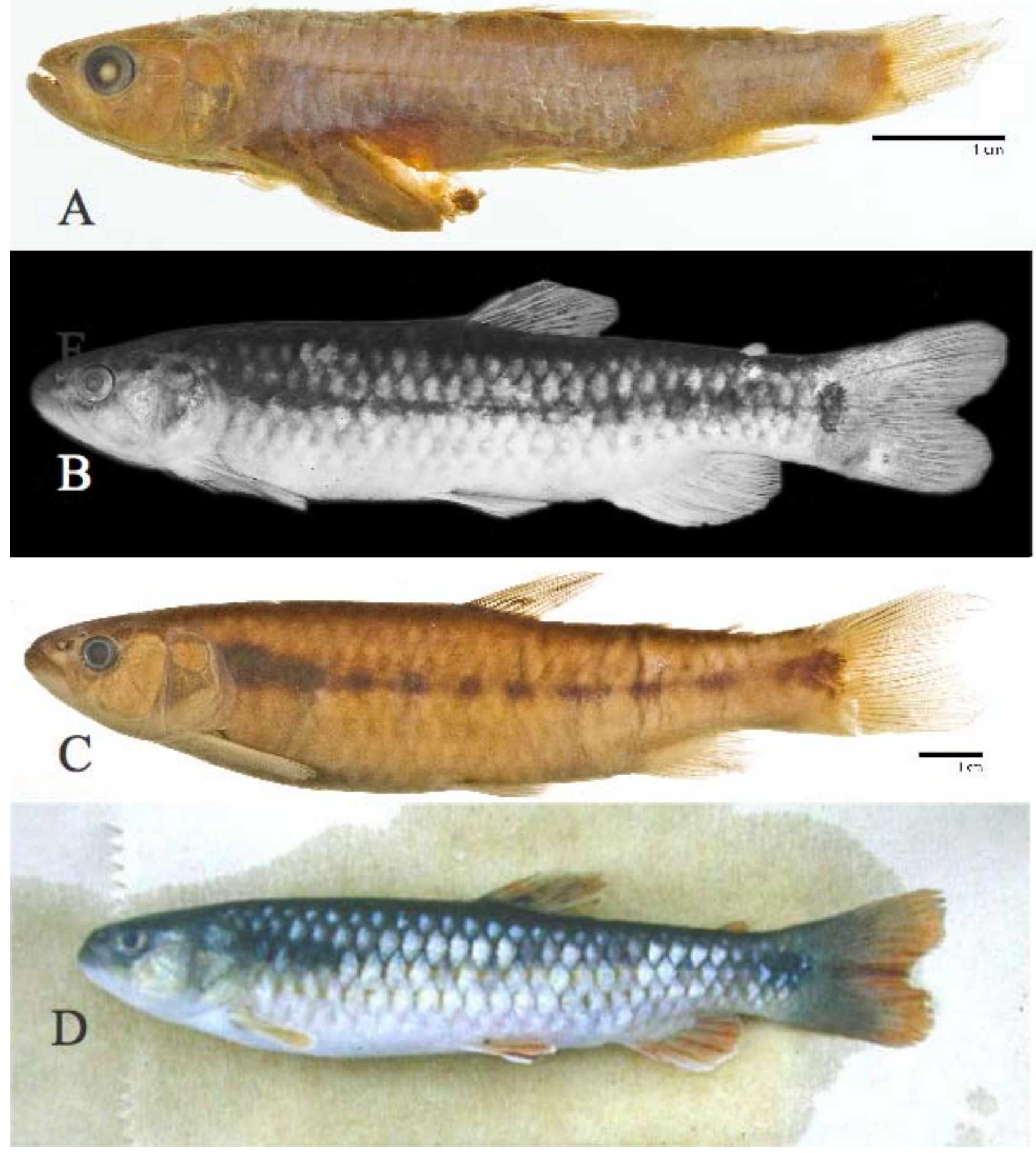

Figura 95. Lebiasina panamensis: 


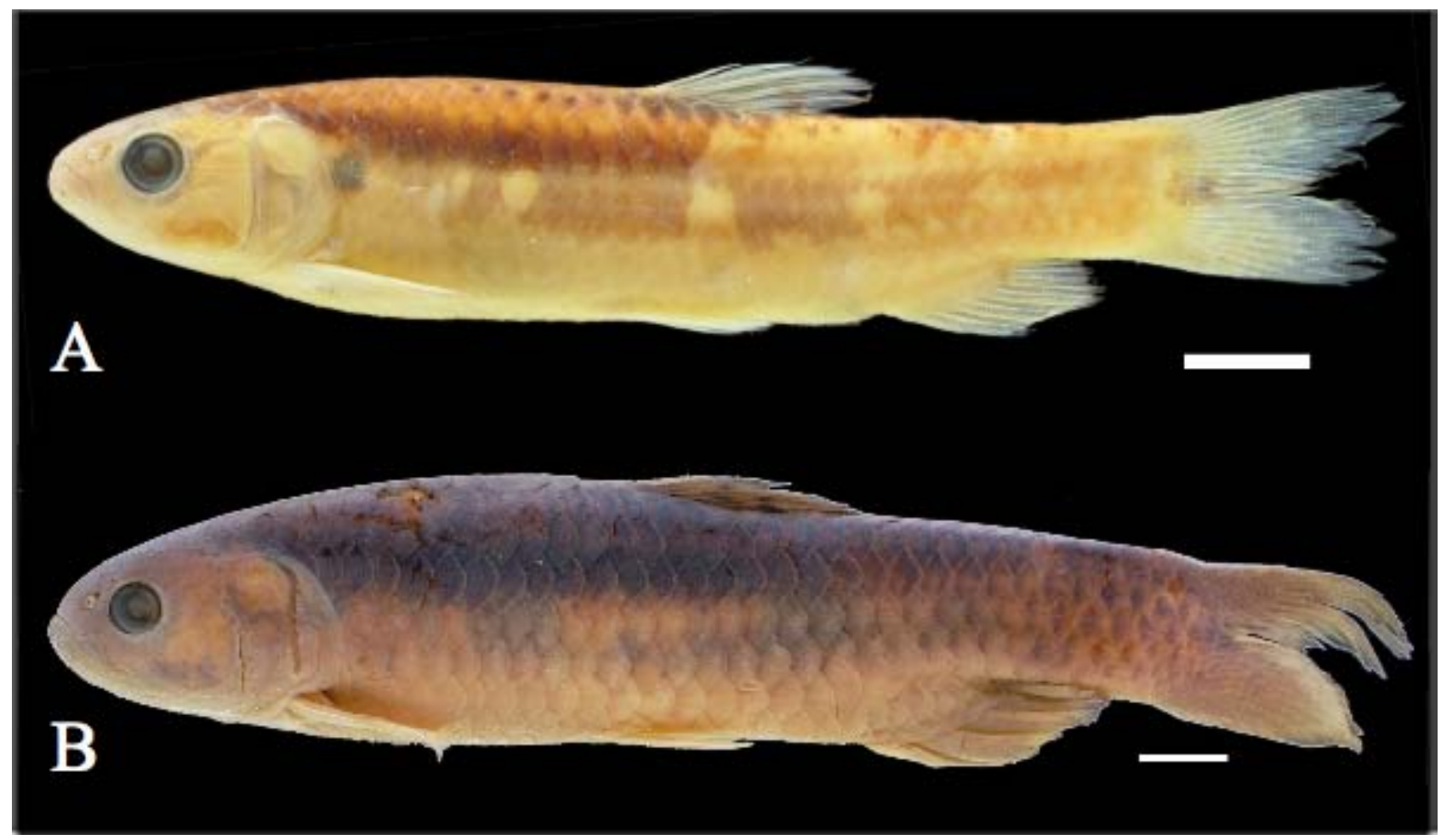

Figura 96. Lebiasina taphorni: 


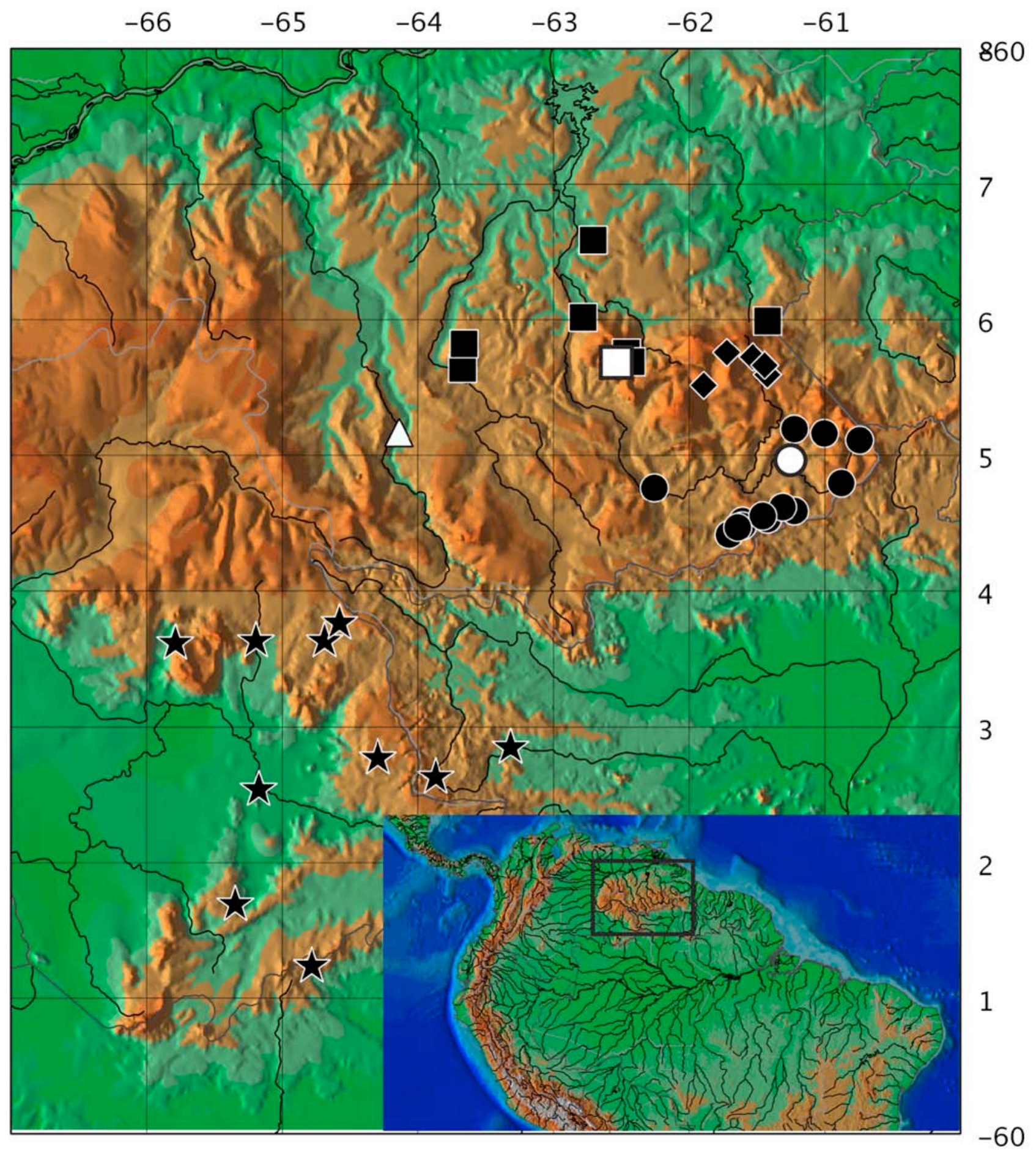

Figura 97. Mapa do norte da América do Sul, na porção oeste do Escudo Guianense, com a distribuição de: Lebiasina taphorni (triângulo), L. unitaeniata (losangos), L. uruyensis (quadrados), L. yuruaniensis (círculos) e L. sp. Parima (estrelas). Localidades-tipo representadas por polígonos brancos 

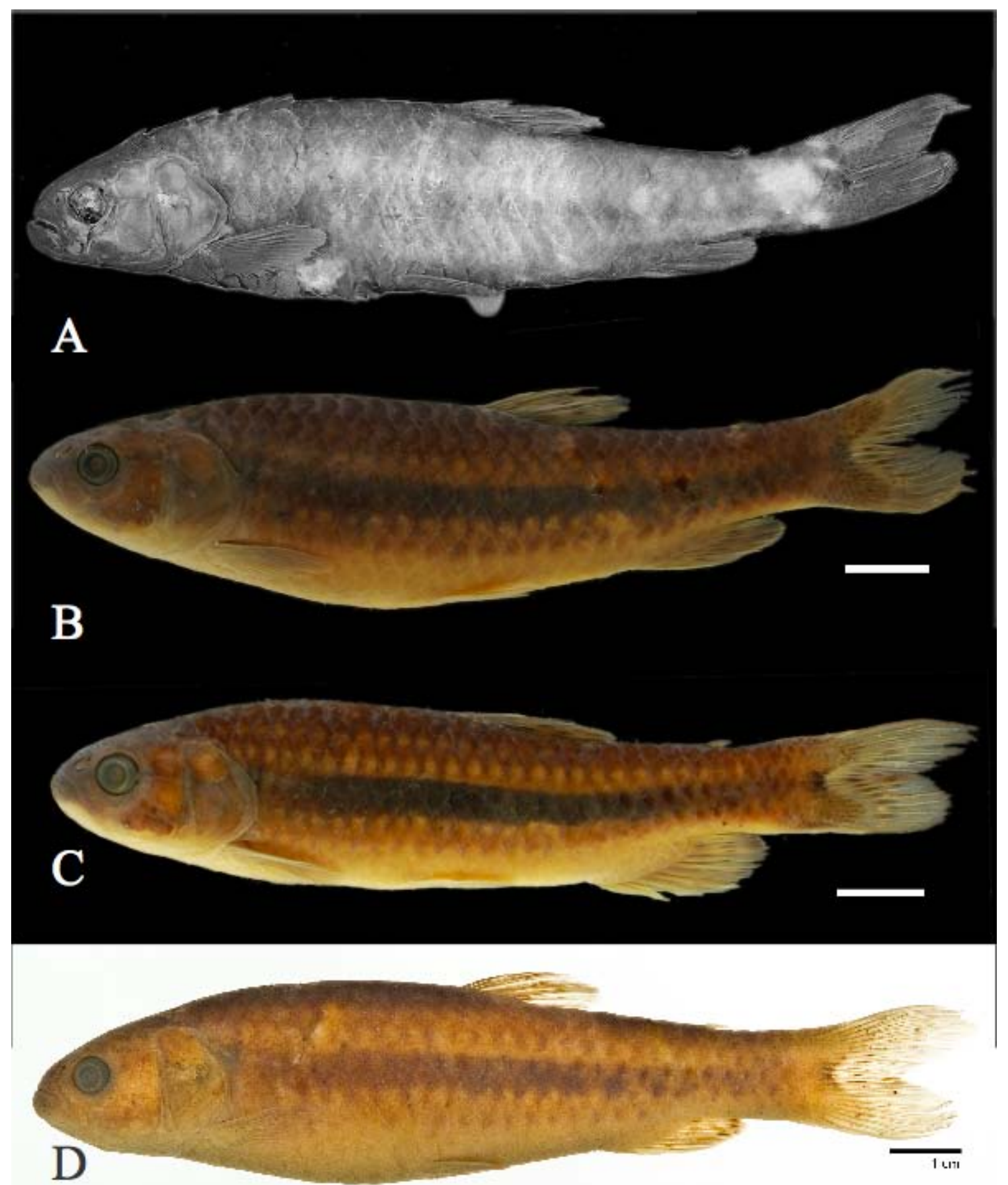

Figura 98. Lebiasina unitaeniata: 

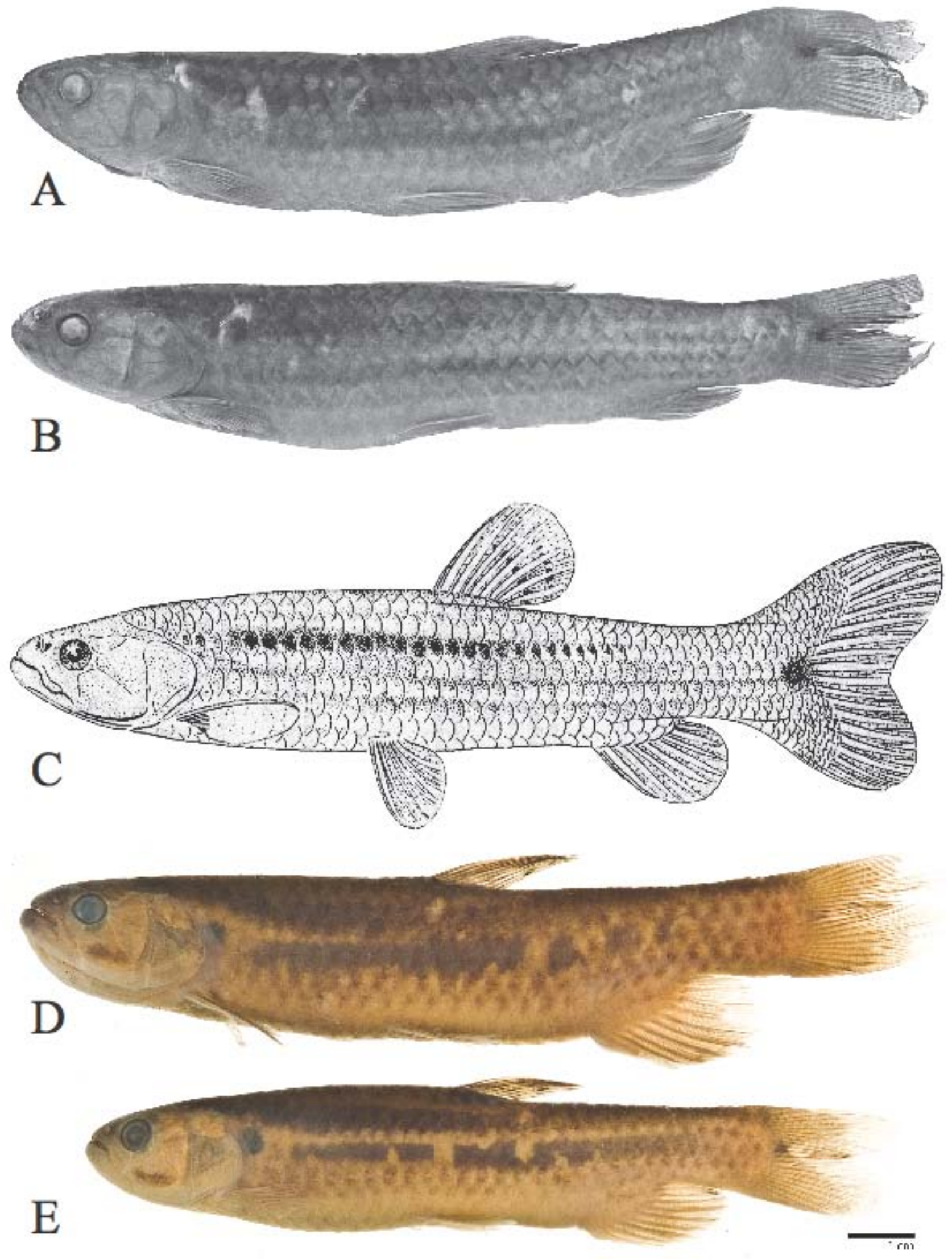

Figura 99. Lebiasina uruyensis 


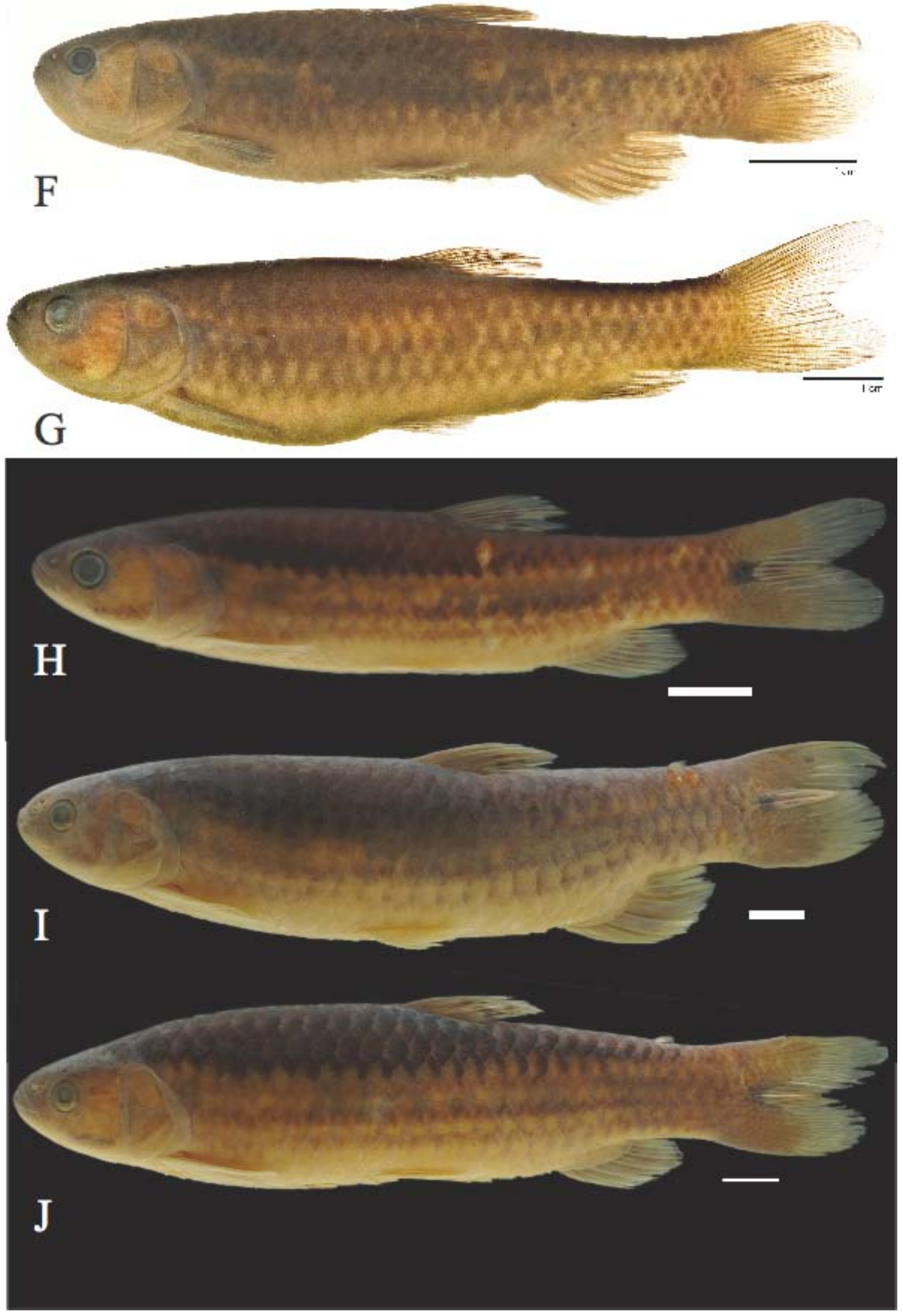

Figura 99 (continuação). 


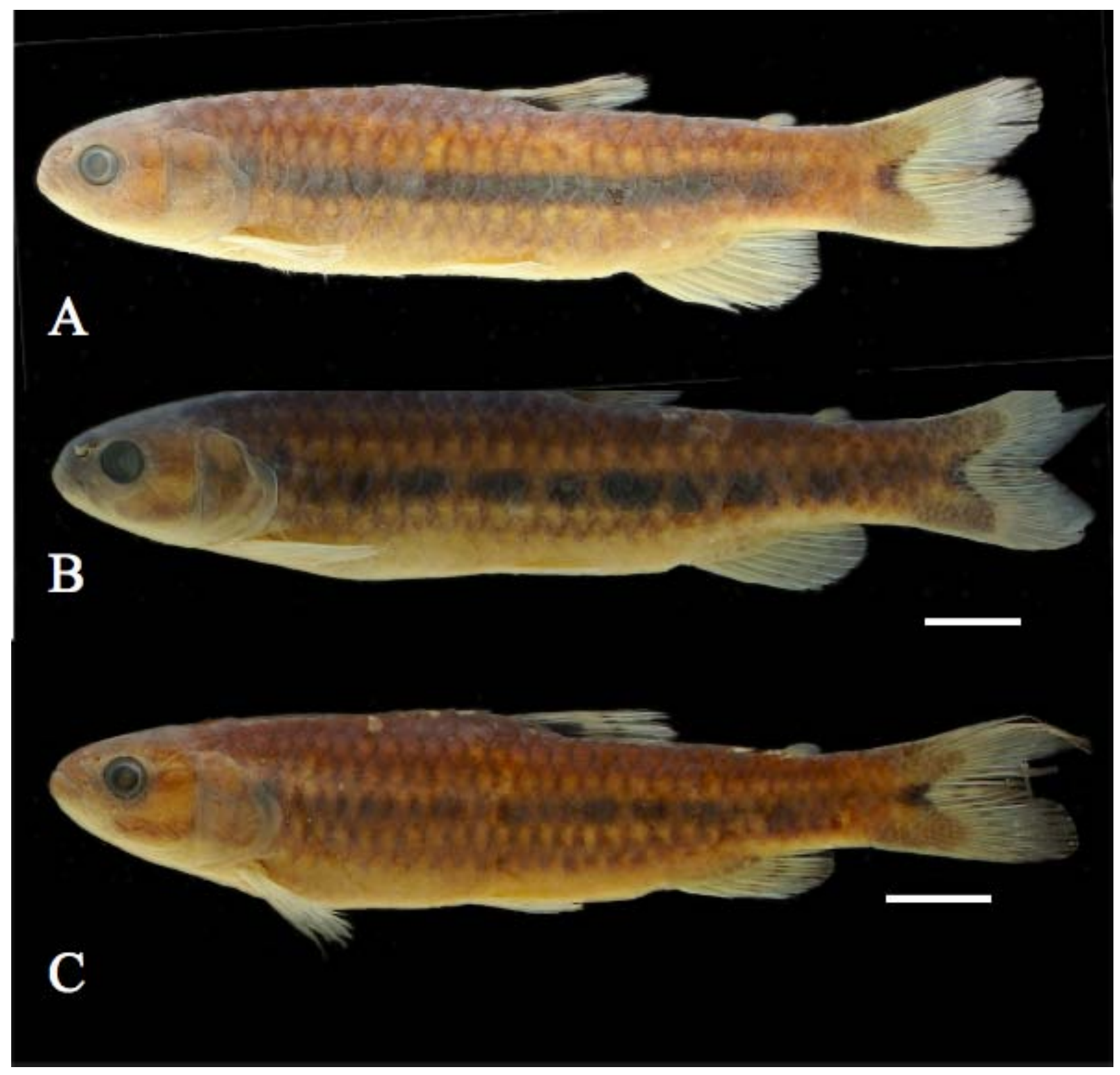

Figura 100. Lebisina yuruaniensis: A- CAR 290 (73.2 mm SL), Venezuela, Bolívar, Quebrada La Burra, Gran Sabana, El Pauji, antes de chegar ao Tepui el Altar; B- CAR 286 (82.3 mm SL), Venezuela, Bolívar, Gran Sabana, rio El Pauji, antes do salto el Pauji. 

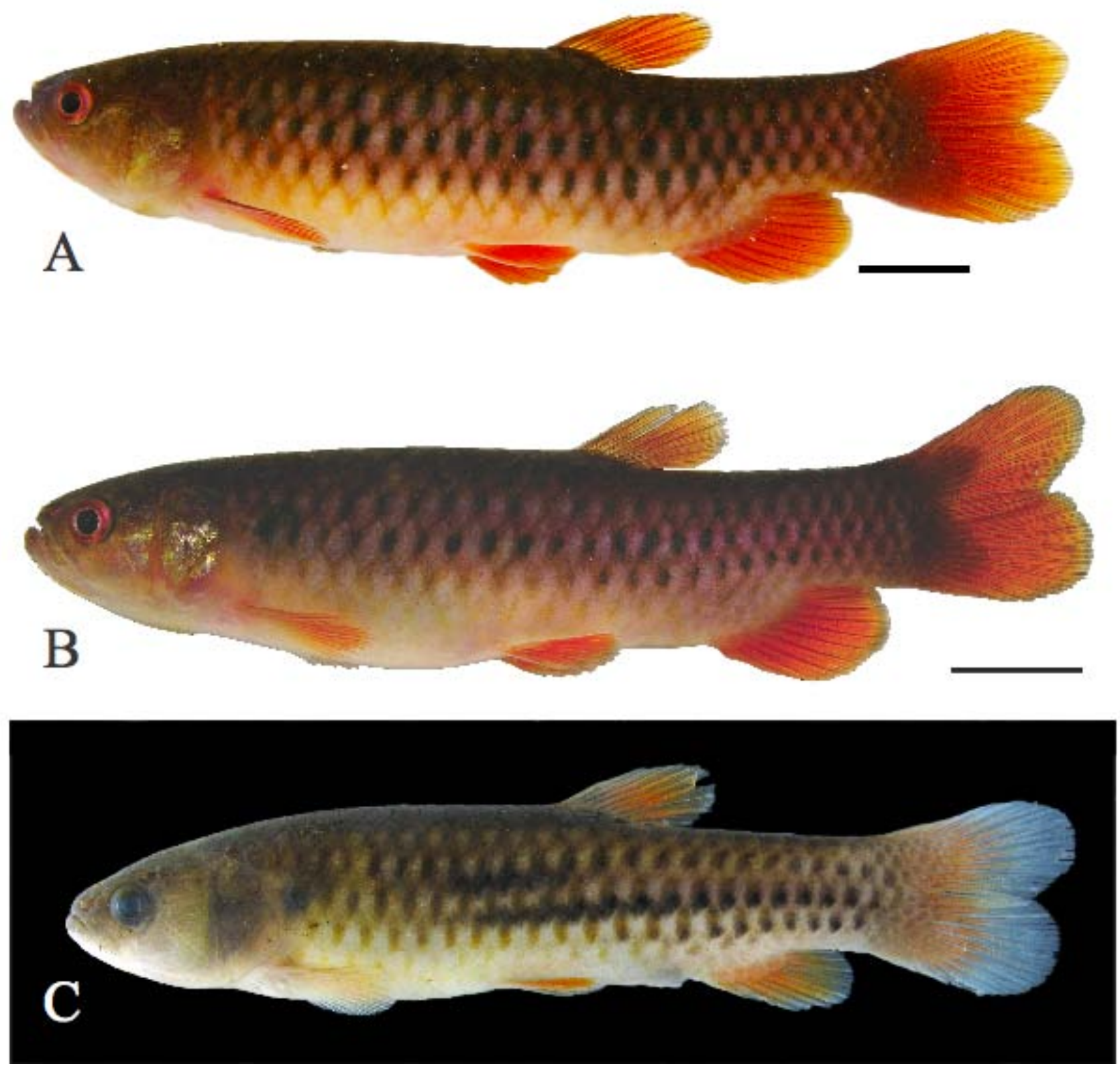

Figura 101. Lebiasina sp. "Curuá-Pinta”: A- MZUSP 99609 holótipo (85.89 mm SL), Brasil, Pará, Altamira, tributário do rio Curuá, bacia do rio Iriri (drenagem do rio Xingu), próximo à BR-163, 0849’12”S 5458'11”W. B- MZUSP 99610 (65.0 mm SL), mesmos dados do holótipo; C- MZUSP 101423 (54.4 mm SL), Brasil, Pará, Altamira, rio Treze de Maio (sistema do rio Iriri, bacia do rio Xingu), próximo à BR163, a montante da barragem, 0845’06”S, 05502’05”'W, 23-I-2009 

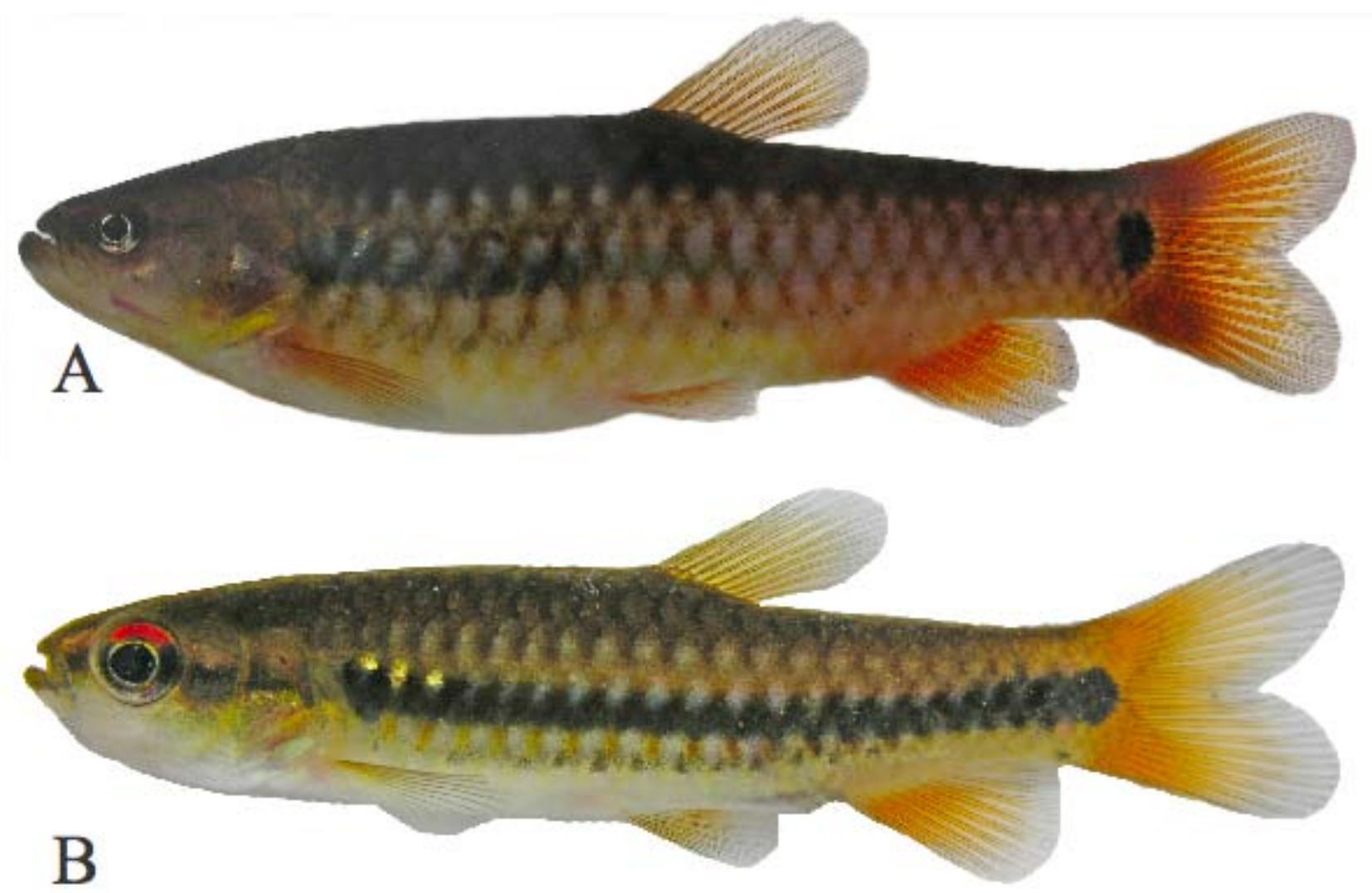

Figura 102. Lebiasina sp. "Curuá-Faixa": A- MZUSP 101375 holótipo (88.8 mm SL), Brasil, Pará, Altamira, tributário do rio Curuá, bacia do rio Iriri (drenagem do rio Xingu), próximo à BR-163, 0849’12” S 05458’11” W; B- MZUSP 99607 (33.7 mm SL) mesmos dados do holótipo. 

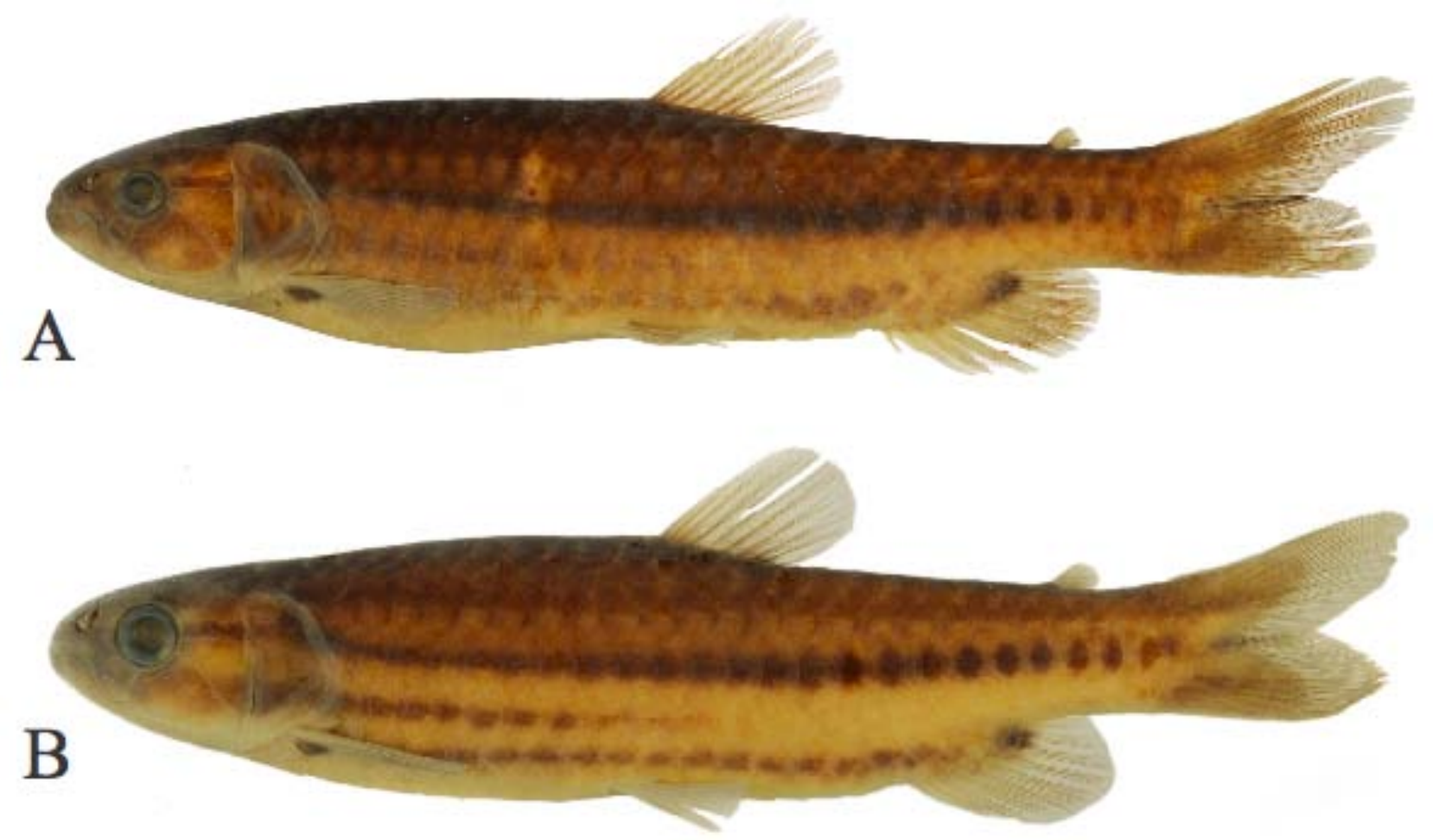

Figura 103. Lebiasina sp. "Parima": A- MNRJ uncat (152.9 mm SL), Brasil, Amazonas, Rio Marari, acampamento entre 700 e 1000m a montante da Missão Marari da aldeia Ianomami, na Serra Tapirapecó, afluente do rio Padauari; B- MNRJ uncat (78.2 mm SL), mesmos dados do holótipo. 


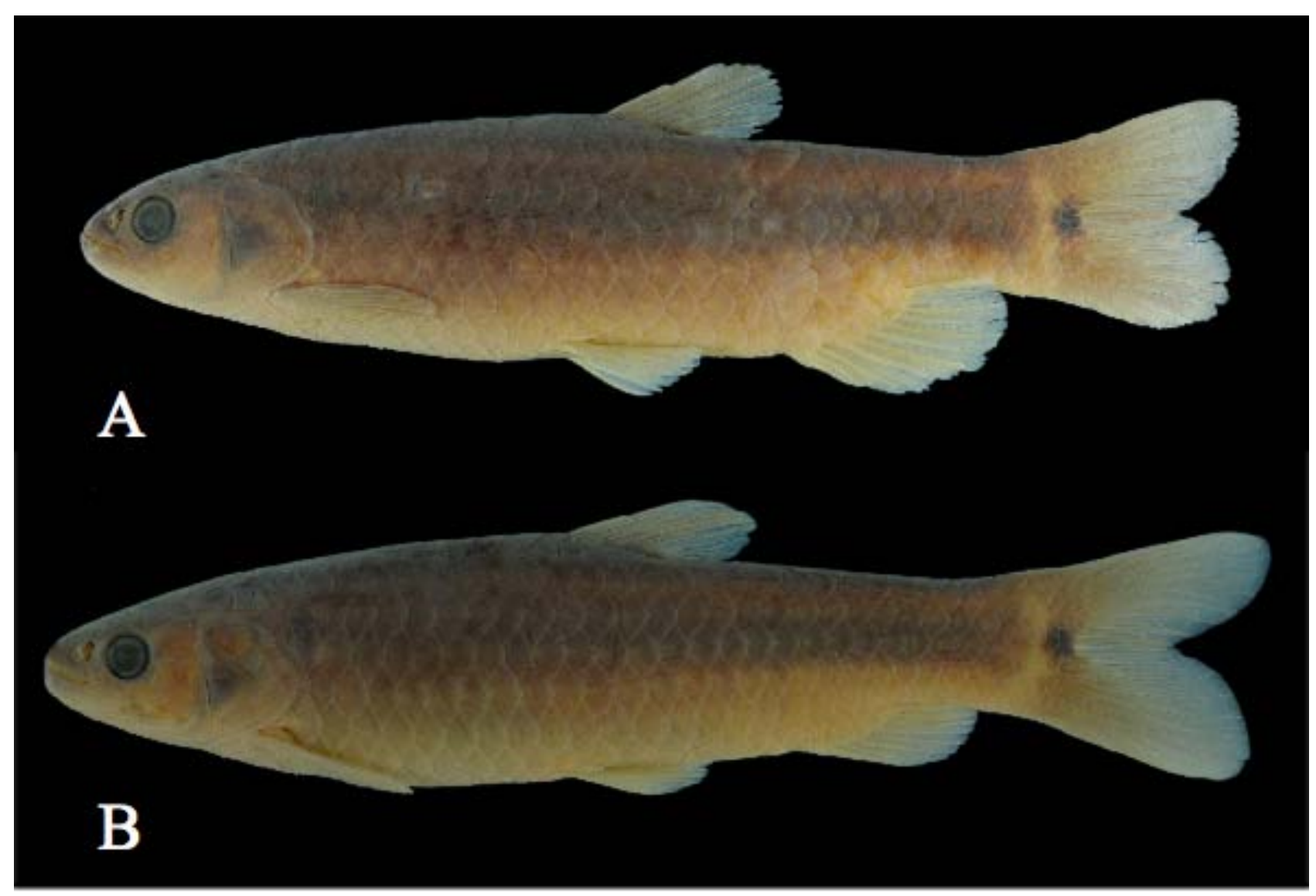

Figura 104. Lebiasina aff. bimaculata I: MUSM 7327 (A- 98.4 mm SL; B- 83.2 mm SL), Peru, Piura, Alto Río Piura. 


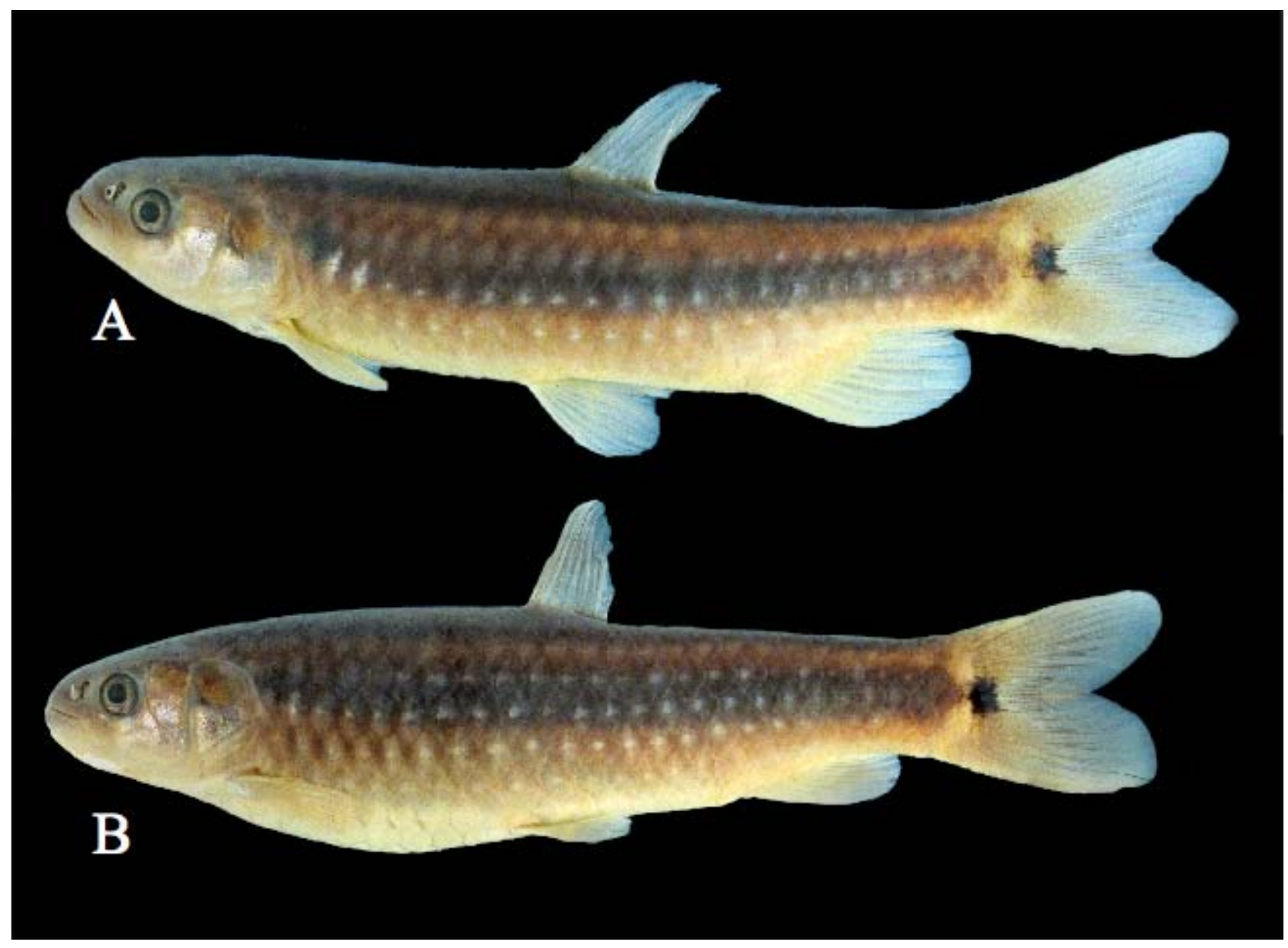

Figura 105. Lebiasina aff. bimaculata II: MUSM 13270 (A- 96.7 mm SL; B- 87.4 mm SL), Peru, Piura, Sullana, Quebrada Salado [04³8'24’S 80¹8'58’W]. 


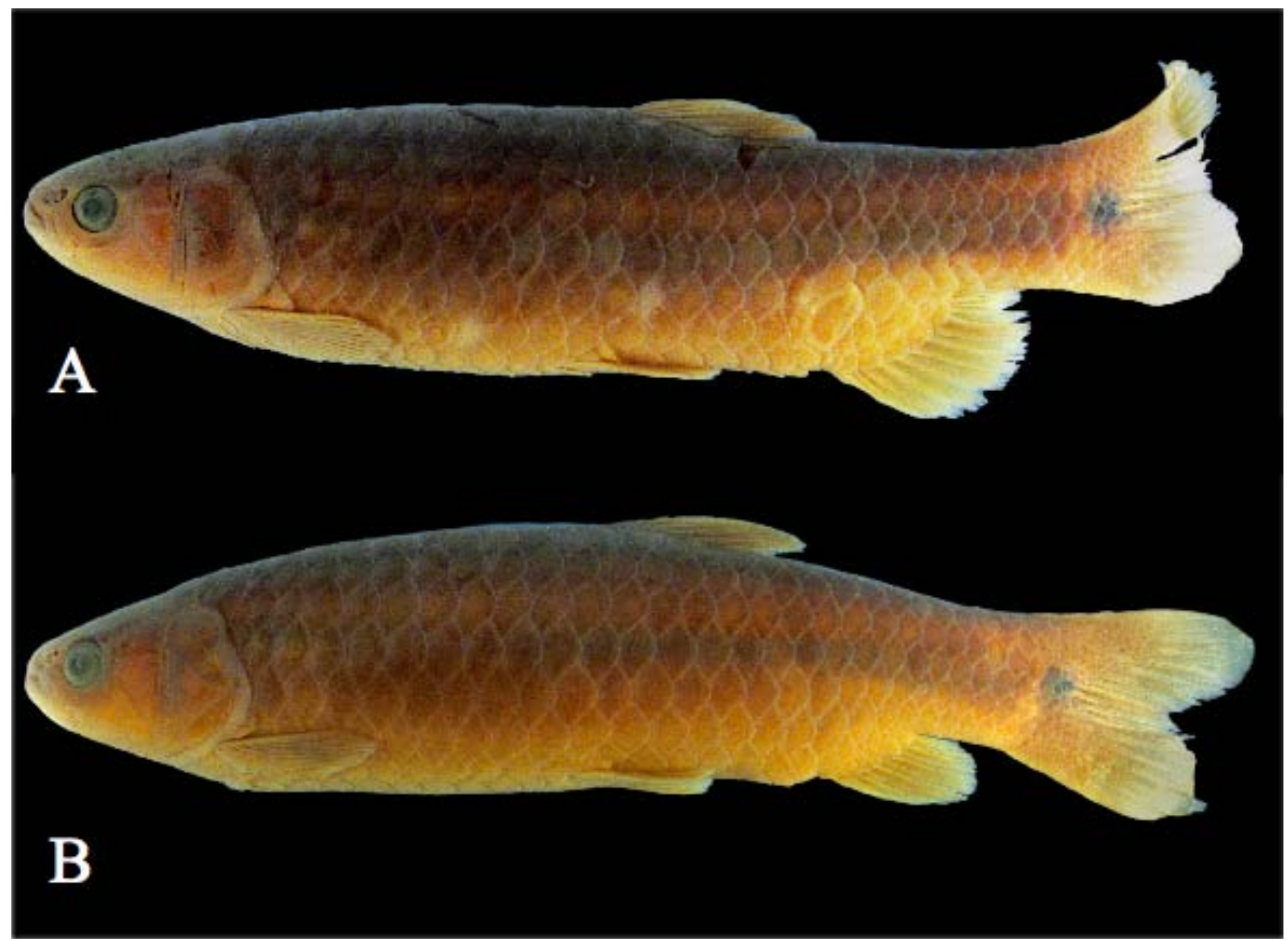

Figura 106. Lebiasina aff. festae: MUSM 6530 (A- $121.3 \mathrm{~mm}$ SL; B- $119.3 \mathrm{~mm}$ SL), Peru, Tumbes, BNT, El Gaucho, Quebrada Faical, 550 m elev., 0359’ S 80³1’ W. 

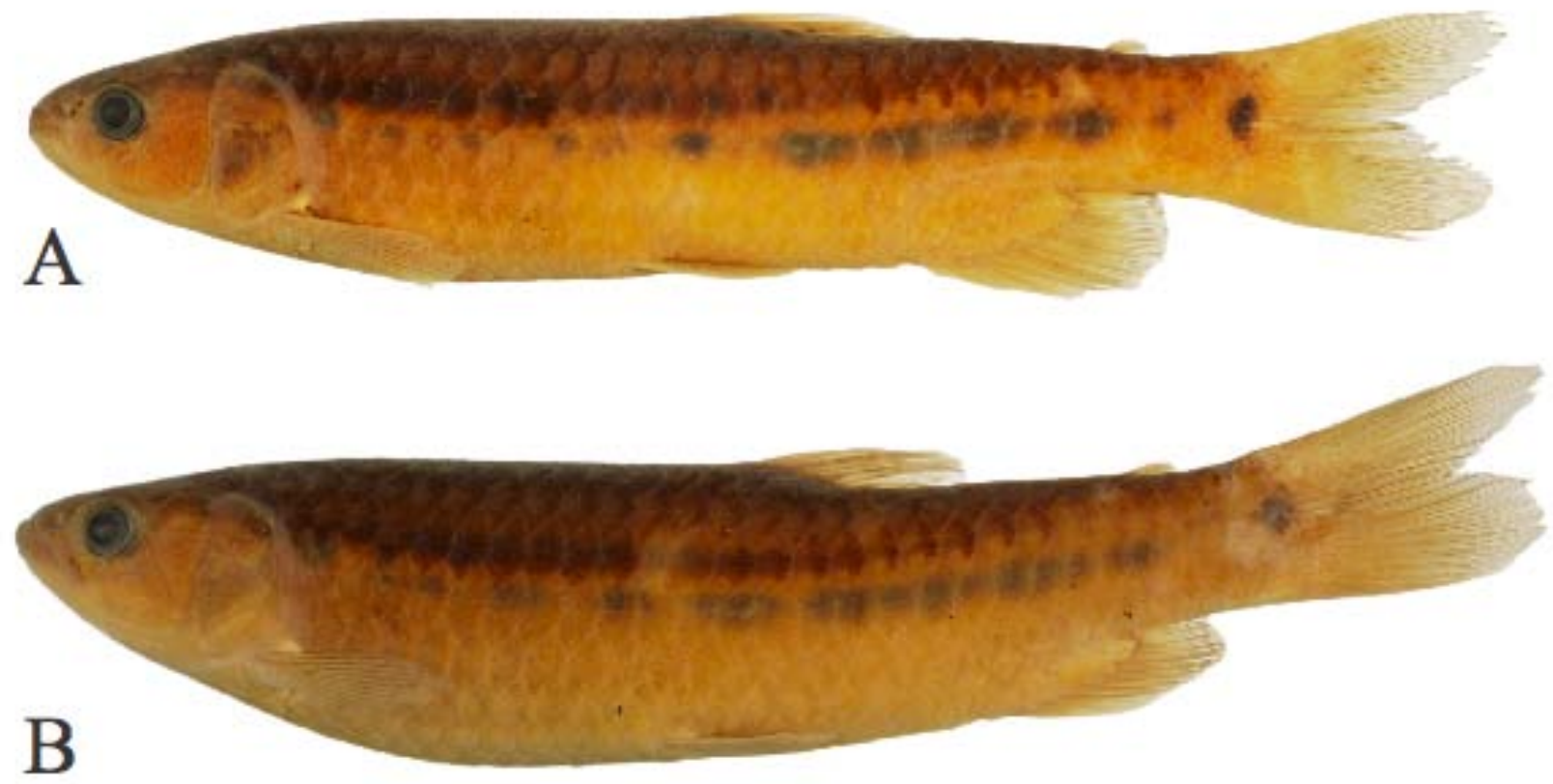

Figura 107. Lebiasina ap. "Azuay”: MEPN 6001 (A- 120.0 mm SL; B- 109.8 mm SL), Equador, Azuay, quebrada sem nome, afluente do rio Guanache, 200m elev., 0303’38’S 7943'50”W. 